\title{
Steatorrhea and nutritional condition in cystic fibrosis children : effects of a proton-pump inhibitor
}

Citation for published version (APA):

Tran, T. M. (1996). Steatorrhea and nutritional condition in cystic fibrosis children : effects of a protonpump inhibitor. [Doctoral Thesis, Maastricht University]. Rijksuniversiteit Limburg. https://doi.org/10.26481/dis.19961017tt

Document status and date:

Published: 01/01/1996

DOI:

10.26481/dis.19961017tt

Document Version:

Publisher's PDF, also known as Version of record

\section{Please check the document version of this publication:}

- A submitted manuscript is the version of the article upon submission and before peer-review. There can be important differences between the submitted version and the official published version of record.

People interested in the research are advised to contact the author for the final version of the publication, or visit the DOI to the publisher's website.

- The final author version and the galley proof are versions of the publication after peer review.

- The final published version features the final layout of the paper including the volume, issue and page numbers.

Link to publication

\footnotetext{
General rights rights.

- You may freely distribute the URL identifying the publication in the public portal. please follow below link for the End User Agreement:

www.umlib.nl/taverne-license

Take down policy

If you believe that this document breaches copyright please contact us at:

repository@maastrichtuniversity.nl

providing details and we will investigate your claim.
}

Copyright and moral rights for the publications made accessible in the public portal are retained by the authors and/or other copyright owners and it is a condition of accessing publications that users recognise and abide by the legal requirements associated with these

- Users may download and print one copy of any publication from the public portal for the purpose of private study or research.

- You may not further distribute the material or use it for any profit-making activity or commercial gain

If the publication is distributed under the terms of Article $25 \mathrm{fa}$ of the Dutch Copyright Act, indicated by the "Taverne" license above, 
STEATORRHEA AND NUTRITIONAL CONDITION IN CYSTIC FIBROSIS CHILDREN EFFECTS OF A PROTON - PUMP INHIBITOR 


\section{CONTENTS}

Chapter 1 General introduction - litterature review - Aims of the study

1. Genetics of cystic fibrosis

2. Pathogenesis

3. Clinical manifestations

4. Diagnosis

5. Therapy

6. Evaluation of steatorrhea

Aims of the study

References

Chapter 2. Methods

1. Methods used for fecal fat determination

2. Methods used for assessment of nutritional condition

Chapter 3 The acid steatocrit: A much improved method

Tran M., Forget P., Van den Neucker A., Strik J., van Kreel B., Kuijten R.

J Pediatr Gastroenterol Nutr 1994; 19: 299-303

Chapter 4 Improved steatocrit results obtained by acidification of fecal homogenates are due to improved fat extraction

M. Tran, P. Forget, A. Van den Neucker, B. Van Kreel

J Pediatr Gastroenterol Nutr 1996; 22: $157-160$

Chapter 5 Clinical use of acid steatocrit

A. Van den Neucker, N. Pestel, T. My Dung Tran, P. Ph. Forget,

H. J. Veeze, J. Bouquet, M. Sinaasappe!

Submitted for publication

Chapter 6 Role of lansoprazole in children with cystic fibrosis: Evidence for improved fat malabsorption and nutritional status Tran TMD, Van den Neucker A, Hendriks JJE, Forget P (junior), Forget $\mathrm{P}$ (senior)

Submitted for publication 
Chapter 7 Anthropometry and body composition methods in children with 84-107 cystic fibrosis: Effects of nutritional intervention My-Dung T. Tran, Anita Van den Neucker, Han J. Hendriks, Bernard van Kreel, Patricia Forget, Guido Heidendal, Pierre-Philippe Forget Submitted for publication

Chapter 8 General discussion 108-112

Summary $113-114$

Samenvatting $115 \cdot 117$

Dankwoord 118-120

Curriculum vitae 
EFFECTS OF A PROTON-PUMP INHIBITOR

\section{PROEFSCHRIFT}

Ter verkijging van de graad van doctor aan de Rijksuniversiteit Limburg te Maastricht, op gezag van de Rector Magnificus, Prof.Mr. M.J. Cohen, volgens het besluit van het College van Dekanen, in het openbaar te verdedigen.

op donderdag 17 oktober 1996 om 16.00 uur

$$
\text { door }
$$

Therese Marie Pascale Thi My Dung Tran geboren op 27 april 1967 te Dinh Tuong, Vietnam 
Promotor:

Co-promotores:

Beoordelingscommissie:
Prof. Dr. C. Blanco

Dr. P-Ph. Forget

Dr. B. van Kreel

Prof. Dr. P.B. Soeters, ( voorzitter )

Prof. Dr. H.S.A. Heymans, (Universiteit van Amsterdann )

Prof. Dr. R.W. Stockbrugger

Prof. Dr. J.M. Wit, ( Rijksuniversiteit Leiden )

Prof. Dr. E.F.M. Wouters

Steatorrhea and nutritional condition in cystic fibrosis children:

Effects of a proton - pump inhibitor /

Therese Marie Pascale Thi My Dung Tran.

Proefschrift Maastricht - Met lit. Opg. - Met samenvatting in het Nederlands.

ISBN 90-5681-011-1

Trefw.: Steatocriet / steatorrhoe / cystic fibrosis / voedingstoestand / proton pomp remmer / lichaamsamenstelling.

Vormgeving: My Dung Tran

Omslagillustratie: Vetbollen in een microscopische faeces preparaat, met Soudan kleuring. 
Aan mijn lieve moeder Voor alle cystic fibrosis kinderen. . 
CHAPTER 1

GENERAL INTRODUCTION 


\section{GENETICS OF CYSTIC FIBROSIS (CF)}

Cystic fibrosis was first described in 1928 by Fanconi (1). It is an autosomal recessive disease and is reported in all racial groups with varying prevalence. In caucasians, CF occurs in 1 out of 2000 live births. Males and females are equally affected. The basic defect is a mutation of the Cystic Fibrosis Transmembrane Regulator (CFTR), a protein responsible for chloride ion transport in response to cAMP mediated signals. The most frequent CF mutation in the caucasian population is a deletion of 3 nucleotides, encoding for phenylalanine at position 508 in the CFTR protein amino acid sequence. Its overall frequency reported by the CF Genetic Analysis Consortium is $68 \%$ (2). Until now, over 200 mutations have been characterized and account for the remaining mutations.

\section{PATHOGENESIS}

It is generally accepted that cAMP stimulated chloride conductance is a function of the CFTR (3). This function is deficient in epithelial cells of CF patients. The inability to secrete chloride and secondarily secrete water results in viscous secretions. Poor clearance of these viscid secretions from the epithelium often results in obstruction of excretory ducts. CFTR has been found in epithelial cells of several organs such as the airways, the sweat glands, the genitourinary system and the gastrointestinal tract including the pancreas and the biliary tract (4). Dysfunction of these organ systems are therefore possibly related to the same underlying defect in the CFTR-gene product.

\section{CLINICAL MANIFESTATIONS}

CF is a multisystem disease with lungs and pancreas mostly affected in young patients.

\section{1 Respiratory tract}

Lung disease accounts for more than $95 \%$ of the morbidity and mortality in CF $(5,6)$. The desiccated mucus in the respiratory tract causes stasis and bronchiolar obstructions, resulting 
in bacterial overgrowth and chronic lung infection. This gives rise to the production of proteases by bacteria and neutrophils. These enzymes hydrolyze important structural proteins of the lung and airways such as elastin, proteoglycans and collagen, leading to instability of bronchial walls and bronchiectasis. Furthermore, these enzymes also alter the mucosal function by increasing the secretion of macromolecular glycoconjugates contributing to a high viscosity of the mucus (7). Bronchiolitis with wheezing is frequent during the first year of life. Some patients remain however, asymptomatic for long periods. When pulmonary disease progresses, exercise intolerance occurs and finally, progressive pulmonary deterioration is the main cause of death in these patients $(6,8)$. As a consequence of improved supportive therapy, survival has increased from 6 months at the end of the fifties (9) to nearly 30 years currently $(10,11)$. Sinusitis and nasal polyposis sometimes occur in CF $(12,13)$.

\section{2 Pancreas}

In the pancreas, obstruction of the ductules is the cause of acinar / ductular distention, followed by dișruption with release of proteolytic enzymes and autodigestion of the pancreas resulting in pancreatic insufficiency with steatorrhea. The changes in the pancreas can occur early during gestation, compromising the normal maturation of the pancreas: Approximately, $85 \%$ of CF patients have steatorrhea (11). In $85-90 \%$ of these cases, exocrine pancreatic insufficiency develops during the first year of life. Decreased secretion of bicarbonate and water first occurs before a decrease of pancreatic enzyme concentration in duodenal fluid can be detected (14-17). Recurrent acute pancreatitis occurs in approximately $10 \%$ of CF patients (18).

Because of fat malabsorption, serum concentrations of fat soluble vitamins are often lowered. Since Vit A conșists of esters of long chain fatty acids, it cannot be absorbed in the absence of pancreatic esterases. Due to its short half life, low serum leveis of Vit A are often found in early untreated CF patients $(19,20)$. Vit $\mathrm{D}$ deficiency resulting in decreased bone mineralization has also been reported in CF patients (21-23). Due to frequent antibiotic therapy, suppression of endogenous vit $\mathrm{K}$ synthesis by anaerobic intestinal bacteria often contribute to a low vit $\mathrm{K}$. serum level in CF patients with steatorrhea. Although Vit B12 is water soluble, serum levels may also be low in CF patients. Binding to intrinsic factor, necessary for absorption, 
can only take place after cobalamin has been released from the R-protein binding by pancreatic enzymes. Decreased pancreatic bicarbonate secretion may play a role herein since the binding affinity of cobalamin for R-protein decreases at neutral or slightly alkaline $\mathrm{pH}$ (24). However, pancreatic enzymes supplements will normalize the Vit B12 serum level.

Abnormal glucose tolerance occurs in $30-75 \%$ of $\mathrm{CF}$ patients while diabetes mellitus develops in 10\% (11). Several diabetogenic factors including increased passive sugar transport (25), increased mucosal absorption of D-glucose (26), decreased beta cell mass (27) and delayed insulin secretion (28) are present in CF. On the contrary, several antidiabetogenic factors such as an increased tissue insulin sensitivity (29) and an increased number of insulin receptors on monocytes (30) have been reported in cystic fibrosis. Moran et al. reported a decreased alpha, beta- and pancreatic polypeptide- cell function in CF patients with exocrine disease compared to those without this disorder. Due to this finding, they suggest that either exocrine disease causes endocrine dysfunction or that a common pathogenic process simultaneously and independently impairs exocrine and endocrine function in CF patients (31). However, the exact etiology of diabetes in CF is still unknown.

\section{5 Mainutrition}

CF children are malnourished when compared to normal controls $(32,33)$. Both, malabsorption accompanying pancreatic insufficiency (34) and high energy expenditure due to chronic lung infection $(35,36)$ are thought to be responsible for the poor nutritional condition in these patients. Moreover, in $\mathrm{CF}$, several intraluminal factors other than pancreatic insufficiency are also considered responsible for fat malabsorption:

1) Increased gastric acid secretion after stimulation with pentagastrin (37):

A high postprandial acid secretion could, by lowering the duodenal $\mathrm{pH}$, contribute to fat malabsorption.

2) Decrease pancreatic bicarbonate secretion (13-16):

Higher gastric acid secretion after meals together with a decrease in pancreatic bicarbonate secretion, has been shown to result in a prolonged postprandial lowering of duodenal pH with 
inactivation of the remaining pancreatic lipase. Moreover, low duodenal $\mathrm{pH}$ also results in bile acid precipitation,, fecal loss of bile acids and a decrease in the bile acid pool, contributing to fat malabsorption

3) Increased glycine to taurine conjugated bile acid ratios:

Due to a relatively deficient supply of taurine compared to glycine and to continous fecal loss of bile acids, newly formed bile acids are mainly conjugated with glycine, leading to high glycine-/taurine- bile acid conjugation ratios (38). The glycine conjugated bile acids precipitate in an acidic environment contributing to the luminal bile acid deficiency in these patients.

\section{4 Intestinal tract}

Gastroesophageal reflux and esophagitis are frequent causes of epigastric pain in CF patients $(39,40)$ and can be responsible for decreased pulmonary functions (41). Peptic ulcers are found in up to $13 \%$ of $\mathrm{CF}$ patients (42) and are thought to be related to the low duodenal $\mathrm{pH}$

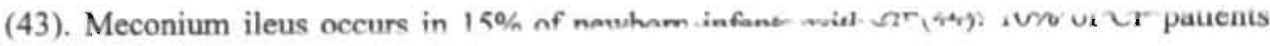
have meconium ileus "equivalents" at a later age with a peak incidence at 20-25 years of age (45). Protein precipitation as a result of decreased duodenal $\mathrm{pH}$ and high secretion viscosity all probably contribute to these obstructive events (11). Up to $25 \%$ of the CF patients have rectal prolapse occurring mostly in children aged 6 - 36 months (46) while intussusception has been shown to occur in $1 \%(47)$.

\section{5 Biliary and Hepatic tracts}

An increased incidence of cholelithiasis has been reported in CF patients (48) and is thought to be related to hypokinesis and increased fasting gallbladder volumes (49). Biliary cirrhosis with hepatosplenomegaly leading to portal hypertension occurs in $25 \%$ of CF patients. Liver steatosis has been reported in $30 \%$ of patients with CF.

\section{6 Genitourinary tract}


More than $95 \%$ of males are infertile due to obstruction of the reproductive tracts (50). Active spermatogenesis does occur but produced spermatozoa are abnormal or immature (51). In $\mathrm{C}^{2}$ women, the reproductive tracts are anatomically normal but fertility is decreased (52). Incree sed viscosity of the cervical mucus is thought to interfere with sperm penetration (53).

\section{7 Sweat gland}

Decreased sodium and chloride reabsorption due to dysregulation of sweat gland duct cell, results in susceptibility of $\mathrm{CF}$ patients to salt depletion during warm weather and durirg gastroenteritis.

\section{Diagnosis}

The standard diagnostic procedure is the sweat test based on increased concentration of electrolytes in the sweat of the patients (54). The sweat test was developed by Gibson ard Cooke (55), whereby the sweat production is stimulated by puocarpine iontopnoresis. Ine then collected sweat is analysed for its chloride and sodium content. However, chloride content has a better diagnostic value than sodium content, since abnormal sodium secretion can also be found in other endocrine diseases. Sweat chloride concentration higher than 60 $\mathrm{mM}$ or sodium above $70 \mathrm{mM}$ measured minimal on two conditions is considered as abnormal, whereas chloride values under $50 \mathrm{mM}$ and sodium value under $30 \mathrm{mM}$ are found in normal persons. Chloride concentrations between 50 and $70 \mathrm{mM}$ are inconclusive. For reliable results, at least $50 \mathrm{mg}$ of sweat should be collected. Low sweat production in the first few weeks of life is the reason for unreliable test results in this age group. In cases of doubt, identification of CFTR-mutation or measurement of intestinal current in a rectal biopt have been reported to be conclusive (56).

\section{Therapy}

The ideal treatment of CF should be the correction of the underlying defect by introduction of a normal copy of the defective gene into these patients genetic material. Gene therapy is 
presently under intensive scrutiny. Adenovirus and recently also the retrovirus seem promising as an effective vector for normal gene transport into the target cells $(57,58)$. Recently, transfer of the CFTR gene to the rat airways epithelia has been successfully performed (59). However, the role of gene therapy in the management of CF patients is not yet settled. Until then, treatment of $\mathrm{CF}$ patients has to focus on improving the nutritional condition, since malnutrition can adversely affect survival (60). The nutritional status of CF patients can be improved by firstly ameliorating the respiratory function, thereby minimizing energy expenditure and secondly, by increasing energy supply either by increasing nutrient intake or by improving nutrient digestion and absorption.

\section{1 Respiratory function support}

Since viscous mucus in the lung is the cause of chronic lung infection, efforts should be made to improve mucus clearance. Although most patients on mucolytics such as acetylcysteine have the feeling of decreased sputum viscosity, studies with acetylcysteine either orally or as aerosol have failed to support this finding (61-63). Alternative methods such as chest percussion combined with postural drainage (64), positive expiratory pressure mask $(65,66)$ and forced expiratory pressure (67) have been suggested to improve mucus clearance. Moreover, $\beta 2$-agonists as aerosol can increase sputum clearance (68) and some bronchodilatating effect has been experienced in CF patients on this regimen $(69,70)$. Corticosteroids, have been found to delay disease progression and to improve lung function in $C_{F}$ patients (71-74) but, short-term adverse effects such as hyperglycemia and long-term adverse effects such as development of cataract and growth retardation preclude the routine use of corticosteroids in these patients (73).

Treatment with antibiotics can reduce the progression of lung infection. Colonisation with Ps. aeruginosa often occur in CF patients and various regimes have failed to eradicate the bacteria (75). Ps. aeruginosa vaccines are presently being evaluated (76). In the end stage, lung transplantation can offer an outcome. The one and two year survival rates approach $70 \%$ and $54 \%$ respectively (77). Amiloride inhalation by blocking sodium reabsorption in the respiratory epithelium, has been shown to increase sputum clearance in a placebo-controlled crosso- 
ver study $(78,79)$. Although improvement in pulmonary function was not found in one study (78), a delay in the deterioration of forced vital capacity (FVC) was reported by an other author (79). Domase (Pulmozyme), a recombinant human desoxyribonuclease which breaks off the sputum DNA, has been reported to increase the forced expiratory volume (FEV1) and FVC safely in CF patients (80-82). Inhalation of $\boldsymbol{\alpha} 1$-antitrypsine inhibits neutrophil elastase (83), which is released from the neutrophils and causes lung damage. Chloride channel facilitators, which directly stimulate a CFTR protein independent anion channel, are presently being evaluated (84).

\section{2 Increase energy supply}

in the past, restricted diets with low fat content were often prescribed for CF patients in order to minimize steatorrhea, abdominal cramps and stool bulk (85-87). Due to both unpalatability and low caloric density, these diets often resulted in malnutrition and growth faillure in these patients (87-89). In the early 1970s, Crozier introduced the use of high fat diets in combination with pancreatic enzymes in order to increase the energy intake of CF patients. This regimen resulted in better growth with evident steatorrhea (90). Moreover, CF children from clinics using low fat diets were reported to show poorer growth (87-89) than those from clinics, encouraging the use of high fat diets (91). In order to further improve the nutritional status and growth of CF patients, feeding intervention studies have been done with different kinds of nutrients such as hypercaloric polymeric, semielemental or elemental diets. It has been shown that interventions making use of very high caloric intakes of polymeric diets (150 - $180 \%$ Recommended Daily Allowance) by overnight nasogastric tube resulted in improved nutritional status in CF adults. In children with CF, the effects of interventions with hypercaloric polymeric diets up to $130 \%$ of RDA are however unconvincing. Luder and coworkers, studying the effects of a 4 year period of nonrestricted fat diet in CF children, found improved $\mathrm{Z}$-scores for weight, height and $\mathrm{BMI}$ for their $\mathrm{CF}$ patients when compared to the national population of $\mathrm{CF}$ patients on fat restricted diets, while no changes were: seen when compared to normal children without CF (92). More recently, studies with hypercaloric polymeric diets with high fat content did not result in significant improvements of Z-scores for weight, height and skinfolds in CF patients (93), whereas parenteral nutrition and either oral or enteral 
elemental and semielemental nutrition have been shown to significantly improve the nutritional condition of these patients (94-106). The results of short-term and long-term studies of feeding interventions on the nutritional status in CF children are summarized in table 1 and 2 . The fact that predigested food can improve the nutritional status better than standard diets, strongly suggests that nutrient maldigestion plays a crucial role in the poor response to oral hypercaloric polymeric diets. The latter hypothesis is further supported by the known inactivation of pancreatic enzymes and bile acids precipitation accompanying the low duodenal pH due to low bicarbonate secretion in CF patients (107-110) . Enteric-coated pancreatic enxyme preparations have therefore been introduced but the low duodenal $\mathrm{pH}$ interferes with the release of enzymes through the acid resistent coating (111). High doses of pancreatic enzymes did not solve the problems of malabsorption (112) and recently, colon strictures have been observed in CF children on high doses of pancreatic enzymes (113-115). Attempts have been made to inhibit gastric acid production in the hope to improve the digestion and absorption of nutrients. However, the reported effects of H2-receptor antagonists and prostaglandine E2 on steatorrhea have been variable and unconvincing (116-125). Results of short-term studies of cimetidine and misoprostol on fat excretion have not been consistent (table 3). This may be partly due to the lack of control of dietary fat intake. In longterm studies cimetidine showed no significant changes in fat excretion and nutritional status in CF children. on the contrary, famotidine, a more potent inhibitor of gastric acid secretion, showed both a significant improved fat absorption coefficient and improved growth parameters (table 4). However, interpretation of growth effects in the latter study is rather difficult because $Z$-score methods have not been used to evaluate growth. Further, in a double blind study, a significant improvement in steatornhea was found when a proton pump inhibitor was added as adjuvant therapy in pancreatic enzyme treated CF adults (112). In children with $\mathrm{CF}$, the effects of proton pump inhibitors on fat absorption and on the nutritional condition have not been reported. 
Table 1 short-term feeding intervention studies in cystic fibrosis.

\begin{tabular}{|c|c|c|c|c|c|c|c|}
\hline Authon & $\begin{array}{l}\text { Eshephend } \\
\text { et ali, 'so }\end{array}$ & $\begin{array}{l}\text { "Shepherd } \\
\text { et al, ' } 13\end{array}$ & $\begin{array}{l}\text { "Bertined } \\
\text { et all, ' } 44\end{array}$ & $\begin{array}{l}\text { mansell } \\
\text { et al, ' } 24\end{array}$ & e. 1., " is & "Loughlin & extil.'95 \\
\hline $\begin{array}{c}\text { Number of } \\
\text { cases }\end{array}$ & 12. & 7 & 10 & 11 & 21 & 10 & 15 \\
\hline Age range & $0.5 \cdot 11 y$ & $5 \cdot 13 y$ & $3-12 y$ & $10-17 y$ & $1-14=$ & $? \cdot 28 y$ & $1-27 y$ \\
\hline $\begin{array}{c}\text { Nutritional } \\
\text { status }\end{array}$ & malnutrition & malnutrition & malnutrition & malnutrition & eormal & malnutrition & malnutrition \\
\hline $\begin{array}{l}\text { Sevdy } \\
\text { duration }\end{array}$ & 1 moenth & 6 month & 1 month & 1 month & 5 days & 6 monchs & 3 monchs \\
\hline $\begin{array}{l}\text { Type of } \\
\text { study }\end{array}$ & $\begin{array}{l}\text { Prospective } \\
\text { own control }\end{array}$ & $\begin{array}{l}\text { wospective } \\
\text { ewn control }\end{array}$ & prospective own control & $\begin{array}{l}\text { prospective } \\
\text { own control }\end{array}$ & $\begin{array}{l}\text { prospective } \\
\text { CF control }\end{array}$ & $\begin{array}{l}\text { prospective } \\
\text { CF elemental } \\
\text { CF polymaric }\end{array}$ & $\begin{array}{l}\text { prodpective own } \\
\text { control }\end{array}$ \\
\hline $\begin{array}{l}\text { Feedine } \\
\text { intervention }\end{array}$ & $\begin{array}{c}\text { TPN } \\
90-100 \% \\
\text { RDA }\end{array}$ & $\begin{array}{l}\text { ilemental } \\
20.40 \% \\
\text { RDA (extra) }\end{array}$ & $110-150 \leqslant$ RDA & $\begin{array}{c}\text { TrN } \\
120 \% R D A\end{array}$ & $\begin{array}{l}\text { mielemental } \\
142 \text { kcal/48 }\end{array}$ & $\begin{array}{l}\text { elemental } \\
35 \% \text { RDA } \\
\text { (extra) versus } \\
\text { hypercaioric }\end{array}$ & $\begin{array}{l}\text { Dyperealoric } \\
\text { polymeric } \\
130 \% \text { RDA }\end{array}$ \\
\hline Roulte & parenteral & enteral & nasogastric & persinternal & ord & enteral & and \\
\hline Eneal & $\begin{array}{l}\text { SDS weight ! } \\
\text { SDS height : } \\
\text { MUACW add } \\
\text { clinical weore ! } \\
\text { FVC, FeVII } \\
\text { PEF ! }\end{array}$ & $\begin{array}{l}\text { SDS weight : } \\
\text { SDS weight I } \\
\text { MUAC \$ std ! } \\
\text { FM L.BM (kg)! } \\
\text { muscle mass (kg)! } \\
\text { clinical score ! } \\
\text { 3-meklis excre । }\end{array}$ & 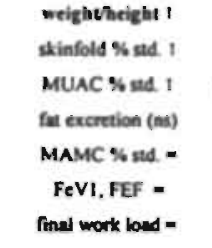 & $\begin{array}{l}\text { weight (kg) t } \\
\text { weight (ew) t } \\
\text { skinfold (mm) 1 } \\
\text { MAMC (cm) ! } \\
\text { MIP, MEP । } \\
\text { FeVI, FEF - }\end{array}$ & $\begin{array}{l}\text { Weight (ky) I } \\
\text { Nexcretion ! } \\
\text { fat absorption coeff. } \\
\text { cient ! }\end{array}$ & 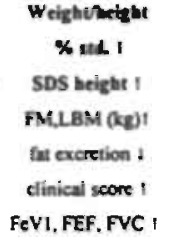 & $\begin{array}{l}\text { SDS weight (ns) } \\
\text { SOS weight (ns) } \\
\text { growth velocily } \\
\quad \text { (ns) } \\
\text { skinfold. (ns) } \\
\text { weighin (kg) t }\end{array}$ \\
\hline $\begin{array}{l}\text { Follow op } \\
\text { (durntion) }\end{array}$ & $\begin{array}{l}\text { dl parameters } \\
\text { improve further } \\
\text { (after months) }\end{array}$ & NR & $\begin{array}{l}\text { Il panmeters I } \\
\text { (after } 2 \text { months) }\end{array}$ & $\begin{array}{l}\text { MLP. MEP = } \\
\text { FeVI. FEF - } \\
\text { (after } 2 \text { months) } \\
\text { dil other } \\
\text { perrecers ! } \\
\text { (and 1-6month) }\end{array}$ & NR & NR & NR \\
\hline
\end{tabular}

MIP : Maximal Inspiratory Pressure MEP : Maximal Expiratory Pressure FeVI : Forced expiratory volume in I sec. SDS : Standard deviation score N-excretion : Fecal Nitrogen excretion MUAC : Mid Upper Am Circumference MAMC : Mid Am Muscle Circumference
FVC : Forced Vital Capicity $\quad 1:$ Improved

FEF : Foreed Expiratory Flow 1 : Decreased

PEF : Peak Expiratory Flow = : unchanged

LBM : Lean Body Mass $\quad$ (ns) : not significant

FM : Fatmass $\quad$ NR: not reported

RDA: Recommended daily allowance

3-meHis excre : 3 methylhistidine excretion in urine 
Table 2 Long-term feeding intervention studies in cystic fibrosis.

\begin{tabular}{|c|c|c|c|c|c|c|c|c|}
\hline Aurthon & et al, '73 & $\begin{array}{l}\text { "Bemy } \\
\text { et all, '75 }\end{array}$ & $\begin{array}{l}\text { "Yises } \\
\text { etial.'78 }\end{array}$ & $\begin{array}{c}\text { Levy } \\
\text { et al, 's5 }\end{array}$ & $\begin{array}{l}\text { moland } \\
\text { et al, 'B6. }\end{array}$ & $\begin{array}{l}\text { "Sheperd } \\
\text { et al', '86 }\end{array}$ & $\begin{array}{l}\text { "Favell } \\
\text { ef at, 's? }\end{array}$ & $\begin{array}{l}\text { "Luder } \\
\mathrm{nad,} \cdot \mathrm{g}\end{array}$ \\
\hline Number of cases & 17 & is & 4 & 14 & 10 & 10 & 36 & 37 \\
\hline Age nange & $2.21 y$ & $10 m-18 y$ & $3-16 y$ & $5-22 y$ & $5 \cdot 20 y$ & $3 \cdot 13 y$ & $3 \cdot 4 m$ & $2 \cdot 27 y$ \\
\hline $\begin{array}{l}\text { Nutrition } \\
\text { stuns }\end{array}$ & mainuarik & malnutrit & malmuterit & mainutrit & mainutrik & malnutrit & normal & malnutrit \\
\hline $\begin{array}{l}\text { Sundy } \\
\text { duration }\end{array}$ & $\begin{array}{c}3 \text { months to } 3 \\
\text { ycers }\end{array}$ & 1 year & I yeat & 1,1 year & $\begin{array}{l}10-36 \\
\text { months }\end{array}$ & I year & 8 months & 4 yean \\
\hline $\begin{array}{l}\text { Type of } \\
\text { twady }\end{array}$ & $\begin{array}{l}\text { peospect } \\
\text { own } \\
\text { sontrol }\end{array}$ & $\begin{array}{l}\text { prospect } \\
\text { CF } \\
\text { control }\end{array}$ & $\begin{array}{l}\text { prosped } \\
\text { CF } \\
\text { enttrol }\end{array}$ & $\begin{array}{l}\text { prospect } \\
\text { CF } \\
\text { sontrol }\end{array}$ & $\begin{array}{l}\text { prospect } \\
\text { own } \\
\text { control }\end{array}$ & $\begin{array}{l}\text { prospect } \\
\text { CF } \\
\text { control }\end{array}$ & $\begin{array}{l}\text { prospect } \\
\text { CF } \\
\text { control }\end{array}$ & $\begin{array}{l}\text { prosped } \\
\text { ewt } \\
\text { control }\end{array}$ \\
\hline $\begin{array}{l}\text { Fetding } \\
\text { intervent }\end{array}$ & $\begin{array}{l}\text { etemetal } \\
\text { S0-100s } \\
\text { RDA }\end{array}$ & $\begin{array}{l}\text { elementad } \\
100 \mathrm{NRDA}\end{array}$ & $\begin{array}{l}\text { elemental } \\
100 \% \mathrm{RDA}\end{array}$ & $\begin{array}{c}\text { (veal) } \\
\text { elemetwal } \\
30 \% R D A \\
\text { (extn) }\end{array}$ & $\begin{array}{l}\text { oredigeat } \\
1000 \text { to } \\
2000 \text { Keal }\end{array}$ & $\begin{array}{l}\text { wielentatal } \\
120-140 \\
\text { NRDA }\end{array}$ & $\begin{array}{c}\text { pregestiail } \\
\text { vensus } \\
\text { standard } \\
120 \mathrm{Kea} / \mathrm{ks}\end{array}$ & $\begin{array}{l}\text { Dypercal } \\
\text { malyenerie } \\
120 \text { S6RDA }\end{array}$ \\
\hline Roule & oral & end & eral & eastrostomy & jejunontomy & enteral & oral & ond \\
\hline Effect & $\begin{array}{c}\text { SDSweil } \\
\text { SDStreit } \\
\text { clinical score ! }\end{array}$ & $\begin{array}{c}\text { SDSeeil } \\
\text { elinical score I } \\
\text { SOS thei (ns) }\end{array}$ & $\begin{array}{l}\text { SDSmeit } \\
\text { SDSteit } \\
\text { sosakf } \\
\text { boneage! }\end{array}$ & $\begin{array}{l}\text { weight (kg)! } \\
\text { beight (em) ! } \\
\text { weihei } \% \text { std. } \\
\text { ! } \\
\text { growth velocily } \\
1 \\
\text { BF } \% \text { ! } \\
\text { FFM ! } \\
\text { TBK ! } \\
\text { TBN ! } \\
\text { :FVC - } \\
\text { :FeVI - }\end{array}$ & $\begin{array}{l}\text { SDSweil } \\
\text { MAMC I } \\
\text { FVC = }\end{array}$ & $\begin{array}{l}\text { SDSweil } \\
\text { SOS hei! } \\
\text { protein syndhes ! } \\
\text { protein catabol ! } \\
\text { FoVI ! } \\
\text { FVC ! } \\
\text { FEF ! }\end{array}$ & $\begin{array}{l}\text { weight (ke) ! } \\
\text { beight (en) ! } \\
\text { growth velocity! }\end{array}$ & $\begin{array}{c}\text { SDSweil (os) } \\
\text { sDs bei (as) } \\
\text { FEF - } \\
\text { BMI । }\end{array}$ \\
\hline $\begin{array}{l}\text { Follow up } \\
\text { (duration) }\end{array}$ & NR & NR & $\begin{array}{c}\text { all } \\
\text { parameters I } \\
\text { excopt } \\
\text { bone exe } \\
\text { (1 yeu) }\end{array}$ & NR & NR & NR & NR & $N R$ \\
\hline
\end{tabular}

\begin{tabular}{|c|c|c|}
\hline $1:$ Improved & LBM : Lean Body Mass & BMI : Body Mass Index \\
\hline I: Decreased & FFM : Fu Free Mass & BF : Body fat \\
\hline$=$ : unchanged & TBN : Total body' nitrogen & $\mathrm{N}$-excrt : Nitrogen excretion \\
\hline RDA : Recommended Daily Allowance & TBK : Toul Body Kalium & (ns) non significant \\
\hline SDSwei : SDS weight & FVC : Forced Vital Capacity & Abs. coeff : absorption coefficient \\
\hline SDShei : SDS height & FeV1: Forced expiratory volume & $\$ \mathrm{FVC}$ and $\mathrm{FeVI}$ decrease in CF control \\
\hline SDSskit : SDS skinfolds & FEF : Forred Expiratory Flow & MAMC : Mid Arm Muscle Circumference \\
\hline
\end{tabular}


Table 3 Effect of short-term use of gastric acid inhibitors on steatorrhes and nutritional status in CF children.

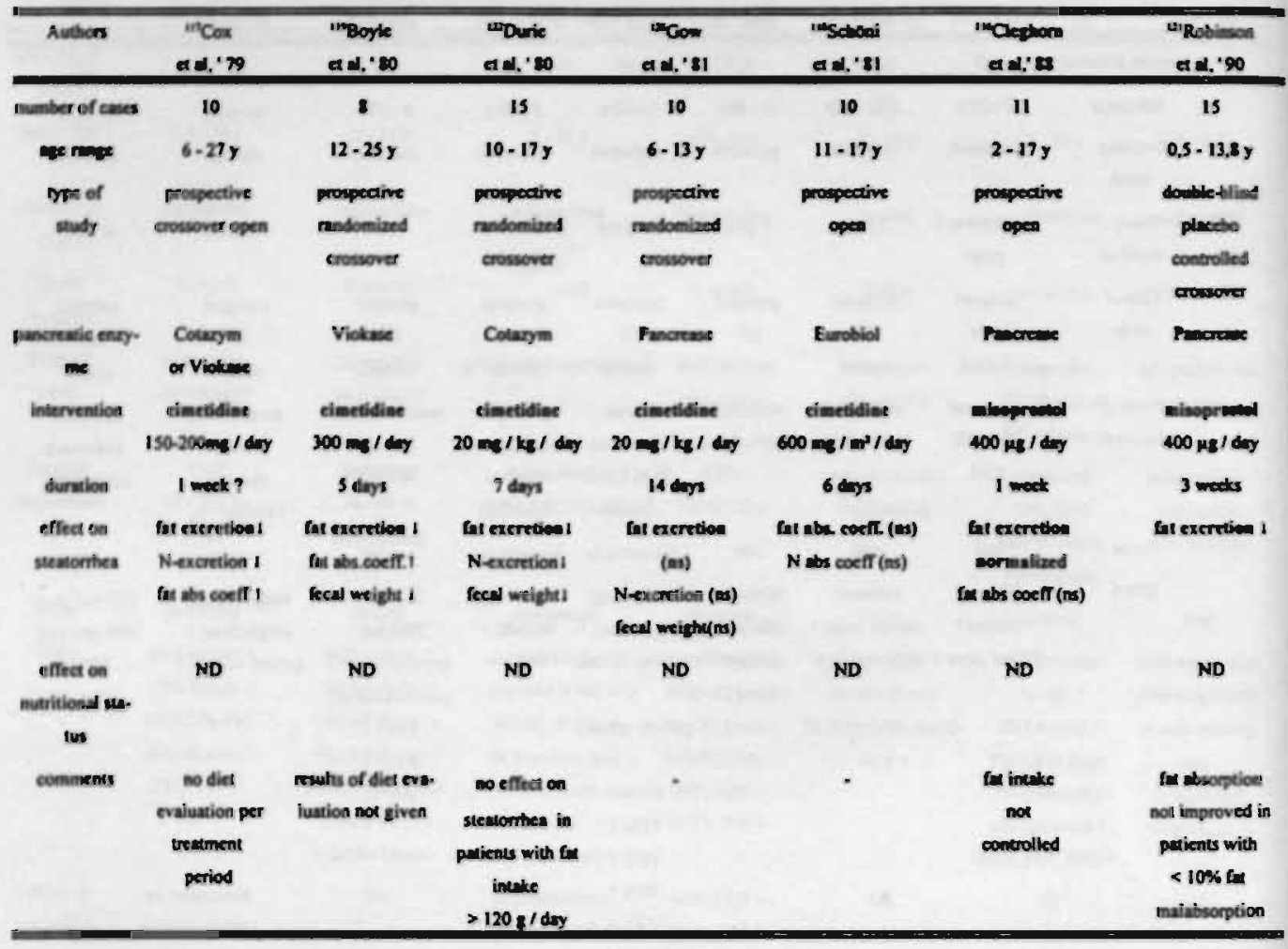

abs coeff : fat absorption coefficient

N-excretion : fecal Nitrogen excretion

(ns) : not significent 
Table 4 Effect of long-term use of gastric acid inhibitors on steatorrtea and nutritional status in CF children.

\begin{tabular}{|c|c|c|c|}
\hline Authors & "arSchoni et al, ' 84 & 'DeChalmers et al, ' 85 & ${ }^{13}$ Carroccio et al, "92 \\
\hline number of cases & 38 & 16 & 10 \\
\hline age range & $\operatorname{mean} 13 y$ & $5 \cdot 19 y$ & $7 \cdot 18 y$ \\
\hline type of study & $\begin{array}{c}\text { prospective randomized } \\
\text { doubleblind }\end{array}$ & double-blind crossover & double-blind crossover \\
\hline pacreatic enxyme & Pancrease & Cotarym & Pancrease \\
\hline \multirow[t]{2}{*}{ intervention } & cinetidine & cimetidine & Ianotidine \\
\hline & $600 \mathrm{mg} / \mathrm{m}^{2} / \mathrm{day}$ & $25 \mathrm{mg} / \mathrm{kg} / \mathrm{day}$ & Ing/kg/day \\
\hline duration & 4 months & 6 months & 6 months \\
\hline \multirow[t]{2}{*}{ effect on steatornhea } & $\begin{array}{l}\text { plasma lipid and } \\
\text { lipoprotein (as) }\end{array}$ & $\begin{array}{l}\text { fat excretion I } \\
\text { N-excretion (ns) }\end{array}$ & $\begin{array}{c}\text { fat absorption coeff. I } \\
\text { fecal weight I }\end{array}$ \\
\hline & & fecal weight (ns) & \\
\hline effect on & weight, height (ns) & SDSweight (ns) & weighe (kg) I \\
\hline \multirow[t]{3}{*}{ nutritional status } & $\begin{array}{l}\text { skinfolds (ns) } \\
\text { TLC, TGV (ns) }\end{array}$ & $\begin{array}{l}\text { SDSheight (ns) } \\
\text { skinfolds (ns) }\end{array}$ & $\begin{array}{c}\text { height (cm) I } \\
\text { clinical score (ns) }\end{array}$ \\
\hline & Raw, sGaw I & bone age (ns) & \\
\hline & & clinical score (ns) & \\
\hline comments & no diet evaluation & $\begin{array}{l}\text { results of diet } \\
\text { evaluation was not given }\end{array}$ & $\begin{array}{l}\text { results of diet } \\
\text { evaluation was not given }\end{array}$ \\
\hline
\end{tabular}

SDS : Standard Deviation Score for age and sex

TLC : Total Lung Capicity

TGV : Thoracic Gas volume

Raw : airway resistance

sGaw : specific conductance

(ns) : not significant 


\section{6 EVALUATION OF STEATORRHEA}

\section{6. 1 Fecal fat balance}

The 3 days fecal fat excretion while patients are on a standard fat diet is the most reliable method for quantitative determination of fecal fat loss. The fat absorption coefficient is calculated by the following formula:

(Fat ingested - fat excreted) / fat ingested X 100

Normal fat absorption coefficient at different ages have been reported as follows:

Age $>1$ year : $295 \%(126-128)$

Age $<1$ year : $>83 \%$ if formula fed and $>93 \%$ if breast fed (126)

Premature infants : 38 - $73 \%$ depending on the formula used (129)

Fecal fat can be determined by either Gravimetric or Titrimetric methods. For both methods, fecal fat is extracted with an organic solvent, the fat content is subsequently measured either by weighing (Gravimetric method) or by titration (Titrimetric method). The Gravimetric method determine all fecal lipid components, resulting in erroneously high results. On the contrary, the titrimetric method only measures fatty acids. Fecal lipids are first saponified and subsequently acidified to liberate fatty acids which are then extracted. Since its first. description in 1949 (130), the titrimetric procedure of van de Kamer has been used as a reference method for the evaluation of malabsorption. The fat balance method is reliable for the quantification of fecal fat loss with a coefficient of variation of $4,6 \%$ (131). However, the determination procedure is time consuming, expensive and necessitates sophisticated apparatus. Further, since the fat excretion is dependent on fat intake, patients have to keep up a strictly fat constant diet of more than 80 gram per day. Moreover, fecal collection have to be done very accurately. The balance method consequently is poorly reliable in outpatients, especially in children and infants. When fat balance is not possible, measuring fecal fat concentration in a fecal sample can be used for the screening of fat malabsorption. Results are then expressed as percent of wet fecal weight (fecal fat concentration). Using the ${ }^{14} \mathrm{C}$. triolein ${ }^{3} \mathrm{H}$-oleic acid test as a reference method, Pedersen et al. have studied the diagnostic 
value of fecal fat concentration as measured by the titrimetric method of van de Kamer in a 72 hours fecal collection without controlling for dietary fat (132). In this study, a similar diagnostic value was found for both fecal fat concentration (FFC) and fecal fat excretion (FFE): The sensitivity, specificity, positive predictive value and negative predictive value of FFC versus FFE were respectively $93,1 \%$ versus $90 \%$; $92,4 \%$ versus $89,4 \% ; 90 \%$ versus $93 \%$ and $89 \%$ versus $90 \%$ with a day to day coefficient of variation of $29 \%$ for FFC and $64 \%$ for FFE. In only $6 \%$ of the patients studied, the FFC when measured in a single day sample differed from the mean 3-day fecal fat concentration value whereas the FFE differed from the mean 3-day fecal fat excretion in $37 \%$ of the patients. FFC correlated weakly but significantly with FFE ( $r=0,55 ; \mathrm{p}<0,01)$ (133). FFC results in pancreatic steatorrhea being higher than in nonpancreatic steatornhea, Bolinn et al. have suggested that FFC could be used for the differentiation of both types of steatornhea (134). This has however not been confirmed by other investigators; who found much overlap in FFC results between pancreatic and nonpancreatic steatorrhea $(132,133,135,136)$. Results of these studies are shown in table 5 .

The utility of FFC as an screening method for fat malabsorption has been limited because of the high interday variation (29\%). This interday variation might be due to the varying fecal water content as reported by Weijers et al. (137). This suggests that if the effect of varying water content could be eliminated, the interday variation of FFC would be much lower. A new method for the semiquantitative determination of FFC, which eliminates the influence of varying fecal water content is the steatocrit.

\section{6. 2 Steatocrit}

This procedure is based on the fact that fecal fat is extracted by centrifugation of diluted stool in a hematocrit capillary at $13000 \mathrm{rpm}$ for 15 minutes (138). After centrifugation, three layers, are distinguished in the capillary; the upper fatty layer $(\mathrm{FL})$, the middle fluid layer and the bottom solid layer (SL). The fecal fat measured by steatocrit is expressed as fecal fat concentration and is calculated as FL / (FL + SL). Reported norrnal values are $<2 \%$ (139). The steatocrit method is very suitable for use in children and infants since it is simple, noninvasive and can be performed on small fecal samples ( 0,5 gram). Moreover, it is inexpensive and. the whole test takes only 20 minutes. Although several authors have reported this method to 
be satisfactory for the evaluation of steatornhea (138-142), some bave reported the steatocrit to be quite unreliable (143). Sugai reported a specificity of $97 \%$ for steatocrit but a sensitivity of $98 \%, 79 \%$ and $29 \%$ for samples with respectively high, moderate and low fat content (144). This low sensitivity observed for samples of low fat content may be due to difficulties with either fat extraction or with obtaining a clear separation between the fatty, aqueous and solid layer, resulting in erroneous results.

\section{6. 3 Sudan staining method}

The presence of fecal fat can be screened for by microscopic examination of stools. The fecal preparation is first acidified and stained with Sudan staining. After heating, fecal fatty acids and triglycerides are seen as fatty globules under the microscope. Dependent on the number and the size of the globules, the fatty globules are classified as normal , slightly increased or definitely increased (145). Weijers et al. studied the agreement between results of the Sudan staining method and chemically measured fecal fat (137). Satisfactory agreement between both methods was found in (60 - $70 \%$ cases) for fecal samples with very low or very high fat content $(<3 \%$ or $>9 \%$ ) but the agreement dropped to $40 \%$ for samples of moderate fat content $(3-9 \%)$.

\section{6. 4 C- Triolein absorption test}

After ingestion, ${ }^{14} \mathrm{C}$-Triolein is digested by pancreatic lipase in the duodenum liberating fatty acids, which on further oxidation yield ${ }^{14} \mathrm{CO}_{2}$ which can be detected in expired air. Although this method is simple, rapid to perform and gives a direct evaluation of pancreatic function, it is not appropriate for use in children because of the radioactivity. Recently, a new non radioactive substrate ${ }^{13} \mathrm{C}$-Triolein has been introduced but this is however expensive and a mass spectrometer is needed in order to use this test (131).

\section{6. 5 Near Infrared Reflectance Analysis}

This method is based on the analysis of the infrared spectrum radiation, reflected by the 
surface of the material under study. Specific peaks for the component to be investigated can be identified and their heights can be related to the concentration of the component studied by using computerised multilinear regression analysis. Besides measuring fecal fat, this apparatus can also be used for the determination of fecal nitrogen and water content. The analysis lasts less than 1 minute and can be performed on small samples ( 2 - 3 gram ). The variation coefficient is $2,1 \%$ and the correlation coefficient with the van de Kamer method is 0,92 (146). However this high correlation is possibly due to the fact that this method is calibrated by the titrimetric method described by van de Kamer. The calibration procedure is difficult and this sophisticated instrument is expensive (147). Further studies are necessary in order to better evaluate the usefulness of near infrared reflectance analysis in clinical practice. 
Table 5 Diagnostic value of fecal fat concentration (FFC) and fecal fat excretion (FFE) in studies of fat malassimilation.

\begin{tabular}{|c|c|c|c|c|c|}
\hline Authon & medenen' ' 4 & "Bollinn' 34 & 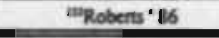 & 'Yembeke' 87 & "Hai et al ' 69 \\
\hline & & 50 & & 369 & 338 \\
\hline Aims of stady & $\begin{array}{l}\text { diapnostic value of FFC } \\
\text { venus FFE }\end{array}$ & diagnontic value of FFC & dingnostic value of FFC & fingnostic value of FFC & Eingnostic value of FFC \\
\hline Method used & 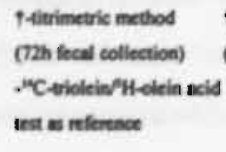 & $\begin{array}{l}\text { Thitrimetric method } \\
\text { (72h fecal collection) }\end{array}$ & $\begin{array}{l}\text { fritrimetric method } \\
\text { (72h fecal collection) }\end{array}$ & $\begin{array}{l}\text { Ttitrimetric method } \\
\text { (72h fecal collection) }\end{array}$ & $\begin{array}{l}\text { frierimemic method } \\
\text { (72h fecal colliection) }\end{array}$ \\
\hline Population (n) & 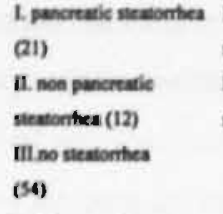 & $\begin{array}{l}\text { 1. pancrealis } \\
\text { steatombea (19) } \\
\text { 11. nonpancreatic } \\
\text { steanomies (B1) }\end{array}$ & 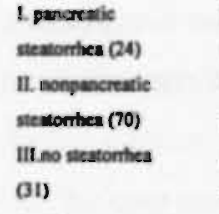 & $\begin{array}{l}\text { I. puncreatic } \\
\text { stemonthes (59) } \\
\text { II. nonpancreatic } \\
\text { stemonthea (53) } \\
\text { III no steatontere sick } \\
\text { ind normai controls (257) }\end{array}$ & $\begin{array}{l}\text { I. puncreatic } \\
\text { sewontea(88) } \\
\text { II. nonpancreatic } \\
\text { stemontea (525) }\end{array}$ \\
\hline Results & 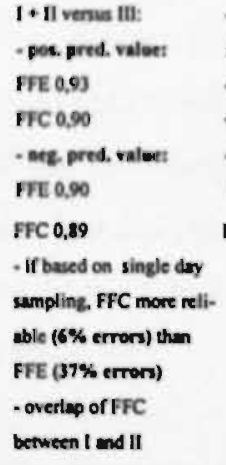 & 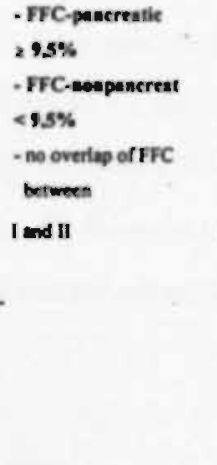 & 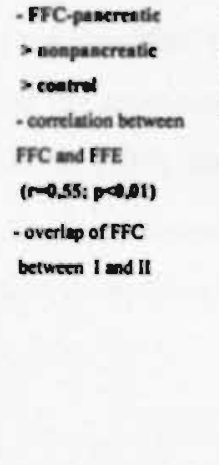 & $\begin{array}{l}\text {-FFC-paserentic }>\text { mo } \\
\text { pancreatic steatorritea } \\
\text { coatrol } \\
\text { - Overlap of FFC } \\
\text { between I and II }\end{array}$ & 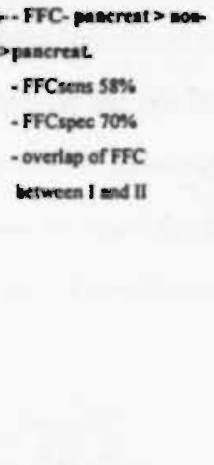 \\
\hline Comments. & 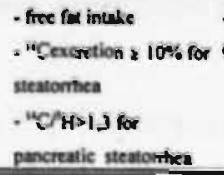 & $\begin{array}{l}\text { - fa diet } \\
90-100 y d d y\end{array}$ & 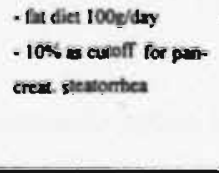 & - Exx diet $280 \mathrm{~g} / \mathrm{day}$ & 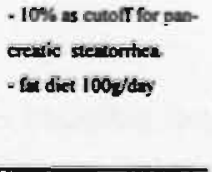 \\
\hline
\end{tabular}

FFC: Fecal fat coricentration

FFE: Fecal fat excretion

† Method as deseribed by van de Kamer (III)

pos. pred. value: positive predictive value

neg. pred. value: negative predictive value

sens: sensitivity

spec: specificity 


\section{AIMS OF THE STUDY}

With age, children with CF show progressing malnutrition mainly attributed to either persisting malabsorption notwithstanding the use of high oral doses of pancreatic enzymes or increased energy consumption secondary to respiratory disease. Prospective studies in young children have shown malnutrition to occur only in patients with pancreatic insufficiency (34). Efforts to either maintain or restore the nutritional condition have shown that, notwithstanding the use of pancreatic enzymes, high nutrient intakes only seems to be effective when administered "digested" either as total parenteral nutrition or as (semi)elemental feedings orally or by tube feeding. The apparent insufficient effect of pancreatic enzymes does not seem to be due to too low administered doses and recently very high doses have been used with the hope of correcting malabsorption. Suggestions have been made that these high doses might be responsible for the recently reported occurence of colitis in these patients (113-115).

Our hypothesis was that persisting malabsorption in these patients is likely to be linked to a low duodenal $\mathrm{pH}$ which interferes with several digestive and absorptive processes such as impeding transport of split fatty acids from the luminal lipid globules to the absorptive area through the mediation of bile salt micelles. If this was correct, antacid treatment should improve fat malabsorption in these patients. The fact that most studies hereover have been inconclusive might be due to the short and inefficient control of duodenal $\mathrm{pH}$ with the drugs used. A recent double-blind control study in adults patients has shown malabsorption to normalize in several patients treated with a proton pump inhibitor (omeprazol) (112). Until now, no studies with proton pump inhibitor have been reported in children.

\section{The aims of the present work were:}

1. Develop an easy, noninvasive, cheap and reliable test for the monitoring of fecal fat loss in pancreatic malabsorption.

2. Evaluate the nutritional condition, the body composition and the presence or persistence of fat malabsorption in our patients with exocrine pancreatic insufficiency accompanying cystic fibrosis. 
3. Evaluate whether or not the use of a proton pump inhibitor (lansoprazole) in our patients with persisting malabsorption improves both the fat malabsorption and the nutritional condition. 


\section{REFERENCES}

(1) G. Fanconi, E. Uehlinger, C. Knauer. Das Coeliaksyndrom bei Angeborener Zysticher Pankreas fibromatose und Bronchiektasien. Wein Med Wschr 1936; 86: 753-756.

(2) CF Genetic analysis consortium. Worldwide survey of the $\Delta \mathrm{F} 508$ mutation. Am J Hum Genet 1990; 47: 354-359.

(3) M. Welsh, A. Smith. Molecular mechanisms of CFTR chloride channel dysfunction in cystic fibrosis. Cell 1993; 73: 1251-1254.

(4) C. Marino, L. Matoveik, F. Gorelick, J. Cohn. Localization of the cystic fibrosis transmembrane conductance regulator in pancreas. J Clin Invest 1991; 88: 712-716.

(5) T. Boat, M. Welsh, A. Beaudet. (1989). In The Metabolic Basis of inherited Disease, C. Scriver, A. Beaudet, W. Sly, D. Valle, eds. (New York: McGraw-Hill,inc.), pp. 2649-2680.

(6) E. Kerem, J. Reisman, M. Corey, G. Canny, H. Levison. Prediction of mortality in patients with cystic fibrosis. N Engl J Med 1992; 326: 1187-91.

(7) C. Sommerhoff, J. Nadel, C. Basbaum et al. Neutrophil elastase and cathepsin G stimulate secretion from culture bovine airway gland serous cells. J Clin Invest 1990;85: 682-689.

(8) L. Sharples, T. Hathaway, C. Dennis, N. Caine, T. Higenbottam, J. Wallwork. Prognosis of patients with cystic fibrosis awaiting heart and lung transplantation. J Heart-Lung-Transplant 1993; 12: 669-74.

(9) J. Britton. Effects of social class, sex, and region of residence on age at death from cystic fibrosis. Br Med J 1989; 298: 483-487.

(10) M. Corey, F. McLaughlin, M. Williams, H. Levison. Comparison of survival, growth and pulmonary function in patients with cystic fibrosis in Boston and Toronto. $\mathrm{J}$ Clin Epidemiol 1988; 41: 583-591.

(11) M. Aitken, S. Fiel. Cystic fibrosis. Dis Mon 1993; 39: 1-52.

(12) P. Brihaye, P. Clement, I. Dab, B. Desprechin. Pathological changes of the lateral nasal wall in patients with cystic fibrosis. Int J Pediatr Otorhinolaryngol 1994; 28: 141-7.

(13) I. Mackay, B. Djazaeri. Chronic sinusitis in cystic fibrosis. J Roy Soc Med 1994; 87 (Suppl 21): 17-19.

(14) B. Hadom, P. Johansen, C. Anderson. Pancreozymin secretin test of exocrine pancreatic function in cystic fibrosis and the significance of the result for the pathogenesis of the disease. 
Can Med Assoc J 1968; 98: 377-385.

(15) B. Hadorn, G. Zoppi, D. Shmerling, A. Prader, I. McIntyre, C. Anderson. Quantitative assessment of exocrine pancreatic function in infants and children. J Pediatr 1968; 73: 39-50.

(16) H. Schachman, E. Lebenthal, K. Khat. Recurrent, acute pancreatitis in patients with normal pancreatic enzymes. Pediatrics 1975 ; 55: 86-95.

(17) K. Gaskin, P. Durie, M. Corey, P. Wei, G. Forstner. Evidence for a primary defect of pancreatic $\mathrm{HCO}_{3}$-secretion in cystic fibrosis. Pediatr Res 1982; 16: 554-557.

(18) A. Atlas, S. Orenstein, D. Orenstein. Pancreatitis in young children with cystic fibrosis. J Pediatr 1992; 120: 756-9.

(19) F. Ahmed, J. Ellis, J. Murphy, S. Wooton, A. Jackson. Excessive faecal loss of vitamin A (retinol) in cystic fibrosis. Arch Dis Child 1990; 65: 589-593.

(20) R. Sokol, M. Reardon, F. Accurso et al. Fat-soluble-vitamin status during the first year of life in infants with cystic fibrosis identified by screening of newborns. Am J Clin Nutr 1989; 50: $1064-71$.

(21) V. Hubbard, P. Farrell, P. di Sant 'Agnese. 25-hydroxylcholecalciferol levels in patients with cystic fibrosis. J Pediatr 1979; 94: 84-86.

(22.) E. Mischler, PJ Chesney, PW Chesney, R. Mazess. Demineralization in cystic fibrosis detected by direct protein absorptiometry. Am J Dis Child 1979; 133: 632-635.

(23) N. Solomons, J. Wagonfeld, C. Rieger et al. Some biochemical indices of nutrition in treated cystic fibrosis patients. Am J Clin Nutr 1981; 34: 462-474.

(24) R. Allen, B. Seetharam, E. Podell, D. Alpers. Effect of proteolytic enzymes on the binding of cobalamin to $\mathrm{R}$ protein and intrinsic factor. J Clin Invest $1978 ; 61$ : 47-54.

(25) M. Murphy, W. Sheldon, A. Brunetto et al. Active and passive sugar absorption in pancreatic insufficiency. J Pediatr Gastroenterol Nutr 1989; 8: 189-194.

(26) L. Frase, A. Strickland, G. Kachel, G. Krejs. Enhanced glucose absorption in the jejunum of patients with cystic fibrosis. Gastroenterology $1985 ; 88: 478-484$.

(27) M. Lohr, P. Goertchen, H. Nizze et al. Cystic fibrosis associated islet changes may provide a basis for diabetes. An immunocytochemical and morphometrical study. Virchows Arch [A] 1989; 414: 179-185.

(28) L. Krueger, A. Lerner, S. Katz, R. Mack, D. Holsclaw, E. Lebenthal. Cystic fibrosis and diabetes mellitus: interactive or idiopathic. J Pediatr Gastroenterol Nutr 1991; 13: 209-219. 
(29) E. Wilmshurst, J. Soeldner, D. Holsclaw. Endogeneous and exogeneous insulin responses in patients with cystic fibrosis. Pediatrics 1975; 55: 75-82.

(30) O. Andersen, S. Garner, C. Heilmann, K. Petersen, W. Petersen, C. Koch. Glucose tolerance and insulin receptor binding to monocytes and erythrocytes in patients with cystic fibrosis. Acta Paediatr Scand 1988; 77: 67-71.

(31) A. Moran, P. Diem, D. Klein, M. Levitt, R. Robertson. pancreatic endocrine function in cystic fibrosis. J Pediatr 1991; 118: 715-723.

(32) H. Berry, F. Kellogg, M. Hunt, R. Ingberg, L. Ricter, C. Gutjahr. Dietary supplement and nutrition in children with cystic fibrosis. Am J Dis Child 1975; 129; 165-171.

(33) J. Dodge, J. Yassa. Food intake and supplementary feeding programs. In: J. Sturgess, ed. perspectives in cystic fibrosis. Toronto: Canadian Cystic Fibrosis Foundation; 1980: 125-136. (34) M. Bronstein, R. Sokol, S. Abman et al. Pancreatic insufficiency, growth, and nutrition in infants identified by newborn screening as having cystic fibrosis. J Pediatr 1992; 120: 533-40. (35) J. Tomezsco, V. Stallings, D. Kawchak, J. Goin, G. Diamond, T. Scanlin. Energy expenditure and genotype of children with cystic fibrosis. Pediatr Res 1994; 35: 451-460.

(36) M. Bronstein, P. Davies, K. Hambidge, F. Accurso. Normal energy expenditure in the infant with presymptomatic cystic fibrosis. J Pediatr 1995; 126: 28-33.

(37) K. Cox, J. Isenberg, M. Ament. Gastric acid hypersecretion in cystic fibrosis. J Pediatr Gastroenterol Nutr 1982; 1: 559-565.

(38) C. Roy, A. Weber, C. Morin et al. Abnormal biliary lipid composition in cystic fibrosis. N Engl J Med 1977; 297: 1301-1305.

(39) A. Malfroot, I. Dab. New insights on gastro-oesophageal reflux in cystic fibrosis by longitudinal follow up. Arch Dis Child 1991; 66: 1339-1345.

(40) S. Cucchiara, F. Santamaria, M. Andreotti et al. Mechanisms of gastro-oesophageal reflux in cystic fibrosis. Arch Dis Child 1991; 66: 617-622.

(41)P. Gustafsson, S. Fransson, N. Kjellman, L. Tibbling. Gastro-oesophageal reflux and severity of pulmonary disease in cystic fibrosis. Scand J Gastroenterol 1991; 26: 449-456.

(42) S. Fiedorek, R. Shulman, W. Klish: Endoscopic detection of peptic ulcer disease in cystic fibrosis. Clin Pediatr (Phila) 1986; 25: 243-246.

(43) P. Robinson, A. Smith, P. Sly: Duodenal $\mathrm{pH}$ in cystic fibrosis and its relationship to fat malabsorption. Dig Dis Sci 1990: 35: 1299-1304. 
(44) J. McPartin, J. Dickson, V. Swain. Meconium ileus, immediate and longterm survival. Arch Dis Child 1972; 47: 207-210.

(45) H. Andersen, K. Hjelt, E. Waever, K. Overgaad. The age related incidence of meconium ileus equivalent in a cystic fibrosis population: the impact of high energy intake. J Pediatr Gastroenterol Nutr 1990; 11:356-360.

(46) L. Kulczyki, H. Schwachman. Studies in cystic fibrosis of the pancreas: occurrence of rectal prolapse. N Engl J Med 1958;259: 409-412.

(47) D. Holsclaw, C. Rocmans, H. Schwachman. Intussusception in patients with cystic fibrosis. Pediatrics 1971; 48:51-58.

(48) H. Rovsing, K. Sloth. Microgallbladder and biliary calculi in mucoviscidosis. Acta Radiol [Onco] 1973; 14: 588-592.

(49) F. Santamaria, P. Vajro, V. Oggero et al. Volume and emptying of the gallbladder in patients with cystic fibrosis. J Pediatr Gastroenterol Nutr 1990; 10: 303-306.

(50) L. Taussig, C. Lobeck, P. Ackerman, J. Kattwinkel: Fertility in males with cystic fibrosis. N Engl J Med 1972; 287: 586-589.

(51) E. Kaplan, H. Shwachman, A. Perlmutter et al.: Reproductive failures in males with cystic fibrosis. N Engl J Med 1968; 279: 65-69.

(52) S. Fitzsimmons: Cystic Fibrosis Foundation Patient Registry 1990 Annual Report. Bethesda, Cystic Fibrosis Foundation, 1991.

(53) P. Tam, P. Verdugo: Control of mucus hydration as a Donnan equilibrium process. Nature 1981: 292: 340-342.

(54) P. Di Sant 'Agnese, R. Darling. G. Perera, E. Shea. Abnormal electrolyte composition of sweat in cystic fibrosis of the pancreas. Clinical significance and relationship to the disease. Pediatries 1953; 12: 549-563.

(55) L. Gibson, R. Cooke. A test for concentration of electrolytes in sweat in cystic fibrosis of the pancreas utilizing in pilocarpine by iontophoresis. Pediatrics 1959; 23: 545-549.

(56) H. Veeze, A. Van den Ouweland, D. Halley et al. The diagnosis of cystic fibrosis: intestinal current measurements, a highly accurate mathod in case of a borderline phenotype. Submitted.

(57) M. Rosenfeld, W. Siegfried, K. Yoshimura et al. Adenovirus-mediated transfer of a recombinant alpha 1-antitrypsin gene to the lung epithelium in vivo. Science.1991; 252:431-4 
(58) B. Pitt, M. Schwarz, J. Pilewski et al. Retrovirus-mediated gene transfer in lungs of living fetal sheep. Gene Ther 1995; 2 : 344-50.

(59) M. Rosenfeld, K. Yoshimura, B. Trapnell et al. In vivo transfer of the human cystic fibrosis transmembrane conductance regulator gene to the airway epithelium. Cell. 1992; 68 : 143-55.

(60) R. Kraemer, A. Rüdeberg, B. Hadorn, E. Rossi. Relative underweight in cystic fibrosis and its prognostic value. Acta Paediatr Scand 1978; 67: 33-37.

(61) S. Rao, D. Wilson, R. Brooks et al. Acute effects of nebulization of n-acetylcysteine on pulmonary mechanics and gas exchange. Am Rev Respir Dis. 1970; 102: 17-22.

(62) W. Waring. Current management of cystic fibrosis. Adv Pediatr. 1976; 23: 401-38.

(63) M. Gotz, R. Kraerner, K. Kerrebijn et al. Oral acatylsysteine in cystic fibrosis. A cooperative study. Eur J Respir Dis. 1980;61: (Suppl 111): 122-6.

(64) J. Reisman, B. Rivington-Law, M. Corey et al. Role of conventional physiotherapy in cystic fibrosis. J Pediatr 1988; 113: 632-6.

(65) H. Steen, A. Redmond, D. O'Neil et al. Evaluation of the PEP mask in cystic fibrosis. Acta Paediatr Scand. 1991; 80: 51-6.

(66) C. Braggion, L. Cappelletti, M. Cornacchia, L. Zanolla, G. Mastella. Short-term effects of three chest physiotherapy regimens in patients hospitalized for pulmonary exacerbations of cystic fibrosis: A cross-over randomized study. Pediatr Pulmonol 1995; 19: 16-22.

(67) J. Pryor, B. Webber, M. Hobson et al. Evaluation of the forced expiratory technique as an adjunct to postural drainage in the treatment of cystic fibrosis. J Pediatr. 1983; 103: 538-42.

(68) P. Sutton, H. Gemmell, N. Innes et al. Use of nebulized saline and nebulized terbutaline as an adjunct to chest physiotherapy. Thorax. 1988; 43: 57-60.

(69) E. Pattishall. Longitudinal response of pulmonary function to bronchodilators in cystic fibrosis. Pediatr Pulmonol. 1990; 9: 80-5.

(70) P. Konig, D. Gayer, J. Shaffer et al. Bronchodilator responsiveness and spontaneous diumal variation of PEFR in patients with cystic fibrosis. Poster presented at the North American Cystic Fibrosis Conference. Washington, DC: 1992 Oct. Abstract.

(71) M. Konstan, P. Byrard, C. Hoppel, P. Davis: Effect of high dose ibuprofen in patients with cystic fibrosis. N Engl J Med 1995; 332: 848.

(72) H. Auerbach, M. Williams, J. Kirkpatrick et al. Alternate-day prednisone reduces morbi- 
dity and improves pulmonary function in cystic fibrosis. Lancet. 1985; 2: 686-8.

(73) B. Rosenstein, H. Eigen. Risk of alternate-day prednisone in patients with cystic fibrosis. Pediatrics. 1991; 87: 245-6.

(74) C. Pantin, R. Stead, M. Hodson et al. Prednisolone in the treatment of airflow obstruction in adults with cystic fibrosis. Thorax. 1986; 41: 34-38.

(75) M. Zach. Pathogenesis and managernent of lung disease in cystic fibrosis. J R Soc Med. 1991; 84 (Suppl 18): 10-7.

(76) McNeil Pharmaceutical. Pseudomonas vaccine tests start. Cystic Fibrosis Currents. 1991; 6(4).

(77) A. Khaghani, B. Madden, M. Hodson et al. Heart-lung transplantation for cystic fibrosis. Paper presented at the North American Cystic Fibrosis Conference. Dallas, TX: 1991 Oct 4.

(78) E. App, M. King, R. Helfesrieder et al. Acute and longterm amiloride inhalation in cystic fibrosis lung disease. Am Rev Respir Dis. 1990; 141: 605-12.

(79) M. Knowles, N. Church, W. Waltner et al. A pilot study of aerosolized amiloride for the treatment of lung disease in cystic fibrosis. N Engl J Med. 1990; 322: 1189-94.

(80) M. Hodson. Clinical studies of rhDNase in moderately and severely affected patients with cystic fibrosis - An Overview. Respiration 1995; 62 (suppl 1); 29-32.

(81) M. Aitken, W. Burke, G. McDonald et al. Recombinant human Dnase inhalation in normal subjects and patients with cystic fibrosis. A phase 1 study. JAMA. 1992; 267: 194751.

(82) R. Hubbard, N. McElvaney, P. Steven et al. A preliminary study of aerosolized recombinant human deoxyribonuclease $I$ in the treatment of cystic fibrosis. N Engl J Med. 1992; $326: 812-5$.

(83) N. McElvaney, R. Hubbard, P. Birrer et al. Aerosol alpha-1-antitrypsin treatment for cystic fibrosis. Lancet. 1991; 337: 392-4.

(84) R. Boucher, E. Cheng, A. Paradiso et al. Chloride secretory response of cystic fibrosis airway epithelia: presentation of calcium but not protein kinase $\mathrm{C}$ and $\mathrm{A}$-dependent mechanism. J Clin Invest. 1989;84: 1424-31.

(85) H. Chase, M. Long, M. Lavin. Cystic fibrosis and malnutrition. J Pediatr 1979; 95: 33747.

(86) C. Roy, A. Silverman, F. Cozzetto. Pediatric Clinical Gastroenterology. 2nd ed. St. 
Louis: CV Mosby, 1975: 615-35.

(87) J. Dodge, J. Yassa. Food intake and supplementary feeding programs. In: Sturgess JM, ed. Perspectives in cystic fibrosis. Procedings of the 8th International Cystic Fibrosis Congress. Toronto: Canadian Cystic Fibrosis Foundation, 1980: 125-36.

(88) H. Parsons, P. Beaudry, A. Dumas, P. Pencharz. Energy needs and growth in children with cystic fibrosis. J Pediatr Gastroenterol Nutr 1983; 2: 44-9.

(89) H. Schwachman, R. Dooley, F. Guilmette, P. Patterson, C. Weil, H. Leubner. Cystic fibrosis of the pancreas with varying degrees of pancreatic insufficiency. Am J Dis Child 1956; 92: 347-68.

(90) D. Crozier. Cystic fibrosis a not so fatal disease. Pediatr Clin North Am 1974; 21: 935 950.

(91) D. Gurwitz, M. Corey, P. Francis, D. Crozier, H. Levison. Perspectives in cystic fibrosis. Pediatr Clin North Am. 1979; 26: 603-615.

(92) E. Luder, M. Kattan,J. Thornton, K. Koehler, R. Bonforte. Efficacy of a nonrestricted fat diet in patients with cystic fibrosis. AJDC. 1989; 143: 458-464.

(93) A. Rettammel, M. Marcus, P. Farrell, S. Sondel, R. Koscik, E. Mischler. Oral supplementation with a high-fat, high-energy product improves nutritional status and alters serum lipids in patients with cystic fibrosis. J Am Diet Assoc. 1995; 95: 454-459.

(94) K. Gaskin, D. Waters, L. Baur, V. Soutter, M. Gruca. Nutritional status, growth and development in children undergoing intensive treatment for cystic fibrosis. Acta Paediatr Scand [Suppl]. 1990; 366: 106-110.

(95) E. O' Loughlin, D. Forbes, H. Parsons, B. Scott, D. Cooper, G. Gall. Nutritional rehabilitation of malnourished patients with cystic fibrosis. Am J Clin Nutr. 1986: 43: 732-737.

(96) R. Shepherd, T. Holt, B. Thomas et al. Nutritional rehabilitation in cystic fibrosis: Controlled studies of effects on nutritional growth retardation, body protein turnover, and course of pulmonary desease. J Pediatr. 1986; 109: 788-94.

(97) R. Shepherd, B. Thomas, D. Bennett, W. Cooksley, L. Ward. Changes in body composition and muscle protein degradation during nutritional supplementation in nutritionally growth-retarded children with cystic fibrosis. J Pediatr Gastroenterol Nutr. 1983; 2: 439-446.

(98) L. Levy, P. Durie, P. Pencharz, M. Corey. Effects of long-term nutritional rehabilitation on body composition and clinical status in malnourished children and adolescents with cystic 
fibrosis. J Pediatr 1985; 107: 225-230.

(99) J. Bertrand, C. Morin, R. Lasalle, J. Patrick, A. Coates. Short-term clinical, nutritional, and functional effects of continuous elemental enteral alimentation in children with cystic fibrosis. J Pediatr. 1984; 104: 41-46.

(100) R. Shepherd, W. Cooksley, and W. Domville. Improved growth and clinical, nutritional, and respiratory changes in response to nutritional therapy in cystic fibrosis. J Pediatr. 1980; 97: 351-357.

(101) J. Yassa, R. Prosser, J. Dodge. Effects of an artificial diet on growth of patients with cystic fibrosis. Arch Dis Child. 1978; 53: 777-783.

(102) J. Allan, A. Mason, A. Moss. Nutritional supplementation in treatment of cystic fibrosis of the pancreas. Am J Dis Child. 1973; 126: 22-26.

(103) A. Manseli, J. Andersen, C. Muttart et al. Short-term pulmonary effects of total parenteral nutrition in children with cystic fibrosis. J Pediatr 1984; 104: 700-705.

(104) M. Canciani, G. Mastella. Absorption of a new semielemental diet in infants with cystic fibrosis. J Pediatr Gastroenterol Nut. 1985; 4: 735-740.

(105) M. Boland, D. Stoski, N. Macdonald, P. Soucy, J. Patrick. Chronic jejunostomy feeding with a non-elemental formula in undernourished patients with cystic fibrosis. Lancet 1986; 1: 232-234.

(106) P. Farrell, E. Mischler, S. Sondel, M. Palta. Predigested formula for infants with cystic fibrosis. Research. 1987; 87: 1353-1356.

(107) P. Regan, J. Malagelada, E. Dimagno, and V. Go. Reduced intraluminal bile acid concentrations and fat maldigestion in pancreatic insufficiency: Correction by treatment. Gastroenterology. 1979; 77: 285-289.

(108) P. Zentler-Munro, W. Fitzpatrick, J. Batten, and T. Northfield. Effect of intrajejunal acidity on aqueous phase bile acid and lipid concentrations in pancreatic steatorrhoea due to cystic fibrosis. Gut. 1984; 25: 500-507.

(109) P. Zentler-Munro, D. Fine, J. Batten, and T. Northfield. Effect of cimetidine on enzyme inactivation, bile acid precipitation, and lipid solubilisation in pancreatic steatorrhoea due to cystic fibrosis. Gut. 1985; 26: 892-901.

(110) A. Weber, C. Roy. Intraduodenal events in cystic fibrosis. J Pediatr Gastroenterol Nutr. 1984; 3 (Suppl. 1): S113-S119. 
(111) S. Dutta, V. Hubbard, M. Appler. Critical examination of therapeutic efficacy of a pHsensitive enteric-coated pancreatic enzyme preparation in treatment of exocrine pancreatic insufficiency secondary to cystic fibrosis. Dig Dis Sci 1988; 33: 1237-44.

(112) H. Heijerman, C. Lamers, W. Bakker. Omeprazole enhances the efficacy of pancreatin (pancrease) in cystic fibrosis. Ann Intern Med. 1991; 114: 200-201.

(113) S. Schwarzenberg, C. Wielinski, I. Shamieh et al. Cystic fibrosis-associated colitis and fibrosing colonopathy. J Pediatr 1995; 127: 565-70.

(114) R. Smyth, D. van Velzen, A. Smyth, D. Lloyd, D. Heaf. Strictures of ascending colon in cystic fibrosis and high strength pancreatic enzymes. The Lancet. 1994; 343: 85-86.

(115) M. Pettei, J. Leonidas, J. Levine, J. Gorvoy. Pancolonic disease in cystic fibrosis and high-dose pancreatic enzyme therapy. J Pediatr 1994; 125: 587-9.

(116) G. Cleghom, R. Shepherd, T. Holt. The use of a synthetic prostaglandin $E_{1}$ analogue (Misoprostol) as an adjunct to pancreatic enzyme replacement in cystic fibrosis. Scand J Gastroenterol. 1988; 23(Suppl 143): 142-147.

(117) K. Cox, J. Isenberg, A. Osher, R. Dooley. The effect of cimetidine on maldigestion in cystic fibrosis. 1979; 94: 488-492.

(118) M. Schöni, R. Kraemer, E. Rossi. Cimetidine and fat malabsorption in children with cystic fibrosis. Helv Paediat Acta. 1981; 36: 359-369.

(119) B. Boyle, W. Long, W. Balistreri, S. Widzer, and N. Huang. Effect of cimetidine and pancreatic enzymes on serum and fecal bile acids and fat absorption in cystic fibrosis. Gastroenterology. 1980; 78: 950-953.

(120) R. Gow, R. Bradbear, P. Francis, R. Shepherd. Comparative study of varying regimens to improve steatornhoea and creatornhoea in cystic fibrosis: effectiveness of an enteric-coated preparation with and without antacids and cimetidine. Lancet 1981; 14: 1071-1074.

(121) P. Robinson and P. Sly. Placebo-controlled trial of misoprostol in cystic fibrosis. J Pediatr Gastroenterol Nutr. 1990; 11: 37-40.

(122) P. Durie, L. Bell, W. Linton, M. Corey, G. Forstner. Effect of cimetidine and sodium bicarbonate on pancreatic replacement therapy in cystic fibrosis. Gut 1980; 21: 778-786.

(123) A. Carroccio, F. Pardo, G. Montalto et al. Use of famotidine in severe exocrine pancreatic insufficiency with persistent maldigestion on enzymatic replacement therapy: A long-term study in cystic fibrosis. Dig Dis Sci 1992; 37: 1441-1446. 
(124) D. Chalmers, R. Brown, M. Miller et al. The influence of longterm cimetidine as an adjuvant to pancreatic enzyme therapy in cystic fibrosis. Acta Paediatr Scand. 1985; 74: 114117.

(125) M. Schöni, R. Kraemer, A. Ruedeberg et al. Long-term cimetidine in children with cystic fibrosis: a randomized double blind study.

(126) J. van de Kamer. Standard methods of clinical chemistry, edited by Seligson D. New York, Academic Press, 1958, Vol 2, p 34.

(127) E. Wollaeger, M. Comfort, A. Osterberg. Total solids, fat and nitrogen in feces: Study of normal persons taking test diets containing moderate amount of fat; comparison with results obtained with normal persons taking test diet containing large amount of fat. Gastroenterology 1947; 9: 272-283.

(128) D. Woodman, W. Yeoman. A simplified method of investigating steatorrhoea. J Clin Pathol 1955; 8:79-80.

(129) M. Davidson, C. Bauer. Patterns of fat excretion in feces of premature infants fed various preparations of milk. Pediatrics 1960; 25: 375-84.

(130) J. van de Kamer, H. Huinink, A. Weyers. Rapid method for the determination of fat in feces. J Biol Chem 1949; 177: 349-55.

(131) B. Lembcke, B. Braden, J. Stein. Diagnostik der steatorrhoe. Z Gastroenterol 1994; 32: 256-261.

(132) N. Thorsgaard Pedersen, H. Halgreen, H. Worning. Estimation of the 3-day faecal fat excretion and fat concentration as a differential test of malabsorption and maldigestion. J Gastroenterol 1987; 22: 91-96.

(133) I. Roberts, C. Poturich, A. Wald. Utility of fecal fat concentrations as screening test in pancreatic insufficiency. Dig Dis Sci 1986; 31: 1021-4.

(134) G. Bo-Linn, J. Fordtran. Fecal fat concentretion on patients with steatorrhea. Gastroenterology 1984; 87: 319-322.

(135) J. Bai, A. Andrüsh, G. Matelo et al. Fecal fat concentration in the differential diagnosis of steatorrhea. Am J Gastroenterol 1989; 84: 27-30.

(136) B. Lembcke, K. Grimm, P. Lankisch. Raised fecal fat concentration is not a valid indicator of pancreatic steatorrhea. Am J Gastroenterol 1987; 82: 526-531.

(137) H. Weijers. Fat absorption in normal and abnormal infants and children with special 
reference to coeliac disease (proefscrift) 1950: 19-23.

(138) P. Phuapradit, A. Narang, P. Mendonca, D. Harris, J. Baum. The steatocrit: a simple method for estimating stool fat content in newborn infants. Arch Dis Child 1981; 56: 725-727. (139) G. Iacono, A. Carroccio, G. Montalto et al. Steatocrit: normal range and physiological variations in preterm and low-birth-weight full-term newborns. Acta Paediatr 1992; 81: 933-4. (140) A. Guarino, L. Tarallo, L. Greco, L. Cesarano, S. Guandalini, A. Rubino. Reference values of the steatocrit and its modifications in diarrheal diseases. J Pediatr Gastroenterol Nutr 1992; 14: 268-274.

(141) C. Colombo, R. Maiavacca, M. Ronchi, E. Consalvo, M. Amoretti, A. Giunta. The steatocrit: a simple method for monitoring fat malabsorption in patients with cystic fibrosis. J Pediatr Gastroenterol Nutr 1987; 6: 926-930.

(142) G. Iacono, A. Carroccio, F. Cavataio et à. Steatocrit test: normal range and physiological variations in infants. J Pediatr Gastroenterol Nutr 1990; 11: 53-57.

(143) M. Walters, J. Kelleher, J. Gilbert, J. Littlewood. Clinical monitoring of steatorrhoea in cystic fibrosis. Arch Dis Child 1990; 65: 99-102.

(144) E. Sugai, G. Srur, H. Vazquez et al. Steatocrit: a reliable semiquantitative method for detection of steatorrhea. J Clin Gastroenterol 1994; 19: 206-9.

(145) G. Drummey, J. Benson, C. Jones. Microscopical examination of the stool for steatornhea. N Engl J Med 1961; 264: 85-7.

(146) L. Benini, S. Caliari, G. Guodi. Near infrared spectrometry for faecal fat measurement: comparison with conventional gravimetric and titrimetric methods. Gut 1989; 30: 1344-1347. (147) O. Bekers, C. Postma, A. Lombarts. Determination of feacal fat by Near-Infrared Spectroscopy. Eur J Chem Cli Biochem 1995; 33: 83-86. 


\section{CHAPTER 2}

METHODS 
The following methods were used in our studies:

\section{Methods used for fecal fat determination:}

\section{1 Steatocrit and Acid Steatocrit}

About $0.5 \mathrm{~g}$ solid stool was weighed and diluted with a volume of deionized water, equal to two times the weight of stool. The stool and water were premixed using a Vortex mixer. Subsequently, the mixture was homogenized using a $5 \mathrm{ml}$ Potter Elvehjem tissue homogenizer. The fecal homogenate was aspirated into a $75 \mu$ l plain haematocrit capillary. This capillary was sealed with wax at one end and centrifuged horizontally (13000 rpm, $15 \mathrm{~min}$ ) in a standard haematocrit centrifuge. After centrifugation, the upper fatty layers (FL) and the bottom solid layers (SL) were measured with a graduated magnifying lens. The steatocrit was calculated as (FL / $(\mathrm{FL}+\mathrm{SL})) \times 100 \%$. Since the fat extraction was not optimal in the steatocrit procedure, we have try to increase this step by adding the perchloric acid $(5 N)$ to the fecal homogenate in a volume equal to $1 / 5$ of the homogenate after homogenization. This acid homogenate was then mixed for 30 seconds using a Vortex mixer and the following steps were the same as the classical steatocrit. This "Acid Steatocrit" is used in our further study.

\section{2 Titrimetric method}

The 72 hours fecal collection was first homogenized and about 5 gram of feces was weighed. The feces was saponified with concentrated potassium hydroxide $(33 \% \mathrm{KOH})$ in ethanol, giving a solution which contains the soaps derived from neutral fats, fatty acids and also soaps originally present in the stool. By adding $\mathrm{HCl}(2 \mathrm{~N})$, fatty acids were obtained. After adding $125 \mathrm{ml}$ toluene, the mixture was shaken vigorously for $2-3$ minutes. $25 \mathrm{ml}$ of the toluene layer containing the fatty acids was then transferred to an erlenmeyer for titration with $0,1 \mathrm{~N}$ tetrabutylammoniumhydroxide solution in propanol/methanol and thymol blue as indicator. The titration was done three times and the mean of this was used for the calculation of fecal fat excretion, which was calculated as followed: 
$125 \mathrm{ml}+4.5 \mathrm{ml}\left(\mathrm{X}-\mathrm{X}_{0}\right) \times 0,1 \mathrm{~N} \times 1 / 3 \times$ total feces weight $(\mathrm{g}) \times 891 \mathrm{~g}=$ Total fecal fat $(\mathrm{g} / 72 \mathrm{~h})$ $25 \mathrm{ml}$ sample weight $(5 g)$

with $125 \mathrm{ml}$ representing the toluene volume used for extraction of the fatty acids, $25 \mathrm{ml}$ representing the titration volume, $4,5 \mathrm{ml}$ is the correction for the volume interaction, $\mathrm{X}$ representing the number of meq of fatty acids titrated, $\mathrm{X}_{0}$ the correction for the acids present in toluene, $0,1 \mathrm{~N}$ the concentration of tetrabutylammoniumhydroxide solution, $1 / 3$ is the conversion factor from fatty acid to fat molecule ( 3 molecule fatty acids derived from 1 molecule fat) and 891 is the molecular weight of stearic acid (C-18-fat).

\section{3 Sudan staining method}

We used the split fat stain, which identifies both triglyceride and fatty acid (1). Several drops of $100 \%$ acetic acid and several drops of Sudan III solution were added. The preparation was subsequently mixed with the coverslip, which was then applied. The slide was gently heated on a lighter until bubbling. All preparations were examined while still warm under high magnification (magnification of 400 ). For quantification of the amount of fat detected microscopically, we used the criteria established by Drummey et al.(2). They are as follows: normal (+): up to 100 fat globules per high power field, varying in a diameter between 1 and $4 \mu \mathrm{m}$, as noted on the micrometer scale always using a magnification of 400 ; Increased $(2+)$ : up to 100 fat globules per high power field, the diameter of fat globules varying between 1 and $8 \mu \mathrm{m}$; Markedly increased $(3+)$ : more than 100 fat globules per high power field, varying in size from 6 to $75 \mu \mathrm{m}$ in diameter.

\section{Methods used for assessment of nutritional condition:}

\subsection{Anthropometry}

Weight, height and 4 skinfolds (biceps, triceps, subscapular and suprailiaca) were expressed as standard deviation scores of the normal population for age and sex by using the growth charts from Gerver and de Bruin (3). 
It has been found that subcutaneous fat as measured by skinfolds is related to the body density (4). This latter is again related to the body fatmass. From these theoretical principes, Gerver and de Bruin have constructed a chart, expressing the relationship between the 4 skinfolds (biceps, triceps, subscapular and suprailiaca) and the percent fat free mass. In our study, the fatmass and fat free mass determined with the anthropometric method were derived from these charts.

\subsection{Dual energy X-ray absorptiometry (DXA)}

This method first developed by Mazess et al., measures sirnultaneously bone mineral, fat and nonbone lean tissue. For a DXA scan, subjects lied supine on a padded table while the scintillation counter moved in a raster pattem across the body from head to foot. The Lunar DPX uses a constant $\mathrm{x}$-ray source and a filter that converts the polychromatic $\mathrm{x}$-ray beam into one that has two main energy peaks $(40 \mathrm{kV}$ and $70 \mathrm{kV})$. The ratio of soft tissue attenuation $\left(R_{5 T}\right)$ at the two energies is measured. The attenuation of pure fat $\left(\mathrm{R}_{F}\right)$ and of bone free lean tissue $\left(R_{L}\right)$ are known from both theoretical calculations and calibration. From this, the fatmass and lean tissue mass were calculated. The bone mineral content was calculated after correction of the overlying soft tissue (5). Body composition measurements in our study were made by a DPX with a pediatric software programme, Lunar version $1.5 \mathrm{e}$. Daily quality assurance test were performed according to the manufacturer 's directions. Total body analysis was performed in all children using a fast scan mode with a sample size of $4,8 \times 9,6 \mathrm{~mm}$, sample interval of $0.03 \mathrm{~s}$ and source collimation of $1,68 \mathrm{~mm}$.

\section{3 Total body water (TBW) and extra cellular volume (ECV)}

TBW and ECV were measured by deuterium oxide (6) and bromide dilution respectively (7). Each subject received orally $20 \mathrm{ml}$ of a mixture of $\mathrm{D}_{2} \mathrm{O}(99,9 \%$ purity) and Bromide salt $(150 \mathrm{mMol} / \mathrm{L}$ ) solution in a volume ratio of 1:1. Saliva and plasma samples were taken before intake of $\mathrm{D}_{2} \mathrm{O}-\mathrm{NaBr}$ solution and 4 hours thereafter when "an equilibrium" has been reached. To prevent saliva dilution by fluid intake which can result in a higher TBW content, patients were told not to take any fluid orally half an hour before saliva. samples were taken. Urine and 
fecal loss of bromide and $\mathrm{D}_{2} \mathrm{O}$ were negligible during the test since $t \frac{1}{2}$ of $\mathrm{D}_{2} \mathrm{O}$ and Bromide is 8 days (7). Saliva samples were obtained making use of dental cotton-wool, that was dried overnight at $100{ }^{\circ} \mathrm{C}$ and kept in a gas-tight tube until use. The cotton-wools and the blood samples were centrifuged and the saliva and serum thus obtained were kept in a stoppered glass vial and stored in a freezer until analysis.

\subsection{Total body water}

D2O concentrations of saliva samples were determined as follows: Calcium carbide $\left(\mathrm{CaC}_{2}\right)$ was placed in the siliconnized vacutainer tube and evacuated for $30 \mathrm{sec}$. with a rotatory vane pump to a total pressure of $0,01 \mathrm{~atm}$. Thereafter, $25 \mu \mathrm{l}$ of salivary sample was injected in the vacutainer tube. This was done in duplicate. $\mathrm{CaC}_{2}$ react with $\mathrm{D}_{2} \mathrm{O}$ forming acetylene gas. $\mathrm{A}$ $25 \mu \mathrm{l}$ of this gas was subsequently injected in duplicate into the GC/CF - IRMS system (gas chromatography/continous flow isotope ratio mass spectrometry) at $2 \mathrm{~min}$. intervals. The mass 27/26 ratio (R27/26) was measured on a Isotope Ratio Mass Spectrometer configured for Acetylene (Finnigan MAT 252 for CF-IRMS) (6). The mean value of 4 determinations was calculated for each sample. By inserting of the tracer/tracee ratio, defined as R27/26 (T4) $\mathrm{R} 27 / 26$ (T0), into the regression equation obtained from the standards, we get the dilution factor of D2O. TBW is calculated as ingested D2O volume/ dilution factor. From the TBW, LBM and FM can calculated by the following formules:

$$
\begin{aligned}
& \operatorname{LBM}(\mathrm{kg})=\text { TBW } /(1,04 \times \mathrm{d}) \\
& \text { BF }(\mathrm{kg})=\text { Weight }- \text { LBM }
\end{aligned}
$$

The 1,04 factor is a correction for the estimated $4 \%$ nonaqueous hydrogen exchange and $d$ is the hydration factor of LBM which varies with age. Because our CF population was young, we used the age dependent hydration factors described by Fomon (8) for children younger than 10 year and by Boileau and Lohman (9) for older children.

\section{3. 2 Bromide space}


Because Bromide resides mainly in the extracellular space, measured of Bromide dilution in serum give us an estimation of the extracellular volume. Bromide was determined by using a Gas Chromatograph type CP 9000 (Chrompack) equiped with an ECD detector after it was converted into a bromoacetone gas. First, perchloric acid was added to the serum sample and centrifugated for deproteinisation. An aliquot of the supernatant was then added to silver nitrate $\left(\mathrm{AgNO}_{3}\right)$ for precipitating of silver bromide and chloride. After centrifugation, the precipitate was taken up in $\mathrm{NH}_{3}$ after that $\mathrm{Na}_{2} \mathrm{~S}$ and $\mathrm{NaOH}$ were added to precipitate the silver as $\mathrm{Ag}_{2} \mathrm{~S}$. A.fter agitation and centrifugation, the supernatant was heated until $d r y_{2} \mathrm{HO}$ was added followed by $\mathrm{H}_{2} \mathrm{O}_{2}$ to oxidize sulfide. After drying, $\mathrm{H}_{2} \mathrm{O}$ was then added and dried again. This was repeated several times. Thereafter, perchloric acid and acetone were added and the reaction is started by addition of $\mathrm{KmnO4}$, with Bromoacetone formed. The solution is then extracted with benzene. The organic phase was separated from the water phase by shaking and centrifugation. The water phase was then removed. An aliquot of the organic solution is then applied to the gas chromatograph for measuring of bromoacetone/internal standard ratio. The bromide concentration was then derived from the bromoaceton standard curves. Because the distribution of Bromide depend on the potential difference between in- and extru-cellular and on the quantity of total body volume, corrected bromide space was calculated as follow:

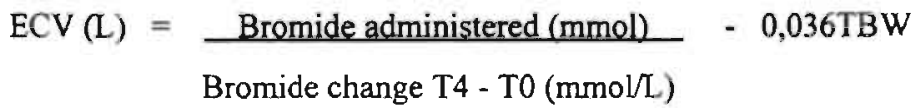

Where $0,036 \mathrm{TBW}$ is the correction factor for the cell potential and for the total body volume (7). 


\section{REFERENCES}

(1) M. Khouri, G. Huang, Y. Shiau. Sudan stain of fecal fat : New insight into an old test. Gastroenterology 1989; 96: 421-7.

(2) G. Drummey, J. Benson, C. Jones. Microscopical examination of the stool for steatorrhea. N Engl J Med 1961; 264: 85-7.

(3) W. Gerver, R. de Bruin. Paediatric Morphometrics: a reference manual. 1th ed. Utrecht: Bunge, 1996.

(4) J. Weststrate, P. Deurenberg. Body composition in children: proposal for a method for calculating body fat percentage from total body density or skinfold-thickness measurements. Am J Clin Nutr 1989: 50: 1104-15.

(5) S. Heymsfield, J. Wang, S. Heshka, J. Kehayias, R. Pierson. Dual-photon absorptiometry: comparison of bone mineral and soft tissue mass measurements in vivo with established methods. Am J Clin Nutr 1989; 49: 1283-9.

(6) B. Van Kreel, F. Van der Vegt, M. Meers, T. Wagenmakers, K. Westerterp, A. Coward. Determination of total body water by a simple and rapid mass spectrometric method. J Mass Spectrom 1996; 31: 108-111.

(7) B. Van Kreel. An Improved bromide assay for the estimation of extracellular water: volume by capillary gas chromatography. Clinica Chimica Acta 1994; 231: 117-128.

(8) S. Fomon, F. Haschke, E. Ziegler, S. Nelson. Body composition of reference children from birth to age 10 years. Am J Clin Nutr 1982; 35: 1169-1175.

(9) Boileau, R. Lohman, M. Slaughter, T. Ball, S. Going, M. Hendrikx. Hydration of the fatfree body in children during maturation. Hum Biol. 56: 651-666. 


\title{
CHAPTER 3
}

\section{THE ACID STEATOCRIT : A MUCH IMPROVED METHOD}

Tran M, Forget P, Van den Neucker A, Strik J, van Kreel B, Kuijten R.

Departments of Pediatrics and Clinical Chemistry, University Hospital Maastricht, Maastricht, The netherlands.

JPediatr Gastroenterol Nutr 1994; 19: 299-303

\begin{abstract}
The steatocrit method has recently been introduced as a simple screening test for steatorrhea. As it seemed likely that separation of feca! homogenate by centrifugation into a lipid phase, a watery phase and a solid phase would be pH-dependent, we evaluated the effect of fecal acidification on steatocrit results in healthy children and in patients with cystic fibrosis and studied the relationship between two steatocrit methods and fecal fat content as measured by a reference chemical method. Steatocrit results increased with the degree of fecal acidification, and maximal results were obtained at the lowest fecal $\mathrm{pH}$ values. Means and SEM for classi$\mathrm{cal}$ and acid steatocrit values were $1.1 \pm 0.4 \%$ (classical) versus $3.8 \pm 1 \%$ (acid) in controls (n $=6$ ) and $5.4 \pm 1.9 \%$ (classical) versus $26.9 \pm 4.3 \%$ (acid) in cystic fibrosis $(n=9)$. The correlations between fecal fat content measured chemically and steatocrit results were 0.18 (p $=0.35)$ and $0.81(p<0.0001)$ for classical and acid steatocrit, respectively. We conclude that acidification of fecal homogenates leads to a marked improvement in the steatocrit method.
\end{abstract}




\section{INTRODUCTION}

The diagnosis of fat malabsorption still mainly relies on the 72-hour faecal fat quantitation in which daily stool fat loss is evaluated by collecting stools for 3 days and determining stool fat content by chemical methods. The most widely used chemical method is the titrimetric method as described by van de Kamer in 1949 (1).

Work by Kouri et al has suggested that the titrimetric method largely overestimates nutritional faecal fat losses because it measures not only malabsorbed exogenous fat but also endoge. nous fat of various origins such as biliary lipids and lipids derived from the turnover of intestinal epithelial cells and gut bacteria (2).

Making use of the staining properties of purified lipids in an artificial matrix, Khouri et al. have suggested the fat absorption coefficient in normal adults is much higher than usually believed (2). Although the microscopic evaluation of steatorrhea by the Soudan stain provides a satisfactory screening method for steatorrhea, it is at best semiquantitative.

The steatocrit has been introduced in recent years as a simple test for the evaluation of fat malabsorption (3-6). Although several authors have reported the method to be satisfactory for the evaluation of steatorrhea, some have reported the steatocrit to be quite unreliable (6). As it has been shown that faecal acidification results in an enhanced sensitivity of the sudan faecal staining method (2), we wondered whether the same modification could improve fat extraction by centrifugation as performed in the steatocrit determination.

Consequently, we evaluated the effects of stool sample acidification on steatocrit determinations and to compared results from previously reported methods with acid steatocrit results in healthy children and in children with cystic fibrosis. We also determined the correlation between steatocrit results and faecal fat concentrations as measured by the reference chernical method of van de Kamer et to evaluate which of the two steatocrit methods gave the best estimate of faecal fat content.

\section{METHODS}

\section{"classic" steatocrit method}


Stool ( $0.5 \mathrm{gr})$ was diluted (1/3) with deionized water and thouroughly homogenized in a $5 \mathrm{ml}$ Potter Elvehjem tissue hornogenizer (Heidolph Elektro KG Kelheim, no. 170-1700/20-200) stamper, tissue grind pestle (size 20 from Kontes Scientific Glassware Instruments, no. 885451-0020). The homogenate was aspirated into a $75 \mu \mathrm{l}$ plain glass haematocrit tube. The capillary tube was subsequently centrifuged horizontally $(13,000 \mathrm{rpm}$ for $15 \mathrm{~min})$ in a standard haematocrit centrifuge.

After centrifugation, the upper (fat) and bottom (solid) layers were measured with a graduated magnifying lens. Steatocrit was calculated as $\mathrm{FL}(\mathrm{FL}+\mathrm{SL})$, where $\mathrm{FL}$ is the fatty-layer length and $\mathrm{SL}$ is the solid-layer length.

\section{"Acid" steatocrit method'}

The method used was exactly the same as the classic steatocrit method except that, before aspirating the homogenate in the capillary tube, perchloric acid in various concentrations ( $5 \mathrm{~N}$ for maximal acidification) was added to the homogenate in a volume equal to $1 / 5$ of the homogenate volume. The resulting acid homogenate was mixed for 30 seconds with a standard Vortex mixer.

\section{Chemical determination of stool fat concentration.}

The method of van de Kamer et al. was used to determine stool fat content (1).

\section{EXPERIMENTAL DESIGN}

\section{Effect of stool homogenate acidification on fat extraction}

To evaluate the effect of stool acidification and thus stool $\mathrm{pH}$ on the length of the fat column obtained by centrifugation, several stool samples from patients with and without steatorrhea were centrifuged after addition of perchloric acid solutions of various concentrations. 


\section{Classic and acid steatocrit}

To compare classic and acid steatocrit results in children with and without steatorrhea, we measured fecal steatocrit by both methods in 6 control children (mean age: 5.8 years, range 3 to 12 years; five boys and one girl) and in 9 children with cystic fibrosis (mean age: 6.9 years; range 0.5 to 20 ; nine boys ). The control children were patients with chronic aspecific respiratory disease without gastrointestinal symptoms and with a normal sweat test. The cystic fibrosis patients all had abnormal sweat tests on severall occasions and were being treated with pancreatic enzymes when steatocrit determinations were performed. As our purpose was to compare classical and acid steatocrit results in the same fecal samples, no attempt was made to quantify the fat content of the diet which was "normal" in all patients.

\section{Correlation between steatocrit results and fecal fat content}

To further compare both steatocrit methods we looked at the relationship between results obtained by each method and fecal fat content results as measured by the method of van de Kamer et al. (1). Steatocrit measurements (classic and acid) and fecal fat content determinations (chemical method) were performed on 27 consecutive stool samples (from adults and children) sent to our laboratory for evaluation of malabsorption. No attempt was made to classify patients in disease categaries as our only goal was to study the relationship between steatocrit results and fecal fat content independent of the presence of disease (clinical results will be published separately).

\section{Statistical methods}

The coefficient of variation of each steatocrit rnethod was determined with duplicate results of each sample for both methods. Pearson correlation coefficient was used to evaluate the relationship between steatocrit results and chemically measured fecal fat content.

\section{RESULTS}


Several steatorrheal stool samples were analysed after acidification with various concentrations of perchloric acid.

A typical finding is shown in figure 1; The upper fat column was seen to increase in length with the degree of homogenate acidification. A typical normal stool sample result (no steatorrhea) is shown in figure 2 . The acid steatocrit remained completely negative in normal samples.

\section{Cystic fibrosis sample}

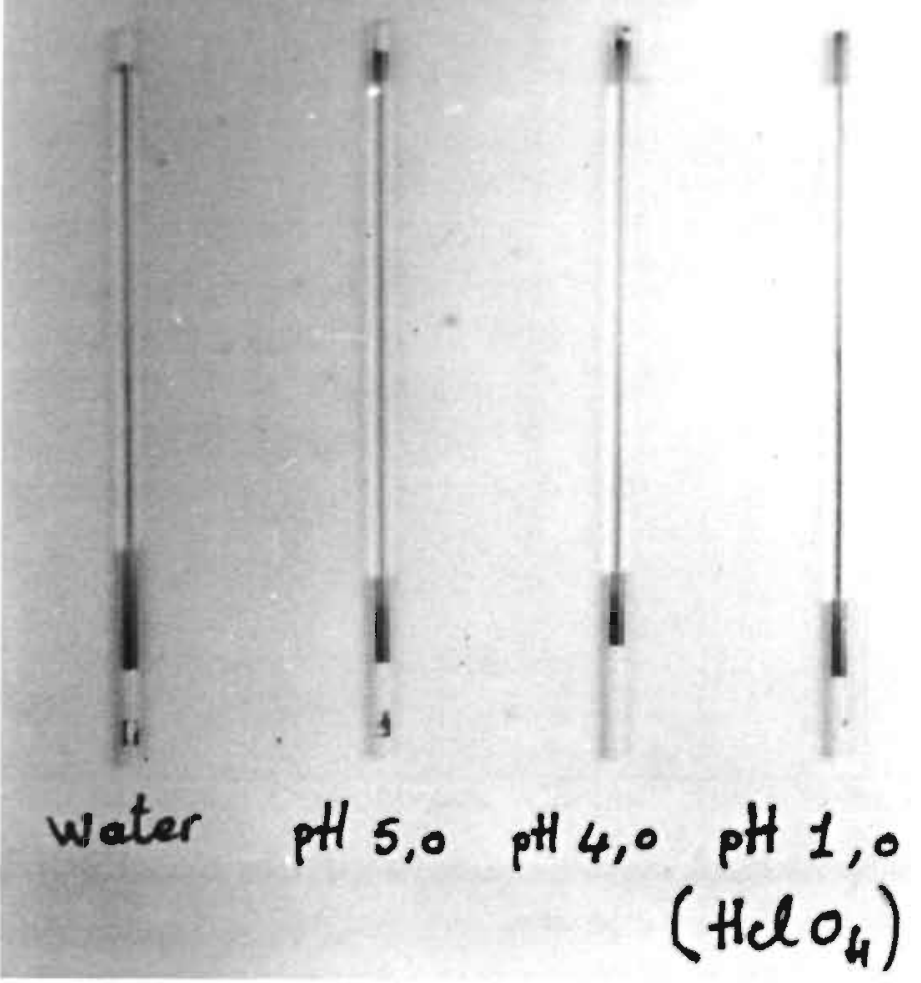

Figure 1 Effect of acidification with various concentrations of perchloric acid on the fat column length (upper part of picture) of a stool sample from a patient with cystic fibrosis. 


\section{normal sample}

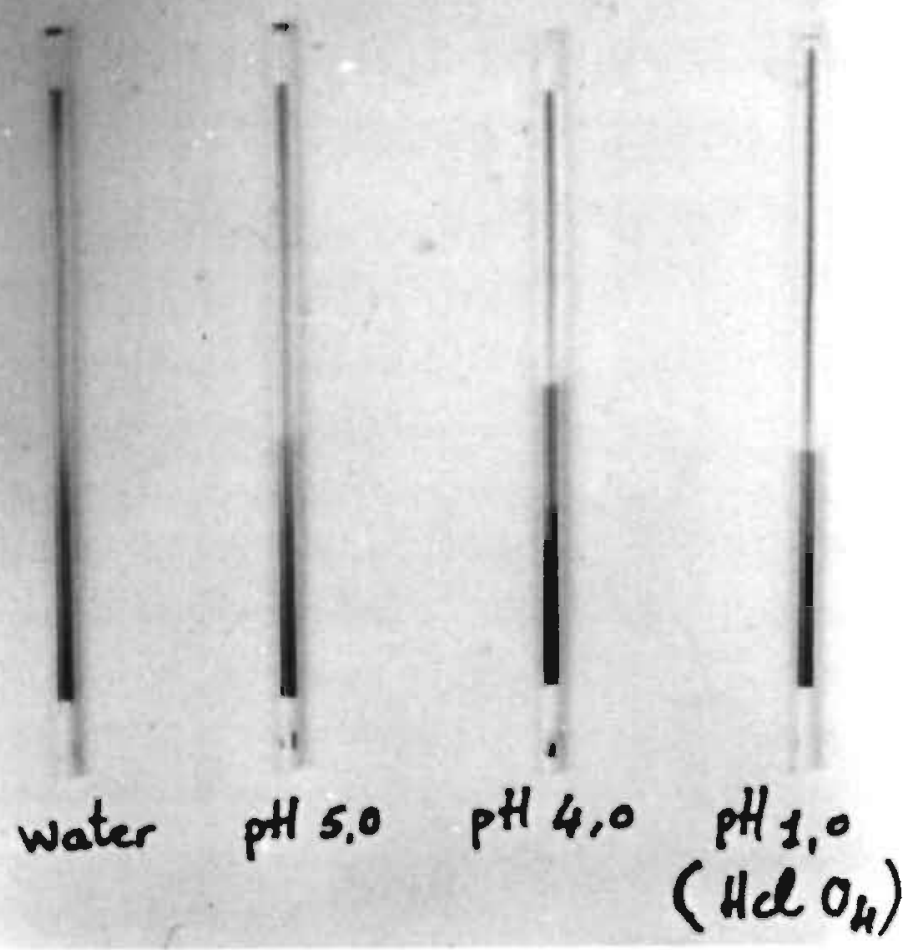

Figure 2 Effect of acidification with various concentrations of perchloric acid on fat extraction from a normal stool sample. Fat layer is absent at all $\mathrm{pH}$ values. 


\section{Classic and acid steatocrit}

Results of classic and acid steatocrit in 6 control and 9 cystic fibrosis patients (figure 3 ) were as follows : Steatocrit means and SEM in control patients were $1.1 \pm 0.4$ and $3.8 \pm 1 \%$ for classic and acid steatocrit, respectively. This difference was not statistically significant. Steatocrit means and SEM in cystic fibrosis patients were $5.4 \pm 1.9$ and $26.9 \pm 4.3 \%$ for classic and acid steatocrit, respectively. This difference is significant $(\mathrm{p}<0.01)$

The precision of the methods was evaluated by comparing the variation coefficients; variation coefficients were 6.9 and $5.1 \%$ for the classic and acid steatocrit methods, respectively.

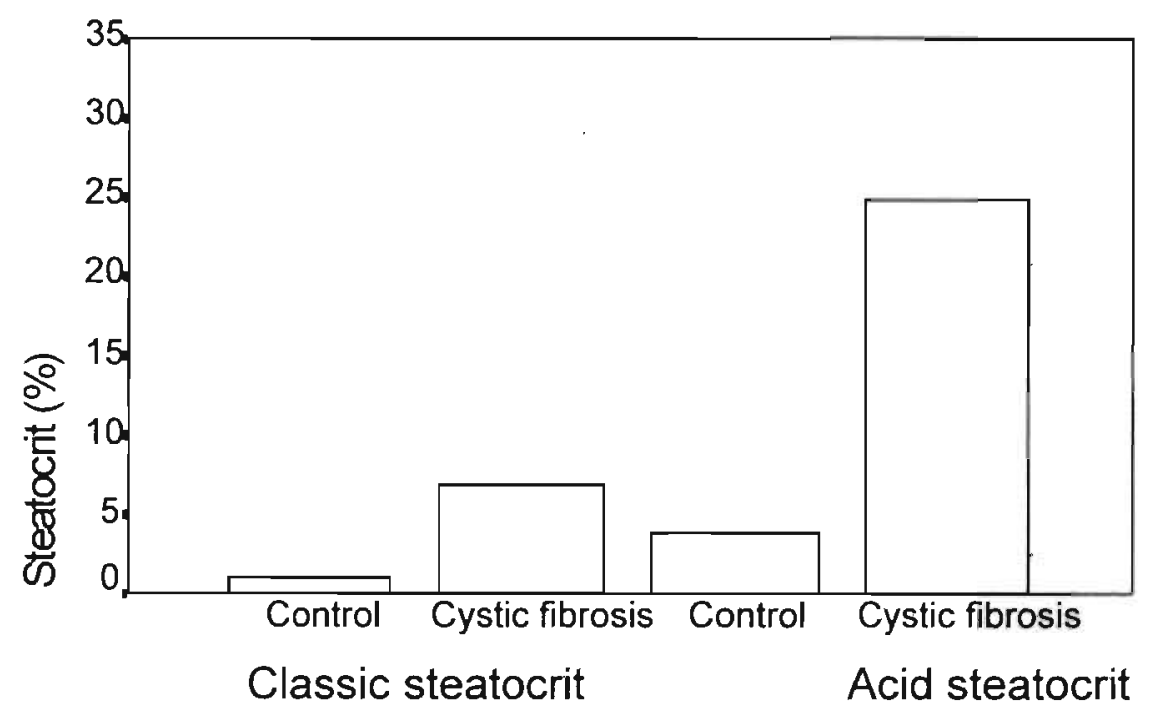

Figure 3 Classic and acid steatocrit results in six controls and nine patients with cystic fibrosis. 


\section{Correlation between steatocrit results and faecal fat content}

The relationship between classic fecal steatocrit and fecal fat content as measured by the reference method of van de Kamer et al. (1) is shown in figure 4. The correlation coefficient. of 0.18 is statistically non-significant $(p=0.35$ ). The relationship between acid fecal steatocrit and fecal fat content is shown in figure 5. The correlation coefficient of 0.81 is highly significant $(\mathrm{p}<0.0001)$.

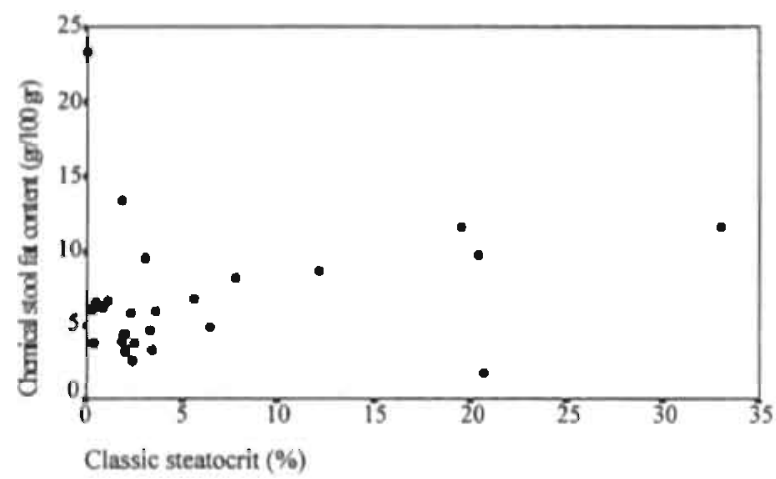

Figure 4 Relationship between classic fecal steatocrit and fecal fat content as measured by the method of van de Kamer et al. $\ln 27$ fecal samples $(r=0.18 ; p=0.35)$.

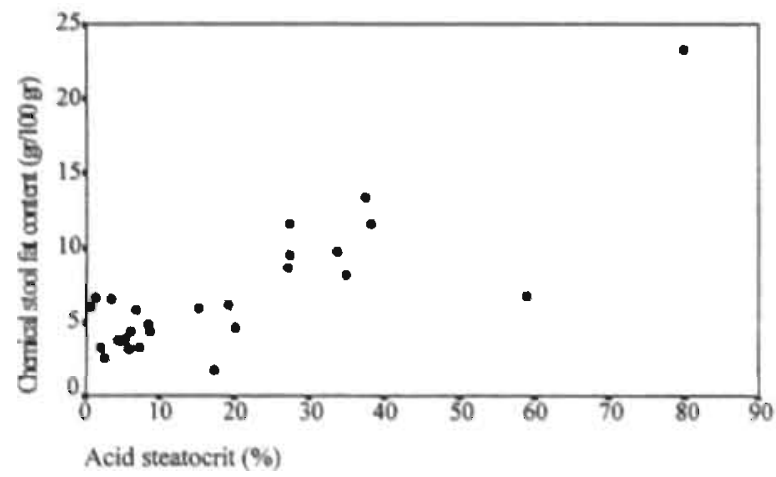

Figure 5 Relationship between acid fecal steatocrit and fat content as measured by the method of van de Kamer et al. In 27 fecal samples ( $r=0.81 ; p<0.0001)$. 


\section{DISCUSSION}

Although several authors have reported the steatocrit method to be reliable for the screening of steatorrhea ( 3-5), Walters et al reported the method to be completely unreliable (6). Methodological inadequacies probably underlie these discrepancies. We have been using the "classic" steatocrit in our department for a few years and have found completely negative results in some patients with proven steatorrhea. We hypothesized that in some patients fat detection might be poor and that a possible solution to the problem would be an improved method of liberating fat during the centrifugation step. It has been shown in a recent study that fecal fat in patients with pancreatic insufficiency mainly consists of fatty acids and that the fecal triglyceride content does not differ from that of normal controls (7).

Fecal fatty acid molecules exist in the form of soaps (8). Further, since the pKa of most fatty acids is lower (about 4.8) than fecal pH, most fatty acids in stool would be present as ionized species or soaps. We speculated that fecal acidification would result in the conversion of ionized fatty acid species and soaps into the protonated species leading to easier separation into lipid and water phases during the centrifugation step of the steatocrit method.

Our results show that the effect of stool homogenate acidification on the length of the upper fatty layer very nicely confirms our predictions. Although we have not checked this point in detail, it can be expected that at the low PH values obtained after maximal acidification as performed in the present study, all fatty acids will be present in the protonated form.

Further, the fact that acidification of fecal samples from patients without steatorthea and with completely negative steatocrit results did not result in the appearance of a fatty layer, probably indicating that the improved fat extraction is not a spurious artifactual finding but the result of better extraction of lost exogenous fat.

Khouri et al have suggested that ionized fatty acids are not readily stainable with Soudan stain, although staining does occur after acidification (2). By alkalinization with sodium hydroxide, the same authors showed that fatty acids lost their ability to form fat droplets and to stain with Sudan red III (2). We suppose that similar mechanisms underlie the improvement of both the fat staining method and fat extraction by fecal acidification as shown in the present study.

A further advantage of acidification is that it enhances the vicible boundaries between the 
various layers, resulting in improved accuracy in the reading of layers lengths. Improved fecal fat extraction by acidification should therefore result in higher diagnostic sensitivity of the steatocrit method.

Our results show classic steatocrit in control children and in children with cystic fibrosis are similar to results published by other authors (4); However, acidified steatocrit results in both control children and cystic fibrosis patients were much higher than those obtained by classic steatocrit. Ongoing work in our laboratory aims at establishing normal population values for acid steatocrit in infants and children.

In order to better interpret the differences found between the steatocrit methods, we compared steatocrit results with fecal fat concentrations measured by the most accepted reference method. Our findings show that only acid steatocrit results correlate very significantly with fecal fat content as measured by the van de Kamer method. The litterature is quite varied on this point. Several studies have looked for a correlation between steatocrit results and either the fat absorption coefficient or 3-day fecal fat excretion. A good correlation was reported by two studies $(4,9)$ while a total lack of correlation was reported by a third author $(6)$. As steatocrit is supposed to reflect fecal fat concentration we preferred to relate steatocrit results to fecal fat concentrations rather than daily excretion or fat absorption coefficients. To our knowledge only one study reporting results in a similar way found a significant relationship between steatocrit results and fecal fat content (3). We think our finding of a lack of correlation between classic steatocrit and fecal fat content results can best be explained by the small number of observations or by the lack of homogeneity in our patient material.

This lack of homogeneity was, however, purposely chosen as we were only interested in the correlation between steatocrit results and fecal fat content. We think a positive correlation between the two steatocrit methods and fecal fat content could have been found but the acid steatocrit method would always better correlate with fecal fat content.

We conclude that acidification of fecal homogenates led to a much better fat extraction by centrifugation, increased sensitivity of the steatocrit method and to a better prediction of fecal fat content as measured by chemical methods.

Acknowledgment: The authors thank the clinical laboratory staff for their kind and expert technical assistance. We are very grateful to Nutricia Netherlands for financial support. 


\section{REFERENCES}

(1) van de Kamer JH, Huinink HTB, Weyers HA. Rapid method for determination of fat in feces.J Biol Chem 1949 ; 177 :349-55.

(2) Khouri MR, Huang G, Shiau YF. Sudan stain of fecal fat : new insight into an old test. Gastroenterology $1989 ; 96: 421-427$.

(3) Phuapradit P, Narang A, Mendonca P, Harris DA, Baum JD. The steatocrit : a simple method for estimating stool fat content in newborn infants.Arch Dis Child $1981 ; 56$ : 725 727.

(4) Colombo C, Maiavacca R, Ronchi M, Consalvo E, Amoretti M, Giunta A. The steatocrit : a simple method for monitoring fat malabsorption in patients with cystic fibrosis.J Pediatr Gastroenterol Nutr $1987 ; 6: 926-930$.

(5) Iacono G, Carroccio A, Cavataio F et al. Steatocrit test : normal range and physiological variation in infants. J Pediatr Gastroenterol Nutr 1990; $11: 53-57$.

(6) Walters MP, Kelleher J, Gilbert J, Littlewood JM. Clinical monitoring of steatorrhea in cystic fibrusis.Arch Dis Child 1990; 65: 99-102.

(7) Khouri MR, Huang G, Shiau YF. Fecal triglyceride excretion is not excessive in pancreatic insufficiency.Gastroenterology 1989; $96: 848-852$.

(8) Shiau YF, Popper DA, Reed M, Umstetter C, Capuzzi D, Levine GM.Intestinal triglycerides are derived from both endogenous and exogenous sources. Am J Physiol 1985; 248 : G164-169.

(9) Guarino A, Tarallo L, Greco L, Cesarano L, Guandalini S, Rubino A. Reference values of the steatocrit and its modifications in diarrheal diseases.J Pediatr Gastroenterol Nutr 1992; 14 : 268-274. 
CHAPTER 4

\title{
IMPROVED STEATOCRIT RESULTS OBTAINED BY ACIDIFICATION OF FECAL HOMOGENATES ARE DUE TO IMPROVED FAT EXTRACTION
}

\author{
M. Tran, P. Forget, A. Van den Neucker and B. Van Kreel
}

Department of Pediatrics and Clinical Chemistry, University Hospital Maastricht, Maastricht, The Netherlands

J Pediatr Gastroenterol Nutr 1996; 22: 157-160

Abstract

Conflicting results have been reported on the value of the steatocrit as a screening test for steatorrhea. We recently modified the test procedure by fecal acidification with the hope of improving fat extraction and consequently the sensitivity of the test. The aim of the present study was to ascertain, whether or not fecal acidification led to improved fat extraction, by comparing the fat content of both fatty and solid layers obtained by centrifugation of 12 acidified (acid steatocrit) and unacidified (classical steatocrit) steatorrheal stool samples.

The fat content of fatty and solid layers was evaluated using of the semiquantitative $(t=1$, $++=2,+++=3$ ) scoring system described by Drummey, for the interpretation of the sudan microscopic method for fecal fat.

The fatty layers sum of scores for the 12 samples examined, was 31 and 16 , for the acid and classical steatocrit respectively. The solid layers sum of scores for the 12 samples, was 13 and 24, for the acid and classical steatocrit respectively. Fat extraction from stool samples was significantly improved after fecal sample acidification $(p<0.005)$. Acid steatocrit results agreed better with chemically measured fecal fat than classical steatocrit results. We conclude that fecal acidification, by improving fat extraction, increases the reliability of the steatocrit method for the detection of steatorrhea. 


\section{INTRODUCTION}

Several methods are in use for the diagnosis of fat malabsorption. One of these is the 72 hour fecal fat quantitation method, which is regarded as the most accurate method to evaluate steatorrhea (1). However, there are several problems. First, it is a laborious method for laboratory technicians, and second, fecal collection for 3-5 days makes the method unpleasant for the patient and sometimes poorly reliable in non collaborating children.

Another well accepted test to screen for fat malabsorption is the Sudan staining method for fecal fat (2). Unfortunately this method is only semiquantitative.

In 1981 Phuapradit introduced the steatocrit method as a new, simple and easily repeatable method for measuring fecal fat content (3).

Although several authors have reported this method to be satisfactory for the evaluation of steatorrhea (3-5), some described it as quite unreliable (6). We have been using this method for years and have often found normal steatocrit values in patients, who, when measured chemically had steatorrhea with an increased fecal fat content.

As it has been shown that fecal acidification results in an enhanced sensitivity of the Sudan fecal staining method (7), we wondered whether fecal acidification could also be used to improve the sensitivity of the steatocrit method.

We consequently modified the reported (8) steatocrit method by adding perchloric acid to the fecal homogenate. Fat extraction was evaluated for classical and acid steatocrit methods, making use of the Sudan microscopic method for fecal fat.

We further compared calculated steatocrit results from acidified and unacidified samples, and related the results to fecal fat content of the same samples, measured by the reference chemical method of van de Kamer et al. (1).

\section{MATERIALS AND METHODS}

\section{Bopulation studied}

Twelve stool samples from 4 premature babies, 3 boys and 1 girl, with a mean gestational age of 35,3 weeks (ranged from $275 / 7$ to $355 / 7$ weeks), were analysed by means of both 
the classical and the acid steatocrit method.

Their postnatal age varied between 11 and 18 days. They received full oral formula feedings. Their weight ranged from $1810 \mathrm{~g}$ to $2360 \mathrm{~g}$.

\section{Steatocrit methods}

$0,5 \mathrm{~g}$ solid stool was weighed and diluted with a volume of deionized water, equal to two times the weight of stool. The stool and water were premixed using a Vortex mixer. Subsequently, the mixture was homogenized using a $5 \mathrm{ml}$ Potter Elvehjem tissue homogenizer. Then, the homogenate was aspirated into a $75 \mu \mathrm{l}$ plain haematocrit capillary. This capillary was sealed with wax at one end and centrifuged horizontally $(13,000 \mathrm{rpm}, 15 \mathrm{~min})$ in a standard haematocrit centrifuge.

The method used for the acid steatocrit was exactly the same as that of the classical steatocrit, the only exception being, that after homogenizing, $5 \mathrm{~N}$ perchloric acid was added to the homogenate in a volume equal to $1 / 5$ of the homogenate. This acid homogenate was then mixed for 30 seconds using a Vortex mixer.

After centrifugation, three layers were distinguished: a basal solid layer, an intermediate liquid layer, and an upper fatty layer. After calculating the steatocrit results for both methods as usual, the capillaries were cut in the middle of the fatty, and of the solid layers using a special glass knife. Subsequently, the layers were removed from the capillaries, using a syringe. A standard amount of each of these fatty and solid layers was then transfer. red to different glass slides for staining with Sudan III dye. In this way, we acquired a total of 48 slides (24 from each steatocrit method, 12 fatty and 12 solid layers) for microscopic evaluation.

\section{Sudan stain method for fecal fat}

For this purpose we used the split fat stain, which identifies both triglyceride and fatty acid

(7). Several drops of $100 \%$ acetic acid and several drops of Sudan III solution were added. The preparation was subsequently mixed with the coverslip, which was then applied. The slide was gently heated on a lighter until bubbling. All preparations were examined while 
still warm under high magnification (magnification of 400 ), by the same person who was blind to the steatocrit methodl used (classical or acid).

For quantification of the amount of fat detected microscopically, we used the criteria established by Drummey et al.(2). They are as follows: normal (+): up to 100 fat globules per high power field, varying in a diameter between 1 and $4 \mu \mathrm{m}$, as noted on the micrometer scale always using a magnification of 400 ; Increased $(2+)$ : up to 100 fat globules per high power field, the diameter of fat globules varying between 1 and $8 \mu \mathrm{m}$; and markedly increased $(3+)$ : more than 100 fat globules per high power field, varying in size from 6 to $75 \mu \mathrm{m}$ in diarneter.

The sum of the fatty and solid layer scores of all our samples, was calculated for both steatocrit methods, and results were compared. Fisher's exact probability test was used to test whether or not the solid layers microscopic fat content was dependent on sample acidification. Finally, calculated acidified and unacidified steatocrit results were compared and related to the chemically measured fecal fat content.

\section{RESULTS}

Table 1 shows that acidification of the fecal homogenates before centrifugation (acid steatocrit method) results in a higher Drummey score in the fatty layers and a lower score in the solid layers. In four specimens (sample 6, 7, 8 and 10), the fatty layers obtained by the classical steatocrit method were so small that we did not succeed in making microscopical slides. Equal results were obtained by both the classical and the acid steatocrit method, in only one sample (sample 11). 
Table 1 Fatty and solid layer microscopical fat scores for both acid and classic steatocrit methods.

\begin{tabular}{|ccccc|}
\hline & \multicolumn{5}{c|}{ SCORES OF FAT GLOBULES } \\
\cline { 2 - 5 } SAMPLES & \multicolumn{3}{c|}{ FATTY LAYERS } & \multicolumn{2}{c|}{ SOLI LAYERS } \\
\cline { 2 - 5 } & ACID & CLASSIC & ACID & CLASSIC \\
\hline 2 & +++ & ++ & + & + \\
3 & ++ & ++ & + & +++ \\
4 & +++ & + & + & +++ \\
5 & +++ & ++ & + & +++ \\
6 & + & - & + & ++ \\
7 & ++ & - & + & ++ \\
8 & +++ & - & + & + \\
9 & +++ & +++ & + & ++ \\
10 & ++ & - & + & + \\
11 & +++ & +++ & + & + \\
12 & +++ & ++ & + & +++ \\
SUM & 31 & 16 & 13 & 24 \\
\hline
\end{tabular}

The sum of the fat scares for fatty and solid layers, and for both steatocrit methods is summa. rized in figure 1. The number of solid layer samples with low microscopic $\left(s^{+}\right)$fat content, was 11 of 12 , and 4 of 12 , for the acidified and unacidified samples respectively $(p<0.005$, Fisher's exact probability test). 


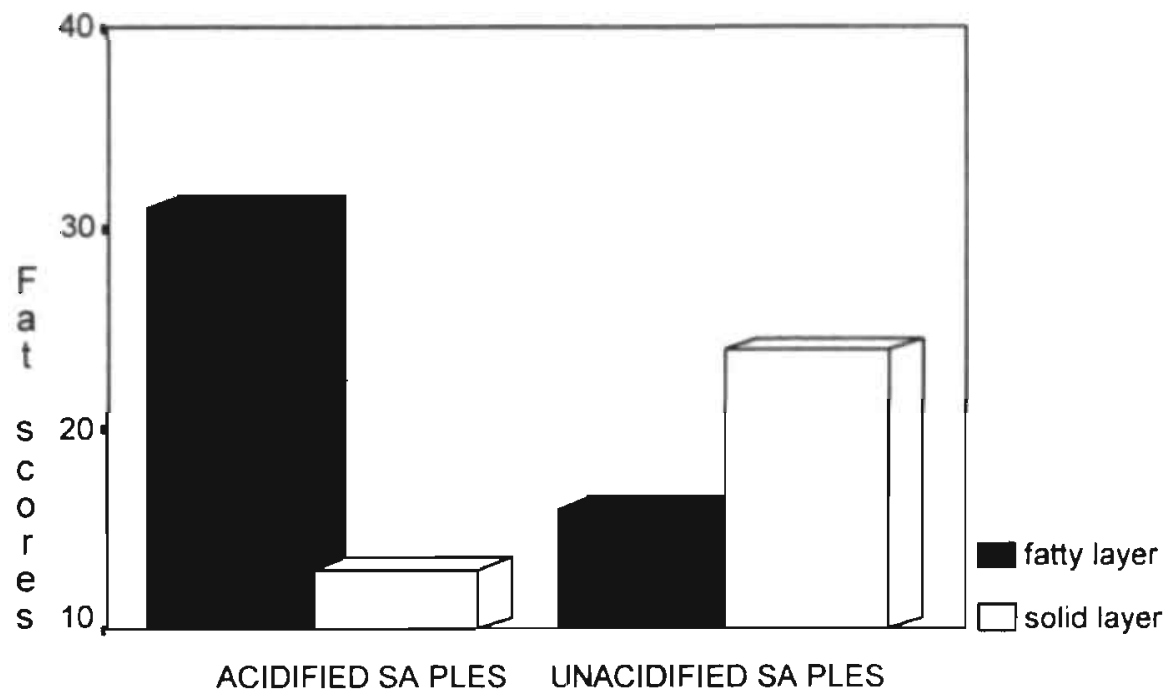

Figure 1 Sum of 12 microscopical Sudan fat globule scores $(1,2,3)$ performed on fatty and solid layers of acidified and unacidified fecal samples. 
The calculated steatocrit results for both steatocrit methods, and the chemically measured fecal fat content for the 12 samples, are shown in table 2. Chemical fat measurements of two samples ( 1 and 2 ) were not performed. The chemically measured fecal fat concentration was very high in all samples and corresponded with high acid steatocrit results, while only 5 classical steatocrit results were elevated.

Table 2 Classic and acid steatocrit results compared to chemically measured fecal fat in 12 steatorrheal fecal samples.

\begin{tabular}{|cccc|}
\hline SAMPLES & $\begin{array}{c}\text { CLASSIC } \\
\text { STEATOCRIT (\%) }\end{array}$ & $\begin{array}{c}\text { ACID } \\
\text { STEATOCRIT (\%) }\end{array}$ & $\begin{array}{c}\text { FECAL FAT } \\
\text { (GRAM \%) }\end{array}$ \\
\hline 1 & 5.3 & 81.7 & - \\
2 & 2.5 & 72.4 & - \\
3 & 5.3 & 71.1 & 16.6 \\
4 & 28.8 & 93.3 & 28.5 \\
5 & 26 & 90.9 & 26.7 \\
6 & 6.2 & 92.6 & 28.3 \\
7 & 3.1 & 92.5 & 18.7 \\
8 & 2.8 & 94.2 & 26.5 \\
9 & 59.8 & 93.7 & 24.3 \\
10 & 6.2 & 96.4 & 10.3 \\
11 & 63.9 & 96 & 27.3 \\
12 & 48.7 & 94.4 & 20.6 \\
\hline
\end{tabular}

\section{DISCUSSION}

There has always been a need for a simple, rapid and easy to perform screening test for fat malabsorption. Such a test would not only be useful for the detection of steatorrhea but also for the therapeutic monitoring of children treated for pancreatic insufficiency.

The steatocrit is a simple and rapid micromethod that can be repeated at short time intervals 
(3). It is inexpensive and not invasive (5). Some authors have reported it as a very satisfactory screening test (3-5), but others have found it quite unreliable (6). Our experience with the method has shown the steatocrit to often be normal, in fecal samples with a very high chemically measured fecal fat content. This could be due to inefficient fecal fat extraction at the centrifugation step. Therefore we recently improved the steatocrit method by acidifying the fecal homogenate before centrifugation (8).

The present study was set up to study the effect of fecal homogenate acidification on fat extraction at the centrifugation step. If fat extraction improves by acidification, we would expect to find more fat globules in the fatty layer and less in the solid layer, after centrifugation of acidified fecal samples, when compared to unacidified samples. Our results are in agreement with our expectations and support the hypothesis that fecal acidification improves fat extraction, and should consequently improve the sensitivity of the steatocrit. Due to various reasons, the fat content of premature infants ' stool, is known to be very high. Confirming the latter, chemical fat measurements of all our samples from 4 premature babies showed very high values. The acid steatocrit seems to reflect these very high fat contents, while classical steatocrit results were high in only 5 of 12 samples. The correlation between chemical fat measurement and acid steatocrit has been reported previously (8). Such a correlation cannot be shown in the present study where only high-fat-content stools were evaluated.

Results of the present study do support our previous findings, confirming, that fecal acidification improves fat extraction at the centrifugation step, and consequently increases the reliability of steatocrit results for the detection of fat malabsorption. Because the Sudan staining staining method for fecal fat is only semiquantitative, we suggest using the acid steatocrit as a good alternative to chemical fat measurement.

Acknowledgement: The authors wish to thank the clinical laboratory staff for their kind and expert technical assistance. We are very grateful to Nutricia Netherlands for financial support. 


\section{REFERENCES}

(1) Van de Kamer JH, Huinink HTB, Weyers HA. Rapid method for determination of fat in feces. J Biol Chem 1949; 177: 349-55.

(2) Drummey GD, Benson JA, Jones CM. Microscopical examination of the stool for steatorrhea. N.Engl J Med 1961; 264: 85-7.

(3) Phuapradit P. Narang A, Mendonca P, Harris DA, Baum JD. The steatocrit: a simple method for estimating stool fat content in newborn infants. Arch Dis Child 1981: 56: 725. 727.

(4) Iacono G, Carroccio A, Cavataio F, Montalto G, Mancusco C, Balsamo V et al. Steatocrit test: normal range and physiological variation in infants. J Pediatr Gastroenterul Nutr 1990; 11: 53-57.

(5) Columbo C, Maiavacca R, Ronchi M, Consalvo E, Amoretti M, Giunta A. The steatocrit: a simple method for monitoring fat malabsorption in patients with cystic fibrosis. J Pediatr Gastroenterol Nutr 1987; 6 : 926-930.

(6) Walters MP, Kelleher J, Gilbert J, Littlewood JM. Clinical monitoring of steatorrhea in cystic fibrosis. Arch Dis Child 1990; 65: 99-102.

(7) Khouri MR, Huang G, Shiau YF. Sudan stain of fecal fat: new insight into an old test. Gastroenterology 1989; 96: 421-427.

(8) Tran M, Forget P, Van den Neucker A, Strik J, van Kreel B, Kuijten R.

The acid steatocrit: a much improved method. J. Pediatr. Gastroenterol Nutr. 1994; 19: 299-303 


\title{
CHAPTER 5
}

\section{CLINICAL USE OF ACID STEATOCRIT}

\author{
A. Van den Neucker', N. Pestel', T. My Dung Tran', P.Ph. Forget',H.J. Veeze', \\ J. Bouquet ${ }^{2}$, M. Sinaasappel ${ }^{2}$.
}

'Department of Pediatrics, University Hospital Maastricht and '2Sophia Children's Hospital Rotterdam, The Netherlands

Submitted for publication

Abstract

Malabsorption of fat is an important gastrointestinal cause of malnutrition and growth retardation in childhood. The golden standard for the evaluation of fat malabsorption is the fecal fat balance method. The acid steatocrit method has recently been introduced as a simple method to evaluate fecal fat. The present study aimed at evaluating the acid steatocrit in clinical practice. Fecal fat excretion and acid steatocrit results were determined in 42 children, half with and half without fat malabsorption. Acid steatocrit results correlated significantly with both fecal fat excretion $(p<0.01)$ and fecal fat concentration $(p<0.001)$. Sensitivity and specificity of the acid steatocrit for the diagnosis of malabsorption was $90 \%$ and $100 \%$ respectively. We consider the acid steatocrit method useful for the screening and monitoring of patients with steatorrhea. Acid steatocrit, Steatorrhoea, Cystic Fibrosis. 


\section{INTRODUCTION}

Malabsorption of fat is the most important gastrointestinal cause of malnutrition and growth retardation in childhood. The detection of steatorrhoea is useful for the diagnosis of intestina! and pancreatic cisease. The gold standard for the evaluation of patients suspected of fat malabsorption is the fat balance method whereby fecal fat is chemically measured according to the method of van de Kamer (1). This method is cumbersome, laborious, expensive and often difficult to manage in children. In 1981 Phuapradit et al. introduced a simple test to evaluate fecal fat content (2). Although some authors found this test quite reliable (3), others did not (4). As previously reported, substantial improvement of the method was obtained by acidification of fecal samples, acid steatocrit (AS) (5).

The present study was designed to compare the fecal fat excretion with the acid steatocrit for the diagnosis of fat malabsorption in children.

\section{PATIENTS}

Forty two children, 23 boys and 19 girls, aged between 6.5 months and 18 years (mean: 6.6 years) were selected for the study. All these children were suspected of fat malabsorption, on the basis of anamnestic and clinical parameters. The different diagnoses of our patients are shown in table 1.

\section{METHODS AND MATERIAL}

Three days stool collections from each patient were collected in separate containers, one container for each day. The stools were frozen at $-18^{\circ} \mathrm{Celsius}$. Fat content in each collection was determined by the titrimetric method described by van de Kamer et al.(1). Acid steatocrit from a single stool sample on day 1 and from a sample out of the homogenized 72 hours collection were determined by the method of Tran et al.(5)Feces $(0.5 \mathrm{gr}$.) was diluted (1/4) with deionized water and thouroughly homogenized making use of a $5 \mathrm{ml}$. Potter Elvehjem tissue homogenizer. Perchloric acid $5 \mathrm{~N}$ was added to the homogenate in a volume equal to $1 / 5$ of the homogenate volume. The resulting acid homogenate was mixed for 30 seconds making 
Table 1 List of diagnosis $(n=42)$.

\begin{tabular}{|cc|}
\hline DIAGNOSIS & NUMBER OF CASES \\
\hline CYSTIC FIBROSIS & 20 \\
MENTAL RETARDATION & 2 \\
RECURRENT DIARRHEA & 5 \\
FAILURE TO THRIVE & 5 \\
COELIAC DISEASE & 2 \\
INFLAMMATORY BOWEL DISEASE & 1 \\
SHORT BOWEL & 1 \\
CHOLEDOCHAL CYSTE & 1 \\
SUCRASE-ISOMALTASE DEFICIENCE & 1 \\
RECURRENT ABDOMINAL PAIN & 1 \\
UNKNOWN & 3 \\
\hline
\end{tabular}

use of a standard Vortex mixer. The homogenate was aspirated into a75 $\mu$ l plain glass haematocrit capillary. The capillary was subsequently centrifuged horizontally (13000 rpm. for 15 min.) in a standard centrifuge. After centrifugation, the lengths of the upper (fat) and the bottom (solid) layers were measured by means of a graduated magnifying lens. Steatocrit was calculated as follows: percentage of (the fatty layer length / (fatty layer length + solid layer length)\}.

In order to validate the diagnostic value of the acid steatocrit we studied two patients groups, one with and one without steatorrhea. We divided the patients according to previous clinical datã and fat excretion results. whereby a fecal fat excretion $23 \mathrm{gr} /$ day was considered as abnormal (6).

\section{RESULTS}

Correlation coefficients between acid steatocrit results from either a șingle stool sample or from the sample taken from the 72 hours homogenized collection, and both the fecal fat excretion and the fecal fat concentration are shown in table 2. 
Table 2 Correlation between the results of the acid steatocrit from either a single stool sample and a sample from the homogenised stool collection and the results of both fat excretion and fecal fat concentration in $\mathbf{4 2}$ children suspected of malabsorption.

\begin{tabular}{|c|c|c|}
\hline ACID STEATOCRIT & FAT EXCRETION & FAT CONCENTRATION \\
\hline SINGLE STOOL & $r=0.4(p \leq 0.01)$ & $r=0.82(p \leq 0.001)$ \\
\hline COLLECTION & $r=0.68(p \leq 0.001)$ & $r=0.82(p \leq 0.001)$ \\
\hline
\end{tabular}

The sensitivity and the specificity of the acid steatocrit determination from either a single stool sample or a sample taken from the 72 hours homogenized collection, and of the fecal fat concentration, for the diagnosis of steatorrhea are shown in table 3.

Table 3 Sensitivity and specificity of the acid steatocrit determination from a single stool sample and from a homogenised stool collection sample and of the fecal concentration, for the diagnosis of steatorrhea.

\begin{tabular}{|c|c|c|}
\hline & SENSITIVITY & SPECIFICITY \\
\hline AS SINGLE STOOL (\%) & $75 \%$ & $84 \%$ \\
\hline AS COLLECTION (\%) & $90 \%$ & $100 \%$ \\
\hline FAT CONCENTRATION (\%) & $100 \%$ & $76 \%$ \\
\hline
\end{tabular}

AS: Acid steatocrit

Fig.1 shows our AS results from the homogenized fecal collection sample related to the fecal fat excretion ( $g /$ day).The reference line for AS was set at the level of $10 \%(5)$, and the cut off reference line for the daily fat excretion was set at the level of $3 \mathrm{gram}$ per day (6).As can be seen from the figure, one false positive and three false negative acid steatocrit results were found in our study population.Regarding these results one should notice that they are very close to the reference lines: the false positive steatocrit result had a value of $16 \%$ and the results of the fecal fat excretion corresponding to the false negative steatocrit results were 4.9 ; 6.4 and $7.7 \mathrm{~g} / \mathrm{day}$, and concern children aged 12.6 and 13 years respectively. 


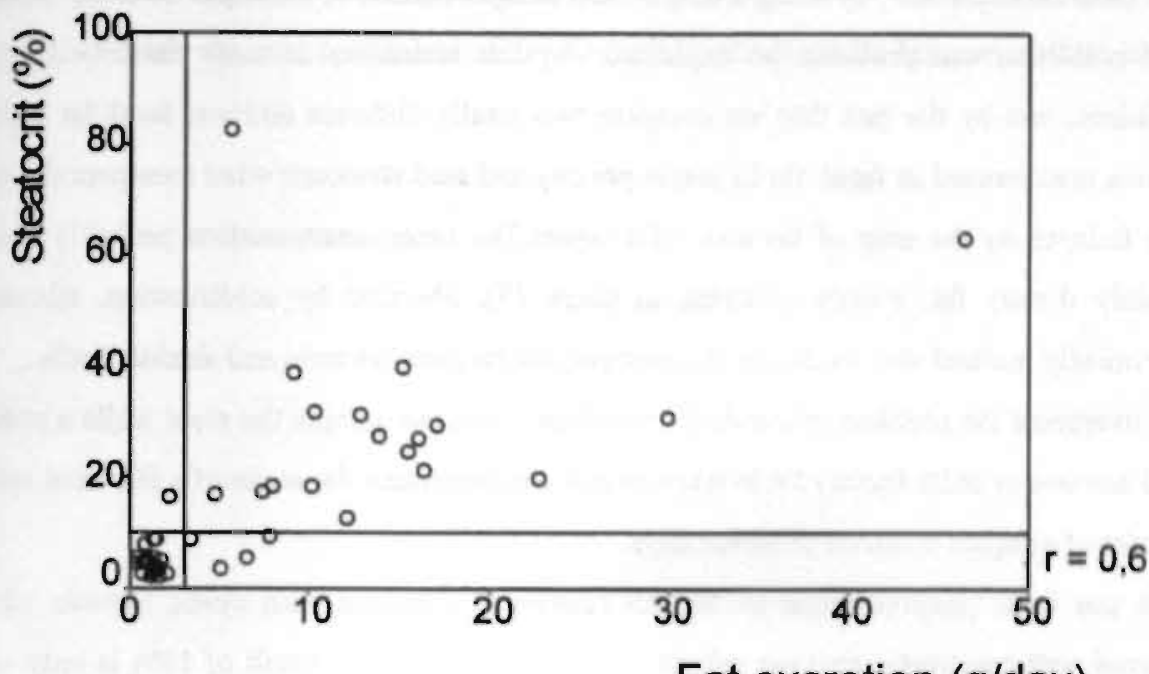

\section{Fat excretion (g/day)}

Figure 1 Relationship between acid steatocrit and fat excretion. Reference lines for acid steatocrit at $10 \%$ and for fat excretion at $3 \mathrm{gram} /$ day.

\section{DISCUSSION}

Since the fecal fat balance excretion as described by van de Kamer is cumbersome, expensive and unpleasant for all involved, there is a need for a simple test. Some authors reported the steatocrit micromethod described by Phuapradit as a simple method for monitoring fat malabsorption (3), and reported a good correlation ( $r=0.93$ ) with the fecal fat excretion. Although others considered the steatocrit method of Phuapradit unreliable and mentioned the difficulty to delineate the fatty layer (4) and the impression that fat remains in the solid layer, as a problem of this method.This problem was solved by acidification of the fecal sample, whereby fat extraction is improved, and steatocrit results correlate much better with chemically measured fecal fat (5).

Our AS results correlate satisfactorily with chemically measured fecal fat concentrations and somewhat less ,but still significantly, with fecal fat excretion.However, our correlation coefficient is lower than the correlation coefficient of the steatocrit without acidification as published in a previous study (3).We have no explanation for this discrepancy, and other 
authors also failed to reproduce these results (4). The lesser correlation of the AS results with the fecal fat excretion, by using a single stool sample instead of a sample from the homogenized collection can probably be explained by the variability of daily fat consumption in children, and by the fact that we compare two totally different entities: fecal fat excretion, which is expressed as fecal fat in grams per day and acid steatocrit what measures the ratio of the fatlayer on the sum of fat and solid layers. The latter determination probably measures mainly dietary fat, mostly occuring as soaps (7), liberated by acidification, whereas the chemically method also measures the endogenous fat from bacteria and shedded cells.

To overcome the problem of the daily variability, one can sample the stool while a standardized amount of daily dietary fat is taken or one can determine the mean of a few acid steatocrit results of samples taken on different days.

The one false positive result of the AS concerned a patient with cystic fibrosis who was treated with pancreatic enzyme substitution therapy. This AS result of $16 \%$ is only slightly elevated considering the values obtained in cystic fibrosis patients on substitution therapy, which are mostly between 20 and $30 \%$.

The three false negative results of the acid steatocrit can probably be explained by the choice of the reference line for the normal fecal fat excretion. Fecal fat excretion higher than $4.5 \mathrm{~g} / 24$ hours is considered pathologic $(6,8)$ for children and adolescents, whereas other authors consider $7 \mathrm{~g} /$ day the uper limit of normal fecal fat excretion in adults (9). The reference line for normal daily fecal fat excretion varies clearly with age and dietary fat intake as previously suggested by Williams (8).Taking account of these remarks, the fat excretion studies of 2 of our 3 patients with false negative steatocrit results could, due to their ages (12 and 13 years), still be considered "normal" and in agreement with AS results .This would reduce the disagreement between the methods to only a few ones.

\section{CONCLUSION}

Acid steatocrit results are highly correlated with the chemically measured fecal fat concentration and significantly correlated with the fecal fat excretion. Although single sample acid steatocrit results are slightly less sensitive and specific than other measured parameters for the diagnosis of steatorrhoea, acid steatocrit measured in the stool samples taken from the homo- 
genized collection compare favourably with the fecal fat concentration. We consider the acid steatocrit method useful for the screening and monitoring of patients with steatorrhoea.If it is necessary to know the real coefficient of fat absorption, the fecal fat balance method is needed. 


\section{REFERENCES}

(1) van de Kamer JH, Huinink HTB, Weyers HA. Rapid method for determination of fat in feces. J Biol Chem 1949; 177:349-55.

(2) Phuapradit P, Narang A, Mendonca P, Harris DA, Baum JD. The steatocrit: a simple method for estimating stool fat content in newborn infants. Arch Dis Child 1981; 56:725-7.

(3) Colombo C, Maiavacca R, Ronchi M, Consalvo E, Amoretti M, Giunta A. The steatocrit: a simple method for monitoring fat malabsorption in patients with cystic fibrosis. J Pediatr Gastroenterol Nutr 1987;6:926-30.

(4) Walters MP, Kelleher J, Gilbert J, Littelwood JM. Clinical monitoring of steatorrhoea in cystic fibrosis. J Pediatr Gastroenterol Nutr 1990; 65:99-102.

(5) Tran M, Forget P, Van den Neucker A, Strik J, Kreel van B, Kuijten R.The acid steatocrit: a much improved method. J Pediatr Gastroenterol Nutr 1994; 19: 299-303.

(6) Navarro J, Schmitz J. Gastroenterologie pédiatrique, Flammarion Médicine Sciences, Paris 1986.

(7) Quinlan PT, Lockton S, Irwin J, Lucas AL. The relationship between stool hardness and stool composition in breast- and forrnula-fed infants. J Pediatr Gastroenterol Nutr 1995; 20:81-90.

(8) Williams HH, Endicott EN, Shepherd ML, Galbraith H, Macy IG. Fat excretion by normal chilldren.J. of Nutrition 1943; 25, 379.

(9) Bai JC, Andrish A, Matelo G, Martinez C, Vazquez H, Boern L, Sambuelli A. Fecal fat concentration in the differential diagnosis of steatorrhoea. Am. J. Gastroenterol. 1989; 27-30. 


\title{
CHAPTER 6
}

ROLE OF LANSOPRAZOLE IN CHILDREN WITH CYSTIC FIBROSIS: EVIDENCE FOR IMPROVED FAT ABSORPTION AND NUTRITIONAL STATUS

\author{
Tran TMD, Van den Neucker A, Hendriks JJE, Forget $\mathrm{P}$ ( junior ), Forget $\mathrm{P}$ ( senior )
}

\section{Department of Pediatrics, University Hospital Maastricht, Maastricht, The Netherlands}

\section{Submitted for publication}

\section{Abstract}

Steatornhea and nutritional parameters were investigated in 15 cystic fibrosis children before starting lansoprazole, after 3 months on lansoprazole ( $15 \mathrm{mg} /$ day) and 3 months after stopping lansoprazole. There were 5 girls and 10 boys with a mean age of 9.5 years (range: 3.1 22.6y). Patients were their own controls. Acid steatocrit, anthropometric methods and DXA were used to evaluate steatornhea and the nutritional status respectively. On lansoprazole, mean \pm SD acid steatocrit values decreased from $37.1 \pm 8.8 \%$ to $28.5 \pm 10.6 \%(p=0.02)$. During lansoprazole therapy, significant mean $Z$-score changes were found for weight $(+0.14 /$ $p=0.02)$, length $(+0.15 / p=0.03)$, subscapular $(+0.61 / p=0.003)$, suprailiaca $(+0.8 / p=$ $0.002)$ and the sum of 4 skinfolds $(+0.61 / p=0.002) . Z$-scores deteriorated again after stopping lansoprazole. Fatmass and bone mineral content increased significantly on lansoprazole $(p=0.008$ and $p=0.005$ resp.). Improvement of subscapular $Z$-score was related to improvement of acid steatocrit values $(p=0.01)$ during treatment. We conclude that lansoprazole as adjuvant therapy significantly improves fat absorption and the nutritional status in CF children. 


\section{INTRODUCTION}

Cystic fibrosis (CF) is an autosomal recessive inherited disease. Defect in the chloride transepithelial transport system results in viscous mucus in various organs with lung and pancreas mostly affected (1). Both, pancreatic insufficiency resulting in malabsorption and high energy expenditure due to increased respiratory work (2-3), are thought to be responsible for the poor nutritional condition in CF patients. Since malnutrition can compromise absorptive and immune function resulting in a shortened survival (4), all efforts should be made in order to improve the nutritional status of these patients. Unfortunately, high doses of pancreatic enzymes did not solve the problems of malabsorption (5) and colon stricture has been observed in CF children on this regimen $(6,7)$. Further, the use of hypercaloric diets did not result in significant improvements of Z-scores for weight, length and skinfolds in CF children (8). Only parenteral nutrition and either oral or enteral elemental and semielemental nutrition have been shown to significantly improve the nutritional condition of these children (9-15).

The latter strongly suggests that nutrient maldigestion plays a crucial role in the poor response to oral hypercaloric diets. As cystic fibrosis patients have a low duodenal $\mathrm{pH}$ probably linked to fat maldigestion (16), inhibition of gastric acid production could improve absorption. The reported effects of $\mathrm{H} 2$-receptor antagonists and prostaglandine E2 on steatorrhea have been variable (17-22). Insufficient inhibition of gastric acid could be responsible for these unconvincing results. Recently, in a double blind study, a significant improvement in steatorrhea was found when a proton-pump inhibitor was added as adjuvant therapy in pancreatic enzyme treated cystic fibrosis patients (23). The effect of proton pump inhibitors on the nutritional condition of children with CF have not yet been reported. The aims of our study were to evaluate the effects of lansoprazole (proton-pump inhibitor) on both steatorrhea and the nutritional condition of CF patients while on enzyme therapy.

\section{SUBJECTS AND METHODS}

\section{Studv design}

As the effect of a proton pump inhibitor on fat balance has been convincingly proven in a 
double blind study (23), we adapted a prospective open study design wherein patients were their own controls. In the month preceding the study, all patients were screened for steatorrhea by measuring fecal acid steatocrit once every 10 days. Patients with a mean acid steatocrit value higher than $25 \%$ (normal values in our laboratory $<20 \%$ ) were invited to take part in the study. After evaluation of nutritional parameters by DXA and anthropometric methods, lansoprazole was added to their standard treatment in a dose of $15 \mathrm{mg}$ day before breakfast for 3 months. When fat malabsorption did not change after 2 months, the dose was doubled in children older than 10 years and weighing more than $30 \mathrm{~kg}$. During the lansoprazole treatment period 9 fecal samples were taken with an interval of 10 days for acid steatocrit measurements. The mean of these 9 measurements was used as a measure of steatorrhea during the treatment period. After 3 months on treatment, the nutritional condition assessment was repeated. All measurements of nutritional condition were performed on a single day. Three fecal samples for acid steatocrit determinations and anthropometric parameters were again measured respectively 1 month and 3 months after stopping lansoprazole therapy. Dietary evaluations were performed at the start, at the end and one month after stopping lansoprazole.

\section{Patients population}

$23 \mathrm{CF}$ out-clinic patients from the academic Hospital Maastricht were recruited. All patients were treated with pancreatic enzymes. Of these, 2 patients were too ill to participate in the study. 21 patients were screened for steatorrhea while on pancrease enzyme. 15 of them who had steatorrhea were included. In most children, the $\mathrm{CF}$ diagnosis had been made during the first year of life by repeated positive sweat tests, all 15 children were considered to have pancreatic insufficiency on the basis of abnormal fecal chymotrypsin, 72 hours fat balance (24) and increased acid steatocrit results (25). Mean energy intake was $113 \%$ RDA (recommended daily allowance). The mean number of pancreas enzyme capsules (Pancrease) taken by 13 of these patients was 20 (range: 11 - 33), one patient took 3 Pancrease capsules (5000E lipase, 2900E amylase, 330E protease) and 6 Panzytrat tablets (25000E lipase, 22500E amylase, 1250E protease) and another one took 10 Creon capsules (8000E lipase, 9000E amylase, $450 \mathrm{E}$ protease) per day. Mean age, weight and length of those 15 children were $9.5 \mathrm{y}$ (range: $3.1-22.6 \mathrm{y}$ ); $29.3 \mathrm{~kg}$ (range: $13.6-67.6 \mathrm{~kg}$ ) and $131 \mathrm{~cm}$ (range: $97.7-184.9 \mathrm{~cm}$ ) 
respectively. Their nutritional status was moderately altered with a mean Body Mass Index (BMI) of 15.6 (range : 13.2 - 18.3). Mean predicted values of FEV1 and FVC were respectively $81.3 \%$ (range: $39-114 \%$ ) and $85.5 \%$ (range: $44-108 \%$ ). Informed patient and parental consent were obtained.

\section{Evaluation of fat malabsorption by acid steatocrif.}

The acid steatocrit was determined as previously reported (25). In short, $0.5 \mathrm{~g}$ solid stool was weighed and diluted with a volume of deionized water, equal to two times the weight of stool. The stool and water were premixed using a Vortex mixer. Subsequently, the mixture was homogenized using a $5 \mathrm{ml}$ Potter Elvehjem tissue homogenizer. After then $5 \mathrm{~N}$ perchloric acid was added to the homogenate in a volume equal to $1 / 5$ of the homogenate. After mixing with the Vortex, the acidified homogenate was aspirated into a $75 \mu \mathrm{l}$ plain haematocrit capillary. This capillary was sealed with wax at one end and centrifuged horizontally $(13000 \mathrm{rpm}, 15$ min). After centrifugation, 3 layers were distinguished: a basal solid layer (SL), an intermediate liquid layer and an upper fatty layer (FL). Acid steatocrit was calculated as (FL / FL + SL)) $\times 100 \%$

\section{EVALUATION OF NUTRITIONAL STATUS}

\section{Anthropometry}

The armcircumference, biceps, triceps, subscapular and suprailiaca skinfolds were measured 3 times on the left side of the body using the Harpenden caliper. Average values were taken. Weight and length were also measured. BMI was calculated as weight / (length ${ }^{2}$ ). The Z score

(Z-score is defined as $\mathrm{X}-\mathrm{x} / \mathrm{S}$ where $\mathrm{X}$ is the patients 's measurement, $\mathrm{x}$ is the mean value for age and sex and $\mathrm{S}$ is the standard deviation of $\mathrm{x}$ ) of all these anthropometric parameters were calculated based on the reference data described by Gerver and de Bruin (26). A negative value indicates values under the mean reference value and a positive or negative change in $Z$ score means catch up or slowing down of growth respectively. All measurements were done 
by the same investigator (TT).

\section{Dual-energy $x$-ray absorptiomerry (DXA)}

DXA measurement is based on the differential tissue attenuation of photons of two energy levels from an X-ray source (27). All patients underwent total body scan performed with a DPX (Lunar Radiation Corp, Madison, WI) total body scanner. The results were analysed with a paediatric software programme, version $1.5 \mathrm{e}$. Daily quality assurance test was performed according to the manufacturer 's directions. Total non bone LBM (lean body mass), total BMC (bone mineral content), total body FM (fatmass) and BMD (bone mineral density) Z . score were measured by DXA procedure. These results were compared to those of the reference population, recently described by Ogle et al., who studied the body composition by DXA in 265 normal individuals aged 4 - 26 year (28).

\section{Diet evaluation}

At the beginning, at the end and one month after stopping lansoprazole nutrient intake was assessed by a specially trained clinical CF dietitian from consecutive 3 day food diaries including one weekend day. Intakes were expressed as kilocalorie per $\mathrm{kg}$ bodyweight for the energy intake and gram per $\mathrm{kg}$ bodyweight for fat-, carbohydrate- and protein-intakes, using the netherlands nutrients table "NEVO" 1993.

\section{Statistic}

All data were analysed by using SPSS statistic program. Anthropometric parameters and body composition results measured before the start and at the end of the trial were compared making use of Wilcoxon one sample test. The sign test was used to compare LBM, FM and BMC assessed by DXA, with the reference population described by Ogle. 


\section{RESULTS}

\section{Eat malabsorption}

Despite standard pancreas enzyme, 15 of 21 children had steatorrhea with an average \pm SD pretreatment acid steatocrit value (mean of 3 determinations in each patient) of $37.1 \% \pm 8.8 \%$. After 3 months of treatment with lansoprazole, there was a significant $(p=0.02)$ improvement in steatorrhea with a mean $\pm \mathrm{SD}$ acid steatocrit value of $28.5 \% \pm 10.6 \%$. Eight patients on lansoprazole had a mean acid steatocrit value lower than $25 \%$ (fig 1 ). In this group the mean decrease was $16 \%$ ( $44.2 \%$ of start value). In 3 children the acid steatocrit value decreased with. $9 \%$ (20.6\% of start value) but was not completely corrected. In 4 children fat malabsorption. did not improve at all. Four children received a double dose of lansoprazole for 1 month, resulting in a decreased acid steatocrit results in 2 (decrease of $8.6 \%$ and $19 \%$ ). Due to social problems one child was dropped out of the study after the lansoprazole period. Mean \pm SD acid steatocrit value for the remaining 14 children in the first month after stopping lansoprazole was $29.7 \% \pm 13.9 \%$, which was not significantly different from the values on lansoprazole. Of 4 children whose acid steatocrit was not changed on lansoprazole, 2 had higher acid. steatocrit values after stopping.

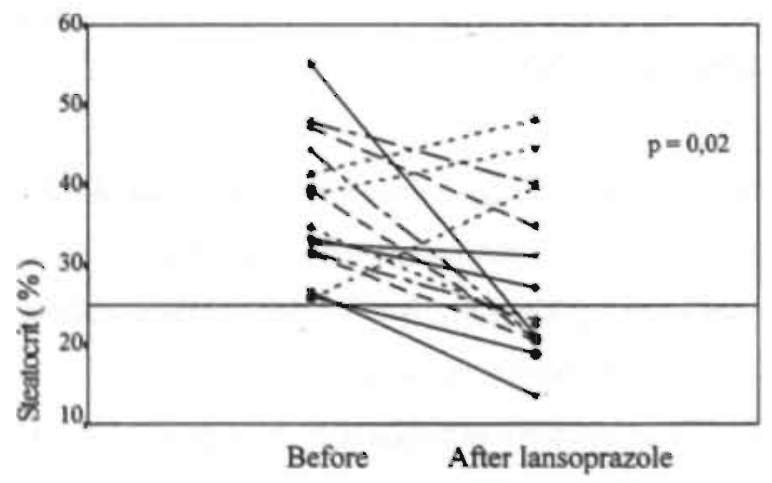

Figure 1 Acid steatocrit before and after 3 months treatment with lansoprazole in 15 CF children. A line through the $25 \%$ value is drawn showing the study inclusion limit. Acid steatocrit values on lansoprazole art significantly decreased $(p=0.02)$. 
Mean and $95 \% \mathrm{Cl}$ (confidence interval) for weight, length, armcircumference, 4 skinfolds and the sum of these 4 skinfolds expressed as Z-score are shown in fig.2. For all parameters except the triceps, the $\mathrm{CI}$ do not include the reference 50 th centile line (Z-score 0 ), underscoring the fact that except for the triceps skinfold, all other anthropometric parameters mean Z-scores were significantly decreased in our CF children when compared to those of the normal population. The suprailiaca skinfold was most abnormal and showed the smallest interindividual variation.

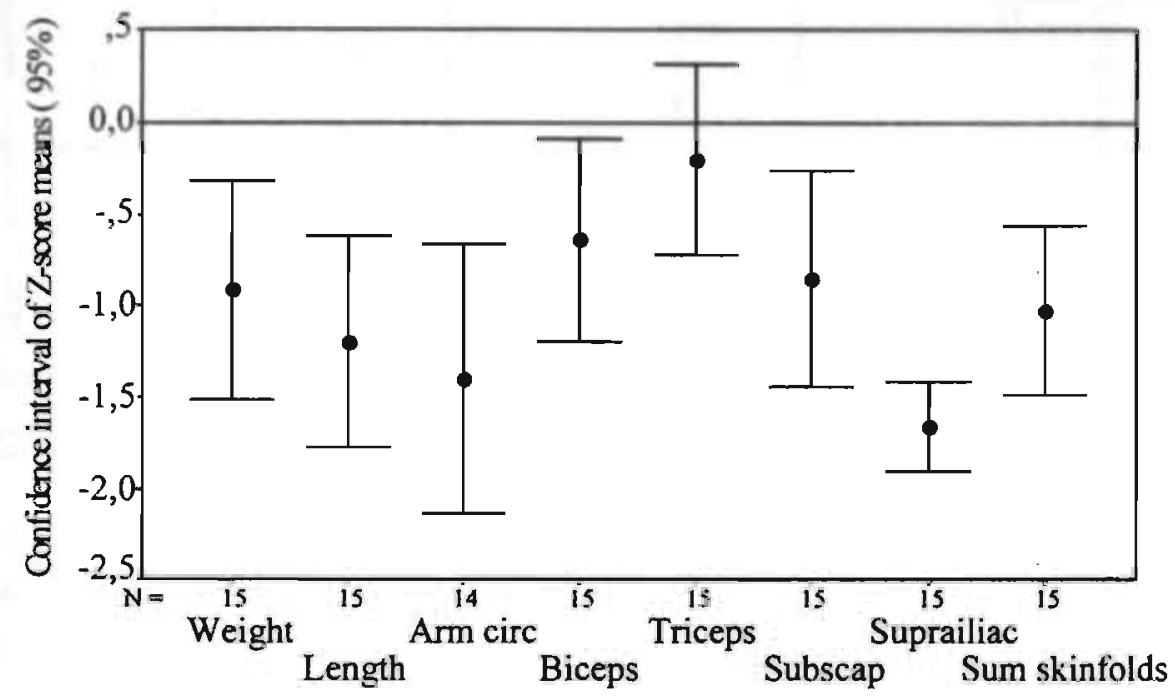

Figure 2 Mean Z-scores and $95 \%$ confidence interval of anthropometric parameters in $15 \mathrm{CF}$, children before lansoprazole therapy. The line through 0 represents the 50th centile of the reference population. The differences between the study group and the reference population are significant when the $\mathrm{CI}$ do not include the Z-score 0 line. All anthropometric parameters were significantly decreased in our CF children except for the triceps skinfold. 
After treatment with lansoprazole, Z-scores of anthropometric parameters improved signifcantly. All parameters moved toward the Z-score 0 line (50th centile for reference population). The Z-scores of biceps, subscapular and sum of the 4 skinfolds did not significantly differ from the reference population any more (fig.3).

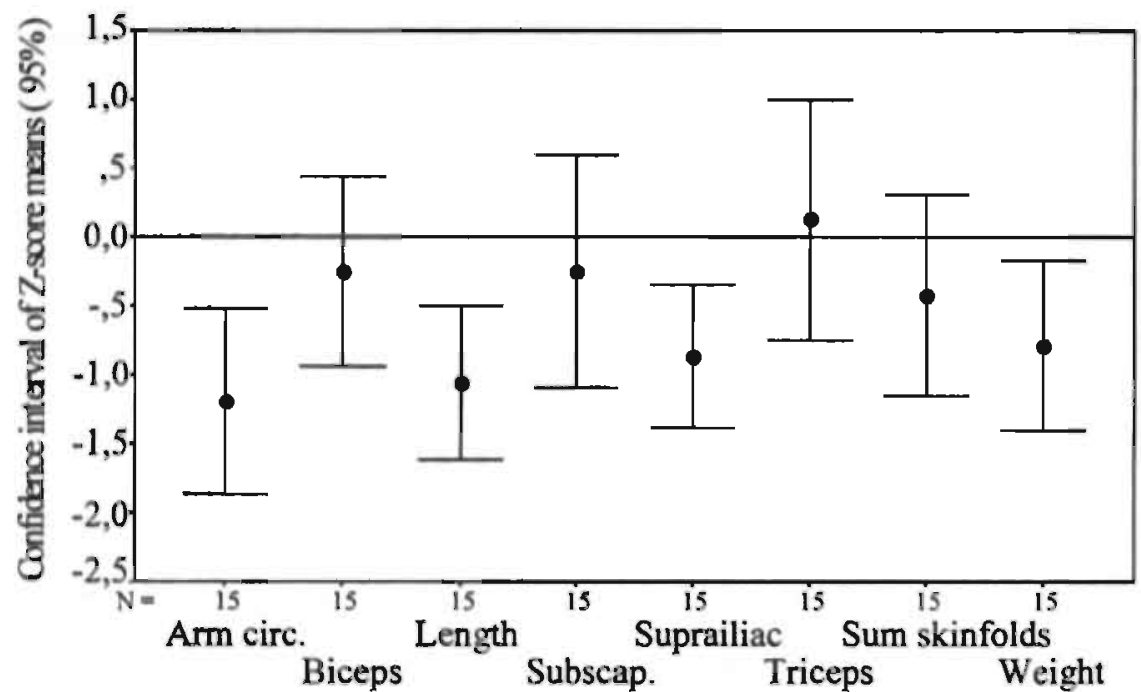

Figure 3 Mean Z-scores and $95 \%$ confidence interval of anthropometric parameters in 15 CF' children on lansoprazole for 3 months. The differences between the study group and the reference population are significant when the $\mathrm{CI}$ do not include the Z-score 0 line. Several parameters (biceps, subscapular and sum of 4 skinfolds) normalized during lansoprazole treatment (see figure 2).

Z-score changes for all anthropometric parameters studied are shown in table: 1. Except for armcircumference, biceps and triceps skinfolds, Z-scores of all parameters improved significantly. Subscapular, suprailiaca and the sum of the 4 skinfolds showed the most significant changes. The acid steatocrit results during lansoprazole treatment were significantly lower ( $p$ $=0.01$ ) in our patient subgroup with subscapular Z-score improvement 20.5 when compared to the subgroup showing lower Z-score changes. Three months after lansoprazole was stopped, 5 children were dropped out of the study; 2 because of the far distances from home, 1 had 
taken lansoprazole again because of increased symptoms of steatorrhea and abdominal pain and 2 because of social problems. Nutritional parameters were therefore evaluated in only 10 children 3 months after stopping lansoprazole. Z-scores of all anthropometric parameters deteriorated, with weight and subscapular Z-score changes reaching statistical significance (table 1).

Table 1 Mean Z-scores of anthropometric parameters in $15 \mathrm{CF}$ children before (T0), after 3 months on lansoprazole (T3) and 3 months after stopping lansoprazole (T6).

\begin{tabular}{|c|c|c|c|c|c|}
\hline $\begin{array}{c}\text { Anthrop. } \\
\text { Parameters }\end{array}$ & $\begin{array}{c}\text { Me } \\
\text { Mean Z-score } \\
(\mathrm{n}=15)\end{array}$ & $\begin{array}{c}\text { T3 } \\
\text { Mean Z-score } \\
(\mathrm{n}=15)\end{array}$ & $\begin{array}{c}\text { T6 } \\
\text { Mean Z-score } \\
(\mathrm{p}=10)\end{array}$ & $\begin{array}{c}\text { T3- T0 } \\
\text { Mean Z-score } \\
(\mathrm{n}=15)\end{array}$ & $\begin{array}{c}\text { T6-T3 } \\
\text { Mean Z-score } \\
(\mathrm{n}=10)\end{array}$ \\
\hline Weight & -0.91 & -0.78 & -1.38 & $0.14(\mathrm{p}=0.02)$ & $-0.6(\mathrm{p}=0.01)$ \\
Length & -1.2 & -1.05 & -1.23 & $0.15(\mathrm{p}=0.03)$ & $-0.18(\mathrm{p}=0.16)$ \\
Armeircum & -1.4 & -1.19 & -1.74 & $0.22(\mathrm{p}=0.05)$ & $-0.55(\mathrm{p}=0.52)$ \\
Biceps & -0.63 & -0.24 & -1 & $0.39(\mathrm{p}=0.06)$ & $-0.76(\mathrm{p}=0.21)$ \\
Triceps & -0.2 & 0.14 & -0.72 & $0.34(\mathrm{p}=0.2)$ & $-0.86(\mathrm{p}=0.26)$ \\
Subscapular & -0.85 & -0.24 & -1.14 & $0.61(\mathrm{p}=0.003)$ & $-0.9(\mathrm{p}=0.03)$ \\
Suprailiaca & -1.66 & -0.86 & -1.13 & $0.8(\mathrm{p}=0.002)$ & $-0.27(\mathrm{p}=0.68)$ \\
Sum skinfolds & -1.02 & -0.41 & -1.16 & $0.61(\mathrm{p}=0.002)$ & $-0.75(\mathrm{p}=0.31)$ \\
\hline
\end{tabular}

\section{Body composition}

Body composition data before and after lansoprazole are given in table 2. All 3 components FM, LBM and BMC were significantly decreased in our 15 CF children when compared to the reference population described by Ogle et al. $(p=0.01 ; p=0.02$ and $p=0.005$ respectively). Bone mineral density Z-score was significantly decreased ( $p \leq 0.05$ ). Significant increases of FM and BMC occurred after 3 months of treatment with lansoprazole. Changes in the subscapular, suprailiaca and sum of the 4 skinfolds $Z$-scores were highly correlated with changes in FM by DXA ( $r=0.81 / r=0.77 / r=0.85$ resp. with $p=0.001)$ (fig 4). 


\section{Diet evaluation}

Mean fat, protein, carbohydrate and energy intakes were $3.1-2.8-3.0 \mathrm{~g} / \mathrm{kg} ; 3.0-2.7-2.8$ $\mathrm{g} / \mathrm{kg} ; 10.4-9.7-9.8 \mathrm{~g} / \mathrm{kg}$ and $2095-1986-1977 \mathrm{kcal} / \mathrm{kg}$ bodyweight at the start, at the end and one month after lansoprazole trial respectively. None of these changes were significant.

Table 2 Body composition before (T0) and after (T3) lansoprazole by DXA.

\begin{tabular}{|c|c|c|c|}
\hline $\begin{array}{c}\text { BODY } \\
\text { COMPOSITION }\end{array}$ & $\begin{array}{c}\text { T0 } \\
(\mathrm{n}=15)\end{array}$ & $\begin{array}{c}\text { T3 } \\
(\mathrm{n}=15)\end{array}$ & $\begin{array}{c}\text { SIGNIFICANCY } \\
(\mathrm{p})\end{array}$ \\
\hline MEAN FATMASS (Kg) & 3.97 & 4.76 & 0.008 \\
MEAN LBM (Kg) & 22.83 & 24.03 & 0.06 \\
MEAN BMC (Kg) & 1.02 & 1.08 & 0.005 \\
MEAN BMD ( Z-SCORE) & -0.55 & -0.58 & 0.65 \\
\hline
\end{tabular}




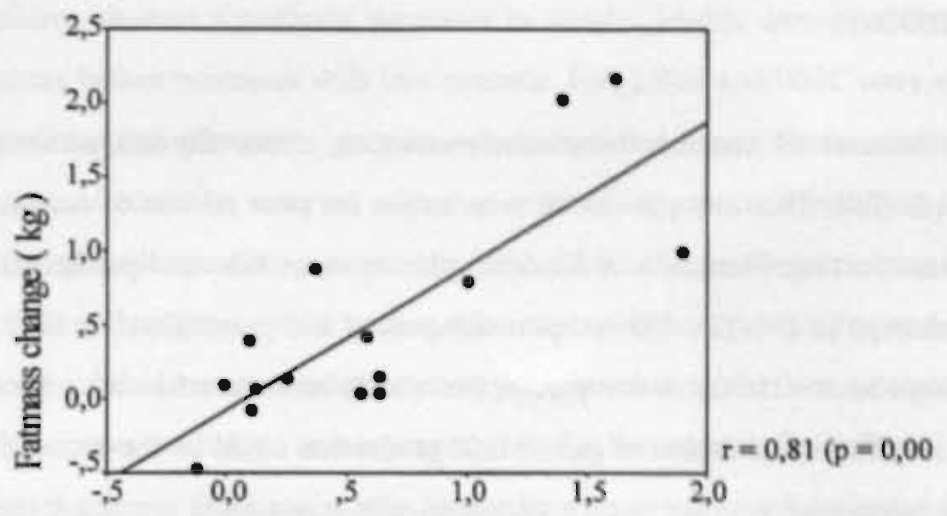

Change in subscapular Z-score

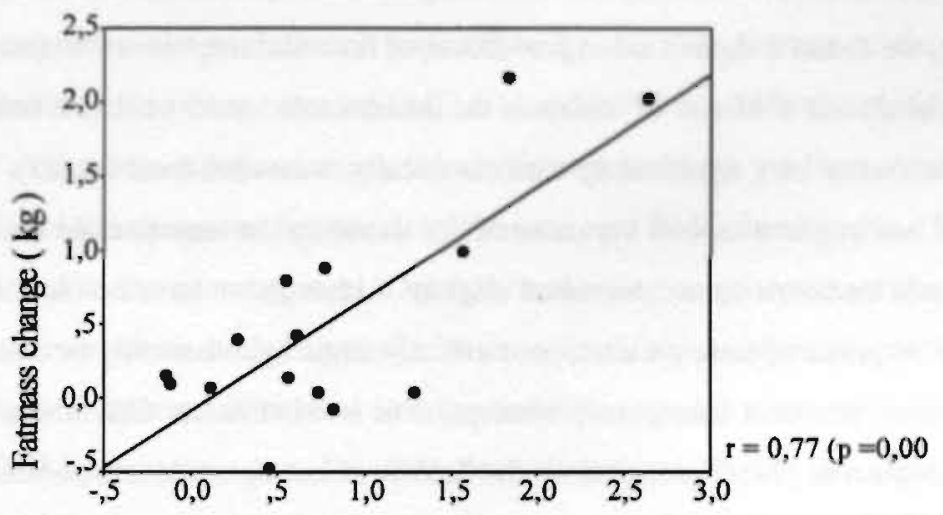

Change in suprailiaca Z-score

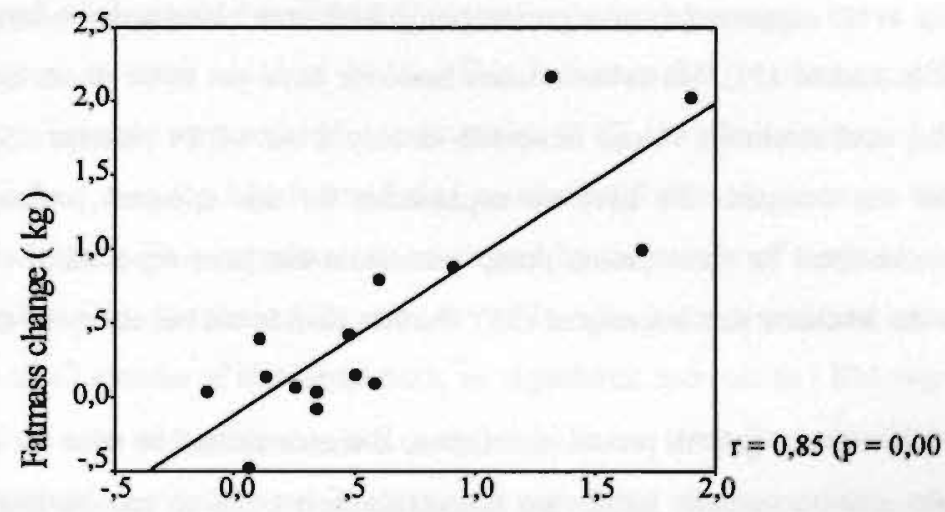

Change in sum of skinfolds Z-score

Figure 4 Relation between changes in subscapular skinfold Z-score, suprailiaca skinfold Z-score, sum of 4 skinfolds Z-score and fatmass as measured by DXA (dual energy X-ray absorptiometry) in 15 CF children. 


\section{DISCUSSION}

Due to a decrease of pancreas bicarbonate secretion, cystic fibrosis patients have a low duodenal $\mathrm{pH}$ (29). This low $\mathrm{pH}$ can be responsible for poor release of enzymes through the acid resistent coating. Further, low duodenal $\mathrm{pH}$ can cause bile acid precipitation resulting in lipid malabsorption (30-32). H2-receptor antagonists and prostaglandine E2 have been used with the hope to reverse the above proces, but results on steatorrhea have been controversial (17-22). Insufficient inhibition of gastric acid production could be the cause of these failures As proton pump inhibitors are known to control acid secretion in a much more effective way (33), they could be more effective in increasing duodenal $\mathrm{pH}$. In agreement with Heijermans et al. (23), we found a significant improvement of fat malabsorption as measured by the acid steatocrit in all but 4 of our $\mathrm{CF}$ children on lansoprazole. Acid steatocrit results have been shown to correlate very significantly with chemically measured fecal fat (25). Acid steatocrit values did not improve in 4 of our patients. By doubling the lansoprazole dose in 2 of these patients, acid steatocrit values decreased slightly. Although we have no clear explanation for the lack of response of these patients, poor efficacy could hypothetically be due to host factors including poor intestinal lansoprazole absorption or interindividual differences in bioavailability of lansoprazole (34). Further, since the halflife of lansoprazole is between 1 and 2 hours and inhibition will be limited to proton pumps active during the effective plasma levels of the drugs, Sachs et al. suggested to give proton pump inhibitors twice a day whenever effective $\mathrm{pH}$ control is desired (33). However, studies hereover have yet to be done. Contrary to our expectations, acid steatocrit values increased in only 8 out of 14 patients one month after lansoprazole was stopped. We have no explanation for this apparent prolonged effect of lansoprazole on fecal fat since proton pump restoration has been reported to occur 50 to 72 hours after the inhibitor was interrupted (33). Further studies are necessary in order to clarify this point.

Because of the normal growth proces in children, Z-scores should be used for the evaluation of anthropometric parameters. Improving Z-scores reflect catch-up growth and consequently improvement in the nutritional status while the reverse is true for deteriorating Z-scores. The recent introduction of DXA methodology makes it possible to evaluate FM, LBM and BMC rapidly and non invasively in children (27). In agreement with previous studies, all except 2 
of our CF children showed significant decreases in weight, length, armeircumference and 4 skinfolds Z-scores before treatment with lansoprazole. FM, LBM and BMC were also significantly decreased despite pancreatic enzyme substitution and hypercaloric supplementation. The catabolic proces could be reversed after 3 months of lansoprazole resulting in Z-scores improvement of all anthropometric parameters, FM, BMC and to a lesser extent LBM. The improved nutritional condition could be due either to higher energy intakes or to improved absorption. As we found somewhat lower energy intakes during the lansoprazole treatment period, a higher intake probably is not responsible for the improved nutritional condition. Further, the fact that lower fecal acid steatocrit results were found in our patients with the best nutritional response as assessed by subscapular Z-score improvements, supports the idea that improved absorption is the main factor responsible for the improvement of the nutritional status in our patients. However increased FM, LBM and BMC are difficult to interpret because results for reference populations expressed as Z-scores have not yet been reported. As Zscore of BMD did not change on lansoprazole, the increased BMC found in our $\mathrm{CF}$ children, is probably linked to the growth proces. Our results showing deterioration of the nutritional condition after interruption of lansoprazole "intervention", are in agreement with those of Bertrand et al., who reported nutritional deterioration after stopping elemental enteral alimentation (14). Oral hypercaloric diets have not been shown to improve Z-scores of weight, length and skinfolds as parameters for nutritional status and growth proces of $\mathrm{CF}$ children (8). Only parenteral or elemental "predigested" enteral nutrition have been shown to reverse the catabolic process in these children (9-15). This indicates that persisting maldigestion or malabsorption is mainly responsible for malnutrition in CF. As alkalinization of duodenal pH improves malabsorption $(16,22)$, it could also, as elemental diets do, improve the nutritional status of CF children. This hypothesis is confirmed by the results of our study. In contrast with $O^{\prime}$ Loughlin (10), Shepherd (12) and Levy (13), who found significant improvement in LBM after 6 to 12 months of elemental diets, no significant increase in LBM was seen in our study. The 3 months of treatment in our study could be too short for a significant change in LBM to be noticed. Our results are in agreement with those of other authors, who evaluated the effect of gluten free diet on body compartments by DXA. Only FM and BMC improved after a 6 months gluten free diet while LBM did not (35). As H2 - receptor antagonists have been shown to significantly decrease nitrogen malabsorption in CF patients (36), we do not 
think that the poor improvement of LBM in our patients can be ascribed to a selective improvement of fat and not of protein malabsorption.

In conclusion, most of our CF children maintained steatorrhea and were malnourished despite optimal treatment with hypercaloric diets and pancreatic enzymes. Lansoprazole as adjuvant therapy resulted in decreased fat malabsorption and improved nutritional status in these $\mathrm{CF}$ children after 3 months of treatment. Longterm evaluation of the effect of lansoprazole on both the nutritional status and lung function parameters have yet to be performed.

\section{Acknowledgment}

we are gratefull to Liesbeth van der Ploeg, Lianne Schoorlemmer dieticians and Piet Willems, Sandra Zimny from the department of nuclear medicine for their invaluable assistance. We also thank all nurses of the pediatric polyclinic for their welwilling support. 


\section{REFERENCES}

(1) M. Welsh, A. Smith. Molecular mechanisms of CFTR chloride channel dysfunction in cystic fibrosis. Cell 1993; 73:1251-1254.

(2) J. Tomezsko, V. Stallings, D. Kawchak, J. Goin, G. Diamond, T. Scanlin. Energy expenditure and genotype of children with cystic fibrosis. Pediatr Res 1994; $35: 451$ - 460.

(3) M. Bronstein, P. Davies, K. Hambidge, F. Accurso. Normal energy expenditure in the infant with presymptomatic cystic fibrosis. J Pediatr 1995; 126: 28-33.

(4) R.Kraemer, A. Rüdeberg, B. Hadorn, E. Rossi. Relative underweight in cystic fibrosis and its prognostic value. Acta Paediatr Scand 1978; 67: 33-37.

(5) P. Robinson, P. Sly. High dose pancreatic enzymes in cystic fibrosis. Arch Dis Child. $1990 ; 65: 311-312$.

(6) E. Lebenthal. High strength pancreatic exocrine enzyme capsules associated with colonic strictures in patients with cystic fibrosis: "more is not necessarily better". J Pediatr Gastroenterol Nutr. 1994; 18: 423-425.

(7) R. Smyth, D. van Velzen, A. Smyth, D. Lloyd, D. Heaf. Strictures of ascending colon in cystic fibrosis and high strength pancreatic enzymes. The Lancet. 1994; 343: 85-86.

(8) A. Rettammel, M. Marcus, P. Farrell, S. Sondel, R. Koscik, E. Mischler. J Am Diet Assoc. 1995; 95: 454-459.

(9) K. Gaskin, D. Waters, L. Baur, V. Soutter, M. Gruca. Acta Paediatr Scand [Suppl]. 1990; 366: $106-110$.

(10) E. O' Loughlin, D. Forbes, H. Parsons, B. Scott, D. Cooper, G. Gall. Nutritional rehabilitation of malnourished patients with cystic fibrosis. Am J Clin Nutr. 1986: 43: 732-737.

(11) R. Shepherd, T. Holt, B. Thomas et al. Nutritional rehabilitation in cystic fibrosis: Controlled studies of effects on nutritional growth retardation, body protein turnover, and course of pulmonary desease. J Pediatr. 1986; 109: 788-94.

(12) R. Shepherd, B. Thomas, D. Bennett, W. Cooksley, L. Ward. Changes in body composition and muscle protein degradation during nutritional supplementation in nutritionally growth-retarded children with cystic fibrosis. J Pediatr Gastroenterol Nutr. 1983; $2: 439-446$.

(13) L. Levy, P. Durie, P. Pencharz, M. Corey. Effects of long-term nutritional rehabilitation on body composition and clinical status in malnourished children and adolescents with cystic 
fibrosis. J Pediatr 1985; 107: 225-230.

(14) J. Bertrand, C. Morin, R. Lasalle, J. Patrick, A. Coates. Short-term clinical, nutritional, and functional effects of continuous elemental enteral alimentation in children with cystic fibrosis. J Pediatr. 1984; 104: 41-46.

(15) R. Shepherd, W. Cooksley, and W. Domville. Improved growth and clinical, nutritional, and respiratory changes in response to nutritional therapy in cystic fibrosis. J Pediatr. 1980; 97: 351-357.

(16) P. Robinson, A. Smith, and P. Sly. Duodenal pH in Cystic fibrosis and its relationship to fat malabsorption. Dig Dis Sci. 1990; 35: 1299-1304.

(17) A. Carroccio, F. Pardo, G. Montalto et al. Use of famotidine in severe exocrine pancreatic insufficiency with persistent maldigestion on enzymatic replacement therapy: A long-term study in cystic fibrosis. Dig Dis Sci 1992; 37: 1441-1446.

(18) D. Chalmers, R. Brown, M. Miller et al. The influence of longterm cimetidine as an adjuvant to pancreatic enzyme therapy in cystic fibrosis. Acta Paediatr Scand. 1985; 74: 114 117.

(19) P. Robinson and P. Sly. Placebo-controlled trial of misoprostol in cystic fibrosis. J Pediatr Gastroenterol Nutr. 1990; 11:37-40.

(20) H. Heijerman, C. Lamers, J. Dijkman, and W. Bakker. Ranitidine compared with the dimethylprostaglandin E2 analogue enprostil as adjunct to pancreatic enzyme replacement in adult cystic fibrosis. Scand J Gastroenterol. 1990; 25 (Suppl 178): 26-31.

(21) M. Schöni, R. Kraemer, E. Rossi. Cimetidine and fat malabsorption in children with cystic fibrosis. Helv Paediat Acta. 1981; 36: 359-369.

(22) B. Boyle, W. Long, W. Balistreri, S. Widzer, and N. Huang. Effect of cimetidine and pancreatic enzymes on serum and fecal bile acids and fat absorption in cystic fibrosis. Gastroenterology. 1980; 78: 950-953.

(23) H. Heijerman, C. Lamers, W. Bakker. Omeprazole enhances the efficacy of pancreatin (pancrease) in cystic fibrosis. Ann İntern Med. 1991; 114: 200-201.

(24) J. van de Kamer, H. Huinink, H. Weyers. Rapid method for determination of fat in feces. J Biol Chem. 1949; 177: 349-55.

(25) M. Tran, P. Forget, A. Van den Neucker, J. Strik, B. van Kreel, and R. Kuijten. The acid steatocrit: A much improved method. J Pediatr Gastroenterol Nutr. 1994; 19: 299-303. 
(26) W. Gerver, R. de Bruin. Paediatric Morphometrics: A reference manual. 1th ed. Utrecht: Bunge, 1995.

(27) R. Mazess, H. Barden, J. Bisek, and J. Hanson. Dual-energy x-ray absorptiometry for total-body and regional bone-mineral and soft-tissue composition. Am J Clin Nutr. 1990; 51:1106-12.

(28) G. Ogle, J. Allen, I. Humphries et al. Body-composition assessment by dual-energy x-ray absorptiometry in subjects aged 4-26 y. Am J Clin Nutr. 1995; 61:746-53.

(29) A. Weber, C. Roy. Intraduodenal events in cystic fibrosis. J Pediatr Gastroenterol Nutr. 1984; 3 (Suppl. 1): S113-S119.

(30) P. Regan, J. Malagelada, E. Dimagno, and V. Go. Reduced intraluminal bile acid concentrations and fat maldigestion in pancreatic insufficiency: Correction by treatment. Gastroenterology. 1979; 77: 285-289.

(31) P. Zentler-Munro, W. Fitzpatrick, J. Batten, and T. Northfield. Effect of intrajejunal acidity on aqueous phase bile acid and lipid concentrations in pancreatic steatorrhoea due to cystic fibrosis. Gut. 1984; 25: 500-507.

(32) P. Zentler-Munro, D. Fine, J. Batten, and T. Northfield. Effect of cimetidine on enzyme inactivation, bile acid precipitation, and lipid solubilisation in pancreatic steatorrhoea due to cystic fibrosis. Gut. 1985; 26: 892-901.

(33) G. Sachs, J. Shin, C. Briving, B. Wallmark, S. Hersey. The pharmacology of the gastric acid pump: The H+, K+ ATPase. Annu Rev Pharmacol Toxicol. 1995; 35: 277-305.

(34) C. Spencer and D. Faulds. Drugs: Focus on Lansoprazole. 1994; 48: 404-430.

(35) G. Barera, P. Brambilla, P. Manzoni, S. Acciuffi, G. Caccia, C. Bianchi. Changes in body composition evaluated by DXA during gluten free diet in celiac children. J Pediatr Gastroenterol Nutr. 1995; 20: 476 "abstr".

(36) K. Cox, J. Isenberg, A. Osher, R. Dooley. The effect of cimetidine on maldigestion in cystic fibrosis. J. Pediatr. 1979; 94: 488-492. 


\title{
CHAPTER 7
}

\section{ANTHROPOMETRY AND BODY COMPOSITION IN CHILDREN WITH CYSTIC FIBROSIS: EFFECTS OF A PROTON - PUMP INHIBITOR}

\author{
(1)My-Dung T.Tran, (1)Anita Van den Neucker, (1)Han J. Hendriks, (")Bernard van Kreel, \\ (1)Patricia Forget, ${ }^{\sigma}$ Guido Heidendal, (1)Pierre-Philippe Forget
}

(1)Department of Pediatrics, (") Clinical Chemistry and ${ }^{\sigma}$ Nuclear Medicine, University Hospital Maastricht, Maastricht, the Netherlands.

Submitted for publication

\section{Abstract}

We studied the body composition of $18 \mathrm{CF}$ children making use of dual-energy X-ray absorptiometry (DEXA), deuterium-bromide and skinfold methods and evaluated the efficacy of these body composition methods for the detection of body composition changes during 3 months therapeutic intervention with lansoprazole. Our $\mathrm{CF}$ patients were malnourished with decreased mean Z-scores for armcircumference $(-1.62)$, biceps $(-0.77)$, subscapular $(-0.92)$, suprailiac skinfolds $(-1.66)$, weight $(-1.03)$ and height $(-1.31)$.Their fatmass was significanly depleted as shown by DEXA, skinfold and total body water (TBW) methods. Extracellular volume (\%) was increased, while intracellular volume (\%) was normal. Only the lean body mass (LBM) as measured by DEXA was decreased $(p=0.02)$. Decreased bone mineral content and bone mineral density $Z$-scores were also found $(p=0.005$ and $p=0.03$ respectively). After treatment with lansoprazole, significant increases in fatmass was found by DEXA and skinfold methods ( $53 \%$ and $97 \%$ of weight changes respectively) whereas weight increase was exelusively ascribed to an increase in LBM with the TBW method. Changes in body. weight however, were not correlated with either fatmass and fat free mass changes as measured by any of these methods. We conclude that results of DEXA, TBW and skinfold methods are not interchangeable and that the methods used are not accurate enough for the differential detection of small changes in fatmass and fat free mass as found in the present study. 


\section{INTRODUCTION}

Due to malabsorption (1), chronic lung infections with increased energy expenditure $(2,3)$ and poor appetite, most cystic fibrosis patients show signs of malnutrition. As malnutrition can affect pulmonary function and shorten survival (4), feeding interventions are sometimes necessary to restore normal growth and body composition. Assessment of body composition changes is necessary for the precise evaluation of nutritional interventions. While different body composition methods have been described, only few studies have, to our knowledge, compared different measurement techniques in pediatric subjects and there are no reports on the efficacy of these methods for the detection of body composition changes during therapeutic interventions. In children, Dual-energy X-ray absorptiometry (DEXA), Total Body Water (TBW) and Skinfold methods are frequently used for the determination of body composition since they are all noninvasive. In this age group, methods used for measuring body composition have to be very precise in order to detect small changes in body composition. The precision for repeated measurements has been reported to be $1-2 \%$ for DEXA, $1.6 \%$ for TBW and either $5 \%$ (intraobserver) or $15 \%$ (interobserver) for the skinfold method (5). In the present study we first evaluated the body composition of our $18 \mathrm{CF}$ children making use of DEXA, skinfolds and TBW (deuterium-bromide)methods and subsequently evaluated the agreement between these results. Secondly, we investigated the sensitivity of these 3 methods for the detection of small changes in body composition of $15 \mathrm{CF}$ children whose nutritional condition improved significantly after intervention with lansoprazole for 3 months. For the purpose of the present study we defined fat free mass by DEXA (FFM-DEXA) as the sum of lean body mass (LBM) and bone mineral content (BMC) and total mass (TM) as DEXA constructed weight $(\mathrm{LBM}+\mathrm{FM}+\mathrm{BMC})$.

\section{SUBJECTS}

\section{Ropulation studied for the comparison of bodv composition methods}

$23 \mathrm{CF}$ children were recruited from the Academic Hospital Maastricht. The Netherlands. Of these 2 patients were too ill to take part in the study and 3 children refused to participate. 18 
children who had no exacerbation 4 weeks before the study were included. Thirteen of them were prepubertal and younger than ten years, 3 children were postpubertal and were between 11.6 - 14.1 years. Two subjects were adolescents of 16.1 and 22.6 years. Fourteen of these 18 children were diagnosed during the first year of life while 16 of them had pancreatic insuffi. ciency (abnormal fecal chymotrypsin and $72 \mathrm{~h}$ fecal fat balance). Their nutritional status was moderate with a mean BMI (body mass index) of 15.6 (range: 13.2 - 23.2). Mean age, weight and height were respectively 9.0 y (range: $2.9-22.6 \mathrm{y}$ ); $27.4 \mathrm{~kg}$ (range: $13.6-67.6 \mathrm{~kg}$ ) and $127.5 \mathrm{~cm}$ (range: 96.2 - $184.9 \mathrm{~cm}$ ). Mean FEV1 (forced expiratory volume in 1 second) and FVC (forced vital capicity) were respectively $84 \%$ (range: $39-117 \%$ ) and $86 \%$ (range: 44 . $109 \%$ ) of predicted values. Mean energy intake was $113 \%$ RDA (recommended daily allowance). All patients were on conventional physiotherapy, pancreatic enzymes and some of them received antibiotics regularly for pulmonary exacerbations.

Weight, height, armcircumferences, TBW, DEXA and skinfolds were measured on the same day. All usual CF medications were continued during the study.

\section{Population studied for the evaluation of changes in body composition}

We included 15 out of 16 children with pancreatic insufficiency as described above who maintained steatorrhea despite pancreatic enzymes and were treated with lansoprazole for 3 months with significant improvement of anthropometric parameters (results will be published separately). Mean age, weight and height of these 15 children were $9.5 \mathrm{y}$ (range: $3.1-22.6 \mathrm{y}$ ); $29.3 \mathrm{~kg}$ (range: $13.6-67.6 \mathrm{~kg}$ ) and $131 \mathrm{~cm}$ (range: $97.7-184.9 \mathrm{~cm}$ ) respectively. Their nutritional status was moderately altered with a mean Body Mass Index (BMI) of 15,6 (range : 13.2 - 18.3). Mean FEV1 and FVC were respectively $81.3 \%$ (range: $39-114 \%$ ) and $85.5 \%$ (range: $44-108 \%$ ) of predicted values.

Anthropometry, DEXA and TBW were measured on the same day just before starting and 3 months after treatment with lansoprazole ( $15 \mathrm{mg} /$ day). Other usual CF medications were continued throughout the study. Informed patient and parental consent were obtained from all study subjects. 


\section{METHODS}

\section{Growth parameters}

Weight, height, upper armcircumferences and 4 skinfold thicknesses (biceps, triceps, subscapular and suprailiac) were measured on the left side of the body in triplicate, using the Harpenden caliper. Average of three measures was taken and was expressed as standard deviation scores of the normal population for age and sex using the growth charts from Gerver and de Bruin (6). BMI was calculated as weight/height ${ }^{2}$. Results of BMI were compared to the reference population described by Westrate and Deurenberg et al. (7). Mid upper arm muscle area was calculated from the mid upper armcircumference and the sum of biceps and triceps skinfolds (6).

\section{Body composition}

Body composition results obtained from all three methods were compared to those of a recently reported pediatric reference population (8). The percentage of fatmass and fat free mass measured by the skinfold method were also compared to those of the reference population described by Gerver and de Bruin (6).

\section{Body composition by anthropometry}

It has been found that subcutaneous fat as measured by skinfolds is related to the body density (9). This latter is itself related to the body fatmass. From these theoretical principles, Gerver and de Bruin have constructed a chart, expressing the relationship between the 4 skinfolds (biceps, triceps, subscapular and suprailiac) and the percent fat free mass (6). In our study, fat free mass determined by this method was derived from these charts and fatmass was then calculated by subtracting FFM from bodyweight.

\section{Bedycomposition by dual-energy x-ray ahsorptiometry}


The theoretical principles for DEXA measurement of body composition and the precision of this method have been described previously (10-12). All DEXA measurements were performed with a Dual Photon X-ray ( Lunar Radiation Corp, Madison, WI ) total body scanner. These results were analysed with a pediatric software programme, version $1.5 \mathrm{e}$. Daily quality assurance tests were performed according to the manufacturer 's directions. Total body analysis was performed in all children using a fast scan mode with a sample size of $4.8 \times 9.6 \mathrm{~mm}$, sample interval of $0.03 \mathrm{~s}$ and source collimation of $1.68 \mathrm{~mm}$. The following body compartments were assessed: total non bone lean body mass, total bone mineral content, total bone mineral density (BMD), total body fatmass and Z-score of BMD.

\section{Body composition by total body water and bromide space}

TBW and ECV were measured by deuterium oxide (13) and bromide dilution respectively (14). Each subject received orally $20 \mathrm{ml}(40 \mathrm{ml}$ was given to the 2 adolescent patients) of a mixture of $\mathrm{D}_{2} \mathrm{O}(99.9 \%$ purity) and Bromide salt $(150 \mathrm{mMol} / \mathrm{L})$ solution in a volume ratio of 1:1. Saliva and plasma samples were taken before intake of $\mathrm{D}_{2} \mathrm{O}-\mathrm{NaBr}$ solution and 4 hours thereafter when an "plateau" has been reached. To prevent saliva dilution by fluid intake which can result in a higher TBW content, patients were told not to take any fluid orally half an hour before saliva samples were taken. Urine and fecal loss of bromide and $\mathrm{D}_{2} \mathrm{O}$ during the equilibriation period were considered negligible as the $\mathrm{D}_{2} \mathrm{O}$ and bromide $\mathrm{Tl} / 2$ are about 8 days (14). Saliva samples were obtained making use of dental cotton-wool, that was dried overnight at $100^{\circ} \mathrm{C}$ and kept in a gas-tight tube until use. The cotton-wools and the blood samples were centrifuged and the saliva and serum thus obtained were kept in a stoppered glass vial and stored in a freezer at $-20^{\circ} \mathrm{C}$ until analysis. Results of TBW, ECV and ICV were compared to the reference values described by Friis-Hansen (15).

\section{TBW ANALYSIS}

$\mathrm{D}_{2} \mathrm{O}$ concentrations of saliva samples were determined as described by van Kreel (14): Calcium carbide $\left(\mathrm{CaC}_{2}\right)$ was placed in the siliconized vacutainer tube and evacuated for $30 \mathrm{sec}$. with a rotatory vane pump to a total pressure of $0,01 \mathrm{~atm}$. Thereafter, $25 \mu \mathrm{l}$ of salivary sample 
was injected in the vacutainer tube. This was done in duplicate. $\mathrm{CaC}_{2}$ react with $\mathrm{D}_{2} \mathrm{O}$ forming acetylene gas. A $25 \mu \mathrm{l}$ sample of this gas was subsequently injected in duplicate into the GC/CF - IRMS system (gas chromatography/continous flow isotope ratio mass spectrometry) at $2 \mathrm{~min}$. intervals. The mass 27/26 ratio (R27/26) was measured on a Isotope Ratio Mass Spectrometer configured for Acetylene (Finnigan MAT 252 for CF-IRMS). The mean value of 4 determinations was calculated for each sample. By inserting the tracer/tracee ratio, defined as R27/26 (T4) - R27/26 (T0), into the regression equation obtained from the standards, we get the dilution factor of $\mathrm{D}_{2} \mathrm{O}$. TBW is calculated as ingested $\mathrm{D} O \mathrm{O}$ volume/dilution factor. FFM and FM are then calculated by the following formules:

$$
\begin{aligned}
& \mathrm{FFM}(\mathrm{kg})=\mathrm{TBW} /(1,04 \mathrm{xd}) \\
& \mathrm{FM}(\mathrm{kg})=\text { Weight }- \text { FFM }
\end{aligned}
$$

The 1,04 factor is a correction for the estimated $4 \%$ nonaqueous hydrogen exchange and $\mathrm{d}$ is the hydration factor of LBM which varies with age and sex. Because our CF population was young, we used the age dependent hydration factors described by Fomon (16) for children younger than 10 year and by Boileau and Lohman (17) for older children.

\section{BROMIDE DILUTION ANALYSIS}

Because bromide resides mainly in the extracellular space, the measurement of bromide dilution gives an estimate of the extracellular volume. Bromide was determined by using a Gas Chromatograph type CP 9000 (Chrompack) equipped with an ECD detector after it was converted into bromoacetone gas (14). First, perchloric acid was added to the serum sample and centrifuged for deproteinisation. An aliquot of the supernatant was then added to silver nitrate $\left(\mathrm{AgNO}_{3}\right)$ for precipitation of silver bromide and chloride. After centrifugation, the precipitate was taken up in $\mathrm{NH}_{3}$ after adding $\mathrm{Na}_{2} \mathrm{~S}$ and $\mathrm{NaOH}$ in order to eliminate the silver. After agitation and centrifugation, the supernatant was heated until dry. $\mathrm{H}_{2} \mathrm{O}$ was added followed by $\mathrm{H}_{2} \mathrm{O}_{2}$ in order to oxidize sulfide. After drying, ${ }_{2} \mathrm{H} \mathrm{O}$ was then added and dried again. This was repeated several times. Thereafter, perchloric acid and acetone were added and the reaction was started by addition of $\mathrm{KmnO} 4$ with Bromoacetone formed. The solution 
is then extracted with benzene. The organic phase was separated from the water phase by shaking and centrifugation. The water phase was then removed. An aliquot of the organic solution is then applied to the gas chromatograph for measuring of the bromoacetone/internal standard ratio. The bromide concentration was then derived from the bromoaceton standard curves. Because the distribution of bromide depends on the potential difference between the in- and extra-cellular compartments and on the total body volume, the corrected bromide space was calculated as follows:

$$
\mathrm{ECV}(\mathrm{L})=\frac{\text { Bromide administered (mmol) }}{\text { Bromide change T4 }-\mathrm{T} 0(\mathrm{mmol} / \mathrm{L})}-0.036 \mathrm{TBW}
$$

Where $0.036 \mathrm{TBW}$ is the correction factor for the cell potential and for the total body volume (14). Body cell mass (BCM) was then calculated by subtracting ECV from TBW.

\section{Statistics}

All data were analysed with SPSS statistic program version 6.0. The sign test was used to compare the growth parameters and body composition results with those of the reference population. The Pearson correlation coefficient was used to determine the relationship between measurements obtained by the various body composition methods. Partial correlation coefficients, controlling for age, were used for the evaluation of the relationships between measured ICV, ECV, mid-upper-arm muscle area and the various body composition results. The between method differences were compared, using the Wilcoxon rank test. The agreement between methods were evaluated by the Statistical method of Bland and Altman (18). 


\section{RESULTS}

\section{Body composition of 18 cf children}

Mean age, nutritional parameters expressed as standard deviation scores (Z-scores) and results of body composition measured by skinfold, DEXA and TBW from 18 CF children are shown in table 1. Compared to the reference population, mean Z-scores for weight, height, BMI, armcircumference and skinfolds (except for the triceps) were significantly decreased (fig 1). The mid-upper-arm muscle area was significantly decreased in our CF population $(p=0.005)$. In absolute terms, all body composition components measured by DEXA such as FM, LBM, BMC and BMD Z-scores were significantly decreased $(p=0.01 ; p=0.02 ; p=0.005$ and $p=$ 0.03 respectively) compared to the control population described by Oggle ( 8 ). When compared to the normal DEXA body composition data reported by Oggle (8), results obtained with either the TBW or the skinfold methods showed only fat mass to be significantly decreased in our patients ( $p=0.03$ and $p=0.05$ respectively). In relative terms, FM-DEXA (compared to normal DEXA data reported by Oggle) and FM-skinfolds (compared to normal skinfolds data reported by Gerver) were also significantly decreased. The BMI was correlated with both FM and FFM measured by all three methods (FM-DEXA $r=0.90$; FM-skinfold $r=0.87$; FMTBW $_{\mathrm{r}}=0.75 ;$ FFM-DEXA $\mathrm{r}=0.79 ;$ FFM-skinfold $\mathrm{r}=0.81$; FFM-TBW $\mathrm{r}=0.8$ with $\mathrm{p}=$ 0.001 for all correlations). As expected strong correlations were found between age on the one hand and FM-DEXA $(r=0.67 p=0.003)$, FFM-DEXA $(r=0.95 p=0.001)$, FM-skinfolds $(r$ $=0.59 p=0.01)$, FFM-skinfolds $(r=0.95 p=0.001)$, FM-TBW $(r=0.47 p=0.047)$, FFMTBW $(r=0.94 p=0.001)$ and BMC-DEXA $(r=0.94 p=0.001)$. No sex differences in body composition data were found. When compared to the reference values described by FrisHansen (15), the ECV and TBW as a percentage of bodyweight were significantly increased ( $p<0.005$ both) while the ICV as percent of bodyweight was normal. The partial correlations (controlling for age) between ECV, ICV, the mid-upper-arm muscle area LBM and FM are shown in table 2. 
Table 1 Characteristics of 18 CF children.

\begin{tabular}{|c|c|c|c|}
\hline & MEAN & SEM & RANGE \\
\hline AGE $\left(Y_{r}\right)$ & 8.97 & 1.16 & $2.9-22.6$ \\
\hline $\mathrm{BW}(\mathrm{Kg})$ & 27.43 & 3.66 & $13.6-67.6$ \\
\hline BW (SDS) & -1.03 & 0.25 & $-2.33-1.36$ \\
\hline$T M(K g)$ & 27.82 & 3.84 & $12.96-67.33$ \\
\hline HEIGHT $(\mathrm{cm})$ & 128 & 6.0 & $96.2-184.9$ \\
\hline HEIGHT (SDS) & -1.31 & 0.25 & $-2.89-0.40$ \\
\hline $\operatorname{BMI}\left(\mathrm{K}_{\mathrm{g}} / \mathrm{m}^{2}\right)$ & 15.6 & 0.57 & $13.21-23.17$ \\
\hline ARMCIRCUMFER (SDS) & -1.62 & 0.31 & $-3.14-1.43$ \\
\hline BICEPS (SDS) & -0.77 & 0.23 & $-1.86-1.33$ \\
\hline TRICEPS (SDS) & -0.33 & 0.23 & $-2-2.33$ \\
\hline SUBSCAPULAR (SDS) & -0.92 & 0.23 & $-2-1.6$ \\
\hline SUPRAILIACA (SDS) & -1.66 & 0.09 & $2.43--0.57$ \\
\hline SUM 4 SKINFOLDS (SDS) & -1.17 & 0.20 & $-2.2-1.2$ \\
\hline FM-DXA (\%) & 12.11 & 1.48 & $6.1-28.8$ \\
\hline FM-TBW (\%) & 10.39 & 1.61 & $0.0-22.2$ \\
\hline FM-SKINFOLD (\%) & 14.44 & 0.94 & $8-23$ \\
\hline FFM-DXA (\%) & 87.9 & 1.5 & $71.2-93.9$ \\
\hline FFM-TBW $(\%)$ & 89.8 & 1.6 & $77.8-101$ \\
\hline FFM-SKINFOLD $(\%)$ & 85.6 & 0.9 & $77-92$ \\
\hline BMC-DXA (Kg) & 1.02 & 0.17 & $0.37-2.68$ \\
\hline TBW (L) & 19.06 & 2.38 & $9.9-47.4$ \\
\hline TBW (\%) & 70.82 & 1.32 & $59.62-79.70$ \\
\hline ICV (L) & 10.96 & 1.78 & $3.71-31.93$ \\
\hline $\operatorname{ICV}(\%)$ & 38.41 & 1.42 & $27.28-51.01$ \\
\hline $\operatorname{ECV}(\mathrm{L})$ & 8.10 & 0.65 & $4.45-15.47$ \\
\hline $\operatorname{ECV}(\%)$ & 32.44 & 1.75 & $19.01-47.69$ \\
\hline
\end{tabular}

BW: Body weight

TM: DEXA constructed weight

BMl: Body mass index
FM: Fat mass

FFM: Fat free mass

BMC: Bone mineral content
TBW: Total body water

ECV: Extracellular volume

ICV: Intracellular volume 


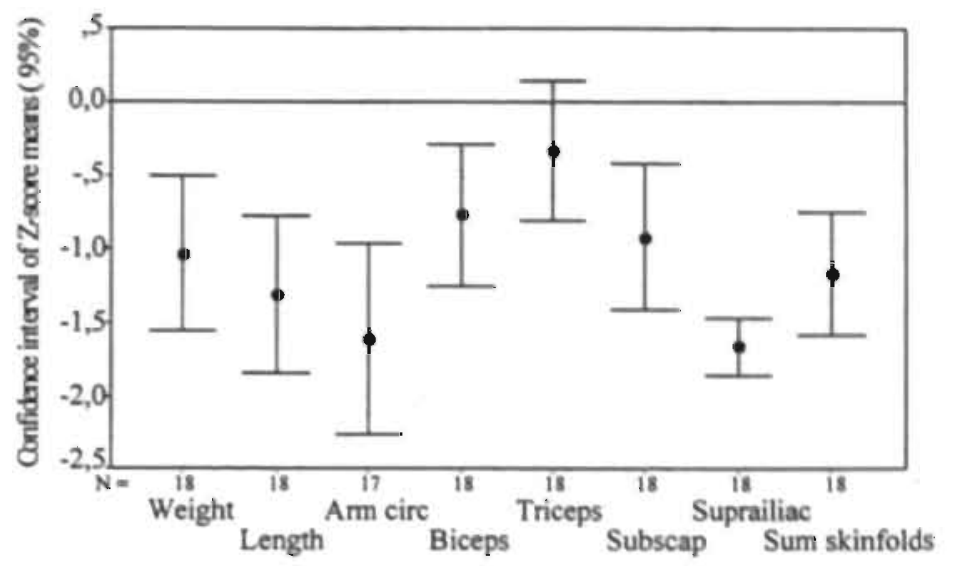

Figure 1 Confidence interval of Z-score means for various anthropometric parameters in cystic fibrosis children showing significantly lower values for all parameters except for the triceps skinfold.

Table 2 Correlation coefficients between muscle area, ECV, ICV and body composition results

\begin{tabular}{cccc}
\hline \hline & MUSCLE AREA $\left(\mathrm{cm}^{2}\right)$ & ECV $(\mathrm{L})$ & ICV (L) \\
\hline \hline LBM-DEXA (Kg) & $0.84(\mathrm{p}=0.001)$ & $0.67(\mathrm{p}=0.004)$ & $0.91(\mathrm{p}=0.001)$ \\
LBM-SKINF (Kg) & $0.90(\mathrm{p}=0.001)$ & $0.58(\mathrm{p}=0.02)$ & $0.92(\mathrm{p}=0.001)$ \\
LBM-TBW (Kg) & $0.86(\mathrm{p}=0.001)$ & $0.63(\mathrm{p}=0.007)$ & $0.95(\mathrm{p}=0.001)$ \\
FM-DEXA (Kg) & $0.62(\mathrm{p}=0.02)$ & $0.15(\mathrm{p}=0.58)$ & $0.53(\mathrm{p}=0.04)$ \\
FM-SKINF (Kg) & $0.61(\mathrm{p}=0.02)$ & $0.23(\mathrm{p}=0.38)$ & $0.53(\mathrm{p}=0.03)$ \\
FM-TBW (Kg) & $0.33(\mathrm{p}=0.21)$ & $-0.004(\mathrm{p}=0.99)$ & $0.20(\mathrm{p}=0.43)$ \\
ECV (L) & $0.45(\mathrm{p}=0.08)$ & & \\
ICV (L) & $0.86(\mathrm{p}=0.001)$ & & \\
\hline \hline
\end{tabular}

LBM-DEXA: Lean body mass by DEXA method LBM-SKINF: Lean body mass by skinfolds method LBM-TBW: Lean body mass by TBW method ECV: Extracellular volume
FM-DEXA: Fatmass by DEXA

FM-SKNNF: Famass by skinfolds method

FM-TBW: Famass by TBW method

ICV: Intracellular volume 
Table 3 Changes in bodyweight and body composition after 3 months on lansoprazole in 15 CF children.

\begin{tabular}{cccc}
\hline \hline & \multicolumn{3}{c}{ T3 - T0 } \\
\cline { 2 - 4 } & MEAN \pm SEM & MINIMUM & MAXIMUM \\
\hline BW (Kg) & $0.97 \pm 0.13$ & 0.4 & 2.1 \\
TM (Kg) & $0.97 \pm 0.15$ & -0.05 & 1.9 \\
FM-DXA (Kg) & $0.52 \pm 0.19$ & -0.46 & 2.18 \\
FM-TBW (Kg) & $-0.23 \pm 0.52$ & -4.85 & 3.44 \\
FM-SKINFOLD (Kg) & $0.94 \pm 0.26$ & 0.05 & 3.52 \\
LBM-DXA (Kg) & $0.43 \pm 0.18$ & -0.96 & 1.46 \\
BMC-DXA (Kg) & $0.03 \pm 0.01$ & -0.03 & 0.09 \\
FFM-DXA (Kg) & $0.41 \pm 0.17$ & -0.98 & 1.03 \\
FFM-TBW (Kg) & $1.27 \pm 0.49$ & -1.84 & 5.35 \\
FFM-SKINFOLD (Kg) & $0.04 \pm 0.26$ & -3.02 & 0.98 \\
TBW (L) & $0.99 \pm 0.39$ & -1.4 & 4.1 \\
ICV (L) & $0.09 \pm 0.41$ & -3.49 & 3.17 \\
ECV (L) & $0.92 \pm 0.46$ & -2.38 & 4.91 \\
\hline \hline
\end{tabular}

T0: Before start lansoprazole

T3: 3 months after lansoprazole

TM: Total mass (DEXA)

BW: Body weight
FFM: Fat free mass

FM: Fatmass

BMC: Bone mineral content

LBM: Lean body mass
TBW: Total body water

ECV: Extracellular water

ICV: Intracellular water 


\section{Limits of agreement between methods}

As only 5 of our patients 3 girls and 2 boys were postpubertal, all results of both boys and girls were analysed together. There was a high correlation between the 3 body composition methods for measuring of FM and FFM (fig 2 and 3). The best correlation for FM determination was between DEXA and the skinfold method $(r=0.98)$. As DEXA is a 3 compartments model, BMC was not included in the lean body mass. After correction for BMC, the correlation coefficient was unchanged. Plots of the paired differences for FM and FFM measured in kilogram versus their mean, with indication of the limits of agreement are shown in figure 4 and figure 5 respectively. Since our population was small, we preferred to use the 10th and 90th centile values instead of $\pm 2 \mathrm{SD}$ for defining the limits of agreement. No intermethod correlations were found between means and differences as shown in figures 4 and 5 . The 50th centile of the differences between FM-TBW versus FM-skinfolds was $-1.68 \mathrm{~kg}(-2.64$ - . $0.46 \mathrm{~kg})$; FM-skinfolds versus FM-DEXA was $0.75 \mathrm{~kg}(-3.01-1.21 \mathrm{~kg})$; FM-TBW versus FMDEXA was $-0,96 \mathrm{~kg}(-5.05--0.03 \mathrm{~kg})$. The 50 th centile of the differences between FFM-TBW versus FFM-DEXA was $0.45 \mathrm{~kg}(-0.70-4.85 \mathrm{~kg})$; FFM-skinfolds versus FFM-DEXA was $0.17 \mathrm{~kg}(-0.77-3.46)$; FFM-TBW versus FFM-skinfolds was $1.68 \mathrm{~kg}(0.46-2.96 \mathrm{~kg})$. The DEXA constructed weight was highly correlated with scale weight $(r=0.999 p=0.001)$. However, the DEXA weight was significantly lower than scale weight $(p=0.003)$; the 50th centile of the differences between bodyweight constructed from DEXA (TM) and scale weight was $-0.52 \mathrm{~kg}(-0.79-0.12)$. Significant differences were found between the means of FFM measured by the TBW and the skinfold methods $(p=0.02)$, the skinfolds and DEXA methods $(p=0.001)$ as well as the TBW and DEXA methods $(p=0.001)$. Only FM results from TBW and skinfolds were significantly different $(p=0.01)$. 


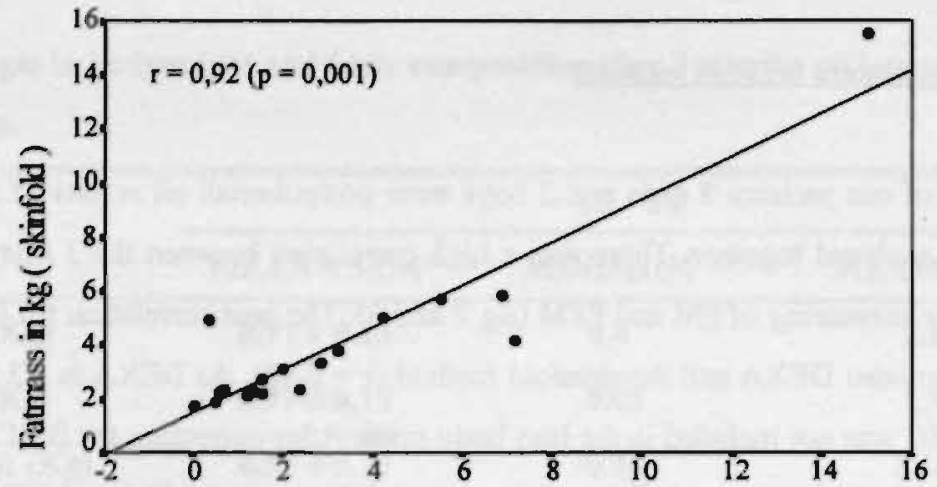

Fatmass in $\mathrm{kg}$ (TBW)

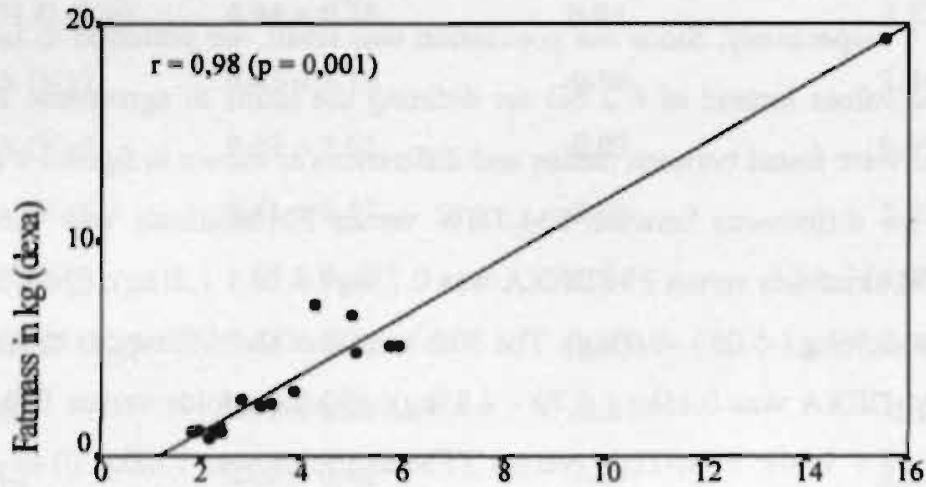

Fatmass in $\mathrm{kg}$ (skinfold)

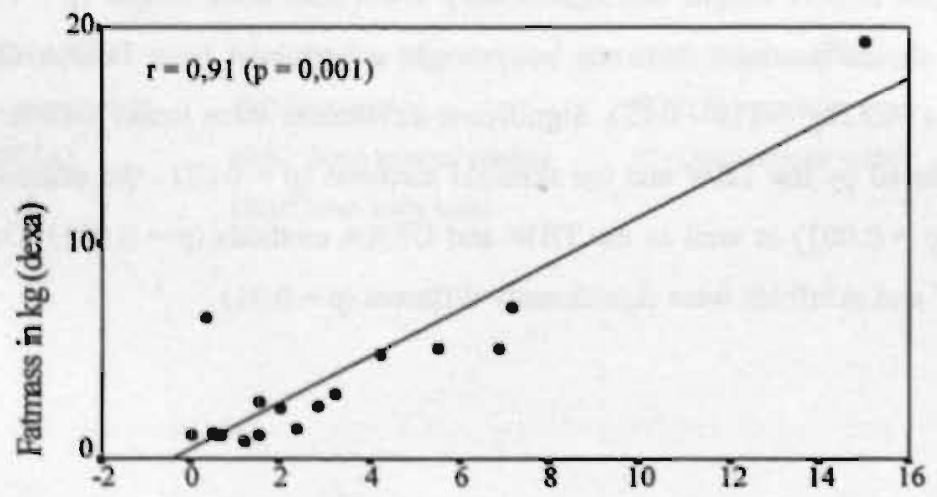

Fatmass in $\mathrm{kg}$ (TBW)

Figure 2 Intermethod fatmasses correlation coefficients. 

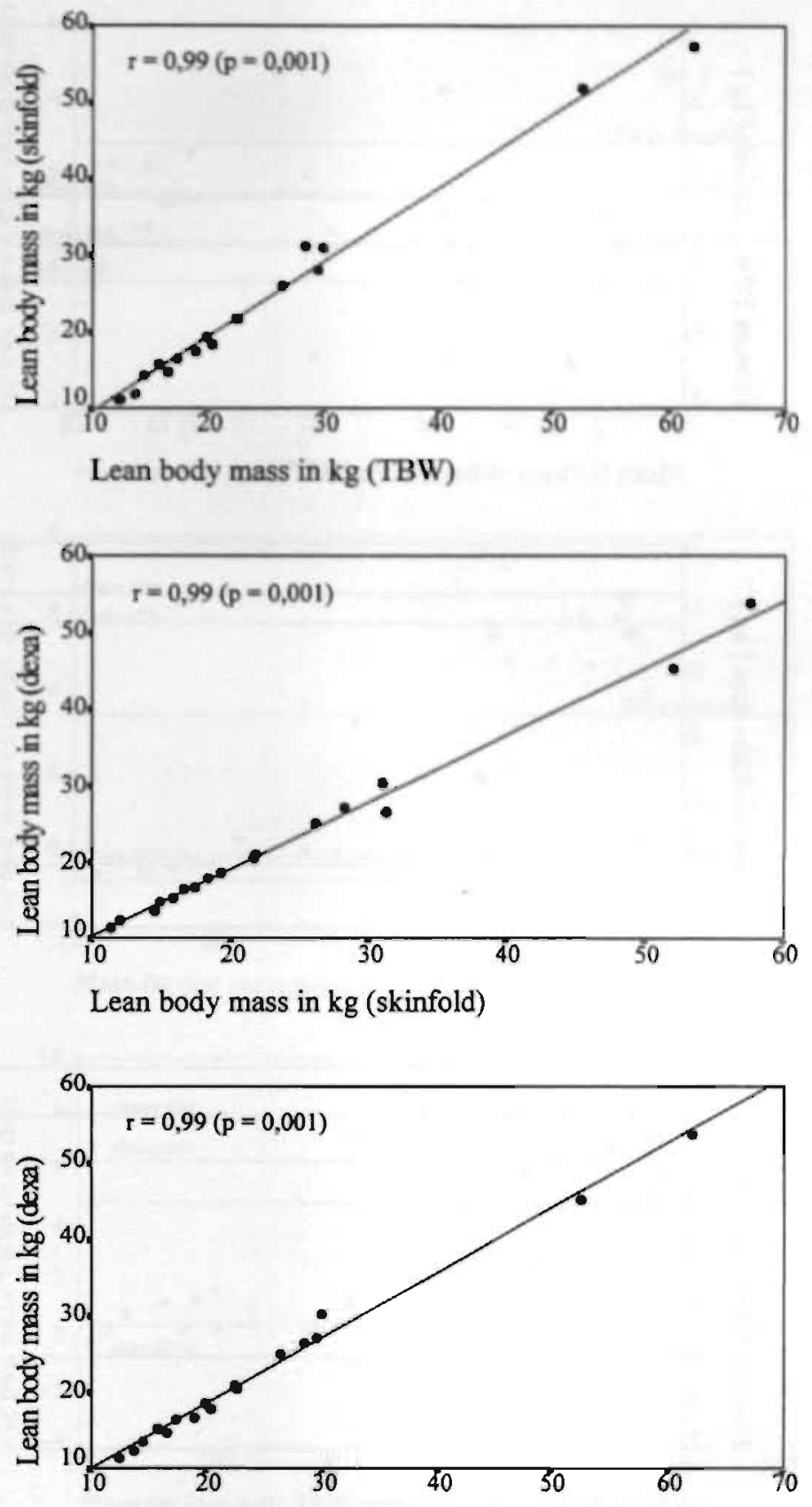

Lean body mass in $\mathrm{kg}$ (TBW)

Figure 3 Intermethod lean body mass correlation coefficients. 


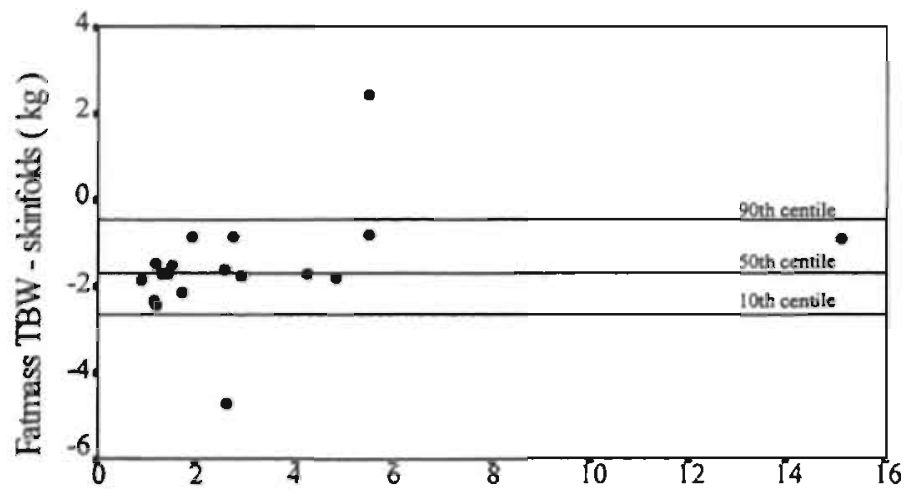

Mean fatmass skinfolds and TBW

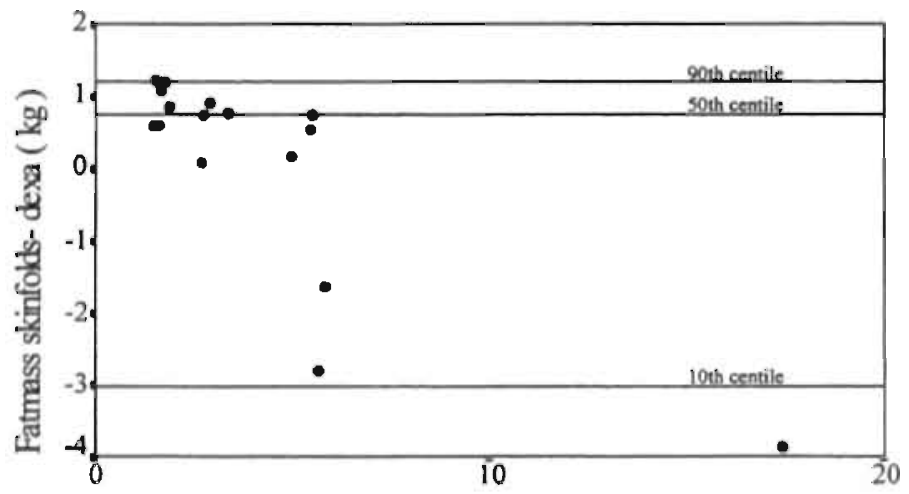

Mean fatmass skinfolds and dexa

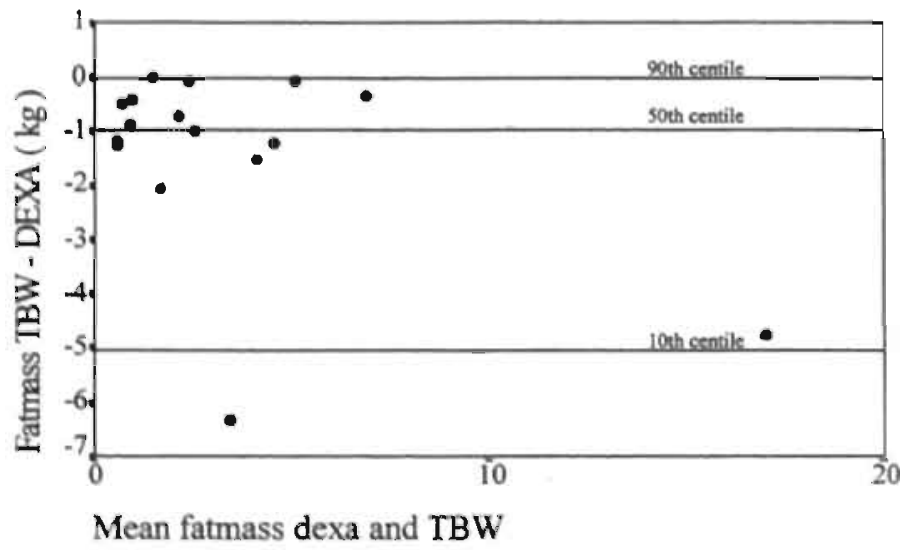

Figure 4 Limits of agreement for fatmass measured by the various methods. 

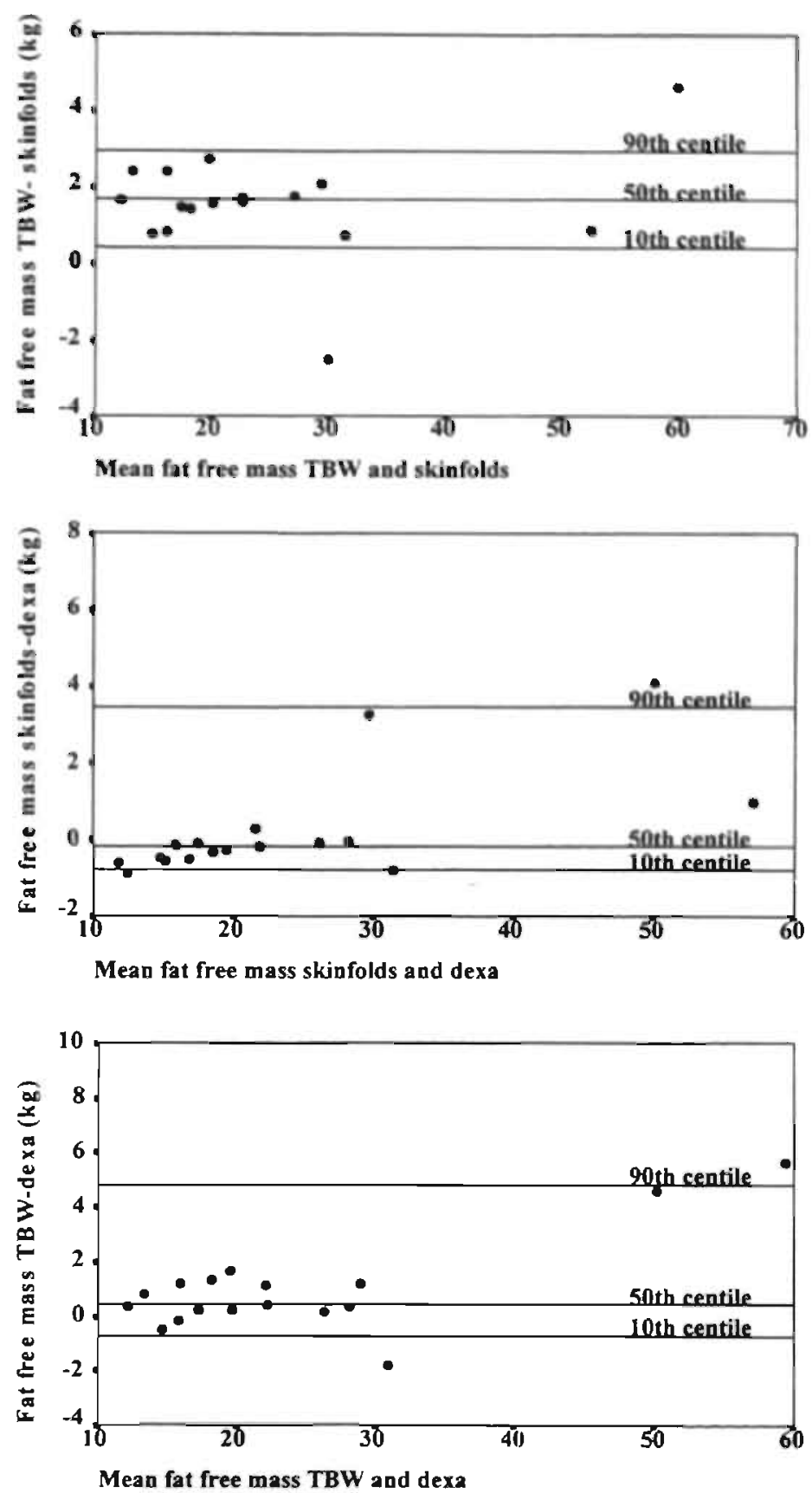

Figure 5 Limits of agreement for fat free mass measured by the various methods. 


\section{Bodv composition changes}

The changes in bodyweight, FM and FFM measured by skinfold, DEXA and TBW are shown in table 3. The increase in bodyweight was the same for both DEXA constructed weight and scale weight. However changes both in FM and FFM were different between methods. Both changes in FM and FFM measured by skinfold were highly correlated with those measured by DEXA ( $r=0.91 p=0.001$ and $r=0.84 p=0.001$ for FM and FFM respectively). Changes in FM measured by the TBW method were not correlated with changes of the same parameter measured by either the DEXA or the skinfold method, whereas changes in FFM-TBW were negatively correlated with those measured by skinfold and DEXA (FFM-TBW versus FFM. skinfold: $r=-0.56 p=0.03$ and FFM-TBW versus FFM-DEXA: $r=-0.52 p=0.05$ ). No correlation was found between changes in bodyweight and changes in FM or FFM measured by any method. Changes in ECV and ICV did not correlate with bodyweight changes. No correlation was found between changes in ICV and changes in LBM by any method. 


\section{DISCUSSION}

In children, effective evaluation of deterioration or catch-up growth can only be achieved by using the Z-score method. Despite high caloric polymeric intake, treatment of steatorrhea and support of pulmonary function, significantly lowered Z-scores for armcircumference, biceps, subscapular, suprailiac, sum of the 4 skinfolds weight and height were found in our patients. As our patients showed decreased weight, height Z-scores and mid upper arm muscle area, we expected both FM and FFM to be decreased. Since all body composition methods are based on assumptions, we used 3 noninvasive methods (DEXA, TBW and skinfolds) to evaluate the body composition of our patients. However, interpretation of the body composition results is difficult due to the lack of reference values for several measuring methods. The results of various methods used were strongly correlated with each other but still showed differences. In absolute terms, only DEXA results were as expected; showing a decrease in all 3 body components measured. Results of the TBW and skinfolds method could not be assessed accurately due to the lack of reference data expressed in absolute terms. When compared to the DEXA reference values, TBW and skinfolds methods only showed a decrease in FM. In relative terms, our CF populations showed an increase in TBW and ECV while the ICV (body cell water mass) appeared well maintained. These results imply a decrease of fatmass, associated with a relative increase in TBW, ECV and consequently FFM (19). In agreement with these: data, our results showing an increased percentage of FFM as evaluated by the skinfold method also implies a decrease in fatmass percentage in our CF patients. According to these results, we believe our CF patients mainly have a depletion of fatmass and bone mineral content with a slight decreased in lean body mass in absolute terms. Comparison of our results with other body composition studies in CF children is difficult: First, the general condition of the studied populations differed between studies and second, methods used for the assessment of the nutritional condition were different. Tomezsko et al. found no significant decrease: in body FM and FFM in their CF children with only significantly decreased suprailiac skinfold thicknesses and subscapular Z-scores. However their CF population was very young and showed only mild symptoms (2). In another study concerning older CF children with abnormal pulmonary function, Johnston et al. did find a significantly lower percentage of body fat (FFM not reported) compared to matched control children similar to our findings with all 3 
methods (20). In agreement with our study, Miller et al. who studied the body composition and muscle protein metabolism in a group undernourished CF children with Z-scores for weight and height similar to those of our CF population, found a significant decrease in FM, FFM and muscle mass (21). The strong correlation we found between components of body composition and age are well known $(8,22,23)$. The lack of sex differences can probably be explained by the prepubertal age of most patients (22). A high correlation was found between mid-upper-arm muscle area, ECV, ICV and LBM and FM. As expected, correlation coeffi. cients between mid-upper-arm muscle area, ECV, ICV and LBM remained high while only weak correlations were found with FM. Correlations were also evaluated after "homogenizing" our patient group by excluding the 2 adolescent patients. Highly significant correlations were again found between the above parameters and LBM while none were found with FM. As expected the between methods results differed significantly. Despite a high correlation between DEXA constructed weight and scale weight, mean DEXA weight was significantly and about 520 gram lower than scale weight. This is in agreement with results from Oggle et al. (8). FM measured by TBW was lower than that measured by either skinfolds or DEXA methods whereas FM-skinfold was often higher than FM-DEXA. The low values of FM when measured by the TBW method might be due to overestimation of FFM by this method. The FFM calculated by TBW is based on the assumption that a fraction of FFM is water. As the water content of FFM decreases with age (17), we used the age dependent FFM hydration fraction to calculate the FFM (17). The mean FFM hydration fraction used in our study was $76.27 \%$ (range: 73.7 - $77.5 \%$ ). In a study of body composition of CF prepubertal children, making use of skinfolds and TBW methods, Tomezco et al. also found a significantly lower body fat percentage with the TBW when compared to the skinfold method, which showed normal results (2). In two compartment models such as the TBW and the skinfolds methods, the densities of FFM is assumed to be constant in the range $18-67$ years but the density does vary depending on the concentrations, of water and mineral in FFM $(24,25)$. Although in our study the variation in water and mineral content was taken into account in the regression equations of skinfolds and TBW methods for the calculation of FFM and FM in the age range below 18 years, the water and mineral content are still population specific depending on the presence of illnesses. The percentage of TBW in CF children has been reported to be increased compared to control children $(19,26)$. Theoretically, the DEXA method has the advantage 
of being independent of biological assumptions about the densities and level of tissue hydration but the accuracy of the method still depends on the internal calibration $(27,28)$. It has been reported that when compared to chemical analysis, DEXA overestimate fat measured in meat blocks with lower fat content and underestimate the content in those with high fat content (29). Moreover, studies comparing DEXA results with those obtained from chemical analysis, using piglets, showed slight inadequacies in the estimation of fatmass and lean body mass $(27,30)$. We think that the between methods differences are most likely related to the various body compartments measured by these 3 methods rather than to inherent inaccuracies in the techniques themselves. This means that results obtained from each of these methods are not interchangeable. An important question to answer is, whether or not any of the used methods is capable of detecting body composition changes occuring during nutritional interventions. DEXA has been introduced as direct method with very good reproducibility $(12,31)$. In this study we compared the sensitivity of DEXA, TBW and skinfolds for detecting small body composition changes in children. For this purpose, we assessed the body composition of 15 $\mathrm{CF}$ children before and 3 months after they were treated with lansoprazole as an adjunct therapy for pancreatic enzymes in order to decrease steatorrhea. All 15 CF children showed significant increases in Z-scores for weight, height and skinfolds (unpublished observations). The evaluation of body composition changes differed depending on the method used. With the DEXA method, $53 \%$ of the weight increase was ascribed to FM, $44 \%$ to FFM and $3 \%$ to BMC. Both DEXA and skinfolds methods showed significant increases in fatmass but the increased FFM was not significant. In contrast, weight increase was exclusively ascribed to an increase in FFM with the TBW method. However, no significant correlations were found between weight changes and either FM, LBM or BMC changes by any method. The correlation coefticient of 0.40 found between weight changes and changes in FFM by DEXA just failed to reach statistical significance $(p=0.07)$. There were also no significant changes in ECV and ICV after intervention. This is in contrast to results reported by Going et al., who studied the changes in body compartments induced by dehydration - rehydration with oral fluid using DEXA method for assessment of body composition changes. They found a correlation between bodyweight changes and changes in TM, soft tissue mass (LBM + FM) and LBM. However, the total weight changes induced in their study was higher than in our study (approximately $1.2 \mathrm{~kg}$ versus $0.97 \mathrm{~kg}$ in our study) and as, the changes in bodyweight were 
induced by water content, the total bodyweight changes were exclusively ascribed to changes in the water content of STM, reflected by the exclusive increase in LBM (32). Since fatmass was mostly depleted in our patients, it is likely that this body compartment will normalize first as a result of an effective intervention.

From the results of this study, we conclude that results measured by different methods are not interchangeable. It is consequently important to use the same method for longitudinal evaluation of body composition. However, the use of DEXA, TBW and skinfolds methods is limited in children in whom only slight changes in bodyweight after intervention are expected $3 \%$ in this study) since the sensitivity is apparently not high enough for the detection of small differential changes in FM and FFM.

Acknowledgment: The authors wish to thank Mia Meers from the department of clinical laboratory, Sandra Zimny and Piet Willems from the department of nuclear medicine for their kind and expert technical assistance. 


\section{REFERENCES}

(1) M. Aitken, S. Fiel. Cystic Fibrosis. Dis Mon 1993;39: 1-52.

(2) J. Tomezsko, T. Scanlin, V. Stallings. Body composition of children with cystic fibrosis with mild clinical manifestations compared with normal children. Am J Clin Nutr 1994; 59: 123-8.

(3) M. Bronstein, P. Davies, K. Hambidge, F. Accurso. Normal energy expenditure in the infant with presymptomotic cystic fibrosis. J Pediatr 1995; 126: 28-33.

(4) R. Kraemer, A. Rüdeberg, B. Hadorn, E. Rossi. Relative underweight in cystic fibrosis and its prognostic value. Acta Paediatr Scand 1978; 67: 33-37.

(5) R. Branson, Y. Vaucher, G. Harrison, M. Vargas, C. Thies. Inter- and intra-observer reliability of skinfold thickness measurements in newborn infants. Hum Biol 1982; 54: 137 143.

(6) W. Gerver, R. de Bruin. Paediatric Morphometrics: A reference manual. 1th ed. Utrecht: Bunge, 1996.

(7) J. Westrate, P. Deurenberg, H. Van Tinteren. Int J Obesity. 1989; 13: 465-477.

(8) G. Ogle, J. Allen, I. Humphries et al. Body-composition assessment by dual-energy x-ray absorptiometry in subjects aged 4-26 y. Am J Clin Nutr. 1995; 61:746-53.

(9) J. Westrate, P. Deurenberg. Body composition in children: proposal for a method for calculating body fat percentage from total body density or skinfold-thickness measurements. Am J Clin Nutr 1989; 50: 1104-15.

(10) R. Mazess, B. Collick, J. Trempe, H. Barden, J. Hanson. Performance evaluation of a dual-energy x-ray bone densitometer. Calcif Tissue Int 1989; 44: 228-232.

(11) W. Peppler, R. Mazess. Total body bone mineral and lean body mass by dual-photon absorptiometry. I. I heory and measurement procedure. Calcif Tissue Int 1981; 33: 353-359.

(12) R. Mazess, H. Barden. J. Bisek. J. Hanson. Dual-energy x-ray absorptiometry for totalbody regional bone-mineral and soft-tissue composition. Am J C'lin Nutr 1990; 51: 1106-12.

(13) B. Van Kreel, F. Van der Vegt, M. Meers, T. Wagenmakers, K. Westerterp, A. Coward. Determination of total body water by a simple and rapid mass spectrometric method. J Mass Spectrom 1996; 31: 108-111.

(14) B. Van Kreel. An improved bromide assay for the estimation of extracellular water 
volume by capillary gas chromatography. Clinica Chimica Acta 1994; 231: 117-128.

(15) B. Friis-Hansen. Body water compartments in children: Changes during growth and related changes in body composition. Pediatrics $1961 ; 28: 169-181$.

(16) S. Fomon, F. Haschke, E. Ziegler, S. Nelson. Body composition of reference children from birth to age 10 years. Am J Clin Nutr 1982; 35: 1169-1175.

(17) R. Boileau, T. Lohman, M. Slaughter, T. Ball, S. Going and M. Hendrix. Hydration of the fat-free body in children during maturation. Hum Biol 1984; 56: 651-666.

(18) J. Bland, D. Altman. Statistical methods for assessing agreement between two methots of clinical measurement. The Lancet 1986; 8: 307-310.

(19) M. Miller, D. Kornhauser. Bromide pharmacokinetics in cystic fibrosis. Arch Pediatr Adolesc Med 1994; 148:266-271.

(20) J. Johnston, M. Leong, E. Checkland, P. Zuberbuhler, P. Conger, A. Quinney. Body fit assessed from body density and estimated from skinfold thickness in normal children ard children with cystic fibrosis. Am J Clinn Nutr 1988; 48: 1362-6.

(21) M. Miller, L. Ward, B. Thomas, W. Cooksley, R. Shepherd. Altered body compositicn and muscle protein degradation in nutritionally growth-retarded children with cystic fibrosis. Am J Clin Nutr 1982; 36: 492-499.

(22) H. Rico, M. Revilla, L.F.Villa, E. Hernández, M. Alvarez de Buergo and M. Villa. Body composition in children and Tanner's stages: A study with Dual-energy X-ray absorptiometry. Metabolism 1993; 42: 967-970.

(23) R. Faulkner, D. Bailey, D. Drinkwater, A. Wilkinson, C. Houston and H. McKay. Regional and total body bone mineral content, bone mineral density and total body tissue composition in children 8 - 16 years of age. Calcif Tissue Int 1993; 53: 7-12.

(24) G. Forbes. Human body composition. New York: Springer-Verlag, 1987.

(25) T. Lohman. Advances in body composition assessment. Champaign, IL: Human Kinetics, 1992

(26) M. Newby, N. Keim, D. Brown. Body composition of adult cystic fibrosis patients and control subjects as deternined by densitometry, bioelectrical impedance, total body electrical conductivity, skinfold measurements, and deuterium oxide dilution. Am J Clin Nutr 1990; 52: 209-13.

(27) K. Ellis, R. Shypailo, J. Pratt, W. Pond. Accuracy of dual-energy x-ray absorptiometry 
for body composition measurements inn children. Am J Clin Nutr 1994; 60: 660-5.

(28) R. Wellens, W. Chumlea, S. Guo, A. Roche, N. Reo, R. Siervogel. Body composition in white adults by dual-energy $\mathrm{x}$-ray absorptiometry, densitometry, and total body water. Am J Clin Nutr 1994; 59: 547-55.

(29) M. Jensen, J. Kanaley, L. Roust et al. Assessment of body composition with use of dualenergy x-ray absorptiometry: Evaluation and comparison with other methods. Mayo Clin Proc 1993; 68: 867-873.

(30) J. Brunton, H. Bayley, S. Atkinson. Validation and application of dual-energy x-ray absorptiometry to measure bone mass and body composition in small infants. Am J Clin Nutr 1993; 58: 839-45.

(31) P. Chilibeck, A. Calder,D. Sale, C. Webber. Reproducibility of dual-energy x-ray absorptiometry. Can Assoc Radiol J 1994; 45: 297-302.

(32) S. Going, M. Massett, M. Hall et al. Detection of small changes in body composition by dual-energy x-ray absorptiometry. Am J Clin Nutr 1993; 57: 845-50. 


\section{CHAPTER 8}

\section{GENERAL DISCUSSION}

Chronic pulmonary infections and poor appetite together with fat malabsorption are the main causes of malnutrition and growth retardation in CF children (1-3). The ideal treatment of CF should be the correction of the underlying defect by introduction of a normal copy of the defective gene into these patients genetic material. Although gene therapy is presently under intensive scrutiny (4-6), the role of this treatment in CF patients is not yet settled. Until then, treatment of these patients has to focus on improving the nutritional condition, since malnutrition can adversely affect survival (7). As $85 \%$ of CF patients have pancreatic insufficiency (8), improved absorption by pancreatic enzymes substitution is one of the main goals. Diagnosis and regular monitoring of fecal fat loss along with close evaluation of growth and the nutritional condition are consequently necessary in the follow up of these patients. Although the fat balance method is considered to be the golden standard for the evaluation of steatorrhea, it is too cumbersome to be used for the frequent monitoring of fat losses in these children. Several studies have shown the measurement of fecal fat concentration to be a valuable alternative to fat excretion studies for the diagnosis of fat malabsorption (9). These studies also shown that the differences in fat excretion between either 3 or 1 day collections are mainly due to day to day variation in stool volume, the stool fat concentration being much more constant. These studies led us to suppose that the repeated measurement of stool fat concentration in stool samples would be a valuable aid to the monitoring of steatorrhea. As chemical measurement of stool fat is time consuming, we looked for an alternative easy measure of fat content. Although the steatocrit looked quite attractive (10) our first results and also results reported by others $(11,12)$ disappointingly often showed low steatocrit results in stools of high fat content.

By acidification of stool homogenates, we could show fat extraction to be much improved and to result in a satisfactory correlation coefficient between chemically measured fecal fat and "acid steatocrit" results. We consequently decided to use the acid steatocrit in an intervention study (proton pump inhibitor) aiming at improving both steatorrhea and the nutritional condi- 
tion in children with $\mathrm{CF}$.

Both anthropometric parameters and body composition methods were used for the evaluation of the nutritional condition. Difficulties arise due to the fact that weight, height and skinfolds are age and sex specific. Although several authors have overcome this problem by expressing results of these parameters as a percentage of the predicted values for age and sex, the use of Z-scores is the preferred method for most authors. Z-scores measure deviations from the median value expressed in standard deviation units. Improving Z-scores reflect catch-up growth while the reverse is true for deteriorating Z-scores. Recently, Gerver and de Bruin have constructed growth charts with standard deviation for weight, height armcircumferences and the 4 skinfolds (biceps, triceps, subscapular and suprailiac) (13). Anthropometric parameters can be easily converted into Z-scores through the use of these reference data for normal children. As weight changes could be due to either changes in fatmass, fat free mass or both, we measured body composition by several methods in order to evaluate body composition before and after our intervention (proton pump inhibitor) study.

Our study results show significant decreases of most measured anthropometric parameters in children with cystic fibrosis. Decrease in skinfold thicknesses were most significant and contrary to a commonly held belief triceps skinfolds were often nomal while subscapular and suprailiac skinfolds were very sensitive indicators of chronic malnutrition in these patients. Our findings support the use of these simple anthropometric measurements for the evaluation of the nutritional condition in children. As far as body composition results are concerned, interpretation of results is uneasy due to the lack of reference values for several measuring methods. Notwithstanding these drawbacks, results of the various methods used were strongly correlated with each other but, still showed differences which preclude the use of these various methods interchangeably. Results should be looked at both in relative and in absolute terms.

In absolute terms, the DEXA method showed a severe decrease of fatmass and a slight decrease of fat free mass and of bone mineral content. Results of the total body water and skinfold method agreed with the DEXA results but could not be accurately assessed due to the lack of reliable reference data.

In relative terms, the deuterium - bromide results showed a relatively increased total body water and extracellular water compartment while the relative body cell water mass appeared 
well maintained. These results imply a decrease of fatmass as percent of bodyweight. Likewise, the fat free mass (\%) measured by the skinfold method was increased in our CF children. All these results agree with each other rather well and show that children with CF have a lowered bodyweight accompanied by a decreased fatmass (\%), an increased fat free mass (\%) and an increased extracellular water compartment (\%) while the intracellular water comparment (\%) appears to be well maintained (table 1).

Table 1 Body composition in children with cystic fibrosis.

\begin{tabular}{||cccccc||}
\hline & $\begin{array}{c}\text { FM } \\
\text { kg (\%) }\end{array}$ & $\begin{array}{c}\text { FFM } \\
\mathbf{k g}(\%)\end{array}$ & $\begin{array}{c}\text { TBW } \\
(\%)\end{array}$ & $\begin{array}{c}\text { ECV } \\
(\%)\end{array}$ & $\begin{array}{c}\text { ICV } \\
(\%)\end{array}$ \\
\hline \hline DEXA & $!(!)$ & $!(1)$ & & & \\
Skinfold & $?(1)$ & $?(1)$ & & & \\
Deuterium & $?(1)$ & $?(1)$ & $(1)$ & $(1)$ & (i) \\
Bromide & $?(1)$ & & &
\end{tabular}

DEXA: Dual energy X - Ray Absorptiometry

FM: Fatmass

FFM: Fat free mass

TBW: Total Body Water

ECV: Extracellular volume

ICV: Intracellular volume

A positive effect of omeprazole on fat absorption has been found in adults with CF (14). However the role of proton pump inhibitors on steatorrhea and its effects on the nutritional condition has not been evaluated in children. We have studied the effect of 3 months treatment of lansoprazole on fat malabsorption and body composition in $15 \mathrm{CF}$ children, maintaining steatorrhea while on pancreatic enzymes. These children showed significant improvements of both fat absorption (as measured by the acid steatocrit) and Z-scores for all parameters except for the biceps and triceps skinfolds and deteriorated again 3 months after lansoprazole was stopped. The increase in skinfold thicknesses Z-scores were accompanied by signifi- 
cant increases in fatmass as measured by the skinfold and the DEXA methods.

Different body composition methods have been described but, only few studies have compared different measurement techniques in pediatric subjects. An important question to answer is whether or not any of these methods is capable of detecting body composition changes occuring during nutritional interventions. Our study comparing the changes in body composition measured by DEXA, TBW and skinfolds methods in 15 CF children, whose nutritional condition improved significantly after intervention with lansoprazole for 3 months, showed different results for each method. Both DEXA and skinfolds methods showed significant increases in fatmass but not in lean body mass in absolute terms. Likewise, the percentage of body cell water mass did not increase significantly after nutritional intervention. On the other hand, the increases in bodyweight were completely ascribed to increases in lean body mass but not in fatmass when evaluated by the TBW method. Since fatmass was mostly depleted in our CF children (as shown by DEXA, skinfolds and total body water methods), it is likely that this body compartment will normalize first as a result of an effective intervention. Our results do not allow firm conclusions as to the effect of lansoprazole on FFM while a significant increase in bone mineral content was found. The bodyweight changes occuring during lansoprazole intervention were unrelated to either fatmass or FFM changes measured by any of the three methods used. We think the weight changes in the various body compartments were too small to be accurately measured by body composition methods.

In conclusion, the acid steatocrit is a reliable, cheap and noninvasive altemative method for the monitoring of fat malabsorption. Most cystic fibrosis patients are malnourished even when lung functions are stable and a hypercaloric diet is used. Body composition studies in these patients mainly show a loss of fat mass and bone mineral content with a relative increase in extracellular water and a normal intracellular water mass (\%). Inhibition of gastric acid secretion by a proton pump inhibitor improved both fat absorption and the nutritional condition of our patients. Methods for the assessment of body composition are not interchangeable and not accurate enough for detecting small changes in fatmass and fat free mass such as measured in our 3 months study. A longterm study is needed in order to better evaluate the effects of lansoprazole on body composition in children with cystic fibrosis. 


\section{REFERENCES}

(1) J. Dodge, J. Yassa. Food intake and supplementary feeding programs. In: J. Sturgess, ed. perspectives in cystic fibrosis. Toronto: Canadian Cystic Fibrosis Foundation; 1980: 125-136. (2) M. Bronstein, R. Sokol, S. Abman et al. Pancreatic insufficiency, growth, and nutrition in infants identified by newborn screening as having cystic fibrosis. J Pediatr 1992; 120: 533-40. (3) J. Tomezsco, V. Stallings, D. Kawchak, J. Goin, G. Diamond, T. Scanlin. Energy expenditure and genotype of children with cystic fibrosis. Pediatr Res 1994; 35: 451-460.

(4) M. Rosenfeld, W. Siegfried, K. Yoshimura et al. Adenovirus-mediated transfer of a recombinant alpha 1-antitrypsin gene to the lung epithelium in vivo. Science. 1991;252: 431-4 (5) B. Pitt, M. Schwarz, J. Pilewski et al. Retrovirus-mediated gene transfer in lungs of living fetal sheep. Gene Ther 1995; 2: 344-50.

(6) M. Rosenfeld, K. Yoshimura, B. Trapnell et al. In vivo transfer of the human cystic fibrosis transmembrane conductance regulator gene to the airway epithelium. Cell. 1992; 68: $143-55$.

(7) R. Kraemer, A. Rüdeberg, B. Hadom, E. Rossi. Relative underweight in cystic fibrosis and its prognostic value. Acta Paediatr Scand 1978; 67: 33-37.

(8) M. Aitken, S. Fiel. Cystic fibrosis. Dis Mon 1993; 39: 1-52.

(9) N. Thorsgaard Pedersen, H. Halgreen, H. Worning. Estimation of the 3-day faecal fat excretion and fat concentration as a differential test of malabsorption and maldigestion. J Gastroenterol 1987; 22: 91-96.

(10) P. Phuapradit, A. Narang, P. Mendonca, D. Harris, J. Baum. The steatocrit: a simple method for estimating stool fat content in newbom infants. Arch Dis Child 1981; 56: 725-727. (11) M. Walters, J. Kelleher, J. Gilbert, J. Littlewood. Clinical monitoring of steatornhoea in cystic fibrosis. Arch Dis Child 1990; 65: 99-102.

(12) E. Sugai, G. Srar, H. Vazquez et al. Steatocrit: a reliable semiquantitative method for detection of steatorrhea. J Clin Gastroenterol 1994; 19: 206-9.

(13) W. Gerver, R. de Bruin. Paediatric Morphometrics: A reference manual. 1 th ed. Utrecht: Bunge, 1996.

(14) H. Heijerman, C. Lamers, W. Bakker. Omeprazole enhances the efficacy of pancreatin (pancrease) in cystic fibrosis. Ann Intern Med. 1991; 114: 200-201. 


\section{SUMMARY}

In chapter one, the pathogenesis, clinical manifestations and treatment modalities of cystic fibrosis are briefly summarized. CF is a multisystem disease, the basic defect is a mutation of the CFTR gene. Until now, more than 200 mutations have been characterized. CFTR has been found in epithelial cells of several organs with the lung and pancreas being mostly affected. The role of gene therapy in the management of CF patients is not yet settled. Until then treatment of these patients has to focus on support of lung function and improved fat absorption in order to maintain a normal nutritional status. From our litterature review, only predigested foods such as (semi)elemental diets and very high-energy polymeric diets, have been reported to improve the nutritional condition in $\mathrm{CF}$ patients. Low duodenal $\mathrm{pH}$ is thought to be at least partly responsible for the persisting maldigestion. Inhibition of gastric acid secretion by a proton pump inhibitor has been shown to improve steatorrhea in CF adults. The effect of proton pump inhibitors on fat absorption and on the nutritional status of children with $\mathrm{CF}$ has not been reported. The effect of treatment on steatorrhea can only be evaluated by regular monitoring of fecal fat loss. The fat balance method being too cumbersome for the repeated evaluation of steatornhea, we first aimed at developing an alternative test suituble for our purpose. This test (acid steatocrit) was subsequently used to evaluate the effect of lansoprizo-le (proton pump inhibitor) on steatorrhea in CF patients showing persisting malabsorption while on pancreatic enzymes. The effects of therapy on the nutritional condition of our patients was evaluated simultaneously.

In chapter two, the methods used in this study are described. For the determination of fecal fat, the titrimetric method described by van de Kamer and the Sudan staining method were used for the comparison of steatocrit and acid steatocrit methods. Anthropometry, dual-energy $\mathrm{X}$-ray absorptiometry. total body water and bromide dilution techniques were used to assess body composition.

In chapter three, four and five, we describe the steatocrit test as an alternative method for the 3 days fecal fat balance method for the monitoring of steatorrhea. Although the steatocrit 
test has been reported to be cheap, simple and noninvasive test, its reliability has been questioned. As this might be due to inadequate fat extraction during the centrifugation step of the steatocrit procedure, we aimed at improving fat extraction by acidification of the fecal homogenate. Results obtained by our modified steatocrit method, called the "acid steatocrit", were highly correlated with those obtained by chemical analysis. We found a high sensitivity and specificity for the acid steatocrit.

Results of the evaluation of the nutritional condition of our patients as well as results concerning the presence of persisting steatorrhea in patients on pancreatic enzymes are described in chapter six. Despite hypercaloric intake and the use of pancreatic enzymes, our CF patients maintained steatorthea and showed signs of malnutrition with significantly decreased Z-scores for weight, height, armcircumference, biceps, subscapular and suprailiac skinfolds. Moreover, their fatmass, lean body mass and bone mineral content were significantly decreased when compared to the reference population described by Oggle et al. Treatment of these CF children with lansoprazole as an adjunct therapy of pancreatic enzymes, resulted in a significant decrease in steatorrhea accompanied by a significant improvement in their nutritional condition.

In chapter seven, we describe results of our body composition studies in our patients before and after treatment with lansoprazole. Although highly correlated, results from these various methods were shown not to be interchangeable. In absolute terms, the DEXA, the TBW and the skinfold methods showed children with $\mathrm{CF}$ to have a severe depletion of fatmass and a slight decrease of FFM. In relative terms, the above results point to lower body fat percentage accompanied by a higher percentage of LBM. Our results with deuterium - bromide do confirm the above results by showing a high relative TBW content and consequently a low relative fat content. Bromide results further show the relative increase of water percentage to be due to a relatively increased extracellular water compartment with a maintained relative body cell water mass. Although small changes in bodyweight were correctly detected by DEXA examination, the latter method was not accurate enough for the differential detection of small changes in FM and FFM. The usefulness of DEXA, TBW and skinfold methods for the assessment of small body composition changes in children is therefore limited. 


\section{SAMENVATTING}

In hoofdstuk cen, zijn de pathogenese, de klinische manifestaties en de therapeutische mogelijkheden voor cystic fibrosis (CF) kort samengevat. Cystic fibrosis is een multisysteem ziekte, waarvan mutatie van de CFTR (cystic fibrosis transmembrane regulator) gene is het basis defect.

Tot dus ver, zijn er meer dan 200 mutaties beschreven. CFTR werd in de epitheel cellen van verschillende organen gevonden. De longen en de pancreas zijn het meest betrokken by deze erfelijke aandoening. De rol van de gen therapie is nog niet bevestigd in de behandeling van CF patienten. De behandeling van deze patienten is er dan ook gericht op de long functies te ondersteunen en een normale voedingstoestand te behouden door het verbeteren van de vet malabsorptie.

Uit het litteratuur overzicht blijkt dat de voedingsstatus van CF patienten alleen effectief te verbeteren is met voorverteerd voedsel zoals (semi)elementaire voeding, of met een zeer hoge energie inname. Een lage duodenale $\mathrm{pH}$ is mede verantwoordelijk voor het slechte verteringsproces. Het is bij volwassen CF patienten bekend dat de vet absorptie significant te verbeteren is door remming van de maagzuur secretie met een proton pomp remmer. $\mathrm{Er}$ is nog geen studie gedaan naar het effect van dit middel op de vet vertering en de voedings status bij $\mathrm{CF}$ kinderen.

Regelmatig monitoring van vet in de ontlasting is noodzakelijk voor de behandeling van vet malabsorptie. De gebruikelijke vet balans methode is hiervoor te omslachtig. Ons eerste doe! was het ontwikkelen van een alternatieve test die snel en makkelijk uitvoerbaar is. Deze test (zure steatocriet) werd dan gebruikt om het effect van een proton pomp remmer (lansoprazol) op steatorrhoea in CF patienten met persisterende malabsorptie onder pancreas enzymen, te evalueren. Daamaast, werd het effect van lansoprazol op de voedingstoestand van onze patienten geevalueerd.

In hoofdstuk twee. beschrijven we de methoden die we gebruikt hebben in deze studie. Voor de bepaling van vet in de ontlasting, werden de titrimetrische methode, beschreven door van de Kamer, en de Sudan kleurings techniek gebruikt om de klassieke steatocriet te: vergelijken 
met de zure steatocriet. De anthropometrische methode, de dual-energy X-ray absorptiometry (DEXA), het totale lichaamswater ( $T B W$ ) en de bromide dilutie technieken werden toegepast om de lichaamsamenstelling te beoordelen.

In hoofdstuk drie, vier en vijf, beschrijven we de steatocriet test als een alternatieve methode voor de 3 dagen vet balans ter monitoring van vet in de ontlasting. Hoewel de steatocriet test werd gezien als een goedkope, simpele en noninvasieve test, de betrouwbaarheid van deze test wordt betwist. Dit is mogelijk toe te schrijven aan de inadequate vet extractie tijdens het centrifugeren van de steatocriet procedure. Ons doel was de vet extractie te verbeteren door het aanzuren van het faeces homogenaat. De resultaten verkregen met deze gemodificeerde steatocriet genaamd "zure steatocriet", correleerden goed met de resultaten van de chemische vet analyse. We vonden een hoge sensitiviteit en specificiteit voor de zure steatocriet test.

In hoofdstuk zes, bestuderen we de mate van vet malabsorptie en de voedingstoestand van onze CF kinderen behandeld met pancreas enzymen. Ondanks de hypercalorische voeding en de behandeling met pancreas enzymen, hadden onze patienten aanhoudende steatorrhoea en toonden tekenen van malnutritie met significante verslechtering van de gemiddelde Z-scores voor gewicht, lengte, armomtrek, biceps, subscapulaire en suprailiacale huidplooien. Bovendien, hun vetmassa, spiermassa en botmineral is significant lager dan die van de normale kinderen, beschreven door Oggle. Na de behandeling van deze kinderen met een proton pomp remmer (lansoprazol) als supplementaire therapie by pancreas enzymen, vonden we een significante vermindering van steatorrhoea met verbetering van de voedingstoestand.

In hoofdstuk zeven, beschrijven we de resultaten van de lichasmsamenstelling van onze patienten voor en na de behandeling met lansoprazol. Ondanks de hoge: correlatie tussen de resultaten van de gebruikte lichamsamenstelling methodes, zijn deze technieken niet uitwisselbaar. In absolute zin, toonden de DEXA, de TBW en de huidplooi methode een emstige depletie van de vetmassa en een lichte afname van de vet-vrije massa by CF kinderen. In relatieve zin, wijzen deze resultaten in de richting van een afnarne van het vet percentage gepaard aan een hoger percentage van lean body mass (LBM). Dit komt overeen met de resultaten van deuterium-bromide, waarbij een hoog TBW' percentage en dus een laag vet 
percentage gevonden werd. De toename in het TBW percentage is toe te schrijven aan het verhoogde percentage extracellulair water terwijl intracellulair water normaal blijft. Alhoewel de verandering in lichaamsgewicht door het DEXA onderzoek correct werd geschat, was geen van de gebruikte lichaamsamenstelling methodes nauwkeurig genoeg voor het schatten van kleine veranderingen in de vetmassa en vet-vrije massa. De bruikbaarheid van DEXA, TBW en huidplooi methoden voor het schatten van kleine veranderingen in de lichaamsamenstelling bij kinderen is daarom beperkt. 


\section{DANKWOORD}

Woorden schieten tekort om mijn dank uit te drukken. Ik ben niet zo goed in taal expresse, toch hoop ik met enkele eenvoudige zinnen iedereen te kunnen bedanken, die het mij mogelik hebben gemaakt dit proefschrift vorm te geven.

Zonder iemand tekort te willen doen, richt ik een speciaal dankwoord tot de volgende peronen:

Prof. Dr. C. Blanco, promotor, beste Carlos, ondanks je drukke taak, heb je toch heel snelen kritisch mijn werkstukken doorgenomen. Hiervoor dank ik je extra.

Dr. P. Ph. Forget, copromotor, beste Philippe, het lukte mij nooit je te tutoyeren, niet vanvege onze persoonlijke contacten, maar vanwege mijn respect voor jou. De manier waarop je let onderzoek stuurde waarbij je mij geheel in mijn waarde en vrijheid liet, was van buitengewoon hoog niveau. Je leerde mij wetenschappelijk denken. Waar nodig was bood je hllp aan, soms ook met het verwerken van de resultaten. De correctie van het manuscript vas binnen korte tiid klaar. Zelfs in ie vakantie. nam ie miin werkstukken mee en was ie berid hiervoor terug te komen. Ik heb genoten van je onuitputtelijke bron van nieuwe ideeën.

Ook in het persoonlijk contact was je aangenaam. Je heb altijd in mij geloofd en stond altijd achter mij. Beste Philippe, zonder jouw inzet en je vertrouwen als begeleider, zou dit proefschrift nooit deze vorm hebben gekregen.

Dr. B. van Kreel, copromotor, de helft van mijn tijd als onderzoeker heb ik in uw laboratorium doorgebracht. Uw deur stond altijd voor mij open. Als het niet lukte met de steatocrit bepaling, heb u altijd nieuwe suggesties. Uw deskundigheid en eerlijkheid was onmisbaar voor het slagen van dit onderzoek.

Prof. Dr. R. H. Kuijten, bedankt voor de mogelijkheden die u hebt gecreeërd voor dit onderzoek.

Drs. A. Van den Neucker, beste Anita, al die jaren ben je voor mij een goede vriendin geweest. Ook als het mij tegen zat, wist je met je nuchtere kijk en eerlijkheid mijn problemen te relativeren. Ik heb genoten van onze discussies en van je gezelschap op verscheidene congressen. Je interesse in anderen en je brede algemene kennis maakte het zeer boeiend. Anita, je hebt mijn "gat" in de Westerse cultuur opgevuld. 
Hooggeleerde leden van de beoordelingscommissie, bedankt voor uw vlotte en kritische beoordeling van dit manuscript.

Alle kinderartsen, neonatologen en arts-assistenten kindergeneeskunde in het AZM dank ik hierbij voor de aanspraak in de afgelopen jaren.

Dr. W. J. M. Gerver en Dr. R. De Bruin, jullie groeicurven hebben grote waarde toegevoegd aan dit onderzoek. Bedankt voor jullie voortreffelijke bijdrage.

Jolanda vain Golde en Rony Nieefjes, beste Rony en Jolanda, bedankt voor het meeleven en de gezellige uren in het AlO-hok, in het restaurant, in het theater aan het Vrijthof, in de bioscoop, bij een van ons thuis of in het zwembad. Bedankt voor het aanhoren van mijn "gezeurd". We hebben goede en slechte tijjden met elkaar doorgemaakt. Ik hoop dat onze vrienschap hierdoor alleen maar sterker is geworden.

Alle medewerkers van het klinisch chemisch laboratorium van het $A Z M$, met name Serva, Lou, Michel, Mia, Theo, Peter en Marian, bedankt voor jullie inzet en betrokkenheid tijdens het onderzoek. Jullie wetenschappelijke interesse was van niveau. Als ik hulp nodig had waren jullie bereid, soms ook ongevraagd, het eigen werk neer te leggen en mij bij. te staan. Bedankt voor de aangename sfeer en de gezellige samenwerking.

Liesbeth van der Ploeg en Lianne Schoorlemmer, dietisten, wil ik danken voor het uitrekenen van de calorieën bij mijn patienten populatie.

Dr. G. A. K. Heidendal, Piet Willems en Sandra Zimny van de nucleaire afdeling, bedankt voor jullie fijnzinnige instructies over de DEXA scan.

Alle poli-assistenten en de secretaressen van de kindergeneeskunde, wil ik danken voor de samenwerking in de afgelopen jaren.

Oom Wim en tante Margriet van der Avoort, bebankt voor jullie steun en betrokkenheid in de afgelopen 15 jaren van mijn leven in Nederland.

Ik ben de firma's Hoechst Marion Roussel B.V. (Hoevelaken) en Janssen-Cilag B.V. (Tilburg) dankbaar voor hun financiële ondersteuning in de drukkosten van dit proefschrift.

Tenslotte, zou dit boek niet volledig zijn zonder hulp en meeleven van mijn familie. Lieve mama, oom Kiet, Manh Hung en Manh Coung, terwijl ik rustig aan mijn proefschrift werkte, hebben jullie voor mijn verbuizing gezorgd.

Manh Coung, bedankt voor het ter beschikbaar stellen van je computer en Manh Hung voor je 
deskundige steun. Als ik met de computer problemen had, kon ik altijd op jullie terugvallen. Oom Kiet, bedankt voor je inzet en betrokkenheid. Nooit hoefde ik je om hulp te vrager, je was er gewoon.

Lieve Mama, zonder jou zou dit boek er nooit zijn gekomen. Heel je leven lang heb je voor ons klaar gestaan. Jouw droom is een goede toekomst voor je kinderen. Daarvoor heb je 15 jaar geleden je leven op het spel gezet. Je stimuleerde ons om te studeren. Rijkdom is aiet belangrijk, maar kennis, dat is de beste bagage die je op onze weg aan ons hebt kumen meegeven. Mama, bedankt voor je betrokkenheid en het aanhoren van mijn frustraties. Met een glimlach en een schouderklop wist je al mijn problemen op te lossen. Mama, ik hou van jou en $\mathrm{ik}$ ben trots dat $\mathrm{jij}$ mijn moeder ben. 


\section{CURRICULUM VITAE}

Thi My Dung Tran werd. op 27 april 1967 te Dinh Tuong in Vietnam geboren.

Na het doorlopen van het basisonderwijs volgde zij, eveneens in Vietnam, drie jaren vervolgonderwijs op voorbereidend wetenschappelijk niveau.

In $1981 \mathrm{kwam}$ zij met haar familie in Nederland.

Op 2 juni 1986 verwierf zij aan de Rijksscholengemeenschap "Den Hulster" te Venlo het diploma Atheneum B. met als eindexamenpakket de vakken: Nederlands, Engels, Wiskunde I en II, Natuurkunde, Scheikunde en Biologie.

Vanaf het najaar 1986 studeerde zij geneeskunde aan de Rijksuniversiteit te Maastricht. Zij behaalde op 13 augustus 1990 haar doctoraal getuigschrift. Op 1 februari 1993 werd het diploma basisarts aldaar aan haar uitgereikt.

Tijdens haar studie verrichte zij wetenschappelijk onderzoek onder leiding van Dr. P. PH. Forget op de afdeling kindergeneeskunde van het Academisch Ziekenhuis Maastricht: "Singel Stool analysis for fat, alfa-animo nitrogen and electrolyt".

Vanaf 1 maart tot 3 november 1993 werkte zij als arts-onderzoeker bij de vakgroep kindergeneeskunde van het A.Z.M. aan het project "Effect of ranitidine in children with chronic abdominal pain".

Van 1 december 1993 tot 1 december 1994 was zij werkzaam als AGNIO kindergeneeskunde in het A.Z.M.

In de periode 1 december 1994 tot 1 april 1996 werkte zij onder leiding van Dr. P. PH. Forget, kinder-gastroenteroloog in het A.Z.M., aan haar promotie-onderzoek. 
Steatorrhea and nutritional condition in cystic fibrosis children effects of a proton-pump inhibitor 
STEATORRHEA AND NUTRITIONAL CONDITION IN CYSTIC FIBROSIS CHILDREN EFFECTS OF A PROTON - PUMP INHIBITOR 


\section{CONTENTS}

Chapter 1 General introduction - litterature review - Aims of the study

1. Genetics of cystic fibrosis

2. Pathogenesis

3. Clinical manifestations

4. Diagnosis

5. Therapy

6. Evaluation of steatorrhea

Aims of the study

References

Chapter 2. Methods

1. Methods used for fecal fat determination

2. Methods used for assessment of nutritional condition

Chapter 3 The acid steatocrit: A much improved method

Tran M., Forget P., Van den Neucker A., Strik J., van Kreel B., Kuijten R.

J Pediatr Gastroenterol Nutr 1994; 19: 299-303

Chapter 4 Improved steatocrit results obtained by acidification of fecal homogenates are due to improved fat extraction

M. Tran, P. Forget, A. Van den Neucker, B. Van Kreel

J Pediatr Gastroenterol Nutr 1996; 22: $157-160$

Chapter 5 Clinical use of acid steatocrit

A. Van den Neucker, N. Pestel, T. My Dung Tran, P. Ph. Forget,

H. J. Veeze, J. Bouquet, M. Sinaasappe!

Submitted for publication

Chapter 6 Role of lansoprazole in children with cystic fibrosis: Evidence for improved fat malabsorption and nutritional status Tran TMD, Van den Neucker A, Hendriks JJE, Forget P (junior), Forget $\mathrm{P}$ (senior)

Submitted for publication 
Chapter 7 Anthropometry and body composition methods in children with 84-107 cystic fibrosis: Effects of nutritional intervention My-Dung T. Tran, Anita Van den Neucker, Han J. Hendriks, Bernard van Kreel, Patricia Forget, Guido Heidendal, Pierre-Philippe Forget Submitted for publication

Chapter 8 General discussion 108-112

Summary $113-114$

Samenvatting $115 \cdot 117$

Dankwoord 118-120

Curriculum vitae 
EFFECTS OF A PROTON-PUMP INHIBITOR

\section{PROEFSCHRIFT}

Ter verkijging van de graad van doctor aan de Rijksuniversiteit Limburg te Maastricht, op gezag van de Rector Magnificus, Prof.Mr. M.J. Cohen, volgens het besluit van het College van Dekanen, in het openbaar te verdedigen.

op donderdag 17 oktober 1996 om 16.00 uur

$$
\text { door }
$$

Therese Marie Pascale Thi My Dung Tran geboren op 27 april 1967 te Dinh Tuong, Vietnam 
Promotor:

Co-promotores:

Beoordelingscommissie:
Prof. Dr. C. Blanco

Dr. P-Ph. Forget

Dr. B. van Kreel

Prof. Dr. P.B. Soeters, ( voorzitter )

Prof. Dr. H.S.A. Heymans, (Universiteit van Amsterdann )

Prof. Dr. R.W. Stockbrugger

Prof. Dr. J.M. Wit, ( Rijksuniversiteit Leiden )

Prof. Dr. E.F.M. Wouters

Steatorrhea and nutritional condition in cystic fibrosis children:

Effects of a proton - pump inhibitor /

Therese Marie Pascale Thi My Dung Tran.

Proefschrift Maastricht - Met lit. Opg. - Met samenvatting in het Nederlands.

ISBN 90-5681-011-1

Trefw.: Steatocriet / steatorrhoe / cystic fibrosis / voedingstoestand / proton pomp remmer / lichaamsamenstelling.

Vormgeving: My Dung Tran

Omslagillustratie: Vetbollen in een microscopische faeces preparaat, met Soudan kleuring. 
Aan mijn lieve moeder Voor alle cystic fibrosis kinderen. . 
CHAPTER 1

GENERAL INTRODUCTION 


\section{GENETICS OF CYSTIC FIBROSIS (CF)}

Cystic fibrosis was first described in 1928 by Fanconi (1). It is an autosomal recessive disease and is reported in all racial groups with varying prevalence. In caucasians, CF occurs in 1 out of 2000 live births. Males and females are equally affected. The basic defect is a mutation of the Cystic Fibrosis Transmembrane Regulator (CFTR), a protein responsible for chloride ion transport in response to cAMP mediated signals. The most frequent CF mutation in the caucasian population is a deletion of 3 nucleotides, encoding for phenylalanine at position 508 in the CFTR protein amino acid sequence. Its overall frequency reported by the CF Genetic Analysis Consortium is $68 \%$ (2). Until now, over 200 mutations have been characterized and account for the remaining mutations.

\section{PATHOGENESIS}

It is generally accepted that cAMP stimulated chloride conductance is a function of the CFTR (3). This function is deficient in epithelial cells of CF patients. The inability to secrete chloride and secondarily secrete water results in viscous secretions. Poor clearance of these viscid secretions from the epithelium often results in obstruction of excretory ducts. CFTR has been found in epithelial cells of several organs such as the airways, the sweat glands, the genitourinary system and the gastrointestinal tract including the pancreas and the biliary tract (4). Dysfunction of these organ systems are therefore possibly related to the same underlying defect in the CFTR-gene product.

\section{CLINICAL MANIFESTATIONS}

CF is a multisystem disease with lungs and pancreas mostly affected in young patients.

\section{1 Respiratory tract}

Lung disease accounts for more than $95 \%$ of the morbidity and mortality in CF $(5,6)$. The desiccated mucus in the respiratory tract causes stasis and bronchiolar obstructions, resulting 
in bacterial overgrowth and chronic lung infection. This gives rise to the production of proteases by bacteria and neutrophils. These enzymes hydrolyze important structural proteins of the lung and airways such as elastin, proteoglycans and collagen, leading to instability of bronchial walls and bronchiectasis. Furthermore, these enzymes also alter the mucosal function by increasing the secretion of macromolecular glycoconjugates contributing to a high viscosity of the mucus (7). Bronchiolitis with wheezing is frequent during the first year of life. Some patients remain however, asymptomatic for long periods. When pulmonary disease progresses, exercise intolerance occurs and finally, progressive pulmonary deterioration is the main cause of death in these patients $(6,8)$. As a consequence of improved supportive therapy, survival has increased from 6 months at the end of the fifties (9) to nearly 30 years currently $(10,11)$. Sinusitis and nasal polyposis sometimes occur in CF $(12,13)$.

\section{2 Pancreas}

In the pancreas, obstruction of the ductules is the cause of acinar / ductular distention, followed by dișruption with release of proteolytic enzymes and autodigestion of the pancreas resulting in pancreatic insufficiency with steatorrhea. The changes in the pancreas can occur early during gestation, compromising the normal maturation of the pancreas: Approximately, $85 \%$ of CF patients have steatorrhea (11). In $85-90 \%$ of these cases, exocrine pancreatic insufficiency develops during the first year of life. Decreased secretion of bicarbonate and water first occurs before a decrease of pancreatic enzyme concentration in duodenal fluid can be detected (14-17). Recurrent acute pancreatitis occurs in approximately $10 \%$ of CF patients (18).

Because of fat malabsorption, serum concentrations of fat soluble vitamins are often lowered. Since Vit A conșists of esters of long chain fatty acids, it cannot be absorbed in the absence of pancreatic esterases. Due to its short half life, low serum leveis of Vit A are often found in early untreated CF patients $(19,20)$. Vit $\mathrm{D}$ deficiency resulting in decreased bone mineralization has also been reported in CF patients (21-23). Due to frequent antibiotic therapy, suppression of endogenous vit $\mathrm{K}$ synthesis by anaerobic intestinal bacteria often contribute to a low vit $\mathrm{K}$. serum level in CF patients with steatorrhea. Although Vit B12 is water soluble, serum levels may also be low in CF patients. Binding to intrinsic factor, necessary for absorption, 
can only take place after cobalamin has been released from the R-protein binding by pancreatic enzymes. Decreased pancreatic bicarbonate secretion may play a role herein since the binding affinity of cobalamin for R-protein decreases at neutral or slightly alkaline $\mathrm{pH}$ (24). However, pancreatic enzymes supplements will normalize the Vit B12 serum level.

Abnormal glucose tolerance occurs in $30-75 \%$ of $\mathrm{CF}$ patients while diabetes mellitus develops in 10\% (11). Several diabetogenic factors including increased passive sugar transport (25), increased mucosal absorption of D-glucose (26), decreased beta cell mass (27) and delayed insulin secretion (28) are present in CF. On the contrary, several antidiabetogenic factors such as an increased tissue insulin sensitivity (29) and an increased number of insulin receptors on monocytes (30) have been reported in cystic fibrosis. Moran et al. reported a decreased alpha, beta- and pancreatic polypeptide- cell function in CF patients with exocrine disease compared to those without this disorder. Due to this finding, they suggest that either exocrine disease causes endocrine dysfunction or that a common pathogenic process simultaneously and independently impairs exocrine and endocrine function in CF patients (31). However, the exact etiology of diabetes in CF is still unknown.

\section{5 Mainutrition}

CF children are malnourished when compared to normal controls $(32,33)$. Both, malabsorption accompanying pancreatic insufficiency (34) and high energy expenditure due to chronic lung infection $(35,36)$ are thought to be responsible for the poor nutritional condition in these patients. Moreover, in $\mathrm{CF}$, several intraluminal factors other than pancreatic insufficiency are also considered responsible for fat malabsorption:

1) Increased gastric acid secretion after stimulation with pentagastrin (37):

A high postprandial acid secretion could, by lowering the duodenal $\mathrm{pH}$, contribute to fat malabsorption.

2) Decrease pancreatic bicarbonate secretion (13-16):

Higher gastric acid secretion after meals together with a decrease in pancreatic bicarbonate secretion, has been shown to result in a prolonged postprandial lowering of duodenal pH with 
inactivation of the remaining pancreatic lipase. Moreover, low duodenal $\mathrm{pH}$ also results in bile acid precipitation,, fecal loss of bile acids and a decrease in the bile acid pool, contributing to fat malabsorption

3) Increased glycine to taurine conjugated bile acid ratios:

Due to a relatively deficient supply of taurine compared to glycine and to continous fecal loss of bile acids, newly formed bile acids are mainly conjugated with glycine, leading to high glycine-/taurine- bile acid conjugation ratios (38). The glycine conjugated bile acids precipitate in an acidic environment contributing to the luminal bile acid deficiency in these patients.

\section{4 Intestinal tract}

Gastroesophageal reflux and esophagitis are frequent causes of epigastric pain in CF patients $(39,40)$ and can be responsible for decreased pulmonary functions (41). Peptic ulcers are found in up to $13 \%$ of $\mathrm{CF}$ patients (42) and are thought to be related to the low duodenal $\mathrm{pH}$

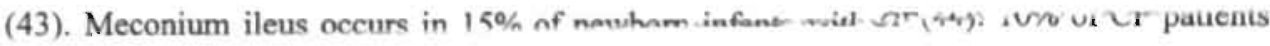
have meconium ileus "equivalents" at a later age with a peak incidence at 20-25 years of age (45). Protein precipitation as a result of decreased duodenal $\mathrm{pH}$ and high secretion viscosity all probably contribute to these obstructive events (11). Up to $25 \%$ of the CF patients have rectal prolapse occurring mostly in children aged 6 - 36 months (46) while intussusception has been shown to occur in $1 \%(47)$.

\section{5 Biliary and Hepatic tracts}

An increased incidence of cholelithiasis has been reported in CF patients (48) and is thought to be related to hypokinesis and increased fasting gallbladder volumes (49). Biliary cirrhosis with hepatosplenomegaly leading to portal hypertension occurs in $25 \%$ of CF patients. Liver steatosis has been reported in $30 \%$ of patients with CF.

\section{6 Genitourinary tract}


More than $95 \%$ of males are infertile due to obstruction of the reproductive tracts (50). Active spermatogenesis does occur but produced spermatozoa are abnormal or immature (51). In $\mathrm{C}^{2}$ women, the reproductive tracts are anatomically normal but fertility is decreased (52). Incree sed viscosity of the cervical mucus is thought to interfere with sperm penetration (53).

\section{7 Sweat gland}

Decreased sodium and chloride reabsorption due to dysregulation of sweat gland duct cell, results in susceptibility of $\mathrm{CF}$ patients to salt depletion during warm weather and durirg gastroenteritis.

\section{Diagnosis}

The standard diagnostic procedure is the sweat test based on increased concentration of electrolytes in the sweat of the patients (54). The sweat test was developed by Gibson ard Cooke (55), whereby the sweat production is stimulated by puocarpine iontopnoresis. Ine then collected sweat is analysed for its chloride and sodium content. However, chloride content has a better diagnostic value than sodium content, since abnormal sodium secretion can also be found in other endocrine diseases. Sweat chloride concentration higher than 60 $\mathrm{mM}$ or sodium above $70 \mathrm{mM}$ measured minimal on two conditions is considered as abnormal, whereas chloride values under $50 \mathrm{mM}$ and sodium value under $30 \mathrm{mM}$ are found in normal persons. Chloride concentrations between 50 and $70 \mathrm{mM}$ are inconclusive. For reliable results, at least $50 \mathrm{mg}$ of sweat should be collected. Low sweat production in the first few weeks of life is the reason for unreliable test results in this age group. In cases of doubt, identification of CFTR-mutation or measurement of intestinal current in a rectal biopt have been reported to be conclusive (56).

\section{Therapy}

The ideal treatment of CF should be the correction of the underlying defect by introduction of a normal copy of the defective gene into these patients genetic material. Gene therapy is 
presently under intensive scrutiny. Adenovirus and recently also the retrovirus seem promising as an effective vector for normal gene transport into the target cells $(57,58)$. Recently, transfer of the CFTR gene to the rat airways epithelia has been successfully performed (59). However, the role of gene therapy in the management of CF patients is not yet settled. Until then, treatment of $\mathrm{CF}$ patients has to focus on improving the nutritional condition, since malnutrition can adversely affect survival (60). The nutritional status of CF patients can be improved by firstly ameliorating the respiratory function, thereby minimizing energy expenditure and secondly, by increasing energy supply either by increasing nutrient intake or by improving nutrient digestion and absorption.

\section{1 Respiratory function support}

Since viscous mucus in the lung is the cause of chronic lung infection, efforts should be made to improve mucus clearance. Although most patients on mucolytics such as acetylcysteine have the feeling of decreased sputum viscosity, studies with acetylcysteine either orally or as aerosol have failed to support this finding (61-63). Alternative methods such as chest percussion combined with postural drainage (64), positive expiratory pressure mask $(65,66)$ and forced expiratory pressure (67) have been suggested to improve mucus clearance. Moreover, $\beta 2$-agonists as aerosol can increase sputum clearance (68) and some bronchodilatating effect has been experienced in CF patients on this regimen $(69,70)$. Corticosteroids, have been found to delay disease progression and to improve lung function in $C_{F}$ patients (71-74) but, short-term adverse effects such as hyperglycemia and long-term adverse effects such as development of cataract and growth retardation preclude the routine use of corticosteroids in these patients (73).

Treatment with antibiotics can reduce the progression of lung infection. Colonisation with Ps. aeruginosa often occur in CF patients and various regimes have failed to eradicate the bacteria (75). Ps. aeruginosa vaccines are presently being evaluated (76). In the end stage, lung transplantation can offer an outcome. The one and two year survival rates approach $70 \%$ and $54 \%$ respectively (77). Amiloride inhalation by blocking sodium reabsorption in the respiratory epithelium, has been shown to increase sputum clearance in a placebo-controlled crosso- 
ver study $(78,79)$. Although improvement in pulmonary function was not found in one study (78), a delay in the deterioration of forced vital capacity (FVC) was reported by an other author (79). Domase (Pulmozyme), a recombinant human desoxyribonuclease which breaks off the sputum DNA, has been reported to increase the forced expiratory volume (FEV1) and FVC safely in CF patients (80-82). Inhalation of $\boldsymbol{\alpha} 1$-antitrypsine inhibits neutrophil elastase (83), which is released from the neutrophils and causes lung damage. Chloride channel facilitators, which directly stimulate a CFTR protein independent anion channel, are presently being evaluated (84).

\section{2 Increase energy supply}

in the past, restricted diets with low fat content were often prescribed for CF patients in order to minimize steatorrhea, abdominal cramps and stool bulk (85-87). Due to both unpalatability and low caloric density, these diets often resulted in malnutrition and growth faillure in these patients (87-89). In the early 1970s, Crozier introduced the use of high fat diets in combination with pancreatic enzymes in order to increase the energy intake of CF patients. This regimen resulted in better growth with evident steatorrhea (90). Moreover, CF children from clinics using low fat diets were reported to show poorer growth (87-89) than those from clinics, encouraging the use of high fat diets (91). In order to further improve the nutritional status and growth of CF patients, feeding intervention studies have been done with different kinds of nutrients such as hypercaloric polymeric, semielemental or elemental diets. It has been shown that interventions making use of very high caloric intakes of polymeric diets (150 - $180 \%$ Recommended Daily Allowance) by overnight nasogastric tube resulted in improved nutritional status in CF adults. In children with CF, the effects of interventions with hypercaloric polymeric diets up to $130 \%$ of RDA are however unconvincing. Luder and coworkers, studying the effects of a 4 year period of nonrestricted fat diet in CF children, found improved $\mathrm{Z}$-scores for weight, height and $\mathrm{BMI}$ for their $\mathrm{CF}$ patients when compared to the national population of $\mathrm{CF}$ patients on fat restricted diets, while no changes were: seen when compared to normal children without CF (92). More recently, studies with hypercaloric polymeric diets with high fat content did not result in significant improvements of Z-scores for weight, height and skinfolds in CF patients (93), whereas parenteral nutrition and either oral or enteral 
elemental and semielemental nutrition have been shown to significantly improve the nutritional condition of these patients (94-106). The results of short-term and long-term studies of feeding interventions on the nutritional status in CF children are summarized in table 1 and 2 . The fact that predigested food can improve the nutritional status better than standard diets, strongly suggests that nutrient maldigestion plays a crucial role in the poor response to oral hypercaloric polymeric diets. The latter hypothesis is further supported by the known inactivation of pancreatic enzymes and bile acids precipitation accompanying the low duodenal pH due to low bicarbonate secretion in CF patients (107-110) . Enteric-coated pancreatic enxyme preparations have therefore been introduced but the low duodenal $\mathrm{pH}$ interferes with the release of enzymes through the acid resistent coating (111). High doses of pancreatic enzymes did not solve the problems of malabsorption (112) and recently, colon strictures have been observed in CF children on high doses of pancreatic enzymes (113-115). Attempts have been made to inhibit gastric acid production in the hope to improve the digestion and absorption of nutrients. However, the reported effects of H2-receptor antagonists and prostaglandine E2 on steatorrhea have been variable and unconvincing (116-125). Results of short-term studies of cimetidine and misoprostol on fat excretion have not been consistent (table 3). This may be partly due to the lack of control of dietary fat intake. In longterm studies cimetidine showed no significant changes in fat excretion and nutritional status in CF children. on the contrary, famotidine, a more potent inhibitor of gastric acid secretion, showed both a significant improved fat absorption coefficient and improved growth parameters (table 4). However, interpretation of growth effects in the latter study is rather difficult because $Z$-score methods have not been used to evaluate growth. Further, in a double blind study, a significant improvement in steatornhea was found when a proton pump inhibitor was added as adjuvant therapy in pancreatic enzyme treated CF adults (112). In children with $\mathrm{CF}$, the effects of proton pump inhibitors on fat absorption and on the nutritional condition have not been reported. 
Table 1 short-term feeding intervention studies in cystic fibrosis.

\begin{tabular}{|c|c|c|c|c|c|c|c|}
\hline Authon & $\begin{array}{l}\text { Eshephend } \\
\text { et ali, 'so }\end{array}$ & $\begin{array}{l}\text { "Shepherd } \\
\text { et al, ' } 13\end{array}$ & $\begin{array}{l}\text { "Bertined } \\
\text { et all, ' } 44\end{array}$ & $\begin{array}{l}\text { mansell } \\
\text { et al, ' } 24\end{array}$ & e. 1., " is & "Loughlin & extil.'95 \\
\hline $\begin{array}{c}\text { Number of } \\
\text { cases }\end{array}$ & 12. & 7 & 10 & 11 & 21 & 10 & 15 \\
\hline Age range & $0.5 \cdot 11 y$ & $5 \cdot 13 y$ & $3-12 y$ & $10-17 y$ & $1-14=$ & $? \cdot 28 y$ & $1-27 y$ \\
\hline $\begin{array}{c}\text { Nutritional } \\
\text { status }\end{array}$ & malnutrition & malnutrition & malnutrition & malnutrition & eormal & malnutrition & malnutrition \\
\hline $\begin{array}{l}\text { Sevdy } \\
\text { duration }\end{array}$ & 1 moenth & 6 month & 1 month & 1 month & 5 days & 6 monchs & 3 monchs \\
\hline $\begin{array}{l}\text { Type of } \\
\text { study }\end{array}$ & $\begin{array}{l}\text { Prospective } \\
\text { own control }\end{array}$ & $\begin{array}{l}\text { wospective } \\
\text { ewn control }\end{array}$ & prospective own control & $\begin{array}{l}\text { prospective } \\
\text { own control }\end{array}$ & $\begin{array}{l}\text { prospective } \\
\text { CF control }\end{array}$ & $\begin{array}{l}\text { prospective } \\
\text { CF elemental } \\
\text { CF polymaric }\end{array}$ & $\begin{array}{l}\text { prodpective own } \\
\text { control }\end{array}$ \\
\hline $\begin{array}{l}\text { Feedine } \\
\text { intervention }\end{array}$ & $\begin{array}{c}\text { TPN } \\
90-100 \% \\
\text { RDA }\end{array}$ & $\begin{array}{l}\text { ilemental } \\
20.40 \% \\
\text { RDA (extra) }\end{array}$ & $110-150 \leqslant$ RDA & $\begin{array}{c}\text { TrN } \\
120 \% R D A\end{array}$ & $\begin{array}{l}\text { mielemental } \\
142 \text { kcal/48 }\end{array}$ & $\begin{array}{l}\text { elemental } \\
35 \% \text { RDA } \\
\text { (extra) versus } \\
\text { hypercaioric }\end{array}$ & $\begin{array}{l}\text { Dyperealoric } \\
\text { polymeric } \\
130 \% \text { RDA }\end{array}$ \\
\hline Roulte & parenteral & enteral & nasogastric & persinternal & ord & enteral & and \\
\hline Eneal & $\begin{array}{l}\text { SDS weight ! } \\
\text { SDS height : } \\
\text { MUACW add } \\
\text { clinical weore ! } \\
\text { FVC, FeVII } \\
\text { PEF ! }\end{array}$ & $\begin{array}{l}\text { SDS weight : } \\
\text { SDS weight I } \\
\text { MUAC \$ std ! } \\
\text { FM L.BM (kg)! } \\
\text { muscle mass (kg)! } \\
\text { clinical score ! } \\
\text { 3-meklis excre । }\end{array}$ & 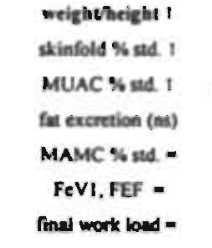 & $\begin{array}{l}\text { weight (kg) t } \\
\text { weight (ew) t } \\
\text { skinfold (mm) 1 } \\
\text { MAMC (cm) ! } \\
\text { MIP, MEP । } \\
\text { FeVI, FEF - }\end{array}$ & $\begin{array}{l}\text { Weight (ky) I } \\
\text { Nexcretion ! } \\
\text { fat absorption coeff. } \\
\text { cient ! }\end{array}$ & 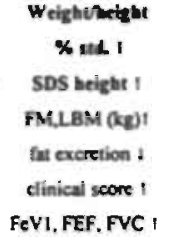 & $\begin{array}{l}\text { SDS weight (ns) } \\
\text { SOS weight (ns) } \\
\text { growth velocily } \\
\quad \text { (ns) } \\
\text { skinfold. (ns) } \\
\text { weighin (kg) t }\end{array}$ \\
\hline $\begin{array}{l}\text { Follow op } \\
\text { (durntion) }\end{array}$ & $\begin{array}{l}\text { dl parameters } \\
\text { improve further } \\
\text { (after months) }\end{array}$ & NR & $\begin{array}{l}\text { Il panmeters I } \\
\text { (after } 2 \text { months) }\end{array}$ & $\begin{array}{l}\text { MLP. MEP = } \\
\text { FeVI. FEF - } \\
\text { (after } 2 \text { months) } \\
\text { dil other } \\
\text { perrecers ! } \\
\text { (and 1-6month) }\end{array}$ & NR & NR & NR \\
\hline
\end{tabular}

MIP : Maximal Inspiratory Pressure MEP : Maximal Expiratory Pressure FeVI : Forced expiratory volume in I sec. SDS : Standard deviation score N-excretion : Fecal Nitrogen excretion MUAC : Mid Upper Am Circumference MAMC : Mid Am Muscle Circumference
FVC : Forced Vital Capicity $\quad 1:$ Improved

FEF : Foreed Expiratory Flow 1 : Decreased

PEF : Peak Expiratory Flow = : unchanged

LBM : Lean Body Mass $\quad$ (ns) : not significant

FM : Fatmass $\quad$ NR: not reported

RDA: Recommended daily allowance

3-meHis excre : 3 methylhistidine excretion in urine 
Table 2 Long-term feeding intervention studies in cystic fibrosis.

\begin{tabular}{|c|c|c|c|c|c|c|c|c|}
\hline Aurthon & et al, '73 & $\begin{array}{l}\text { "Bemy } \\
\text { et all, '75 }\end{array}$ & $\begin{array}{l}\text { "Yises } \\
\text { etial.'78 }\end{array}$ & $\begin{array}{c}\text { Levy } \\
\text { et al, 's5 }\end{array}$ & $\begin{array}{l}\text { moland } \\
\text { et al, 'B6. }\end{array}$ & $\begin{array}{l}\text { "Sheperd } \\
\text { et al', '86 }\end{array}$ & $\begin{array}{l}\text { "Favell } \\
\text { ef at, 's? }\end{array}$ & $\begin{array}{l}\text { "Luder } \\
\mathrm{nad,} \cdot \mathrm{g}\end{array}$ \\
\hline Number of cases & 17 & is & 4 & 14 & 10 & 10 & 36 & 37 \\
\hline Age nange & $2.21 y$ & $10 m-18 y$ & $3-16 y$ & $5-22 y$ & $5 \cdot 20 y$ & $3 \cdot 13 y$ & $3 \cdot 4 m$ & $2 \cdot 27 y$ \\
\hline $\begin{array}{l}\text { Nutrition } \\
\text { stuns }\end{array}$ & mainuarik & malnutrit & malmuterit & mainutrit & mainutrik & malnutrit & normal & malnutrit \\
\hline $\begin{array}{l}\text { Sundy } \\
\text { duration }\end{array}$ & $\begin{array}{c}3 \text { months to } 3 \\
\text { ycers }\end{array}$ & 1 year & I yeat & 1,1 year & $\begin{array}{l}10-36 \\
\text { months }\end{array}$ & I year & 8 months & 4 yean \\
\hline $\begin{array}{l}\text { Type of } \\
\text { twady }\end{array}$ & $\begin{array}{l}\text { peospect } \\
\text { own } \\
\text { sontrol }\end{array}$ & $\begin{array}{l}\text { prospect } \\
\text { CF } \\
\text { control }\end{array}$ & $\begin{array}{l}\text { prosped } \\
\text { CF } \\
\text { enttrol }\end{array}$ & $\begin{array}{l}\text { prospect } \\
\text { CF } \\
\text { sontrol }\end{array}$ & $\begin{array}{l}\text { prospect } \\
\text { own } \\
\text { control }\end{array}$ & $\begin{array}{l}\text { prospect } \\
\text { CF } \\
\text { control }\end{array}$ & $\begin{array}{l}\text { prospect } \\
\text { CF } \\
\text { control }\end{array}$ & $\begin{array}{l}\text { prosped } \\
\text { ewt } \\
\text { control }\end{array}$ \\
\hline $\begin{array}{l}\text { Fetding } \\
\text { intervent }\end{array}$ & $\begin{array}{l}\text { etemetal } \\
\text { S0-100s } \\
\text { RDA }\end{array}$ & $\begin{array}{l}\text { elementad } \\
100 \mathrm{NRDA}\end{array}$ & $\begin{array}{l}\text { elemental } \\
100 \% \mathrm{RDA}\end{array}$ & $\begin{array}{c}\text { (veal) } \\
\text { elemetwal } \\
30 \% R D A \\
\text { (extn) }\end{array}$ & $\begin{array}{l}\text { oredigeat } \\
1000 \text { to } \\
2000 \text { Keal }\end{array}$ & $\begin{array}{l}\text { wielentatal } \\
120-140 \\
\text { NRDA }\end{array}$ & $\begin{array}{c}\text { pregestiail } \\
\text { vensus } \\
\text { standard } \\
120 \mathrm{Kea} / \mathrm{ks}\end{array}$ & $\begin{array}{l}\text { Dypercal } \\
\text { malyenerie } \\
120 \text { S6RDA }\end{array}$ \\
\hline Roule & oral & end & eral & eastrostomy & jejunontomy & enteral & oral & ond \\
\hline Effect & $\begin{array}{c}\text { SDSweil } \\
\text { SDStreit } \\
\text { clinical score ! }\end{array}$ & $\begin{array}{c}\text { SDSeeil } \\
\text { elinical score I } \\
\text { SOS thei (ns) }\end{array}$ & $\begin{array}{l}\text { SDSmeit } \\
\text { SDSteit } \\
\text { sosakf } \\
\text { boneage! }\end{array}$ & $\begin{array}{l}\text { weight (kg)! } \\
\text { beight (em) ! } \\
\text { weihei } \% \text { std. } \\
\text { ! } \\
\text { growth velocily } \\
1 \\
\text { BF } \% \text { ! } \\
\text { FFM ! } \\
\text { TBK ! } \\
\text { TBN ! } \\
\text { :FVC - } \\
\text { :FeVI - }\end{array}$ & $\begin{array}{l}\text { SDSweil } \\
\text { MAMC I } \\
\text { FVC = }\end{array}$ & $\begin{array}{l}\text { SDSweil } \\
\text { SOS hei! } \\
\text { protein syndhes ! } \\
\text { protein catabol ! } \\
\text { FoVI ! } \\
\text { FVC ! } \\
\text { FEF ! }\end{array}$ & $\begin{array}{l}\text { weight (ke) ! } \\
\text { beight (en) ! } \\
\text { growth velocity! }\end{array}$ & $\begin{array}{c}\text { SDSweil (os) } \\
\text { sDs bei (as) } \\
\text { FEF - } \\
\text { BMI । }\end{array}$ \\
\hline $\begin{array}{l}\text { Follow up } \\
\text { (duration) }\end{array}$ & NR & NR & $\begin{array}{c}\text { all } \\
\text { parameters I } \\
\text { excopt } \\
\text { bone exe } \\
\text { (1 yeu) }\end{array}$ & NR & NR & NR & NR & $N R$ \\
\hline
\end{tabular}

\begin{tabular}{|c|c|c|}
\hline $1:$ Improved & LBM : Lean Body Mass & BMI : Body Mass Index \\
\hline I: Decreased & FFM : Fu Free Mass & BF : Body fat \\
\hline$=$ : unchanged & TBN : Total body' nitrogen & $\mathrm{N}$-excrt : Nitrogen excretion \\
\hline RDA : Recommended Daily Allowance & TBK : Toul Body Kalium & (ns) non significant \\
\hline SDSwei : SDS weight & FVC : Forced Vital Capacity & Abs. coeff : absorption coefficient \\
\hline SDShei : SDS height & FeV1: Forced expiratory volume & $\$ \mathrm{FVC}$ and $\mathrm{FeVI}$ decrease in CF control \\
\hline SDSskit : SDS skinfolds & FEF : Forred Expiratory Flow & MAMC : Mid Arm Muscle Circumference \\
\hline
\end{tabular}


Table 3 Effect of short-term use of gastric acid inhibitors on steatorrhes and nutritional status in CF children.

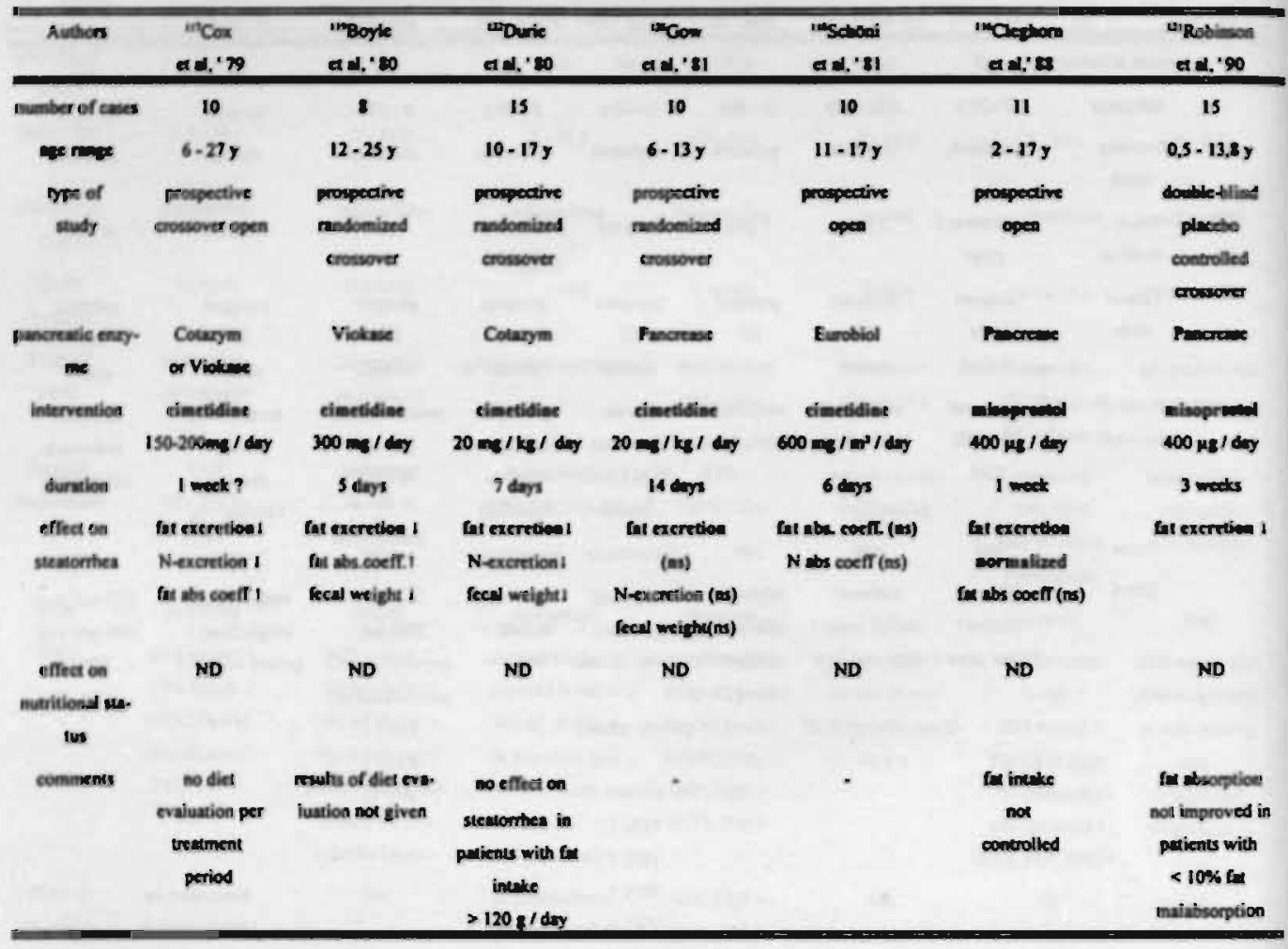

abs coeff : fat absorption coefficient

N-excretion : fecal Nitrogen excretion

(ns) : not significent 
Table 4 Effect of long-term use of gastric acid inhibitors on steatorrtea and nutritional status in CF children.

\begin{tabular}{|c|c|c|c|}
\hline Authors & "arSchoni et al, ' 84 & 'DeChalmers et al, ' 85 & ${ }^{13}$ Carroccio et al, "92 \\
\hline number of cases & 38 & 16 & 10 \\
\hline age range & $\operatorname{mean} 13 y$ & $5 \cdot 19 y$ & $7 \cdot 18 y$ \\
\hline type of study & $\begin{array}{c}\text { prospective randomized } \\
\text { doubleblind }\end{array}$ & double-blind crossover & double-blind crossover \\
\hline pacreatic enxyme & Pancrease & Cotarym & Pancrease \\
\hline \multirow[t]{2}{*}{ intervention } & cinetidine & cimetidine & Ianotidine \\
\hline & $600 \mathrm{mg} / \mathrm{m}^{2} / \mathrm{day}$ & $25 \mathrm{mg} / \mathrm{kg} / \mathrm{day}$ & Ing/kg/day \\
\hline duration & 4 months & 6 months & 6 months \\
\hline \multirow[t]{2}{*}{ effect on steatornhea } & $\begin{array}{l}\text { plasma lipid and } \\
\text { lipoprotein (as) }\end{array}$ & $\begin{array}{l}\text { fat excretion I } \\
\text { N-excretion (ns) }\end{array}$ & $\begin{array}{c}\text { fat absorption coeff. I } \\
\text { fecal weight I }\end{array}$ \\
\hline & & fecal weight (ns) & \\
\hline effect on & weight, height (ns) & SDSweight (ns) & weighe (kg) I \\
\hline \multirow[t]{3}{*}{ nutritional status } & $\begin{array}{l}\text { skinfolds (ns) } \\
\text { TLC, TGV (ns) }\end{array}$ & $\begin{array}{l}\text { SDSheight (ns) } \\
\text { skinfolds (ns) }\end{array}$ & $\begin{array}{c}\text { height (cm) I } \\
\text { clinical score (ns) }\end{array}$ \\
\hline & Raw, sGaw I & bone age (ns) & \\
\hline & & clinical score (ns) & \\
\hline comments & no diet evaluation & $\begin{array}{l}\text { results of diet } \\
\text { evaluation was not given }\end{array}$ & $\begin{array}{l}\text { results of diet } \\
\text { evaluation was not given }\end{array}$ \\
\hline
\end{tabular}

SDS : Standard Deviation Score for age and sex

TLC : Total Lung Capicity

TGV : Thoracic Gas volume

Raw : airway resistance

sGaw : specific conductance

(ns) : not significant 


\section{6 EVALUATION OF STEATORRHEA}

\section{6. 1 Fecal fat balance}

The 3 days fecal fat excretion while patients are on a standard fat diet is the most reliable method for quantitative determination of fecal fat loss. The fat absorption coefficient is calculated by the following formula:

(Fat ingested - fat excreted) / fat ingested X 100

Normal fat absorption coefficient at different ages have been reported as follows:

Age $>1$ year : $295 \%(126-128)$

Age $<1$ year : $>83 \%$ if formula fed and $>93 \%$ if breast fed (126)

Premature infants : 38 - $73 \%$ depending on the formula used (129)

Fecal fat can be determined by either Gravimetric or Titrimetric methods. For both methods, fecal fat is extracted with an organic solvent, the fat content is subsequently measured either by weighing (Gravimetric method) or by titration (Titrimetric method). The Gravimetric method determine all fecal lipid components, resulting in erroneously high results. On the contrary, the titrimetric method only measures fatty acids. Fecal lipids are first saponified and subsequently acidified to liberate fatty acids which are then extracted. Since its first. description in 1949 (130), the titrimetric procedure of van de Kamer has been used as a reference method for the evaluation of malabsorption. The fat balance method is reliable for the quantification of fecal fat loss with a coefficient of variation of $4,6 \%$ (131). However, the determination procedure is time consuming, expensive and necessitates sophisticated apparatus. Further, since the fat excretion is dependent on fat intake, patients have to keep up a strictly fat constant diet of more than 80 gram per day. Moreover, fecal collection have to be done very accurately. The balance method consequently is poorly reliable in outpatients, especially in children and infants. When fat balance is not possible, measuring fecal fat concentration in a fecal sample can be used for the screening of fat malabsorption. Results are then expressed as percent of wet fecal weight (fecal fat concentration). Using the ${ }^{14} \mathrm{C}$. triolein ${ }^{3} \mathrm{H}$-oleic acid test as a reference method, Pedersen et al. have studied the diagnostic 
value of fecal fat concentration as measured by the titrimetric method of van de Kamer in a 72 hours fecal collection without controlling for dietary fat (132). In this study, a similar diagnostic value was found for both fecal fat concentration (FFC) and fecal fat excretion (FFE): The sensitivity, specificity, positive predictive value and negative predictive value of FFC versus FFE were respectively $93,1 \%$ versus $90 \%$; $92,4 \%$ versus $89,4 \% ; 90 \%$ versus $93 \%$ and $89 \%$ versus $90 \%$ with a day to day coefficient of variation of $29 \%$ for FFC and $64 \%$ for FFE. In only $6 \%$ of the patients studied, the FFC when measured in a single day sample differed from the mean 3-day fecal fat concentration value whereas the FFE differed from the mean 3-day fecal fat excretion in $37 \%$ of the patients. FFC correlated weakly but significantly with FFE ( $r=0,55 ; \mathrm{p}<0,01)$ (133). FFC results in pancreatic steatorrhea being higher than in nonpancreatic steatornhea, Bolinn et al. have suggested that FFC could be used for the differentiation of both types of steatornhea (134). This has however not been confirmed by other investigators; who found much overlap in FFC results between pancreatic and nonpancreatic steatorrhea $(132,133,135,136)$. Results of these studies are shown in table 5 .

The utility of FFC as an screening method for fat malabsorption has been limited because of the high interday variation (29\%). This interday variation might be due to the varying fecal water content as reported by Weijers et al. (137). This suggests that if the effect of varying water content could be eliminated, the interday variation of FFC would be much lower. A new method for the semiquantitative determination of FFC, which eliminates the influence of varying fecal water content is the steatocrit.

\section{6. 2 Steatocrit}

This procedure is based on the fact that fecal fat is extracted by centrifugation of diluted stool in a hematocrit capillary at $13000 \mathrm{rpm}$ for 15 minutes (138). After centrifugation, three layers, are distinguished in the capillary; the upper fatty layer $(\mathrm{FL})$, the middle fluid layer and the bottom solid layer (SL). The fecal fat measured by steatocrit is expressed as fecal fat concentration and is calculated as FL / (FL + SL). Reported norrnal values are $<2 \%$ (139). The steatocrit method is very suitable for use in children and infants since it is simple, noninvasive and can be performed on small fecal samples ( 0,5 gram). Moreover, it is inexpensive and. the whole test takes only 20 minutes. Although several authors have reported this method to 
be satisfactory for the evaluation of steatornhea (138-142), some bave reported the steatocrit to be quite unreliable (143). Sugai reported a specificity of $97 \%$ for steatocrit but a sensitivity of $98 \%, 79 \%$ and $29 \%$ for samples with respectively high, moderate and low fat content (144). This low sensitivity observed for samples of low fat content may be due to difficulties with either fat extraction or with obtaining a clear separation between the fatty, aqueous and solid layer, resulting in erroneous results.

\section{6. 3 Sudan staining method}

The presence of fecal fat can be screened for by microscopic examination of stools. The fecal preparation is first acidified and stained with Sudan staining. After heating, fecal fatty acids and triglycerides are seen as fatty globules under the microscope. Dependent on the number and the size of the globules, the fatty globules are classified as normal , slightly increased or definitely increased (145). Weijers et al. studied the agreement between results of the Sudan staining method and chemically measured fecal fat (137). Satisfactory agreement between both methods was found in (60 - $70 \%$ cases) for fecal samples with very low or very high fat content $(<3 \%$ or $>9 \%$ ) but the agreement dropped to $40 \%$ for samples of moderate fat content $(3-9 \%)$.

\section{6. 4 C- Triolein absorption test}

After ingestion, ${ }^{14} \mathrm{C}$-Triolein is digested by pancreatic lipase in the duodenum liberating fatty acids, which on further oxidation yield ${ }^{14} \mathrm{CO}_{2}$ which can be detected in expired air. Although this method is simple, rapid to perform and gives a direct evaluation of pancreatic function, it is not appropriate for use in children because of the radioactivity. Recently, a new non radioactive substrate ${ }^{13} \mathrm{C}$-Triolein has been introduced but this is however expensive and a mass spectrometer is needed in order to use this test (131).

\section{6. 5 Near Infrared Reflectance Analysis}

This method is based on the analysis of the infrared spectrum radiation, reflected by the 
surface of the material under study. Specific peaks for the component to be investigated can be identified and their heights can be related to the concentration of the component studied by using computerised multilinear regression analysis. Besides measuring fecal fat, this apparatus can also be used for the determination of fecal nitrogen and water content. The analysis lasts less than 1 minute and can be performed on small samples ( 2 - 3 gram ). The variation coefficient is $2,1 \%$ and the correlation coefficient with the van de Kamer method is 0,92 (146). However this high correlation is possibly due to the fact that this method is calibrated by the titrimetric method described by van de Kamer. The calibration procedure is difficult and this sophisticated instrument is expensive (147). Further studies are necessary in order to better evaluate the usefulness of near infrared reflectance analysis in clinical practice. 
Table 5 Diagnostic value of fecal fat concentration (FFC) and fecal fat excretion (FFE) in studies of fat malassimilation.

\begin{tabular}{|c|c|c|c|c|c|}
\hline Authon & medenen' ' 4 & "Bollinn' 34 & 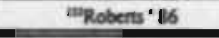 & 'Yembeke' 87 & "Hai et al ' 69 \\
\hline & & 50 & & 369 & 338 \\
\hline Aims of stady & $\begin{array}{l}\text { diapnostic value of FFC } \\
\text { venus FFE }\end{array}$ & diagnontic value of FFC & dingnostic value of FFC & fingnostic value of FFC & Eingnostic value of FFC \\
\hline Method used & 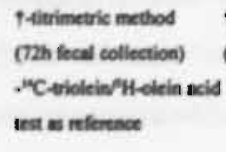 & $\begin{array}{l}\text { Thitrimetric method } \\
\text { (72h fecal collection) }\end{array}$ & $\begin{array}{l}\text { fritrimetric method } \\
\text { (72h fecal collection) }\end{array}$ & $\begin{array}{l}\text { Ttitrimetric method } \\
\text { (72h fecal collection) }\end{array}$ & $\begin{array}{l}\text { frierimemic method } \\
\text { (72h fecal colliection) }\end{array}$ \\
\hline Population (n) & 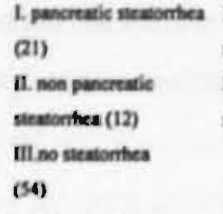 & $\begin{array}{l}\text { 1. pancrealis } \\
\text { steatombea (19) } \\
\text { 11. nonpancreatic } \\
\text { steanomies (B1) }\end{array}$ & 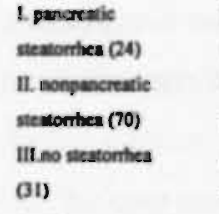 & $\begin{array}{l}\text { I. puncreatic } \\
\text { stemonthes (59) } \\
\text { II. nonpancreatic } \\
\text { stemonthea (53) } \\
\text { III no steatontere sick } \\
\text { ind normai controls (257) }\end{array}$ & $\begin{array}{l}\text { I. puncreatic } \\
\text { sewontea(88) } \\
\text { II. nonpancreatic } \\
\text { stemontea (525) }\end{array}$ \\
\hline Results & 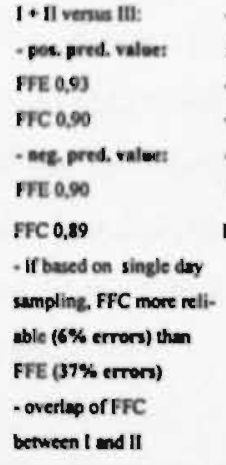 & 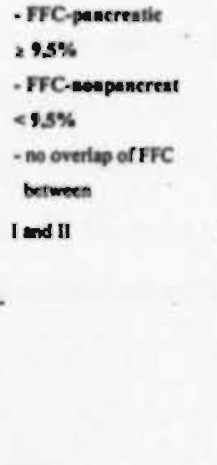 & 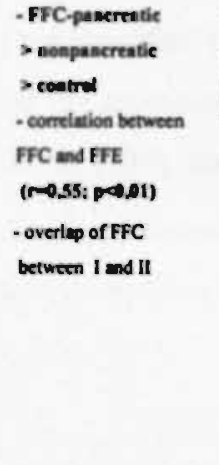 & $\begin{array}{l}\text {-FFC-paserentic }>\text { mo } \\
\text { pancreatic steatorritea } \\
\text { coatrol } \\
\text { - Overlap of FFC } \\
\text { between I and II }\end{array}$ & 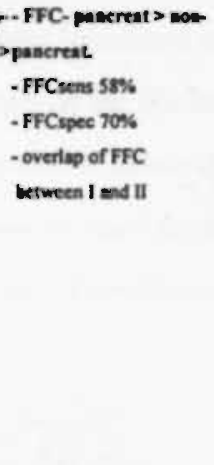 \\
\hline Comments. & 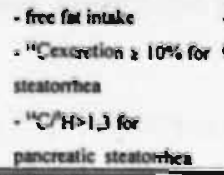 & $\begin{array}{l}\text { - fa diet } \\
90-100 y d d y\end{array}$ & 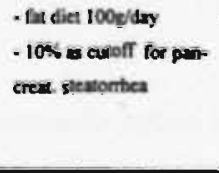 & - Exx diet $280 \mathrm{~g} / \mathrm{day}$ & 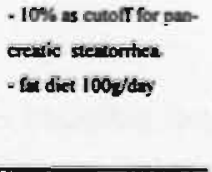 \\
\hline
\end{tabular}

FFC: Fecal fat coricentration

FFE: Fecal fat excretion

† Method as deseribed by van de Kamer (III)

pos. pred. value: positive predictive value

neg. pred. value: negative predictive value

sens: sensitivity

spec: specificity 


\section{AIMS OF THE STUDY}

With age, children with CF show progressing malnutrition mainly attributed to either persisting malabsorption notwithstanding the use of high oral doses of pancreatic enzymes or increased energy consumption secondary to respiratory disease. Prospective studies in young children have shown malnutrition to occur only in patients with pancreatic insufficiency (34). Efforts to either maintain or restore the nutritional condition have shown that, notwithstanding the use of pancreatic enzymes, high nutrient intakes only seems to be effective when administered "digested" either as total parenteral nutrition or as (semi)elemental feedings orally or by tube feeding. The apparent insufficient effect of pancreatic enzymes does not seem to be due to too low administered doses and recently very high doses have been used with the hope of correcting malabsorption. Suggestions have been made that these high doses might be responsible for the recently reported occurence of colitis in these patients (113-115).

Our hypothesis was that persisting malabsorption in these patients is likely to be linked to a low duodenal $\mathrm{pH}$ which interferes with several digestive and absorptive processes such as impeding transport of split fatty acids from the luminal lipid globules to the absorptive area through the mediation of bile salt micelles. If this was correct, antacid treatment should improve fat malabsorption in these patients. The fact that most studies hereover have been inconclusive might be due to the short and inefficient control of duodenal $\mathrm{pH}$ with the drugs used. A recent double-blind control study in adults patients has shown malabsorption to normalize in several patients treated with a proton pump inhibitor (omeprazol) (112). Until now, no studies with proton pump inhibitor have been reported in children.

\section{The aims of the present work were:}

1. Develop an easy, noninvasive, cheap and reliable test for the monitoring of fecal fat loss in pancreatic malabsorption.

2. Evaluate the nutritional condition, the body composition and the presence or persistence of fat malabsorption in our patients with exocrine pancreatic insufficiency accompanying cystic fibrosis. 
3. Evaluate whether or not the use of a proton pump inhibitor (lansoprazole) in our patients with persisting malabsorption improves both the fat malabsorption and the nutritional condition. 


\section{REFERENCES}

(1) G. Fanconi, E. Uehlinger, C. Knauer. Das Coeliaksyndrom bei Angeborener Zysticher Pankreas fibromatose und Bronchiektasien. Wein Med Wschr 1936; 86: 753-756.

(2) CF Genetic analysis consortium. Worldwide survey of the $\Delta \mathrm{F} 508$ mutation. Am J Hum Genet 1990; 47: 354-359.

(3) M. Welsh, A. Smith. Molecular mechanisms of CFTR chloride channel dysfunction in cystic fibrosis. Cell 1993; 73: 1251-1254.

(4) C. Marino, L. Matoveik, F. Gorelick, J. Cohn. Localization of the cystic fibrosis transmembrane conductance regulator in pancreas. J Clin Invest 1991; 88: 712-716.

(5) T. Boat, M. Welsh, A. Beaudet. (1989). In The Metabolic Basis of inherited Disease, C. Scriver, A. Beaudet, W. Sly, D. Valle, eds. (New York: McGraw-Hill,inc.), pp. 2649-2680.

(6) E. Kerem, J. Reisman, M. Corey, G. Canny, H. Levison. Prediction of mortality in patients with cystic fibrosis. N Engl J Med 1992; 326: 1187-91.

(7) C. Sommerhoff, J. Nadel, C. Basbaum et al. Neutrophil elastase and cathepsin G stimulate secretion from culture bovine airway gland serous cells. J Clin Invest 1990;85: 682-689.

(8) L. Sharples, T. Hathaway, C. Dennis, N. Caine, T. Higenbottam, J. Wallwork. Prognosis of patients with cystic fibrosis awaiting heart and lung transplantation. J Heart-Lung-Transplant 1993; 12: 669-74.

(9) J. Britton. Effects of social class, sex, and region of residence on age at death from cystic fibrosis. Br Med J 1989; 298: 483-487.

(10) M. Corey, F. McLaughlin, M. Williams, H. Levison. Comparison of survival, growth and pulmonary function in patients with cystic fibrosis in Boston and Toronto. $\mathrm{J}$ Clin Epidemiol 1988; 41: 583-591.

(11) M. Aitken, S. Fiel. Cystic fibrosis. Dis Mon 1993; 39: 1-52.

(12) P. Brihaye, P. Clement, I. Dab, B. Desprechin. Pathological changes of the lateral nasal wall in patients with cystic fibrosis. Int J Pediatr Otorhinolaryngol 1994; 28: 141-7.

(13) I. Mackay, B. Djazaeri. Chronic sinusitis in cystic fibrosis. J Roy Soc Med 1994; 87 (Suppl 21): 17-19.

(14) B. Hadom, P. Johansen, C. Anderson. Pancreozymin secretin test of exocrine pancreatic function in cystic fibrosis and the significance of the result for the pathogenesis of the disease. 
Can Med Assoc J 1968; 98: 377-385.

(15) B. Hadorn, G. Zoppi, D. Shmerling, A. Prader, I. McIntyre, C. Anderson. Quantitative assessment of exocrine pancreatic function in infants and children. J Pediatr 1968; 73: 39-50.

(16) H. Schachman, E. Lebenthal, K. Khat. Recurrent, acute pancreatitis in patients with normal pancreatic enzymes. Pediatrics 1975 ; 55: 86-95.

(17) K. Gaskin, P. Durie, M. Corey, P. Wei, G. Forstner. Evidence for a primary defect of pancreatic $\mathrm{HCO}_{3}$-secretion in cystic fibrosis. Pediatr Res 1982; 16: 554-557.

(18) A. Atlas, S. Orenstein, D. Orenstein. Pancreatitis in young children with cystic fibrosis. J Pediatr 1992; 120: 756-9.

(19) F. Ahmed, J. Ellis, J. Murphy, S. Wooton, A. Jackson. Excessive faecal loss of vitamin A (retinol) in cystic fibrosis. Arch Dis Child 1990; 65: 589-593.

(20) R. Sokol, M. Reardon, F. Accurso et al. Fat-soluble-vitamin status during the first year of life in infants with cystic fibrosis identified by screening of newborns. Am J Clin Nutr 1989; 50: $1064-71$.

(21) V. Hubbard, P. Farrell, P. di Sant 'Agnese. 25-hydroxylcholecalciferol levels in patients with cystic fibrosis. J Pediatr 1979; 94: 84-86.

(22.) E. Mischler, PJ Chesney, PW Chesney, R. Mazess. Demineralization in cystic fibrosis detected by direct protein absorptiometry. Am J Dis Child 1979; 133: 632-635.

(23) N. Solomons, J. Wagonfeld, C. Rieger et al. Some biochemical indices of nutrition in treated cystic fibrosis patients. Am J Clin Nutr 1981; 34: 462-474.

(24) R. Allen, B. Seetharam, E. Podell, D. Alpers. Effect of proteolytic enzymes on the binding of cobalamin to $\mathrm{R}$ protein and intrinsic factor. J Clin Invest $1978 ; 61$ : 47-54.

(25) M. Murphy, W. Sheldon, A. Brunetto et al. Active and passive sugar absorption in pancreatic insufficiency. J Pediatr Gastroenterol Nutr 1989; 8: 189-194.

(26) L. Frase, A. Strickland, G. Kachel, G. Krejs. Enhanced glucose absorption in the jejunum of patients with cystic fibrosis. Gastroenterology $1985 ; 88: 478-484$.

(27) M. Lohr, P. Goertchen, H. Nizze et al. Cystic fibrosis associated islet changes may provide a basis for diabetes. An immunocytochemical and morphometrical study. Virchows Arch [A] 1989; 414: 179-185.

(28) L. Krueger, A. Lerner, S. Katz, R. Mack, D. Holsclaw, E. Lebenthal. Cystic fibrosis and diabetes mellitus: interactive or idiopathic. J Pediatr Gastroenterol Nutr 1991; 13: 209-219. 
(29) E. Wilmshurst, J. Soeldner, D. Holsclaw. Endogeneous and exogeneous insulin responses in patients with cystic fibrosis. Pediatrics 1975; 55: 75-82.

(30) O. Andersen, S. Garner, C. Heilmann, K. Petersen, W. Petersen, C. Koch. Glucose tolerance and insulin receptor binding to monocytes and erythrocytes in patients with cystic fibrosis. Acta Paediatr Scand 1988; 77: 67-71.

(31) A. Moran, P. Diem, D. Klein, M. Levitt, R. Robertson. pancreatic endocrine function in cystic fibrosis. J Pediatr 1991; 118: 715-723.

(32) H. Berry, F. Kellogg, M. Hunt, R. Ingberg, L. Ricter, C. Gutjahr. Dietary supplement and nutrition in children with cystic fibrosis. Am J Dis Child 1975; 129; 165-171.

(33) J. Dodge, J. Yassa. Food intake and supplementary feeding programs. In: J. Sturgess, ed. perspectives in cystic fibrosis. Toronto: Canadian Cystic Fibrosis Foundation; 1980: 125-136. (34) M. Bronstein, R. Sokol, S. Abman et al. Pancreatic insufficiency, growth, and nutrition in infants identified by newborn screening as having cystic fibrosis. J Pediatr 1992; 120: 533-40. (35) J. Tomezsco, V. Stallings, D. Kawchak, J. Goin, G. Diamond, T. Scanlin. Energy expenditure and genotype of children with cystic fibrosis. Pediatr Res 1994; 35: 451-460.

(36) M. Bronstein, P. Davies, K. Hambidge, F. Accurso. Normal energy expenditure in the infant with presymptomatic cystic fibrosis. J Pediatr 1995; 126: 28-33.

(37) K. Cox, J. Isenberg, M. Ament. Gastric acid hypersecretion in cystic fibrosis. J Pediatr Gastroenterol Nutr 1982; 1: 559-565.

(38) C. Roy, A. Weber, C. Morin et al. Abnormal biliary lipid composition in cystic fibrosis. N Engl J Med 1977; 297: 1301-1305.

(39) A. Malfroot, I. Dab. New insights on gastro-oesophageal reflux in cystic fibrosis by longitudinal follow up. Arch Dis Child 1991; 66: 1339-1345.

(40) S. Cucchiara, F. Santamaria, M. Andreotti et al. Mechanisms of gastro-oesophageal reflux in cystic fibrosis. Arch Dis Child 1991; 66: 617-622.

(41)P. Gustafsson, S. Fransson, N. Kjellman, L. Tibbling. Gastro-oesophageal reflux and severity of pulmonary disease in cystic fibrosis. Scand J Gastroenterol 1991; 26: 449-456.

(42) S. Fiedorek, R. Shulman, W. Klish: Endoscopic detection of peptic ulcer disease in cystic fibrosis. Clin Pediatr (Phila) 1986; 25: 243-246.

(43) P. Robinson, A. Smith, P. Sly: Duodenal $\mathrm{pH}$ in cystic fibrosis and its relationship to fat malabsorption. Dig Dis Sci 1990: 35: 1299-1304. 
(44) J. McPartin, J. Dickson, V. Swain. Meconium ileus, immediate and longterm survival. Arch Dis Child 1972; 47: 207-210.

(45) H. Andersen, K. Hjelt, E. Waever, K. Overgaad. The age related incidence of meconium ileus equivalent in a cystic fibrosis population: the impact of high energy intake. J Pediatr Gastroenterol Nutr 1990; 11:356-360.

(46) L. Kulczyki, H. Schwachman. Studies in cystic fibrosis of the pancreas: occurrence of rectal prolapse. N Engl J Med 1958;259: 409-412.

(47) D. Holsclaw, C. Rocmans, H. Schwachman. Intussusception in patients with cystic fibrosis. Pediatrics 1971; 48:51-58.

(48) H. Rovsing, K. Sloth. Microgallbladder and biliary calculi in mucoviscidosis. Acta Radiol [Onco] 1973; 14: 588-592.

(49) F. Santamaria, P. Vajro, V. Oggero et al. Volume and emptying of the gallbladder in patients with cystic fibrosis. J Pediatr Gastroenterol Nutr 1990; 10: 303-306.

(50) L. Taussig, C. Lobeck, P. Ackerman, J. Kattwinkel: Fertility in males with cystic fibrosis. N Engl J Med 1972; 287: 586-589.

(51) E. Kaplan, H. Shwachman, A. Perlmutter et al.: Reproductive failures in males with cystic fibrosis. N Engl J Med 1968; 279: 65-69.

(52) S. Fitzsimmons: Cystic Fibrosis Foundation Patient Registry 1990 Annual Report. Bethesda, Cystic Fibrosis Foundation, 1991.

(53) P. Tam, P. Verdugo: Control of mucus hydration as a Donnan equilibrium process. Nature 1981: 292: 340-342.

(54) P. Di Sant 'Agnese, R. Darling. G. Perera, E. Shea. Abnormal electrolyte composition of sweat in cystic fibrosis of the pancreas. Clinical significance and relationship to the disease. Pediatries 1953; 12: 549-563.

(55) L. Gibson, R. Cooke. A test for concentration of electrolytes in sweat in cystic fibrosis of the pancreas utilizing in pilocarpine by iontophoresis. Pediatrics 1959; 23: 545-549.

(56) H. Veeze, A. Van den Ouweland, D. Halley et al. The diagnosis of cystic fibrosis: intestinal current measurements, a highly accurate mathod in case of a borderline phenotype. Submitted.

(57) M. Rosenfeld, W. Siegfried, K. Yoshimura et al. Adenovirus-mediated transfer of a recombinant alpha 1-antitrypsin gene to the lung epithelium in vivo. Science.1991; 252:431-4 
(58) B. Pitt, M. Schwarz, J. Pilewski et al. Retrovirus-mediated gene transfer in lungs of living fetal sheep. Gene Ther 1995; 2 : 344-50.

(59) M. Rosenfeld, K. Yoshimura, B. Trapnell et al. In vivo transfer of the human cystic fibrosis transmembrane conductance regulator gene to the airway epithelium. Cell. 1992; 68 : 143-55.

(60) R. Kraemer, A. Rüdeberg, B. Hadorn, E. Rossi. Relative underweight in cystic fibrosis and its prognostic value. Acta Paediatr Scand 1978; 67: 33-37.

(61) S. Rao, D. Wilson, R. Brooks et al. Acute effects of nebulization of n-acetylcysteine on pulmonary mechanics and gas exchange. Am Rev Respir Dis. 1970; 102: 17-22.

(62) W. Waring. Current management of cystic fibrosis. Adv Pediatr. 1976; 23: 401-38.

(63) M. Gotz, R. Kraerner, K. Kerrebijn et al. Oral acatylsysteine in cystic fibrosis. A cooperative study. Eur J Respir Dis. 1980;61: (Suppl 111): 122-6.

(64) J. Reisman, B. Rivington-Law, M. Corey et al. Role of conventional physiotherapy in cystic fibrosis. J Pediatr 1988; 113: 632-6.

(65) H. Steen, A. Redmond, D. O'Neil et al. Evaluation of the PEP mask in cystic fibrosis. Acta Paediatr Scand. 1991; 80: 51-6.

(66) C. Braggion, L. Cappelletti, M. Cornacchia, L. Zanolla, G. Mastella. Short-term effects of three chest physiotherapy regimens in patients hospitalized for pulmonary exacerbations of cystic fibrosis: A cross-over randomized study. Pediatr Pulmonol 1995; 19: 16-22.

(67) J. Pryor, B. Webber, M. Hobson et al. Evaluation of the forced expiratory technique as an adjunct to postural drainage in the treatment of cystic fibrosis. J Pediatr. 1983; 103: 538-42.

(68) P. Sutton, H. Gemmell, N. Innes et al. Use of nebulized saline and nebulized terbutaline as an adjunct to chest physiotherapy. Thorax. 1988; 43: 57-60.

(69) E. Pattishall. Longitudinal response of pulmonary function to bronchodilators in cystic fibrosis. Pediatr Pulmonol. 1990; 9: 80-5.

(70) P. Konig, D. Gayer, J. Shaffer et al. Bronchodilator responsiveness and spontaneous diumal variation of PEFR in patients with cystic fibrosis. Poster presented at the North American Cystic Fibrosis Conference. Washington, DC: 1992 Oct. Abstract.

(71) M. Konstan, P. Byrard, C. Hoppel, P. Davis: Effect of high dose ibuprofen in patients with cystic fibrosis. N Engl J Med 1995; 332: 848.

(72) H. Auerbach, M. Williams, J. Kirkpatrick et al. Alternate-day prednisone reduces morbi- 
dity and improves pulmonary function in cystic fibrosis. Lancet. 1985; 2: 686-8.

(73) B. Rosenstein, H. Eigen. Risk of alternate-day prednisone in patients with cystic fibrosis. Pediatrics. 1991; 87: 245-6.

(74) C. Pantin, R. Stead, M. Hodson et al. Prednisolone in the treatment of airflow obstruction in adults with cystic fibrosis. Thorax. 1986; 41: 34-38.

(75) M. Zach. Pathogenesis and managernent of lung disease in cystic fibrosis. J R Soc Med. 1991; 84 (Suppl 18): 10-7.

(76) McNeil Pharmaceutical. Pseudomonas vaccine tests start. Cystic Fibrosis Currents. 1991; 6(4).

(77) A. Khaghani, B. Madden, M. Hodson et al. Heart-lung transplantation for cystic fibrosis. Paper presented at the North American Cystic Fibrosis Conference. Dallas, TX: 1991 Oct 4.

(78) E. App, M. King, R. Helfesrieder et al. Acute and longterm amiloride inhalation in cystic fibrosis lung disease. Am Rev Respir Dis. 1990; 141: 605-12.

(79) M. Knowles, N. Church, W. Waltner et al. A pilot study of aerosolized amiloride for the treatment of lung disease in cystic fibrosis. N Engl J Med. 1990; 322: 1189-94.

(80) M. Hodson. Clinical studies of rhDNase in moderately and severely affected patients with cystic fibrosis - An Overview. Respiration 1995; 62 (suppl 1); 29-32.

(81) M. Aitken, W. Burke, G. McDonald et al. Recombinant human Dnase inhalation in normal subjects and patients with cystic fibrosis. A phase 1 study. JAMA. 1992; 267: 194751.

(82) R. Hubbard, N. McElvaney, P. Steven et al. A preliminary study of aerosolized recombinant human deoxyribonuclease $I$ in the treatment of cystic fibrosis. N Engl J Med. 1992; $326: 812-5$.

(83) N. McElvaney, R. Hubbard, P. Birrer et al. Aerosol alpha-1-antitrypsin treatment for cystic fibrosis. Lancet. 1991; 337: 392-4.

(84) R. Boucher, E. Cheng, A. Paradiso et al. Chloride secretory response of cystic fibrosis airway epithelia: presentation of calcium but not protein kinase $\mathrm{C}$ and $\mathrm{A}$-dependent mechanism. J Clin Invest. 1989;84: 1424-31.

(85) H. Chase, M. Long, M. Lavin. Cystic fibrosis and malnutrition. J Pediatr 1979; 95: 33747.

(86) C. Roy, A. Silverman, F. Cozzetto. Pediatric Clinical Gastroenterology. 2nd ed. St. 
Louis: CV Mosby, 1975: 615-35.

(87) J. Dodge, J. Yassa. Food intake and supplementary feeding programs. In: Sturgess JM, ed. Perspectives in cystic fibrosis. Procedings of the 8th International Cystic Fibrosis Congress. Toronto: Canadian Cystic Fibrosis Foundation, 1980: 125-36.

(88) H. Parsons, P. Beaudry, A. Dumas, P. Pencharz. Energy needs and growth in children with cystic fibrosis. J Pediatr Gastroenterol Nutr 1983; 2: 44-9.

(89) H. Schwachman, R. Dooley, F. Guilmette, P. Patterson, C. Weil, H. Leubner. Cystic fibrosis of the pancreas with varying degrees of pancreatic insufficiency. Am J Dis Child 1956; 92: 347-68.

(90) D. Crozier. Cystic fibrosis a not so fatal disease. Pediatr Clin North Am 1974; 21: 935 950.

(91) D. Gurwitz, M. Corey, P. Francis, D. Crozier, H. Levison. Perspectives in cystic fibrosis. Pediatr Clin North Am. 1979; 26: 603-615.

(92) E. Luder, M. Kattan,J. Thornton, K. Koehler, R. Bonforte. Efficacy of a nonrestricted fat diet in patients with cystic fibrosis. AJDC. 1989; 143: 458-464.

(93) A. Rettammel, M. Marcus, P. Farrell, S. Sondel, R. Koscik, E. Mischler. Oral supplementation with a high-fat, high-energy product improves nutritional status and alters serum lipids in patients with cystic fibrosis. J Am Diet Assoc. 1995; 95: 454-459.

(94) K. Gaskin, D. Waters, L. Baur, V. Soutter, M. Gruca. Nutritional status, growth and development in children undergoing intensive treatment for cystic fibrosis. Acta Paediatr Scand [Suppl]. 1990; 366: 106-110.

(95) E. O' Loughlin, D. Forbes, H. Parsons, B. Scott, D. Cooper, G. Gall. Nutritional rehabilitation of malnourished patients with cystic fibrosis. Am J Clin Nutr. 1986: 43: 732-737.

(96) R. Shepherd, T. Holt, B. Thomas et al. Nutritional rehabilitation in cystic fibrosis: Controlled studies of effects on nutritional growth retardation, body protein turnover, and course of pulmonary desease. J Pediatr. 1986; 109: 788-94.

(97) R. Shepherd, B. Thomas, D. Bennett, W. Cooksley, L. Ward. Changes in body composition and muscle protein degradation during nutritional supplementation in nutritionally growth-retarded children with cystic fibrosis. J Pediatr Gastroenterol Nutr. 1983; 2: 439-446.

(98) L. Levy, P. Durie, P. Pencharz, M. Corey. Effects of long-term nutritional rehabilitation on body composition and clinical status in malnourished children and adolescents with cystic 
fibrosis. J Pediatr 1985; 107: 225-230.

(99) J. Bertrand, C. Morin, R. Lasalle, J. Patrick, A. Coates. Short-term clinical, nutritional, and functional effects of continuous elemental enteral alimentation in children with cystic fibrosis. J Pediatr. 1984; 104: 41-46.

(100) R. Shepherd, W. Cooksley, and W. Domville. Improved growth and clinical, nutritional, and respiratory changes in response to nutritional therapy in cystic fibrosis. J Pediatr. 1980; 97: 351-357.

(101) J. Yassa, R. Prosser, J. Dodge. Effects of an artificial diet on growth of patients with cystic fibrosis. Arch Dis Child. 1978; 53: 777-783.

(102) J. Allan, A. Mason, A. Moss. Nutritional supplementation in treatment of cystic fibrosis of the pancreas. Am J Dis Child. 1973; 126: 22-26.

(103) A. Manseli, J. Andersen, C. Muttart et al. Short-term pulmonary effects of total parenteral nutrition in children with cystic fibrosis. J Pediatr 1984; 104: 700-705.

(104) M. Canciani, G. Mastella. Absorption of a new semielemental diet in infants with cystic fibrosis. J Pediatr Gastroenterol Nut. 1985; 4: 735-740.

(105) M. Boland, D. Stoski, N. Macdonald, P. Soucy, J. Patrick. Chronic jejunostomy feeding with a non-elemental formula in undernourished patients with cystic fibrosis. Lancet 1986; 1: 232-234.

(106) P. Farrell, E. Mischler, S. Sondel, M. Palta. Predigested formula for infants with cystic fibrosis. Research. 1987; 87: 1353-1356.

(107) P. Regan, J. Malagelada, E. Dimagno, and V. Go. Reduced intraluminal bile acid concentrations and fat maldigestion in pancreatic insufficiency: Correction by treatment. Gastroenterology. 1979; 77: 285-289.

(108) P. Zentler-Munro, W. Fitzpatrick, J. Batten, and T. Northfield. Effect of intrajejunal acidity on aqueous phase bile acid and lipid concentrations in pancreatic steatorrhoea due to cystic fibrosis. Gut. 1984; 25: 500-507.

(109) P. Zentler-Munro, D. Fine, J. Batten, and T. Northfield. Effect of cimetidine on enzyme inactivation, bile acid precipitation, and lipid solubilisation in pancreatic steatorrhoea due to cystic fibrosis. Gut. 1985; 26: 892-901.

(110) A. Weber, C. Roy. Intraduodenal events in cystic fibrosis. J Pediatr Gastroenterol Nutr. 1984; 3 (Suppl. 1): S113-S119. 
(111) S. Dutta, V. Hubbard, M. Appler. Critical examination of therapeutic efficacy of a pHsensitive enteric-coated pancreatic enzyme preparation in treatment of exocrine pancreatic insufficiency secondary to cystic fibrosis. Dig Dis Sci 1988; 33: 1237-44.

(112) H. Heijerman, C. Lamers, W. Bakker. Omeprazole enhances the efficacy of pancreatin (pancrease) in cystic fibrosis. Ann Intern Med. 1991; 114: 200-201.

(113) S. Schwarzenberg, C. Wielinski, I. Shamieh et al. Cystic fibrosis-associated colitis and fibrosing colonopathy. J Pediatr 1995; 127: 565-70.

(114) R. Smyth, D. van Velzen, A. Smyth, D. Lloyd, D. Heaf. Strictures of ascending colon in cystic fibrosis and high strength pancreatic enzymes. The Lancet. 1994; 343: 85-86.

(115) M. Pettei, J. Leonidas, J. Levine, J. Gorvoy. Pancolonic disease in cystic fibrosis and high-dose pancreatic enzyme therapy. J Pediatr 1994; 125: 587-9.

(116) G. Cleghom, R. Shepherd, T. Holt. The use of a synthetic prostaglandin $E_{1}$ analogue (Misoprostol) as an adjunct to pancreatic enzyme replacement in cystic fibrosis. Scand J Gastroenterol. 1988; 23(Suppl 143): 142-147.

(117) K. Cox, J. Isenberg, A. Osher, R. Dooley. The effect of cimetidine on maldigestion in cystic fibrosis. 1979; 94: 488-492.

(118) M. Schöni, R. Kraemer, E. Rossi. Cimetidine and fat malabsorption in children with cystic fibrosis. Helv Paediat Acta. 1981; 36: 359-369.

(119) B. Boyle, W. Long, W. Balistreri, S. Widzer, and N. Huang. Effect of cimetidine and pancreatic enzymes on serum and fecal bile acids and fat absorption in cystic fibrosis. Gastroenterology. 1980; 78: 950-953.

(120) R. Gow, R. Bradbear, P. Francis, R. Shepherd. Comparative study of varying regimens to improve steatornhoea and creatornhoea in cystic fibrosis: effectiveness of an enteric-coated preparation with and without antacids and cimetidine. Lancet 1981; 14: 1071-1074.

(121) P. Robinson and P. Sly. Placebo-controlled trial of misoprostol in cystic fibrosis. J Pediatr Gastroenterol Nutr. 1990; 11: 37-40.

(122) P. Durie, L. Bell, W. Linton, M. Corey, G. Forstner. Effect of cimetidine and sodium bicarbonate on pancreatic replacement therapy in cystic fibrosis. Gut 1980; 21: 778-786.

(123) A. Carroccio, F. Pardo, G. Montalto et al. Use of famotidine in severe exocrine pancreatic insufficiency with persistent maldigestion on enzymatic replacement therapy: A long-term study in cystic fibrosis. Dig Dis Sci 1992; 37: 1441-1446. 
(124) D. Chalmers, R. Brown, M. Miller et al. The influence of longterm cimetidine as an adjuvant to pancreatic enzyme therapy in cystic fibrosis. Acta Paediatr Scand. 1985; 74: 114117.

(125) M. Schöni, R. Kraemer, A. Ruedeberg et al. Long-term cimetidine in children with cystic fibrosis: a randomized double blind study.

(126) J. van de Kamer. Standard methods of clinical chemistry, edited by Seligson D. New York, Academic Press, 1958, Vol 2, p 34.

(127) E. Wollaeger, M. Comfort, A. Osterberg. Total solids, fat and nitrogen in feces: Study of normal persons taking test diets containing moderate amount of fat; comparison with results obtained with normal persons taking test diet containing large amount of fat. Gastroenterology 1947; 9: 272-283.

(128) D. Woodman, W. Yeoman. A simplified method of investigating steatorrhoea. J Clin Pathol 1955; 8:79-80.

(129) M. Davidson, C. Bauer. Patterns of fat excretion in feces of premature infants fed various preparations of milk. Pediatrics 1960; 25: 375-84.

(130) J. van de Kamer, H. Huinink, A. Weyers. Rapid method for the determination of fat in feces. J Biol Chem 1949; 177: 349-55.

(131) B. Lembcke, B. Braden, J. Stein. Diagnostik der steatorrhoe. Z Gastroenterol 1994; 32: 256-261.

(132) N. Thorsgaard Pedersen, H. Halgreen, H. Worning. Estimation of the 3-day faecal fat excretion and fat concentration as a differential test of malabsorption and maldigestion. J Gastroenterol 1987; 22: 91-96.

(133) I. Roberts, C. Poturich, A. Wald. Utility of fecal fat concentrations as screening test in pancreatic insufficiency. Dig Dis Sci 1986; 31: 1021-4.

(134) G. Bo-Linn, J. Fordtran. Fecal fat concentretion on patients with steatorrhea. Gastroenterology 1984; 87: 319-322.

(135) J. Bai, A. Andrüsh, G. Matelo et al. Fecal fat concentration in the differential diagnosis of steatorrhea. Am J Gastroenterol 1989; 84: 27-30.

(136) B. Lembcke, K. Grimm, P. Lankisch. Raised fecal fat concentration is not a valid indicator of pancreatic steatorrhea. Am J Gastroenterol 1987; 82: 526-531.

(137) H. Weijers. Fat absorption in normal and abnormal infants and children with special 
reference to coeliac disease (proefscrift) 1950: 19-23.

(138) P. Phuapradit, A. Narang, P. Mendonca, D. Harris, J. Baum. The steatocrit: a simple method for estimating stool fat content in newborn infants. Arch Dis Child 1981; 56: 725-727. (139) G. Iacono, A. Carroccio, G. Montalto et al. Steatocrit: normal range and physiological variations in preterm and low-birth-weight full-term newborns. Acta Paediatr 1992; 81: 933-4. (140) A. Guarino, L. Tarallo, L. Greco, L. Cesarano, S. Guandalini, A. Rubino. Reference values of the steatocrit and its modifications in diarrheal diseases. J Pediatr Gastroenterol Nutr 1992; 14: 268-274.

(141) C. Colombo, R. Maiavacca, M. Ronchi, E. Consalvo, M. Amoretti, A. Giunta. The steatocrit: a simple method for monitoring fat malabsorption in patients with cystic fibrosis. J Pediatr Gastroenterol Nutr 1987; 6: 926-930.

(142) G. Iacono, A. Carroccio, F. Cavataio et à. Steatocrit test: normal range and physiological variations in infants. J Pediatr Gastroenterol Nutr 1990; 11: 53-57.

(143) M. Walters, J. Kelleher, J. Gilbert, J. Littlewood. Clinical monitoring of steatorrhoea in cystic fibrosis. Arch Dis Child 1990; 65: 99-102.

(144) E. Sugai, G. Srur, H. Vazquez et al. Steatocrit: a reliable semiquantitative method for detection of steatorrhea. J Clin Gastroenterol 1994; 19: 206-9.

(145) G. Drummey, J. Benson, C. Jones. Microscopical examination of the stool for steatornhea. N Engl J Med 1961; 264: 85-7.

(146) L. Benini, S. Caliari, G. Guodi. Near infrared spectrometry for faecal fat measurement: comparison with conventional gravimetric and titrimetric methods. Gut 1989; 30: 1344-1347. (147) O. Bekers, C. Postma, A. Lombarts. Determination of feacal fat by Near-Infrared Spectroscopy. Eur J Chem Cli Biochem 1995; 33: 83-86. 


\section{CHAPTER 2}

METHODS 
The following methods were used in our studies:

\section{Methods used for fecal fat determination:}

\section{1 Steatocrit and Acid Steatocrit}

About $0.5 \mathrm{~g}$ solid stool was weighed and diluted with a volume of deionized water, equal to two times the weight of stool. The stool and water were premixed using a Vortex mixer. Subsequently, the mixture was homogenized using a $5 \mathrm{ml}$ Potter Elvehjem tissue homogenizer. The fecal homogenate was aspirated into a $75 \mu$ l plain haematocrit capillary. This capillary was sealed with wax at one end and centrifuged horizontally (13000 rpm, $15 \mathrm{~min}$ ) in a standard haematocrit centrifuge. After centrifugation, the upper fatty layers (FL) and the bottom solid layers (SL) were measured with a graduated magnifying lens. The steatocrit was calculated as (FL / $(\mathrm{FL}+\mathrm{SL})) \times 100 \%$. Since the fat extraction was not optimal in the steatocrit procedure, we have try to increase this step by adding the perchloric acid $(5 N)$ to the fecal homogenate in a volume equal to $1 / 5$ of the homogenate after homogenization. This acid homogenate was then mixed for 30 seconds using a Vortex mixer and the following steps were the same as the classical steatocrit. This "Acid Steatocrit" is used in our further study.

\section{2 Titrimetric method}

The 72 hours fecal collection was first homogenized and about 5 gram of feces was weighed. The feces was saponified with concentrated potassium hydroxide $(33 \% \mathrm{KOH})$ in ethanol, giving a solution which contains the soaps derived from neutral fats, fatty acids and also soaps originally present in the stool. By adding $\mathrm{HCl}(2 \mathrm{~N})$, fatty acids were obtained. After adding $125 \mathrm{ml}$ toluene, the mixture was shaken vigorously for $2-3$ minutes. $25 \mathrm{ml}$ of the toluene layer containing the fatty acids was then transferred to an erlenmeyer for titration with $0,1 \mathrm{~N}$ tetrabutylammoniumhydroxide solution in propanol/methanol and thymol blue as indicator. The titration was done three times and the mean of this was used for the calculation of fecal fat excretion, which was calculated as followed: 
$125 \mathrm{ml}+4.5 \mathrm{ml}\left(\mathrm{X}-\mathrm{X}_{0}\right) \times 0,1 \mathrm{~N} \times 1 / 3 \times$ total feces weight $(\mathrm{g}) \times 891 \mathrm{~g}=$ Total fecal fat $(\mathrm{g} / 72 \mathrm{~h})$ $25 \mathrm{ml}$ sample weight $(5 g)$

with $125 \mathrm{ml}$ representing the toluene volume used for extraction of the fatty acids, $25 \mathrm{ml}$ representing the titration volume, $4,5 \mathrm{ml}$ is the correction for the volume interaction, $\mathrm{X}$ representing the number of meq of fatty acids titrated, $\mathrm{X}_{0}$ the correction for the acids present in toluene, $0,1 \mathrm{~N}$ the concentration of tetrabutylammoniumhydroxide solution, $1 / 3$ is the conversion factor from fatty acid to fat molecule ( 3 molecule fatty acids derived from 1 molecule fat) and 891 is the molecular weight of stearic acid (C-18-fat).

\section{3 Sudan staining method}

We used the split fat stain, which identifies both triglyceride and fatty acid (1). Several drops of $100 \%$ acetic acid and several drops of Sudan III solution were added. The preparation was subsequently mixed with the coverslip, which was then applied. The slide was gently heated on a lighter until bubbling. All preparations were examined while still warm under high magnification (magnification of 400 ). For quantification of the amount of fat detected microscopically, we used the criteria established by Drummey et al.(2). They are as follows: normal (+): up to 100 fat globules per high power field, varying in a diameter between 1 and $4 \mu \mathrm{m}$, as noted on the micrometer scale always using a magnification of 400 ; Increased $(2+)$ : up to 100 fat globules per high power field, the diameter of fat globules varying between 1 and $8 \mu \mathrm{m}$; Markedly increased $(3+)$ : more than 100 fat globules per high power field, varying in size from 6 to $75 \mu \mathrm{m}$ in diameter.

\section{Methods used for assessment of nutritional condition:}

\subsection{Anthropometry}

Weight, height and 4 skinfolds (biceps, triceps, subscapular and suprailiaca) were expressed as standard deviation scores of the normal population for age and sex by using the growth charts from Gerver and de Bruin (3). 
It has been found that subcutaneous fat as measured by skinfolds is related to the body density (4). This latter is again related to the body fatmass. From these theoretical principes, Gerver and de Bruin have constructed a chart, expressing the relationship between the 4 skinfolds (biceps, triceps, subscapular and suprailiaca) and the percent fat free mass. In our study, the fatmass and fat free mass determined with the anthropometric method were derived from these charts.

\subsection{Dual energy X-ray absorptiometry (DXA)}

This method first developed by Mazess et al., measures sirnultaneously bone mineral, fat and nonbone lean tissue. For a DXA scan, subjects lied supine on a padded table while the scintillation counter moved in a raster pattem across the body from head to foot. The Lunar DPX uses a constant $\mathrm{x}$-ray source and a filter that converts the polychromatic $\mathrm{x}$-ray beam into one that has two main energy peaks $(40 \mathrm{kV}$ and $70 \mathrm{kV})$. The ratio of soft tissue attenuation $\left(R_{5 T}\right)$ at the two energies is measured. The attenuation of pure fat $\left(\mathrm{R}_{F}\right)$ and of bone free lean tissue $\left(R_{L}\right)$ are known from both theoretical calculations and calibration. From this, the fatmass and lean tissue mass were calculated. The bone mineral content was calculated after correction of the overlying soft tissue (5). Body composition measurements in our study were made by a DPX with a pediatric software programme, Lunar version $1.5 \mathrm{e}$. Daily quality assurance test were performed according to the manufacturer 's directions. Total body analysis was performed in all children using a fast scan mode with a sample size of $4,8 \times 9,6 \mathrm{~mm}$, sample interval of $0.03 \mathrm{~s}$ and source collimation of $1,68 \mathrm{~mm}$.

\section{3 Total body water (TBW) and extra cellular volume (ECV)}

TBW and ECV were measured by deuterium oxide (6) and bromide dilution respectively (7). Each subject received orally $20 \mathrm{ml}$ of a mixture of $\mathrm{D}_{2} \mathrm{O}(99,9 \%$ purity) and Bromide salt $(150 \mathrm{mMol} / \mathrm{L}$ ) solution in a volume ratio of 1:1. Saliva and plasma samples were taken before intake of $\mathrm{D}_{2} \mathrm{O}-\mathrm{NaBr}$ solution and 4 hours thereafter when "an equilibrium" has been reached. To prevent saliva dilution by fluid intake which can result in a higher TBW content, patients were told not to take any fluid orally half an hour before saliva. samples were taken. Urine and 
fecal loss of bromide and $\mathrm{D}_{2} \mathrm{O}$ were negligible during the test since $t \frac{1}{2}$ of $\mathrm{D}_{2} \mathrm{O}$ and Bromide is 8 days (7). Saliva samples were obtained making use of dental cotton-wool, that was dried overnight at $100{ }^{\circ} \mathrm{C}$ and kept in a gas-tight tube until use. The cotton-wools and the blood samples were centrifuged and the saliva and serum thus obtained were kept in a stoppered glass vial and stored in a freezer until analysis.

\subsection{Total body water}

D2O concentrations of saliva samples were determined as follows: Calcium carbide $\left(\mathrm{CaC}_{2}\right)$ was placed in the siliconnized vacutainer tube and evacuated for $30 \mathrm{sec}$. with a rotatory vane pump to a total pressure of $0,01 \mathrm{~atm}$. Thereafter, $25 \mu \mathrm{l}$ of salivary sample was injected in the vacutainer tube. This was done in duplicate. $\mathrm{CaC}_{2}$ react with $\mathrm{D}_{2} \mathrm{O}$ forming acetylene gas. $\mathrm{A}$ $25 \mu \mathrm{l}$ of this gas was subsequently injected in duplicate into the GC/CF - IRMS system (gas chromatography/continous flow isotope ratio mass spectrometry) at $2 \mathrm{~min}$. intervals. The mass 27/26 ratio (R27/26) was measured on a Isotope Ratio Mass Spectrometer configured for Acetylene (Finnigan MAT 252 for CF-IRMS) (6). The mean value of 4 determinations was calculated for each sample. By inserting of the tracer/tracee ratio, defined as R27/26 (T4) $\mathrm{R} 27 / 26$ (T0), into the regression equation obtained from the standards, we get the dilution factor of D2O. TBW is calculated as ingested D2O volume/ dilution factor. From the TBW, LBM and FM can calculated by the following formules:

$$
\begin{aligned}
& \operatorname{LBM}(\mathrm{kg})=\text { TBW } /(1,04 \times \mathrm{d}) \\
& \text { BF }(\mathrm{kg})=\text { Weight }- \text { LBM }
\end{aligned}
$$

The 1,04 factor is a correction for the estimated $4 \%$ nonaqueous hydrogen exchange and $d$ is the hydration factor of LBM which varies with age. Because our CF population was young, we used the age dependent hydration factors described by Fomon (8) for children younger than 10 year and by Boileau and Lohman (9) for older children.

\section{3. 2 Bromide space}


Because Bromide resides mainly in the extracellular space, measured of Bromide dilution in serum give us an estimation of the extracellular volume. Bromide was determined by using a Gas Chromatograph type CP 9000 (Chrompack) equiped with an ECD detector after it was converted into a bromoacetone gas. First, perchloric acid was added to the serum sample and centrifugated for deproteinisation. An aliquot of the supernatant was then added to silver nitrate $\left(\mathrm{AgNO}_{3}\right)$ for precipitating of silver bromide and chloride. After centrifugation, the precipitate was taken up in $\mathrm{NH}_{3}$ after that $\mathrm{Na}_{2} \mathrm{~S}$ and $\mathrm{NaOH}$ were added to precipitate the silver as $\mathrm{Ag}_{2} \mathrm{~S}$. A.fter agitation and centrifugation, the supernatant was heated until $d r y_{2} \mathrm{HO}$ was added followed by $\mathrm{H}_{2} \mathrm{O}_{2}$ to oxidize sulfide. After drying, $\mathrm{H}_{2} \mathrm{O}$ was then added and dried again. This was repeated several times. Thereafter, perchloric acid and acetone were added and the reaction is started by addition of $\mathrm{KmnO4}$, with Bromoacetone formed. The solution is then extracted with benzene. The organic phase was separated from the water phase by shaking and centrifugation. The water phase was then removed. An aliquot of the organic solution is then applied to the gas chromatograph for measuring of bromoacetone/internal standard ratio. The bromide concentration was then derived from the bromoaceton standard curves. Because the distribution of Bromide depend on the potential difference between in- and extru-cellular and on the quantity of total body volume, corrected bromide space was calculated as follow:

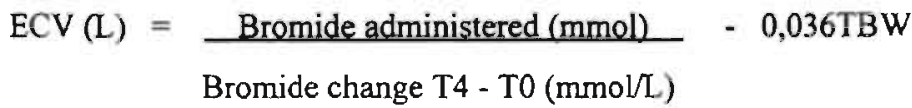

Where $0,036 \mathrm{TBW}$ is the correction factor for the cell potential and for the total body volume (7). 


\section{REFERENCES}

(1) M. Khouri, G. Huang, Y. Shiau. Sudan stain of fecal fat : New insight into an old test. Gastroenterology 1989; 96: 421-7.

(2) G. Drummey, J. Benson, C. Jones. Microscopical examination of the stool for steatorrhea. N Engl J Med 1961; 264: 85-7.

(3) W. Gerver, R. de Bruin. Paediatric Morphometrics: a reference manual. 1th ed. Utrecht: Bunge, 1996.

(4) J. Weststrate, P. Deurenberg. Body composition in children: proposal for a method for calculating body fat percentage from total body density or skinfold-thickness measurements. Am J Clin Nutr 1989: 50: 1104-15.

(5) S. Heymsfield, J. Wang, S. Heshka, J. Kehayias, R. Pierson. Dual-photon absorptiometry: comparison of bone mineral and soft tissue mass measurements in vivo with established methods. Am J Clin Nutr 1989; 49: 1283-9.

(6) B. Van Kreel, F. Van der Vegt, M. Meers, T. Wagenmakers, K. Westerterp, A. Coward. Determination of total body water by a simple and rapid mass spectrometric method. J Mass Spectrom 1996; 31: 108-111.

(7) B. Van Kreel. An Improved bromide assay for the estimation of extracellular water: volume by capillary gas chromatography. Clinica Chimica Acta 1994; 231: 117-128.

(8) S. Fomon, F. Haschke, E. Ziegler, S. Nelson. Body composition of reference children from birth to age 10 years. Am J Clin Nutr 1982; 35: 1169-1175.

(9) Boileau, R. Lohman, M. Slaughter, T. Ball, S. Going, M. Hendrikx. Hydration of the fatfree body in children during maturation. Hum Biol. 56: 651-666. 


\title{
CHAPTER 3
}

\section{THE ACID STEATOCRIT : A MUCH IMPROVED METHOD}

Tran M, Forget P, Van den Neucker A, Strik J, van Kreel B, Kuijten R.

Departments of Pediatrics and Clinical Chemistry, University Hospital Maastricht, Maastricht, The netherlands.

JPediatr Gastroenterol Nutr 1994; 19: 299-303

\begin{abstract}
The steatocrit method has recently been introduced as a simple screening test for steatorrhea. As it seemed likely that separation of feca! homogenate by centrifugation into a lipid phase, a watery phase and a solid phase would be pH-dependent, we evaluated the effect of fecal acidification on steatocrit results in healthy children and in patients with cystic fibrosis and studied the relationship between two steatocrit methods and fecal fat content as measured by a reference chemical method. Steatocrit results increased with the degree of fecal acidification, and maximal results were obtained at the lowest fecal $\mathrm{pH}$ values. Means and SEM for classi$\mathrm{cal}$ and acid steatocrit values were $1.1 \pm 0.4 \%$ (classical) versus $3.8 \pm 1 \%$ (acid) in controls (n $=6$ ) and $5.4 \pm 1.9 \%$ (classical) versus $26.9 \pm 4.3 \%$ (acid) in cystic fibrosis $(n=9)$. The correlations between fecal fat content measured chemically and steatocrit results were 0.18 (p $=0.35)$ and $0.81(p<0.0001)$ for classical and acid steatocrit, respectively. We conclude that acidification of fecal homogenates leads to a marked improvement in the steatocrit method.
\end{abstract}




\section{INTRODUCTION}

The diagnosis of fat malabsorption still mainly relies on the 72-hour faecal fat quantitation in which daily stool fat loss is evaluated by collecting stools for 3 days and determining stool fat content by chemical methods. The most widely used chemical method is the titrimetric method as described by van de Kamer in 1949 (1).

Work by Kouri et al has suggested that the titrimetric method largely overestimates nutritional faecal fat losses because it measures not only malabsorbed exogenous fat but also endoge. nous fat of various origins such as biliary lipids and lipids derived from the turnover of intestinal epithelial cells and gut bacteria (2).

Making use of the staining properties of purified lipids in an artificial matrix, Khouri et al. have suggested the fat absorption coefficient in normal adults is much higher than usually believed (2). Although the microscopic evaluation of steatorrhea by the Soudan stain provides a satisfactory screening method for steatorrhea, it is at best semiquantitative.

The steatocrit has been introduced in recent years as a simple test for the evaluation of fat malabsorption (3-6). Although several authors have reported the method to be satisfactory for the evaluation of steatorrhea, some have reported the steatocrit to be quite unreliable (6). As it has been shown that faecal acidification results in an enhanced sensitivity of the sudan faecal staining method (2), we wondered whether the same modification could improve fat extraction by centrifugation as performed in the steatocrit determination.

Consequently, we evaluated the effects of stool sample acidification on steatocrit determinations and to compared results from previously reported methods with acid steatocrit results in healthy children and in children with cystic fibrosis. We also determined the correlation between steatocrit results and faecal fat concentrations as measured by the reference chernical method of van de Kamer et to evaluate which of the two steatocrit methods gave the best estimate of faecal fat content.

\section{METHODS}

\section{"classic" steatocrit method}


Stool ( $0.5 \mathrm{gr})$ was diluted (1/3) with deionized water and thouroughly homogenized in a $5 \mathrm{ml}$ Potter Elvehjem tissue hornogenizer (Heidolph Elektro KG Kelheim, no. 170-1700/20-200) stamper, tissue grind pestle (size 20 from Kontes Scientific Glassware Instruments, no. 885451-0020). The homogenate was aspirated into a $75 \mu \mathrm{l}$ plain glass haematocrit tube. The capillary tube was subsequently centrifuged horizontally $(13,000 \mathrm{rpm}$ for $15 \mathrm{~min})$ in a standard haematocrit centrifuge.

After centrifugation, the upper (fat) and bottom (solid) layers were measured with a graduated magnifying lens. Steatocrit was calculated as $\mathrm{FL}(\mathrm{FL}+\mathrm{SL})$, where $\mathrm{FL}$ is the fatty-layer length and $\mathrm{SL}$ is the solid-layer length.

\section{"Acid" steatocrit method'}

The method used was exactly the same as the classic steatocrit method except that, before aspirating the homogenate in the capillary tube, perchloric acid in various concentrations ( $5 \mathrm{~N}$ for maximal acidification) was added to the homogenate in a volume equal to $1 / 5$ of the homogenate volume. The resulting acid homogenate was mixed for 30 seconds with a standard Vortex mixer.

\section{Chemical determination of stool fat concentration.}

The method of van de Kamer et al. was used to determine stool fat content (1).

\section{EXPERIMENTAL DESIGN}

\section{Effect of stool homogenate acidification on fat extraction}

To evaluate the effect of stool acidification and thus stool $\mathrm{pH}$ on the length of the fat column obtained by centrifugation, several stool samples from patients with and without steatorrhea were centrifuged after addition of perchloric acid solutions of various concentrations. 


\section{Classic and acid steatocrit}

To compare classic and acid steatocrit results in children with and without steatorrhea, we measured fecal steatocrit by both methods in 6 control children (mean age: 5.8 years, range 3 to 12 years; five boys and one girl) and in 9 children with cystic fibrosis (mean age: 6.9 years; range 0.5 to 20 ; nine boys ). The control children were patients with chronic aspecific respiratory disease without gastrointestinal symptoms and with a normal sweat test. The cystic fibrosis patients all had abnormal sweat tests on severall occasions and were being treated with pancreatic enzymes when steatocrit determinations were performed. As our purpose was to compare classical and acid steatocrit results in the same fecal samples, no attempt was made to quantify the fat content of the diet which was "normal" in all patients.

\section{Correlation between steatocrit results and fecal fat content}

To further compare both steatocrit methods we looked at the relationship between results obtained by each method and fecal fat content results as measured by the method of van de Kamer et al. (1). Steatocrit measurements (classic and acid) and fecal fat content determinations (chemical method) were performed on 27 consecutive stool samples (from adults and children) sent to our laboratory for evaluation of malabsorption. No attempt was made to classify patients in disease categaries as our only goal was to study the relationship between steatocrit results and fecal fat content independent of the presence of disease (clinical results will be published separately).

\section{Statistical methods}

The coefficient of variation of each steatocrit rnethod was determined with duplicate results of each sample for both methods. Pearson correlation coefficient was used to evaluate the relationship between steatocrit results and chemically measured fecal fat content.

\section{RESULTS}


Several steatorrheal stool samples were analysed after acidification with various concentrations of perchloric acid.

A typical finding is shown in figure 1; The upper fat column was seen to increase in length with the degree of homogenate acidification. A typical normal stool sample result (no steatorrhea) is shown in figure 2 . The acid steatocrit remained completely negative in normal samples.

\section{Cystic fibrosis sample}

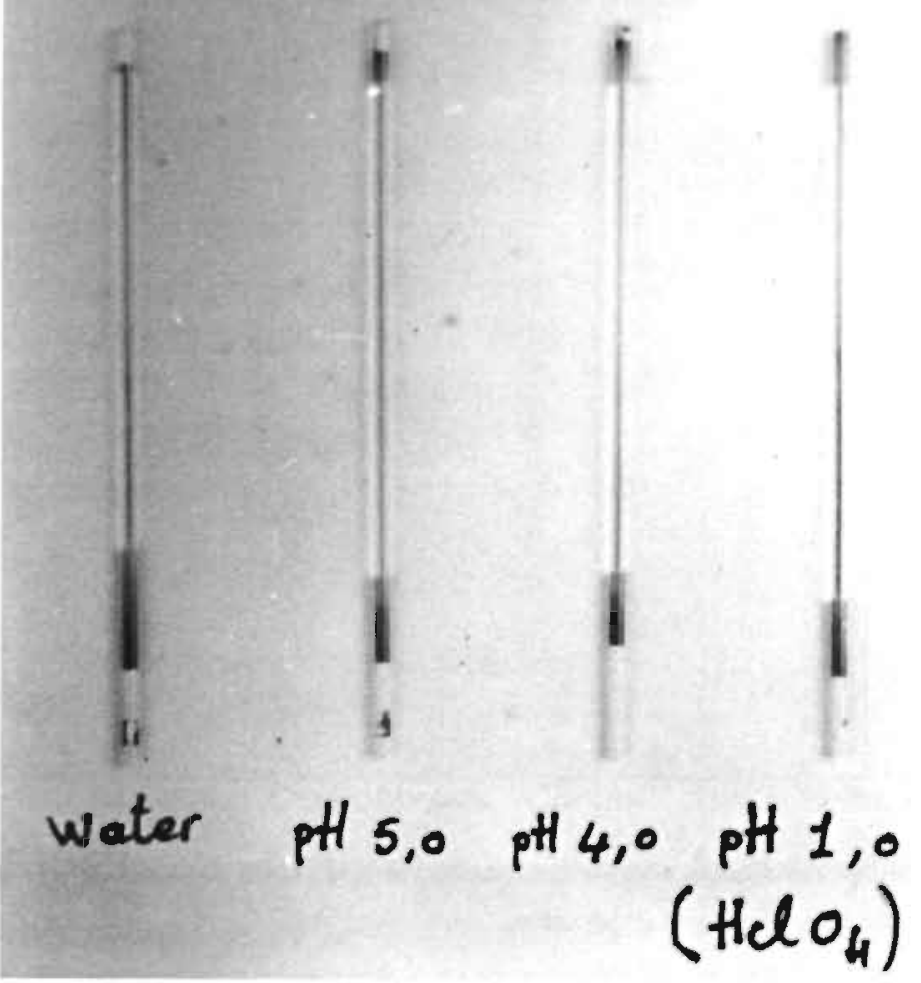

Figure 1 Effect of acidification with various concentrations of perchloric acid on the fat column length (upper part of picture) of a stool sample from a patient with cystic fibrosis. 


\section{normal sample}

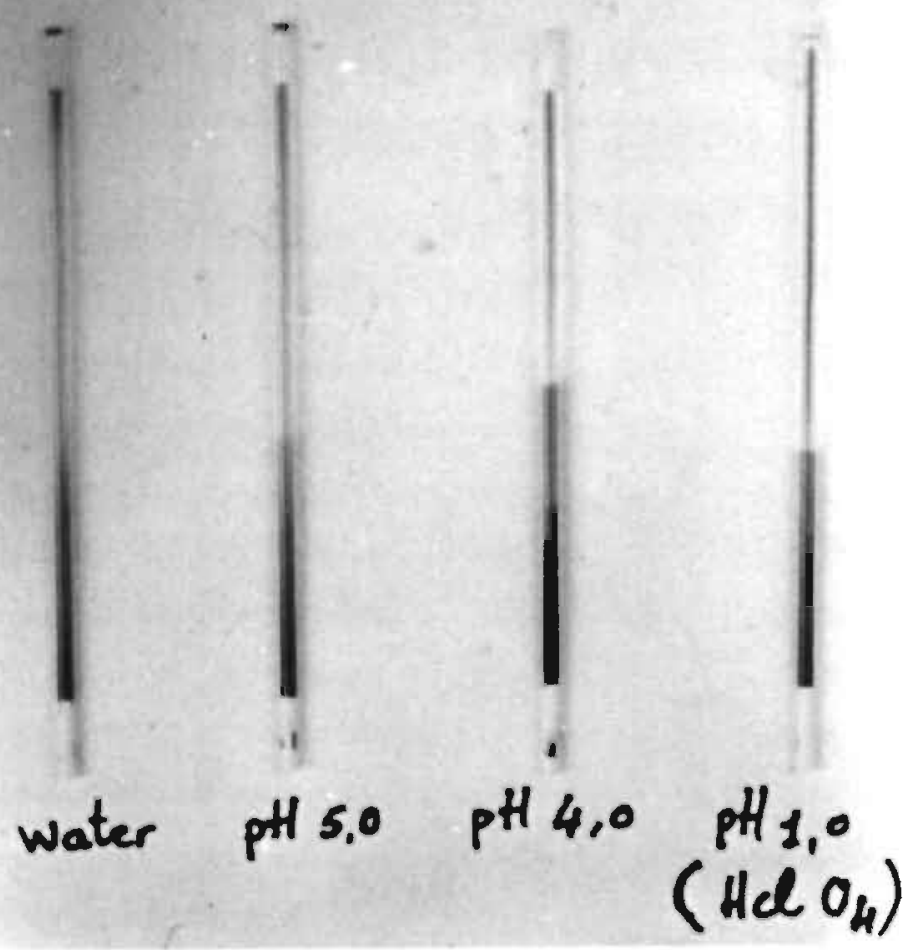

Figure 2 Effect of acidification with various concentrations of perchloric acid on fat extraction from a normal stool sample. Fat layer is absent at all $\mathrm{pH}$ values. 


\section{Classic and acid steatocrit}

Results of classic and acid steatocrit in 6 control and 9 cystic fibrosis patients (figure 3 ) were as follows : Steatocrit means and SEM in control patients were $1.1 \pm 0.4$ and $3.8 \pm 1 \%$ for classic and acid steatocrit, respectively. This difference was not statistically significant. Steatocrit means and SEM in cystic fibrosis patients were $5.4 \pm 1.9$ and $26.9 \pm 4.3 \%$ for classic and acid steatocrit, respectively. This difference is significant $(\mathrm{p}<0.01)$

The precision of the methods was evaluated by comparing the variation coefficients; variation coefficients were 6.9 and $5.1 \%$ for the classic and acid steatocrit methods, respectively.

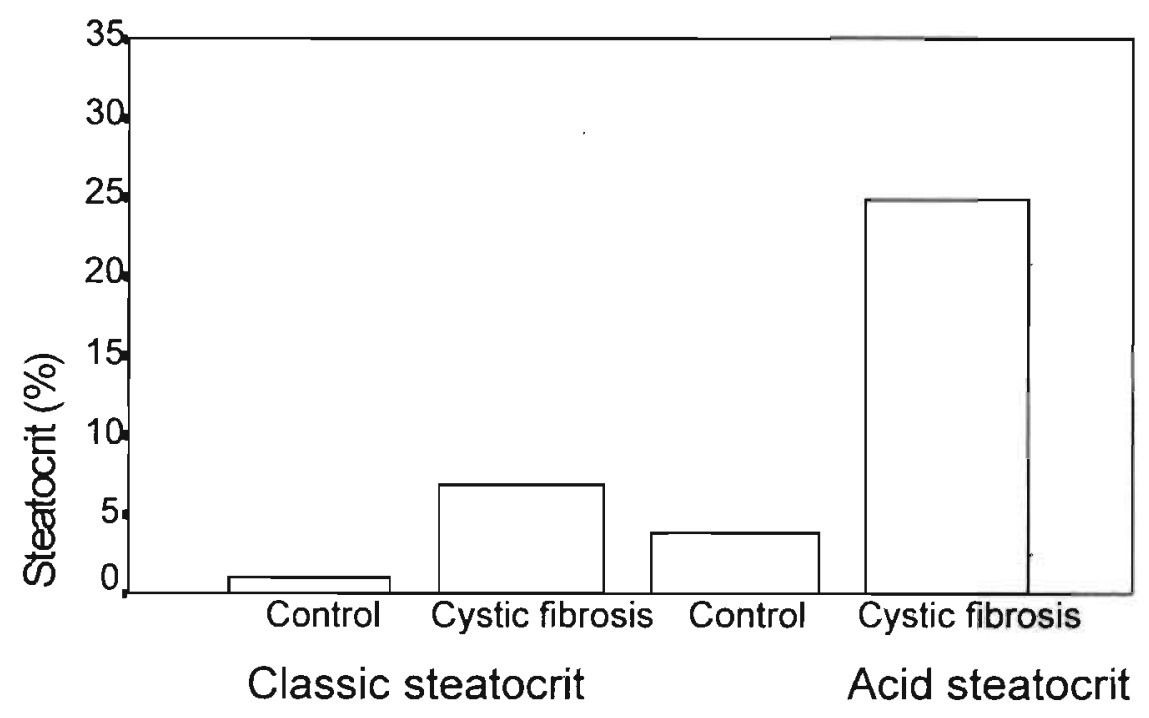

Figure 3 Classic and acid steatocrit results in six controls and nine patients with cystic fibrosis. 


\section{Correlation between steatocrit results and faecal fat content}

The relationship between classic fecal steatocrit and fecal fat content as measured by the reference method of van de Kamer et al. (1) is shown in figure 4. The correlation coefficient. of 0.18 is statistically non-significant $(p=0.35$ ). The relationship between acid fecal steatocrit and fecal fat content is shown in figure 5. The correlation coefficient of 0.81 is highly significant $(\mathrm{p}<0.0001)$.

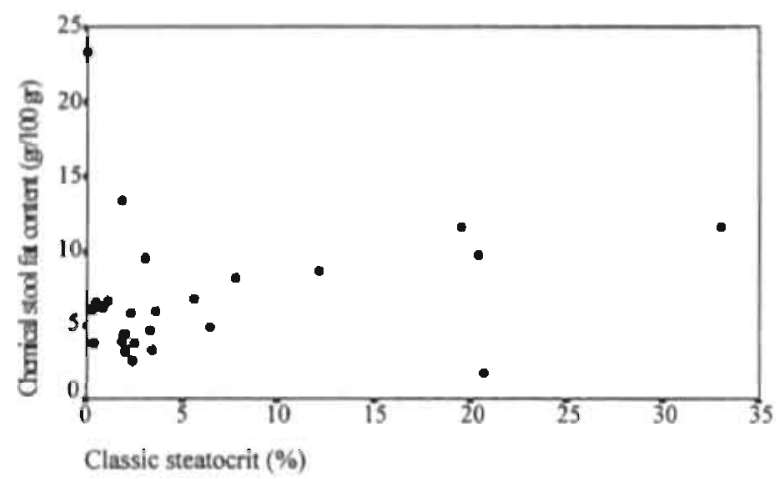

Figure 4 Relationship between classic fecal steatocrit and fecal fat content as measured by the method of van de Kamer et al. $\ln 27$ fecal samples $(r=0.18 ; p=0.35)$.

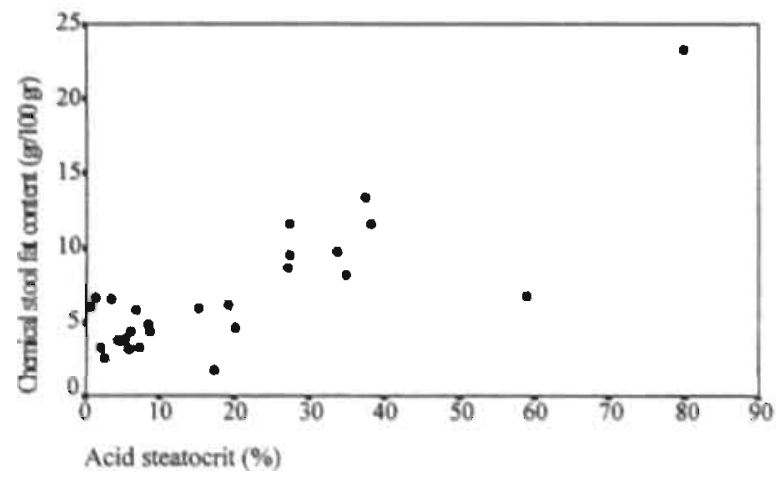

Figure 5 Relationship between acid fecal steatocrit and fat content as measured by the method of van de Kamer et al. In 27 fecal samples ( $r=0.81 ; p<0.0001)$. 


\section{DISCUSSION}

Although several authors have reported the steatocrit method to be reliable for the screening of steatorrhea ( 3-5), Walters et al reported the method to be completely unreliable (6). Methodological inadequacies probably underlie these discrepancies. We have been using the "classic" steatocrit in our department for a few years and have found completely negative results in some patients with proven steatorrhea. We hypothesized that in some patients fat detection might be poor and that a possible solution to the problem would be an improved method of liberating fat during the centrifugation step. It has been shown in a recent study that fecal fat in patients with pancreatic insufficiency mainly consists of fatty acids and that the fecal triglyceride content does not differ from that of normal controls (7).

Fecal fatty acid molecules exist in the form of soaps (8). Further, since the pKa of most fatty acids is lower (about 4.8) than fecal pH, most fatty acids in stool would be present as ionized species or soaps. We speculated that fecal acidification would result in the conversion of ionized fatty acid species and soaps into the protonated species leading to easier separation into lipid and water phases during the centrifugation step of the steatocrit method.

Our results show that the effect of stool homogenate acidification on the length of the upper fatty layer very nicely confirms our predictions. Although we have not checked this point in detail, it can be expected that at the low PH values obtained after maximal acidification as performed in the present study, all fatty acids will be present in the protonated form.

Further, the fact that acidification of fecal samples from patients without steatorthea and with completely negative steatocrit results did not result in the appearance of a fatty layer, probably indicating that the improved fat extraction is not a spurious artifactual finding but the result of better extraction of lost exogenous fat.

Khouri et al have suggested that ionized fatty acids are not readily stainable with Soudan stain, although staining does occur after acidification (2). By alkalinization with sodium hydroxide, the same authors showed that fatty acids lost their ability to form fat droplets and to stain with Sudan red III (2). We suppose that similar mechanisms underlie the improvement of both the fat staining method and fat extraction by fecal acidification as shown in the present study.

A further advantage of acidification is that it enhances the vicible boundaries between the 
various layers, resulting in improved accuracy in the reading of layers lengths. Improved fecal fat extraction by acidification should therefore result in higher diagnostic sensitivity of the steatocrit method.

Our results show classic steatocrit in control children and in children with cystic fibrosis are similar to results published by other authors (4); However, acidified steatocrit results in both control children and cystic fibrosis patients were much higher than those obtained by classic steatocrit. Ongoing work in our laboratory aims at establishing normal population values for acid steatocrit in infants and children.

In order to better interpret the differences found between the steatocrit methods, we compared steatocrit results with fecal fat concentrations measured by the most accepted reference method. Our findings show that only acid steatocrit results correlate very significantly with fecal fat content as measured by the van de Kamer method. The litterature is quite varied on this point. Several studies have looked for a correlation between steatocrit results and either the fat absorption coefficient or 3-day fecal fat excretion. A good correlation was reported by two studies $(4,9)$ while a total lack of correlation was reported by a third author $(6)$. As steatocrit is supposed to reflect fecal fat concentration we preferred to relate steatocrit results to fecal fat concentrations rather than daily excretion or fat absorption coefficients. To our knowledge only one study reporting results in a similar way found a significant relationship between steatocrit results and fecal fat content (3). We think our finding of a lack of correlation between classic steatocrit and fecal fat content results can best be explained by the small number of observations or by the lack of homogeneity in our patient material.

This lack of homogeneity was, however, purposely chosen as we were only interested in the correlation between steatocrit results and fecal fat content. We think a positive correlation between the two steatocrit methods and fecal fat content could have been found but the acid steatocrit method would always better correlate with fecal fat content.

We conclude that acidification of fecal homogenates led to a much better fat extraction by centrifugation, increased sensitivity of the steatocrit method and to a better prediction of fecal fat content as measured by chemical methods.

Acknowledgment: The authors thank the clinical laboratory staff for their kind and expert technical assistance. We are very grateful to Nutricia Netherlands for financial support. 


\section{REFERENCES}

(1) van de Kamer JH, Huinink HTB, Weyers HA. Rapid method for determination of fat in feces.J Biol Chem 1949 ; 177 :349-55.

(2) Khouri MR, Huang G, Shiau YF. Sudan stain of fecal fat : new insight into an old test. Gastroenterology $1989 ; 96: 421-427$.

(3) Phuapradit P, Narang A, Mendonca P, Harris DA, Baum JD. The steatocrit : a simple method for estimating stool fat content in newborn infants.Arch Dis Child $1981 ; 56$ : 725 727.

(4) Colombo C, Maiavacca R, Ronchi M, Consalvo E, Amoretti M, Giunta A. The steatocrit : a simple method for monitoring fat malabsorption in patients with cystic fibrosis.J Pediatr Gastroenterol Nutr $1987 ; 6: 926-930$.

(5) Iacono G, Carroccio A, Cavataio F et al. Steatocrit test : normal range and physiological variation in infants. J Pediatr Gastroenterol Nutr 1990; $11: 53-57$.

(6) Walters MP, Kelleher J, Gilbert J, Littlewood JM. Clinical monitoring of steatorrhea in cystic fibrusis.Arch Dis Child 1990; 65: 99-102.

(7) Khouri MR, Huang G, Shiau YF. Fecal triglyceride excretion is not excessive in pancreatic insufficiency.Gastroenterology 1989; $96: 848-852$.

(8) Shiau YF, Popper DA, Reed M, Umstetter C, Capuzzi D, Levine GM.Intestinal triglycerides are derived from both endogenous and exogenous sources. Am J Physiol 1985; 248 : G164-169.

(9) Guarino A, Tarallo L, Greco L, Cesarano L, Guandalini S, Rubino A. Reference values of the steatocrit and its modifications in diarrheal diseases.J Pediatr Gastroenterol Nutr 1992; 14 : 268-274. 
CHAPTER 4

\title{
IMPROVED STEATOCRIT RESULTS OBTAINED BY ACIDIFICATION OF FECAL HOMOGENATES ARE DUE TO IMPROVED FAT EXTRACTION
}

\author{
M. Tran, P. Forget, A. Van den Neucker and B. Van Kreel
}

Department of Pediatrics and Clinical Chemistry, University Hospital Maastricht, Maastricht, The Netherlands

J Pediatr Gastroenterol Nutr 1996; 22: 157-160

Abstract

Conflicting results have been reported on the value of the steatocrit as a screening test for steatorrhea. We recently modified the test procedure by fecal acidification with the hope of improving fat extraction and consequently the sensitivity of the test. The aim of the present study was to ascertain, whether or not fecal acidification led to improved fat extraction, by comparing the fat content of both fatty and solid layers obtained by centrifugation of 12 acidified (acid steatocrit) and unacidified (classical steatocrit) steatorrheal stool samples.

The fat content of fatty and solid layers was evaluated using of the semiquantitative $(t=1$, $++=2,+++=3$ ) scoring system described by Drummey, for the interpretation of the sudan microscopic method for fecal fat.

The fatty layers sum of scores for the 12 samples examined, was 31 and 16 , for the acid and classical steatocrit respectively. The solid layers sum of scores for the 12 samples, was 13 and 24, for the acid and classical steatocrit respectively. Fat extraction from stool samples was significantly improved after fecal sample acidification $(p<0.005)$. Acid steatocrit results agreed better with chemically measured fecal fat than classical steatocrit results. We conclude that fecal acidification, by improving fat extraction, increases the reliability of the steatocrit method for the detection of steatorrhea. 


\section{INTRODUCTION}

Several methods are in use for the diagnosis of fat malabsorption. One of these is the 72 hour fecal fat quantitation method, which is regarded as the most accurate method to evaluate steatorrhea (1). However, there are several problems. First, it is a laborious method for laboratory technicians, and second, fecal collection for 3-5 days makes the method unpleasant for the patient and sometimes poorly reliable in non collaborating children.

Another well accepted test to screen for fat malabsorption is the Sudan staining method for fecal fat (2). Unfortunately this method is only semiquantitative.

In 1981 Phuapradit introduced the steatocrit method as a new, simple and easily repeatable method for measuring fecal fat content (3).

Although several authors have reported this method to be satisfactory for the evaluation of steatorrhea (3-5), some described it as quite unreliable (6). We have been using this method for years and have often found normal steatocrit values in patients, who, when measured chemically had steatorrhea with an increased fecal fat content.

As it has been shown that fecal acidification results in an enhanced sensitivity of the Sudan fecal staining method (7), we wondered whether fecal acidification could also be used to improve the sensitivity of the steatocrit method.

We consequently modified the reported (8) steatocrit method by adding perchloric acid to the fecal homogenate. Fat extraction was evaluated for classical and acid steatocrit methods, making use of the Sudan microscopic method for fecal fat.

We further compared calculated steatocrit results from acidified and unacidified samples, and related the results to fecal fat content of the same samples, measured by the reference chemical method of van de Kamer et al. (1).

\section{MATERIALS AND METHODS}

\section{Bopulation studied}

Twelve stool samples from 4 premature babies, 3 boys and 1 girl, with a mean gestational age of 35,3 weeks (ranged from $275 / 7$ to $355 / 7$ weeks), were analysed by means of both 
the classical and the acid steatocrit method.

Their postnatal age varied between 11 and 18 days. They received full oral formula feedings. Their weight ranged from $1810 \mathrm{~g}$ to $2360 \mathrm{~g}$.

\section{Steatocrit methods}

$0,5 \mathrm{~g}$ solid stool was weighed and diluted with a volume of deionized water, equal to two times the weight of stool. The stool and water were premixed using a Vortex mixer. Subsequently, the mixture was homogenized using a $5 \mathrm{ml}$ Potter Elvehjem tissue homogenizer. Then, the homogenate was aspirated into a $75 \mu \mathrm{l}$ plain haematocrit capillary. This capillary was sealed with wax at one end and centrifuged horizontally $(13,000 \mathrm{rpm}, 15 \mathrm{~min})$ in a standard haematocrit centrifuge.

The method used for the acid steatocrit was exactly the same as that of the classical steatocrit, the only exception being, that after homogenizing, $5 \mathrm{~N}$ perchloric acid was added to the homogenate in a volume equal to $1 / 5$ of the homogenate. This acid homogenate was then mixed for 30 seconds using a Vortex mixer.

After centrifugation, three layers were distinguished: a basal solid layer, an intermediate liquid layer, and an upper fatty layer. After calculating the steatocrit results for both methods as usual, the capillaries were cut in the middle of the fatty, and of the solid layers using a special glass knife. Subsequently, the layers were removed from the capillaries, using a syringe. A standard amount of each of these fatty and solid layers was then transfer. red to different glass slides for staining with Sudan III dye. In this way, we acquired a total of 48 slides (24 from each steatocrit method, 12 fatty and 12 solid layers) for microscopic evaluation.

\section{Sudan stain method for fecal fat}

For this purpose we used the split fat stain, which identifies both triglyceride and fatty acid

(7). Several drops of $100 \%$ acetic acid and several drops of Sudan III solution were added. The preparation was subsequently mixed with the coverslip, which was then applied. The slide was gently heated on a lighter until bubbling. All preparations were examined while 
still warm under high magnification (magnification of 400 ), by the same person who was blind to the steatocrit methodl used (classical or acid).

For quantification of the amount of fat detected microscopically, we used the criteria established by Drummey et al.(2). They are as follows: normal (+): up to 100 fat globules per high power field, varying in a diameter between 1 and $4 \mu \mathrm{m}$, as noted on the micrometer scale always using a magnification of 400 ; Increased $(2+)$ : up to 100 fat globules per high power field, the diameter of fat globules varying between 1 and $8 \mu \mathrm{m}$; and markedly increased $(3+)$ : more than 100 fat globules per high power field, varying in size from 6 to $75 \mu \mathrm{m}$ in diarneter.

The sum of the fatty and solid layer scores of all our samples, was calculated for both steatocrit methods, and results were compared. Fisher's exact probability test was used to test whether or not the solid layers microscopic fat content was dependent on sample acidification. Finally, calculated acidified and unacidified steatocrit results were compared and related to the chemically measured fecal fat content.

\section{RESULTS}

Table 1 shows that acidification of the fecal homogenates before centrifugation (acid steatocrit method) results in a higher Drummey score in the fatty layers and a lower score in the solid layers. In four specimens (sample 6, 7, 8 and 10), the fatty layers obtained by the classical steatocrit method were so small that we did not succeed in making microscopical slides. Equal results were obtained by both the classical and the acid steatocrit method, in only one sample (sample 11). 
Table 1 Fatty and solid layer microscopical fat scores for both acid and classic steatocrit methods.

\begin{tabular}{|ccccc|}
\hline & \multicolumn{5}{c|}{ SCORES OF FAT GLOBULES } \\
\cline { 2 - 5 } SAMPLES & \multicolumn{3}{c|}{ FATTY LAYERS } & \multicolumn{2}{c|}{ SOLI LAYERS } \\
\cline { 2 - 5 } & ACID & CLASSIC & ACID & CLASSIC \\
\hline 2 & +++ & ++ & + & + \\
3 & ++ & ++ & + & +++ \\
4 & +++ & + & + & +++ \\
5 & +++ & ++ & + & +++ \\
6 & + & - & + & ++ \\
7 & ++ & - & + & ++ \\
8 & +++ & - & + & + \\
9 & +++ & +++ & + & ++ \\
10 & ++ & - & + & + \\
11 & +++ & +++ & + & + \\
12 & +++ & ++ & + & +++ \\
SUM & 31 & 16 & 13 & 24 \\
\hline
\end{tabular}

The sum of the fat scares for fatty and solid layers, and for both steatocrit methods is summa. rized in figure 1. The number of solid layer samples with low microscopic $\left(s^{+}\right)$fat content, was 11 of 12 , and 4 of 12 , for the acidified and unacidified samples respectively $(p<0.005$, Fisher's exact probability test). 


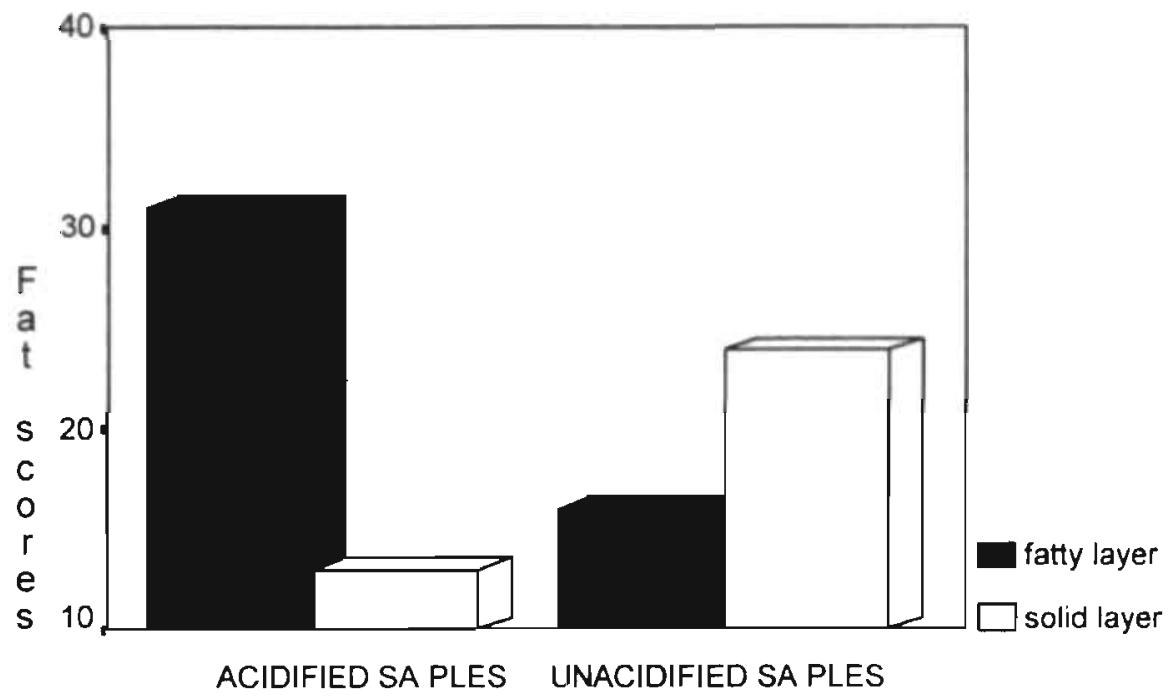

Figure 1 Sum of 12 microscopical Sudan fat globule scores $(1,2,3)$ performed on fatty and solid layers of acidified and unacidified fecal samples. 
The calculated steatocrit results for both steatocrit methods, and the chemically measured fecal fat content for the 12 samples, are shown in table 2. Chemical fat measurements of two samples ( 1 and 2 ) were not performed. The chemically measured fecal fat concentration was very high in all samples and corresponded with high acid steatocrit results, while only 5 classical steatocrit results were elevated.

Table 2 Classic and acid steatocrit results compared to chemically measured fecal fat in 12 steatorrheal fecal samples.

\begin{tabular}{|cccc|}
\hline SAMPLES & $\begin{array}{c}\text { CLASSIC } \\
\text { STEATOCRIT (\%) }\end{array}$ & $\begin{array}{c}\text { ACID } \\
\text { STEATOCRIT (\%) }\end{array}$ & $\begin{array}{c}\text { FECAL FAT } \\
\text { (GRAM \%) }\end{array}$ \\
\hline 1 & 5.3 & 81.7 & - \\
2 & 2.5 & 72.4 & - \\
3 & 5.3 & 71.1 & 16.6 \\
4 & 28.8 & 93.3 & 28.5 \\
5 & 26 & 90.9 & 26.7 \\
6 & 6.2 & 92.6 & 28.3 \\
7 & 3.1 & 92.5 & 18.7 \\
8 & 2.8 & 94.2 & 26.5 \\
9 & 59.8 & 93.7 & 24.3 \\
10 & 6.2 & 96.4 & 10.3 \\
11 & 63.9 & 96 & 27.3 \\
12 & 48.7 & 94.4 & 20.6 \\
\hline
\end{tabular}

\section{DISCUSSION}

There has always been a need for a simple, rapid and easy to perform screening test for fat malabsorption. Such a test would not only be useful for the detection of steatorrhea but also for the therapeutic monitoring of children treated for pancreatic insufficiency.

The steatocrit is a simple and rapid micromethod that can be repeated at short time intervals 
(3). It is inexpensive and not invasive (5). Some authors have reported it as a very satisfactory screening test (3-5), but others have found it quite unreliable (6). Our experience with the method has shown the steatocrit to often be normal, in fecal samples with a very high chemically measured fecal fat content. This could be due to inefficient fecal fat extraction at the centrifugation step. Therefore we recently improved the steatocrit method by acidifying the fecal homogenate before centrifugation (8).

The present study was set up to study the effect of fecal homogenate acidification on fat extraction at the centrifugation step. If fat extraction improves by acidification, we would expect to find more fat globules in the fatty layer and less in the solid layer, after centrifugation of acidified fecal samples, when compared to unacidified samples. Our results are in agreement with our expectations and support the hypothesis that fecal acidification improves fat extraction, and should consequently improve the sensitivity of the steatocrit. Due to various reasons, the fat content of premature infants ' stool, is known to be very high. Confirming the latter, chemical fat measurements of all our samples from 4 premature babies showed very high values. The acid steatocrit seems to reflect these very high fat contents, while classical steatocrit results were high in only 5 of 12 samples. The correlation between chemical fat measurement and acid steatocrit has been reported previously (8). Such a correlation cannot be shown in the present study where only high-fat-content stools were evaluated.

Results of the present study do support our previous findings, confirming, that fecal acidification improves fat extraction at the centrifugation step, and consequently increases the reliability of steatocrit results for the detection of fat malabsorption. Because the Sudan staining staining method for fecal fat is only semiquantitative, we suggest using the acid steatocrit as a good alternative to chemical fat measurement.

Acknowledgement: The authors wish to thank the clinical laboratory staff for their kind and expert technical assistance. We are very grateful to Nutricia Netherlands for financial support. 


\section{REFERENCES}

(1) Van de Kamer JH, Huinink HTB, Weyers HA. Rapid method for determination of fat in feces. J Biol Chem 1949; 177: 349-55.

(2) Drummey GD, Benson JA, Jones CM. Microscopical examination of the stool for steatorrhea. N.Engl J Med 1961; 264: 85-7.

(3) Phuapradit P. Narang A, Mendonca P, Harris DA, Baum JD. The steatocrit: a simple method for estimating stool fat content in newborn infants. Arch Dis Child 1981: 56: 725. 727.

(4) Iacono G, Carroccio A, Cavataio F, Montalto G, Mancusco C, Balsamo V et al. Steatocrit test: normal range and physiological variation in infants. J Pediatr Gastroenterul Nutr 1990; 11: 53-57.

(5) Columbo C, Maiavacca R, Ronchi M, Consalvo E, Amoretti M, Giunta A. The steatocrit: a simple method for monitoring fat malabsorption in patients with cystic fibrosis. J Pediatr Gastroenterol Nutr 1987; 6 : 926-930.

(6) Walters MP, Kelleher J, Gilbert J, Littlewood JM. Clinical monitoring of steatorrhea in cystic fibrosis. Arch Dis Child 1990; 65: 99-102.

(7) Khouri MR, Huang G, Shiau YF. Sudan stain of fecal fat: new insight into an old test. Gastroenterology 1989; 96: 421-427.

(8) Tran M, Forget P, Van den Neucker A, Strik J, van Kreel B, Kuijten R.

The acid steatocrit: a much improved method. J. Pediatr. Gastroenterol Nutr. 1994; 19: 299-303 


\title{
CHAPTER 5
}

\section{CLINICAL USE OF ACID STEATOCRIT}

\author{
A. Van den Neucker', N. Pestel', T. My Dung Tran', P.Ph. Forget',H.J. Veeze', \\ J. Bouquet ${ }^{2}$, M. Sinaasappel ${ }^{2}$.
}

'Department of Pediatrics, University Hospital Maastricht and '2Sophia Children's Hospital Rotterdam, The Netherlands

Submitted for publication

Abstract

Malabsorption of fat is an important gastrointestinal cause of malnutrition and growth retardation in childhood. The golden standard for the evaluation of fat malabsorption is the fecal fat balance method. The acid steatocrit method has recently been introduced as a simple method to evaluate fecal fat. The present study aimed at evaluating the acid steatocrit in clinical practice. Fecal fat excretion and acid steatocrit results were determined in 42 children, half with and half without fat malabsorption. Acid steatocrit results correlated significantly with both fecal fat excretion $(p<0.01)$ and fecal fat concentration $(p<0.001)$. Sensitivity and specificity of the acid steatocrit for the diagnosis of malabsorption was $90 \%$ and $100 \%$ respectively. We consider the acid steatocrit method useful for the screening and monitoring of patients with steatorrhea. Acid steatocrit, Steatorrhoea, Cystic Fibrosis. 


\section{INTRODUCTION}

Malabsorption of fat is the most important gastrointestinal cause of malnutrition and growth retardation in childhood. The detection of steatorrhoea is useful for the diagnosis of intestina! and pancreatic cisease. The gold standard for the evaluation of patients suspected of fat malabsorption is the fat balance method whereby fecal fat is chemically measured according to the method of van de Kamer (1). This method is cumbersome, laborious, expensive and often difficult to manage in children. In 1981 Phuapradit et al. introduced a simple test to evaluate fecal fat content (2). Although some authors found this test quite reliable (3), others did not (4). As previously reported, substantial improvement of the method was obtained by acidification of fecal samples, acid steatocrit (AS) (5).

The present study was designed to compare the fecal fat excretion with the acid steatocrit for the diagnosis of fat malabsorption in children.

\section{PATIENTS}

Forty two children, 23 boys and 19 girls, aged between 6.5 months and 18 years (mean: 6.6 years) were selected for the study. All these children were suspected of fat malabsorption, on the basis of anamnestic and clinical parameters. The different diagnoses of our patients are shown in table 1.

\section{METHODS AND MATERIAL}

Three days stool collections from each patient were collected in separate containers, one container for each day. The stools were frozen at $-18^{\circ} \mathrm{Celsius}$. Fat content in each collection was determined by the titrimetric method described by van de Kamer et al.(1). Acid steatocrit from a single stool sample on day 1 and from a sample out of the homogenized 72 hours collection were determined by the method of Tran et al.(5)Feces $(0.5 \mathrm{gr}$.) was diluted (1/4) with deionized water and thouroughly homogenized making use of a $5 \mathrm{ml}$. Potter Elvehjem tissue homogenizer. Perchloric acid $5 \mathrm{~N}$ was added to the homogenate in a volume equal to $1 / 5$ of the homogenate volume. The resulting acid homogenate was mixed for 30 seconds making 
Table 1 List of diagnosis $(n=42)$.

\begin{tabular}{|cc|}
\hline DIAGNOSIS & NUMBER OF CASES \\
\hline CYSTIC FIBROSIS & 20 \\
MENTAL RETARDATION & 2 \\
RECURRENT DIARRHEA & 5 \\
FAILURE TO THRIVE & 5 \\
COELIAC DISEASE & 2 \\
INFLAMMATORY BOWEL DISEASE & 1 \\
SHORT BOWEL & 1 \\
CHOLEDOCHAL CYSTE & 1 \\
SUCRASE-ISOMALTASE DEFICIENCE & 1 \\
RECURRENT ABDOMINAL PAIN & 1 \\
UNKNOWN & 3 \\
\hline
\end{tabular}

use of a standard Vortex mixer. The homogenate was aspirated into a75 $\mu$ l plain glass haematocrit capillary. The capillary was subsequently centrifuged horizontally (13000 rpm. for 15 min.) in a standard centrifuge. After centrifugation, the lengths of the upper (fat) and the bottom (solid) layers were measured by means of a graduated magnifying lens. Steatocrit was calculated as follows: percentage of (the fatty layer length / (fatty layer length + solid layer length)\}.

In order to validate the diagnostic value of the acid steatocrit we studied two patients groups, one with and one without steatorrhea. We divided the patients according to previous clinical datã and fat excretion results. whereby a fecal fat excretion $23 \mathrm{gr} /$ day was considered as abnormal (6).

\section{RESULTS}

Correlation coefficients between acid steatocrit results from either a șingle stool sample or from the sample taken from the 72 hours homogenized collection, and both the fecal fat excretion and the fecal fat concentration are shown in table 2. 
Table 2 Correlation between the results of the acid steatocrit from either a single stool sample and a sample from the homogenised stool collection and the results of both fat excretion and fecal fat concentration in $\mathbf{4 2}$ children suspected of malabsorption.

\begin{tabular}{|c|c|c|}
\hline ACID STEATOCRIT & FAT EXCRETION & FAT CONCENTRATION \\
\hline SINGLE STOOL & $r=0.4(p \leq 0.01)$ & $r=0.82(p \leq 0.001)$ \\
\hline COLLECTION & $r=0.68(p \leq 0.001)$ & $r=0.82(p \leq 0.001)$ \\
\hline
\end{tabular}

The sensitivity and the specificity of the acid steatocrit determination from either a single stool sample or a sample taken from the 72 hours homogenized collection, and of the fecal fat concentration, for the diagnosis of steatorrhea are shown in table 3.

Table 3 Sensitivity and specificity of the acid steatocrit determination from a single stool sample and from a homogenised stool collection sample and of the fecal concentration, for the diagnosis of steatorrhea.

\begin{tabular}{|c|c|c|}
\hline & SENSITIVITY & SPECIFICITY \\
\hline AS SINGLE STOOL (\%) & $75 \%$ & $84 \%$ \\
\hline AS COLLECTION (\%) & $90 \%$ & $100 \%$ \\
\hline FAT CONCENTRATION (\%) & $100 \%$ & $76 \%$ \\
\hline
\end{tabular}

AS: Acid steatocrit

Fig.1 shows our AS results from the homogenized fecal collection sample related to the fecal fat excretion ( $g /$ day).The reference line for AS was set at the level of $10 \%(5)$, and the cut off reference line for the daily fat excretion was set at the level of $3 \mathrm{gram}$ per day (6).As can be seen from the figure, one false positive and three false negative acid steatocrit results were found in our study population.Regarding these results one should notice that they are very close to the reference lines: the false positive steatocrit result had a value of $16 \%$ and the results of the fecal fat excretion corresponding to the false negative steatocrit results were 4.9 ; 6.4 and $7.7 \mathrm{~g} / \mathrm{day}$, and concern children aged 12.6 and 13 years respectively. 


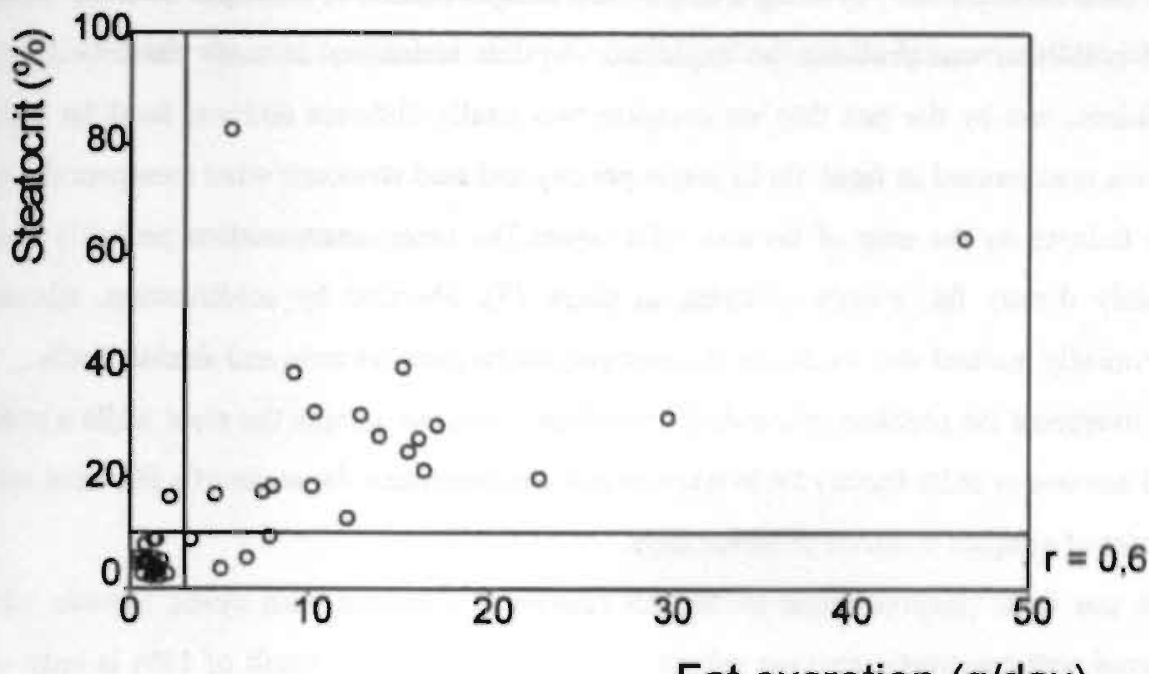

\section{Fat excretion (g/day)}

Figure 1 Relationship between acid steatocrit and fat excretion. Reference lines for acid steatocrit at $10 \%$ and for fat excretion at $3 \mathrm{gram} /$ day.

\section{DISCUSSION}

Since the fecal fat balance excretion as described by van de Kamer is cumbersome, expensive and unpleasant for all involved, there is a need for a simple test. Some authors reported the steatocrit micromethod described by Phuapradit as a simple method for monitoring fat malabsorption (3), and reported a good correlation ( $r=0.93$ ) with the fecal fat excretion. Although others considered the steatocrit method of Phuapradit unreliable and mentioned the difficulty to delineate the fatty layer (4) and the impression that fat remains in the solid layer, as a problem of this method.This problem was solved by acidification of the fecal sample, whereby fat extraction is improved, and steatocrit results correlate much better with chemically measured fecal fat (5).

Our AS results correlate satisfactorily with chemically measured fecal fat concentrations and somewhat less ,but still significantly, with fecal fat excretion.However, our correlation coefficient is lower than the correlation coefficient of the steatocrit without acidification as published in a previous study (3).We have no explanation for this discrepancy, and other 
authors also failed to reproduce these results (4). The lesser correlation of the AS results with the fecal fat excretion, by using a single stool sample instead of a sample from the homogenized collection can probably be explained by the variability of daily fat consumption in children, and by the fact that we compare two totally different entities: fecal fat excretion, which is expressed as fecal fat in grams per day and acid steatocrit what measures the ratio of the fatlayer on the sum of fat and solid layers. The latter determination probably measures mainly dietary fat, mostly occuring as soaps (7), liberated by acidification, whereas the chemically method also measures the endogenous fat from bacteria and shedded cells.

To overcome the problem of the daily variability, one can sample the stool while a standardized amount of daily dietary fat is taken or one can determine the mean of a few acid steatocrit results of samples taken on different days.

The one false positive result of the AS concerned a patient with cystic fibrosis who was treated with pancreatic enzyme substitution therapy. This AS result of $16 \%$ is only slightly elevated considering the values obtained in cystic fibrosis patients on substitution therapy, which are mostly between 20 and $30 \%$.

The three false negative results of the acid steatocrit can probably be explained by the choice of the reference line for the normal fecal fat excretion. Fecal fat excretion higher than $4.5 \mathrm{~g} / 24$ hours is considered pathologic $(6,8)$ for children and adolescents, whereas other authors consider $7 \mathrm{~g} /$ day the uper limit of normal fecal fat excretion in adults (9). The reference line for normal daily fecal fat excretion varies clearly with age and dietary fat intake as previously suggested by Williams (8).Taking account of these remarks, the fat excretion studies of 2 of our 3 patients with false negative steatocrit results could, due to their ages (12 and 13 years), still be considered "normal" and in agreement with AS results .This would reduce the disagreement between the methods to only a few ones.

\section{CONCLUSION}

Acid steatocrit results are highly correlated with the chemically measured fecal fat concentration and significantly correlated with the fecal fat excretion. Although single sample acid steatocrit results are slightly less sensitive and specific than other measured parameters for the diagnosis of steatorrhoea, acid steatocrit measured in the stool samples taken from the homo- 
genized collection compare favourably with the fecal fat concentration. We consider the acid steatocrit method useful for the screening and monitoring of patients with steatorrhoea.If it is necessary to know the real coefficient of fat absorption, the fecal fat balance method is needed. 


\section{REFERENCES}

(1) van de Kamer JH, Huinink HTB, Weyers HA. Rapid method for determination of fat in feces. J Biol Chem 1949; 177:349-55.

(2) Phuapradit P, Narang A, Mendonca P, Harris DA, Baum JD. The steatocrit: a simple method for estimating stool fat content in newborn infants. Arch Dis Child 1981; 56:725-7.

(3) Colombo C, Maiavacca R, Ronchi M, Consalvo E, Amoretti M, Giunta A. The steatocrit: a simple method for monitoring fat malabsorption in patients with cystic fibrosis. J Pediatr Gastroenterol Nutr 1987;6:926-30.

(4) Walters MP, Kelleher J, Gilbert J, Littelwood JM. Clinical monitoring of steatorrhoea in cystic fibrosis. J Pediatr Gastroenterol Nutr 1990; 65:99-102.

(5) Tran M, Forget P, Van den Neucker A, Strik J, Kreel van B, Kuijten R.The acid steatocrit: a much improved method. J Pediatr Gastroenterol Nutr 1994; 19: 299-303.

(6) Navarro J, Schmitz J. Gastroenterologie pédiatrique, Flammarion Médicine Sciences, Paris 1986.

(7) Quinlan PT, Lockton S, Irwin J, Lucas AL. The relationship between stool hardness and stool composition in breast- and forrnula-fed infants. J Pediatr Gastroenterol Nutr 1995; 20:81-90.

(8) Williams HH, Endicott EN, Shepherd ML, Galbraith H, Macy IG. Fat excretion by normal chilldren.J. of Nutrition 1943; 25, 379.

(9) Bai JC, Andrish A, Matelo G, Martinez C, Vazquez H, Boern L, Sambuelli A. Fecal fat concentration in the differential diagnosis of steatorrhoea. Am. J. Gastroenterol. 1989; 27-30. 


\title{
CHAPTER 6
}

ROLE OF LANSOPRAZOLE IN CHILDREN WITH CYSTIC FIBROSIS: EVIDENCE FOR IMPROVED FAT ABSORPTION AND NUTRITIONAL STATUS

\author{
Tran TMD, Van den Neucker A, Hendriks JJE, Forget $\mathrm{P}$ ( junior ), Forget $\mathrm{P}$ ( senior )
}

\section{Department of Pediatrics, University Hospital Maastricht, Maastricht, The Netherlands}

\section{Submitted for publication}

\section{Abstract}

Steatornhea and nutritional parameters were investigated in 15 cystic fibrosis children before starting lansoprazole, after 3 months on lansoprazole ( $15 \mathrm{mg} /$ day) and 3 months after stopping lansoprazole. There were 5 girls and 10 boys with a mean age of 9.5 years (range: 3.1 22.6y). Patients were their own controls. Acid steatocrit, anthropometric methods and DXA were used to evaluate steatornhea and the nutritional status respectively. On lansoprazole, mean \pm SD acid steatocrit values decreased from $37.1 \pm 8.8 \%$ to $28.5 \pm 10.6 \%(p=0.02)$. During lansoprazole therapy, significant mean $Z$-score changes were found for weight $(+0.14 /$ $p=0.02)$, length $(+0.15 / p=0.03)$, subscapular $(+0.61 / p=0.003)$, suprailiaca $(+0.8 / p=$ $0.002)$ and the sum of 4 skinfolds $(+0.61 / p=0.002) . Z$-scores deteriorated again after stopping lansoprazole. Fatmass and bone mineral content increased significantly on lansoprazole $(p=0.008$ and $p=0.005$ resp.). Improvement of subscapular $Z$-score was related to improvement of acid steatocrit values $(p=0.01)$ during treatment. We conclude that lansoprazole as adjuvant therapy significantly improves fat absorption and the nutritional status in CF children. 


\section{INTRODUCTION}

Cystic fibrosis (CF) is an autosomal recessive inherited disease. Defect in the chloride transepithelial transport system results in viscous mucus in various organs with lung and pancreas mostly affected (1). Both, pancreatic insufficiency resulting in malabsorption and high energy expenditure due to increased respiratory work (2-3), are thought to be responsible for the poor nutritional condition in CF patients. Since malnutrition can compromise absorptive and immune function resulting in a shortened survival (4), all efforts should be made in order to improve the nutritional status of these patients. Unfortunately, high doses of pancreatic enzymes did not solve the problems of malabsorption (5) and colon stricture has been observed in CF children on this regimen $(6,7)$. Further, the use of hypercaloric diets did not result in significant improvements of Z-scores for weight, length and skinfolds in CF children (8). Only parenteral nutrition and either oral or enteral elemental and semielemental nutrition have been shown to significantly improve the nutritional condition of these children (9-15).

The latter strongly suggests that nutrient maldigestion plays a crucial role in the poor response to oral hypercaloric diets. As cystic fibrosis patients have a low duodenal $\mathrm{pH}$ probably linked to fat maldigestion (16), inhibition of gastric acid production could improve absorption. The reported effects of $\mathrm{H} 2$-receptor antagonists and prostaglandine E2 on steatorrhea have been variable (17-22). Insufficient inhibition of gastric acid could be responsible for these unconvincing results. Recently, in a double blind study, a significant improvement in steatorrhea was found when a proton-pump inhibitor was added as adjuvant therapy in pancreatic enzyme treated cystic fibrosis patients (23). The effect of proton pump inhibitors on the nutritional condition of children with CF have not yet been reported. The aims of our study were to evaluate the effects of lansoprazole (proton-pump inhibitor) on both steatorrhea and the nutritional condition of CF patients while on enzyme therapy.

\section{SUBJECTS AND METHODS}

\section{Studv design}

As the effect of a proton pump inhibitor on fat balance has been convincingly proven in a 
double blind study (23), we adapted a prospective open study design wherein patients were their own controls. In the month preceding the study, all patients were screened for steatorrhea by measuring fecal acid steatocrit once every 10 days. Patients with a mean acid steatocrit value higher than $25 \%$ (normal values in our laboratory $<20 \%$ ) were invited to take part in the study. After evaluation of nutritional parameters by DXA and anthropometric methods, lansoprazole was added to their standard treatment in a dose of $15 \mathrm{mg}$ day before breakfast for 3 months. When fat malabsorption did not change after 2 months, the dose was doubled in children older than 10 years and weighing more than $30 \mathrm{~kg}$. During the lansoprazole treatment period 9 fecal samples were taken with an interval of 10 days for acid steatocrit measurements. The mean of these 9 measurements was used as a measure of steatorrhea during the treatment period. After 3 months on treatment, the nutritional condition assessment was repeated. All measurements of nutritional condition were performed on a single day. Three fecal samples for acid steatocrit determinations and anthropometric parameters were again measured respectively 1 month and 3 months after stopping lansoprazole therapy. Dietary evaluations were performed at the start, at the end and one month after stopping lansoprazole.

\section{Patients population}

$23 \mathrm{CF}$ out-clinic patients from the academic Hospital Maastricht were recruited. All patients were treated with pancreatic enzymes. Of these, 2 patients were too ill to participate in the study. 21 patients were screened for steatorrhea while on pancrease enzyme. 15 of them who had steatorrhea were included. In most children, the $\mathrm{CF}$ diagnosis had been made during the first year of life by repeated positive sweat tests, all 15 children were considered to have pancreatic insufficiency on the basis of abnormal fecal chymotrypsin, 72 hours fat balance (24) and increased acid steatocrit results (25). Mean energy intake was $113 \%$ RDA (recommended daily allowance). The mean number of pancreas enzyme capsules (Pancrease) taken by 13 of these patients was 20 (range: 11 - 33), one patient took 3 Pancrease capsules (5000E lipase, 2900E amylase, 330E protease) and 6 Panzytrat tablets (25000E lipase, 22500E amylase, 1250E protease) and another one took 10 Creon capsules (8000E lipase, 9000E amylase, $450 \mathrm{E}$ protease) per day. Mean age, weight and length of those 15 children were $9.5 \mathrm{y}$ (range: $3.1-22.6 \mathrm{y}$ ); $29.3 \mathrm{~kg}$ (range: $13.6-67.6 \mathrm{~kg}$ ) and $131 \mathrm{~cm}$ (range: $97.7-184.9 \mathrm{~cm}$ ) 
respectively. Their nutritional status was moderately altered with a mean Body Mass Index (BMI) of 15.6 (range : 13.2 - 18.3). Mean predicted values of FEV1 and FVC were respectively $81.3 \%$ (range: $39-114 \%$ ) and $85.5 \%$ (range: $44-108 \%$ ). Informed patient and parental consent were obtained.

\section{Evaluation of fat malabsorption by acid steatocrif.}

The acid steatocrit was determined as previously reported (25). In short, $0.5 \mathrm{~g}$ solid stool was weighed and diluted with a volume of deionized water, equal to two times the weight of stool. The stool and water were premixed using a Vortex mixer. Subsequently, the mixture was homogenized using a $5 \mathrm{ml}$ Potter Elvehjem tissue homogenizer. After then $5 \mathrm{~N}$ perchloric acid was added to the homogenate in a volume equal to $1 / 5$ of the homogenate. After mixing with the Vortex, the acidified homogenate was aspirated into a $75 \mu \mathrm{l}$ plain haematocrit capillary. This capillary was sealed with wax at one end and centrifuged horizontally $(13000 \mathrm{rpm}, 15$ min). After centrifugation, 3 layers were distinguished: a basal solid layer (SL), an intermediate liquid layer and an upper fatty layer (FL). Acid steatocrit was calculated as (FL / FL + SL)) $\times 100 \%$

\section{EVALUATION OF NUTRITIONAL STATUS}

\section{Anthropometry}

The armcircumference, biceps, triceps, subscapular and suprailiaca skinfolds were measured 3 times on the left side of the body using the Harpenden caliper. Average values were taken. Weight and length were also measured. BMI was calculated as weight / (length ${ }^{2}$ ). The Z score

(Z-score is defined as $\mathrm{X}-\mathrm{x} / \mathrm{S}$ where $\mathrm{X}$ is the patients 's measurement, $\mathrm{x}$ is the mean value for age and sex and $\mathrm{S}$ is the standard deviation of $\mathrm{x}$ ) of all these anthropometric parameters were calculated based on the reference data described by Gerver and de Bruin (26). A negative value indicates values under the mean reference value and a positive or negative change in $Z$ score means catch up or slowing down of growth respectively. All measurements were done 
by the same investigator (TT).

\section{Dual-energy $x$-ray absorptiomerry (DXA)}

DXA measurement is based on the differential tissue attenuation of photons of two energy levels from an X-ray source (27). All patients underwent total body scan performed with a DPX (Lunar Radiation Corp, Madison, WI) total body scanner. The results were analysed with a paediatric software programme, version $1.5 \mathrm{e}$. Daily quality assurance test was performed according to the manufacturer 's directions. Total non bone LBM (lean body mass), total BMC (bone mineral content), total body FM (fatmass) and BMD (bone mineral density) Z . score were measured by DXA procedure. These results were compared to those of the reference population, recently described by Ogle et al., who studied the body composition by DXA in 265 normal individuals aged 4 - 26 year (28).

\section{Diet evaluation}

At the beginning, at the end and one month after stopping lansoprazole nutrient intake was assessed by a specially trained clinical CF dietitian from consecutive 3 day food diaries including one weekend day. Intakes were expressed as kilocalorie per $\mathrm{kg}$ bodyweight for the energy intake and gram per $\mathrm{kg}$ bodyweight for fat-, carbohydrate- and protein-intakes, using the netherlands nutrients table "NEVO" 1993.

\section{Statistic}

All data were analysed by using SPSS statistic program. Anthropometric parameters and body composition results measured before the start and at the end of the trial were compared making use of Wilcoxon one sample test. The sign test was used to compare LBM, FM and BMC assessed by DXA, with the reference population described by Ogle. 


\section{RESULTS}

\section{Eat malabsorption}

Despite standard pancreas enzyme, 15 of 21 children had steatorrhea with an average \pm SD pretreatment acid steatocrit value (mean of 3 determinations in each patient) of $37.1 \% \pm 8.8 \%$. After 3 months of treatment with lansoprazole, there was a significant $(p=0.02)$ improvement in steatorrhea with a mean $\pm \mathrm{SD}$ acid steatocrit value of $28.5 \% \pm 10.6 \%$. Eight patients on lansoprazole had a mean acid steatocrit value lower than $25 \%$ (fig 1 ). In this group the mean decrease was $16 \%$ ( $44.2 \%$ of start value). In 3 children the acid steatocrit value decreased with. $9 \%$ (20.6\% of start value) but was not completely corrected. In 4 children fat malabsorption. did not improve at all. Four children received a double dose of lansoprazole for 1 month, resulting in a decreased acid steatocrit results in 2 (decrease of $8.6 \%$ and $19 \%$ ). Due to social problems one child was dropped out of the study after the lansoprazole period. Mean \pm SD acid steatocrit value for the remaining 14 children in the first month after stopping lansoprazole was $29.7 \% \pm 13.9 \%$, which was not significantly different from the values on lansoprazole. Of 4 children whose acid steatocrit was not changed on lansoprazole, 2 had higher acid. steatocrit values after stopping.

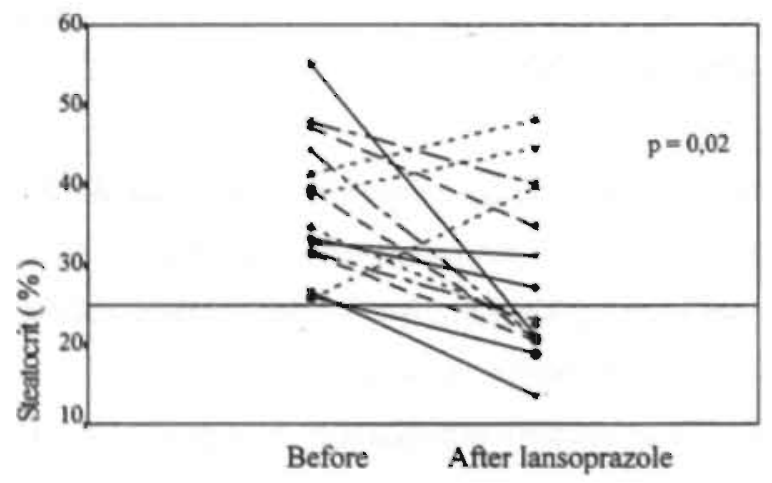

Figure 1 Acid steatocrit before and after 3 months treatment with lansoprazole in 15 CF children. A line through the $25 \%$ value is drawn showing the study inclusion limit. Acid steatocrit values on lansoprazole art significantly decreased $(p=0.02)$. 
Mean and $95 \% \mathrm{Cl}$ (confidence interval) for weight, length, armcircumference, 4 skinfolds and the sum of these 4 skinfolds expressed as Z-score are shown in fig.2. For all parameters except the triceps, the $\mathrm{CI}$ do not include the reference 50 th centile line (Z-score 0 ), underscoring the fact that except for the triceps skinfold, all other anthropometric parameters mean Z-scores were significantly decreased in our CF children when compared to those of the normal population. The suprailiaca skinfold was most abnormal and showed the smallest interindividual variation.

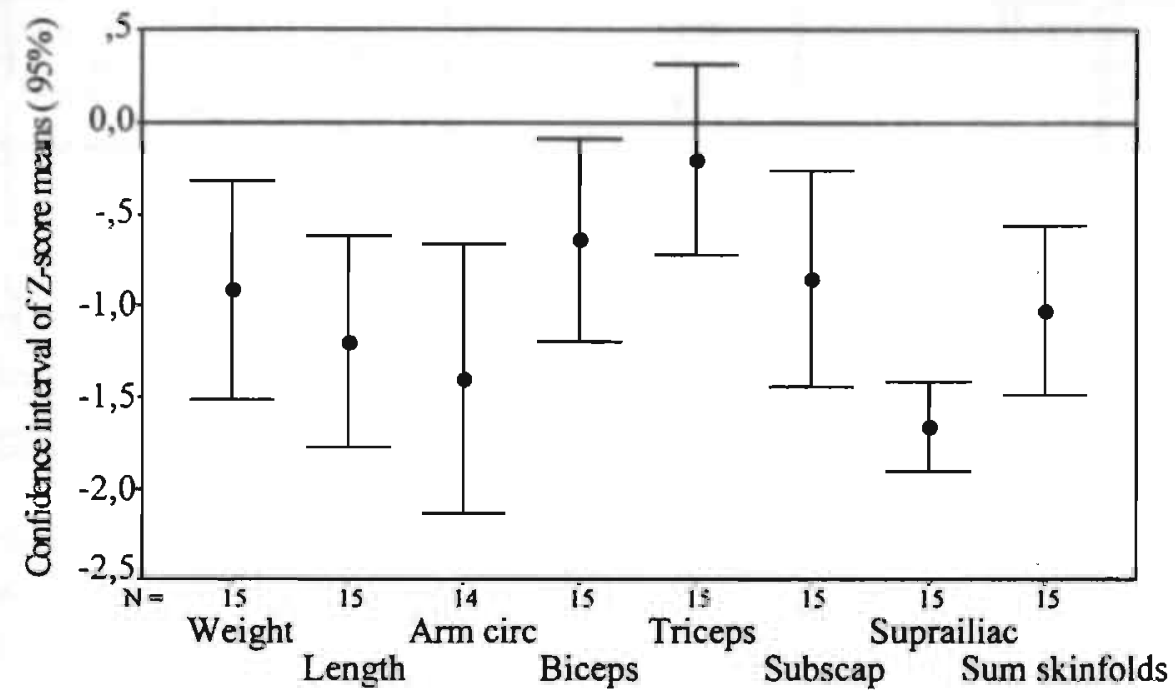

Figure 2 Mean Z-scores and $95 \%$ confidence interval of anthropometric parameters in $15 \mathrm{CF}$, children before lansoprazole therapy. The line through 0 represents the 50th centile of the reference population. The differences between the study group and the reference population are significant when the $\mathrm{CI}$ do not include the Z-score 0 line. All anthropometric parameters were significantly decreased in our CF children except for the triceps skinfold. 
After treatment with lansoprazole, Z-scores of anthropometric parameters improved signifcantly. All parameters moved toward the Z-score 0 line (50th centile for reference population). The Z-scores of biceps, subscapular and sum of the 4 skinfolds did not significantly differ from the reference population any more (fig.3).

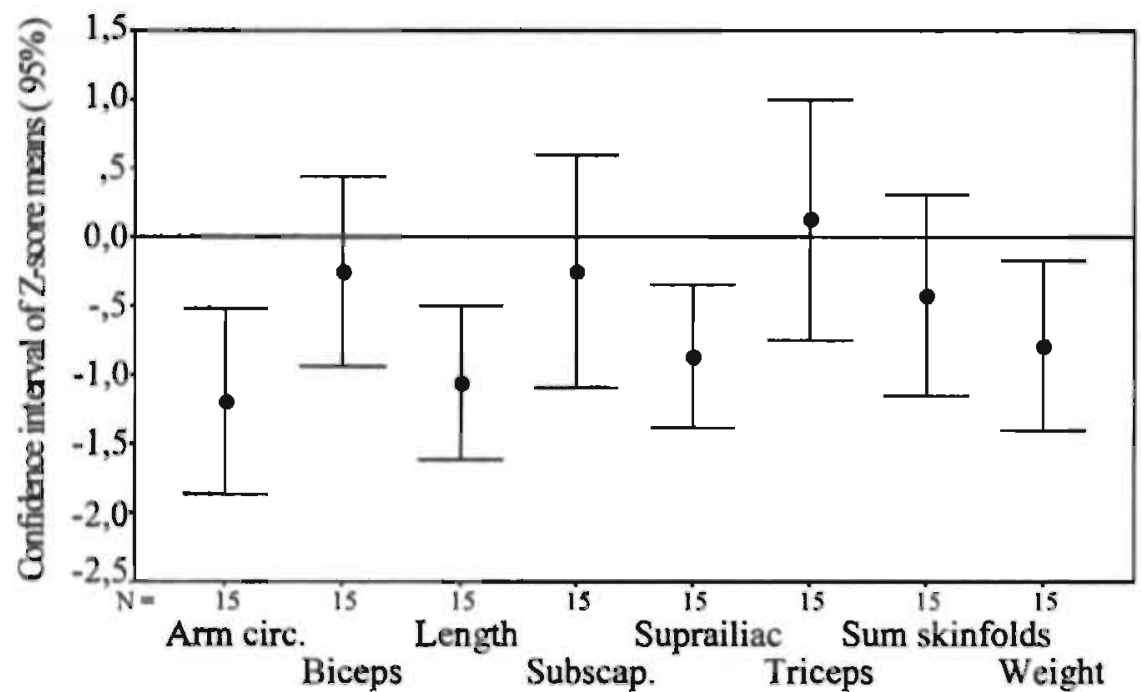

Figure 3 Mean Z-scores and $95 \%$ confidence interval of anthropometric parameters in 15 CF' children on lansoprazole for 3 months. The differences between the study group and the reference population are significant when the $\mathrm{CI}$ do not include the Z-score 0 line. Several parameters (biceps, subscapular and sum of 4 skinfolds) normalized during lansoprazole treatment (see figure 2).

Z-score changes for all anthropometric parameters studied are shown in table: 1. Except for armcircumference, biceps and triceps skinfolds, Z-scores of all parameters improved significantly. Subscapular, suprailiaca and the sum of the 4 skinfolds showed the most significant changes. The acid steatocrit results during lansoprazole treatment were significantly lower ( $p$ $=0.01$ ) in our patient subgroup with subscapular Z-score improvement 20.5 when compared to the subgroup showing lower Z-score changes. Three months after lansoprazole was stopped, 5 children were dropped out of the study; 2 because of the far distances from home, 1 had 
taken lansoprazole again because of increased symptoms of steatorrhea and abdominal pain and 2 because of social problems. Nutritional parameters were therefore evaluated in only 10 children 3 months after stopping lansoprazole. Z-scores of all anthropometric parameters deteriorated, with weight and subscapular Z-score changes reaching statistical significance (table 1).

Table 1 Mean Z-scores of anthropometric parameters in $15 \mathrm{CF}$ children before (T0), after 3 months on lansoprazole (T3) and 3 months after stopping lansoprazole (T6).

\begin{tabular}{|c|c|c|c|c|c|}
\hline $\begin{array}{c}\text { Anthrop. } \\
\text { Parameters }\end{array}$ & $\begin{array}{c}\text { Me } \\
\text { Mean Z-score } \\
(\mathrm{n}=15)\end{array}$ & $\begin{array}{c}\text { T3 } \\
\text { Mean Z-score } \\
(\mathrm{n}=15)\end{array}$ & $\begin{array}{c}\text { T6 } \\
\text { Mean Z-score } \\
(\mathrm{p}=10)\end{array}$ & $\begin{array}{c}\text { T3- T0 } \\
\text { Mean Z-score } \\
(\mathrm{n}=15)\end{array}$ & $\begin{array}{c}\text { T6-T3 } \\
\text { Mean Z-score } \\
(\mathrm{n}=10)\end{array}$ \\
\hline Weight & -0.91 & -0.78 & -1.38 & $0.14(\mathrm{p}=0.02)$ & $-0.6(\mathrm{p}=0.01)$ \\
Length & -1.2 & -1.05 & -1.23 & $0.15(\mathrm{p}=0.03)$ & $-0.18(\mathrm{p}=0.16)$ \\
Armeircum & -1.4 & -1.19 & -1.74 & $0.22(\mathrm{p}=0.05)$ & $-0.55(\mathrm{p}=0.52)$ \\
Biceps & -0.63 & -0.24 & -1 & $0.39(\mathrm{p}=0.06)$ & $-0.76(\mathrm{p}=0.21)$ \\
Triceps & -0.2 & 0.14 & -0.72 & $0.34(\mathrm{p}=0.2)$ & $-0.86(\mathrm{p}=0.26)$ \\
Subscapular & -0.85 & -0.24 & -1.14 & $0.61(\mathrm{p}=0.003)$ & $-0.9(\mathrm{p}=0.03)$ \\
Suprailiaca & -1.66 & -0.86 & -1.13 & $0.8(\mathrm{p}=0.002)$ & $-0.27(\mathrm{p}=0.68)$ \\
Sum skinfolds & -1.02 & -0.41 & -1.16 & $0.61(\mathrm{p}=0.002)$ & $-0.75(\mathrm{p}=0.31)$ \\
\hline
\end{tabular}

\section{Body composition}

Body composition data before and after lansoprazole are given in table 2. All 3 components FM, LBM and BMC were significantly decreased in our 15 CF children when compared to the reference population described by Ogle et al. $(p=0.01 ; p=0.02$ and $p=0.005$ respectively). Bone mineral density Z-score was significantly decreased ( $p \leq 0.05$ ). Significant increases of FM and BMC occurred after 3 months of treatment with lansoprazole. Changes in the subscapular, suprailiaca and sum of the 4 skinfolds $Z$-scores were highly correlated with changes in FM by DXA ( $r=0.81 / r=0.77 / r=0.85$ resp. with $p=0.001)$ (fig 4). 


\section{Diet evaluation}

Mean fat, protein, carbohydrate and energy intakes were $3.1-2.8-3.0 \mathrm{~g} / \mathrm{kg} ; 3.0-2.7-2.8$ $\mathrm{g} / \mathrm{kg} ; 10.4-9.7-9.8 \mathrm{~g} / \mathrm{kg}$ and $2095-1986-1977 \mathrm{kcal} / \mathrm{kg}$ bodyweight at the start, at the end and one month after lansoprazole trial respectively. None of these changes were significant.

Table 2 Body composition before (T0) and after (T3) lansoprazole by DXA.

\begin{tabular}{|c|c|c|c|}
\hline $\begin{array}{c}\text { BODY } \\
\text { COMPOSITION }\end{array}$ & $\begin{array}{c}\text { T0 } \\
(\mathrm{n}=15)\end{array}$ & $\begin{array}{c}\text { T3 } \\
(\mathrm{n}=15)\end{array}$ & $\begin{array}{c}\text { SIGNIFICANCY } \\
(\mathrm{p})\end{array}$ \\
\hline MEAN FATMASS (Kg) & 3.97 & 4.76 & 0.008 \\
MEAN LBM (Kg) & 22.83 & 24.03 & 0.06 \\
MEAN BMC (Kg) & 1.02 & 1.08 & 0.005 \\
MEAN BMD ( Z-SCORE) & -0.55 & -0.58 & 0.65 \\
\hline
\end{tabular}




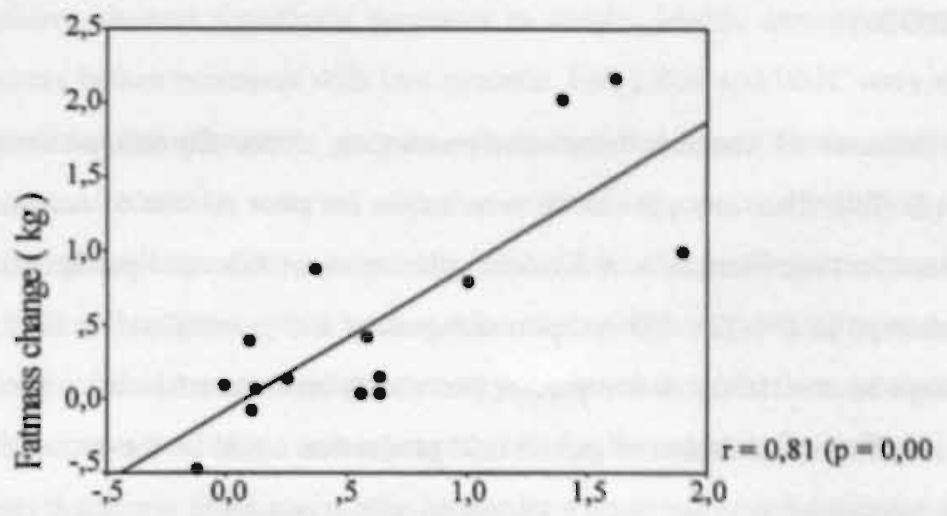

Change in subscapular Z-score

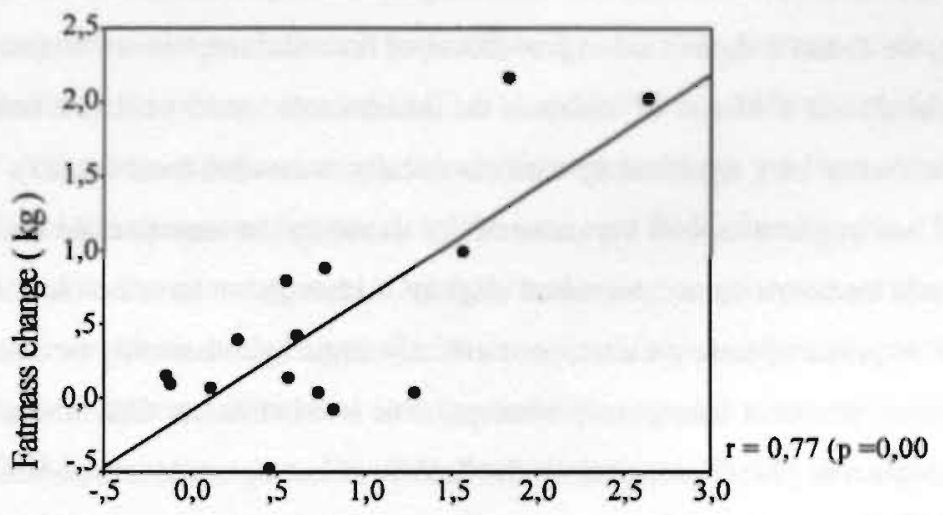

Change in suprailiaca Z-score

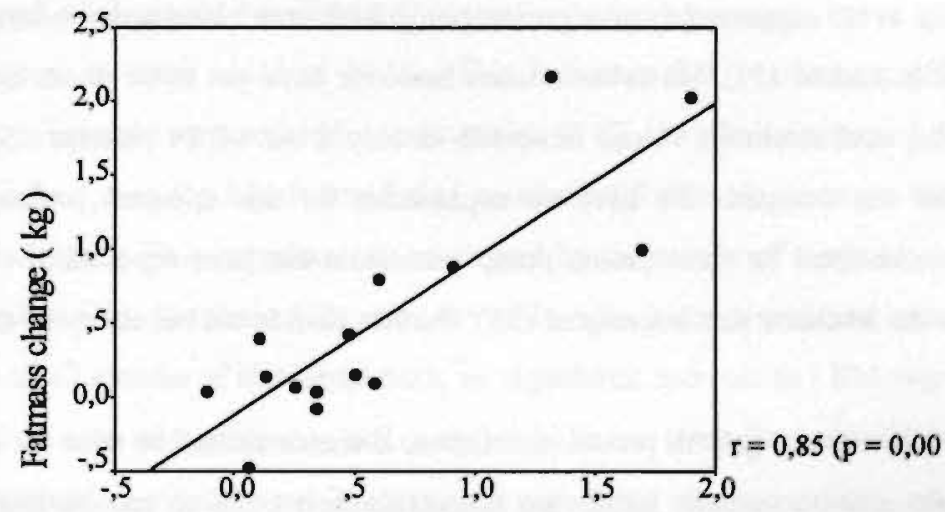

Change in sum of skinfolds Z-score

Figure 4 Relation between changes in subscapular skinfold Z-score, suprailiaca skinfold Z-score, sum of 4 skinfolds Z-score and fatmass as measured by DXA (dual energy X-ray absorptiometry) in 15 CF children. 


\section{DISCUSSION}

Due to a decrease of pancreas bicarbonate secretion, cystic fibrosis patients have a low duodenal $\mathrm{pH}$ (29). This low $\mathrm{pH}$ can be responsible for poor release of enzymes through the acid resistent coating. Further, low duodenal $\mathrm{pH}$ can cause bile acid precipitation resulting in lipid malabsorption (30-32). H2-receptor antagonists and prostaglandine E2 have been used with the hope to reverse the above proces, but results on steatorrhea have been controversial (17-22). Insufficient inhibition of gastric acid production could be the cause of these failures As proton pump inhibitors are known to control acid secretion in a much more effective way (33), they could be more effective in increasing duodenal $\mathrm{pH}$. In agreement with Heijermans et al. (23), we found a significant improvement of fat malabsorption as measured by the acid steatocrit in all but 4 of our $\mathrm{CF}$ children on lansoprazole. Acid steatocrit results have been shown to correlate very significantly with chemically measured fecal fat (25). Acid steatocrit values did not improve in 4 of our patients. By doubling the lansoprazole dose in 2 of these patients, acid steatocrit values decreased slightly. Although we have no clear explanation for the lack of response of these patients, poor efficacy could hypothetically be due to host factors including poor intestinal lansoprazole absorption or interindividual differences in bioavailability of lansoprazole (34). Further, since the halflife of lansoprazole is between 1 and 2 hours and inhibition will be limited to proton pumps active during the effective plasma levels of the drugs, Sachs et al. suggested to give proton pump inhibitors twice a day whenever effective $\mathrm{pH}$ control is desired (33). However, studies hereover have yet to be done. Contrary to our expectations, acid steatocrit values increased in only 8 out of 14 patients one month after lansoprazole was stopped. We have no explanation for this apparent prolonged effect of lansoprazole on fecal fat since proton pump restoration has been reported to occur 50 to 72 hours after the inhibitor was interrupted (33). Further studies are necessary in order to clarify this point.

Because of the normal growth proces in children, Z-scores should be used for the evaluation of anthropometric parameters. Improving Z-scores reflect catch-up growth and consequently improvement in the nutritional status while the reverse is true for deteriorating Z-scores. The recent introduction of DXA methodology makes it possible to evaluate FM, LBM and BMC rapidly and non invasively in children (27). In agreement with previous studies, all except 2 
of our CF children showed significant decreases in weight, length, armeircumference and 4 skinfolds Z-scores before treatment with lansoprazole. FM, LBM and BMC were also significantly decreased despite pancreatic enzyme substitution and hypercaloric supplementation. The catabolic proces could be reversed after 3 months of lansoprazole resulting in Z-scores improvement of all anthropometric parameters, FM, BMC and to a lesser extent LBM. The improved nutritional condition could be due either to higher energy intakes or to improved absorption. As we found somewhat lower energy intakes during the lansoprazole treatment period, a higher intake probably is not responsible for the improved nutritional condition. Further, the fact that lower fecal acid steatocrit results were found in our patients with the best nutritional response as assessed by subscapular Z-score improvements, supports the idea that improved absorption is the main factor responsible for the improvement of the nutritional status in our patients. However increased FM, LBM and BMC are difficult to interpret because results for reference populations expressed as Z-scores have not yet been reported. As Zscore of BMD did not change on lansoprazole, the increased BMC found in our $\mathrm{CF}$ children, is probably linked to the growth proces. Our results showing deterioration of the nutritional condition after interruption of lansoprazole "intervention", are in agreement with those of Bertrand et al., who reported nutritional deterioration after stopping elemental enteral alimentation (14). Oral hypercaloric diets have not been shown to improve Z-scores of weight, length and skinfolds as parameters for nutritional status and growth proces of $\mathrm{CF}$ children (8). Only parenteral or elemental "predigested" enteral nutrition have been shown to reverse the catabolic process in these children (9-15). This indicates that persisting maldigestion or malabsorption is mainly responsible for malnutrition in CF. As alkalinization of duodenal pH improves malabsorption $(16,22)$, it could also, as elemental diets do, improve the nutritional status of CF children. This hypothesis is confirmed by the results of our study. In contrast with $O^{\prime}$ Loughlin (10), Shepherd (12) and Levy (13), who found significant improvement in LBM after 6 to 12 months of elemental diets, no significant increase in LBM was seen in our study. The 3 months of treatment in our study could be too short for a significant change in LBM to be noticed. Our results are in agreement with those of other authors, who evaluated the effect of gluten free diet on body compartments by DXA. Only FM and BMC improved after a 6 months gluten free diet while LBM did not (35). As H2 - receptor antagonists have been shown to significantly decrease nitrogen malabsorption in CF patients (36), we do not 
think that the poor improvement of LBM in our patients can be ascribed to a selective improvement of fat and not of protein malabsorption.

In conclusion, most of our CF children maintained steatorrhea and were malnourished despite optimal treatment with hypercaloric diets and pancreatic enzymes. Lansoprazole as adjuvant therapy resulted in decreased fat malabsorption and improved nutritional status in these $\mathrm{CF}$ children after 3 months of treatment. Longterm evaluation of the effect of lansoprazole on both the nutritional status and lung function parameters have yet to be performed.

\section{Acknowledgment}

we are gratefull to Liesbeth van der Ploeg, Lianne Schoorlemmer dieticians and Piet Willems, Sandra Zimny from the department of nuclear medicine for their invaluable assistance. We also thank all nurses of the pediatric polyclinic for their welwilling support. 


\section{REFERENCES}

(1) M. Welsh, A. Smith. Molecular mechanisms of CFTR chloride channel dysfunction in cystic fibrosis. Cell 1993; 73:1251-1254.

(2) J. Tomezsko, V. Stallings, D. Kawchak, J. Goin, G. Diamond, T. Scanlin. Energy expenditure and genotype of children with cystic fibrosis. Pediatr Res 1994; $35: 451$ - 460.

(3) M. Bronstein, P. Davies, K. Hambidge, F. Accurso. Normal energy expenditure in the infant with presymptomatic cystic fibrosis. J Pediatr 1995; 126: 28-33.

(4) R.Kraemer, A. Rüdeberg, B. Hadorn, E. Rossi. Relative underweight in cystic fibrosis and its prognostic value. Acta Paediatr Scand 1978; 67: 33-37.

(5) P. Robinson, P. Sly. High dose pancreatic enzymes in cystic fibrosis. Arch Dis Child. $1990 ; 65: 311-312$.

(6) E. Lebenthal. High strength pancreatic exocrine enzyme capsules associated with colonic strictures in patients with cystic fibrosis: "more is not necessarily better". J Pediatr Gastroenterol Nutr. 1994; 18: 423-425.

(7) R. Smyth, D. van Velzen, A. Smyth, D. Lloyd, D. Heaf. Strictures of ascending colon in cystic fibrosis and high strength pancreatic enzymes. The Lancet. 1994; 343: 85-86.

(8) A. Rettammel, M. Marcus, P. Farrell, S. Sondel, R. Koscik, E. Mischler. J Am Diet Assoc. 1995; 95: 454-459.

(9) K. Gaskin, D. Waters, L. Baur, V. Soutter, M. Gruca. Acta Paediatr Scand [Suppl]. 1990; 366: $106-110$.

(10) E. O' Loughlin, D. Forbes, H. Parsons, B. Scott, D. Cooper, G. Gall. Nutritional rehabilitation of malnourished patients with cystic fibrosis. Am J Clin Nutr. 1986: 43: 732-737.

(11) R. Shepherd, T. Holt, B. Thomas et al. Nutritional rehabilitation in cystic fibrosis: Controlled studies of effects on nutritional growth retardation, body protein turnover, and course of pulmonary desease. J Pediatr. 1986; 109: 788-94.

(12) R. Shepherd, B. Thomas, D. Bennett, W. Cooksley, L. Ward. Changes in body composition and muscle protein degradation during nutritional supplementation in nutritionally growth-retarded children with cystic fibrosis. J Pediatr Gastroenterol Nutr. 1983; $2: 439-446$.

(13) L. Levy, P. Durie, P. Pencharz, M. Corey. Effects of long-term nutritional rehabilitation on body composition and clinical status in malnourished children and adolescents with cystic 
fibrosis. J Pediatr 1985; 107: 225-230.

(14) J. Bertrand, C. Morin, R. Lasalle, J. Patrick, A. Coates. Short-term clinical, nutritional, and functional effects of continuous elemental enteral alimentation in children with cystic fibrosis. J Pediatr. 1984; 104: 41-46.

(15) R. Shepherd, W. Cooksley, and W. Domville. Improved growth and clinical, nutritional, and respiratory changes in response to nutritional therapy in cystic fibrosis. J Pediatr. 1980; 97: 351-357.

(16) P. Robinson, A. Smith, and P. Sly. Duodenal pH in Cystic fibrosis and its relationship to fat malabsorption. Dig Dis Sci. 1990; 35: 1299-1304.

(17) A. Carroccio, F. Pardo, G. Montalto et al. Use of famotidine in severe exocrine pancreatic insufficiency with persistent maldigestion on enzymatic replacement therapy: A long-term study in cystic fibrosis. Dig Dis Sci 1992; 37: 1441-1446.

(18) D. Chalmers, R. Brown, M. Miller et al. The influence of longterm cimetidine as an adjuvant to pancreatic enzyme therapy in cystic fibrosis. Acta Paediatr Scand. 1985; 74: 114 117.

(19) P. Robinson and P. Sly. Placebo-controlled trial of misoprostol in cystic fibrosis. J Pediatr Gastroenterol Nutr. 1990; 11:37-40.

(20) H. Heijerman, C. Lamers, J. Dijkman, and W. Bakker. Ranitidine compared with the dimethylprostaglandin E2 analogue enprostil as adjunct to pancreatic enzyme replacement in adult cystic fibrosis. Scand J Gastroenterol. 1990; 25 (Suppl 178): 26-31.

(21) M. Schöni, R. Kraemer, E. Rossi. Cimetidine and fat malabsorption in children with cystic fibrosis. Helv Paediat Acta. 1981; 36: 359-369.

(22) B. Boyle, W. Long, W. Balistreri, S. Widzer, and N. Huang. Effect of cimetidine and pancreatic enzymes on serum and fecal bile acids and fat absorption in cystic fibrosis. Gastroenterology. 1980; 78: 950-953.

(23) H. Heijerman, C. Lamers, W. Bakker. Omeprazole enhances the efficacy of pancreatin (pancrease) in cystic fibrosis. Ann İntern Med. 1991; 114: 200-201.

(24) J. van de Kamer, H. Huinink, H. Weyers. Rapid method for determination of fat in feces. J Biol Chem. 1949; 177: 349-55.

(25) M. Tran, P. Forget, A. Van den Neucker, J. Strik, B. van Kreel, and R. Kuijten. The acid steatocrit: A much improved method. J Pediatr Gastroenterol Nutr. 1994; 19: 299-303. 
(26) W. Gerver, R. de Bruin. Paediatric Morphometrics: A reference manual. 1th ed. Utrecht: Bunge, 1995.

(27) R. Mazess, H. Barden, J. Bisek, and J. Hanson. Dual-energy x-ray absorptiometry for total-body and regional bone-mineral and soft-tissue composition. Am J Clin Nutr. 1990; 51:1106-12.

(28) G. Ogle, J. Allen, I. Humphries et al. Body-composition assessment by dual-energy x-ray absorptiometry in subjects aged 4-26 y. Am J Clin Nutr. 1995; 61:746-53.

(29) A. Weber, C. Roy. Intraduodenal events in cystic fibrosis. J Pediatr Gastroenterol Nutr. 1984; 3 (Suppl. 1): S113-S119.

(30) P. Regan, J. Malagelada, E. Dimagno, and V. Go. Reduced intraluminal bile acid concentrations and fat maldigestion in pancreatic insufficiency: Correction by treatment. Gastroenterology. 1979; 77: 285-289.

(31) P. Zentler-Munro, W. Fitzpatrick, J. Batten, and T. Northfield. Effect of intrajejunal acidity on aqueous phase bile acid and lipid concentrations in pancreatic steatorrhoea due to cystic fibrosis. Gut. 1984; 25: 500-507.

(32) P. Zentler-Munro, D. Fine, J. Batten, and T. Northfield. Effect of cimetidine on enzyme inactivation, bile acid precipitation, and lipid solubilisation in pancreatic steatorrhoea due to cystic fibrosis. Gut. 1985; 26: 892-901.

(33) G. Sachs, J. Shin, C. Briving, B. Wallmark, S. Hersey. The pharmacology of the gastric acid pump: The H+, K+ ATPase. Annu Rev Pharmacol Toxicol. 1995; 35: 277-305.

(34) C. Spencer and D. Faulds. Drugs: Focus on Lansoprazole. 1994; 48: 404-430.

(35) G. Barera, P. Brambilla, P. Manzoni, S. Acciuffi, G. Caccia, C. Bianchi. Changes in body composition evaluated by DXA during gluten free diet in celiac children. J Pediatr Gastroenterol Nutr. 1995; 20: 476 "abstr".

(36) K. Cox, J. Isenberg, A. Osher, R. Dooley. The effect of cimetidine on maldigestion in cystic fibrosis. J. Pediatr. 1979; 94: 488-492. 


\title{
CHAPTER 7
}

\section{ANTHROPOMETRY AND BODY COMPOSITION IN CHILDREN WITH CYSTIC FIBROSIS: EFFECTS OF A PROTON - PUMP INHIBITOR}

\author{
(1)My-Dung T.Tran, (1)Anita Van den Neucker, (1)Han J. Hendriks, (")Bernard van Kreel, \\ (1)Patricia Forget, ${ }^{\sigma}$ Guido Heidendal, (1)Pierre-Philippe Forget
}

(1)Department of Pediatrics, (") Clinical Chemistry and ${ }^{\sigma}$ Nuclear Medicine, University Hospital Maastricht, Maastricht, the Netherlands.

Submitted for publication

\section{Abstract}

We studied the body composition of $18 \mathrm{CF}$ children making use of dual-energy X-ray absorptiometry (DEXA), deuterium-bromide and skinfold methods and evaluated the efficacy of these body composition methods for the detection of body composition changes during 3 months therapeutic intervention with lansoprazole. Our $\mathrm{CF}$ patients were malnourished with decreased mean Z-scores for armcircumference $(-1.62)$, biceps $(-0.77)$, subscapular $(-0.92)$, suprailiac skinfolds $(-1.66)$, weight $(-1.03)$ and height $(-1.31)$.Their fatmass was significanly depleted as shown by DEXA, skinfold and total body water (TBW) methods. Extracellular volume (\%) was increased, while intracellular volume (\%) was normal. Only the lean body mass (LBM) as measured by DEXA was decreased $(p=0.02)$. Decreased bone mineral content and bone mineral density $Z$-scores were also found $(p=0.005$ and $p=0.03$ respectively). After treatment with lansoprazole, significant increases in fatmass was found by DEXA and skinfold methods ( $53 \%$ and $97 \%$ of weight changes respectively) whereas weight increase was exelusively ascribed to an increase in LBM with the TBW method. Changes in body. weight however, were not correlated with either fatmass and fat free mass changes as measured by any of these methods. We conclude that results of DEXA, TBW and skinfold methods are not interchangeable and that the methods used are not accurate enough for the differential detection of small changes in fatmass and fat free mass as found in the present study. 


\section{INTRODUCTION}

Due to malabsorption (1), chronic lung infections with increased energy expenditure $(2,3)$ and poor appetite, most cystic fibrosis patients show signs of malnutrition. As malnutrition can affect pulmonary function and shorten survival (4), feeding interventions are sometimes necessary to restore normal growth and body composition. Assessment of body composition changes is necessary for the precise evaluation of nutritional interventions. While different body composition methods have been described, only few studies have, to our knowledge, compared different measurement techniques in pediatric subjects and there are no reports on the efficacy of these methods for the detection of body composition changes during therapeutic interventions. In children, Dual-energy X-ray absorptiometry (DEXA), Total Body Water (TBW) and Skinfold methods are frequently used for the determination of body composition since they are all noninvasive. In this age group, methods used for measuring body composition have to be very precise in order to detect small changes in body composition. The precision for repeated measurements has been reported to be $1-2 \%$ for DEXA, $1.6 \%$ for TBW and either $5 \%$ (intraobserver) or $15 \%$ (interobserver) for the skinfold method (5). In the present study we first evaluated the body composition of our $18 \mathrm{CF}$ children making use of DEXA, skinfolds and TBW (deuterium-bromide)methods and subsequently evaluated the agreement between these results. Secondly, we investigated the sensitivity of these 3 methods for the detection of small changes in body composition of $15 \mathrm{CF}$ children whose nutritional condition improved significantly after intervention with lansoprazole for 3 months. For the purpose of the present study we defined fat free mass by DEXA (FFM-DEXA) as the sum of lean body mass (LBM) and bone mineral content (BMC) and total mass (TM) as DEXA constructed weight $(\mathrm{LBM}+\mathrm{FM}+\mathrm{BMC})$.

\section{SUBJECTS}

\section{Ropulation studied for the comparison of bodv composition methods}

$23 \mathrm{CF}$ children were recruited from the Academic Hospital Maastricht. The Netherlands. Of these 2 patients were too ill to take part in the study and 3 children refused to participate. 18 
children who had no exacerbation 4 weeks before the study were included. Thirteen of them were prepubertal and younger than ten years, 3 children were postpubertal and were between 11.6 - 14.1 years. Two subjects were adolescents of 16.1 and 22.6 years. Fourteen of these 18 children were diagnosed during the first year of life while 16 of them had pancreatic insuffi. ciency (abnormal fecal chymotrypsin and $72 \mathrm{~h}$ fecal fat balance). Their nutritional status was moderate with a mean BMI (body mass index) of 15.6 (range: 13.2 - 23.2). Mean age, weight and height were respectively 9.0 y (range: $2.9-22.6 \mathrm{y}$ ); $27.4 \mathrm{~kg}$ (range: $13.6-67.6 \mathrm{~kg}$ ) and $127.5 \mathrm{~cm}$ (range: 96.2 - $184.9 \mathrm{~cm}$ ). Mean FEV1 (forced expiratory volume in 1 second) and FVC (forced vital capicity) were respectively $84 \%$ (range: $39-117 \%$ ) and $86 \%$ (range: 44 . $109 \%$ ) of predicted values. Mean energy intake was $113 \%$ RDA (recommended daily allowance). All patients were on conventional physiotherapy, pancreatic enzymes and some of them received antibiotics regularly for pulmonary exacerbations.

Weight, height, armcircumferences, TBW, DEXA and skinfolds were measured on the same day. All usual CF medications were continued during the study.

\section{Population studied for the evaluation of changes in body composition}

We included 15 out of 16 children with pancreatic insufficiency as described above who maintained steatorrhea despite pancreatic enzymes and were treated with lansoprazole for 3 months with significant improvement of anthropometric parameters (results will be published separately). Mean age, weight and height of these 15 children were $9.5 \mathrm{y}$ (range: $3.1-22.6 \mathrm{y}$ ); $29.3 \mathrm{~kg}$ (range: $13.6-67.6 \mathrm{~kg}$ ) and $131 \mathrm{~cm}$ (range: $97.7-184.9 \mathrm{~cm}$ ) respectively. Their nutritional status was moderately altered with a mean Body Mass Index (BMI) of 15,6 (range : 13.2 - 18.3). Mean FEV1 and FVC were respectively $81.3 \%$ (range: $39-114 \%$ ) and $85.5 \%$ (range: $44-108 \%$ ) of predicted values.

Anthropometry, DEXA and TBW were measured on the same day just before starting and 3 months after treatment with lansoprazole ( $15 \mathrm{mg} /$ day). Other usual CF medications were continued throughout the study. Informed patient and parental consent were obtained from all study subjects. 


\section{METHODS}

\section{Growth parameters}

Weight, height, upper armcircumferences and 4 skinfold thicknesses (biceps, triceps, subscapular and suprailiac) were measured on the left side of the body in triplicate, using the Harpenden caliper. Average of three measures was taken and was expressed as standard deviation scores of the normal population for age and sex using the growth charts from Gerver and de Bruin (6). BMI was calculated as weight/height ${ }^{2}$. Results of BMI were compared to the reference population described by Westrate and Deurenberg et al. (7). Mid upper arm muscle area was calculated from the mid upper armcircumference and the sum of biceps and triceps skinfolds (6).

\section{Body composition}

Body composition results obtained from all three methods were compared to those of a recently reported pediatric reference population (8). The percentage of fatmass and fat free mass measured by the skinfold method were also compared to those of the reference population described by Gerver and de Bruin (6).

\section{Body composition by anthropometry}

It has been found that subcutaneous fat as measured by skinfolds is related to the body density (9). This latter is itself related to the body fatmass. From these theoretical principles, Gerver and de Bruin have constructed a chart, expressing the relationship between the 4 skinfolds (biceps, triceps, subscapular and suprailiac) and the percent fat free mass (6). In our study, fat free mass determined by this method was derived from these charts and fatmass was then calculated by subtracting FFM from bodyweight.

\section{Bedycomposition by dual-energy x-ray ahsorptiometry}


The theoretical principles for DEXA measurement of body composition and the precision of this method have been described previously (10-12). All DEXA measurements were performed with a Dual Photon X-ray ( Lunar Radiation Corp, Madison, WI ) total body scanner. These results were analysed with a pediatric software programme, version $1.5 \mathrm{e}$. Daily quality assurance tests were performed according to the manufacturer 's directions. Total body analysis was performed in all children using a fast scan mode with a sample size of $4.8 \times 9.6 \mathrm{~mm}$, sample interval of $0.03 \mathrm{~s}$ and source collimation of $1.68 \mathrm{~mm}$. The following body compartments were assessed: total non bone lean body mass, total bone mineral content, total bone mineral density (BMD), total body fatmass and Z-score of BMD.

\section{Body composition by total body water and bromide space}

TBW and ECV were measured by deuterium oxide (13) and bromide dilution respectively (14). Each subject received orally $20 \mathrm{ml}(40 \mathrm{ml}$ was given to the 2 adolescent patients) of a mixture of $\mathrm{D}_{2} \mathrm{O}(99.9 \%$ purity) and Bromide salt $(150 \mathrm{mMol} / \mathrm{L})$ solution in a volume ratio of 1:1. Saliva and plasma samples were taken before intake of $\mathrm{D}_{2} \mathrm{O}-\mathrm{NaBr}$ solution and 4 hours thereafter when an "plateau" has been reached. To prevent saliva dilution by fluid intake which can result in a higher TBW content, patients were told not to take any fluid orally half an hour before saliva samples were taken. Urine and fecal loss of bromide and $\mathrm{D}_{2} \mathrm{O}$ during the equilibriation period were considered negligible as the $\mathrm{D}_{2} \mathrm{O}$ and bromide $\mathrm{Tl} / 2$ are about 8 days (14). Saliva samples were obtained making use of dental cotton-wool, that was dried overnight at $100^{\circ} \mathrm{C}$ and kept in a gas-tight tube until use. The cotton-wools and the blood samples were centrifuged and the saliva and serum thus obtained were kept in a stoppered glass vial and stored in a freezer at $-20^{\circ} \mathrm{C}$ until analysis. Results of TBW, ECV and ICV were compared to the reference values described by Friis-Hansen (15).

\section{TBW ANALYSIS}

$\mathrm{D}_{2} \mathrm{O}$ concentrations of saliva samples were determined as described by van Kreel (14): Calcium carbide $\left(\mathrm{CaC}_{2}\right)$ was placed in the siliconized vacutainer tube and evacuated for $30 \mathrm{sec}$. with a rotatory vane pump to a total pressure of $0,01 \mathrm{~atm}$. Thereafter, $25 \mu \mathrm{l}$ of salivary sample 
was injected in the vacutainer tube. This was done in duplicate. $\mathrm{CaC}_{2}$ react with $\mathrm{D}_{2} \mathrm{O}$ forming acetylene gas. A $25 \mu \mathrm{l}$ sample of this gas was subsequently injected in duplicate into the GC/CF - IRMS system (gas chromatography/continous flow isotope ratio mass spectrometry) at $2 \mathrm{~min}$. intervals. The mass 27/26 ratio (R27/26) was measured on a Isotope Ratio Mass Spectrometer configured for Acetylene (Finnigan MAT 252 for CF-IRMS). The mean value of 4 determinations was calculated for each sample. By inserting the tracer/tracee ratio, defined as R27/26 (T4) - R27/26 (T0), into the regression equation obtained from the standards, we get the dilution factor of $\mathrm{D}_{2} \mathrm{O}$. TBW is calculated as ingested $\mathrm{D} O \mathrm{O}$ volume/dilution factor. FFM and FM are then calculated by the following formules:

$$
\begin{aligned}
& \mathrm{FFM}(\mathrm{kg})=\mathrm{TBW} /(1,04 \mathrm{xd}) \\
& \mathrm{FM}(\mathrm{kg})=\text { Weight }- \text { FFM }
\end{aligned}
$$

The 1,04 factor is a correction for the estimated $4 \%$ nonaqueous hydrogen exchange and $\mathrm{d}$ is the hydration factor of LBM which varies with age and sex. Because our CF population was young, we used the age dependent hydration factors described by Fomon (16) for children younger than 10 year and by Boileau and Lohman (17) for older children.

\section{BROMIDE DILUTION ANALYSIS}

Because bromide resides mainly in the extracellular space, the measurement of bromide dilution gives an estimate of the extracellular volume. Bromide was determined by using a Gas Chromatograph type CP 9000 (Chrompack) equipped with an ECD detector after it was converted into bromoacetone gas (14). First, perchloric acid was added to the serum sample and centrifuged for deproteinisation. An aliquot of the supernatant was then added to silver nitrate $\left(\mathrm{AgNO}_{3}\right)$ for precipitation of silver bromide and chloride. After centrifugation, the precipitate was taken up in $\mathrm{NH}_{3}$ after adding $\mathrm{Na}_{2} \mathrm{~S}$ and $\mathrm{NaOH}$ in order to eliminate the silver. After agitation and centrifugation, the supernatant was heated until dry. $\mathrm{H}_{2} \mathrm{O}$ was added followed by $\mathrm{H}_{2} \mathrm{O}_{2}$ in order to oxidize sulfide. After drying, ${ }_{2} \mathrm{H} \mathrm{O}$ was then added and dried again. This was repeated several times. Thereafter, perchloric acid and acetone were added and the reaction was started by addition of $\mathrm{KmnO} 4$ with Bromoacetone formed. The solution 
is then extracted with benzene. The organic phase was separated from the water phase by shaking and centrifugation. The water phase was then removed. An aliquot of the organic solution is then applied to the gas chromatograph for measuring of the bromoacetone/internal standard ratio. The bromide concentration was then derived from the bromoaceton standard curves. Because the distribution of bromide depends on the potential difference between the in- and extra-cellular compartments and on the total body volume, the corrected bromide space was calculated as follows:

$$
\mathrm{ECV}(\mathrm{L})=\frac{\text { Bromide administered (mmol) }}{\text { Bromide change T4 }-\mathrm{T} 0(\mathrm{mmol} / \mathrm{L})}-0.036 \mathrm{TBW}
$$

Where $0.036 \mathrm{TBW}$ is the correction factor for the cell potential and for the total body volume (14). Body cell mass (BCM) was then calculated by subtracting ECV from TBW.

\section{Statistics}

All data were analysed with SPSS statistic program version 6.0. The sign test was used to compare the growth parameters and body composition results with those of the reference population. The Pearson correlation coefficient was used to determine the relationship between measurements obtained by the various body composition methods. Partial correlation coefficients, controlling for age, were used for the evaluation of the relationships between measured ICV, ECV, mid-upper-arm muscle area and the various body composition results. The between method differences were compared, using the Wilcoxon rank test. The agreement between methods were evaluated by the Statistical method of Bland and Altman (18). 


\section{RESULTS}

\section{Body composition of 18 cf children}

Mean age, nutritional parameters expressed as standard deviation scores (Z-scores) and results of body composition measured by skinfold, DEXA and TBW from 18 CF children are shown in table 1. Compared to the reference population, mean Z-scores for weight, height, BMI, armcircumference and skinfolds (except for the triceps) were significantly decreased (fig 1). The mid-upper-arm muscle area was significantly decreased in our CF population $(p=0.005)$. In absolute terms, all body composition components measured by DEXA such as FM, LBM, BMC and BMD Z-scores were significantly decreased $(p=0.01 ; p=0.02 ; p=0.005$ and $p=$ 0.03 respectively) compared to the control population described by Oggle ( 8 ). When compared to the normal DEXA body composition data reported by Oggle (8), results obtained with either the TBW or the skinfold methods showed only fat mass to be significantly decreased in our patients ( $p=0.03$ and $p=0.05$ respectively). In relative terms, FM-DEXA (compared to normal DEXA data reported by Oggle) and FM-skinfolds (compared to normal skinfolds data reported by Gerver) were also significantly decreased. The BMI was correlated with both FM and FFM measured by all three methods (FM-DEXA $r=0.90$; FM-skinfold $r=0.87$; FMTBW $_{\mathrm{r}}=0.75 ;$ FFM-DEXA $\mathrm{r}=0.79 ;$ FFM-skinfold $\mathrm{r}=0.81$; FFM-TBW $\mathrm{r}=0.8$ with $\mathrm{p}=$ 0.001 for all correlations). As expected strong correlations were found between age on the one hand and FM-DEXA $(r=0.67 p=0.003)$, FFM-DEXA $(r=0.95 p=0.001)$, FM-skinfolds $(r$ $=0.59 p=0.01)$, FFM-skinfolds $(r=0.95 p=0.001)$, FM-TBW $(r=0.47 p=0.047)$, FFMTBW $(r=0.94 p=0.001)$ and BMC-DEXA $(r=0.94 p=0.001)$. No sex differences in body composition data were found. When compared to the reference values described by FrisHansen (15), the ECV and TBW as a percentage of bodyweight were significantly increased ( $p<0.005$ both) while the ICV as percent of bodyweight was normal. The partial correlations (controlling for age) between ECV, ICV, the mid-upper-arm muscle area LBM and FM are shown in table 2. 
Table 1 Characteristics of 18 CF children.

\begin{tabular}{|c|c|c|c|}
\hline & MEAN & SEM & RANGE \\
\hline AGE $\left(Y_{r}\right)$ & 8.97 & 1.16 & $2.9-22.6$ \\
\hline $\mathrm{BW}(\mathrm{Kg})$ & 27.43 & 3.66 & $13.6-67.6$ \\
\hline BW (SDS) & -1.03 & 0.25 & $-2.33-1.36$ \\
\hline$T M(K g)$ & 27.82 & 3.84 & $12.96-67.33$ \\
\hline HEIGHT $(\mathrm{cm})$ & 128 & 6.0 & $96.2-184.9$ \\
\hline HEIGHT (SDS) & -1.31 & 0.25 & $-2.89-0.40$ \\
\hline $\operatorname{BMI}\left(\mathrm{K}_{\mathrm{g}} / \mathrm{m}^{2}\right)$ & 15.6 & 0.57 & $13.21-23.17$ \\
\hline ARMCIRCUMFER (SDS) & -1.62 & 0.31 & $-3.14-1.43$ \\
\hline BICEPS (SDS) & -0.77 & 0.23 & $-1.86-1.33$ \\
\hline TRICEPS (SDS) & -0.33 & 0.23 & $-2-2.33$ \\
\hline SUBSCAPULAR (SDS) & -0.92 & 0.23 & $-2-1.6$ \\
\hline SUPRAILIACA (SDS) & -1.66 & 0.09 & $2.43--0.57$ \\
\hline SUM 4 SKINFOLDS (SDS) & -1.17 & 0.20 & $-2.2-1.2$ \\
\hline FM-DXA (\%) & 12.11 & 1.48 & $6.1-28.8$ \\
\hline FM-TBW (\%) & 10.39 & 1.61 & $0.0-22.2$ \\
\hline FM-SKINFOLD (\%) & 14.44 & 0.94 & $8-23$ \\
\hline FFM-DXA (\%) & 87.9 & 1.5 & $71.2-93.9$ \\
\hline FFM-TBW $(\%)$ & 89.8 & 1.6 & $77.8-101$ \\
\hline FFM-SKINFOLD $(\%)$ & 85.6 & 0.9 & $77-92$ \\
\hline BMC-DXA (Kg) & 1.02 & 0.17 & $0.37-2.68$ \\
\hline TBW (L) & 19.06 & 2.38 & $9.9-47.4$ \\
\hline TBW (\%) & 70.82 & 1.32 & $59.62-79.70$ \\
\hline ICV (L) & 10.96 & 1.78 & $3.71-31.93$ \\
\hline $\operatorname{ICV}(\%)$ & 38.41 & 1.42 & $27.28-51.01$ \\
\hline $\operatorname{ECV}(\mathrm{L})$ & 8.10 & 0.65 & $4.45-15.47$ \\
\hline $\operatorname{ECV}(\%)$ & 32.44 & 1.75 & $19.01-47.69$ \\
\hline
\end{tabular}

BW: Body weight

TM: DEXA constructed weight

BMl: Body mass index
FM: Fat mass

FFM: Fat free mass

BMC: Bone mineral content
TBW: Total body water

ECV: Extracellular volume

ICV: Intracellular volume 


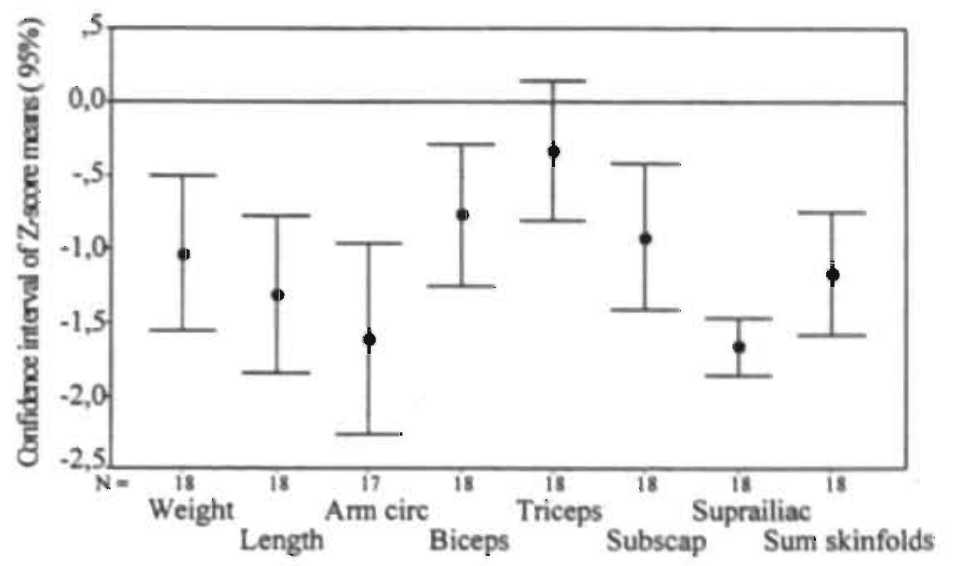

Figure 1 Confidence interval of Z-score means for various anthropometric parameters in cystic fibrosis children showing significantly lower values for all parameters except for the triceps skinfold.

Table 2 Correlation coefficients between muscle area, ECV, ICV and body composition results

\begin{tabular}{cccc}
\hline \hline & MUSCLE AREA $\left(\mathrm{cm}^{2}\right)$ & ECV $(\mathrm{L})$ & ICV (L) \\
\hline \hline LBM-DEXA (Kg) & $0.84(\mathrm{p}=0.001)$ & $0.67(\mathrm{p}=0.004)$ & $0.91(\mathrm{p}=0.001)$ \\
LBM-SKINF (Kg) & $0.90(\mathrm{p}=0.001)$ & $0.58(\mathrm{p}=0.02)$ & $0.92(\mathrm{p}=0.001)$ \\
LBM-TBW (Kg) & $0.86(\mathrm{p}=0.001)$ & $0.63(\mathrm{p}=0.007)$ & $0.95(\mathrm{p}=0.001)$ \\
FM-DEXA (Kg) & $0.62(\mathrm{p}=0.02)$ & $0.15(\mathrm{p}=0.58)$ & $0.53(\mathrm{p}=0.04)$ \\
FM-SKINF (Kg) & $0.61(\mathrm{p}=0.02)$ & $0.23(\mathrm{p}=0.38)$ & $0.53(\mathrm{p}=0.03)$ \\
FM-TBW (Kg) & $0.33(\mathrm{p}=0.21)$ & $-0.004(\mathrm{p}=0.99)$ & $0.20(\mathrm{p}=0.43)$ \\
ECV (L) & $0.45(\mathrm{p}=0.08)$ & & \\
ICV (L) & $0.86(\mathrm{p}=0.001)$ & & \\
\hline \hline
\end{tabular}

LBM-DEXA: Lean body mass by DEXA method LBM-SKINF: Lean body mass by skinfolds method LBM-TBW: Lean body mass by TBW method ECV: Extracellular volume
FM-DEXA: Fatmass by DEXA

FM-SKNNF: Famass by skinfolds method

FM-TBW: Famass by TBW method

ICV: Intracellular volume 
Table 3 Changes in bodyweight and body composition after 3 months on lansoprazole in 15 CF children.

\begin{tabular}{cccc}
\hline \hline & \multicolumn{3}{c}{ T3 - T0 } \\
\cline { 2 - 4 } & MEAN \pm SEM & MINIMUM & MAXIMUM \\
\hline BW (Kg) & $0.97 \pm 0.13$ & 0.4 & 2.1 \\
TM (Kg) & $0.97 \pm 0.15$ & -0.05 & 1.9 \\
FM-DXA (Kg) & $0.52 \pm 0.19$ & -0.46 & 2.18 \\
FM-TBW (Kg) & $-0.23 \pm 0.52$ & -4.85 & 3.44 \\
FM-SKINFOLD (Kg) & $0.94 \pm 0.26$ & 0.05 & 3.52 \\
LBM-DXA (Kg) & $0.43 \pm 0.18$ & -0.96 & 1.46 \\
BMC-DXA (Kg) & $0.03 \pm 0.01$ & -0.03 & 0.09 \\
FFM-DXA (Kg) & $0.41 \pm 0.17$ & -0.98 & 1.03 \\
FFM-TBW (Kg) & $1.27 \pm 0.49$ & -1.84 & 5.35 \\
FFM-SKINFOLD (Kg) & $0.04 \pm 0.26$ & -3.02 & 0.98 \\
TBW (L) & $0.99 \pm 0.39$ & -1.4 & 4.1 \\
ICV (L) & $0.09 \pm 0.41$ & -3.49 & 3.17 \\
ECV (L) & $0.92 \pm 0.46$ & -2.38 & 4.91 \\
\hline \hline
\end{tabular}

T0: Before start lansoprazole

T3: 3 months after lansoprazole

TM: Total mass (DEXA)

BW: Body weight
FFM: Fat free mass

FM: Fatmass

BMC: Bone mineral content

LBM: Lean body mass
TBW: Total body water

ECV: Extracellular water

ICV: Intracellular water 


\section{Limits of agreement between methods}

As only 5 of our patients 3 girls and 2 boys were postpubertal, all results of both boys and girls were analysed together. There was a high correlation between the 3 body composition methods for measuring of FM and FFM (fig 2 and 3). The best correlation for FM determination was between DEXA and the skinfold method $(r=0.98)$. As DEXA is a 3 compartments model, BMC was not included in the lean body mass. After correction for BMC, the correlation coefficient was unchanged. Plots of the paired differences for FM and FFM measured in kilogram versus their mean, with indication of the limits of agreement are shown in figure 4 and figure 5 respectively. Since our population was small, we preferred to use the 10th and 90th centile values instead of $\pm 2 \mathrm{SD}$ for defining the limits of agreement. No intermethod correlations were found between means and differences as shown in figures 4 and 5 . The 50th centile of the differences between FM-TBW versus FM-skinfolds was $-1.68 \mathrm{~kg}(-2.64$ - . $0.46 \mathrm{~kg})$; FM-skinfolds versus FM-DEXA was $0.75 \mathrm{~kg}(-3.01-1.21 \mathrm{~kg})$; FM-TBW versus FMDEXA was $-0,96 \mathrm{~kg}(-5.05--0.03 \mathrm{~kg})$. The 50 th centile of the differences between FFM-TBW versus FFM-DEXA was $0.45 \mathrm{~kg}(-0.70-4.85 \mathrm{~kg})$; FFM-skinfolds versus FFM-DEXA was $0.17 \mathrm{~kg}(-0.77-3.46)$; FFM-TBW versus FFM-skinfolds was $1.68 \mathrm{~kg}(0.46-2.96 \mathrm{~kg})$. The DEXA constructed weight was highly correlated with scale weight $(r=0.999 p=0.001)$. However, the DEXA weight was significantly lower than scale weight $(p=0.003)$; the 50th centile of the differences between bodyweight constructed from DEXA (TM) and scale weight was $-0.52 \mathrm{~kg}(-0.79-0.12)$. Significant differences were found between the means of FFM measured by the TBW and the skinfold methods $(p=0.02)$, the skinfolds and DEXA methods $(p=0.001)$ as well as the TBW and DEXA methods $(p=0.001)$. Only FM results from TBW and skinfolds were significantly different $(p=0.01)$. 


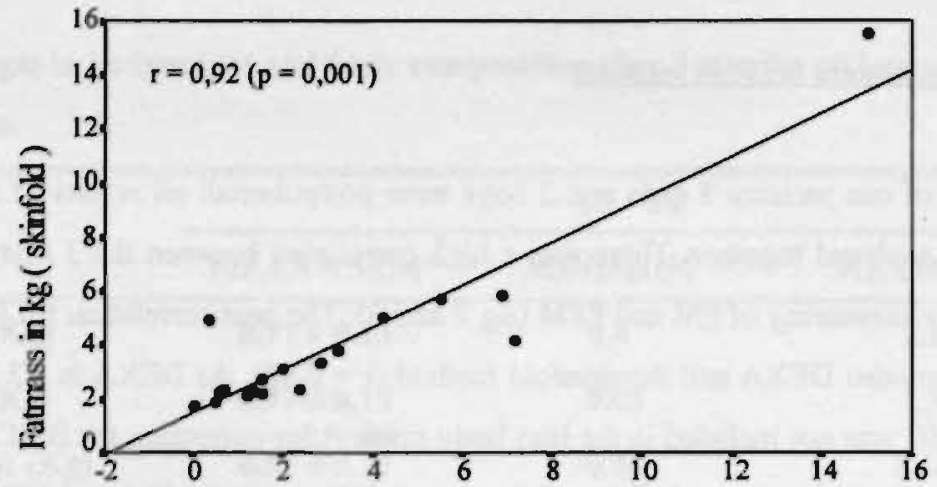

Fatmass in $\mathrm{kg}$ (TBW)

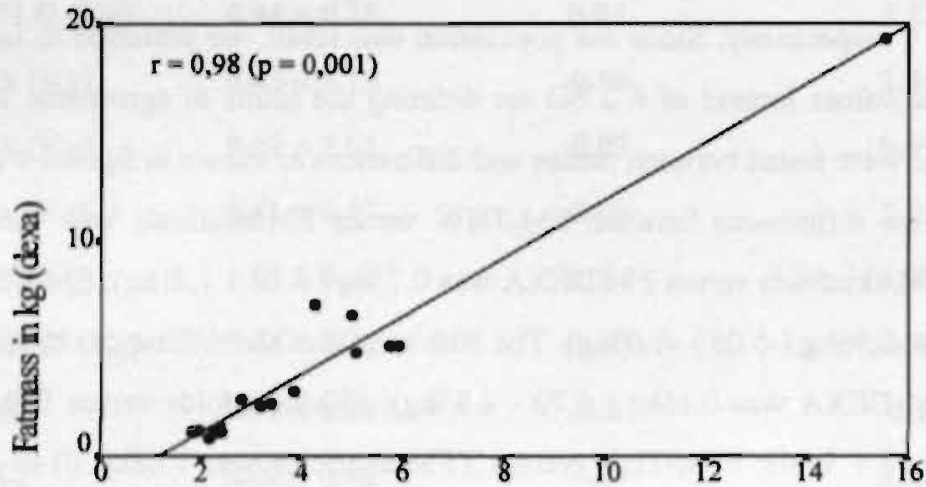

Fatmass in $\mathrm{kg}$ (skinfold)

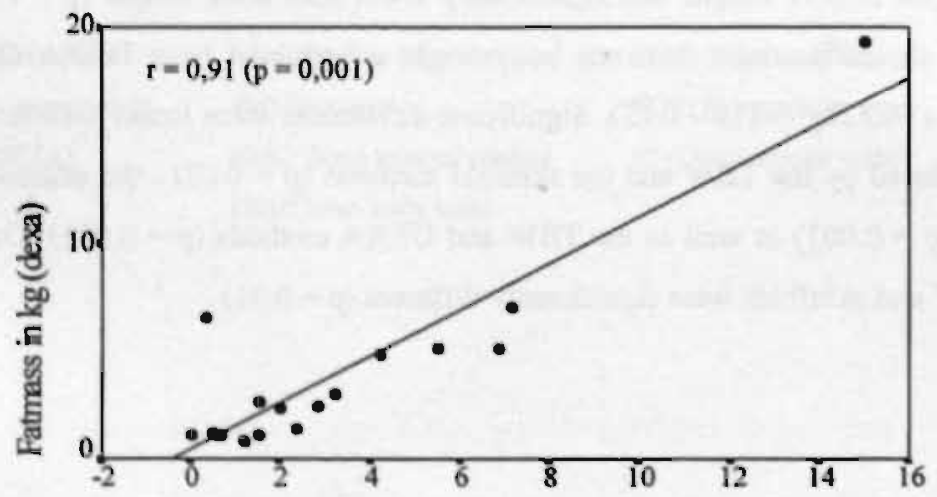

Fatmass in $\mathrm{kg}$ (TBW)

Figure 2 Intermethod fatmasses correlation coefficients. 

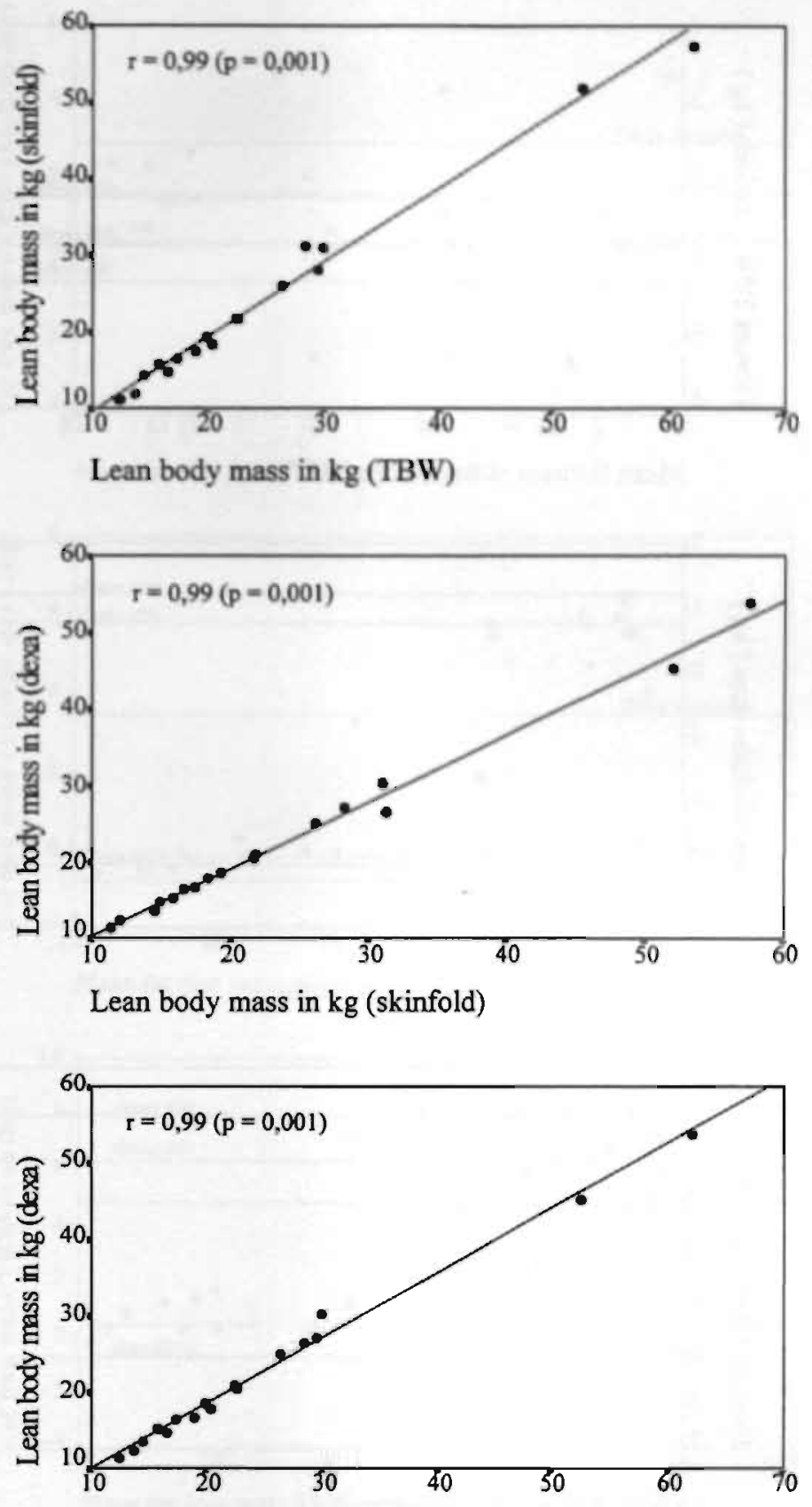

Lean body mass in $\mathrm{kg}$ (TBW)

Figure 3 Intermethod lean body mass correlation coefficients. 


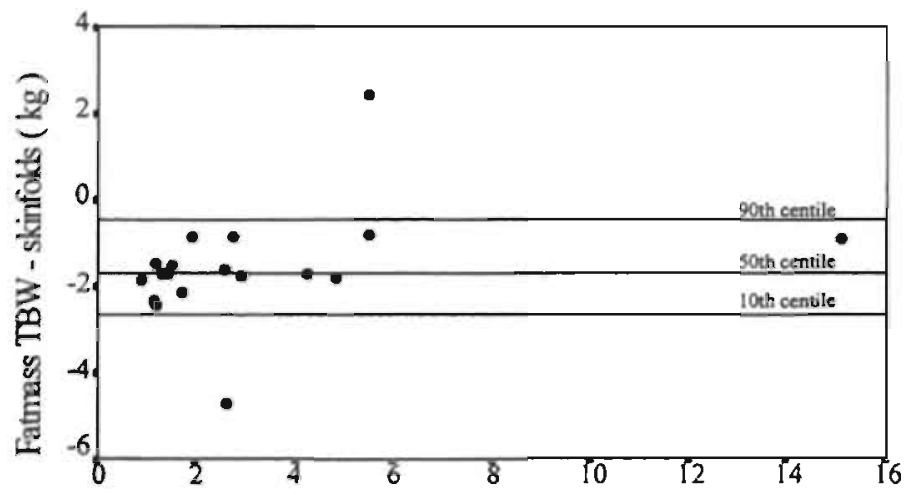

Mean fatmass skinfolds and TBW

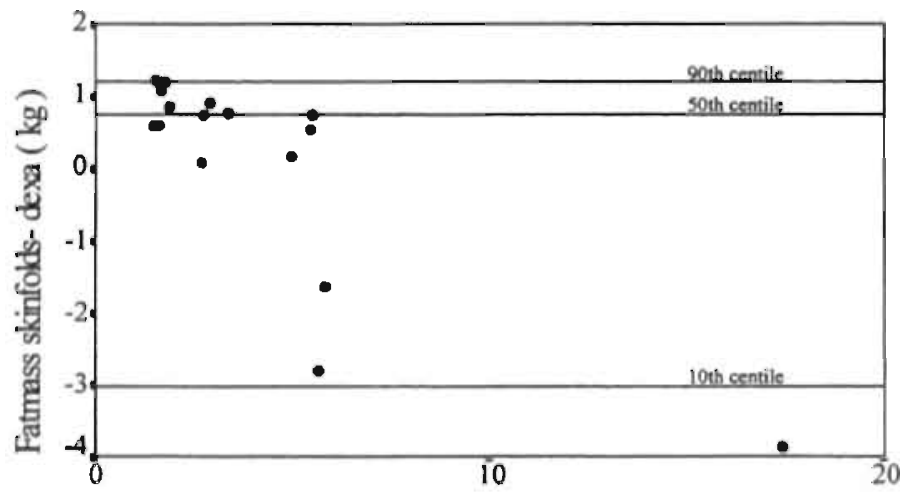

Mean fatmass skinfolds and dexa

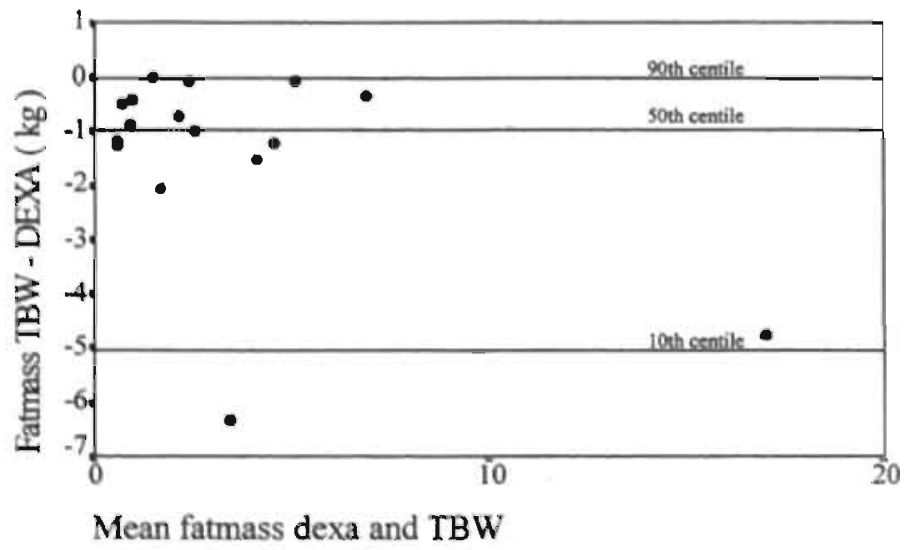

Figure 4 Limits of agreement for fatmass measured by the various methods. 

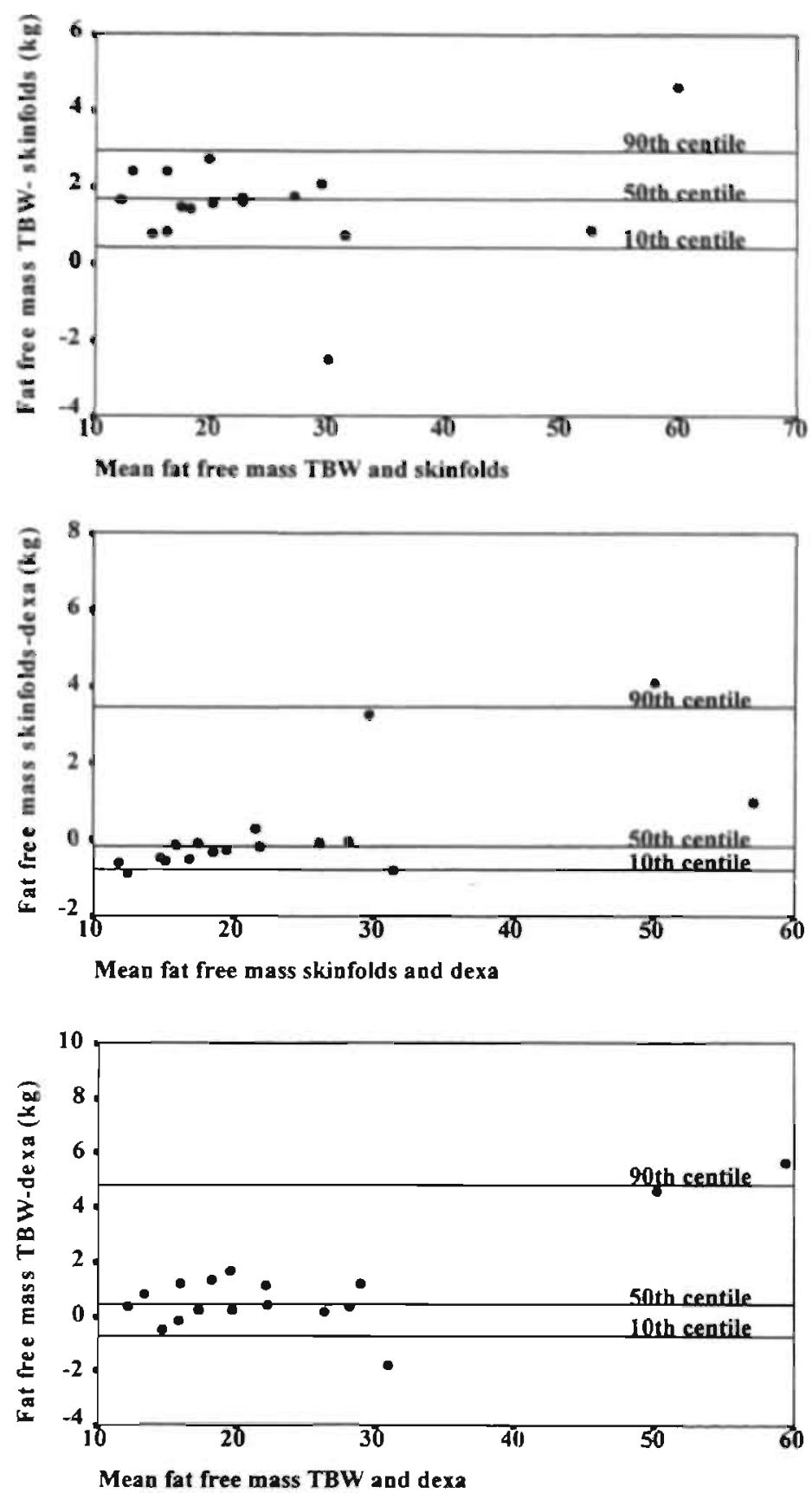

Figure 5 Limits of agreement for fat free mass measured by the various methods. 


\section{Bodv composition changes}

The changes in bodyweight, FM and FFM measured by skinfold, DEXA and TBW are shown in table 3. The increase in bodyweight was the same for both DEXA constructed weight and scale weight. However changes both in FM and FFM were different between methods. Both changes in FM and FFM measured by skinfold were highly correlated with those measured by DEXA ( $r=0.91 p=0.001$ and $r=0.84 p=0.001$ for FM and FFM respectively). Changes in FM measured by the TBW method were not correlated with changes of the same parameter measured by either the DEXA or the skinfold method, whereas changes in FFM-TBW were negatively correlated with those measured by skinfold and DEXA (FFM-TBW versus FFM. skinfold: $r=-0.56 p=0.03$ and FFM-TBW versus FFM-DEXA: $r=-0.52 p=0.05$ ). No correlation was found between changes in bodyweight and changes in FM or FFM measured by any method. Changes in ECV and ICV did not correlate with bodyweight changes. No correlation was found between changes in ICV and changes in LBM by any method. 


\section{DISCUSSION}

In children, effective evaluation of deterioration or catch-up growth can only be achieved by using the Z-score method. Despite high caloric polymeric intake, treatment of steatorrhea and support of pulmonary function, significantly lowered Z-scores for armcircumference, biceps, subscapular, suprailiac, sum of the 4 skinfolds weight and height were found in our patients. As our patients showed decreased weight, height Z-scores and mid upper arm muscle area, we expected both FM and FFM to be decreased. Since all body composition methods are based on assumptions, we used 3 noninvasive methods (DEXA, TBW and skinfolds) to evaluate the body composition of our patients. However, interpretation of the body composition results is difficult due to the lack of reference values for several measuring methods. The results of various methods used were strongly correlated with each other but still showed differences. In absolute terms, only DEXA results were as expected; showing a decrease in all 3 body components measured. Results of the TBW and skinfolds method could not be assessed accurately due to the lack of reference data expressed in absolute terms. When compared to the DEXA reference values, TBW and skinfolds methods only showed a decrease in FM. In relative terms, our CF populations showed an increase in TBW and ECV while the ICV (body cell water mass) appeared well maintained. These results imply a decrease of fatmass, associated with a relative increase in TBW, ECV and consequently FFM (19). In agreement with these: data, our results showing an increased percentage of FFM as evaluated by the skinfold method also implies a decrease in fatmass percentage in our CF patients. According to these results, we believe our CF patients mainly have a depletion of fatmass and bone mineral content with a slight decreased in lean body mass in absolute terms. Comparison of our results with other body composition studies in CF children is difficult: First, the general condition of the studied populations differed between studies and second, methods used for the assessment of the nutritional condition were different. Tomezsko et al. found no significant decrease: in body FM and FFM in their CF children with only significantly decreased suprailiac skinfold thicknesses and subscapular Z-scores. However their CF population was very young and showed only mild symptoms (2). In another study concerning older CF children with abnormal pulmonary function, Johnston et al. did find a significantly lower percentage of body fat (FFM not reported) compared to matched control children similar to our findings with all 3 
methods (20). In agreement with our study, Miller et al. who studied the body composition and muscle protein metabolism in a group undernourished CF children with Z-scores for weight and height similar to those of our CF population, found a significant decrease in FM, FFM and muscle mass (21). The strong correlation we found between components of body composition and age are well known $(8,22,23)$. The lack of sex differences can probably be explained by the prepubertal age of most patients (22). A high correlation was found between mid-upper-arm muscle area, ECV, ICV and LBM and FM. As expected, correlation coeffi. cients between mid-upper-arm muscle area, ECV, ICV and LBM remained high while only weak correlations were found with FM. Correlations were also evaluated after "homogenizing" our patient group by excluding the 2 adolescent patients. Highly significant correlations were again found between the above parameters and LBM while none were found with FM. As expected the between methods results differed significantly. Despite a high correlation between DEXA constructed weight and scale weight, mean DEXA weight was significantly and about 520 gram lower than scale weight. This is in agreement with results from Oggle et al. (8). FM measured by TBW was lower than that measured by either skinfolds or DEXA methods whereas FM-skinfold was often higher than FM-DEXA. The low values of FM when measured by the TBW method might be due to overestimation of FFM by this method. The FFM calculated by TBW is based on the assumption that a fraction of FFM is water. As the water content of FFM decreases with age (17), we used the age dependent FFM hydration fraction to calculate the FFM (17). The mean FFM hydration fraction used in our study was $76.27 \%$ (range: 73.7 - $77.5 \%$ ). In a study of body composition of CF prepubertal children, making use of skinfolds and TBW methods, Tomezco et al. also found a significantly lower body fat percentage with the TBW when compared to the skinfold method, which showed normal results (2). In two compartment models such as the TBW and the skinfolds methods, the densities of FFM is assumed to be constant in the range $18-67$ years but the density does vary depending on the concentrations, of water and mineral in FFM $(24,25)$. Although in our study the variation in water and mineral content was taken into account in the regression equations of skinfolds and TBW methods for the calculation of FFM and FM in the age range below 18 years, the water and mineral content are still population specific depending on the presence of illnesses. The percentage of TBW in CF children has been reported to be increased compared to control children $(19,26)$. Theoretically, the DEXA method has the advantage 
of being independent of biological assumptions about the densities and level of tissue hydration but the accuracy of the method still depends on the internal calibration $(27,28)$. It has been reported that when compared to chemical analysis, DEXA overestimate fat measured in meat blocks with lower fat content and underestimate the content in those with high fat content (29). Moreover, studies comparing DEXA results with those obtained from chemical analysis, using piglets, showed slight inadequacies in the estimation of fatmass and lean body mass $(27,30)$. We think that the between methods differences are most likely related to the various body compartments measured by these 3 methods rather than to inherent inaccuracies in the techniques themselves. This means that results obtained from each of these methods are not interchangeable. An important question to answer is, whether or not any of the used methods is capable of detecting body composition changes occuring during nutritional interventions. DEXA has been introduced as direct method with very good reproducibility $(12,31)$. In this study we compared the sensitivity of DEXA, TBW and skinfolds for detecting small body composition changes in children. For this purpose, we assessed the body composition of 15 $\mathrm{CF}$ children before and 3 months after they were treated with lansoprazole as an adjunct therapy for pancreatic enzymes in order to decrease steatorrhea. All 15 CF children showed significant increases in Z-scores for weight, height and skinfolds (unpublished observations). The evaluation of body composition changes differed depending on the method used. With the DEXA method, $53 \%$ of the weight increase was ascribed to FM, $44 \%$ to FFM and $3 \%$ to BMC. Both DEXA and skinfolds methods showed significant increases in fatmass but the increased FFM was not significant. In contrast, weight increase was exclusively ascribed to an increase in FFM with the TBW method. However, no significant correlations were found between weight changes and either FM, LBM or BMC changes by any method. The correlation coefticient of 0.40 found between weight changes and changes in FFM by DEXA just failed to reach statistical significance $(p=0.07)$. There were also no significant changes in ECV and ICV after intervention. This is in contrast to results reported by Going et al., who studied the changes in body compartments induced by dehydration - rehydration with oral fluid using DEXA method for assessment of body composition changes. They found a correlation between bodyweight changes and changes in TM, soft tissue mass (LBM + FM) and LBM. However, the total weight changes induced in their study was higher than in our study (approximately $1.2 \mathrm{~kg}$ versus $0.97 \mathrm{~kg}$ in our study) and as, the changes in bodyweight were 
induced by water content, the total bodyweight changes were exclusively ascribed to changes in the water content of STM, reflected by the exclusive increase in LBM (32). Since fatmass was mostly depleted in our patients, it is likely that this body compartment will normalize first as a result of an effective intervention.

From the results of this study, we conclude that results measured by different methods are not interchangeable. It is consequently important to use the same method for longitudinal evaluation of body composition. However, the use of DEXA, TBW and skinfolds methods is limited in children in whom only slight changes in bodyweight after intervention are expected $3 \%$ in this study) since the sensitivity is apparently not high enough for the detection of small differential changes in FM and FFM.

Acknowledgment: The authors wish to thank Mia Meers from the department of clinical laboratory, Sandra Zimny and Piet Willems from the department of nuclear medicine for their kind and expert technical assistance. 


\section{REFERENCES}

(1) M. Aitken, S. Fiel. Cystic Fibrosis. Dis Mon 1993;39: 1-52.

(2) J. Tomezsko, T. Scanlin, V. Stallings. Body composition of children with cystic fibrosis with mild clinical manifestations compared with normal children. Am J Clin Nutr 1994; 59: 123-8.

(3) M. Bronstein, P. Davies, K. Hambidge, F. Accurso. Normal energy expenditure in the infant with presymptomotic cystic fibrosis. J Pediatr 1995; 126: 28-33.

(4) R. Kraemer, A. Rüdeberg, B. Hadorn, E. Rossi. Relative underweight in cystic fibrosis and its prognostic value. Acta Paediatr Scand 1978; 67: 33-37.

(5) R. Branson, Y. Vaucher, G. Harrison, M. Vargas, C. Thies. Inter- and intra-observer reliability of skinfold thickness measurements in newborn infants. Hum Biol 1982; 54: 137 143.

(6) W. Gerver, R. de Bruin. Paediatric Morphometrics: A reference manual. 1th ed. Utrecht: Bunge, 1996.

(7) J. Westrate, P. Deurenberg, H. Van Tinteren. Int J Obesity. 1989; 13: 465-477.

(8) G. Ogle, J. Allen, I. Humphries et al. Body-composition assessment by dual-energy x-ray absorptiometry in subjects aged 4-26 y. Am J Clin Nutr. 1995; 61:746-53.

(9) J. Westrate, P. Deurenberg. Body composition in children: proposal for a method for calculating body fat percentage from total body density or skinfold-thickness measurements. Am J Clin Nutr 1989; 50: 1104-15.

(10) R. Mazess, B. Collick, J. Trempe, H. Barden, J. Hanson. Performance evaluation of a dual-energy x-ray bone densitometer. Calcif Tissue Int 1989; 44: 228-232.

(11) W. Peppler, R. Mazess. Total body bone mineral and lean body mass by dual-photon absorptiometry. I. I heory and measurement procedure. Calcif Tissue Int 1981; 33: 353-359.

(12) R. Mazess, H. Barden. J. Bisek. J. Hanson. Dual-energy x-ray absorptiometry for totalbody regional bone-mineral and soft-tissue composition. Am J C'lin Nutr 1990; 51: 1106-12.

(13) B. Van Kreel, F. Van der Vegt, M. Meers, T. Wagenmakers, K. Westerterp, A. Coward. Determination of total body water by a simple and rapid mass spectrometric method. J Mass Spectrom 1996; 31: 108-111.

(14) B. Van Kreel. An improved bromide assay for the estimation of extracellular water 
volume by capillary gas chromatography. Clinica Chimica Acta 1994; 231: 117-128.

(15) B. Friis-Hansen. Body water compartments in children: Changes during growth and related changes in body composition. Pediatrics $1961 ; 28: 169-181$.

(16) S. Fomon, F. Haschke, E. Ziegler, S. Nelson. Body composition of reference children from birth to age 10 years. Am J Clin Nutr 1982; 35: 1169-1175.

(17) R. Boileau, T. Lohman, M. Slaughter, T. Ball, S. Going and M. Hendrix. Hydration of the fat-free body in children during maturation. Hum Biol 1984; 56: 651-666.

(18) J. Bland, D. Altman. Statistical methods for assessing agreement between two methots of clinical measurement. The Lancet 1986; 8: 307-310.

(19) M. Miller, D. Kornhauser. Bromide pharmacokinetics in cystic fibrosis. Arch Pediatr Adolesc Med 1994; 148:266-271.

(20) J. Johnston, M. Leong, E. Checkland, P. Zuberbuhler, P. Conger, A. Quinney. Body fit assessed from body density and estimated from skinfold thickness in normal children ard children with cystic fibrosis. Am J Clinn Nutr 1988; 48: 1362-6.

(21) M. Miller, L. Ward, B. Thomas, W. Cooksley, R. Shepherd. Altered body compositicn and muscle protein degradation in nutritionally growth-retarded children with cystic fibrosis. Am J Clin Nutr 1982; 36: 492-499.

(22) H. Rico, M. Revilla, L.F.Villa, E. Hernández, M. Alvarez de Buergo and M. Villa. Body composition in children and Tanner's stages: A study with Dual-energy X-ray absorptiometry. Metabolism 1993; 42: 967-970.

(23) R. Faulkner, D. Bailey, D. Drinkwater, A. Wilkinson, C. Houston and H. McKay. Regional and total body bone mineral content, bone mineral density and total body tissue composition in children 8 - 16 years of age. Calcif Tissue Int 1993; 53: 7-12.

(24) G. Forbes. Human body composition. New York: Springer-Verlag, 1987.

(25) T. Lohman. Advances in body composition assessment. Champaign, IL: Human Kinetics, 1992

(26) M. Newby, N. Keim, D. Brown. Body composition of adult cystic fibrosis patients and control subjects as deternined by densitometry, bioelectrical impedance, total body electrical conductivity, skinfold measurements, and deuterium oxide dilution. Am J Clin Nutr 1990; 52: 209-13.

(27) K. Ellis, R. Shypailo, J. Pratt, W. Pond. Accuracy of dual-energy x-ray absorptiometry 
for body composition measurements inn children. Am J Clin Nutr 1994; 60: 660-5.

(28) R. Wellens, W. Chumlea, S. Guo, A. Roche, N. Reo, R. Siervogel. Body composition in white adults by dual-energy $\mathrm{x}$-ray absorptiometry, densitometry, and total body water. Am J Clin Nutr 1994; 59: 547-55.

(29) M. Jensen, J. Kanaley, L. Roust et al. Assessment of body composition with use of dualenergy x-ray absorptiometry: Evaluation and comparison with other methods. Mayo Clin Proc 1993; 68: 867-873.

(30) J. Brunton, H. Bayley, S. Atkinson. Validation and application of dual-energy x-ray absorptiometry to measure bone mass and body composition in small infants. Am J Clin Nutr 1993; 58: 839-45.

(31) P. Chilibeck, A. Calder,D. Sale, C. Webber. Reproducibility of dual-energy x-ray absorptiometry. Can Assoc Radiol J 1994; 45: 297-302.

(32) S. Going, M. Massett, M. Hall et al. Detection of small changes in body composition by dual-energy x-ray absorptiometry. Am J Clin Nutr 1993; 57: 845-50. 


\section{CHAPTER 8}

\section{GENERAL DISCUSSION}

Chronic pulmonary infections and poor appetite together with fat malabsorption are the main causes of malnutrition and growth retardation in CF children (1-3). The ideal treatment of CF should be the correction of the underlying defect by introduction of a normal copy of the defective gene into these patients genetic material. Although gene therapy is presently under intensive scrutiny (4-6), the role of this treatment in CF patients is not yet settled. Until then, treatment of these patients has to focus on improving the nutritional condition, since malnutrition can adversely affect survival (7). As $85 \%$ of CF patients have pancreatic insufficiency (8), improved absorption by pancreatic enzymes substitution is one of the main goals. Diagnosis and regular monitoring of fecal fat loss along with close evaluation of growth and the nutritional condition are consequently necessary in the follow up of these patients. Although the fat balance method is considered to be the golden standard for the evaluation of steatorrhea, it is too cumbersome to be used for the frequent monitoring of fat losses in these children. Several studies have shown the measurement of fecal fat concentration to be a valuable alternative to fat excretion studies for the diagnosis of fat malabsorption (9). These studies also shown that the differences in fat excretion between either 3 or 1 day collections are mainly due to day to day variation in stool volume, the stool fat concentration being much more constant. These studies led us to suppose that the repeated measurement of stool fat concentration in stool samples would be a valuable aid to the monitoring of steatorrhea. As chemical measurement of stool fat is time consuming, we looked for an alternative easy measure of fat content. Although the steatocrit looked quite attractive (10) our first results and also results reported by others $(11,12)$ disappointingly often showed low steatocrit results in stools of high fat content.

By acidification of stool homogenates, we could show fat extraction to be much improved and to result in a satisfactory correlation coefficient between chemically measured fecal fat and "acid steatocrit" results. We consequently decided to use the acid steatocrit in an intervention study (proton pump inhibitor) aiming at improving both steatorrhea and the nutritional condi- 
tion in children with $\mathrm{CF}$.

Both anthropometric parameters and body composition methods were used for the evaluation of the nutritional condition. Difficulties arise due to the fact that weight, height and skinfolds are age and sex specific. Although several authors have overcome this problem by expressing results of these parameters as a percentage of the predicted values for age and sex, the use of Z-scores is the preferred method for most authors. Z-scores measure deviations from the median value expressed in standard deviation units. Improving Z-scores reflect catch-up growth while the reverse is true for deteriorating Z-scores. Recently, Gerver and de Bruin have constructed growth charts with standard deviation for weight, height armcircumferences and the 4 skinfolds (biceps, triceps, subscapular and suprailiac) (13). Anthropometric parameters can be easily converted into Z-scores through the use of these reference data for normal children. As weight changes could be due to either changes in fatmass, fat free mass or both, we measured body composition by several methods in order to evaluate body composition before and after our intervention (proton pump inhibitor) study.

Our study results show significant decreases of most measured anthropometric parameters in children with cystic fibrosis. Decrease in skinfold thicknesses were most significant and contrary to a commonly held belief triceps skinfolds were often nomal while subscapular and suprailiac skinfolds were very sensitive indicators of chronic malnutrition in these patients. Our findings support the use of these simple anthropometric measurements for the evaluation of the nutritional condition in children. As far as body composition results are concerned, interpretation of results is uneasy due to the lack of reference values for several measuring methods. Notwithstanding these drawbacks, results of the various methods used were strongly correlated with each other but, still showed differences which preclude the use of these various methods interchangeably. Results should be looked at both in relative and in absolute terms.

In absolute terms, the DEXA method showed a severe decrease of fatmass and a slight decrease of fat free mass and of bone mineral content. Results of the total body water and skinfold method agreed with the DEXA results but could not be accurately assessed due to the lack of reliable reference data.

In relative terms, the deuterium - bromide results showed a relatively increased total body water and extracellular water compartment while the relative body cell water mass appeared 
well maintained. These results imply a decrease of fatmass as percent of bodyweight. Likewise, the fat free mass (\%) measured by the skinfold method was increased in our CF children. All these results agree with each other rather well and show that children with CF have a lowered bodyweight accompanied by a decreased fatmass (\%), an increased fat free mass (\%) and an increased extracellular water compartment (\%) while the intracellular water comparment (\%) appears to be well maintained (table 1).

Table 1 Body composition in children with cystic fibrosis.

\begin{tabular}{||cccccc||}
\hline & $\begin{array}{c}\text { FM } \\
\text { kg (\%) }\end{array}$ & $\begin{array}{c}\text { FFM } \\
\mathbf{k g}(\%)\end{array}$ & $\begin{array}{c}\text { TBW } \\
(\%)\end{array}$ & $\begin{array}{c}\text { ECV } \\
(\%)\end{array}$ & $\begin{array}{c}\text { ICV } \\
(\%)\end{array}$ \\
\hline \hline DEXA & $!(!)$ & $!(1)$ & & & \\
Skinfold & $?(1)$ & $?(1)$ & & & \\
Deuterium & $?(1)$ & $?(1)$ & $(1)$ & $(1)$ & (i) \\
Bromide & $?(1)$ & & &
\end{tabular}

DEXA: Dual energy X - Ray Absorptiometry

FM: Fatmass

FFM: Fat free mass

TBW: Total Body Water

ECV: Extracellular volume

ICV: Intracellular volume

A positive effect of omeprazole on fat absorption has been found in adults with CF (14). However the role of proton pump inhibitors on steatorrhea and its effects on the nutritional condition has not been evaluated in children. We have studied the effect of 3 months treatment of lansoprazole on fat malabsorption and body composition in $15 \mathrm{CF}$ children, maintaining steatorrhea while on pancreatic enzymes. These children showed significant improvements of both fat absorption (as measured by the acid steatocrit) and Z-scores for all parameters except for the biceps and triceps skinfolds and deteriorated again 3 months after lansoprazole was stopped. The increase in skinfold thicknesses Z-scores were accompanied by signifi- 
cant increases in fatmass as measured by the skinfold and the DEXA methods.

Different body composition methods have been described but, only few studies have compared different measurement techniques in pediatric subjects. An important question to answer is whether or not any of these methods is capable of detecting body composition changes occuring during nutritional interventions. Our study comparing the changes in body composition measured by DEXA, TBW and skinfolds methods in 15 CF children, whose nutritional condition improved significantly after intervention with lansoprazole for 3 months, showed different results for each method. Both DEXA and skinfolds methods showed significant increases in fatmass but not in lean body mass in absolute terms. Likewise, the percentage of body cell water mass did not increase significantly after nutritional intervention. On the other hand, the increases in bodyweight were completely ascribed to increases in lean body mass but not in fatmass when evaluated by the TBW method. Since fatmass was mostly depleted in our CF children (as shown by DEXA, skinfolds and total body water methods), it is likely that this body compartment will normalize first as a result of an effective intervention. Our results do not allow firm conclusions as to the effect of lansoprazole on FFM while a significant increase in bone mineral content was found. The bodyweight changes occuring during lansoprazole intervention were unrelated to either fatmass or FFM changes measured by any of the three methods used. We think the weight changes in the various body compartments were too small to be accurately measured by body composition methods.

In conclusion, the acid steatocrit is a reliable, cheap and noninvasive altemative method for the monitoring of fat malabsorption. Most cystic fibrosis patients are malnourished even when lung functions are stable and a hypercaloric diet is used. Body composition studies in these patients mainly show a loss of fat mass and bone mineral content with a relative increase in extracellular water and a normal intracellular water mass (\%). Inhibition of gastric acid secretion by a proton pump inhibitor improved both fat absorption and the nutritional condition of our patients. Methods for the assessment of body composition are not interchangeable and not accurate enough for detecting small changes in fatmass and fat free mass such as measured in our 3 months study. A longterm study is needed in order to better evaluate the effects of lansoprazole on body composition in children with cystic fibrosis. 


\section{REFERENCES}

(1) J. Dodge, J. Yassa. Food intake and supplementary feeding programs. In: J. Sturgess, ed. perspectives in cystic fibrosis. Toronto: Canadian Cystic Fibrosis Foundation; 1980: 125-136. (2) M. Bronstein, R. Sokol, S. Abman et al. Pancreatic insufficiency, growth, and nutrition in infants identified by newborn screening as having cystic fibrosis. J Pediatr 1992; 120: 533-40. (3) J. Tomezsco, V. Stallings, D. Kawchak, J. Goin, G. Diamond, T. Scanlin. Energy expenditure and genotype of children with cystic fibrosis. Pediatr Res 1994; 35: 451-460.

(4) M. Rosenfeld, W. Siegfried, K. Yoshimura et al. Adenovirus-mediated transfer of a recombinant alpha 1-antitrypsin gene to the lung epithelium in vivo. Science. 1991;252: 431-4 (5) B. Pitt, M. Schwarz, J. Pilewski et al. Retrovirus-mediated gene transfer in lungs of living fetal sheep. Gene Ther 1995; 2: 344-50.

(6) M. Rosenfeld, K. Yoshimura, B. Trapnell et al. In vivo transfer of the human cystic fibrosis transmembrane conductance regulator gene to the airway epithelium. Cell. 1992; 68: $143-55$.

(7) R. Kraemer, A. Rüdeberg, B. Hadom, E. Rossi. Relative underweight in cystic fibrosis and its prognostic value. Acta Paediatr Scand 1978; 67: 33-37.

(8) M. Aitken, S. Fiel. Cystic fibrosis. Dis Mon 1993; 39: 1-52.

(9) N. Thorsgaard Pedersen, H. Halgreen, H. Worning. Estimation of the 3-day faecal fat excretion and fat concentration as a differential test of malabsorption and maldigestion. J Gastroenterol 1987; 22: 91-96.

(10) P. Phuapradit, A. Narang, P. Mendonca, D. Harris, J. Baum. The steatocrit: a simple method for estimating stool fat content in newbom infants. Arch Dis Child 1981; 56: 725-727. (11) M. Walters, J. Kelleher, J. Gilbert, J. Littlewood. Clinical monitoring of steatornhoea in cystic fibrosis. Arch Dis Child 1990; 65: 99-102.

(12) E. Sugai, G. Srar, H. Vazquez et al. Steatocrit: a reliable semiquantitative method for detection of steatorrhea. J Clin Gastroenterol 1994; 19: 206-9.

(13) W. Gerver, R. de Bruin. Paediatric Morphometrics: A reference manual. 1 th ed. Utrecht: Bunge, 1996.

(14) H. Heijerman, C. Lamers, W. Bakker. Omeprazole enhances the efficacy of pancreatin (pancrease) in cystic fibrosis. Ann Intern Med. 1991; 114: 200-201. 


\section{SUMMARY}

In chapter one, the pathogenesis, clinical manifestations and treatment modalities of cystic fibrosis are briefly summarized. CF is a multisystem disease, the basic defect is a mutation of the CFTR gene. Until now, more than 200 mutations have been characterized. CFTR has been found in epithelial cells of several organs with the lung and pancreas being mostly affected. The role of gene therapy in the management of CF patients is not yet settled. Until then treatment of these patients has to focus on support of lung function and improved fat absorption in order to maintain a normal nutritional status. From our litterature review, only predigested foods such as (semi)elemental diets and very high-energy polymeric diets, have been reported to improve the nutritional condition in $\mathrm{CF}$ patients. Low duodenal $\mathrm{pH}$ is thought to be at least partly responsible for the persisting maldigestion. Inhibition of gastric acid secretion by a proton pump inhibitor has been shown to improve steatorrhea in CF adults. The effect of proton pump inhibitors on fat absorption and on the nutritional status of children with $\mathrm{CF}$ has not been reported. The effect of treatment on steatorrhea can only be evaluated by regular monitoring of fecal fat loss. The fat balance method being too cumbersome for the repeated evaluation of steatornhea, we first aimed at developing an alternative test suituble for our purpose. This test (acid steatocrit) was subsequently used to evaluate the effect of lansoprizo-le (proton pump inhibitor) on steatorrhea in CF patients showing persisting malabsorption while on pancreatic enzymes. The effects of therapy on the nutritional condition of our patients was evaluated simultaneously.

In chapter two, the methods used in this study are described. For the determination of fecal fat, the titrimetric method described by van de Kamer and the Sudan staining method were used for the comparison of steatocrit and acid steatocrit methods. Anthropometry, dual-energy $\mathrm{X}$-ray absorptiometry. total body water and bromide dilution techniques were used to assess body composition.

In chapter three, four and five, we describe the steatocrit test as an alternative method for the 3 days fecal fat balance method for the monitoring of steatorrhea. Although the steatocrit 
test has been reported to be cheap, simple and noninvasive test, its reliability has been questioned. As this might be due to inadequate fat extraction during the centrifugation step of the steatocrit procedure, we aimed at improving fat extraction by acidification of the fecal homogenate. Results obtained by our modified steatocrit method, called the "acid steatocrit", were highly correlated with those obtained by chemical analysis. We found a high sensitivity and specificity for the acid steatocrit.

Results of the evaluation of the nutritional condition of our patients as well as results concerning the presence of persisting steatorrhea in patients on pancreatic enzymes are described in chapter six. Despite hypercaloric intake and the use of pancreatic enzymes, our CF patients maintained steatorthea and showed signs of malnutrition with significantly decreased Z-scores for weight, height, armcircumference, biceps, subscapular and suprailiac skinfolds. Moreover, their fatmass, lean body mass and bone mineral content were significantly decreased when compared to the reference population described by Oggle et al. Treatment of these CF children with lansoprazole as an adjunct therapy of pancreatic enzymes, resulted in a significant decrease in steatorrhea accompanied by a significant improvement in their nutritional condition.

In chapter seven, we describe results of our body composition studies in our patients before and after treatment with lansoprazole. Although highly correlated, results from these various methods were shown not to be interchangeable. In absolute terms, the DEXA, the TBW and the skinfold methods showed children with $\mathrm{CF}$ to have a severe depletion of fatmass and a slight decrease of FFM. In relative terms, the above results point to lower body fat percentage accompanied by a higher percentage of LBM. Our results with deuterium - bromide do confirm the above results by showing a high relative TBW content and consequently a low relative fat content. Bromide results further show the relative increase of water percentage to be due to a relatively increased extracellular water compartment with a maintained relative body cell water mass. Although small changes in bodyweight were correctly detected by DEXA examination, the latter method was not accurate enough for the differential detection of small changes in FM and FFM. The usefulness of DEXA, TBW and skinfold methods for the assessment of small body composition changes in children is therefore limited. 


\section{SAMENVATTING}

In hoofdstuk cen, zijn de pathogenese, de klinische manifestaties en de therapeutische mogelijkheden voor cystic fibrosis (CF) kort samengevat. Cystic fibrosis is een multisysteem ziekte, waarvan mutatie van de CFTR (cystic fibrosis transmembrane regulator) gene is het basis defect.

Tot dus ver, zijn er meer dan 200 mutaties beschreven. CFTR werd in de epitheel cellen van verschillende organen gevonden. De longen en de pancreas zijn het meest betrokken by deze erfelijke aandoening. De rol van de gen therapie is nog niet bevestigd in de behandeling van CF patienten. De behandeling van deze patienten is er dan ook gericht op de long functies te ondersteunen en een normale voedingstoestand te behouden door het verbeteren van de vet malabsorptie.

Uit het litteratuur overzicht blijkt dat de voedingsstatus van CF patienten alleen effectief te verbeteren is met voorverteerd voedsel zoals (semi)elementaire voeding, of met een zeer hoge energie inname. Een lage duodenale $\mathrm{pH}$ is mede verantwoordelijk voor het slechte verteringsproces. Het is bij volwassen CF patienten bekend dat de vet absorptie significant te verbeteren is door remming van de maagzuur secretie met een proton pomp remmer. $\mathrm{Er}$ is nog geen studie gedaan naar het effect van dit middel op de vet vertering en de voedings status bij $\mathrm{CF}$ kinderen.

Regelmatig monitoring van vet in de ontlasting is noodzakelijk voor de behandeling van vet malabsorptie. De gebruikelijke vet balans methode is hiervoor te omslachtig. Ons eerste doe! was het ontwikkelen van een alternatieve test die snel en makkelijk uitvoerbaar is. Deze test (zure steatocriet) werd dan gebruikt om het effect van een proton pomp remmer (lansoprazol) op steatorrhoea in CF patienten met persisterende malabsorptie onder pancreas enzymen, te evalueren. Daamaast, werd het effect van lansoprazol op de voedingstoestand van onze patienten geevalueerd.

In hoofdstuk twee. beschrijven we de methoden die we gebruikt hebben in deze studie. Voor de bepaling van vet in de ontlasting, werden de titrimetrische methode, beschreven door van de Kamer, en de Sudan kleurings techniek gebruikt om de klassieke steatocriet te: vergelijken 
met de zure steatocriet. De anthropometrische methode, de dual-energy X-ray absorptiometry (DEXA), het totale lichaamswater ( $T B W$ ) en de bromide dilutie technieken werden toegepast om de lichaamsamenstelling te beoordelen.

In hoofdstuk drie, vier en vijf, beschrijven we de steatocriet test als een alternatieve methode voor de 3 dagen vet balans ter monitoring van vet in de ontlasting. Hoewel de steatocriet test werd gezien als een goedkope, simpele en noninvasieve test, de betrouwbaarheid van deze test wordt betwist. Dit is mogelijk toe te schrijven aan de inadequate vet extractie tijdens het centrifugeren van de steatocriet procedure. Ons doel was de vet extractie te verbeteren door het aanzuren van het faeces homogenaat. De resultaten verkregen met deze gemodificeerde steatocriet genaamd "zure steatocriet", correleerden goed met de resultaten van de chemische vet analyse. We vonden een hoge sensitiviteit en specificiteit voor de zure steatocriet test.

In hoofdstuk zes, bestuderen we de mate van vet malabsorptie en de voedingstoestand van onze CF kinderen behandeld met pancreas enzymen. Ondanks de hypercalorische voeding en de behandeling met pancreas enzymen, hadden onze patienten aanhoudende steatorrhoea en toonden tekenen van malnutritie met significante verslechtering van de gemiddelde Z-scores voor gewicht, lengte, armomtrek, biceps, subscapulaire en suprailiacale huidplooien. Bovendien, hun vetmassa, spiermassa en botmineral is significant lager dan die van de normale kinderen, beschreven door Oggle. Na de behandeling van deze kinderen met een proton pomp remmer (lansoprazol) als supplementaire therapie by pancreas enzymen, vonden we een significante vermindering van steatorrhoea met verbetering van de voedingstoestand.

In hoofdstuk zeven, beschrijven we de resultaten van de lichasmsamenstelling van onze patienten voor en na de behandeling met lansoprazol. Ondanks de hoge: correlatie tussen de resultaten van de gebruikte lichamsamenstelling methodes, zijn deze technieken niet uitwisselbaar. In absolute zin, toonden de DEXA, de TBW en de huidplooi methode een emstige depletie van de vetmassa en een lichte afname van de vet-vrije massa by CF kinderen. In relatieve zin, wijzen deze resultaten in de richting van een afnarne van het vet percentage gepaard aan een hoger percentage van lean body mass (LBM). Dit komt overeen met de resultaten van deuterium-bromide, waarbij een hoog TBW' percentage en dus een laag vet 
percentage gevonden werd. De toename in het TBW percentage is toe te schrijven aan het verhoogde percentage extracellulair water terwijl intracellulair water normaal blijft. Alhoewel de verandering in lichaamsgewicht door het DEXA onderzoek correct werd geschat, was geen van de gebruikte lichaamsamenstelling methodes nauwkeurig genoeg voor het schatten van kleine veranderingen in de vetmassa en vet-vrije massa. De bruikbaarheid van DEXA, TBW en huidplooi methoden voor het schatten van kleine veranderingen in de lichaamsamenstelling bij kinderen is daarom beperkt. 


\section{DANKWOORD}

Woorden schieten tekort om mijn dank uit te drukken. Ik ben niet zo goed in taal expresse, toch hoop ik met enkele eenvoudige zinnen iedereen te kunnen bedanken, die het mij mogelik hebben gemaakt dit proefschrift vorm te geven.

Zonder iemand tekort te willen doen, richt ik een speciaal dankwoord tot de volgende peronen:

Prof. Dr. C. Blanco, promotor, beste Carlos, ondanks je drukke taak, heb je toch heel snelen kritisch mijn werkstukken doorgenomen. Hiervoor dank ik je extra.

Dr. P. Ph. Forget, copromotor, beste Philippe, het lukte mij nooit je te tutoyeren, niet vanvege onze persoonlijke contacten, maar vanwege mijn respect voor jou. De manier waarop je let onderzoek stuurde waarbij je mij geheel in mijn waarde en vrijheid liet, was van buitengewoon hoog niveau. Je leerde mij wetenschappelijk denken. Waar nodig was bood je hllp aan, soms ook met het verwerken van de resultaten. De correctie van het manuscript vas binnen korte tiid klaar. Zelfs in ie vakantie. nam ie miin werkstukken mee en was ie berid hiervoor terug te komen. Ik heb genoten van je onuitputtelijke bron van nieuwe ideeën.

Ook in het persoonlijk contact was je aangenaam. Je heb altijd in mij geloofd en stond altijd achter mij. Beste Philippe, zonder jouw inzet en je vertrouwen als begeleider, zou dit proefschrift nooit deze vorm hebben gekregen.

Dr. B. van Kreel, copromotor, de helft van mijn tijd als onderzoeker heb ik in uw laboratorium doorgebracht. Uw deur stond altijd voor mij open. Als het niet lukte met de steatocrit bepaling, heb u altijd nieuwe suggesties. Uw deskundigheid en eerlijkheid was onmisbaar voor het slagen van dit onderzoek.

Prof. Dr. R. H. Kuijten, bedankt voor de mogelijkheden die u hebt gecreeërd voor dit onderzoek.

Drs. A. Van den Neucker, beste Anita, al die jaren ben je voor mij een goede vriendin geweest. Ook als het mij tegen zat, wist je met je nuchtere kijk en eerlijkheid mijn problemen te relativeren. Ik heb genoten van onze discussies en van je gezelschap op verscheidene congressen. Je interesse in anderen en je brede algemene kennis maakte het zeer boeiend. Anita, je hebt mijn "gat" in de Westerse cultuur opgevuld. 
Hooggeleerde leden van de beoordelingscommissie, bedankt voor uw vlotte en kritische beoordeling van dit manuscript.

Alle kinderartsen, neonatologen en arts-assistenten kindergeneeskunde in het AZM dank ik hierbij voor de aanspraak in de afgelopen jaren.

Dr. W. J. M. Gerver en Dr. R. De Bruin, jullie groeicurven hebben grote waarde toegevoegd aan dit onderzoek. Bedankt voor jullie voortreffelijke bijdrage.

Jolanda vain Golde en Rony Nieefjes, beste Rony en Jolanda, bedankt voor het meeleven en de gezellige uren in het AlO-hok, in het restaurant, in het theater aan het Vrijthof, in de bioscoop, bij een van ons thuis of in het zwembad. Bedankt voor het aanhoren van mijn "gezeurd". We hebben goede en slechte tijjden met elkaar doorgemaakt. Ik hoop dat onze vrienschap hierdoor alleen maar sterker is geworden.

Alle medewerkers van het klinisch chemisch laboratorium van het $A Z M$, met name Serva, Lou, Michel, Mia, Theo, Peter en Marian, bedankt voor jullie inzet en betrokkenheid tijdens het onderzoek. Jullie wetenschappelijke interesse was van niveau. Als ik hulp nodig had waren jullie bereid, soms ook ongevraagd, het eigen werk neer te leggen en mij bij. te staan. Bedankt voor de aangename sfeer en de gezellige samenwerking.

Liesbeth van der Ploeg en Lianne Schoorlemmer, dietisten, wil ik danken voor het uitrekenen van de calorieën bij mijn patienten populatie.

Dr. G. A. K. Heidendal, Piet Willems en Sandra Zimny van de nucleaire afdeling, bedankt voor jullie fijnzinnige instructies over de DEXA scan.

Alle poli-assistenten en de secretaressen van de kindergeneeskunde, wil ik danken voor de samenwerking in de afgelopen jaren.

Oom Wim en tante Margriet van der Avoort, bebankt voor jullie steun en betrokkenheid in de afgelopen 15 jaren van mijn leven in Nederland.

Ik ben de firma's Hoechst Marion Roussel B.V. (Hoevelaken) en Janssen-Cilag B.V. (Tilburg) dankbaar voor hun financiële ondersteuning in de drukkosten van dit proefschrift.

Tenslotte, zou dit boek niet volledig zijn zonder hulp en meeleven van mijn familie. Lieve mama, oom Kiet, Manh Hung en Manh Coung, terwijl ik rustig aan mijn proefschrift werkte, hebben jullie voor mijn verbuizing gezorgd.

Manh Coung, bedankt voor het ter beschikbaar stellen van je computer en Manh Hung voor je 
deskundige steun. Als ik met de computer problemen had, kon ik altijd op jullie terugvallen. Oom Kiet, bedankt voor je inzet en betrokkenheid. Nooit hoefde ik je om hulp te vrager, je was er gewoon.

Lieve Mama, zonder jou zou dit boek er nooit zijn gekomen. Heel je leven lang heb je voor ons klaar gestaan. Jouw droom is een goede toekomst voor je kinderen. Daarvoor heb je 15 jaar geleden je leven op het spel gezet. Je stimuleerde ons om te studeren. Rijkdom is aiet belangrijk, maar kennis, dat is de beste bagage die je op onze weg aan ons hebt kumen meegeven. Mama, bedankt voor je betrokkenheid en het aanhoren van mijn frustraties. Met een glimlach en een schouderklop wist je al mijn problemen op te lossen. Mama, ik hou van jou en $\mathrm{ik}$ ben trots dat $\mathrm{jij}$ mijn moeder ben. 


\section{CURRICULUM VITAE}

Thi My Dung Tran werd. op 27 april 1967 te Dinh Tuong in Vietnam geboren.

Na het doorlopen van het basisonderwijs volgde zij, eveneens in Vietnam, drie jaren vervolgonderwijs op voorbereidend wetenschappelijk niveau.

In $1981 \mathrm{kwam}$ zij met haar familie in Nederland.

Op 2 juni 1986 verwierf zij aan de Rijksscholengemeenschap "Den Hulster" te Venlo het diploma Atheneum B. met als eindexamenpakket de vakken: Nederlands, Engels, Wiskunde I en II, Natuurkunde, Scheikunde en Biologie.

Vanaf het najaar 1986 studeerde zij geneeskunde aan de Rijksuniversiteit te Maastricht. Zij behaalde op 13 augustus 1990 haar doctoraal getuigschrift. Op 1 februari 1993 werd het diploma basisarts aldaar aan haar uitgereikt.

Tijdens haar studie verrichte zij wetenschappelijk onderzoek onder leiding van Dr. P. PH. Forget op de afdeling kindergeneeskunde van het Academisch Ziekenhuis Maastricht: "Singel Stool analysis for fat, alfa-animo nitrogen and electrolyt".

Vanaf 1 maart tot 3 november 1993 werkte zij als arts-onderzoeker bij de vakgroep kindergeneeskunde van het A.Z.M. aan het project "Effect of ranitidine in children with chronic abdominal pain".

Van 1 december 1993 tot 1 december 1994 was zij werkzaam als AGNIO kindergeneeskunde in het A.Z.M.

In de periode 1 december 1994 tot 1 april 1996 werkte zij onder leiding van Dr. P. PH. Forget, kinder-gastroenteroloog in het A.Z.M., aan haar promotie-onderzoek. 
Steatorrhea and nutritional condition in cystic fibrosis children effects of a proton-pump inhibitor 
STEATORRHEA AND NUTRITIONAL CONDITION IN CYSTIC FIBROSIS CHILDREN EFFECTS OF A PROTON - PUMP INHIBITOR 


\section{CONTENTS}

Chapter 1 General introduction - litterature review - Aims of the study

1. Genetics of cystic fibrosis

2. Pathogenesis

3. Clinical manifestations

4. Diagnosis

5. Therapy

6. Evaluation of steatorrhea

Aims of the study

References

Chapter 2. Methods

1. Methods used for fecal fat determination

2. Methods used for assessment of nutritional condition

Chapter 3 The acid steatocrit: A much improved method

Tran M., Forget P., Van den Neucker A., Strik J., van Kreel B., Kuijten R.

J Pediatr Gastroenterol Nutr 1994; 19: 299-303

Chapter 4 Improved steatocrit results obtained by acidification of fecal homogenates are due to improved fat extraction

M. Tran, P. Forget, A. Van den Neucker, B. Van Kreel

J Pediatr Gastroenterol Nutr 1996; 22: $157-160$

Chapter 5 Clinical use of acid steatocrit

A. Van den Neucker, N. Pestel, T. My Dung Tran, P. Ph. Forget,

H. J. Veeze, J. Bouquet, M. Sinaasappe!

Submitted for publication

Chapter 6 Role of lansoprazole in children with cystic fibrosis: Evidence for improved fat malabsorption and nutritional status Tran TMD, Van den Neucker A, Hendriks JJE, Forget P (junior), Forget $\mathrm{P}$ (senior)

Submitted for publication 
Chapter 7 Anthropometry and body composition methods in children with 84-107 cystic fibrosis: Effects of nutritional intervention My-Dung T. Tran, Anita Van den Neucker, Han J. Hendriks, Bernard van Kreel, Patricia Forget, Guido Heidendal, Pierre-Philippe Forget Submitted for publication

Chapter 8 General discussion 108-112

Summary $113-114$

Samenvatting $115 \cdot 117$

Dankwoord 118-120

Curriculum vitae 
EFFECTS OF A PROTON-PUMP INHIBITOR

\section{PROEFSCHRIFT}

Ter verkijging van de graad van doctor aan de Rijksuniversiteit Limburg te Maastricht, op gezag van de Rector Magnificus, Prof.Mr. M.J. Cohen, volgens het besluit van het College van Dekanen, in het openbaar te verdedigen.

op donderdag 17 oktober 1996 om 16.00 uur

$$
\text { door }
$$

Therese Marie Pascale Thi My Dung Tran geboren op 27 april 1967 te Dinh Tuong, Vietnam 
Promotor:

Co-promotores:

Beoordelingscommissie:
Prof. Dr. C. Blanco

Dr. P-Ph. Forget

Dr. B. van Kreel

Prof. Dr. P.B. Soeters, ( voorzitter )

Prof. Dr. H.S.A. Heymans, (Universiteit van Amsterdann )

Prof. Dr. R.W. Stockbrugger

Prof. Dr. J.M. Wit, ( Rijksuniversiteit Leiden )

Prof. Dr. E.F.M. Wouters

Steatorrhea and nutritional condition in cystic fibrosis children:

Effects of a proton - pump inhibitor /

Therese Marie Pascale Thi My Dung Tran.

Proefschrift Maastricht - Met lit. Opg. - Met samenvatting in het Nederlands.

ISBN 90-5681-011-1

Trefw.: Steatocriet / steatorrhoe / cystic fibrosis / voedingstoestand / proton pomp remmer / lichaamsamenstelling.

Vormgeving: My Dung Tran

Omslagillustratie: Vetbollen in een microscopische faeces preparaat, met Soudan kleuring. 
Aan mijn lieve moeder Voor alle cystic fibrosis kinderen. . 
CHAPTER 1

GENERAL INTRODUCTION 


\section{GENETICS OF CYSTIC FIBROSIS (CF)}

Cystic fibrosis was first described in 1928 by Fanconi (1). It is an autosomal recessive disease and is reported in all racial groups with varying prevalence. In caucasians, CF occurs in 1 out of 2000 live births. Males and females are equally affected. The basic defect is a mutation of the Cystic Fibrosis Transmembrane Regulator (CFTR), a protein responsible for chloride ion transport in response to cAMP mediated signals. The most frequent CF mutation in the caucasian population is a deletion of 3 nucleotides, encoding for phenylalanine at position 508 in the CFTR protein amino acid sequence. Its overall frequency reported by the CF Genetic Analysis Consortium is $68 \%$ (2). Until now, over 200 mutations have been characterized and account for the remaining mutations.

\section{PATHOGENESIS}

It is generally accepted that cAMP stimulated chloride conductance is a function of the CFTR (3). This function is deficient in epithelial cells of CF patients. The inability to secrete chloride and secondarily secrete water results in viscous secretions. Poor clearance of these viscid secretions from the epithelium often results in obstruction of excretory ducts. CFTR has been found in epithelial cells of several organs such as the airways, the sweat glands, the genitourinary system and the gastrointestinal tract including the pancreas and the biliary tract (4). Dysfunction of these organ systems are therefore possibly related to the same underlying defect in the CFTR-gene product.

\section{CLINICAL MANIFESTATIONS}

CF is a multisystem disease with lungs and pancreas mostly affected in young patients.

\section{1 Respiratory tract}

Lung disease accounts for more than $95 \%$ of the morbidity and mortality in CF $(5,6)$. The desiccated mucus in the respiratory tract causes stasis and bronchiolar obstructions, resulting 
in bacterial overgrowth and chronic lung infection. This gives rise to the production of proteases by bacteria and neutrophils. These enzymes hydrolyze important structural proteins of the lung and airways such as elastin, proteoglycans and collagen, leading to instability of bronchial walls and bronchiectasis. Furthermore, these enzymes also alter the mucosal function by increasing the secretion of macromolecular glycoconjugates contributing to a high viscosity of the mucus (7). Bronchiolitis with wheezing is frequent during the first year of life. Some patients remain however, asymptomatic for long periods. When pulmonary disease progresses, exercise intolerance occurs and finally, progressive pulmonary deterioration is the main cause of death in these patients $(6,8)$. As a consequence of improved supportive therapy, survival has increased from 6 months at the end of the fifties (9) to nearly 30 years currently $(10,11)$. Sinusitis and nasal polyposis sometimes occur in CF $(12,13)$.

\section{2 Pancreas}

In the pancreas, obstruction of the ductules is the cause of acinar / ductular distention, followed by dișruption with release of proteolytic enzymes and autodigestion of the pancreas resulting in pancreatic insufficiency with steatorrhea. The changes in the pancreas can occur early during gestation, compromising the normal maturation of the pancreas: Approximately, $85 \%$ of CF patients have steatorrhea (11). In $85-90 \%$ of these cases, exocrine pancreatic insufficiency develops during the first year of life. Decreased secretion of bicarbonate and water first occurs before a decrease of pancreatic enzyme concentration in duodenal fluid can be detected (14-17). Recurrent acute pancreatitis occurs in approximately $10 \%$ of CF patients (18).

Because of fat malabsorption, serum concentrations of fat soluble vitamins are often lowered. Since Vit A conșists of esters of long chain fatty acids, it cannot be absorbed in the absence of pancreatic esterases. Due to its short half life, low serum leveis of Vit A are often found in early untreated CF patients $(19,20)$. Vit $\mathrm{D}$ deficiency resulting in decreased bone mineralization has also been reported in CF patients (21-23). Due to frequent antibiotic therapy, suppression of endogenous vit $\mathrm{K}$ synthesis by anaerobic intestinal bacteria often contribute to a low vit $\mathrm{K}$. serum level in CF patients with steatorrhea. Although Vit B12 is water soluble, serum levels may also be low in CF patients. Binding to intrinsic factor, necessary for absorption, 
can only take place after cobalamin has been released from the R-protein binding by pancreatic enzymes. Decreased pancreatic bicarbonate secretion may play a role herein since the binding affinity of cobalamin for R-protein decreases at neutral or slightly alkaline $\mathrm{pH}$ (24). However, pancreatic enzymes supplements will normalize the Vit B12 serum level.

Abnormal glucose tolerance occurs in $30-75 \%$ of $\mathrm{CF}$ patients while diabetes mellitus develops in 10\% (11). Several diabetogenic factors including increased passive sugar transport (25), increased mucosal absorption of D-glucose (26), decreased beta cell mass (27) and delayed insulin secretion (28) are present in CF. On the contrary, several antidiabetogenic factors such as an increased tissue insulin sensitivity (29) and an increased number of insulin receptors on monocytes (30) have been reported in cystic fibrosis. Moran et al. reported a decreased alpha, beta- and pancreatic polypeptide- cell function in CF patients with exocrine disease compared to those without this disorder. Due to this finding, they suggest that either exocrine disease causes endocrine dysfunction or that a common pathogenic process simultaneously and independently impairs exocrine and endocrine function in CF patients (31). However, the exact etiology of diabetes in CF is still unknown.

\section{5 Mainutrition}

CF children are malnourished when compared to normal controls $(32,33)$. Both, malabsorption accompanying pancreatic insufficiency (34) and high energy expenditure due to chronic lung infection $(35,36)$ are thought to be responsible for the poor nutritional condition in these patients. Moreover, in $\mathrm{CF}$, several intraluminal factors other than pancreatic insufficiency are also considered responsible for fat malabsorption:

1) Increased gastric acid secretion after stimulation with pentagastrin (37):

A high postprandial acid secretion could, by lowering the duodenal $\mathrm{pH}$, contribute to fat malabsorption.

2) Decrease pancreatic bicarbonate secretion (13-16):

Higher gastric acid secretion after meals together with a decrease in pancreatic bicarbonate secretion, has been shown to result in a prolonged postprandial lowering of duodenal pH with 
inactivation of the remaining pancreatic lipase. Moreover, low duodenal $\mathrm{pH}$ also results in bile acid precipitation,, fecal loss of bile acids and a decrease in the bile acid pool, contributing to fat malabsorption

3) Increased glycine to taurine conjugated bile acid ratios:

Due to a relatively deficient supply of taurine compared to glycine and to continous fecal loss of bile acids, newly formed bile acids are mainly conjugated with glycine, leading to high glycine-/taurine- bile acid conjugation ratios (38). The glycine conjugated bile acids precipitate in an acidic environment contributing to the luminal bile acid deficiency in these patients.

\section{4 Intestinal tract}

Gastroesophageal reflux and esophagitis are frequent causes of epigastric pain in CF patients $(39,40)$ and can be responsible for decreased pulmonary functions (41). Peptic ulcers are found in up to $13 \%$ of $\mathrm{CF}$ patients (42) and are thought to be related to the low duodenal $\mathrm{pH}$

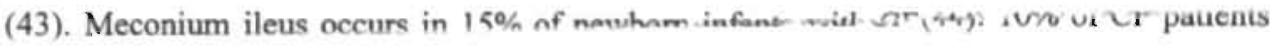
have meconium ileus "equivalents" at a later age with a peak incidence at 20-25 years of age (45). Protein precipitation as a result of decreased duodenal $\mathrm{pH}$ and high secretion viscosity all probably contribute to these obstructive events (11). Up to $25 \%$ of the CF patients have rectal prolapse occurring mostly in children aged 6 - 36 months (46) while intussusception has been shown to occur in $1 \%(47)$.

\section{5 Biliary and Hepatic tracts}

An increased incidence of cholelithiasis has been reported in CF patients (48) and is thought to be related to hypokinesis and increased fasting gallbladder volumes (49). Biliary cirrhosis with hepatosplenomegaly leading to portal hypertension occurs in $25 \%$ of CF patients. Liver steatosis has been reported in $30 \%$ of patients with CF.

\section{6 Genitourinary tract}


More than $95 \%$ of males are infertile due to obstruction of the reproductive tracts (50). Active spermatogenesis does occur but produced spermatozoa are abnormal or immature (51). In $\mathrm{C}^{2}$ women, the reproductive tracts are anatomically normal but fertility is decreased (52). Incree sed viscosity of the cervical mucus is thought to interfere with sperm penetration (53).

\section{7 Sweat gland}

Decreased sodium and chloride reabsorption due to dysregulation of sweat gland duct cell, results in susceptibility of $\mathrm{CF}$ patients to salt depletion during warm weather and durirg gastroenteritis.

\section{Diagnosis}

The standard diagnostic procedure is the sweat test based on increased concentration of electrolytes in the sweat of the patients (54). The sweat test was developed by Gibson ard Cooke (55), whereby the sweat production is stimulated by puocarpine iontopnoresis. Ine then collected sweat is analysed for its chloride and sodium content. However, chloride content has a better diagnostic value than sodium content, since abnormal sodium secretion can also be found in other endocrine diseases. Sweat chloride concentration higher than 60 $\mathrm{mM}$ or sodium above $70 \mathrm{mM}$ measured minimal on two conditions is considered as abnormal, whereas chloride values under $50 \mathrm{mM}$ and sodium value under $30 \mathrm{mM}$ are found in normal persons. Chloride concentrations between 50 and $70 \mathrm{mM}$ are inconclusive. For reliable results, at least $50 \mathrm{mg}$ of sweat should be collected. Low sweat production in the first few weeks of life is the reason for unreliable test results in this age group. In cases of doubt, identification of CFTR-mutation or measurement of intestinal current in a rectal biopt have been reported to be conclusive (56).

\section{Therapy}

The ideal treatment of CF should be the correction of the underlying defect by introduction of a normal copy of the defective gene into these patients genetic material. Gene therapy is 
presently under intensive scrutiny. Adenovirus and recently also the retrovirus seem promising as an effective vector for normal gene transport into the target cells $(57,58)$. Recently, transfer of the CFTR gene to the rat airways epithelia has been successfully performed (59). However, the role of gene therapy in the management of CF patients is not yet settled. Until then, treatment of $\mathrm{CF}$ patients has to focus on improving the nutritional condition, since malnutrition can adversely affect survival (60). The nutritional status of CF patients can be improved by firstly ameliorating the respiratory function, thereby minimizing energy expenditure and secondly, by increasing energy supply either by increasing nutrient intake or by improving nutrient digestion and absorption.

\section{1 Respiratory function support}

Since viscous mucus in the lung is the cause of chronic lung infection, efforts should be made to improve mucus clearance. Although most patients on mucolytics such as acetylcysteine have the feeling of decreased sputum viscosity, studies with acetylcysteine either orally or as aerosol have failed to support this finding (61-63). Alternative methods such as chest percussion combined with postural drainage (64), positive expiratory pressure mask $(65,66)$ and forced expiratory pressure (67) have been suggested to improve mucus clearance. Moreover, $\beta 2$-agonists as aerosol can increase sputum clearance (68) and some bronchodilatating effect has been experienced in CF patients on this regimen $(69,70)$. Corticosteroids, have been found to delay disease progression and to improve lung function in $C_{F}$ patients (71-74) but, short-term adverse effects such as hyperglycemia and long-term adverse effects such as development of cataract and growth retardation preclude the routine use of corticosteroids in these patients (73).

Treatment with antibiotics can reduce the progression of lung infection. Colonisation with Ps. aeruginosa often occur in CF patients and various regimes have failed to eradicate the bacteria (75). Ps. aeruginosa vaccines are presently being evaluated (76). In the end stage, lung transplantation can offer an outcome. The one and two year survival rates approach $70 \%$ and $54 \%$ respectively (77). Amiloride inhalation by blocking sodium reabsorption in the respiratory epithelium, has been shown to increase sputum clearance in a placebo-controlled crosso- 
ver study $(78,79)$. Although improvement in pulmonary function was not found in one study (78), a delay in the deterioration of forced vital capacity (FVC) was reported by an other author (79). Domase (Pulmozyme), a recombinant human desoxyribonuclease which breaks off the sputum DNA, has been reported to increase the forced expiratory volume (FEV1) and FVC safely in CF patients (80-82). Inhalation of $\boldsymbol{\alpha} 1$-antitrypsine inhibits neutrophil elastase (83), which is released from the neutrophils and causes lung damage. Chloride channel facilitators, which directly stimulate a CFTR protein independent anion channel, are presently being evaluated (84).

\section{2 Increase energy supply}

in the past, restricted diets with low fat content were often prescribed for CF patients in order to minimize steatorrhea, abdominal cramps and stool bulk (85-87). Due to both unpalatability and low caloric density, these diets often resulted in malnutrition and growth faillure in these patients (87-89). In the early 1970s, Crozier introduced the use of high fat diets in combination with pancreatic enzymes in order to increase the energy intake of CF patients. This regimen resulted in better growth with evident steatorrhea (90). Moreover, CF children from clinics using low fat diets were reported to show poorer growth (87-89) than those from clinics, encouraging the use of high fat diets (91). In order to further improve the nutritional status and growth of CF patients, feeding intervention studies have been done with different kinds of nutrients such as hypercaloric polymeric, semielemental or elemental diets. It has been shown that interventions making use of very high caloric intakes of polymeric diets (150 - $180 \%$ Recommended Daily Allowance) by overnight nasogastric tube resulted in improved nutritional status in CF adults. In children with CF, the effects of interventions with hypercaloric polymeric diets up to $130 \%$ of RDA are however unconvincing. Luder and coworkers, studying the effects of a 4 year period of nonrestricted fat diet in CF children, found improved $\mathrm{Z}$-scores for weight, height and $\mathrm{BMI}$ for their $\mathrm{CF}$ patients when compared to the national population of $\mathrm{CF}$ patients on fat restricted diets, while no changes were: seen when compared to normal children without CF (92). More recently, studies with hypercaloric polymeric diets with high fat content did not result in significant improvements of Z-scores for weight, height and skinfolds in CF patients (93), whereas parenteral nutrition and either oral or enteral 
elemental and semielemental nutrition have been shown to significantly improve the nutritional condition of these patients (94-106). The results of short-term and long-term studies of feeding interventions on the nutritional status in CF children are summarized in table 1 and 2 . The fact that predigested food can improve the nutritional status better than standard diets, strongly suggests that nutrient maldigestion plays a crucial role in the poor response to oral hypercaloric polymeric diets. The latter hypothesis is further supported by the known inactivation of pancreatic enzymes and bile acids precipitation accompanying the low duodenal pH due to low bicarbonate secretion in CF patients (107-110) . Enteric-coated pancreatic enxyme preparations have therefore been introduced but the low duodenal $\mathrm{pH}$ interferes with the release of enzymes through the acid resistent coating (111). High doses of pancreatic enzymes did not solve the problems of malabsorption (112) and recently, colon strictures have been observed in CF children on high doses of pancreatic enzymes (113-115). Attempts have been made to inhibit gastric acid production in the hope to improve the digestion and absorption of nutrients. However, the reported effects of H2-receptor antagonists and prostaglandine E2 on steatorrhea have been variable and unconvincing (116-125). Results of short-term studies of cimetidine and misoprostol on fat excretion have not been consistent (table 3). This may be partly due to the lack of control of dietary fat intake. In longterm studies cimetidine showed no significant changes in fat excretion and nutritional status in CF children. on the contrary, famotidine, a more potent inhibitor of gastric acid secretion, showed both a significant improved fat absorption coefficient and improved growth parameters (table 4). However, interpretation of growth effects in the latter study is rather difficult because $Z$-score methods have not been used to evaluate growth. Further, in a double blind study, a significant improvement in steatornhea was found when a proton pump inhibitor was added as adjuvant therapy in pancreatic enzyme treated CF adults (112). In children with $\mathrm{CF}$, the effects of proton pump inhibitors on fat absorption and on the nutritional condition have not been reported. 
Table 1 short-term feeding intervention studies in cystic fibrosis.

\begin{tabular}{|c|c|c|c|c|c|c|c|}
\hline Authon & $\begin{array}{l}\text { Eshephend } \\
\text { et ali, 'so }\end{array}$ & $\begin{array}{l}\text { "Shepherd } \\
\text { et al, ' } 13\end{array}$ & $\begin{array}{l}\text { "Bertined } \\
\text { et all, ' } 44\end{array}$ & $\begin{array}{l}\text { mansell } \\
\text { et al, ' } 24\end{array}$ & e. 1., " is & "Loughlin & extil.'95 \\
\hline $\begin{array}{c}\text { Number of } \\
\text { cases }\end{array}$ & 12. & 7 & 10 & 11 & 21 & 10 & 15 \\
\hline Age range & $0.5 \cdot 11 y$ & $5 \cdot 13 y$ & $3-12 y$ & $10-17 y$ & $1-14=$ & $? \cdot 28 y$ & $1-27 y$ \\
\hline $\begin{array}{c}\text { Nutritional } \\
\text { status }\end{array}$ & malnutrition & malnutrition & malnutrition & malnutrition & eormal & malnutrition & malnutrition \\
\hline $\begin{array}{l}\text { Sevdy } \\
\text { duration }\end{array}$ & 1 moenth & 6 month & 1 month & 1 month & 5 days & 6 monchs & 3 monchs \\
\hline $\begin{array}{l}\text { Type of } \\
\text { study }\end{array}$ & $\begin{array}{l}\text { Prospective } \\
\text { own control }\end{array}$ & $\begin{array}{l}\text { wospective } \\
\text { ewn control }\end{array}$ & prospective own control & $\begin{array}{l}\text { prospective } \\
\text { own control }\end{array}$ & $\begin{array}{l}\text { prospective } \\
\text { CF control }\end{array}$ & $\begin{array}{l}\text { prospective } \\
\text { CF elemental } \\
\text { CF polymaric }\end{array}$ & $\begin{array}{l}\text { prodpective own } \\
\text { control }\end{array}$ \\
\hline $\begin{array}{l}\text { Feedine } \\
\text { intervention }\end{array}$ & $\begin{array}{c}\text { TPN } \\
90-100 \% \\
\text { RDA }\end{array}$ & $\begin{array}{l}\text { ilemental } \\
20.40 \% \\
\text { RDA (extra) }\end{array}$ & $110-150 \leqslant$ RDA & $\begin{array}{c}\text { TrN } \\
120 \% R D A\end{array}$ & $\begin{array}{l}\text { mielemental } \\
142 \text { kcal/48 }\end{array}$ & $\begin{array}{l}\text { elemental } \\
35 \% \text { RDA } \\
\text { (extra) versus } \\
\text { hypercaioric }\end{array}$ & $\begin{array}{l}\text { Dyperealoric } \\
\text { polymeric } \\
130 \% \text { RDA }\end{array}$ \\
\hline Roulte & parenteral & enteral & nasogastric & persinternal & ord & enteral & and \\
\hline Eneal & $\begin{array}{l}\text { SDS weight ! } \\
\text { SDS height : } \\
\text { MUACW add } \\
\text { clinical weore ! } \\
\text { FVC, FeVII } \\
\text { PEF ! }\end{array}$ & $\begin{array}{l}\text { SDS weight : } \\
\text { SDS weight I } \\
\text { MUAC \$ std ! } \\
\text { FM L.BM (kg)! } \\
\text { muscle mass (kg)! } \\
\text { clinical score ! } \\
\text { 3-meklis excre । }\end{array}$ & 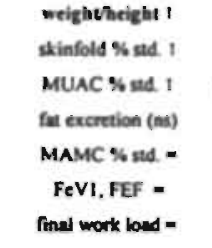 & $\begin{array}{l}\text { weight (kg) t } \\
\text { weight (ew) t } \\
\text { skinfold (mm) 1 } \\
\text { MAMC (cm) ! } \\
\text { MIP, MEP । } \\
\text { FeVI, FEF - }\end{array}$ & $\begin{array}{l}\text { Weight (ky) I } \\
\text { Nexcretion ! } \\
\text { fat absorption coeff. } \\
\text { cient ! }\end{array}$ & 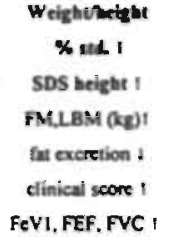 & $\begin{array}{l}\text { SDS weight (ns) } \\
\text { SOS weight (ns) } \\
\text { growth velocily } \\
\quad \text { (ns) } \\
\text { skinfold. (ns) } \\
\text { weighin (kg) t }\end{array}$ \\
\hline $\begin{array}{l}\text { Follow op } \\
\text { (durntion) }\end{array}$ & $\begin{array}{l}\text { dl parameters } \\
\text { improve further } \\
\text { (after months) }\end{array}$ & NR & $\begin{array}{l}\text { Il panmeters I } \\
\text { (after } 2 \text { months) }\end{array}$ & $\begin{array}{l}\text { MLP. MEP = } \\
\text { FeVI. FEF - } \\
\text { (after } 2 \text { months) } \\
\text { dil other } \\
\text { perrecers ! } \\
\text { (and 1-6month) }\end{array}$ & NR & NR & NR \\
\hline
\end{tabular}

MIP : Maximal Inspiratory Pressure MEP : Maximal Expiratory Pressure FeVI : Forced expiratory volume in I sec. SDS : Standard deviation score N-excretion : Fecal Nitrogen excretion MUAC : Mid Upper Am Circumference MAMC : Mid Am Muscle Circumference
FVC : Forced Vital Capicity $\quad 1:$ Improved

FEF : Foreed Expiratory Flow 1 : Decreased

PEF : Peak Expiratory Flow = : unchanged

LBM : Lean Body Mass $\quad$ (ns) : not significant

FM : Fatmass $\quad$ NR: not reported

RDA: Recommended daily allowance

3-meHis excre : 3 methylhistidine excretion in urine 
Table 2 Long-term feeding intervention studies in cystic fibrosis.

\begin{tabular}{|c|c|c|c|c|c|c|c|c|}
\hline Aurthon & et al, '73 & $\begin{array}{l}\text { "Bemy } \\
\text { et all, '75 }\end{array}$ & $\begin{array}{l}\text { "Yises } \\
\text { etial.'78 }\end{array}$ & $\begin{array}{c}\text { Levy } \\
\text { et al, 's5 }\end{array}$ & $\begin{array}{l}\text { moland } \\
\text { et al, 'B6. }\end{array}$ & $\begin{array}{l}\text { "Sheperd } \\
\text { et al', '86 }\end{array}$ & $\begin{array}{l}\text { "Favell } \\
\text { ef at, 's? }\end{array}$ & $\begin{array}{l}\text { "Luder } \\
\mathrm{nad,} \cdot \mathrm{g}\end{array}$ \\
\hline Number of cases & 17 & is & 4 & 14 & 10 & 10 & 36 & 37 \\
\hline Age nange & $2.21 y$ & $10 m-18 y$ & $3-16 y$ & $5-22 y$ & $5 \cdot 20 y$ & $3 \cdot 13 y$ & $3 \cdot 4 m$ & $2 \cdot 27 y$ \\
\hline $\begin{array}{l}\text { Nutrition } \\
\text { stuns }\end{array}$ & mainuarik & malnutrit & malmuterit & mainutrit & mainutrik & malnutrit & normal & malnutrit \\
\hline $\begin{array}{l}\text { Sundy } \\
\text { duration }\end{array}$ & $\begin{array}{c}3 \text { months to } 3 \\
\text { ycers }\end{array}$ & 1 year & I yeat & 1,1 year & $\begin{array}{l}10-36 \\
\text { months }\end{array}$ & I year & 8 months & 4 yean \\
\hline $\begin{array}{l}\text { Type of } \\
\text { twady }\end{array}$ & $\begin{array}{l}\text { peospect } \\
\text { own } \\
\text { sontrol }\end{array}$ & $\begin{array}{l}\text { prospect } \\
\text { CF } \\
\text { control }\end{array}$ & $\begin{array}{l}\text { prosped } \\
\text { CF } \\
\text { enttrol }\end{array}$ & $\begin{array}{l}\text { prospect } \\
\text { CF } \\
\text { sontrol }\end{array}$ & $\begin{array}{l}\text { prospect } \\
\text { own } \\
\text { control }\end{array}$ & $\begin{array}{l}\text { prospect } \\
\text { CF } \\
\text { control }\end{array}$ & $\begin{array}{l}\text { prospect } \\
\text { CF } \\
\text { control }\end{array}$ & $\begin{array}{l}\text { prosped } \\
\text { ewt } \\
\text { control }\end{array}$ \\
\hline $\begin{array}{l}\text { Fetding } \\
\text { intervent }\end{array}$ & $\begin{array}{l}\text { etemetal } \\
\text { S0-100s } \\
\text { RDA }\end{array}$ & $\begin{array}{l}\text { elementad } \\
100 \mathrm{NRDA}\end{array}$ & $\begin{array}{l}\text { elemental } \\
100 \% \mathrm{RDA}\end{array}$ & $\begin{array}{c}\text { (veal) } \\
\text { elemetwal } \\
30 \% R D A \\
\text { (extn) }\end{array}$ & $\begin{array}{l}\text { oredigeat } \\
1000 \text { to } \\
2000 \text { Keal }\end{array}$ & $\begin{array}{l}\text { wielentatal } \\
120-140 \\
\text { NRDA }\end{array}$ & $\begin{array}{c}\text { pregestiail } \\
\text { vensus } \\
\text { standard } \\
120 \mathrm{Kea} / \mathrm{ks}\end{array}$ & $\begin{array}{l}\text { Dypercal } \\
\text { malyenerie } \\
120 \text { S6RDA }\end{array}$ \\
\hline Roule & oral & end & eral & eastrostomy & jejunontomy & enteral & oral & ond \\
\hline Effect & $\begin{array}{c}\text { SDSweil } \\
\text { SDStreit } \\
\text { clinical score ! }\end{array}$ & $\begin{array}{c}\text { SDSeeil } \\
\text { elinical score I } \\
\text { SOS thei (ns) }\end{array}$ & $\begin{array}{l}\text { SDSmeit } \\
\text { SDSteit } \\
\text { sosakf } \\
\text { boneage! }\end{array}$ & $\begin{array}{l}\text { weight (kg)! } \\
\text { beight (em) ! } \\
\text { weihei } \% \text { std. } \\
\text { ! } \\
\text { growth velocily } \\
1 \\
\text { BF } \% \text { ! } \\
\text { FFM ! } \\
\text { TBK ! } \\
\text { TBN ! } \\
\text { :FVC - } \\
\text { :FeVI - }\end{array}$ & $\begin{array}{l}\text { SDSweil } \\
\text { MAMC I } \\
\text { FVC = }\end{array}$ & $\begin{array}{l}\text { SDSweil } \\
\text { SOS hei! } \\
\text { protein syndhes ! } \\
\text { protein catabol ! } \\
\text { FoVI ! } \\
\text { FVC ! } \\
\text { FEF ! }\end{array}$ & $\begin{array}{l}\text { weight (ke) ! } \\
\text { beight (en) ! } \\
\text { growth velocity! }\end{array}$ & $\begin{array}{c}\text { SDSweil (os) } \\
\text { sDs bei (as) } \\
\text { FEF - } \\
\text { BMI । }\end{array}$ \\
\hline $\begin{array}{l}\text { Follow up } \\
\text { (duration) }\end{array}$ & NR & NR & $\begin{array}{c}\text { all } \\
\text { parameters I } \\
\text { excopt } \\
\text { bone exe } \\
\text { (1 yeu) }\end{array}$ & NR & NR & NR & NR & $N R$ \\
\hline
\end{tabular}

\begin{tabular}{|c|c|c|}
\hline $1:$ Improved & LBM : Lean Body Mass & BMI : Body Mass Index \\
\hline I: Decreased & FFM : Fu Free Mass & BF : Body fat \\
\hline$=$ : unchanged & TBN : Total body' nitrogen & $\mathrm{N}$-excrt : Nitrogen excretion \\
\hline RDA : Recommended Daily Allowance & TBK : Toul Body Kalium & (ns) non significant \\
\hline SDSwei : SDS weight & FVC : Forced Vital Capacity & Abs. coeff : absorption coefficient \\
\hline SDShei : SDS height & FeV1: Forced expiratory volume & $\$ \mathrm{FVC}$ and $\mathrm{FeVI}$ decrease in CF control \\
\hline SDSskit : SDS skinfolds & FEF : Forred Expiratory Flow & MAMC : Mid Arm Muscle Circumference \\
\hline
\end{tabular}


Table 3 Effect of short-term use of gastric acid inhibitors on steatorrhes and nutritional status in CF children.

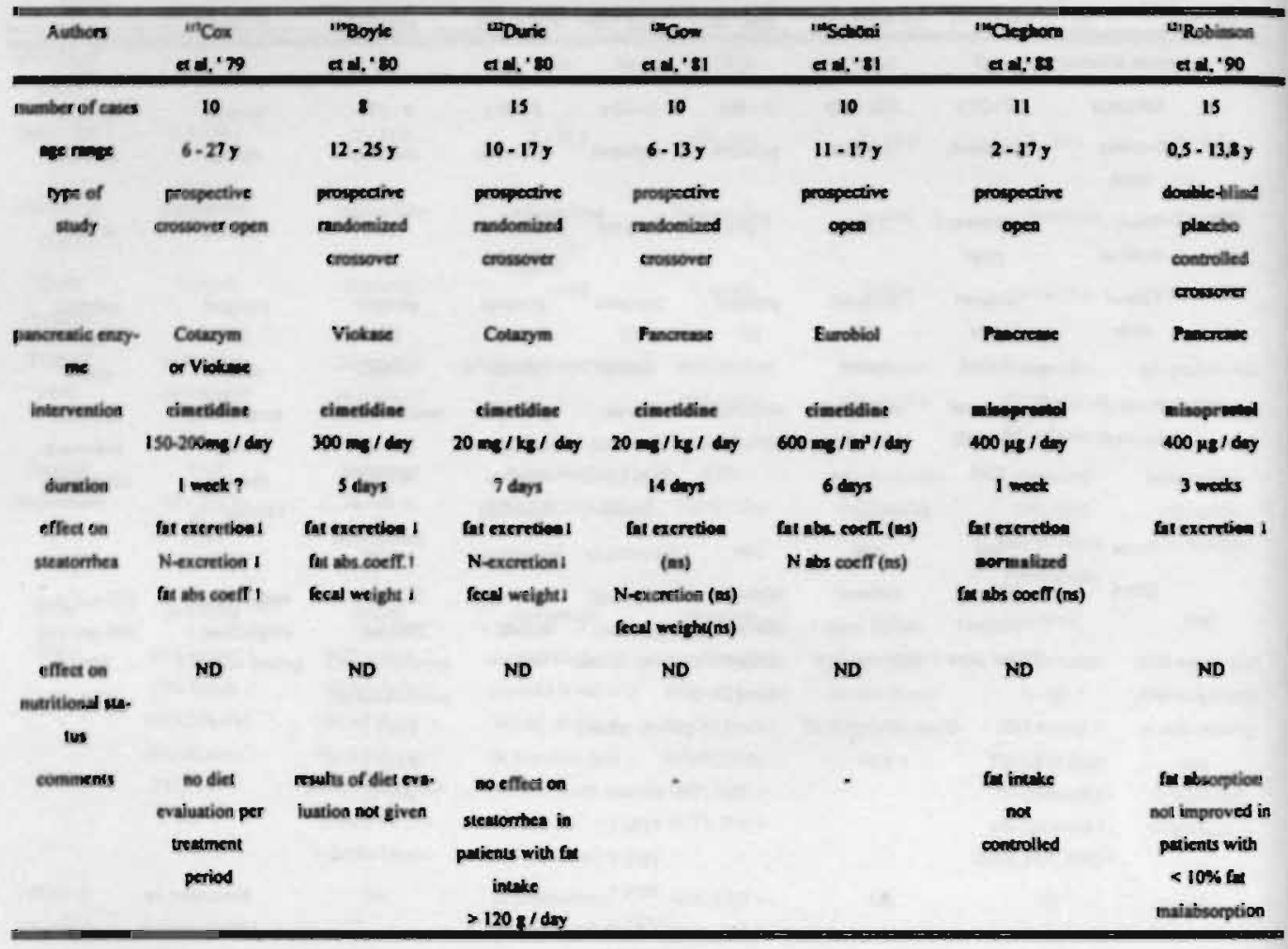

abs coeff : fat absorption coefficient

N-excretion : fecal Nitrogen excretion

(ns) : not significent 
Table 4 Effect of long-term use of gastric acid inhibitors on steatorrtea and nutritional status in CF children.

\begin{tabular}{|c|c|c|c|}
\hline Authors & "arSchoni et al, ' 84 & 'DeChalmers et al, ' 85 & ${ }^{13}$ Carroccio et al, "92 \\
\hline number of cases & 38 & 16 & 10 \\
\hline age range & $\operatorname{mean} 13 y$ & $5 \cdot 19 y$ & $7 \cdot 18 y$ \\
\hline type of study & $\begin{array}{c}\text { prospective randomized } \\
\text { doubleblind }\end{array}$ & double-blind crossover & double-blind crossover \\
\hline pacreatic enxyme & Pancrease & Cotarym & Pancrease \\
\hline \multirow[t]{2}{*}{ intervention } & cinetidine & cimetidine & Ianotidine \\
\hline & $600 \mathrm{mg} / \mathrm{m}^{2} / \mathrm{day}$ & $25 \mathrm{mg} / \mathrm{kg} / \mathrm{day}$ & Ing/kg/day \\
\hline duration & 4 months & 6 months & 6 months \\
\hline \multirow[t]{2}{*}{ effect on steatornhea } & $\begin{array}{l}\text { plasma lipid and } \\
\text { lipoprotein (as) }\end{array}$ & $\begin{array}{l}\text { fat excretion I } \\
\text { N-excretion (ns) }\end{array}$ & $\begin{array}{c}\text { fat absorption coeff. I } \\
\text { fecal weight I }\end{array}$ \\
\hline & & fecal weight (ns) & \\
\hline effect on & weight, height (ns) & SDSweight (ns) & weighe (kg) I \\
\hline \multirow[t]{3}{*}{ nutritional status } & $\begin{array}{l}\text { skinfolds (ns) } \\
\text { TLC, TGV (ns) }\end{array}$ & $\begin{array}{l}\text { SDSheight (ns) } \\
\text { skinfolds (ns) }\end{array}$ & $\begin{array}{c}\text { height (cm) I } \\
\text { clinical score (ns) }\end{array}$ \\
\hline & Raw, sGaw I & bone age (ns) & \\
\hline & & clinical score (ns) & \\
\hline comments & no diet evaluation & $\begin{array}{l}\text { results of diet } \\
\text { evaluation was not given }\end{array}$ & $\begin{array}{l}\text { results of diet } \\
\text { evaluation was not given }\end{array}$ \\
\hline
\end{tabular}

SDS : Standard Deviation Score for age and sex

TLC : Total Lung Capicity

TGV : Thoracic Gas volume

Raw : airway resistance

sGaw : specific conductance

(ns) : not significant 


\section{6 EVALUATION OF STEATORRHEA}

\section{6. 1 Fecal fat balance}

The 3 days fecal fat excretion while patients are on a standard fat diet is the most reliable method for quantitative determination of fecal fat loss. The fat absorption coefficient is calculated by the following formula:

(Fat ingested - fat excreted) / fat ingested X 100

Normal fat absorption coefficient at different ages have been reported as follows:

Age $>1$ year : $295 \%(126-128)$

Age $<1$ year : $>83 \%$ if formula fed and $>93 \%$ if breast fed (126)

Premature infants : 38 - $73 \%$ depending on the formula used (129)

Fecal fat can be determined by either Gravimetric or Titrimetric methods. For both methods, fecal fat is extracted with an organic solvent, the fat content is subsequently measured either by weighing (Gravimetric method) or by titration (Titrimetric method). The Gravimetric method determine all fecal lipid components, resulting in erroneously high results. On the contrary, the titrimetric method only measures fatty acids. Fecal lipids are first saponified and subsequently acidified to liberate fatty acids which are then extracted. Since its first. description in 1949 (130), the titrimetric procedure of van de Kamer has been used as a reference method for the evaluation of malabsorption. The fat balance method is reliable for the quantification of fecal fat loss with a coefficient of variation of $4,6 \%$ (131). However, the determination procedure is time consuming, expensive and necessitates sophisticated apparatus. Further, since the fat excretion is dependent on fat intake, patients have to keep up a strictly fat constant diet of more than 80 gram per day. Moreover, fecal collection have to be done very accurately. The balance method consequently is poorly reliable in outpatients, especially in children and infants. When fat balance is not possible, measuring fecal fat concentration in a fecal sample can be used for the screening of fat malabsorption. Results are then expressed as percent of wet fecal weight (fecal fat concentration). Using the ${ }^{14} \mathrm{C}$. triolein ${ }^{3} \mathrm{H}$-oleic acid test as a reference method, Pedersen et al. have studied the diagnostic 
value of fecal fat concentration as measured by the titrimetric method of van de Kamer in a 72 hours fecal collection without controlling for dietary fat (132). In this study, a similar diagnostic value was found for both fecal fat concentration (FFC) and fecal fat excretion (FFE): The sensitivity, specificity, positive predictive value and negative predictive value of FFC versus FFE were respectively $93,1 \%$ versus $90 \%$; $92,4 \%$ versus $89,4 \% ; 90 \%$ versus $93 \%$ and $89 \%$ versus $90 \%$ with a day to day coefficient of variation of $29 \%$ for FFC and $64 \%$ for FFE. In only $6 \%$ of the patients studied, the FFC when measured in a single day sample differed from the mean 3-day fecal fat concentration value whereas the FFE differed from the mean 3-day fecal fat excretion in $37 \%$ of the patients. FFC correlated weakly but significantly with FFE ( $r=0,55 ; \mathrm{p}<0,01)$ (133). FFC results in pancreatic steatorrhea being higher than in nonpancreatic steatornhea, Bolinn et al. have suggested that FFC could be used for the differentiation of both types of steatornhea (134). This has however not been confirmed by other investigators; who found much overlap in FFC results between pancreatic and nonpancreatic steatorrhea $(132,133,135,136)$. Results of these studies are shown in table 5 .

The utility of FFC as an screening method for fat malabsorption has been limited because of the high interday variation (29\%). This interday variation might be due to the varying fecal water content as reported by Weijers et al. (137). This suggests that if the effect of varying water content could be eliminated, the interday variation of FFC would be much lower. A new method for the semiquantitative determination of FFC, which eliminates the influence of varying fecal water content is the steatocrit.

\section{6. 2 Steatocrit}

This procedure is based on the fact that fecal fat is extracted by centrifugation of diluted stool in a hematocrit capillary at $13000 \mathrm{rpm}$ for 15 minutes (138). After centrifugation, three layers, are distinguished in the capillary; the upper fatty layer $(\mathrm{FL})$, the middle fluid layer and the bottom solid layer (SL). The fecal fat measured by steatocrit is expressed as fecal fat concentration and is calculated as FL / (FL + SL). Reported norrnal values are $<2 \%$ (139). The steatocrit method is very suitable for use in children and infants since it is simple, noninvasive and can be performed on small fecal samples ( 0,5 gram). Moreover, it is inexpensive and. the whole test takes only 20 minutes. Although several authors have reported this method to 
be satisfactory for the evaluation of steatornhea (138-142), some bave reported the steatocrit to be quite unreliable (143). Sugai reported a specificity of $97 \%$ for steatocrit but a sensitivity of $98 \%, 79 \%$ and $29 \%$ for samples with respectively high, moderate and low fat content (144). This low sensitivity observed for samples of low fat content may be due to difficulties with either fat extraction or with obtaining a clear separation between the fatty, aqueous and solid layer, resulting in erroneous results.

\section{6. 3 Sudan staining method}

The presence of fecal fat can be screened for by microscopic examination of stools. The fecal preparation is first acidified and stained with Sudan staining. After heating, fecal fatty acids and triglycerides are seen as fatty globules under the microscope. Dependent on the number and the size of the globules, the fatty globules are classified as normal , slightly increased or definitely increased (145). Weijers et al. studied the agreement between results of the Sudan staining method and chemically measured fecal fat (137). Satisfactory agreement between both methods was found in (60 - $70 \%$ cases) for fecal samples with very low or very high fat content $(<3 \%$ or $>9 \%$ ) but the agreement dropped to $40 \%$ for samples of moderate fat content $(3-9 \%)$.

\section{6. 4 C- Triolein absorption test}

After ingestion, ${ }^{14} \mathrm{C}$-Triolein is digested by pancreatic lipase in the duodenum liberating fatty acids, which on further oxidation yield ${ }^{14} \mathrm{CO}_{2}$ which can be detected in expired air. Although this method is simple, rapid to perform and gives a direct evaluation of pancreatic function, it is not appropriate for use in children because of the radioactivity. Recently, a new non radioactive substrate ${ }^{13} \mathrm{C}$-Triolein has been introduced but this is however expensive and a mass spectrometer is needed in order to use this test (131).

\section{6. 5 Near Infrared Reflectance Analysis}

This method is based on the analysis of the infrared spectrum radiation, reflected by the 
surface of the material under study. Specific peaks for the component to be investigated can be identified and their heights can be related to the concentration of the component studied by using computerised multilinear regression analysis. Besides measuring fecal fat, this apparatus can also be used for the determination of fecal nitrogen and water content. The analysis lasts less than 1 minute and can be performed on small samples ( 2 - 3 gram ). The variation coefficient is $2,1 \%$ and the correlation coefficient with the van de Kamer method is 0,92 (146). However this high correlation is possibly due to the fact that this method is calibrated by the titrimetric method described by van de Kamer. The calibration procedure is difficult and this sophisticated instrument is expensive (147). Further studies are necessary in order to better evaluate the usefulness of near infrared reflectance analysis in clinical practice. 
Table 5 Diagnostic value of fecal fat concentration (FFC) and fecal fat excretion (FFE) in studies of fat malassimilation.

\begin{tabular}{|c|c|c|c|c|c|}
\hline Authon & medenen' ' 4 & "Bollinn' 34 & 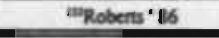 & 'Yembeke' 87 & "Hai et al ' 69 \\
\hline & & 50 & & 369 & 338 \\
\hline Aims of stady & $\begin{array}{l}\text { diapnostic value of FFC } \\
\text { venus FFE }\end{array}$ & diagnontic value of FFC & dingnostic value of FFC & fingnostic value of FFC & Eingnostic value of FFC \\
\hline Method used & 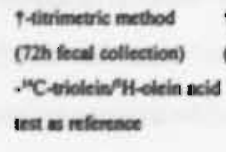 & $\begin{array}{l}\text { Thitrimetric method } \\
\text { (72h fecal collection) }\end{array}$ & $\begin{array}{l}\text { fritrimetric method } \\
\text { (72h fecal collection) }\end{array}$ & $\begin{array}{l}\text { Ttitrimetric method } \\
\text { (72h fecal collection) }\end{array}$ & $\begin{array}{l}\text { frierimemic method } \\
\text { (72h fecal colliection) }\end{array}$ \\
\hline Population (n) & 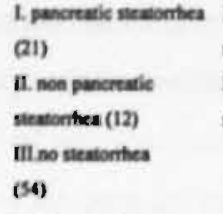 & $\begin{array}{l}\text { 1. pancrealis } \\
\text { steatombea (19) } \\
\text { 11. nonpancreatic } \\
\text { steanomies (B1) }\end{array}$ & 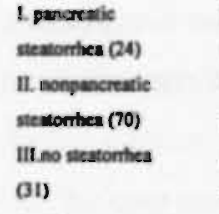 & $\begin{array}{l}\text { I. puncreatic } \\
\text { stemonthes (59) } \\
\text { II. nonpancreatic } \\
\text { stemonthea (53) } \\
\text { III no steatontere sick } \\
\text { ind normai controls (257) }\end{array}$ & $\begin{array}{l}\text { I. puncreatic } \\
\text { sewontea(88) } \\
\text { II. nonpancreatic } \\
\text { stemontea (525) }\end{array}$ \\
\hline Results & 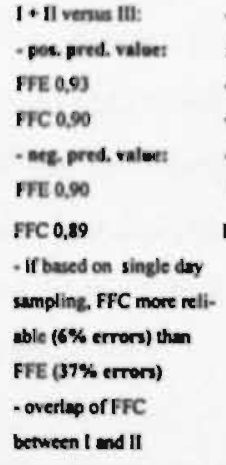 & 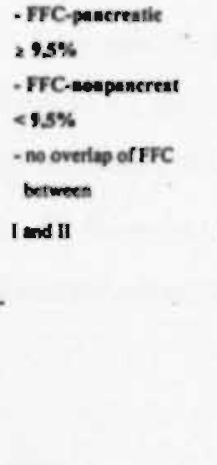 & 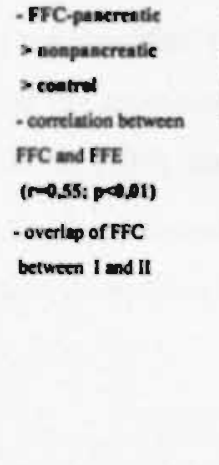 & $\begin{array}{l}\text {-FFC-paserentic }>\text { mo } \\
\text { pancreatic steatorritea } \\
\text { coatrol } \\
\text { - Overlap of FFC } \\
\text { between I and II }\end{array}$ & 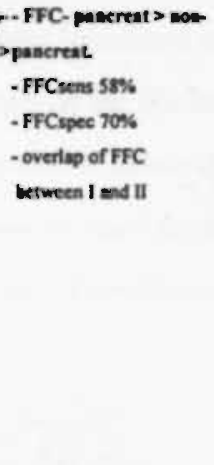 \\
\hline Comments. & 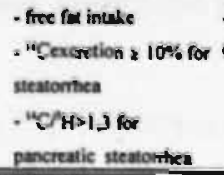 & $\begin{array}{l}\text { - fa diet } \\
90-100 y d d y\end{array}$ & 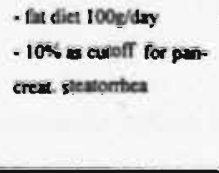 & - Exx diet $280 \mathrm{~g} / \mathrm{day}$ & 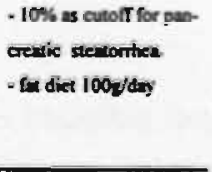 \\
\hline
\end{tabular}

FFC: Fecal fat coricentration

FFE: Fecal fat excretion

† Method as deseribed by van de Kamer (III)

pos. pred. value: positive predictive value

neg. pred. value: negative predictive value

sens: sensitivity

spec: specificity 


\section{AIMS OF THE STUDY}

With age, children with CF show progressing malnutrition mainly attributed to either persisting malabsorption notwithstanding the use of high oral doses of pancreatic enzymes or increased energy consumption secondary to respiratory disease. Prospective studies in young children have shown malnutrition to occur only in patients with pancreatic insufficiency (34). Efforts to either maintain or restore the nutritional condition have shown that, notwithstanding the use of pancreatic enzymes, high nutrient intakes only seems to be effective when administered "digested" either as total parenteral nutrition or as (semi)elemental feedings orally or by tube feeding. The apparent insufficient effect of pancreatic enzymes does not seem to be due to too low administered doses and recently very high doses have been used with the hope of correcting malabsorption. Suggestions have been made that these high doses might be responsible for the recently reported occurence of colitis in these patients (113-115).

Our hypothesis was that persisting malabsorption in these patients is likely to be linked to a low duodenal $\mathrm{pH}$ which interferes with several digestive and absorptive processes such as impeding transport of split fatty acids from the luminal lipid globules to the absorptive area through the mediation of bile salt micelles. If this was correct, antacid treatment should improve fat malabsorption in these patients. The fact that most studies hereover have been inconclusive might be due to the short and inefficient control of duodenal $\mathrm{pH}$ with the drugs used. A recent double-blind control study in adults patients has shown malabsorption to normalize in several patients treated with a proton pump inhibitor (omeprazol) (112). Until now, no studies with proton pump inhibitor have been reported in children.

\section{The aims of the present work were:}

1. Develop an easy, noninvasive, cheap and reliable test for the monitoring of fecal fat loss in pancreatic malabsorption.

2. Evaluate the nutritional condition, the body composition and the presence or persistence of fat malabsorption in our patients with exocrine pancreatic insufficiency accompanying cystic fibrosis. 
3. Evaluate whether or not the use of a proton pump inhibitor (lansoprazole) in our patients with persisting malabsorption improves both the fat malabsorption and the nutritional condition. 


\section{REFERENCES}

(1) G. Fanconi, E. Uehlinger, C. Knauer. Das Coeliaksyndrom bei Angeborener Zysticher Pankreas fibromatose und Bronchiektasien. Wein Med Wschr 1936; 86: 753-756.

(2) CF Genetic analysis consortium. Worldwide survey of the $\Delta \mathrm{F} 508$ mutation. Am J Hum Genet 1990; 47: 354-359.

(3) M. Welsh, A. Smith. Molecular mechanisms of CFTR chloride channel dysfunction in cystic fibrosis. Cell 1993; 73: 1251-1254.

(4) C. Marino, L. Matoveik, F. Gorelick, J. Cohn. Localization of the cystic fibrosis transmembrane conductance regulator in pancreas. J Clin Invest 1991; 88: 712-716.

(5) T. Boat, M. Welsh, A. Beaudet. (1989). In The Metabolic Basis of inherited Disease, C. Scriver, A. Beaudet, W. Sly, D. Valle, eds. (New York: McGraw-Hill,inc.), pp. 2649-2680.

(6) E. Kerem, J. Reisman, M. Corey, G. Canny, H. Levison. Prediction of mortality in patients with cystic fibrosis. N Engl J Med 1992; 326: 1187-91.

(7) C. Sommerhoff, J. Nadel, C. Basbaum et al. Neutrophil elastase and cathepsin G stimulate secretion from culture bovine airway gland serous cells. J Clin Invest 1990;85: 682-689.

(8) L. Sharples, T. Hathaway, C. Dennis, N. Caine, T. Higenbottam, J. Wallwork. Prognosis of patients with cystic fibrosis awaiting heart and lung transplantation. J Heart-Lung-Transplant 1993; 12: 669-74.

(9) J. Britton. Effects of social class, sex, and region of residence on age at death from cystic fibrosis. Br Med J 1989; 298: 483-487.

(10) M. Corey, F. McLaughlin, M. Williams, H. Levison. Comparison of survival, growth and pulmonary function in patients with cystic fibrosis in Boston and Toronto. $\mathrm{J}$ Clin Epidemiol 1988; 41: 583-591.

(11) M. Aitken, S. Fiel. Cystic fibrosis. Dis Mon 1993; 39: 1-52.

(12) P. Brihaye, P. Clement, I. Dab, B. Desprechin. Pathological changes of the lateral nasal wall in patients with cystic fibrosis. Int J Pediatr Otorhinolaryngol 1994; 28: 141-7.

(13) I. Mackay, B. Djazaeri. Chronic sinusitis in cystic fibrosis. J Roy Soc Med 1994; 87 (Suppl 21): 17-19.

(14) B. Hadom, P. Johansen, C. Anderson. Pancreozymin secretin test of exocrine pancreatic function in cystic fibrosis and the significance of the result for the pathogenesis of the disease. 
Can Med Assoc J 1968; 98: 377-385.

(15) B. Hadorn, G. Zoppi, D. Shmerling, A. Prader, I. McIntyre, C. Anderson. Quantitative assessment of exocrine pancreatic function in infants and children. J Pediatr 1968; 73: 39-50.

(16) H. Schachman, E. Lebenthal, K. Khat. Recurrent, acute pancreatitis in patients with normal pancreatic enzymes. Pediatrics 1975 ; 55: 86-95.

(17) K. Gaskin, P. Durie, M. Corey, P. Wei, G. Forstner. Evidence for a primary defect of pancreatic $\mathrm{HCO}_{3}$-secretion in cystic fibrosis. Pediatr Res 1982; 16: 554-557.

(18) A. Atlas, S. Orenstein, D. Orenstein. Pancreatitis in young children with cystic fibrosis. J Pediatr 1992; 120: 756-9.

(19) F. Ahmed, J. Ellis, J. Murphy, S. Wooton, A. Jackson. Excessive faecal loss of vitamin A (retinol) in cystic fibrosis. Arch Dis Child 1990; 65: 589-593.

(20) R. Sokol, M. Reardon, F. Accurso et al. Fat-soluble-vitamin status during the first year of life in infants with cystic fibrosis identified by screening of newborns. Am J Clin Nutr 1989; 50: $1064-71$.

(21) V. Hubbard, P. Farrell, P. di Sant 'Agnese. 25-hydroxylcholecalciferol levels in patients with cystic fibrosis. J Pediatr 1979; 94: 84-86.

(22.) E. Mischler, PJ Chesney, PW Chesney, R. Mazess. Demineralization in cystic fibrosis detected by direct protein absorptiometry. Am J Dis Child 1979; 133: 632-635.

(23) N. Solomons, J. Wagonfeld, C. Rieger et al. Some biochemical indices of nutrition in treated cystic fibrosis patients. Am J Clin Nutr 1981; 34: 462-474.

(24) R. Allen, B. Seetharam, E. Podell, D. Alpers. Effect of proteolytic enzymes on the binding of cobalamin to $\mathrm{R}$ protein and intrinsic factor. J Clin Invest $1978 ; 61$ : 47-54.

(25) M. Murphy, W. Sheldon, A. Brunetto et al. Active and passive sugar absorption in pancreatic insufficiency. J Pediatr Gastroenterol Nutr 1989; 8: 189-194.

(26) L. Frase, A. Strickland, G. Kachel, G. Krejs. Enhanced glucose absorption in the jejunum of patients with cystic fibrosis. Gastroenterology $1985 ; 88: 478-484$.

(27) M. Lohr, P. Goertchen, H. Nizze et al. Cystic fibrosis associated islet changes may provide a basis for diabetes. An immunocytochemical and morphometrical study. Virchows Arch [A] 1989; 414: 179-185.

(28) L. Krueger, A. Lerner, S. Katz, R. Mack, D. Holsclaw, E. Lebenthal. Cystic fibrosis and diabetes mellitus: interactive or idiopathic. J Pediatr Gastroenterol Nutr 1991; 13: 209-219. 
(29) E. Wilmshurst, J. Soeldner, D. Holsclaw. Endogeneous and exogeneous insulin responses in patients with cystic fibrosis. Pediatrics 1975; 55: 75-82.

(30) O. Andersen, S. Garner, C. Heilmann, K. Petersen, W. Petersen, C. Koch. Glucose tolerance and insulin receptor binding to monocytes and erythrocytes in patients with cystic fibrosis. Acta Paediatr Scand 1988; 77: 67-71.

(31) A. Moran, P. Diem, D. Klein, M. Levitt, R. Robertson. pancreatic endocrine function in cystic fibrosis. J Pediatr 1991; 118: 715-723.

(32) H. Berry, F. Kellogg, M. Hunt, R. Ingberg, L. Ricter, C. Gutjahr. Dietary supplement and nutrition in children with cystic fibrosis. Am J Dis Child 1975; 129; 165-171.

(33) J. Dodge, J. Yassa. Food intake and supplementary feeding programs. In: J. Sturgess, ed. perspectives in cystic fibrosis. Toronto: Canadian Cystic Fibrosis Foundation; 1980: 125-136. (34) M. Bronstein, R. Sokol, S. Abman et al. Pancreatic insufficiency, growth, and nutrition in infants identified by newborn screening as having cystic fibrosis. J Pediatr 1992; 120: 533-40. (35) J. Tomezsco, V. Stallings, D. Kawchak, J. Goin, G. Diamond, T. Scanlin. Energy expenditure and genotype of children with cystic fibrosis. Pediatr Res 1994; 35: 451-460.

(36) M. Bronstein, P. Davies, K. Hambidge, F. Accurso. Normal energy expenditure in the infant with presymptomatic cystic fibrosis. J Pediatr 1995; 126: 28-33.

(37) K. Cox, J. Isenberg, M. Ament. Gastric acid hypersecretion in cystic fibrosis. J Pediatr Gastroenterol Nutr 1982; 1: 559-565.

(38) C. Roy, A. Weber, C. Morin et al. Abnormal biliary lipid composition in cystic fibrosis. N Engl J Med 1977; 297: 1301-1305.

(39) A. Malfroot, I. Dab. New insights on gastro-oesophageal reflux in cystic fibrosis by longitudinal follow up. Arch Dis Child 1991; 66: 1339-1345.

(40) S. Cucchiara, F. Santamaria, M. Andreotti et al. Mechanisms of gastro-oesophageal reflux in cystic fibrosis. Arch Dis Child 1991; 66: 617-622.

(41)P. Gustafsson, S. Fransson, N. Kjellman, L. Tibbling. Gastro-oesophageal reflux and severity of pulmonary disease in cystic fibrosis. Scand J Gastroenterol 1991; 26: 449-456.

(42) S. Fiedorek, R. Shulman, W. Klish: Endoscopic detection of peptic ulcer disease in cystic fibrosis. Clin Pediatr (Phila) 1986; 25: 243-246.

(43) P. Robinson, A. Smith, P. Sly: Duodenal $\mathrm{pH}$ in cystic fibrosis and its relationship to fat malabsorption. Dig Dis Sci 1990: 35: 1299-1304. 
(44) J. McPartin, J. Dickson, V. Swain. Meconium ileus, immediate and longterm survival. Arch Dis Child 1972; 47: 207-210.

(45) H. Andersen, K. Hjelt, E. Waever, K. Overgaad. The age related incidence of meconium ileus equivalent in a cystic fibrosis population: the impact of high energy intake. J Pediatr Gastroenterol Nutr 1990; 11:356-360.

(46) L. Kulczyki, H. Schwachman. Studies in cystic fibrosis of the pancreas: occurrence of rectal prolapse. N Engl J Med 1958;259: 409-412.

(47) D. Holsclaw, C. Rocmans, H. Schwachman. Intussusception in patients with cystic fibrosis. Pediatrics 1971; 48:51-58.

(48) H. Rovsing, K. Sloth. Microgallbladder and biliary calculi in mucoviscidosis. Acta Radiol [Onco] 1973; 14: 588-592.

(49) F. Santamaria, P. Vajro, V. Oggero et al. Volume and emptying of the gallbladder in patients with cystic fibrosis. J Pediatr Gastroenterol Nutr 1990; 10: 303-306.

(50) L. Taussig, C. Lobeck, P. Ackerman, J. Kattwinkel: Fertility in males with cystic fibrosis. N Engl J Med 1972; 287: 586-589.

(51) E. Kaplan, H. Shwachman, A. Perlmutter et al.: Reproductive failures in males with cystic fibrosis. N Engl J Med 1968; 279: 65-69.

(52) S. Fitzsimmons: Cystic Fibrosis Foundation Patient Registry 1990 Annual Report. Bethesda, Cystic Fibrosis Foundation, 1991.

(53) P. Tam, P. Verdugo: Control of mucus hydration as a Donnan equilibrium process. Nature 1981: 292: 340-342.

(54) P. Di Sant 'Agnese, R. Darling. G. Perera, E. Shea. Abnormal electrolyte composition of sweat in cystic fibrosis of the pancreas. Clinical significance and relationship to the disease. Pediatries 1953; 12: 549-563.

(55) L. Gibson, R. Cooke. A test for concentration of electrolytes in sweat in cystic fibrosis of the pancreas utilizing in pilocarpine by iontophoresis. Pediatrics 1959; 23: 545-549.

(56) H. Veeze, A. Van den Ouweland, D. Halley et al. The diagnosis of cystic fibrosis: intestinal current measurements, a highly accurate mathod in case of a borderline phenotype. Submitted.

(57) M. Rosenfeld, W. Siegfried, K. Yoshimura et al. Adenovirus-mediated transfer of a recombinant alpha 1-antitrypsin gene to the lung epithelium in vivo. Science.1991; 252:431-4 
(58) B. Pitt, M. Schwarz, J. Pilewski et al. Retrovirus-mediated gene transfer in lungs of living fetal sheep. Gene Ther 1995; 2 : 344-50.

(59) M. Rosenfeld, K. Yoshimura, B. Trapnell et al. In vivo transfer of the human cystic fibrosis transmembrane conductance regulator gene to the airway epithelium. Cell. 1992; 68 : 143-55.

(60) R. Kraemer, A. Rüdeberg, B. Hadorn, E. Rossi. Relative underweight in cystic fibrosis and its prognostic value. Acta Paediatr Scand 1978; 67: 33-37.

(61) S. Rao, D. Wilson, R. Brooks et al. Acute effects of nebulization of n-acetylcysteine on pulmonary mechanics and gas exchange. Am Rev Respir Dis. 1970; 102: 17-22.

(62) W. Waring. Current management of cystic fibrosis. Adv Pediatr. 1976; 23: 401-38.

(63) M. Gotz, R. Kraerner, K. Kerrebijn et al. Oral acatylsysteine in cystic fibrosis. A cooperative study. Eur J Respir Dis. 1980;61: (Suppl 111): 122-6.

(64) J. Reisman, B. Rivington-Law, M. Corey et al. Role of conventional physiotherapy in cystic fibrosis. J Pediatr 1988; 113: 632-6.

(65) H. Steen, A. Redmond, D. O'Neil et al. Evaluation of the PEP mask in cystic fibrosis. Acta Paediatr Scand. 1991; 80: 51-6.

(66) C. Braggion, L. Cappelletti, M. Cornacchia, L. Zanolla, G. Mastella. Short-term effects of three chest physiotherapy regimens in patients hospitalized for pulmonary exacerbations of cystic fibrosis: A cross-over randomized study. Pediatr Pulmonol 1995; 19: 16-22.

(67) J. Pryor, B. Webber, M. Hobson et al. Evaluation of the forced expiratory technique as an adjunct to postural drainage in the treatment of cystic fibrosis. J Pediatr. 1983; 103: 538-42.

(68) P. Sutton, H. Gemmell, N. Innes et al. Use of nebulized saline and nebulized terbutaline as an adjunct to chest physiotherapy. Thorax. 1988; 43: 57-60.

(69) E. Pattishall. Longitudinal response of pulmonary function to bronchodilators in cystic fibrosis. Pediatr Pulmonol. 1990; 9: 80-5.

(70) P. Konig, D. Gayer, J. Shaffer et al. Bronchodilator responsiveness and spontaneous diumal variation of PEFR in patients with cystic fibrosis. Poster presented at the North American Cystic Fibrosis Conference. Washington, DC: 1992 Oct. Abstract.

(71) M. Konstan, P. Byrard, C. Hoppel, P. Davis: Effect of high dose ibuprofen in patients with cystic fibrosis. N Engl J Med 1995; 332: 848.

(72) H. Auerbach, M. Williams, J. Kirkpatrick et al. Alternate-day prednisone reduces morbi- 
dity and improves pulmonary function in cystic fibrosis. Lancet. 1985; 2: 686-8.

(73) B. Rosenstein, H. Eigen. Risk of alternate-day prednisone in patients with cystic fibrosis. Pediatrics. 1991; 87: 245-6.

(74) C. Pantin, R. Stead, M. Hodson et al. Prednisolone in the treatment of airflow obstruction in adults with cystic fibrosis. Thorax. 1986; 41: 34-38.

(75) M. Zach. Pathogenesis and managernent of lung disease in cystic fibrosis. J R Soc Med. 1991; 84 (Suppl 18): 10-7.

(76) McNeil Pharmaceutical. Pseudomonas vaccine tests start. Cystic Fibrosis Currents. 1991; 6(4).

(77) A. Khaghani, B. Madden, M. Hodson et al. Heart-lung transplantation for cystic fibrosis. Paper presented at the North American Cystic Fibrosis Conference. Dallas, TX: 1991 Oct 4.

(78) E. App, M. King, R. Helfesrieder et al. Acute and longterm amiloride inhalation in cystic fibrosis lung disease. Am Rev Respir Dis. 1990; 141: 605-12.

(79) M. Knowles, N. Church, W. Waltner et al. A pilot study of aerosolized amiloride for the treatment of lung disease in cystic fibrosis. N Engl J Med. 1990; 322: 1189-94.

(80) M. Hodson. Clinical studies of rhDNase in moderately and severely affected patients with cystic fibrosis - An Overview. Respiration 1995; 62 (suppl 1); 29-32.

(81) M. Aitken, W. Burke, G. McDonald et al. Recombinant human Dnase inhalation in normal subjects and patients with cystic fibrosis. A phase 1 study. JAMA. 1992; 267: 194751.

(82) R. Hubbard, N. McElvaney, P. Steven et al. A preliminary study of aerosolized recombinant human deoxyribonuclease $I$ in the treatment of cystic fibrosis. N Engl J Med. 1992; $326: 812-5$.

(83) N. McElvaney, R. Hubbard, P. Birrer et al. Aerosol alpha-1-antitrypsin treatment for cystic fibrosis. Lancet. 1991; 337: 392-4.

(84) R. Boucher, E. Cheng, A. Paradiso et al. Chloride secretory response of cystic fibrosis airway epithelia: presentation of calcium but not protein kinase $\mathrm{C}$ and $\mathrm{A}$-dependent mechanism. J Clin Invest. 1989;84: 1424-31.

(85) H. Chase, M. Long, M. Lavin. Cystic fibrosis and malnutrition. J Pediatr 1979; 95: 33747.

(86) C. Roy, A. Silverman, F. Cozzetto. Pediatric Clinical Gastroenterology. 2nd ed. St. 
Louis: CV Mosby, 1975: 615-35.

(87) J. Dodge, J. Yassa. Food intake and supplementary feeding programs. In: Sturgess JM, ed. Perspectives in cystic fibrosis. Procedings of the 8th International Cystic Fibrosis Congress. Toronto: Canadian Cystic Fibrosis Foundation, 1980: 125-36.

(88) H. Parsons, P. Beaudry, A. Dumas, P. Pencharz. Energy needs and growth in children with cystic fibrosis. J Pediatr Gastroenterol Nutr 1983; 2: 44-9.

(89) H. Schwachman, R. Dooley, F. Guilmette, P. Patterson, C. Weil, H. Leubner. Cystic fibrosis of the pancreas with varying degrees of pancreatic insufficiency. Am J Dis Child 1956; 92: 347-68.

(90) D. Crozier. Cystic fibrosis a not so fatal disease. Pediatr Clin North Am 1974; 21: 935 950.

(91) D. Gurwitz, M. Corey, P. Francis, D. Crozier, H. Levison. Perspectives in cystic fibrosis. Pediatr Clin North Am. 1979; 26: 603-615.

(92) E. Luder, M. Kattan,J. Thornton, K. Koehler, R. Bonforte. Efficacy of a nonrestricted fat diet in patients with cystic fibrosis. AJDC. 1989; 143: 458-464.

(93) A. Rettammel, M. Marcus, P. Farrell, S. Sondel, R. Koscik, E. Mischler. Oral supplementation with a high-fat, high-energy product improves nutritional status and alters serum lipids in patients with cystic fibrosis. J Am Diet Assoc. 1995; 95: 454-459.

(94) K. Gaskin, D. Waters, L. Baur, V. Soutter, M. Gruca. Nutritional status, growth and development in children undergoing intensive treatment for cystic fibrosis. Acta Paediatr Scand [Suppl]. 1990; 366: 106-110.

(95) E. O' Loughlin, D. Forbes, H. Parsons, B. Scott, D. Cooper, G. Gall. Nutritional rehabilitation of malnourished patients with cystic fibrosis. Am J Clin Nutr. 1986: 43: 732-737.

(96) R. Shepherd, T. Holt, B. Thomas et al. Nutritional rehabilitation in cystic fibrosis: Controlled studies of effects on nutritional growth retardation, body protein turnover, and course of pulmonary desease. J Pediatr. 1986; 109: 788-94.

(97) R. Shepherd, B. Thomas, D. Bennett, W. Cooksley, L. Ward. Changes in body composition and muscle protein degradation during nutritional supplementation in nutritionally growth-retarded children with cystic fibrosis. J Pediatr Gastroenterol Nutr. 1983; 2: 439-446.

(98) L. Levy, P. Durie, P. Pencharz, M. Corey. Effects of long-term nutritional rehabilitation on body composition and clinical status in malnourished children and adolescents with cystic 
fibrosis. J Pediatr 1985; 107: 225-230.

(99) J. Bertrand, C. Morin, R. Lasalle, J. Patrick, A. Coates. Short-term clinical, nutritional, and functional effects of continuous elemental enteral alimentation in children with cystic fibrosis. J Pediatr. 1984; 104: 41-46.

(100) R. Shepherd, W. Cooksley, and W. Domville. Improved growth and clinical, nutritional, and respiratory changes in response to nutritional therapy in cystic fibrosis. J Pediatr. 1980; 97: 351-357.

(101) J. Yassa, R. Prosser, J. Dodge. Effects of an artificial diet on growth of patients with cystic fibrosis. Arch Dis Child. 1978; 53: 777-783.

(102) J. Allan, A. Mason, A. Moss. Nutritional supplementation in treatment of cystic fibrosis of the pancreas. Am J Dis Child. 1973; 126: 22-26.

(103) A. Manseli, J. Andersen, C. Muttart et al. Short-term pulmonary effects of total parenteral nutrition in children with cystic fibrosis. J Pediatr 1984; 104: 700-705.

(104) M. Canciani, G. Mastella. Absorption of a new semielemental diet in infants with cystic fibrosis. J Pediatr Gastroenterol Nut. 1985; 4: 735-740.

(105) M. Boland, D. Stoski, N. Macdonald, P. Soucy, J. Patrick. Chronic jejunostomy feeding with a non-elemental formula in undernourished patients with cystic fibrosis. Lancet 1986; 1: 232-234.

(106) P. Farrell, E. Mischler, S. Sondel, M. Palta. Predigested formula for infants with cystic fibrosis. Research. 1987; 87: 1353-1356.

(107) P. Regan, J. Malagelada, E. Dimagno, and V. Go. Reduced intraluminal bile acid concentrations and fat maldigestion in pancreatic insufficiency: Correction by treatment. Gastroenterology. 1979; 77: 285-289.

(108) P. Zentler-Munro, W. Fitzpatrick, J. Batten, and T. Northfield. Effect of intrajejunal acidity on aqueous phase bile acid and lipid concentrations in pancreatic steatorrhoea due to cystic fibrosis. Gut. 1984; 25: 500-507.

(109) P. Zentler-Munro, D. Fine, J. Batten, and T. Northfield. Effect of cimetidine on enzyme inactivation, bile acid precipitation, and lipid solubilisation in pancreatic steatorrhoea due to cystic fibrosis. Gut. 1985; 26: 892-901.

(110) A. Weber, C. Roy. Intraduodenal events in cystic fibrosis. J Pediatr Gastroenterol Nutr. 1984; 3 (Suppl. 1): S113-S119. 
(111) S. Dutta, V. Hubbard, M. Appler. Critical examination of therapeutic efficacy of a pHsensitive enteric-coated pancreatic enzyme preparation in treatment of exocrine pancreatic insufficiency secondary to cystic fibrosis. Dig Dis Sci 1988; 33: 1237-44.

(112) H. Heijerman, C. Lamers, W. Bakker. Omeprazole enhances the efficacy of pancreatin (pancrease) in cystic fibrosis. Ann Intern Med. 1991; 114: 200-201.

(113) S. Schwarzenberg, C. Wielinski, I. Shamieh et al. Cystic fibrosis-associated colitis and fibrosing colonopathy. J Pediatr 1995; 127: 565-70.

(114) R. Smyth, D. van Velzen, A. Smyth, D. Lloyd, D. Heaf. Strictures of ascending colon in cystic fibrosis and high strength pancreatic enzymes. The Lancet. 1994; 343: 85-86.

(115) M. Pettei, J. Leonidas, J. Levine, J. Gorvoy. Pancolonic disease in cystic fibrosis and high-dose pancreatic enzyme therapy. J Pediatr 1994; 125: 587-9.

(116) G. Cleghom, R. Shepherd, T. Holt. The use of a synthetic prostaglandin $E_{1}$ analogue (Misoprostol) as an adjunct to pancreatic enzyme replacement in cystic fibrosis. Scand J Gastroenterol. 1988; 23(Suppl 143): 142-147.

(117) K. Cox, J. Isenberg, A. Osher, R. Dooley. The effect of cimetidine on maldigestion in cystic fibrosis. 1979; 94: 488-492.

(118) M. Schöni, R. Kraemer, E. Rossi. Cimetidine and fat malabsorption in children with cystic fibrosis. Helv Paediat Acta. 1981; 36: 359-369.

(119) B. Boyle, W. Long, W. Balistreri, S. Widzer, and N. Huang. Effect of cimetidine and pancreatic enzymes on serum and fecal bile acids and fat absorption in cystic fibrosis. Gastroenterology. 1980; 78: 950-953.

(120) R. Gow, R. Bradbear, P. Francis, R. Shepherd. Comparative study of varying regimens to improve steatornhoea and creatornhoea in cystic fibrosis: effectiveness of an enteric-coated preparation with and without antacids and cimetidine. Lancet 1981; 14: 1071-1074.

(121) P. Robinson and P. Sly. Placebo-controlled trial of misoprostol in cystic fibrosis. J Pediatr Gastroenterol Nutr. 1990; 11: 37-40.

(122) P. Durie, L. Bell, W. Linton, M. Corey, G. Forstner. Effect of cimetidine and sodium bicarbonate on pancreatic replacement therapy in cystic fibrosis. Gut 1980; 21: 778-786.

(123) A. Carroccio, F. Pardo, G. Montalto et al. Use of famotidine in severe exocrine pancreatic insufficiency with persistent maldigestion on enzymatic replacement therapy: A long-term study in cystic fibrosis. Dig Dis Sci 1992; 37: 1441-1446. 
(124) D. Chalmers, R. Brown, M. Miller et al. The influence of longterm cimetidine as an adjuvant to pancreatic enzyme therapy in cystic fibrosis. Acta Paediatr Scand. 1985; 74: 114117.

(125) M. Schöni, R. Kraemer, A. Ruedeberg et al. Long-term cimetidine in children with cystic fibrosis: a randomized double blind study.

(126) J. van de Kamer. Standard methods of clinical chemistry, edited by Seligson D. New York, Academic Press, 1958, Vol 2, p 34.

(127) E. Wollaeger, M. Comfort, A. Osterberg. Total solids, fat and nitrogen in feces: Study of normal persons taking test diets containing moderate amount of fat; comparison with results obtained with normal persons taking test diet containing large amount of fat. Gastroenterology 1947; 9: 272-283.

(128) D. Woodman, W. Yeoman. A simplified method of investigating steatorrhoea. J Clin Pathol 1955; 8:79-80.

(129) M. Davidson, C. Bauer. Patterns of fat excretion in feces of premature infants fed various preparations of milk. Pediatrics 1960; 25: 375-84.

(130) J. van de Kamer, H. Huinink, A. Weyers. Rapid method for the determination of fat in feces. J Biol Chem 1949; 177: 349-55.

(131) B. Lembcke, B. Braden, J. Stein. Diagnostik der steatorrhoe. Z Gastroenterol 1994; 32: 256-261.

(132) N. Thorsgaard Pedersen, H. Halgreen, H. Worning. Estimation of the 3-day faecal fat excretion and fat concentration as a differential test of malabsorption and maldigestion. J Gastroenterol 1987; 22: 91-96.

(133) I. Roberts, C. Poturich, A. Wald. Utility of fecal fat concentrations as screening test in pancreatic insufficiency. Dig Dis Sci 1986; 31: 1021-4.

(134) G. Bo-Linn, J. Fordtran. Fecal fat concentretion on patients with steatorrhea. Gastroenterology 1984; 87: 319-322.

(135) J. Bai, A. Andrüsh, G. Matelo et al. Fecal fat concentration in the differential diagnosis of steatorrhea. Am J Gastroenterol 1989; 84: 27-30.

(136) B. Lembcke, K. Grimm, P. Lankisch. Raised fecal fat concentration is not a valid indicator of pancreatic steatorrhea. Am J Gastroenterol 1987; 82: 526-531.

(137) H. Weijers. Fat absorption in normal and abnormal infants and children with special 
reference to coeliac disease (proefscrift) 1950: 19-23.

(138) P. Phuapradit, A. Narang, P. Mendonca, D. Harris, J. Baum. The steatocrit: a simple method for estimating stool fat content in newborn infants. Arch Dis Child 1981; 56: 725-727. (139) G. Iacono, A. Carroccio, G. Montalto et al. Steatocrit: normal range and physiological variations in preterm and low-birth-weight full-term newborns. Acta Paediatr 1992; 81: 933-4. (140) A. Guarino, L. Tarallo, L. Greco, L. Cesarano, S. Guandalini, A. Rubino. Reference values of the steatocrit and its modifications in diarrheal diseases. J Pediatr Gastroenterol Nutr 1992; 14: 268-274.

(141) C. Colombo, R. Maiavacca, M. Ronchi, E. Consalvo, M. Amoretti, A. Giunta. The steatocrit: a simple method for monitoring fat malabsorption in patients with cystic fibrosis. J Pediatr Gastroenterol Nutr 1987; 6: 926-930.

(142) G. Iacono, A. Carroccio, F. Cavataio et à. Steatocrit test: normal range and physiological variations in infants. J Pediatr Gastroenterol Nutr 1990; 11: 53-57.

(143) M. Walters, J. Kelleher, J. Gilbert, J. Littlewood. Clinical monitoring of steatorrhoea in cystic fibrosis. Arch Dis Child 1990; 65: 99-102.

(144) E. Sugai, G. Srur, H. Vazquez et al. Steatocrit: a reliable semiquantitative method for detection of steatorrhea. J Clin Gastroenterol 1994; 19: 206-9.

(145) G. Drummey, J. Benson, C. Jones. Microscopical examination of the stool for steatornhea. N Engl J Med 1961; 264: 85-7.

(146) L. Benini, S. Caliari, G. Guodi. Near infrared spectrometry for faecal fat measurement: comparison with conventional gravimetric and titrimetric methods. Gut 1989; 30: 1344-1347. (147) O. Bekers, C. Postma, A. Lombarts. Determination of feacal fat by Near-Infrared Spectroscopy. Eur J Chem Cli Biochem 1995; 33: 83-86. 


\section{CHAPTER 2}

METHODS 
The following methods were used in our studies:

\section{Methods used for fecal fat determination:}

\section{1 Steatocrit and Acid Steatocrit}

About $0.5 \mathrm{~g}$ solid stool was weighed and diluted with a volume of deionized water, equal to two times the weight of stool. The stool and water were premixed using a Vortex mixer. Subsequently, the mixture was homogenized using a $5 \mathrm{ml}$ Potter Elvehjem tissue homogenizer. The fecal homogenate was aspirated into a $75 \mu$ l plain haematocrit capillary. This capillary was sealed with wax at one end and centrifuged horizontally (13000 rpm, $15 \mathrm{~min}$ ) in a standard haematocrit centrifuge. After centrifugation, the upper fatty layers (FL) and the bottom solid layers (SL) were measured with a graduated magnifying lens. The steatocrit was calculated as (FL / $(\mathrm{FL}+\mathrm{SL})) \times 100 \%$. Since the fat extraction was not optimal in the steatocrit procedure, we have try to increase this step by adding the perchloric acid $(5 N)$ to the fecal homogenate in a volume equal to $1 / 5$ of the homogenate after homogenization. This acid homogenate was then mixed for 30 seconds using a Vortex mixer and the following steps were the same as the classical steatocrit. This "Acid Steatocrit" is used in our further study.

\section{2 Titrimetric method}

The 72 hours fecal collection was first homogenized and about 5 gram of feces was weighed. The feces was saponified with concentrated potassium hydroxide $(33 \% \mathrm{KOH})$ in ethanol, giving a solution which contains the soaps derived from neutral fats, fatty acids and also soaps originally present in the stool. By adding $\mathrm{HCl}(2 \mathrm{~N})$, fatty acids were obtained. After adding $125 \mathrm{ml}$ toluene, the mixture was shaken vigorously for $2-3$ minutes. $25 \mathrm{ml}$ of the toluene layer containing the fatty acids was then transferred to an erlenmeyer for titration with $0,1 \mathrm{~N}$ tetrabutylammoniumhydroxide solution in propanol/methanol and thymol blue as indicator. The titration was done three times and the mean of this was used for the calculation of fecal fat excretion, which was calculated as followed: 
$125 \mathrm{ml}+4.5 \mathrm{ml}\left(\mathrm{X}-\mathrm{X}_{0}\right) \times 0,1 \mathrm{~N} \times 1 / 3 \times$ total feces weight $(\mathrm{g}) \times 891 \mathrm{~g}=$ Total fecal fat $(\mathrm{g} / 72 \mathrm{~h})$ $25 \mathrm{ml}$ sample weight $(5 g)$

with $125 \mathrm{ml}$ representing the toluene volume used for extraction of the fatty acids, $25 \mathrm{ml}$ representing the titration volume, $4,5 \mathrm{ml}$ is the correction for the volume interaction, $\mathrm{X}$ representing the number of meq of fatty acids titrated, $\mathrm{X}_{0}$ the correction for the acids present in toluene, $0,1 \mathrm{~N}$ the concentration of tetrabutylammoniumhydroxide solution, $1 / 3$ is the conversion factor from fatty acid to fat molecule ( 3 molecule fatty acids derived from 1 molecule fat) and 891 is the molecular weight of stearic acid (C-18-fat).

\section{3 Sudan staining method}

We used the split fat stain, which identifies both triglyceride and fatty acid (1). Several drops of $100 \%$ acetic acid and several drops of Sudan III solution were added. The preparation was subsequently mixed with the coverslip, which was then applied. The slide was gently heated on a lighter until bubbling. All preparations were examined while still warm under high magnification (magnification of 400 ). For quantification of the amount of fat detected microscopically, we used the criteria established by Drummey et al.(2). They are as follows: normal (+): up to 100 fat globules per high power field, varying in a diameter between 1 and $4 \mu \mathrm{m}$, as noted on the micrometer scale always using a magnification of 400 ; Increased $(2+)$ : up to 100 fat globules per high power field, the diameter of fat globules varying between 1 and $8 \mu \mathrm{m}$; Markedly increased $(3+)$ : more than 100 fat globules per high power field, varying in size from 6 to $75 \mu \mathrm{m}$ in diameter.

\section{Methods used for assessment of nutritional condition:}

\subsection{Anthropometry}

Weight, height and 4 skinfolds (biceps, triceps, subscapular and suprailiaca) were expressed as standard deviation scores of the normal population for age and sex by using the growth charts from Gerver and de Bruin (3). 
It has been found that subcutaneous fat as measured by skinfolds is related to the body density (4). This latter is again related to the body fatmass. From these theoretical principes, Gerver and de Bruin have constructed a chart, expressing the relationship between the 4 skinfolds (biceps, triceps, subscapular and suprailiaca) and the percent fat free mass. In our study, the fatmass and fat free mass determined with the anthropometric method were derived from these charts.

\subsection{Dual energy X-ray absorptiometry (DXA)}

This method first developed by Mazess et al., measures sirnultaneously bone mineral, fat and nonbone lean tissue. For a DXA scan, subjects lied supine on a padded table while the scintillation counter moved in a raster pattem across the body from head to foot. The Lunar DPX uses a constant $\mathrm{x}$-ray source and a filter that converts the polychromatic $\mathrm{x}$-ray beam into one that has two main energy peaks $(40 \mathrm{kV}$ and $70 \mathrm{kV})$. The ratio of soft tissue attenuation $\left(R_{5 T}\right)$ at the two energies is measured. The attenuation of pure fat $\left(\mathrm{R}_{F}\right)$ and of bone free lean tissue $\left(R_{L}\right)$ are known from both theoretical calculations and calibration. From this, the fatmass and lean tissue mass were calculated. The bone mineral content was calculated after correction of the overlying soft tissue (5). Body composition measurements in our study were made by a DPX with a pediatric software programme, Lunar version $1.5 \mathrm{e}$. Daily quality assurance test were performed according to the manufacturer 's directions. Total body analysis was performed in all children using a fast scan mode with a sample size of $4,8 \times 9,6 \mathrm{~mm}$, sample interval of $0.03 \mathrm{~s}$ and source collimation of $1,68 \mathrm{~mm}$.

\section{3 Total body water (TBW) and extra cellular volume (ECV)}

TBW and ECV were measured by deuterium oxide (6) and bromide dilution respectively (7). Each subject received orally $20 \mathrm{ml}$ of a mixture of $\mathrm{D}_{2} \mathrm{O}(99,9 \%$ purity) and Bromide salt $(150 \mathrm{mMol} / \mathrm{L}$ ) solution in a volume ratio of 1:1. Saliva and plasma samples were taken before intake of $\mathrm{D}_{2} \mathrm{O}-\mathrm{NaBr}$ solution and 4 hours thereafter when "an equilibrium" has been reached. To prevent saliva dilution by fluid intake which can result in a higher TBW content, patients were told not to take any fluid orally half an hour before saliva. samples were taken. Urine and 
fecal loss of bromide and $\mathrm{D}_{2} \mathrm{O}$ were negligible during the test since $t \frac{1}{2}$ of $\mathrm{D}_{2} \mathrm{O}$ and Bromide is 8 days (7). Saliva samples were obtained making use of dental cotton-wool, that was dried overnight at $100{ }^{\circ} \mathrm{C}$ and kept in a gas-tight tube until use. The cotton-wools and the blood samples were centrifuged and the saliva and serum thus obtained were kept in a stoppered glass vial and stored in a freezer until analysis.

\subsection{Total body water}

D2O concentrations of saliva samples were determined as follows: Calcium carbide $\left(\mathrm{CaC}_{2}\right)$ was placed in the siliconnized vacutainer tube and evacuated for $30 \mathrm{sec}$. with a rotatory vane pump to a total pressure of $0,01 \mathrm{~atm}$. Thereafter, $25 \mu \mathrm{l}$ of salivary sample was injected in the vacutainer tube. This was done in duplicate. $\mathrm{CaC}_{2}$ react with $\mathrm{D}_{2} \mathrm{O}$ forming acetylene gas. $\mathrm{A}$ $25 \mu \mathrm{l}$ of this gas was subsequently injected in duplicate into the GC/CF - IRMS system (gas chromatography/continous flow isotope ratio mass spectrometry) at $2 \mathrm{~min}$. intervals. The mass 27/26 ratio (R27/26) was measured on a Isotope Ratio Mass Spectrometer configured for Acetylene (Finnigan MAT 252 for CF-IRMS) (6). The mean value of 4 determinations was calculated for each sample. By inserting of the tracer/tracee ratio, defined as R27/26 (T4) $\mathrm{R} 27 / 26$ (T0), into the regression equation obtained from the standards, we get the dilution factor of D2O. TBW is calculated as ingested D2O volume/ dilution factor. From the TBW, LBM and FM can calculated by the following formules:

$$
\begin{aligned}
& \operatorname{LBM}(\mathrm{kg})=\text { TBW } /(1,04 \times \mathrm{d}) \\
& \text { BF }(\mathrm{kg})=\text { Weight }- \text { LBM }
\end{aligned}
$$

The 1,04 factor is a correction for the estimated $4 \%$ nonaqueous hydrogen exchange and $d$ is the hydration factor of LBM which varies with age. Because our CF population was young, we used the age dependent hydration factors described by Fomon (8) for children younger than 10 year and by Boileau and Lohman (9) for older children.

\section{3. 2 Bromide space}


Because Bromide resides mainly in the extracellular space, measured of Bromide dilution in serum give us an estimation of the extracellular volume. Bromide was determined by using a Gas Chromatograph type CP 9000 (Chrompack) equiped with an ECD detector after it was converted into a bromoacetone gas. First, perchloric acid was added to the serum sample and centrifugated for deproteinisation. An aliquot of the supernatant was then added to silver nitrate $\left(\mathrm{AgNO}_{3}\right)$ for precipitating of silver bromide and chloride. After centrifugation, the precipitate was taken up in $\mathrm{NH}_{3}$ after that $\mathrm{Na}_{2} \mathrm{~S}$ and $\mathrm{NaOH}$ were added to precipitate the silver as $\mathrm{Ag}_{2} \mathrm{~S}$. A.fter agitation and centrifugation, the supernatant was heated until $d r y_{2} \mathrm{HO}$ was added followed by $\mathrm{H}_{2} \mathrm{O}_{2}$ to oxidize sulfide. After drying, $\mathrm{H}_{2} \mathrm{O}$ was then added and dried again. This was repeated several times. Thereafter, perchloric acid and acetone were added and the reaction is started by addition of $\mathrm{KmnO4}$, with Bromoacetone formed. The solution is then extracted with benzene. The organic phase was separated from the water phase by shaking and centrifugation. The water phase was then removed. An aliquot of the organic solution is then applied to the gas chromatograph for measuring of bromoacetone/internal standard ratio. The bromide concentration was then derived from the bromoaceton standard curves. Because the distribution of Bromide depend on the potential difference between in- and extru-cellular and on the quantity of total body volume, corrected bromide space was calculated as follow:

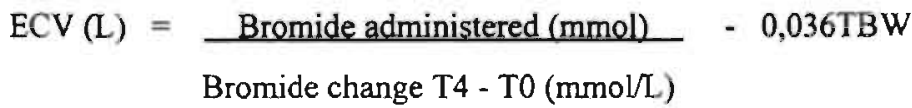

Where $0,036 \mathrm{TBW}$ is the correction factor for the cell potential and for the total body volume (7). 


\section{REFERENCES}

(1) M. Khouri, G. Huang, Y. Shiau. Sudan stain of fecal fat : New insight into an old test. Gastroenterology 1989; 96: 421-7.

(2) G. Drummey, J. Benson, C. Jones. Microscopical examination of the stool for steatorrhea. N Engl J Med 1961; 264: 85-7.

(3) W. Gerver, R. de Bruin. Paediatric Morphometrics: a reference manual. 1th ed. Utrecht: Bunge, 1996.

(4) J. Weststrate, P. Deurenberg. Body composition in children: proposal for a method for calculating body fat percentage from total body density or skinfold-thickness measurements. Am J Clin Nutr 1989: 50: 1104-15.

(5) S. Heymsfield, J. Wang, S. Heshka, J. Kehayias, R. Pierson. Dual-photon absorptiometry: comparison of bone mineral and soft tissue mass measurements in vivo with established methods. Am J Clin Nutr 1989; 49: 1283-9.

(6) B. Van Kreel, F. Van der Vegt, M. Meers, T. Wagenmakers, K. Westerterp, A. Coward. Determination of total body water by a simple and rapid mass spectrometric method. J Mass Spectrom 1996; 31: 108-111.

(7) B. Van Kreel. An Improved bromide assay for the estimation of extracellular water: volume by capillary gas chromatography. Clinica Chimica Acta 1994; 231: 117-128.

(8) S. Fomon, F. Haschke, E. Ziegler, S. Nelson. Body composition of reference children from birth to age 10 years. Am J Clin Nutr 1982; 35: 1169-1175.

(9) Boileau, R. Lohman, M. Slaughter, T. Ball, S. Going, M. Hendrikx. Hydration of the fatfree body in children during maturation. Hum Biol. 56: 651-666. 


\title{
CHAPTER 3
}

\section{THE ACID STEATOCRIT : A MUCH IMPROVED METHOD}

Tran M, Forget P, Van den Neucker A, Strik J, van Kreel B, Kuijten R.

Departments of Pediatrics and Clinical Chemistry, University Hospital Maastricht, Maastricht, The netherlands.

JPediatr Gastroenterol Nutr 1994; 19: 299-303

\begin{abstract}
The steatocrit method has recently been introduced as a simple screening test for steatorrhea. As it seemed likely that separation of feca! homogenate by centrifugation into a lipid phase, a watery phase and a solid phase would be pH-dependent, we evaluated the effect of fecal acidification on steatocrit results in healthy children and in patients with cystic fibrosis and studied the relationship between two steatocrit methods and fecal fat content as measured by a reference chemical method. Steatocrit results increased with the degree of fecal acidification, and maximal results were obtained at the lowest fecal $\mathrm{pH}$ values. Means and SEM for classi$\mathrm{cal}$ and acid steatocrit values were $1.1 \pm 0.4 \%$ (classical) versus $3.8 \pm 1 \%$ (acid) in controls (n $=6$ ) and $5.4 \pm 1.9 \%$ (classical) versus $26.9 \pm 4.3 \%$ (acid) in cystic fibrosis $(n=9)$. The correlations between fecal fat content measured chemically and steatocrit results were 0.18 (p $=0.35)$ and $0.81(p<0.0001)$ for classical and acid steatocrit, respectively. We conclude that acidification of fecal homogenates leads to a marked improvement in the steatocrit method.
\end{abstract}




\section{INTRODUCTION}

The diagnosis of fat malabsorption still mainly relies on the 72-hour faecal fat quantitation in which daily stool fat loss is evaluated by collecting stools for 3 days and determining stool fat content by chemical methods. The most widely used chemical method is the titrimetric method as described by van de Kamer in 1949 (1).

Work by Kouri et al has suggested that the titrimetric method largely overestimates nutritional faecal fat losses because it measures not only malabsorbed exogenous fat but also endoge. nous fat of various origins such as biliary lipids and lipids derived from the turnover of intestinal epithelial cells and gut bacteria (2).

Making use of the staining properties of purified lipids in an artificial matrix, Khouri et al. have suggested the fat absorption coefficient in normal adults is much higher than usually believed (2). Although the microscopic evaluation of steatorrhea by the Soudan stain provides a satisfactory screening method for steatorrhea, it is at best semiquantitative.

The steatocrit has been introduced in recent years as a simple test for the evaluation of fat malabsorption (3-6). Although several authors have reported the method to be satisfactory for the evaluation of steatorrhea, some have reported the steatocrit to be quite unreliable (6). As it has been shown that faecal acidification results in an enhanced sensitivity of the sudan faecal staining method (2), we wondered whether the same modification could improve fat extraction by centrifugation as performed in the steatocrit determination.

Consequently, we evaluated the effects of stool sample acidification on steatocrit determinations and to compared results from previously reported methods with acid steatocrit results in healthy children and in children with cystic fibrosis. We also determined the correlation between steatocrit results and faecal fat concentrations as measured by the reference chernical method of van de Kamer et to evaluate which of the two steatocrit methods gave the best estimate of faecal fat content.

\section{METHODS}

\section{"classic" steatocrit method}


Stool ( $0.5 \mathrm{gr})$ was diluted (1/3) with deionized water and thouroughly homogenized in a $5 \mathrm{ml}$ Potter Elvehjem tissue hornogenizer (Heidolph Elektro KG Kelheim, no. 170-1700/20-200) stamper, tissue grind pestle (size 20 from Kontes Scientific Glassware Instruments, no. 885451-0020). The homogenate was aspirated into a $75 \mu \mathrm{l}$ plain glass haematocrit tube. The capillary tube was subsequently centrifuged horizontally $(13,000 \mathrm{rpm}$ for $15 \mathrm{~min})$ in a standard haematocrit centrifuge.

After centrifugation, the upper (fat) and bottom (solid) layers were measured with a graduated magnifying lens. Steatocrit was calculated as $\mathrm{FL}(\mathrm{FL}+\mathrm{SL})$, where $\mathrm{FL}$ is the fatty-layer length and $\mathrm{SL}$ is the solid-layer length.

\section{"Acid" steatocrit method'}

The method used was exactly the same as the classic steatocrit method except that, before aspirating the homogenate in the capillary tube, perchloric acid in various concentrations ( $5 \mathrm{~N}$ for maximal acidification) was added to the homogenate in a volume equal to $1 / 5$ of the homogenate volume. The resulting acid homogenate was mixed for 30 seconds with a standard Vortex mixer.

\section{Chemical determination of stool fat concentration.}

The method of van de Kamer et al. was used to determine stool fat content (1).

\section{EXPERIMENTAL DESIGN}

\section{Effect of stool homogenate acidification on fat extraction}

To evaluate the effect of stool acidification and thus stool $\mathrm{pH}$ on the length of the fat column obtained by centrifugation, several stool samples from patients with and without steatorrhea were centrifuged after addition of perchloric acid solutions of various concentrations. 


\section{Classic and acid steatocrit}

To compare classic and acid steatocrit results in children with and without steatorrhea, we measured fecal steatocrit by both methods in 6 control children (mean age: 5.8 years, range 3 to 12 years; five boys and one girl) and in 9 children with cystic fibrosis (mean age: 6.9 years; range 0.5 to 20 ; nine boys ). The control children were patients with chronic aspecific respiratory disease without gastrointestinal symptoms and with a normal sweat test. The cystic fibrosis patients all had abnormal sweat tests on severall occasions and were being treated with pancreatic enzymes when steatocrit determinations were performed. As our purpose was to compare classical and acid steatocrit results in the same fecal samples, no attempt was made to quantify the fat content of the diet which was "normal" in all patients.

\section{Correlation between steatocrit results and fecal fat content}

To further compare both steatocrit methods we looked at the relationship between results obtained by each method and fecal fat content results as measured by the method of van de Kamer et al. (1). Steatocrit measurements (classic and acid) and fecal fat content determinations (chemical method) were performed on 27 consecutive stool samples (from adults and children) sent to our laboratory for evaluation of malabsorption. No attempt was made to classify patients in disease categaries as our only goal was to study the relationship between steatocrit results and fecal fat content independent of the presence of disease (clinical results will be published separately).

\section{Statistical methods}

The coefficient of variation of each steatocrit rnethod was determined with duplicate results of each sample for both methods. Pearson correlation coefficient was used to evaluate the relationship between steatocrit results and chemically measured fecal fat content.

\section{RESULTS}


Several steatorrheal stool samples were analysed after acidification with various concentrations of perchloric acid.

A typical finding is shown in figure 1; The upper fat column was seen to increase in length with the degree of homogenate acidification. A typical normal stool sample result (no steatorrhea) is shown in figure 2 . The acid steatocrit remained completely negative in normal samples.

\section{Cystic fibrosis sample}

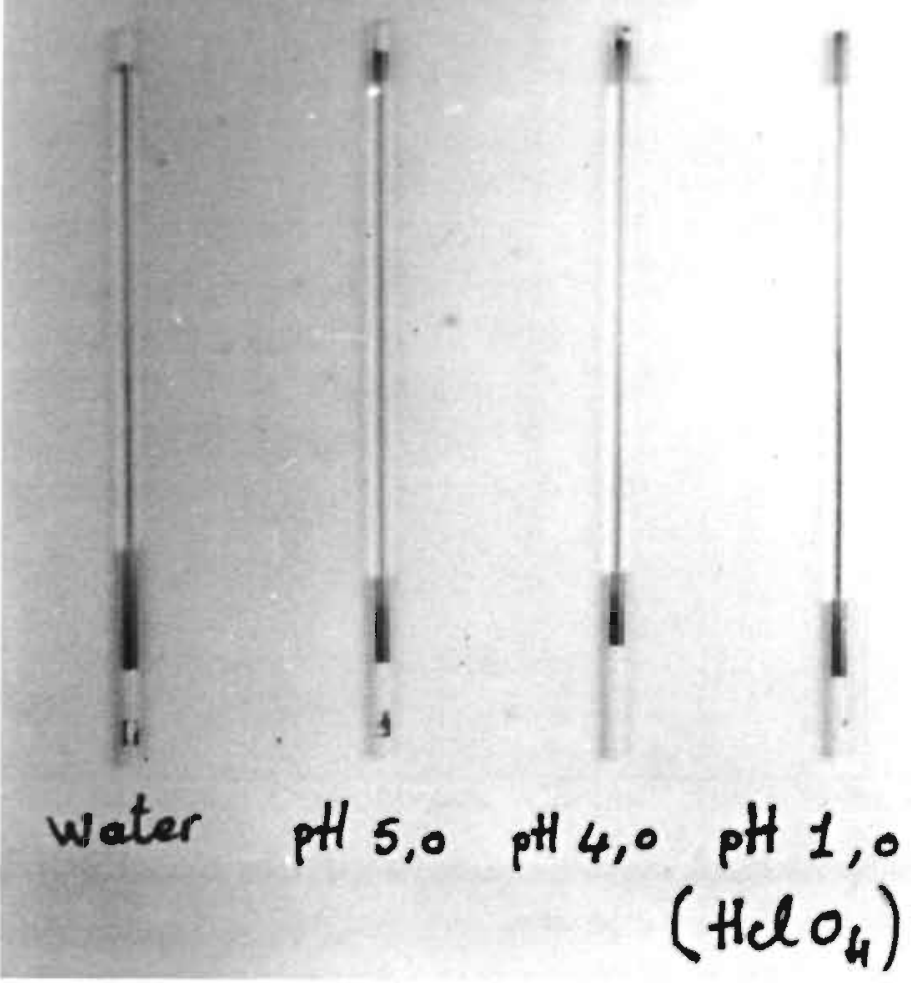

Figure 1 Effect of acidification with various concentrations of perchloric acid on the fat column length (upper part of picture) of a stool sample from a patient with cystic fibrosis. 


\section{normal sample}

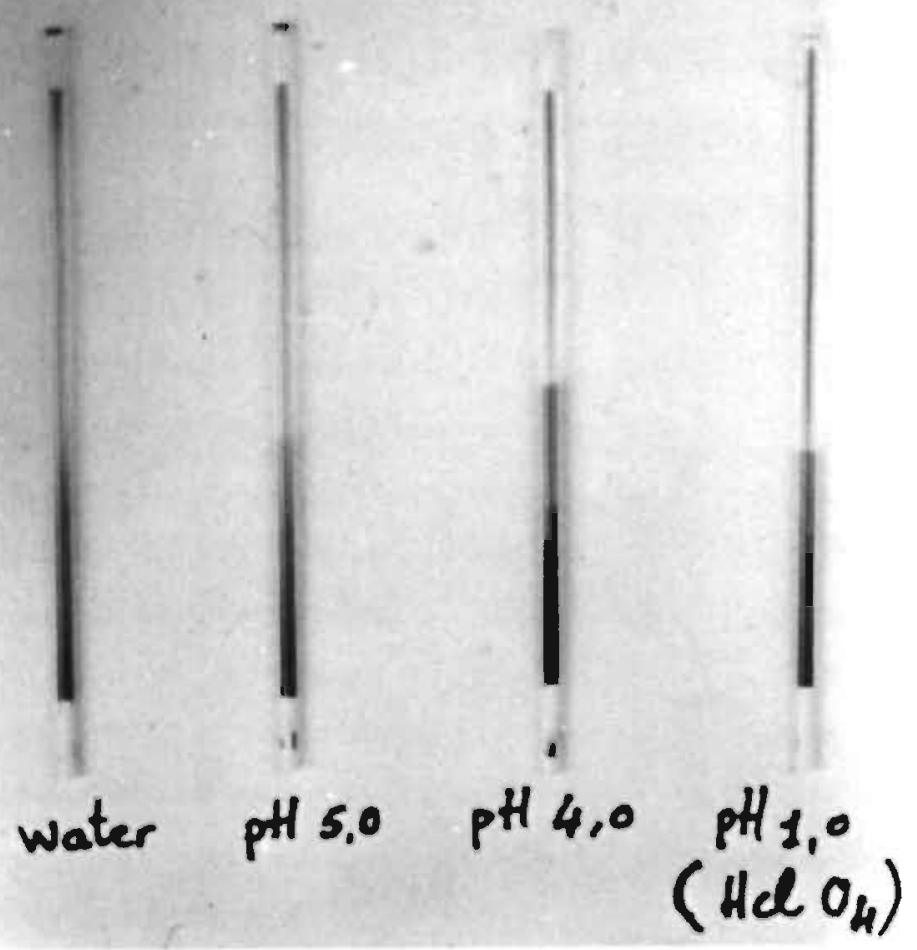

Figure 2 Effect of acidification with various concentrations of perchloric acid on fat extraction from a normal stool sample. Fat layer is absent at all $\mathrm{pH}$ values. 


\section{Classic and acid steatocrit}

Results of classic and acid steatocrit in 6 control and 9 cystic fibrosis patients (figure 3 ) were as follows : Steatocrit means and SEM in control patients were $1.1 \pm 0.4$ and $3.8 \pm 1 \%$ for classic and acid steatocrit, respectively. This difference was not statistically significant. Steatocrit means and SEM in cystic fibrosis patients were $5.4 \pm 1.9$ and $26.9 \pm 4.3 \%$ for classic and acid steatocrit, respectively. This difference is significant $(\mathrm{p}<0.01)$

The precision of the methods was evaluated by comparing the variation coefficients; variation coefficients were 6.9 and $5.1 \%$ for the classic and acid steatocrit methods, respectively.

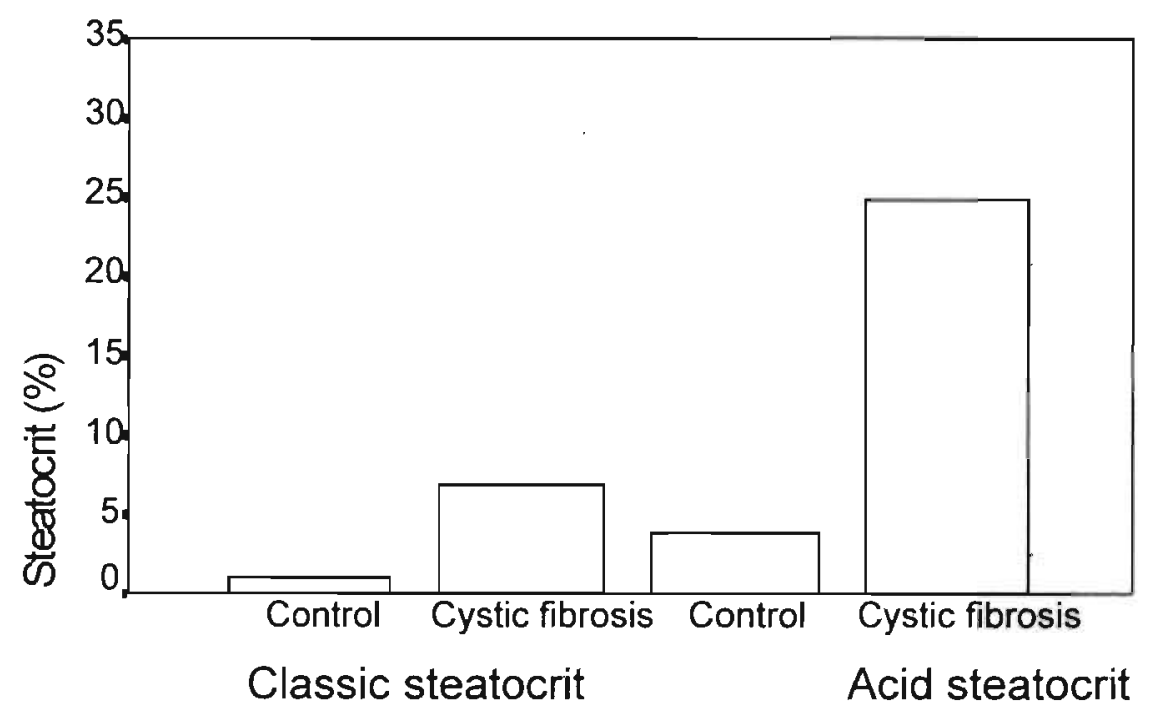

Figure 3 Classic and acid steatocrit results in six controls and nine patients with cystic fibrosis. 


\section{Correlation between steatocrit results and faecal fat content}

The relationship between classic fecal steatocrit and fecal fat content as measured by the reference method of van de Kamer et al. (1) is shown in figure 4. The correlation coefficient. of 0.18 is statistically non-significant $(p=0.35$ ). The relationship between acid fecal steatocrit and fecal fat content is shown in figure 5. The correlation coefficient of 0.81 is highly significant $(\mathrm{p}<0.0001)$.

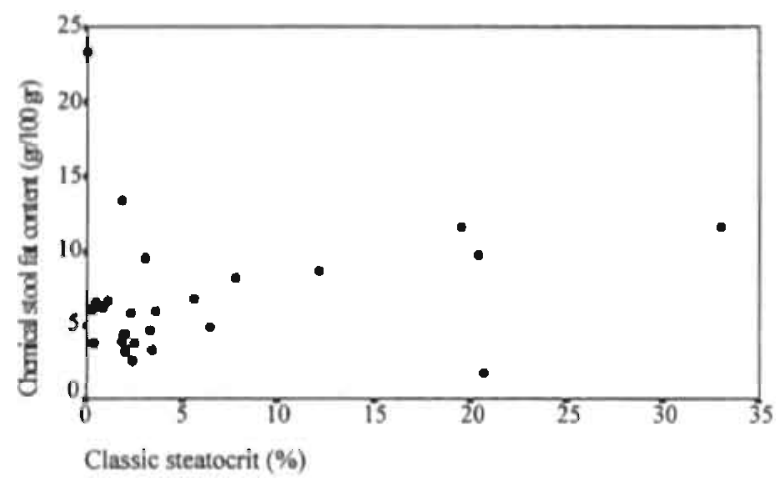

Figure 4 Relationship between classic fecal steatocrit and fecal fat content as measured by the method of van de Kamer et al. $\ln 27$ fecal samples $(r=0.18 ; p=0.35)$.

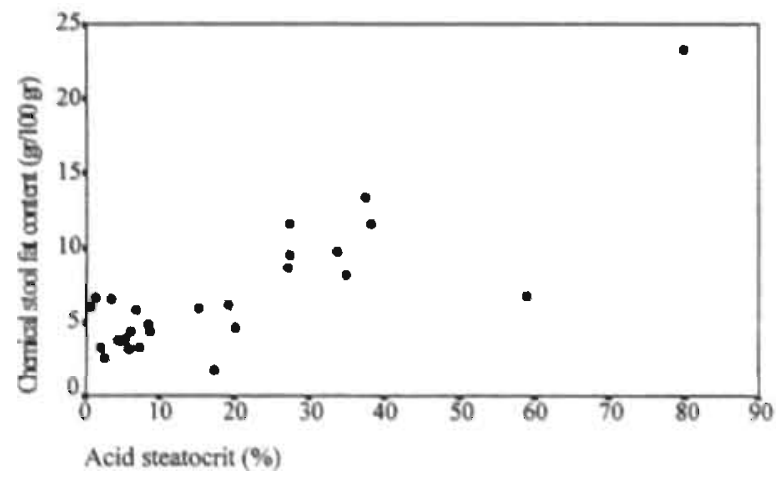

Figure 5 Relationship between acid fecal steatocrit and fat content as measured by the method of van de Kamer et al. In 27 fecal samples ( $r=0.81 ; p<0.0001)$. 


\section{DISCUSSION}

Although several authors have reported the steatocrit method to be reliable for the screening of steatorrhea ( 3-5), Walters et al reported the method to be completely unreliable (6). Methodological inadequacies probably underlie these discrepancies. We have been using the "classic" steatocrit in our department for a few years and have found completely negative results in some patients with proven steatorrhea. We hypothesized that in some patients fat detection might be poor and that a possible solution to the problem would be an improved method of liberating fat during the centrifugation step. It has been shown in a recent study that fecal fat in patients with pancreatic insufficiency mainly consists of fatty acids and that the fecal triglyceride content does not differ from that of normal controls (7).

Fecal fatty acid molecules exist in the form of soaps (8). Further, since the pKa of most fatty acids is lower (about 4.8) than fecal pH, most fatty acids in stool would be present as ionized species or soaps. We speculated that fecal acidification would result in the conversion of ionized fatty acid species and soaps into the protonated species leading to easier separation into lipid and water phases during the centrifugation step of the steatocrit method.

Our results show that the effect of stool homogenate acidification on the length of the upper fatty layer very nicely confirms our predictions. Although we have not checked this point in detail, it can be expected that at the low PH values obtained after maximal acidification as performed in the present study, all fatty acids will be present in the protonated form.

Further, the fact that acidification of fecal samples from patients without steatorthea and with completely negative steatocrit results did not result in the appearance of a fatty layer, probably indicating that the improved fat extraction is not a spurious artifactual finding but the result of better extraction of lost exogenous fat.

Khouri et al have suggested that ionized fatty acids are not readily stainable with Soudan stain, although staining does occur after acidification (2). By alkalinization with sodium hydroxide, the same authors showed that fatty acids lost their ability to form fat droplets and to stain with Sudan red III (2). We suppose that similar mechanisms underlie the improvement of both the fat staining method and fat extraction by fecal acidification as shown in the present study.

A further advantage of acidification is that it enhances the vicible boundaries between the 
various layers, resulting in improved accuracy in the reading of layers lengths. Improved fecal fat extraction by acidification should therefore result in higher diagnostic sensitivity of the steatocrit method.

Our results show classic steatocrit in control children and in children with cystic fibrosis are similar to results published by other authors (4); However, acidified steatocrit results in both control children and cystic fibrosis patients were much higher than those obtained by classic steatocrit. Ongoing work in our laboratory aims at establishing normal population values for acid steatocrit in infants and children.

In order to better interpret the differences found between the steatocrit methods, we compared steatocrit results with fecal fat concentrations measured by the most accepted reference method. Our findings show that only acid steatocrit results correlate very significantly with fecal fat content as measured by the van de Kamer method. The litterature is quite varied on this point. Several studies have looked for a correlation between steatocrit results and either the fat absorption coefficient or 3-day fecal fat excretion. A good correlation was reported by two studies $(4,9)$ while a total lack of correlation was reported by a third author $(6)$. As steatocrit is supposed to reflect fecal fat concentration we preferred to relate steatocrit results to fecal fat concentrations rather than daily excretion or fat absorption coefficients. To our knowledge only one study reporting results in a similar way found a significant relationship between steatocrit results and fecal fat content (3). We think our finding of a lack of correlation between classic steatocrit and fecal fat content results can best be explained by the small number of observations or by the lack of homogeneity in our patient material.

This lack of homogeneity was, however, purposely chosen as we were only interested in the correlation between steatocrit results and fecal fat content. We think a positive correlation between the two steatocrit methods and fecal fat content could have been found but the acid steatocrit method would always better correlate with fecal fat content.

We conclude that acidification of fecal homogenates led to a much better fat extraction by centrifugation, increased sensitivity of the steatocrit method and to a better prediction of fecal fat content as measured by chemical methods.

Acknowledgment: The authors thank the clinical laboratory staff for their kind and expert technical assistance. We are very grateful to Nutricia Netherlands for financial support. 


\section{REFERENCES}

(1) van de Kamer JH, Huinink HTB, Weyers HA. Rapid method for determination of fat in feces.J Biol Chem 1949 ; 177 :349-55.

(2) Khouri MR, Huang G, Shiau YF. Sudan stain of fecal fat : new insight into an old test. Gastroenterology $1989 ; 96: 421-427$.

(3) Phuapradit P, Narang A, Mendonca P, Harris DA, Baum JD. The steatocrit : a simple method for estimating stool fat content in newborn infants.Arch Dis Child $1981 ; 56$ : 725 727.

(4) Colombo C, Maiavacca R, Ronchi M, Consalvo E, Amoretti M, Giunta A. The steatocrit : a simple method for monitoring fat malabsorption in patients with cystic fibrosis.J Pediatr Gastroenterol Nutr $1987 ; 6: 926-930$.

(5) Iacono G, Carroccio A, Cavataio F et al. Steatocrit test : normal range and physiological variation in infants. J Pediatr Gastroenterol Nutr 1990; $11: 53-57$.

(6) Walters MP, Kelleher J, Gilbert J, Littlewood JM. Clinical monitoring of steatorrhea in cystic fibrusis.Arch Dis Child 1990; 65: 99-102.

(7) Khouri MR, Huang G, Shiau YF. Fecal triglyceride excretion is not excessive in pancreatic insufficiency.Gastroenterology 1989; $96: 848-852$.

(8) Shiau YF, Popper DA, Reed M, Umstetter C, Capuzzi D, Levine GM.Intestinal triglycerides are derived from both endogenous and exogenous sources. Am J Physiol 1985; 248 : G164-169.

(9) Guarino A, Tarallo L, Greco L, Cesarano L, Guandalini S, Rubino A. Reference values of the steatocrit and its modifications in diarrheal diseases.J Pediatr Gastroenterol Nutr 1992; 14 : 268-274. 
CHAPTER 4

\title{
IMPROVED STEATOCRIT RESULTS OBTAINED BY ACIDIFICATION OF FECAL HOMOGENATES ARE DUE TO IMPROVED FAT EXTRACTION
}

\author{
M. Tran, P. Forget, A. Van den Neucker and B. Van Kreel
}

Department of Pediatrics and Clinical Chemistry, University Hospital Maastricht, Maastricht, The Netherlands

J Pediatr Gastroenterol Nutr 1996; 22: 157-160

Abstract

Conflicting results have been reported on the value of the steatocrit as a screening test for steatorrhea. We recently modified the test procedure by fecal acidification with the hope of improving fat extraction and consequently the sensitivity of the test. The aim of the present study was to ascertain, whether or not fecal acidification led to improved fat extraction, by comparing the fat content of both fatty and solid layers obtained by centrifugation of 12 acidified (acid steatocrit) and unacidified (classical steatocrit) steatorrheal stool samples.

The fat content of fatty and solid layers was evaluated using of the semiquantitative $(t=1$, $++=2,+++=3$ ) scoring system described by Drummey, for the interpretation of the sudan microscopic method for fecal fat.

The fatty layers sum of scores for the 12 samples examined, was 31 and 16 , for the acid and classical steatocrit respectively. The solid layers sum of scores for the 12 samples, was 13 and 24, for the acid and classical steatocrit respectively. Fat extraction from stool samples was significantly improved after fecal sample acidification $(p<0.005)$. Acid steatocrit results agreed better with chemically measured fecal fat than classical steatocrit results. We conclude that fecal acidification, by improving fat extraction, increases the reliability of the steatocrit method for the detection of steatorrhea. 


\section{INTRODUCTION}

Several methods are in use for the diagnosis of fat malabsorption. One of these is the 72 hour fecal fat quantitation method, which is regarded as the most accurate method to evaluate steatorrhea (1). However, there are several problems. First, it is a laborious method for laboratory technicians, and second, fecal collection for 3-5 days makes the method unpleasant for the patient and sometimes poorly reliable in non collaborating children.

Another well accepted test to screen for fat malabsorption is the Sudan staining method for fecal fat (2). Unfortunately this method is only semiquantitative.

In 1981 Phuapradit introduced the steatocrit method as a new, simple and easily repeatable method for measuring fecal fat content (3).

Although several authors have reported this method to be satisfactory for the evaluation of steatorrhea (3-5), some described it as quite unreliable (6). We have been using this method for years and have often found normal steatocrit values in patients, who, when measured chemically had steatorrhea with an increased fecal fat content.

As it has been shown that fecal acidification results in an enhanced sensitivity of the Sudan fecal staining method (7), we wondered whether fecal acidification could also be used to improve the sensitivity of the steatocrit method.

We consequently modified the reported (8) steatocrit method by adding perchloric acid to the fecal homogenate. Fat extraction was evaluated for classical and acid steatocrit methods, making use of the Sudan microscopic method for fecal fat.

We further compared calculated steatocrit results from acidified and unacidified samples, and related the results to fecal fat content of the same samples, measured by the reference chemical method of van de Kamer et al. (1).

\section{MATERIALS AND METHODS}

\section{Bopulation studied}

Twelve stool samples from 4 premature babies, 3 boys and 1 girl, with a mean gestational age of 35,3 weeks (ranged from $275 / 7$ to $355 / 7$ weeks), were analysed by means of both 
the classical and the acid steatocrit method.

Their postnatal age varied between 11 and 18 days. They received full oral formula feedings. Their weight ranged from $1810 \mathrm{~g}$ to $2360 \mathrm{~g}$.

\section{Steatocrit methods}

$0,5 \mathrm{~g}$ solid stool was weighed and diluted with a volume of deionized water, equal to two times the weight of stool. The stool and water were premixed using a Vortex mixer. Subsequently, the mixture was homogenized using a $5 \mathrm{ml}$ Potter Elvehjem tissue homogenizer. Then, the homogenate was aspirated into a $75 \mu \mathrm{l}$ plain haematocrit capillary. This capillary was sealed with wax at one end and centrifuged horizontally $(13,000 \mathrm{rpm}, 15 \mathrm{~min})$ in a standard haematocrit centrifuge.

The method used for the acid steatocrit was exactly the same as that of the classical steatocrit, the only exception being, that after homogenizing, $5 \mathrm{~N}$ perchloric acid was added to the homogenate in a volume equal to $1 / 5$ of the homogenate. This acid homogenate was then mixed for 30 seconds using a Vortex mixer.

After centrifugation, three layers were distinguished: a basal solid layer, an intermediate liquid layer, and an upper fatty layer. After calculating the steatocrit results for both methods as usual, the capillaries were cut in the middle of the fatty, and of the solid layers using a special glass knife. Subsequently, the layers were removed from the capillaries, using a syringe. A standard amount of each of these fatty and solid layers was then transfer. red to different glass slides for staining with Sudan III dye. In this way, we acquired a total of 48 slides (24 from each steatocrit method, 12 fatty and 12 solid layers) for microscopic evaluation.

\section{Sudan stain method for fecal fat}

For this purpose we used the split fat stain, which identifies both triglyceride and fatty acid

(7). Several drops of $100 \%$ acetic acid and several drops of Sudan III solution were added. The preparation was subsequently mixed with the coverslip, which was then applied. The slide was gently heated on a lighter until bubbling. All preparations were examined while 
still warm under high magnification (magnification of 400 ), by the same person who was blind to the steatocrit methodl used (classical or acid).

For quantification of the amount of fat detected microscopically, we used the criteria established by Drummey et al.(2). They are as follows: normal (+): up to 100 fat globules per high power field, varying in a diameter between 1 and $4 \mu \mathrm{m}$, as noted on the micrometer scale always using a magnification of 400 ; Increased $(2+)$ : up to 100 fat globules per high power field, the diameter of fat globules varying between 1 and $8 \mu \mathrm{m}$; and markedly increased $(3+)$ : more than 100 fat globules per high power field, varying in size from 6 to $75 \mu \mathrm{m}$ in diarneter.

The sum of the fatty and solid layer scores of all our samples, was calculated for both steatocrit methods, and results were compared. Fisher's exact probability test was used to test whether or not the solid layers microscopic fat content was dependent on sample acidification. Finally, calculated acidified and unacidified steatocrit results were compared and related to the chemically measured fecal fat content.

\section{RESULTS}

Table 1 shows that acidification of the fecal homogenates before centrifugation (acid steatocrit method) results in a higher Drummey score in the fatty layers and a lower score in the solid layers. In four specimens (sample 6, 7, 8 and 10), the fatty layers obtained by the classical steatocrit method were so small that we did not succeed in making microscopical slides. Equal results were obtained by both the classical and the acid steatocrit method, in only one sample (sample 11). 
Table 1 Fatty and solid layer microscopical fat scores for both acid and classic steatocrit methods.

\begin{tabular}{|ccccc|}
\hline & \multicolumn{5}{c|}{ SCORES OF FAT GLOBULES } \\
\cline { 2 - 5 } SAMPLES & \multicolumn{3}{c|}{ FATTY LAYERS } & \multicolumn{2}{c|}{ SOLI LAYERS } \\
\cline { 2 - 5 } & ACID & CLASSIC & ACID & CLASSIC \\
\hline 2 & +++ & ++ & + & + \\
3 & ++ & ++ & + & +++ \\
4 & +++ & + & + & +++ \\
5 & +++ & ++ & + & +++ \\
6 & + & - & + & ++ \\
7 & ++ & - & + & ++ \\
8 & +++ & - & + & + \\
9 & +++ & +++ & + & ++ \\
10 & ++ & - & + & + \\
11 & +++ & +++ & + & + \\
12 & +++ & ++ & + & +++ \\
SUM & 31 & 16 & 13 & 24 \\
\hline
\end{tabular}

The sum of the fat scares for fatty and solid layers, and for both steatocrit methods is summa. rized in figure 1. The number of solid layer samples with low microscopic $\left(s^{+}\right)$fat content, was 11 of 12 , and 4 of 12 , for the acidified and unacidified samples respectively $(p<0.005$, Fisher's exact probability test). 


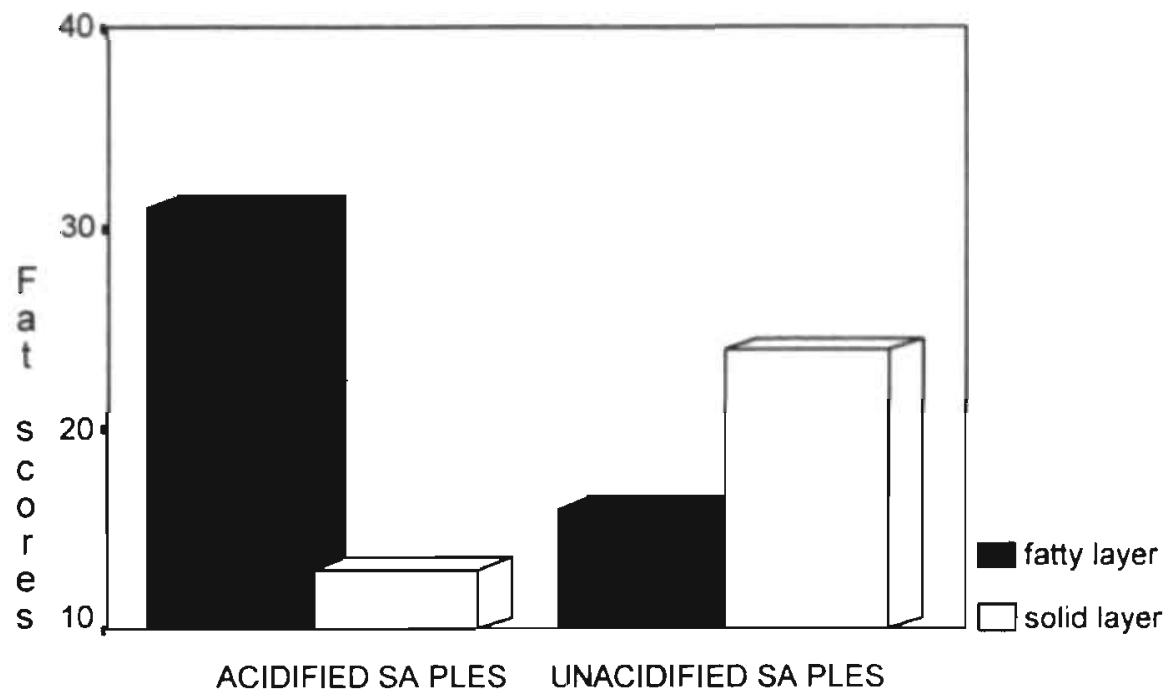

Figure 1 Sum of 12 microscopical Sudan fat globule scores $(1,2,3)$ performed on fatty and solid layers of acidified and unacidified fecal samples. 
The calculated steatocrit results for both steatocrit methods, and the chemically measured fecal fat content for the 12 samples, are shown in table 2. Chemical fat measurements of two samples ( 1 and 2 ) were not performed. The chemically measured fecal fat concentration was very high in all samples and corresponded with high acid steatocrit results, while only 5 classical steatocrit results were elevated.

Table 2 Classic and acid steatocrit results compared to chemically measured fecal fat in 12 steatorrheal fecal samples.

\begin{tabular}{|cccc|}
\hline SAMPLES & $\begin{array}{c}\text { CLASSIC } \\
\text { STEATOCRIT (\%) }\end{array}$ & $\begin{array}{c}\text { ACID } \\
\text { STEATOCRIT (\%) }\end{array}$ & $\begin{array}{c}\text { FECAL FAT } \\
\text { (GRAM \%) }\end{array}$ \\
\hline 1 & 5.3 & 81.7 & - \\
2 & 2.5 & 72.4 & - \\
3 & 5.3 & 71.1 & 16.6 \\
4 & 28.8 & 93.3 & 28.5 \\
5 & 26 & 90.9 & 26.7 \\
6 & 6.2 & 92.6 & 28.3 \\
7 & 3.1 & 92.5 & 18.7 \\
8 & 2.8 & 94.2 & 26.5 \\
9 & 59.8 & 93.7 & 24.3 \\
10 & 6.2 & 96.4 & 10.3 \\
11 & 63.9 & 96 & 27.3 \\
12 & 48.7 & 94.4 & 20.6 \\
\hline
\end{tabular}

\section{DISCUSSION}

There has always been a need for a simple, rapid and easy to perform screening test for fat malabsorption. Such a test would not only be useful for the detection of steatorrhea but also for the therapeutic monitoring of children treated for pancreatic insufficiency.

The steatocrit is a simple and rapid micromethod that can be repeated at short time intervals 
(3). It is inexpensive and not invasive (5). Some authors have reported it as a very satisfactory screening test (3-5), but others have found it quite unreliable (6). Our experience with the method has shown the steatocrit to often be normal, in fecal samples with a very high chemically measured fecal fat content. This could be due to inefficient fecal fat extraction at the centrifugation step. Therefore we recently improved the steatocrit method by acidifying the fecal homogenate before centrifugation (8).

The present study was set up to study the effect of fecal homogenate acidification on fat extraction at the centrifugation step. If fat extraction improves by acidification, we would expect to find more fat globules in the fatty layer and less in the solid layer, after centrifugation of acidified fecal samples, when compared to unacidified samples. Our results are in agreement with our expectations and support the hypothesis that fecal acidification improves fat extraction, and should consequently improve the sensitivity of the steatocrit. Due to various reasons, the fat content of premature infants ' stool, is known to be very high. Confirming the latter, chemical fat measurements of all our samples from 4 premature babies showed very high values. The acid steatocrit seems to reflect these very high fat contents, while classical steatocrit results were high in only 5 of 12 samples. The correlation between chemical fat measurement and acid steatocrit has been reported previously (8). Such a correlation cannot be shown in the present study where only high-fat-content stools were evaluated.

Results of the present study do support our previous findings, confirming, that fecal acidification improves fat extraction at the centrifugation step, and consequently increases the reliability of steatocrit results for the detection of fat malabsorption. Because the Sudan staining staining method for fecal fat is only semiquantitative, we suggest using the acid steatocrit as a good alternative to chemical fat measurement.

Acknowledgement: The authors wish to thank the clinical laboratory staff for their kind and expert technical assistance. We are very grateful to Nutricia Netherlands for financial support. 


\section{REFERENCES}

(1) Van de Kamer JH, Huinink HTB, Weyers HA. Rapid method for determination of fat in feces. J Biol Chem 1949; 177: 349-55.

(2) Drummey GD, Benson JA, Jones CM. Microscopical examination of the stool for steatorrhea. N.Engl J Med 1961; 264: 85-7.

(3) Phuapradit P. Narang A, Mendonca P, Harris DA, Baum JD. The steatocrit: a simple method for estimating stool fat content in newborn infants. Arch Dis Child 1981: 56: 725. 727.

(4) Iacono G, Carroccio A, Cavataio F, Montalto G, Mancusco C, Balsamo V et al. Steatocrit test: normal range and physiological variation in infants. J Pediatr Gastroenterul Nutr 1990; 11: 53-57.

(5) Columbo C, Maiavacca R, Ronchi M, Consalvo E, Amoretti M, Giunta A. The steatocrit: a simple method for monitoring fat malabsorption in patients with cystic fibrosis. J Pediatr Gastroenterol Nutr 1987; 6 : 926-930.

(6) Walters MP, Kelleher J, Gilbert J, Littlewood JM. Clinical monitoring of steatorrhea in cystic fibrosis. Arch Dis Child 1990; 65: 99-102.

(7) Khouri MR, Huang G, Shiau YF. Sudan stain of fecal fat: new insight into an old test. Gastroenterology 1989; 96: 421-427.

(8) Tran M, Forget P, Van den Neucker A, Strik J, van Kreel B, Kuijten R.

The acid steatocrit: a much improved method. J. Pediatr. Gastroenterol Nutr. 1994; 19: 299-303 


\title{
CHAPTER 5
}

\section{CLINICAL USE OF ACID STEATOCRIT}

\author{
A. Van den Neucker', N. Pestel', T. My Dung Tran', P.Ph. Forget',H.J. Veeze', \\ J. Bouquet ${ }^{2}$, M. Sinaasappel ${ }^{2}$.
}

'Department of Pediatrics, University Hospital Maastricht and '2Sophia Children's Hospital Rotterdam, The Netherlands

Submitted for publication

Abstract

Malabsorption of fat is an important gastrointestinal cause of malnutrition and growth retardation in childhood. The golden standard for the evaluation of fat malabsorption is the fecal fat balance method. The acid steatocrit method has recently been introduced as a simple method to evaluate fecal fat. The present study aimed at evaluating the acid steatocrit in clinical practice. Fecal fat excretion and acid steatocrit results were determined in 42 children, half with and half without fat malabsorption. Acid steatocrit results correlated significantly with both fecal fat excretion $(p<0.01)$ and fecal fat concentration $(p<0.001)$. Sensitivity and specificity of the acid steatocrit for the diagnosis of malabsorption was $90 \%$ and $100 \%$ respectively. We consider the acid steatocrit method useful for the screening and monitoring of patients with steatorrhea. Acid steatocrit, Steatorrhoea, Cystic Fibrosis. 


\section{INTRODUCTION}

Malabsorption of fat is the most important gastrointestinal cause of malnutrition and growth retardation in childhood. The detection of steatorrhoea is useful for the diagnosis of intestina! and pancreatic cisease. The gold standard for the evaluation of patients suspected of fat malabsorption is the fat balance method whereby fecal fat is chemically measured according to the method of van de Kamer (1). This method is cumbersome, laborious, expensive and often difficult to manage in children. In 1981 Phuapradit et al. introduced a simple test to evaluate fecal fat content (2). Although some authors found this test quite reliable (3), others did not (4). As previously reported, substantial improvement of the method was obtained by acidification of fecal samples, acid steatocrit (AS) (5).

The present study was designed to compare the fecal fat excretion with the acid steatocrit for the diagnosis of fat malabsorption in children.

\section{PATIENTS}

Forty two children, 23 boys and 19 girls, aged between 6.5 months and 18 years (mean: 6.6 years) were selected for the study. All these children were suspected of fat malabsorption, on the basis of anamnestic and clinical parameters. The different diagnoses of our patients are shown in table 1.

\section{METHODS AND MATERIAL}

Three days stool collections from each patient were collected in separate containers, one container for each day. The stools were frozen at $-18^{\circ} \mathrm{Celsius}$. Fat content in each collection was determined by the titrimetric method described by van de Kamer et al.(1). Acid steatocrit from a single stool sample on day 1 and from a sample out of the homogenized 72 hours collection were determined by the method of Tran et al.(5)Feces $(0.5 \mathrm{gr}$.) was diluted (1/4) with deionized water and thouroughly homogenized making use of a $5 \mathrm{ml}$. Potter Elvehjem tissue homogenizer. Perchloric acid $5 \mathrm{~N}$ was added to the homogenate in a volume equal to $1 / 5$ of the homogenate volume. The resulting acid homogenate was mixed for 30 seconds making 
Table 1 List of diagnosis $(n=42)$.

\begin{tabular}{|cc|}
\hline DIAGNOSIS & NUMBER OF CASES \\
\hline CYSTIC FIBROSIS & 20 \\
MENTAL RETARDATION & 2 \\
RECURRENT DIARRHEA & 5 \\
FAILURE TO THRIVE & 5 \\
COELIAC DISEASE & 2 \\
INFLAMMATORY BOWEL DISEASE & 1 \\
SHORT BOWEL & 1 \\
CHOLEDOCHAL CYSTE & 1 \\
SUCRASE-ISOMALTASE DEFICIENCE & 1 \\
RECURRENT ABDOMINAL PAIN & 1 \\
UNKNOWN & 3 \\
\hline
\end{tabular}

use of a standard Vortex mixer. The homogenate was aspirated into a75 $\mu$ l plain glass haematocrit capillary. The capillary was subsequently centrifuged horizontally (13000 rpm. for 15 min.) in a standard centrifuge. After centrifugation, the lengths of the upper (fat) and the bottom (solid) layers were measured by means of a graduated magnifying lens. Steatocrit was calculated as follows: percentage of (the fatty layer length / (fatty layer length + solid layer length)\}.

In order to validate the diagnostic value of the acid steatocrit we studied two patients groups, one with and one without steatorrhea. We divided the patients according to previous clinical datã and fat excretion results. whereby a fecal fat excretion $23 \mathrm{gr} /$ day was considered as abnormal (6).

\section{RESULTS}

Correlation coefficients between acid steatocrit results from either a șingle stool sample or from the sample taken from the 72 hours homogenized collection, and both the fecal fat excretion and the fecal fat concentration are shown in table 2. 
Table 2 Correlation between the results of the acid steatocrit from either a single stool sample and a sample from the homogenised stool collection and the results of both fat excretion and fecal fat concentration in $\mathbf{4 2}$ children suspected of malabsorption.

\begin{tabular}{|c|c|c|}
\hline ACID STEATOCRIT & FAT EXCRETION & FAT CONCENTRATION \\
\hline SINGLE STOOL & $r=0.4(p \leq 0.01)$ & $r=0.82(p \leq 0.001)$ \\
\hline COLLECTION & $r=0.68(p \leq 0.001)$ & $r=0.82(p \leq 0.001)$ \\
\hline
\end{tabular}

The sensitivity and the specificity of the acid steatocrit determination from either a single stool sample or a sample taken from the 72 hours homogenized collection, and of the fecal fat concentration, for the diagnosis of steatorrhea are shown in table 3.

Table 3 Sensitivity and specificity of the acid steatocrit determination from a single stool sample and from a homogenised stool collection sample and of the fecal concentration, for the diagnosis of steatorrhea.

\begin{tabular}{|c|c|c|}
\hline & SENSITIVITY & SPECIFICITY \\
\hline AS SINGLE STOOL (\%) & $75 \%$ & $84 \%$ \\
\hline AS COLLECTION (\%) & $90 \%$ & $100 \%$ \\
\hline FAT CONCENTRATION (\%) & $100 \%$ & $76 \%$ \\
\hline
\end{tabular}

AS: Acid steatocrit

Fig.1 shows our AS results from the homogenized fecal collection sample related to the fecal fat excretion ( $g /$ day).The reference line for AS was set at the level of $10 \%(5)$, and the cut off reference line for the daily fat excretion was set at the level of $3 \mathrm{gram}$ per day (6).As can be seen from the figure, one false positive and three false negative acid steatocrit results were found in our study population.Regarding these results one should notice that they are very close to the reference lines: the false positive steatocrit result had a value of $16 \%$ and the results of the fecal fat excretion corresponding to the false negative steatocrit results were 4.9 ; 6.4 and $7.7 \mathrm{~g} / \mathrm{day}$, and concern children aged 12.6 and 13 years respectively. 


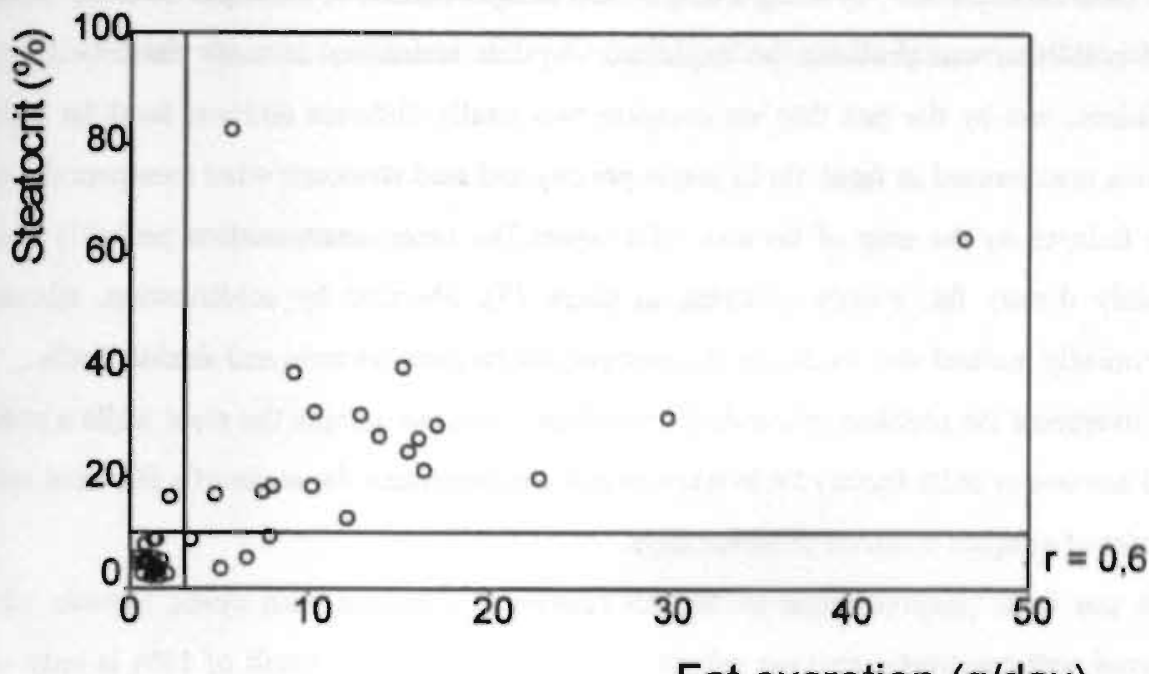

\section{Fat excretion (g/day)}

Figure 1 Relationship between acid steatocrit and fat excretion. Reference lines for acid steatocrit at $10 \%$ and for fat excretion at $3 \mathrm{gram} /$ day.

\section{DISCUSSION}

Since the fecal fat balance excretion as described by van de Kamer is cumbersome, expensive and unpleasant for all involved, there is a need for a simple test. Some authors reported the steatocrit micromethod described by Phuapradit as a simple method for monitoring fat malabsorption (3), and reported a good correlation ( $r=0.93$ ) with the fecal fat excretion. Although others considered the steatocrit method of Phuapradit unreliable and mentioned the difficulty to delineate the fatty layer (4) and the impression that fat remains in the solid layer, as a problem of this method.This problem was solved by acidification of the fecal sample, whereby fat extraction is improved, and steatocrit results correlate much better with chemically measured fecal fat (5).

Our AS results correlate satisfactorily with chemically measured fecal fat concentrations and somewhat less ,but still significantly, with fecal fat excretion.However, our correlation coefficient is lower than the correlation coefficient of the steatocrit without acidification as published in a previous study (3).We have no explanation for this discrepancy, and other 
authors also failed to reproduce these results (4). The lesser correlation of the AS results with the fecal fat excretion, by using a single stool sample instead of a sample from the homogenized collection can probably be explained by the variability of daily fat consumption in children, and by the fact that we compare two totally different entities: fecal fat excretion, which is expressed as fecal fat in grams per day and acid steatocrit what measures the ratio of the fatlayer on the sum of fat and solid layers. The latter determination probably measures mainly dietary fat, mostly occuring as soaps (7), liberated by acidification, whereas the chemically method also measures the endogenous fat from bacteria and shedded cells.

To overcome the problem of the daily variability, one can sample the stool while a standardized amount of daily dietary fat is taken or one can determine the mean of a few acid steatocrit results of samples taken on different days.

The one false positive result of the AS concerned a patient with cystic fibrosis who was treated with pancreatic enzyme substitution therapy. This AS result of $16 \%$ is only slightly elevated considering the values obtained in cystic fibrosis patients on substitution therapy, which are mostly between 20 and $30 \%$.

The three false negative results of the acid steatocrit can probably be explained by the choice of the reference line for the normal fecal fat excretion. Fecal fat excretion higher than $4.5 \mathrm{~g} / 24$ hours is considered pathologic $(6,8)$ for children and adolescents, whereas other authors consider $7 \mathrm{~g} /$ day the uper limit of normal fecal fat excretion in adults (9). The reference line for normal daily fecal fat excretion varies clearly with age and dietary fat intake as previously suggested by Williams (8).Taking account of these remarks, the fat excretion studies of 2 of our 3 patients with false negative steatocrit results could, due to their ages (12 and 13 years), still be considered "normal" and in agreement with AS results .This would reduce the disagreement between the methods to only a few ones.

\section{CONCLUSION}

Acid steatocrit results are highly correlated with the chemically measured fecal fat concentration and significantly correlated with the fecal fat excretion. Although single sample acid steatocrit results are slightly less sensitive and specific than other measured parameters for the diagnosis of steatorrhoea, acid steatocrit measured in the stool samples taken from the homo- 
genized collection compare favourably with the fecal fat concentration. We consider the acid steatocrit method useful for the screening and monitoring of patients with steatorrhoea.If it is necessary to know the real coefficient of fat absorption, the fecal fat balance method is needed. 


\section{REFERENCES}

(1) van de Kamer JH, Huinink HTB, Weyers HA. Rapid method for determination of fat in feces. J Biol Chem 1949; 177:349-55.

(2) Phuapradit P, Narang A, Mendonca P, Harris DA, Baum JD. The steatocrit: a simple method for estimating stool fat content in newborn infants. Arch Dis Child 1981; 56:725-7.

(3) Colombo C, Maiavacca R, Ronchi M, Consalvo E, Amoretti M, Giunta A. The steatocrit: a simple method for monitoring fat malabsorption in patients with cystic fibrosis. J Pediatr Gastroenterol Nutr 1987;6:926-30.

(4) Walters MP, Kelleher J, Gilbert J, Littelwood JM. Clinical monitoring of steatorrhoea in cystic fibrosis. J Pediatr Gastroenterol Nutr 1990; 65:99-102.

(5) Tran M, Forget P, Van den Neucker A, Strik J, Kreel van B, Kuijten R.The acid steatocrit: a much improved method. J Pediatr Gastroenterol Nutr 1994; 19: 299-303.

(6) Navarro J, Schmitz J. Gastroenterologie pédiatrique, Flammarion Médicine Sciences, Paris 1986.

(7) Quinlan PT, Lockton S, Irwin J, Lucas AL. The relationship between stool hardness and stool composition in breast- and forrnula-fed infants. J Pediatr Gastroenterol Nutr 1995; 20:81-90.

(8) Williams HH, Endicott EN, Shepherd ML, Galbraith H, Macy IG. Fat excretion by normal chilldren.J. of Nutrition 1943; 25, 379.

(9) Bai JC, Andrish A, Matelo G, Martinez C, Vazquez H, Boern L, Sambuelli A. Fecal fat concentration in the differential diagnosis of steatorrhoea. Am. J. Gastroenterol. 1989; 27-30. 


\title{
CHAPTER 6
}

ROLE OF LANSOPRAZOLE IN CHILDREN WITH CYSTIC FIBROSIS: EVIDENCE FOR IMPROVED FAT ABSORPTION AND NUTRITIONAL STATUS

\author{
Tran TMD, Van den Neucker A, Hendriks JJE, Forget $\mathrm{P}$ ( junior ), Forget $\mathrm{P}$ ( senior )
}

\section{Department of Pediatrics, University Hospital Maastricht, Maastricht, The Netherlands}

\section{Submitted for publication}

\section{Abstract}

Steatornhea and nutritional parameters were investigated in 15 cystic fibrosis children before starting lansoprazole, after 3 months on lansoprazole ( $15 \mathrm{mg} /$ day) and 3 months after stopping lansoprazole. There were 5 girls and 10 boys with a mean age of 9.5 years (range: 3.1 22.6y). Patients were their own controls. Acid steatocrit, anthropometric methods and DXA were used to evaluate steatornhea and the nutritional status respectively. On lansoprazole, mean \pm SD acid steatocrit values decreased from $37.1 \pm 8.8 \%$ to $28.5 \pm 10.6 \%(p=0.02)$. During lansoprazole therapy, significant mean $Z$-score changes were found for weight $(+0.14 /$ $p=0.02)$, length $(+0.15 / p=0.03)$, subscapular $(+0.61 / p=0.003)$, suprailiaca $(+0.8 / p=$ $0.002)$ and the sum of 4 skinfolds $(+0.61 / p=0.002) . Z$-scores deteriorated again after stopping lansoprazole. Fatmass and bone mineral content increased significantly on lansoprazole $(p=0.008$ and $p=0.005$ resp.). Improvement of subscapular $Z$-score was related to improvement of acid steatocrit values $(p=0.01)$ during treatment. We conclude that lansoprazole as adjuvant therapy significantly improves fat absorption and the nutritional status in CF children. 


\section{INTRODUCTION}

Cystic fibrosis (CF) is an autosomal recessive inherited disease. Defect in the chloride transepithelial transport system results in viscous mucus in various organs with lung and pancreas mostly affected (1). Both, pancreatic insufficiency resulting in malabsorption and high energy expenditure due to increased respiratory work (2-3), are thought to be responsible for the poor nutritional condition in CF patients. Since malnutrition can compromise absorptive and immune function resulting in a shortened survival (4), all efforts should be made in order to improve the nutritional status of these patients. Unfortunately, high doses of pancreatic enzymes did not solve the problems of malabsorption (5) and colon stricture has been observed in CF children on this regimen $(6,7)$. Further, the use of hypercaloric diets did not result in significant improvements of Z-scores for weight, length and skinfolds in CF children (8). Only parenteral nutrition and either oral or enteral elemental and semielemental nutrition have been shown to significantly improve the nutritional condition of these children (9-15).

The latter strongly suggests that nutrient maldigestion plays a crucial role in the poor response to oral hypercaloric diets. As cystic fibrosis patients have a low duodenal $\mathrm{pH}$ probably linked to fat maldigestion (16), inhibition of gastric acid production could improve absorption. The reported effects of $\mathrm{H} 2$-receptor antagonists and prostaglandine E2 on steatorrhea have been variable (17-22). Insufficient inhibition of gastric acid could be responsible for these unconvincing results. Recently, in a double blind study, a significant improvement in steatorrhea was found when a proton-pump inhibitor was added as adjuvant therapy in pancreatic enzyme treated cystic fibrosis patients (23). The effect of proton pump inhibitors on the nutritional condition of children with CF have not yet been reported. The aims of our study were to evaluate the effects of lansoprazole (proton-pump inhibitor) on both steatorrhea and the nutritional condition of CF patients while on enzyme therapy.

\section{SUBJECTS AND METHODS}

\section{Studv design}

As the effect of a proton pump inhibitor on fat balance has been convincingly proven in a 
double blind study (23), we adapted a prospective open study design wherein patients were their own controls. In the month preceding the study, all patients were screened for steatorrhea by measuring fecal acid steatocrit once every 10 days. Patients with a mean acid steatocrit value higher than $25 \%$ (normal values in our laboratory $<20 \%$ ) were invited to take part in the study. After evaluation of nutritional parameters by DXA and anthropometric methods, lansoprazole was added to their standard treatment in a dose of $15 \mathrm{mg}$ day before breakfast for 3 months. When fat malabsorption did not change after 2 months, the dose was doubled in children older than 10 years and weighing more than $30 \mathrm{~kg}$. During the lansoprazole treatment period 9 fecal samples were taken with an interval of 10 days for acid steatocrit measurements. The mean of these 9 measurements was used as a measure of steatorrhea during the treatment period. After 3 months on treatment, the nutritional condition assessment was repeated. All measurements of nutritional condition were performed on a single day. Three fecal samples for acid steatocrit determinations and anthropometric parameters were again measured respectively 1 month and 3 months after stopping lansoprazole therapy. Dietary evaluations were performed at the start, at the end and one month after stopping lansoprazole.

\section{Patients population}

$23 \mathrm{CF}$ out-clinic patients from the academic Hospital Maastricht were recruited. All patients were treated with pancreatic enzymes. Of these, 2 patients were too ill to participate in the study. 21 patients were screened for steatorrhea while on pancrease enzyme. 15 of them who had steatorrhea were included. In most children, the $\mathrm{CF}$ diagnosis had been made during the first year of life by repeated positive sweat tests, all 15 children were considered to have pancreatic insufficiency on the basis of abnormal fecal chymotrypsin, 72 hours fat balance (24) and increased acid steatocrit results (25). Mean energy intake was $113 \%$ RDA (recommended daily allowance). The mean number of pancreas enzyme capsules (Pancrease) taken by 13 of these patients was 20 (range: 11 - 33), one patient took 3 Pancrease capsules (5000E lipase, 2900E amylase, 330E protease) and 6 Panzytrat tablets (25000E lipase, 22500E amylase, 1250E protease) and another one took 10 Creon capsules (8000E lipase, 9000E amylase, $450 \mathrm{E}$ protease) per day. Mean age, weight and length of those 15 children were $9.5 \mathrm{y}$ (range: $3.1-22.6 \mathrm{y}$ ); $29.3 \mathrm{~kg}$ (range: $13.6-67.6 \mathrm{~kg}$ ) and $131 \mathrm{~cm}$ (range: $97.7-184.9 \mathrm{~cm}$ ) 
respectively. Their nutritional status was moderately altered with a mean Body Mass Index (BMI) of 15.6 (range : 13.2 - 18.3). Mean predicted values of FEV1 and FVC were respectively $81.3 \%$ (range: $39-114 \%$ ) and $85.5 \%$ (range: $44-108 \%$ ). Informed patient and parental consent were obtained.

\section{Evaluation of fat malabsorption by acid steatocrif.}

The acid steatocrit was determined as previously reported (25). In short, $0.5 \mathrm{~g}$ solid stool was weighed and diluted with a volume of deionized water, equal to two times the weight of stool. The stool and water were premixed using a Vortex mixer. Subsequently, the mixture was homogenized using a $5 \mathrm{ml}$ Potter Elvehjem tissue homogenizer. After then $5 \mathrm{~N}$ perchloric acid was added to the homogenate in a volume equal to $1 / 5$ of the homogenate. After mixing with the Vortex, the acidified homogenate was aspirated into a $75 \mu \mathrm{l}$ plain haematocrit capillary. This capillary was sealed with wax at one end and centrifuged horizontally $(13000 \mathrm{rpm}, 15$ min). After centrifugation, 3 layers were distinguished: a basal solid layer (SL), an intermediate liquid layer and an upper fatty layer (FL). Acid steatocrit was calculated as (FL / FL + SL)) $\times 100 \%$

\section{EVALUATION OF NUTRITIONAL STATUS}

\section{Anthropometry}

The armcircumference, biceps, triceps, subscapular and suprailiaca skinfolds were measured 3 times on the left side of the body using the Harpenden caliper. Average values were taken. Weight and length were also measured. BMI was calculated as weight / (length ${ }^{2}$ ). The Z score

(Z-score is defined as $\mathrm{X}-\mathrm{x} / \mathrm{S}$ where $\mathrm{X}$ is the patients 's measurement, $\mathrm{x}$ is the mean value for age and sex and $\mathrm{S}$ is the standard deviation of $\mathrm{x}$ ) of all these anthropometric parameters were calculated based on the reference data described by Gerver and de Bruin (26). A negative value indicates values under the mean reference value and a positive or negative change in $Z$ score means catch up or slowing down of growth respectively. All measurements were done 
by the same investigator (TT).

\section{Dual-energy $x$-ray absorptiomerry (DXA)}

DXA measurement is based on the differential tissue attenuation of photons of two energy levels from an X-ray source (27). All patients underwent total body scan performed with a DPX (Lunar Radiation Corp, Madison, WI) total body scanner. The results were analysed with a paediatric software programme, version $1.5 \mathrm{e}$. Daily quality assurance test was performed according to the manufacturer 's directions. Total non bone LBM (lean body mass), total BMC (bone mineral content), total body FM (fatmass) and BMD (bone mineral density) Z . score were measured by DXA procedure. These results were compared to those of the reference population, recently described by Ogle et al., who studied the body composition by DXA in 265 normal individuals aged 4 - 26 year (28).

\section{Diet evaluation}

At the beginning, at the end and one month after stopping lansoprazole nutrient intake was assessed by a specially trained clinical CF dietitian from consecutive 3 day food diaries including one weekend day. Intakes were expressed as kilocalorie per $\mathrm{kg}$ bodyweight for the energy intake and gram per $\mathrm{kg}$ bodyweight for fat-, carbohydrate- and protein-intakes, using the netherlands nutrients table "NEVO" 1993.

\section{Statistic}

All data were analysed by using SPSS statistic program. Anthropometric parameters and body composition results measured before the start and at the end of the trial were compared making use of Wilcoxon one sample test. The sign test was used to compare LBM, FM and BMC assessed by DXA, with the reference population described by Ogle. 


\section{RESULTS}

\section{Eat malabsorption}

Despite standard pancreas enzyme, 15 of 21 children had steatorrhea with an average \pm SD pretreatment acid steatocrit value (mean of 3 determinations in each patient) of $37.1 \% \pm 8.8 \%$. After 3 months of treatment with lansoprazole, there was a significant $(p=0.02)$ improvement in steatorrhea with a mean $\pm \mathrm{SD}$ acid steatocrit value of $28.5 \% \pm 10.6 \%$. Eight patients on lansoprazole had a mean acid steatocrit value lower than $25 \%$ (fig 1 ). In this group the mean decrease was $16 \%$ ( $44.2 \%$ of start value). In 3 children the acid steatocrit value decreased with. $9 \%$ (20.6\% of start value) but was not completely corrected. In 4 children fat malabsorption. did not improve at all. Four children received a double dose of lansoprazole for 1 month, resulting in a decreased acid steatocrit results in 2 (decrease of $8.6 \%$ and $19 \%$ ). Due to social problems one child was dropped out of the study after the lansoprazole period. Mean \pm SD acid steatocrit value for the remaining 14 children in the first month after stopping lansoprazole was $29.7 \% \pm 13.9 \%$, which was not significantly different from the values on lansoprazole. Of 4 children whose acid steatocrit was not changed on lansoprazole, 2 had higher acid. steatocrit values after stopping.

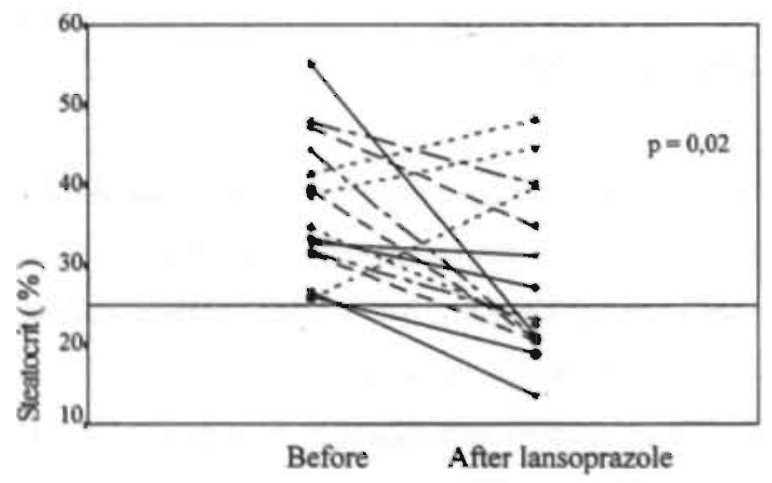

Figure 1 Acid steatocrit before and after 3 months treatment with lansoprazole in 15 CF children. A line through the $25 \%$ value is drawn showing the study inclusion limit. Acid steatocrit values on lansoprazole art significantly decreased $(p=0.02)$. 
Mean and $95 \% \mathrm{Cl}$ (confidence interval) for weight, length, armcircumference, 4 skinfolds and the sum of these 4 skinfolds expressed as Z-score are shown in fig.2. For all parameters except the triceps, the $\mathrm{CI}$ do not include the reference 50 th centile line (Z-score 0 ), underscoring the fact that except for the triceps skinfold, all other anthropometric parameters mean Z-scores were significantly decreased in our CF children when compared to those of the normal population. The suprailiaca skinfold was most abnormal and showed the smallest interindividual variation.

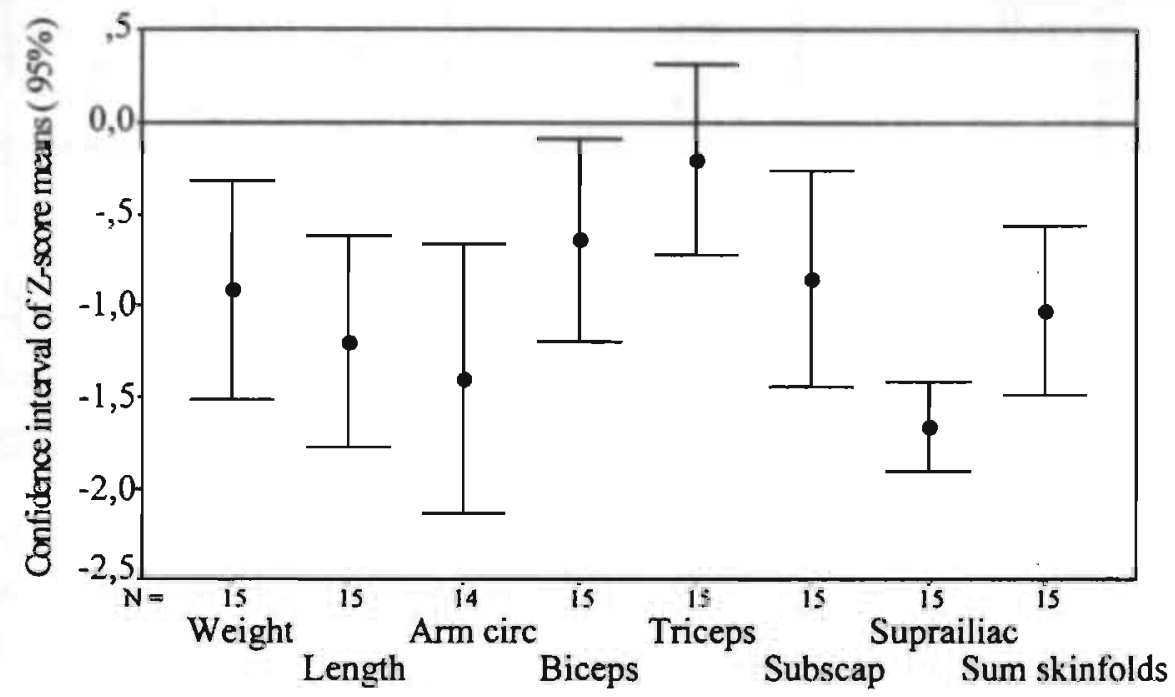

Figure 2 Mean Z-scores and $95 \%$ confidence interval of anthropometric parameters in $15 \mathrm{CF}$, children before lansoprazole therapy. The line through 0 represents the 50th centile of the reference population. The differences between the study group and the reference population are significant when the $\mathrm{CI}$ do not include the Z-score 0 line. All anthropometric parameters were significantly decreased in our CF children except for the triceps skinfold. 
After treatment with lansoprazole, Z-scores of anthropometric parameters improved signifcantly. All parameters moved toward the Z-score 0 line (50th centile for reference population). The Z-scores of biceps, subscapular and sum of the 4 skinfolds did not significantly differ from the reference population any more (fig.3).

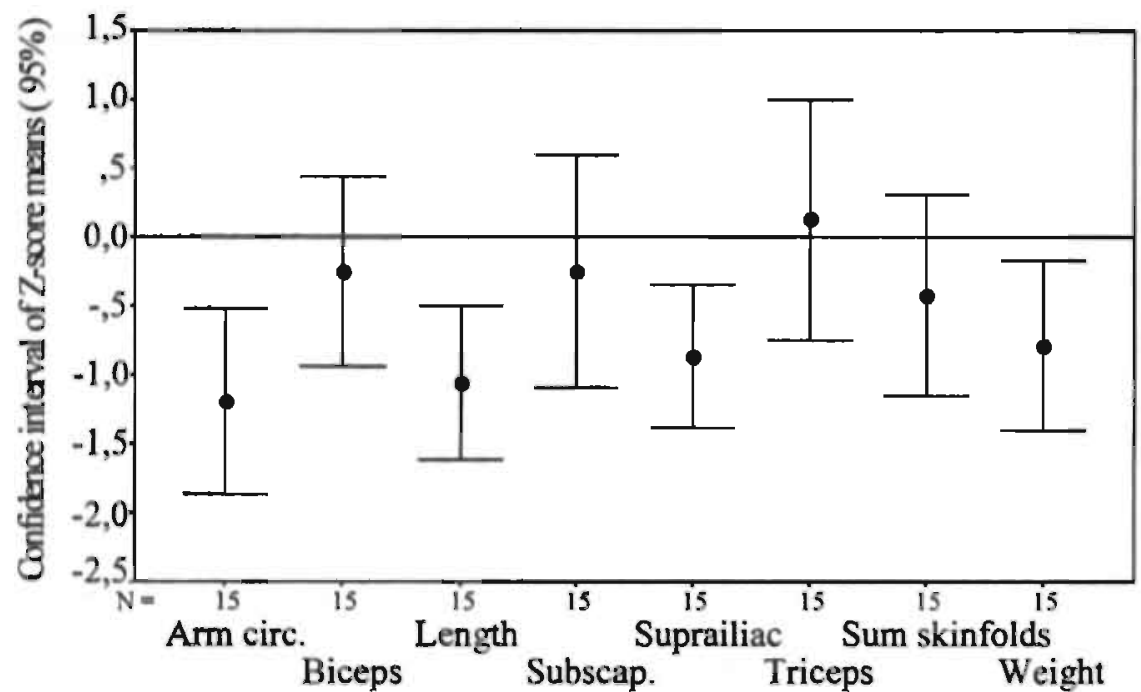

Figure 3 Mean Z-scores and $95 \%$ confidence interval of anthropometric parameters in 15 CF' children on lansoprazole for 3 months. The differences between the study group and the reference population are significant when the $\mathrm{CI}$ do not include the Z-score 0 line. Several parameters (biceps, subscapular and sum of 4 skinfolds) normalized during lansoprazole treatment (see figure 2).

Z-score changes for all anthropometric parameters studied are shown in table: 1. Except for armcircumference, biceps and triceps skinfolds, Z-scores of all parameters improved significantly. Subscapular, suprailiaca and the sum of the 4 skinfolds showed the most significant changes. The acid steatocrit results during lansoprazole treatment were significantly lower ( $p$ $=0.01$ ) in our patient subgroup with subscapular Z-score improvement 20.5 when compared to the subgroup showing lower Z-score changes. Three months after lansoprazole was stopped, 5 children were dropped out of the study; 2 because of the far distances from home, 1 had 
taken lansoprazole again because of increased symptoms of steatorrhea and abdominal pain and 2 because of social problems. Nutritional parameters were therefore evaluated in only 10 children 3 months after stopping lansoprazole. Z-scores of all anthropometric parameters deteriorated, with weight and subscapular Z-score changes reaching statistical significance (table 1).

Table 1 Mean Z-scores of anthropometric parameters in $15 \mathrm{CF}$ children before (T0), after 3 months on lansoprazole (T3) and 3 months after stopping lansoprazole (T6).

\begin{tabular}{|c|c|c|c|c|c|}
\hline $\begin{array}{c}\text { Anthrop. } \\
\text { Parameters }\end{array}$ & $\begin{array}{c}\text { Me } \\
\text { Mean Z-score } \\
(\mathrm{n}=15)\end{array}$ & $\begin{array}{c}\text { T3 } \\
\text { Mean Z-score } \\
(\mathrm{n}=15)\end{array}$ & $\begin{array}{c}\text { T6 } \\
\text { Mean Z-score } \\
(\mathrm{p}=10)\end{array}$ & $\begin{array}{c}\text { T3- T0 } \\
\text { Mean Z-score } \\
(\mathrm{n}=15)\end{array}$ & $\begin{array}{c}\text { T6-T3 } \\
\text { Mean Z-score } \\
(\mathrm{n}=10)\end{array}$ \\
\hline Weight & -0.91 & -0.78 & -1.38 & $0.14(\mathrm{p}=0.02)$ & $-0.6(\mathrm{p}=0.01)$ \\
Length & -1.2 & -1.05 & -1.23 & $0.15(\mathrm{p}=0.03)$ & $-0.18(\mathrm{p}=0.16)$ \\
Armeircum & -1.4 & -1.19 & -1.74 & $0.22(\mathrm{p}=0.05)$ & $-0.55(\mathrm{p}=0.52)$ \\
Biceps & -0.63 & -0.24 & -1 & $0.39(\mathrm{p}=0.06)$ & $-0.76(\mathrm{p}=0.21)$ \\
Triceps & -0.2 & 0.14 & -0.72 & $0.34(\mathrm{p}=0.2)$ & $-0.86(\mathrm{p}=0.26)$ \\
Subscapular & -0.85 & -0.24 & -1.14 & $0.61(\mathrm{p}=0.003)$ & $-0.9(\mathrm{p}=0.03)$ \\
Suprailiaca & -1.66 & -0.86 & -1.13 & $0.8(\mathrm{p}=0.002)$ & $-0.27(\mathrm{p}=0.68)$ \\
Sum skinfolds & -1.02 & -0.41 & -1.16 & $0.61(\mathrm{p}=0.002)$ & $-0.75(\mathrm{p}=0.31)$ \\
\hline
\end{tabular}

\section{Body composition}

Body composition data before and after lansoprazole are given in table 2. All 3 components FM, LBM and BMC were significantly decreased in our 15 CF children when compared to the reference population described by Ogle et al. $(p=0.01 ; p=0.02$ and $p=0.005$ respectively). Bone mineral density Z-score was significantly decreased ( $p \leq 0.05$ ). Significant increases of FM and BMC occurred after 3 months of treatment with lansoprazole. Changes in the subscapular, suprailiaca and sum of the 4 skinfolds $Z$-scores were highly correlated with changes in FM by DXA ( $r=0.81 / r=0.77 / r=0.85$ resp. with $p=0.001)$ (fig 4). 


\section{Diet evaluation}

Mean fat, protein, carbohydrate and energy intakes were $3.1-2.8-3.0 \mathrm{~g} / \mathrm{kg} ; 3.0-2.7-2.8$ $\mathrm{g} / \mathrm{kg} ; 10.4-9.7-9.8 \mathrm{~g} / \mathrm{kg}$ and $2095-1986-1977 \mathrm{kcal} / \mathrm{kg}$ bodyweight at the start, at the end and one month after lansoprazole trial respectively. None of these changes were significant.

Table 2 Body composition before (T0) and after (T3) lansoprazole by DXA.

\begin{tabular}{|c|c|c|c|}
\hline $\begin{array}{c}\text { BODY } \\
\text { COMPOSITION }\end{array}$ & $\begin{array}{c}\text { T0 } \\
(\mathrm{n}=15)\end{array}$ & $\begin{array}{c}\text { T3 } \\
(\mathrm{n}=15)\end{array}$ & $\begin{array}{c}\text { SIGNIFICANCY } \\
(\mathrm{p})\end{array}$ \\
\hline MEAN FATMASS (Kg) & 3.97 & 4.76 & 0.008 \\
MEAN LBM (Kg) & 22.83 & 24.03 & 0.06 \\
MEAN BMC (Kg) & 1.02 & 1.08 & 0.005 \\
MEAN BMD ( Z-SCORE) & -0.55 & -0.58 & 0.65 \\
\hline
\end{tabular}




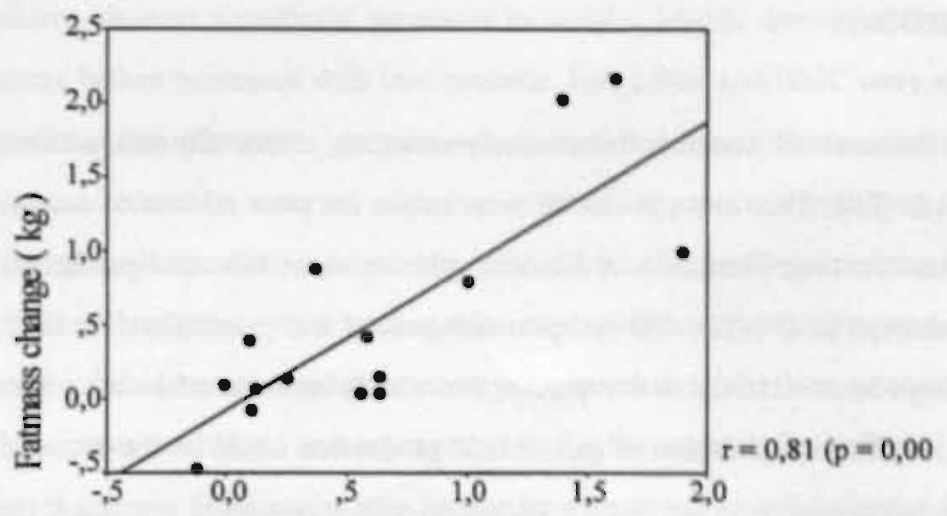

Change in subscapular Z-score

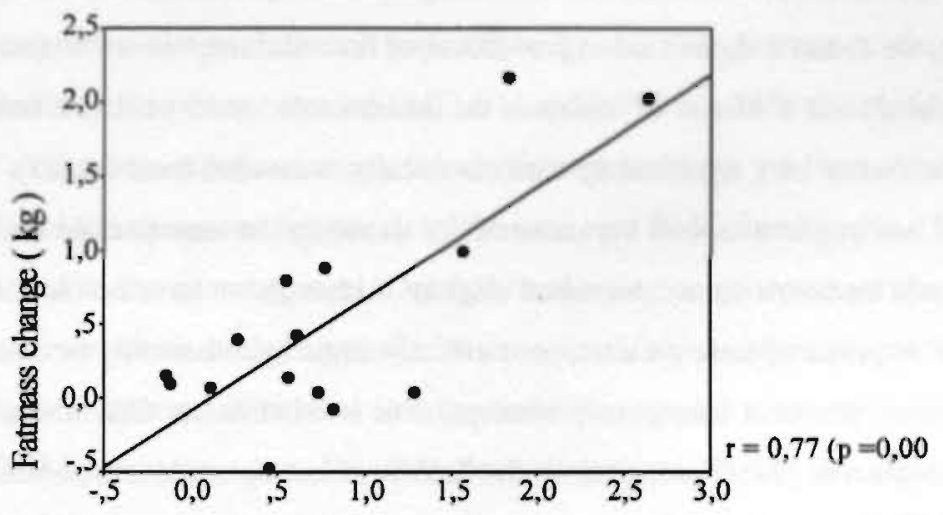

Change in suprailiaca Z-score

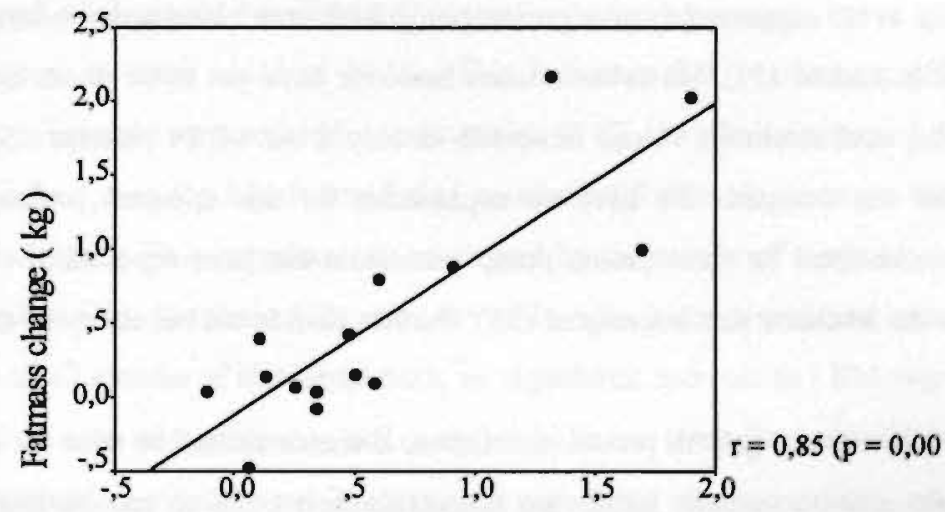

Change in sum of skinfolds Z-score

Figure 4 Relation between changes in subscapular skinfold Z-score, suprailiaca skinfold Z-score, sum of 4 skinfolds Z-score and fatmass as measured by DXA (dual energy X-ray absorptiometry) in 15 CF children. 


\section{DISCUSSION}

Due to a decrease of pancreas bicarbonate secretion, cystic fibrosis patients have a low duodenal $\mathrm{pH}$ (29). This low $\mathrm{pH}$ can be responsible for poor release of enzymes through the acid resistent coating. Further, low duodenal $\mathrm{pH}$ can cause bile acid precipitation resulting in lipid malabsorption (30-32). H2-receptor antagonists and prostaglandine E2 have been used with the hope to reverse the above proces, but results on steatorrhea have been controversial (17-22). Insufficient inhibition of gastric acid production could be the cause of these failures As proton pump inhibitors are known to control acid secretion in a much more effective way (33), they could be more effective in increasing duodenal $\mathrm{pH}$. In agreement with Heijermans et al. (23), we found a significant improvement of fat malabsorption as measured by the acid steatocrit in all but 4 of our $\mathrm{CF}$ children on lansoprazole. Acid steatocrit results have been shown to correlate very significantly with chemically measured fecal fat (25). Acid steatocrit values did not improve in 4 of our patients. By doubling the lansoprazole dose in 2 of these patients, acid steatocrit values decreased slightly. Although we have no clear explanation for the lack of response of these patients, poor efficacy could hypothetically be due to host factors including poor intestinal lansoprazole absorption or interindividual differences in bioavailability of lansoprazole (34). Further, since the halflife of lansoprazole is between 1 and 2 hours and inhibition will be limited to proton pumps active during the effective plasma levels of the drugs, Sachs et al. suggested to give proton pump inhibitors twice a day whenever effective $\mathrm{pH}$ control is desired (33). However, studies hereover have yet to be done. Contrary to our expectations, acid steatocrit values increased in only 8 out of 14 patients one month after lansoprazole was stopped. We have no explanation for this apparent prolonged effect of lansoprazole on fecal fat since proton pump restoration has been reported to occur 50 to 72 hours after the inhibitor was interrupted (33). Further studies are necessary in order to clarify this point.

Because of the normal growth proces in children, Z-scores should be used for the evaluation of anthropometric parameters. Improving Z-scores reflect catch-up growth and consequently improvement in the nutritional status while the reverse is true for deteriorating Z-scores. The recent introduction of DXA methodology makes it possible to evaluate FM, LBM and BMC rapidly and non invasively in children (27). In agreement with previous studies, all except 2 
of our CF children showed significant decreases in weight, length, armeircumference and 4 skinfolds Z-scores before treatment with lansoprazole. FM, LBM and BMC were also significantly decreased despite pancreatic enzyme substitution and hypercaloric supplementation. The catabolic proces could be reversed after 3 months of lansoprazole resulting in Z-scores improvement of all anthropometric parameters, FM, BMC and to a lesser extent LBM. The improved nutritional condition could be due either to higher energy intakes or to improved absorption. As we found somewhat lower energy intakes during the lansoprazole treatment period, a higher intake probably is not responsible for the improved nutritional condition. Further, the fact that lower fecal acid steatocrit results were found in our patients with the best nutritional response as assessed by subscapular Z-score improvements, supports the idea that improved absorption is the main factor responsible for the improvement of the nutritional status in our patients. However increased FM, LBM and BMC are difficult to interpret because results for reference populations expressed as Z-scores have not yet been reported. As Zscore of BMD did not change on lansoprazole, the increased BMC found in our $\mathrm{CF}$ children, is probably linked to the growth proces. Our results showing deterioration of the nutritional condition after interruption of lansoprazole "intervention", are in agreement with those of Bertrand et al., who reported nutritional deterioration after stopping elemental enteral alimentation (14). Oral hypercaloric diets have not been shown to improve Z-scores of weight, length and skinfolds as parameters for nutritional status and growth proces of $\mathrm{CF}$ children (8). Only parenteral or elemental "predigested" enteral nutrition have been shown to reverse the catabolic process in these children (9-15). This indicates that persisting maldigestion or malabsorption is mainly responsible for malnutrition in CF. As alkalinization of duodenal pH improves malabsorption $(16,22)$, it could also, as elemental diets do, improve the nutritional status of CF children. This hypothesis is confirmed by the results of our study. In contrast with $O^{\prime}$ Loughlin (10), Shepherd (12) and Levy (13), who found significant improvement in LBM after 6 to 12 months of elemental diets, no significant increase in LBM was seen in our study. The 3 months of treatment in our study could be too short for a significant change in LBM to be noticed. Our results are in agreement with those of other authors, who evaluated the effect of gluten free diet on body compartments by DXA. Only FM and BMC improved after a 6 months gluten free diet while LBM did not (35). As H2 - receptor antagonists have been shown to significantly decrease nitrogen malabsorption in CF patients (36), we do not 
think that the poor improvement of LBM in our patients can be ascribed to a selective improvement of fat and not of protein malabsorption.

In conclusion, most of our CF children maintained steatorrhea and were malnourished despite optimal treatment with hypercaloric diets and pancreatic enzymes. Lansoprazole as adjuvant therapy resulted in decreased fat malabsorption and improved nutritional status in these $\mathrm{CF}$ children after 3 months of treatment. Longterm evaluation of the effect of lansoprazole on both the nutritional status and lung function parameters have yet to be performed.

\section{Acknowledgment}

we are gratefull to Liesbeth van der Ploeg, Lianne Schoorlemmer dieticians and Piet Willems, Sandra Zimny from the department of nuclear medicine for their invaluable assistance. We also thank all nurses of the pediatric polyclinic for their welwilling support. 


\section{REFERENCES}

(1) M. Welsh, A. Smith. Molecular mechanisms of CFTR chloride channel dysfunction in cystic fibrosis. Cell 1993; 73:1251-1254.

(2) J. Tomezsko, V. Stallings, D. Kawchak, J. Goin, G. Diamond, T. Scanlin. Energy expenditure and genotype of children with cystic fibrosis. Pediatr Res 1994; $35: 451$ - 460.

(3) M. Bronstein, P. Davies, K. Hambidge, F. Accurso. Normal energy expenditure in the infant with presymptomatic cystic fibrosis. J Pediatr 1995; 126: 28-33.

(4) R.Kraemer, A. Rüdeberg, B. Hadorn, E. Rossi. Relative underweight in cystic fibrosis and its prognostic value. Acta Paediatr Scand 1978; 67: 33-37.

(5) P. Robinson, P. Sly. High dose pancreatic enzymes in cystic fibrosis. Arch Dis Child. $1990 ; 65: 311-312$.

(6) E. Lebenthal. High strength pancreatic exocrine enzyme capsules associated with colonic strictures in patients with cystic fibrosis: "more is not necessarily better". J Pediatr Gastroenterol Nutr. 1994; 18: 423-425.

(7) R. Smyth, D. van Velzen, A. Smyth, D. Lloyd, D. Heaf. Strictures of ascending colon in cystic fibrosis and high strength pancreatic enzymes. The Lancet. 1994; 343: 85-86.

(8) A. Rettammel, M. Marcus, P. Farrell, S. Sondel, R. Koscik, E. Mischler. J Am Diet Assoc. 1995; 95: 454-459.

(9) K. Gaskin, D. Waters, L. Baur, V. Soutter, M. Gruca. Acta Paediatr Scand [Suppl]. 1990; 366: $106-110$.

(10) E. O' Loughlin, D. Forbes, H. Parsons, B. Scott, D. Cooper, G. Gall. Nutritional rehabilitation of malnourished patients with cystic fibrosis. Am J Clin Nutr. 1986: 43: 732-737.

(11) R. Shepherd, T. Holt, B. Thomas et al. Nutritional rehabilitation in cystic fibrosis: Controlled studies of effects on nutritional growth retardation, body protein turnover, and course of pulmonary desease. J Pediatr. 1986; 109: 788-94.

(12) R. Shepherd, B. Thomas, D. Bennett, W. Cooksley, L. Ward. Changes in body composition and muscle protein degradation during nutritional supplementation in nutritionally growth-retarded children with cystic fibrosis. J Pediatr Gastroenterol Nutr. 1983; $2: 439-446$.

(13) L. Levy, P. Durie, P. Pencharz, M. Corey. Effects of long-term nutritional rehabilitation on body composition and clinical status in malnourished children and adolescents with cystic 
fibrosis. J Pediatr 1985; 107: 225-230.

(14) J. Bertrand, C. Morin, R. Lasalle, J. Patrick, A. Coates. Short-term clinical, nutritional, and functional effects of continuous elemental enteral alimentation in children with cystic fibrosis. J Pediatr. 1984; 104: 41-46.

(15) R. Shepherd, W. Cooksley, and W. Domville. Improved growth and clinical, nutritional, and respiratory changes in response to nutritional therapy in cystic fibrosis. J Pediatr. 1980; 97: 351-357.

(16) P. Robinson, A. Smith, and P. Sly. Duodenal pH in Cystic fibrosis and its relationship to fat malabsorption. Dig Dis Sci. 1990; 35: 1299-1304.

(17) A. Carroccio, F. Pardo, G. Montalto et al. Use of famotidine in severe exocrine pancreatic insufficiency with persistent maldigestion on enzymatic replacement therapy: A long-term study in cystic fibrosis. Dig Dis Sci 1992; 37: 1441-1446.

(18) D. Chalmers, R. Brown, M. Miller et al. The influence of longterm cimetidine as an adjuvant to pancreatic enzyme therapy in cystic fibrosis. Acta Paediatr Scand. 1985; 74: 114 117.

(19) P. Robinson and P. Sly. Placebo-controlled trial of misoprostol in cystic fibrosis. J Pediatr Gastroenterol Nutr. 1990; 11:37-40.

(20) H. Heijerman, C. Lamers, J. Dijkman, and W. Bakker. Ranitidine compared with the dimethylprostaglandin E2 analogue enprostil as adjunct to pancreatic enzyme replacement in adult cystic fibrosis. Scand J Gastroenterol. 1990; 25 (Suppl 178): 26-31.

(21) M. Schöni, R. Kraemer, E. Rossi. Cimetidine and fat malabsorption in children with cystic fibrosis. Helv Paediat Acta. 1981; 36: 359-369.

(22) B. Boyle, W. Long, W. Balistreri, S. Widzer, and N. Huang. Effect of cimetidine and pancreatic enzymes on serum and fecal bile acids and fat absorption in cystic fibrosis. Gastroenterology. 1980; 78: 950-953.

(23) H. Heijerman, C. Lamers, W. Bakker. Omeprazole enhances the efficacy of pancreatin (pancrease) in cystic fibrosis. Ann İntern Med. 1991; 114: 200-201.

(24) J. van de Kamer, H. Huinink, H. Weyers. Rapid method for determination of fat in feces. J Biol Chem. 1949; 177: 349-55.

(25) M. Tran, P. Forget, A. Van den Neucker, J. Strik, B. van Kreel, and R. Kuijten. The acid steatocrit: A much improved method. J Pediatr Gastroenterol Nutr. 1994; 19: 299-303. 
(26) W. Gerver, R. de Bruin. Paediatric Morphometrics: A reference manual. 1th ed. Utrecht: Bunge, 1995.

(27) R. Mazess, H. Barden, J. Bisek, and J. Hanson. Dual-energy x-ray absorptiometry for total-body and regional bone-mineral and soft-tissue composition. Am J Clin Nutr. 1990; 51:1106-12.

(28) G. Ogle, J. Allen, I. Humphries et al. Body-composition assessment by dual-energy x-ray absorptiometry in subjects aged 4-26 y. Am J Clin Nutr. 1995; 61:746-53.

(29) A. Weber, C. Roy. Intraduodenal events in cystic fibrosis. J Pediatr Gastroenterol Nutr. 1984; 3 (Suppl. 1): S113-S119.

(30) P. Regan, J. Malagelada, E. Dimagno, and V. Go. Reduced intraluminal bile acid concentrations and fat maldigestion in pancreatic insufficiency: Correction by treatment. Gastroenterology. 1979; 77: 285-289.

(31) P. Zentler-Munro, W. Fitzpatrick, J. Batten, and T. Northfield. Effect of intrajejunal acidity on aqueous phase bile acid and lipid concentrations in pancreatic steatorrhoea due to cystic fibrosis. Gut. 1984; 25: 500-507.

(32) P. Zentler-Munro, D. Fine, J. Batten, and T. Northfield. Effect of cimetidine on enzyme inactivation, bile acid precipitation, and lipid solubilisation in pancreatic steatorrhoea due to cystic fibrosis. Gut. 1985; 26: 892-901.

(33) G. Sachs, J. Shin, C. Briving, B. Wallmark, S. Hersey. The pharmacology of the gastric acid pump: The H+, K+ ATPase. Annu Rev Pharmacol Toxicol. 1995; 35: 277-305.

(34) C. Spencer and D. Faulds. Drugs: Focus on Lansoprazole. 1994; 48: 404-430.

(35) G. Barera, P. Brambilla, P. Manzoni, S. Acciuffi, G. Caccia, C. Bianchi. Changes in body composition evaluated by DXA during gluten free diet in celiac children. J Pediatr Gastroenterol Nutr. 1995; 20: 476 "abstr".

(36) K. Cox, J. Isenberg, A. Osher, R. Dooley. The effect of cimetidine on maldigestion in cystic fibrosis. J. Pediatr. 1979; 94: 488-492. 


\title{
CHAPTER 7
}

\section{ANTHROPOMETRY AND BODY COMPOSITION IN CHILDREN WITH CYSTIC FIBROSIS: EFFECTS OF A PROTON - PUMP INHIBITOR}

\author{
(1)My-Dung T.Tran, (1)Anita Van den Neucker, (1)Han J. Hendriks, (")Bernard van Kreel, \\ (1)Patricia Forget, ${ }^{\sigma}$ Guido Heidendal, (1)Pierre-Philippe Forget
}

(1)Department of Pediatrics, (") Clinical Chemistry and ${ }^{\sigma}$ Nuclear Medicine, University Hospital Maastricht, Maastricht, the Netherlands.

Submitted for publication

\section{Abstract}

We studied the body composition of $18 \mathrm{CF}$ children making use of dual-energy X-ray absorptiometry (DEXA), deuterium-bromide and skinfold methods and evaluated the efficacy of these body composition methods for the detection of body composition changes during 3 months therapeutic intervention with lansoprazole. Our $\mathrm{CF}$ patients were malnourished with decreased mean Z-scores for armcircumference $(-1.62)$, biceps $(-0.77)$, subscapular $(-0.92)$, suprailiac skinfolds $(-1.66)$, weight $(-1.03)$ and height $(-1.31)$.Their fatmass was significanly depleted as shown by DEXA, skinfold and total body water (TBW) methods. Extracellular volume (\%) was increased, while intracellular volume (\%) was normal. Only the lean body mass (LBM) as measured by DEXA was decreased $(p=0.02)$. Decreased bone mineral content and bone mineral density $Z$-scores were also found $(p=0.005$ and $p=0.03$ respectively). After treatment with lansoprazole, significant increases in fatmass was found by DEXA and skinfold methods ( $53 \%$ and $97 \%$ of weight changes respectively) whereas weight increase was exelusively ascribed to an increase in LBM with the TBW method. Changes in body. weight however, were not correlated with either fatmass and fat free mass changes as measured by any of these methods. We conclude that results of DEXA, TBW and skinfold methods are not interchangeable and that the methods used are not accurate enough for the differential detection of small changes in fatmass and fat free mass as found in the present study. 


\section{INTRODUCTION}

Due to malabsorption (1), chronic lung infections with increased energy expenditure $(2,3)$ and poor appetite, most cystic fibrosis patients show signs of malnutrition. As malnutrition can affect pulmonary function and shorten survival (4), feeding interventions are sometimes necessary to restore normal growth and body composition. Assessment of body composition changes is necessary for the precise evaluation of nutritional interventions. While different body composition methods have been described, only few studies have, to our knowledge, compared different measurement techniques in pediatric subjects and there are no reports on the efficacy of these methods for the detection of body composition changes during therapeutic interventions. In children, Dual-energy X-ray absorptiometry (DEXA), Total Body Water (TBW) and Skinfold methods are frequently used for the determination of body composition since they are all noninvasive. In this age group, methods used for measuring body composition have to be very precise in order to detect small changes in body composition. The precision for repeated measurements has been reported to be $1-2 \%$ for DEXA, $1.6 \%$ for TBW and either $5 \%$ (intraobserver) or $15 \%$ (interobserver) for the skinfold method (5). In the present study we first evaluated the body composition of our $18 \mathrm{CF}$ children making use of DEXA, skinfolds and TBW (deuterium-bromide)methods and subsequently evaluated the agreement between these results. Secondly, we investigated the sensitivity of these 3 methods for the detection of small changes in body composition of $15 \mathrm{CF}$ children whose nutritional condition improved significantly after intervention with lansoprazole for 3 months. For the purpose of the present study we defined fat free mass by DEXA (FFM-DEXA) as the sum of lean body mass (LBM) and bone mineral content (BMC) and total mass (TM) as DEXA constructed weight $(\mathrm{LBM}+\mathrm{FM}+\mathrm{BMC})$.

\section{SUBJECTS}

\section{Ropulation studied for the comparison of bodv composition methods}

$23 \mathrm{CF}$ children were recruited from the Academic Hospital Maastricht. The Netherlands. Of these 2 patients were too ill to take part in the study and 3 children refused to participate. 18 
children who had no exacerbation 4 weeks before the study were included. Thirteen of them were prepubertal and younger than ten years, 3 children were postpubertal and were between 11.6 - 14.1 years. Two subjects were adolescents of 16.1 and 22.6 years. Fourteen of these 18 children were diagnosed during the first year of life while 16 of them had pancreatic insuffi. ciency (abnormal fecal chymotrypsin and $72 \mathrm{~h}$ fecal fat balance). Their nutritional status was moderate with a mean BMI (body mass index) of 15.6 (range: 13.2 - 23.2). Mean age, weight and height were respectively 9.0 y (range: $2.9-22.6 \mathrm{y}$ ); $27.4 \mathrm{~kg}$ (range: $13.6-67.6 \mathrm{~kg}$ ) and $127.5 \mathrm{~cm}$ (range: 96.2 - $184.9 \mathrm{~cm}$ ). Mean FEV1 (forced expiratory volume in 1 second) and FVC (forced vital capicity) were respectively $84 \%$ (range: $39-117 \%$ ) and $86 \%$ (range: 44 . $109 \%$ ) of predicted values. Mean energy intake was $113 \%$ RDA (recommended daily allowance). All patients were on conventional physiotherapy, pancreatic enzymes and some of them received antibiotics regularly for pulmonary exacerbations.

Weight, height, armcircumferences, TBW, DEXA and skinfolds were measured on the same day. All usual CF medications were continued during the study.

\section{Population studied for the evaluation of changes in body composition}

We included 15 out of 16 children with pancreatic insufficiency as described above who maintained steatorrhea despite pancreatic enzymes and were treated with lansoprazole for 3 months with significant improvement of anthropometric parameters (results will be published separately). Mean age, weight and height of these 15 children were $9.5 \mathrm{y}$ (range: $3.1-22.6 \mathrm{y}$ ); $29.3 \mathrm{~kg}$ (range: $13.6-67.6 \mathrm{~kg}$ ) and $131 \mathrm{~cm}$ (range: $97.7-184.9 \mathrm{~cm}$ ) respectively. Their nutritional status was moderately altered with a mean Body Mass Index (BMI) of 15,6 (range : 13.2 - 18.3). Mean FEV1 and FVC were respectively $81.3 \%$ (range: $39-114 \%$ ) and $85.5 \%$ (range: $44-108 \%$ ) of predicted values.

Anthropometry, DEXA and TBW were measured on the same day just before starting and 3 months after treatment with lansoprazole ( $15 \mathrm{mg} /$ day). Other usual CF medications were continued throughout the study. Informed patient and parental consent were obtained from all study subjects. 


\section{METHODS}

\section{Growth parameters}

Weight, height, upper armcircumferences and 4 skinfold thicknesses (biceps, triceps, subscapular and suprailiac) were measured on the left side of the body in triplicate, using the Harpenden caliper. Average of three measures was taken and was expressed as standard deviation scores of the normal population for age and sex using the growth charts from Gerver and de Bruin (6). BMI was calculated as weight/height ${ }^{2}$. Results of BMI were compared to the reference population described by Westrate and Deurenberg et al. (7). Mid upper arm muscle area was calculated from the mid upper armcircumference and the sum of biceps and triceps skinfolds (6).

\section{Body composition}

Body composition results obtained from all three methods were compared to those of a recently reported pediatric reference population (8). The percentage of fatmass and fat free mass measured by the skinfold method were also compared to those of the reference population described by Gerver and de Bruin (6).

\section{Body composition by anthropometry}

It has been found that subcutaneous fat as measured by skinfolds is related to the body density (9). This latter is itself related to the body fatmass. From these theoretical principles, Gerver and de Bruin have constructed a chart, expressing the relationship between the 4 skinfolds (biceps, triceps, subscapular and suprailiac) and the percent fat free mass (6). In our study, fat free mass determined by this method was derived from these charts and fatmass was then calculated by subtracting FFM from bodyweight.

\section{Bedycomposition by dual-energy x-ray ahsorptiometry}


The theoretical principles for DEXA measurement of body composition and the precision of this method have been described previously (10-12). All DEXA measurements were performed with a Dual Photon X-ray ( Lunar Radiation Corp, Madison, WI ) total body scanner. These results were analysed with a pediatric software programme, version $1.5 \mathrm{e}$. Daily quality assurance tests were performed according to the manufacturer 's directions. Total body analysis was performed in all children using a fast scan mode with a sample size of $4.8 \times 9.6 \mathrm{~mm}$, sample interval of $0.03 \mathrm{~s}$ and source collimation of $1.68 \mathrm{~mm}$. The following body compartments were assessed: total non bone lean body mass, total bone mineral content, total bone mineral density (BMD), total body fatmass and Z-score of BMD.

\section{Body composition by total body water and bromide space}

TBW and ECV were measured by deuterium oxide (13) and bromide dilution respectively (14). Each subject received orally $20 \mathrm{ml}(40 \mathrm{ml}$ was given to the 2 adolescent patients) of a mixture of $\mathrm{D}_{2} \mathrm{O}(99.9 \%$ purity) and Bromide salt $(150 \mathrm{mMol} / \mathrm{L})$ solution in a volume ratio of 1:1. Saliva and plasma samples were taken before intake of $\mathrm{D}_{2} \mathrm{O}-\mathrm{NaBr}$ solution and 4 hours thereafter when an "plateau" has been reached. To prevent saliva dilution by fluid intake which can result in a higher TBW content, patients were told not to take any fluid orally half an hour before saliva samples were taken. Urine and fecal loss of bromide and $\mathrm{D}_{2} \mathrm{O}$ during the equilibriation period were considered negligible as the $\mathrm{D}_{2} \mathrm{O}$ and bromide $\mathrm{Tl} / 2$ are about 8 days (14). Saliva samples were obtained making use of dental cotton-wool, that was dried overnight at $100^{\circ} \mathrm{C}$ and kept in a gas-tight tube until use. The cotton-wools and the blood samples were centrifuged and the saliva and serum thus obtained were kept in a stoppered glass vial and stored in a freezer at $-20^{\circ} \mathrm{C}$ until analysis. Results of TBW, ECV and ICV were compared to the reference values described by Friis-Hansen (15).

\section{TBW ANALYSIS}

$\mathrm{D}_{2} \mathrm{O}$ concentrations of saliva samples were determined as described by van Kreel (14): Calcium carbide $\left(\mathrm{CaC}_{2}\right)$ was placed in the siliconized vacutainer tube and evacuated for $30 \mathrm{sec}$. with a rotatory vane pump to a total pressure of $0,01 \mathrm{~atm}$. Thereafter, $25 \mu \mathrm{l}$ of salivary sample 
was injected in the vacutainer tube. This was done in duplicate. $\mathrm{CaC}_{2}$ react with $\mathrm{D}_{2} \mathrm{O}$ forming acetylene gas. A $25 \mu \mathrm{l}$ sample of this gas was subsequently injected in duplicate into the GC/CF - IRMS system (gas chromatography/continous flow isotope ratio mass spectrometry) at $2 \mathrm{~min}$. intervals. The mass 27/26 ratio (R27/26) was measured on a Isotope Ratio Mass Spectrometer configured for Acetylene (Finnigan MAT 252 for CF-IRMS). The mean value of 4 determinations was calculated for each sample. By inserting the tracer/tracee ratio, defined as R27/26 (T4) - R27/26 (T0), into the regression equation obtained from the standards, we get the dilution factor of $\mathrm{D}_{2} \mathrm{O}$. TBW is calculated as ingested $\mathrm{D} O \mathrm{O}$ volume/dilution factor. FFM and FM are then calculated by the following formules:

$$
\begin{aligned}
& \mathrm{FFM}(\mathrm{kg})=\mathrm{TBW} /(1,04 \mathrm{xd}) \\
& \mathrm{FM}(\mathrm{kg})=\text { Weight }- \text { FFM }
\end{aligned}
$$

The 1,04 factor is a correction for the estimated $4 \%$ nonaqueous hydrogen exchange and $\mathrm{d}$ is the hydration factor of LBM which varies with age and sex. Because our CF population was young, we used the age dependent hydration factors described by Fomon (16) for children younger than 10 year and by Boileau and Lohman (17) for older children.

\section{BROMIDE DILUTION ANALYSIS}

Because bromide resides mainly in the extracellular space, the measurement of bromide dilution gives an estimate of the extracellular volume. Bromide was determined by using a Gas Chromatograph type CP 9000 (Chrompack) equipped with an ECD detector after it was converted into bromoacetone gas (14). First, perchloric acid was added to the serum sample and centrifuged for deproteinisation. An aliquot of the supernatant was then added to silver nitrate $\left(\mathrm{AgNO}_{3}\right)$ for precipitation of silver bromide and chloride. After centrifugation, the precipitate was taken up in $\mathrm{NH}_{3}$ after adding $\mathrm{Na}_{2} \mathrm{~S}$ and $\mathrm{NaOH}$ in order to eliminate the silver. After agitation and centrifugation, the supernatant was heated until dry. $\mathrm{H}_{2} \mathrm{O}$ was added followed by $\mathrm{H}_{2} \mathrm{O}_{2}$ in order to oxidize sulfide. After drying, ${ }_{2} \mathrm{H} \mathrm{O}$ was then added and dried again. This was repeated several times. Thereafter, perchloric acid and acetone were added and the reaction was started by addition of $\mathrm{KmnO} 4$ with Bromoacetone formed. The solution 
is then extracted with benzene. The organic phase was separated from the water phase by shaking and centrifugation. The water phase was then removed. An aliquot of the organic solution is then applied to the gas chromatograph for measuring of the bromoacetone/internal standard ratio. The bromide concentration was then derived from the bromoaceton standard curves. Because the distribution of bromide depends on the potential difference between the in- and extra-cellular compartments and on the total body volume, the corrected bromide space was calculated as follows:

$$
\mathrm{ECV}(\mathrm{L})=\frac{\text { Bromide administered (mmol) }}{\text { Bromide change T4 }-\mathrm{T} 0(\mathrm{mmol} / \mathrm{L})}-0.036 \mathrm{TBW}
$$

Where $0.036 \mathrm{TBW}$ is the correction factor for the cell potential and for the total body volume (14). Body cell mass (BCM) was then calculated by subtracting ECV from TBW.

\section{Statistics}

All data were analysed with SPSS statistic program version 6.0. The sign test was used to compare the growth parameters and body composition results with those of the reference population. The Pearson correlation coefficient was used to determine the relationship between measurements obtained by the various body composition methods. Partial correlation coefficients, controlling for age, were used for the evaluation of the relationships between measured ICV, ECV, mid-upper-arm muscle area and the various body composition results. The between method differences were compared, using the Wilcoxon rank test. The agreement between methods were evaluated by the Statistical method of Bland and Altman (18). 


\section{RESULTS}

\section{Body composition of 18 cf children}

Mean age, nutritional parameters expressed as standard deviation scores (Z-scores) and results of body composition measured by skinfold, DEXA and TBW from 18 CF children are shown in table 1. Compared to the reference population, mean Z-scores for weight, height, BMI, armcircumference and skinfolds (except for the triceps) were significantly decreased (fig 1). The mid-upper-arm muscle area was significantly decreased in our CF population $(p=0.005)$. In absolute terms, all body composition components measured by DEXA such as FM, LBM, BMC and BMD Z-scores were significantly decreased $(p=0.01 ; p=0.02 ; p=0.005$ and $p=$ 0.03 respectively) compared to the control population described by Oggle ( 8 ). When compared to the normal DEXA body composition data reported by Oggle (8), results obtained with either the TBW or the skinfold methods showed only fat mass to be significantly decreased in our patients ( $p=0.03$ and $p=0.05$ respectively). In relative terms, FM-DEXA (compared to normal DEXA data reported by Oggle) and FM-skinfolds (compared to normal skinfolds data reported by Gerver) were also significantly decreased. The BMI was correlated with both FM and FFM measured by all three methods (FM-DEXA $r=0.90$; FM-skinfold $r=0.87$; FMTBW $_{\mathrm{r}}=0.75 ;$ FFM-DEXA $\mathrm{r}=0.79 ;$ FFM-skinfold $\mathrm{r}=0.81$; FFM-TBW $\mathrm{r}=0.8$ with $\mathrm{p}=$ 0.001 for all correlations). As expected strong correlations were found between age on the one hand and FM-DEXA $(r=0.67 p=0.003)$, FFM-DEXA $(r=0.95 p=0.001)$, FM-skinfolds $(r$ $=0.59 p=0.01)$, FFM-skinfolds $(r=0.95 p=0.001)$, FM-TBW $(r=0.47 p=0.047)$, FFMTBW $(r=0.94 p=0.001)$ and BMC-DEXA $(r=0.94 p=0.001)$. No sex differences in body composition data were found. When compared to the reference values described by FrisHansen (15), the ECV and TBW as a percentage of bodyweight were significantly increased ( $p<0.005$ both) while the ICV as percent of bodyweight was normal. The partial correlations (controlling for age) between ECV, ICV, the mid-upper-arm muscle area LBM and FM are shown in table 2. 
Table 1 Characteristics of 18 CF children.

\begin{tabular}{|c|c|c|c|}
\hline & MEAN & SEM & RANGE \\
\hline AGE $\left(Y_{r}\right)$ & 8.97 & 1.16 & $2.9-22.6$ \\
\hline $\mathrm{BW}(\mathrm{Kg})$ & 27.43 & 3.66 & $13.6-67.6$ \\
\hline BW (SDS) & -1.03 & 0.25 & $-2.33-1.36$ \\
\hline$T M(K g)$ & 27.82 & 3.84 & $12.96-67.33$ \\
\hline HEIGHT $(\mathrm{cm})$ & 128 & 6.0 & $96.2-184.9$ \\
\hline HEIGHT (SDS) & -1.31 & 0.25 & $-2.89-0.40$ \\
\hline $\operatorname{BMI}\left(\mathrm{K}_{\mathrm{g}} / \mathrm{m}^{2}\right)$ & 15.6 & 0.57 & $13.21-23.17$ \\
\hline ARMCIRCUMFER (SDS) & -1.62 & 0.31 & $-3.14-1.43$ \\
\hline BICEPS (SDS) & -0.77 & 0.23 & $-1.86-1.33$ \\
\hline TRICEPS (SDS) & -0.33 & 0.23 & $-2-2.33$ \\
\hline SUBSCAPULAR (SDS) & -0.92 & 0.23 & $-2-1.6$ \\
\hline SUPRAILIACA (SDS) & -1.66 & 0.09 & $2.43--0.57$ \\
\hline SUM 4 SKINFOLDS (SDS) & -1.17 & 0.20 & $-2.2-1.2$ \\
\hline FM-DXA (\%) & 12.11 & 1.48 & $6.1-28.8$ \\
\hline FM-TBW (\%) & 10.39 & 1.61 & $0.0-22.2$ \\
\hline FM-SKINFOLD (\%) & 14.44 & 0.94 & $8-23$ \\
\hline FFM-DXA (\%) & 87.9 & 1.5 & $71.2-93.9$ \\
\hline FFM-TBW $(\%)$ & 89.8 & 1.6 & $77.8-101$ \\
\hline FFM-SKINFOLD $(\%)$ & 85.6 & 0.9 & $77-92$ \\
\hline BMC-DXA (Kg) & 1.02 & 0.17 & $0.37-2.68$ \\
\hline TBW (L) & 19.06 & 2.38 & $9.9-47.4$ \\
\hline TBW (\%) & 70.82 & 1.32 & $59.62-79.70$ \\
\hline ICV (L) & 10.96 & 1.78 & $3.71-31.93$ \\
\hline $\operatorname{ICV}(\%)$ & 38.41 & 1.42 & $27.28-51.01$ \\
\hline $\operatorname{ECV}(\mathrm{L})$ & 8.10 & 0.65 & $4.45-15.47$ \\
\hline $\operatorname{ECV}(\%)$ & 32.44 & 1.75 & $19.01-47.69$ \\
\hline
\end{tabular}

BW: Body weight

TM: DEXA constructed weight

BMl: Body mass index
FM: Fat mass

FFM: Fat free mass

BMC: Bone mineral content
TBW: Total body water

ECV: Extracellular volume

ICV: Intracellular volume 


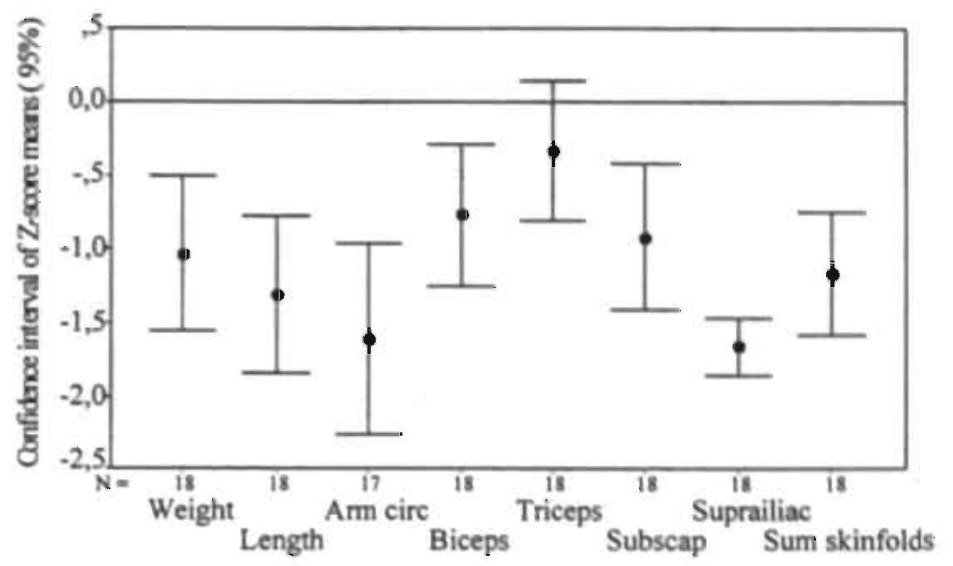

Figure 1 Confidence interval of Z-score means for various anthropometric parameters in cystic fibrosis children showing significantly lower values for all parameters except for the triceps skinfold.

Table 2 Correlation coefficients between muscle area, ECV, ICV and body composition results

\begin{tabular}{cccc}
\hline \hline & MUSCLE AREA $\left(\mathrm{cm}^{2}\right)$ & ECV $(\mathrm{L})$ & ICV (L) \\
\hline \hline LBM-DEXA (Kg) & $0.84(\mathrm{p}=0.001)$ & $0.67(\mathrm{p}=0.004)$ & $0.91(\mathrm{p}=0.001)$ \\
LBM-SKINF (Kg) & $0.90(\mathrm{p}=0.001)$ & $0.58(\mathrm{p}=0.02)$ & $0.92(\mathrm{p}=0.001)$ \\
LBM-TBW (Kg) & $0.86(\mathrm{p}=0.001)$ & $0.63(\mathrm{p}=0.007)$ & $0.95(\mathrm{p}=0.001)$ \\
FM-DEXA (Kg) & $0.62(\mathrm{p}=0.02)$ & $0.15(\mathrm{p}=0.58)$ & $0.53(\mathrm{p}=0.04)$ \\
FM-SKINF (Kg) & $0.61(\mathrm{p}=0.02)$ & $0.23(\mathrm{p}=0.38)$ & $0.53(\mathrm{p}=0.03)$ \\
FM-TBW (Kg) & $0.33(\mathrm{p}=0.21)$ & $-0.004(\mathrm{p}=0.99)$ & $0.20(\mathrm{p}=0.43)$ \\
ECV (L) & $0.45(\mathrm{p}=0.08)$ & & \\
ICV (L) & $0.86(\mathrm{p}=0.001)$ & & \\
\hline \hline
\end{tabular}

LBM-DEXA: Lean body mass by DEXA method LBM-SKINF: Lean body mass by skinfolds method LBM-TBW: Lean body mass by TBW method ECV: Extracellular volume
FM-DEXA: Fatmass by DEXA

FM-SKNNF: Famass by skinfolds method

FM-TBW: Famass by TBW method

ICV: Intracellular volume 
Table 3 Changes in bodyweight and body composition after 3 months on lansoprazole in 15 CF children.

\begin{tabular}{cccc}
\hline \hline & \multicolumn{3}{c}{ T3 - T0 } \\
\cline { 2 - 4 } & MEAN \pm SEM & MINIMUM & MAXIMUM \\
\hline BW (Kg) & $0.97 \pm 0.13$ & 0.4 & 2.1 \\
TM (Kg) & $0.97 \pm 0.15$ & -0.05 & 1.9 \\
FM-DXA (Kg) & $0.52 \pm 0.19$ & -0.46 & 2.18 \\
FM-TBW (Kg) & $-0.23 \pm 0.52$ & -4.85 & 3.44 \\
FM-SKINFOLD (Kg) & $0.94 \pm 0.26$ & 0.05 & 3.52 \\
LBM-DXA (Kg) & $0.43 \pm 0.18$ & -0.96 & 1.46 \\
BMC-DXA (Kg) & $0.03 \pm 0.01$ & -0.03 & 0.09 \\
FFM-DXA (Kg) & $0.41 \pm 0.17$ & -0.98 & 1.03 \\
FFM-TBW (Kg) & $1.27 \pm 0.49$ & -1.84 & 5.35 \\
FFM-SKINFOLD (Kg) & $0.04 \pm 0.26$ & -3.02 & 0.98 \\
TBW (L) & $0.99 \pm 0.39$ & -1.4 & 4.1 \\
ICV (L) & $0.09 \pm 0.41$ & -3.49 & 3.17 \\
ECV (L) & $0.92 \pm 0.46$ & -2.38 & 4.91 \\
\hline \hline
\end{tabular}

T0: Before start lansoprazole

T3: 3 months after lansoprazole

TM: Total mass (DEXA)

BW: Body weight
FFM: Fat free mass

FM: Fatmass

BMC: Bone mineral content

LBM: Lean body mass
TBW: Total body water

ECV: Extracellular water

ICV: Intracellular water 


\section{Limits of agreement between methods}

As only 5 of our patients 3 girls and 2 boys were postpubertal, all results of both boys and girls were analysed together. There was a high correlation between the 3 body composition methods for measuring of FM and FFM (fig 2 and 3). The best correlation for FM determination was between DEXA and the skinfold method $(r=0.98)$. As DEXA is a 3 compartments model, BMC was not included in the lean body mass. After correction for BMC, the correlation coefficient was unchanged. Plots of the paired differences for FM and FFM measured in kilogram versus their mean, with indication of the limits of agreement are shown in figure 4 and figure 5 respectively. Since our population was small, we preferred to use the 10th and 90th centile values instead of $\pm 2 \mathrm{SD}$ for defining the limits of agreement. No intermethod correlations were found between means and differences as shown in figures 4 and 5 . The 50th centile of the differences between FM-TBW versus FM-skinfolds was $-1.68 \mathrm{~kg}(-2.64$ - . $0.46 \mathrm{~kg})$; FM-skinfolds versus FM-DEXA was $0.75 \mathrm{~kg}(-3.01-1.21 \mathrm{~kg})$; FM-TBW versus FMDEXA was $-0,96 \mathrm{~kg}(-5.05--0.03 \mathrm{~kg})$. The 50 th centile of the differences between FFM-TBW versus FFM-DEXA was $0.45 \mathrm{~kg}(-0.70-4.85 \mathrm{~kg})$; FFM-skinfolds versus FFM-DEXA was $0.17 \mathrm{~kg}(-0.77-3.46)$; FFM-TBW versus FFM-skinfolds was $1.68 \mathrm{~kg}(0.46-2.96 \mathrm{~kg})$. The DEXA constructed weight was highly correlated with scale weight $(r=0.999 p=0.001)$. However, the DEXA weight was significantly lower than scale weight $(p=0.003)$; the 50th centile of the differences between bodyweight constructed from DEXA (TM) and scale weight was $-0.52 \mathrm{~kg}(-0.79-0.12)$. Significant differences were found between the means of FFM measured by the TBW and the skinfold methods $(p=0.02)$, the skinfolds and DEXA methods $(p=0.001)$ as well as the TBW and DEXA methods $(p=0.001)$. Only FM results from TBW and skinfolds were significantly different $(p=0.01)$. 


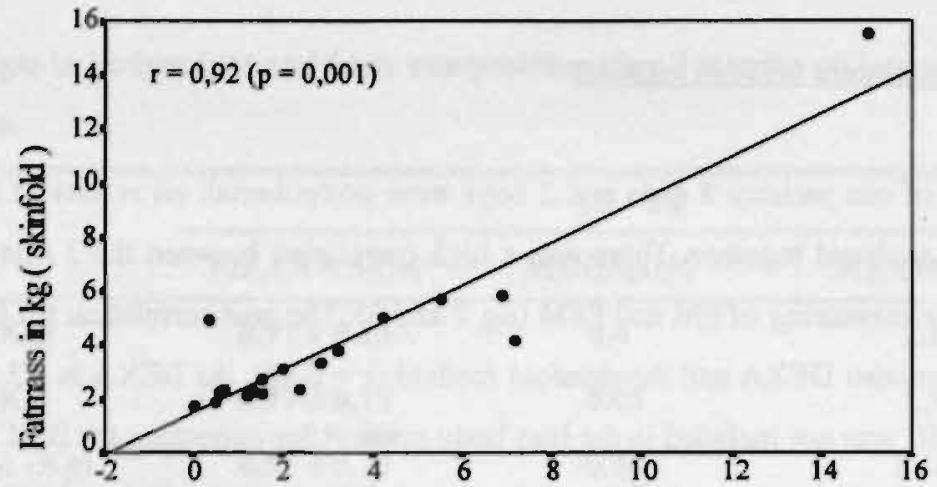

Fatmass in $\mathrm{kg}$ (TBW)

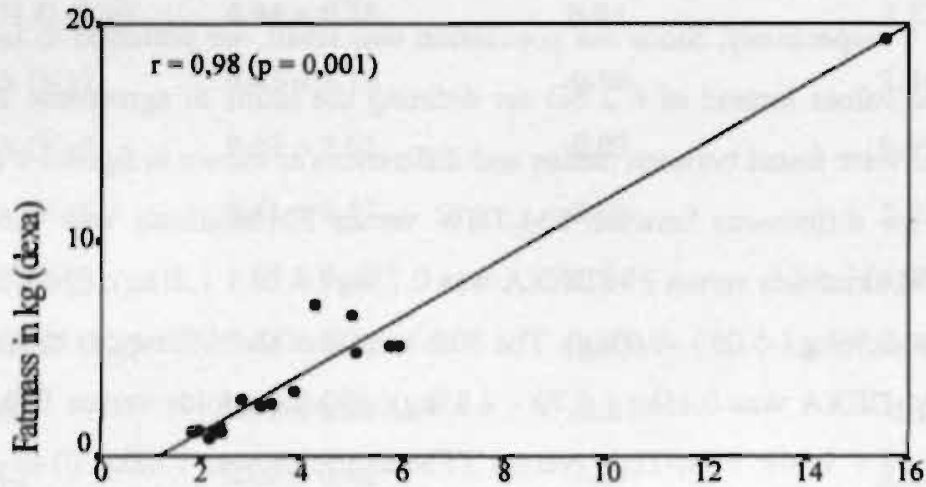

Fatmass in $\mathrm{kg}$ (skinfold)

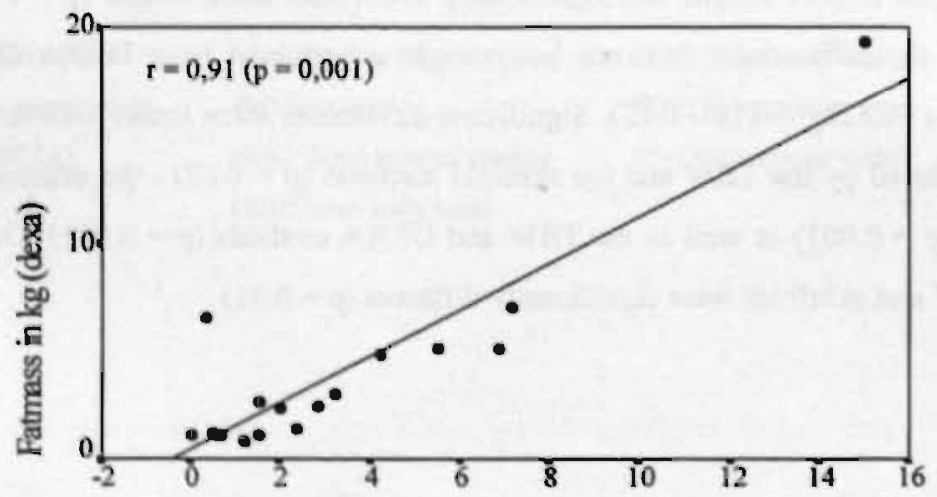

Fatmass in $\mathrm{kg}$ (TBW)

Figure 2 Intermethod fatmasses correlation coefficients. 

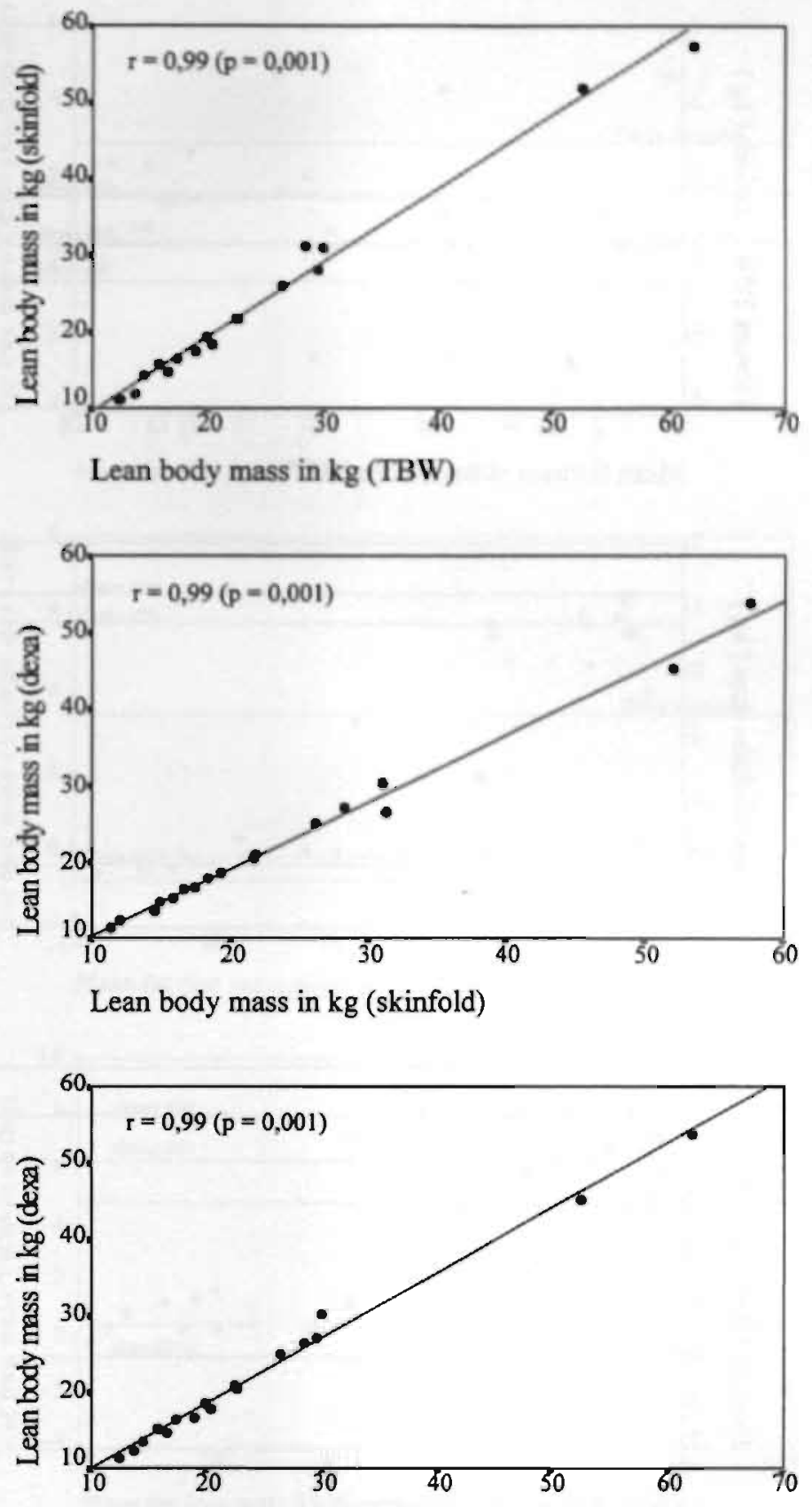

Lean body mass in $\mathrm{kg}$ (TBW)

Figure 3 Intermethod lean body mass correlation coefficients. 


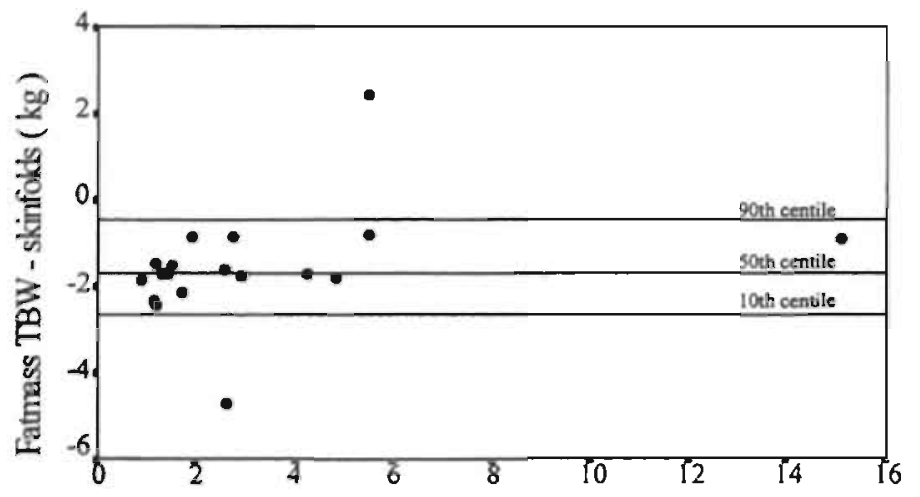

Mean fatmass skinfolds and TBW

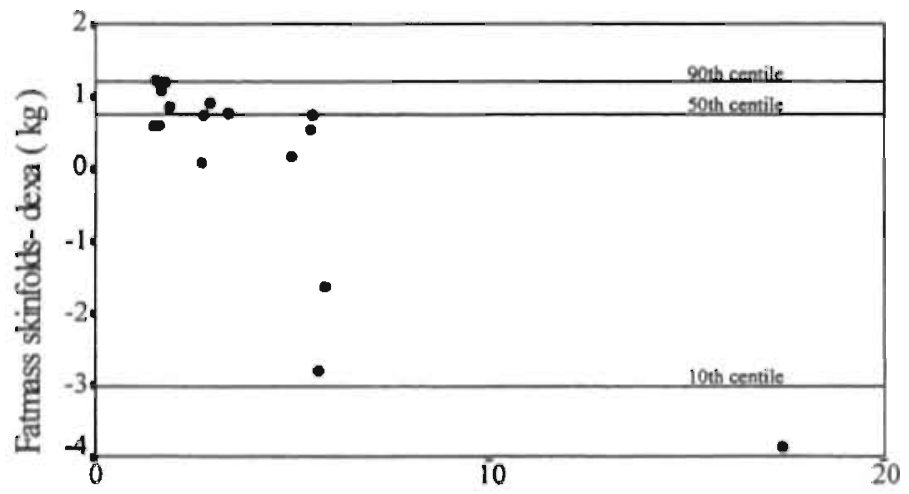

Mean fatmass skinfolds and dexa

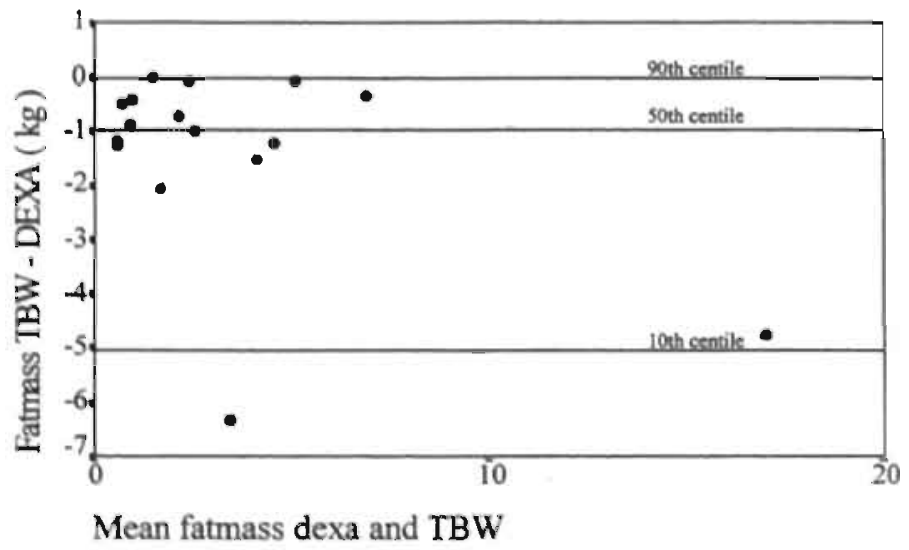

Figure 4 Limits of agreement for fatmass measured by the various methods. 

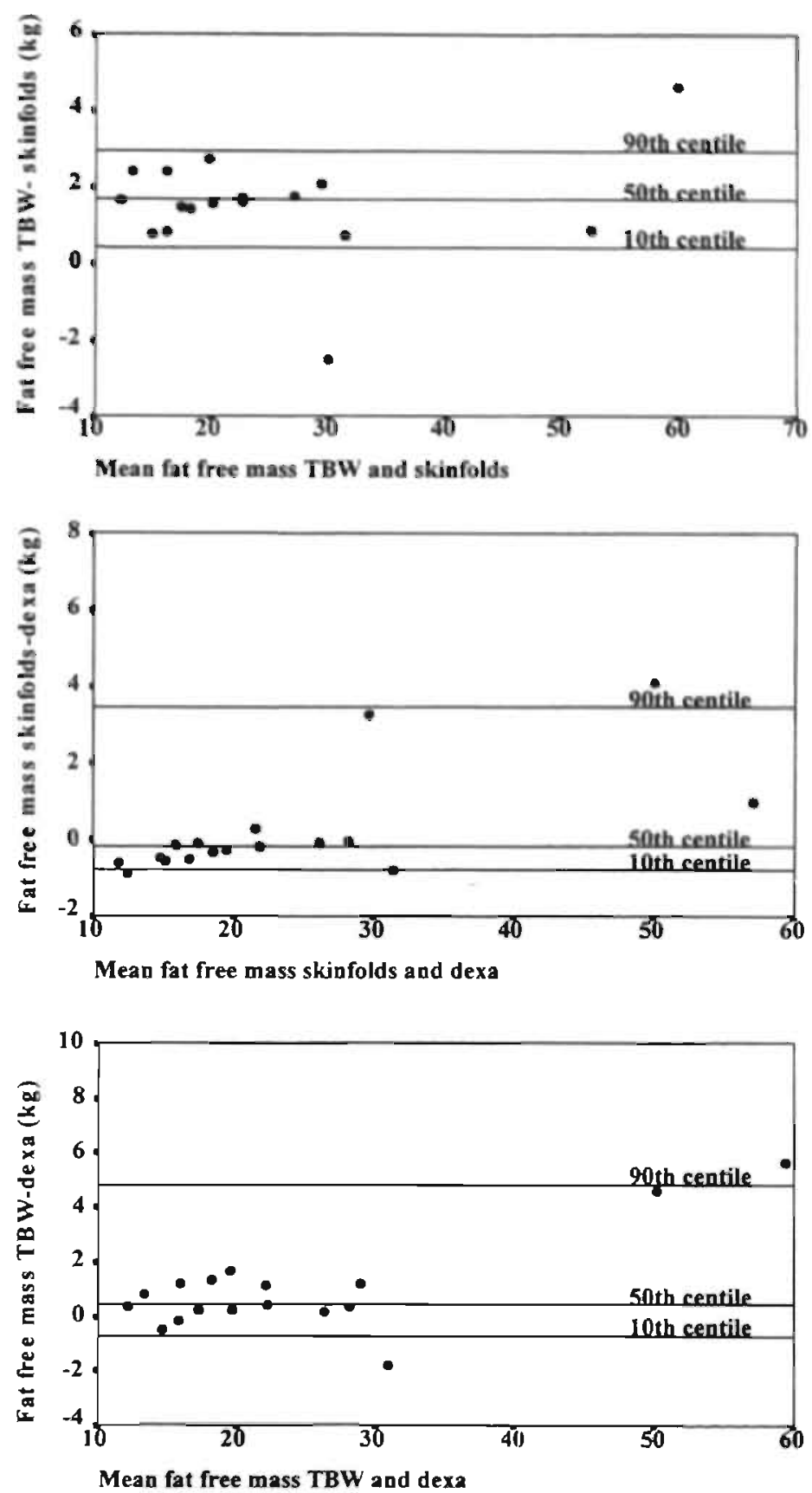

Figure 5 Limits of agreement for fat free mass measured by the various methods. 


\section{Bodv composition changes}

The changes in bodyweight, FM and FFM measured by skinfold, DEXA and TBW are shown in table 3. The increase in bodyweight was the same for both DEXA constructed weight and scale weight. However changes both in FM and FFM were different between methods. Both changes in FM and FFM measured by skinfold were highly correlated with those measured by DEXA ( $r=0.91 p=0.001$ and $r=0.84 p=0.001$ for FM and FFM respectively). Changes in FM measured by the TBW method were not correlated with changes of the same parameter measured by either the DEXA or the skinfold method, whereas changes in FFM-TBW were negatively correlated with those measured by skinfold and DEXA (FFM-TBW versus FFM. skinfold: $r=-0.56 p=0.03$ and FFM-TBW versus FFM-DEXA: $r=-0.52 p=0.05$ ). No correlation was found between changes in bodyweight and changes in FM or FFM measured by any method. Changes in ECV and ICV did not correlate with bodyweight changes. No correlation was found between changes in ICV and changes in LBM by any method. 


\section{DISCUSSION}

In children, effective evaluation of deterioration or catch-up growth can only be achieved by using the Z-score method. Despite high caloric polymeric intake, treatment of steatorrhea and support of pulmonary function, significantly lowered Z-scores for armcircumference, biceps, subscapular, suprailiac, sum of the 4 skinfolds weight and height were found in our patients. As our patients showed decreased weight, height Z-scores and mid upper arm muscle area, we expected both FM and FFM to be decreased. Since all body composition methods are based on assumptions, we used 3 noninvasive methods (DEXA, TBW and skinfolds) to evaluate the body composition of our patients. However, interpretation of the body composition results is difficult due to the lack of reference values for several measuring methods. The results of various methods used were strongly correlated with each other but still showed differences. In absolute terms, only DEXA results were as expected; showing a decrease in all 3 body components measured. Results of the TBW and skinfolds method could not be assessed accurately due to the lack of reference data expressed in absolute terms. When compared to the DEXA reference values, TBW and skinfolds methods only showed a decrease in FM. In relative terms, our CF populations showed an increase in TBW and ECV while the ICV (body cell water mass) appeared well maintained. These results imply a decrease of fatmass, associated with a relative increase in TBW, ECV and consequently FFM (19). In agreement with these: data, our results showing an increased percentage of FFM as evaluated by the skinfold method also implies a decrease in fatmass percentage in our CF patients. According to these results, we believe our CF patients mainly have a depletion of fatmass and bone mineral content with a slight decreased in lean body mass in absolute terms. Comparison of our results with other body composition studies in CF children is difficult: First, the general condition of the studied populations differed between studies and second, methods used for the assessment of the nutritional condition were different. Tomezsko et al. found no significant decrease: in body FM and FFM in their CF children with only significantly decreased suprailiac skinfold thicknesses and subscapular Z-scores. However their CF population was very young and showed only mild symptoms (2). In another study concerning older CF children with abnormal pulmonary function, Johnston et al. did find a significantly lower percentage of body fat (FFM not reported) compared to matched control children similar to our findings with all 3 
methods (20). In agreement with our study, Miller et al. who studied the body composition and muscle protein metabolism in a group undernourished CF children with Z-scores for weight and height similar to those of our CF population, found a significant decrease in FM, FFM and muscle mass (21). The strong correlation we found between components of body composition and age are well known $(8,22,23)$. The lack of sex differences can probably be explained by the prepubertal age of most patients (22). A high correlation was found between mid-upper-arm muscle area, ECV, ICV and LBM and FM. As expected, correlation coeffi. cients between mid-upper-arm muscle area, ECV, ICV and LBM remained high while only weak correlations were found with FM. Correlations were also evaluated after "homogenizing" our patient group by excluding the 2 adolescent patients. Highly significant correlations were again found between the above parameters and LBM while none were found with FM. As expected the between methods results differed significantly. Despite a high correlation between DEXA constructed weight and scale weight, mean DEXA weight was significantly and about 520 gram lower than scale weight. This is in agreement with results from Oggle et al. (8). FM measured by TBW was lower than that measured by either skinfolds or DEXA methods whereas FM-skinfold was often higher than FM-DEXA. The low values of FM when measured by the TBW method might be due to overestimation of FFM by this method. The FFM calculated by TBW is based on the assumption that a fraction of FFM is water. As the water content of FFM decreases with age (17), we used the age dependent FFM hydration fraction to calculate the FFM (17). The mean FFM hydration fraction used in our study was $76.27 \%$ (range: 73.7 - $77.5 \%$ ). In a study of body composition of CF prepubertal children, making use of skinfolds and TBW methods, Tomezco et al. also found a significantly lower body fat percentage with the TBW when compared to the skinfold method, which showed normal results (2). In two compartment models such as the TBW and the skinfolds methods, the densities of FFM is assumed to be constant in the range $18-67$ years but the density does vary depending on the concentrations, of water and mineral in FFM $(24,25)$. Although in our study the variation in water and mineral content was taken into account in the regression equations of skinfolds and TBW methods for the calculation of FFM and FM in the age range below 18 years, the water and mineral content are still population specific depending on the presence of illnesses. The percentage of TBW in CF children has been reported to be increased compared to control children $(19,26)$. Theoretically, the DEXA method has the advantage 
of being independent of biological assumptions about the densities and level of tissue hydration but the accuracy of the method still depends on the internal calibration $(27,28)$. It has been reported that when compared to chemical analysis, DEXA overestimate fat measured in meat blocks with lower fat content and underestimate the content in those with high fat content (29). Moreover, studies comparing DEXA results with those obtained from chemical analysis, using piglets, showed slight inadequacies in the estimation of fatmass and lean body mass $(27,30)$. We think that the between methods differences are most likely related to the various body compartments measured by these 3 methods rather than to inherent inaccuracies in the techniques themselves. This means that results obtained from each of these methods are not interchangeable. An important question to answer is, whether or not any of the used methods is capable of detecting body composition changes occuring during nutritional interventions. DEXA has been introduced as direct method with very good reproducibility $(12,31)$. In this study we compared the sensitivity of DEXA, TBW and skinfolds for detecting small body composition changes in children. For this purpose, we assessed the body composition of 15 $\mathrm{CF}$ children before and 3 months after they were treated with lansoprazole as an adjunct therapy for pancreatic enzymes in order to decrease steatorrhea. All 15 CF children showed significant increases in Z-scores for weight, height and skinfolds (unpublished observations). The evaluation of body composition changes differed depending on the method used. With the DEXA method, $53 \%$ of the weight increase was ascribed to FM, $44 \%$ to FFM and $3 \%$ to BMC. Both DEXA and skinfolds methods showed significant increases in fatmass but the increased FFM was not significant. In contrast, weight increase was exclusively ascribed to an increase in FFM with the TBW method. However, no significant correlations were found between weight changes and either FM, LBM or BMC changes by any method. The correlation coefticient of 0.40 found between weight changes and changes in FFM by DEXA just failed to reach statistical significance $(p=0.07)$. There were also no significant changes in ECV and ICV after intervention. This is in contrast to results reported by Going et al., who studied the changes in body compartments induced by dehydration - rehydration with oral fluid using DEXA method for assessment of body composition changes. They found a correlation between bodyweight changes and changes in TM, soft tissue mass (LBM + FM) and LBM. However, the total weight changes induced in their study was higher than in our study (approximately $1.2 \mathrm{~kg}$ versus $0.97 \mathrm{~kg}$ in our study) and as, the changes in bodyweight were 
induced by water content, the total bodyweight changes were exclusively ascribed to changes in the water content of STM, reflected by the exclusive increase in LBM (32). Since fatmass was mostly depleted in our patients, it is likely that this body compartment will normalize first as a result of an effective intervention.

From the results of this study, we conclude that results measured by different methods are not interchangeable. It is consequently important to use the same method for longitudinal evaluation of body composition. However, the use of DEXA, TBW and skinfolds methods is limited in children in whom only slight changes in bodyweight after intervention are expected $3 \%$ in this study) since the sensitivity is apparently not high enough for the detection of small differential changes in FM and FFM.

Acknowledgment: The authors wish to thank Mia Meers from the department of clinical laboratory, Sandra Zimny and Piet Willems from the department of nuclear medicine for their kind and expert technical assistance. 


\section{REFERENCES}

(1) M. Aitken, S. Fiel. Cystic Fibrosis. Dis Mon 1993;39: 1-52.

(2) J. Tomezsko, T. Scanlin, V. Stallings. Body composition of children with cystic fibrosis with mild clinical manifestations compared with normal children. Am J Clin Nutr 1994; 59: 123-8.

(3) M. Bronstein, P. Davies, K. Hambidge, F. Accurso. Normal energy expenditure in the infant with presymptomotic cystic fibrosis. J Pediatr 1995; 126: 28-33.

(4) R. Kraemer, A. Rüdeberg, B. Hadorn, E. Rossi. Relative underweight in cystic fibrosis and its prognostic value. Acta Paediatr Scand 1978; 67: 33-37.

(5) R. Branson, Y. Vaucher, G. Harrison, M. Vargas, C. Thies. Inter- and intra-observer reliability of skinfold thickness measurements in newborn infants. Hum Biol 1982; 54: 137 143.

(6) W. Gerver, R. de Bruin. Paediatric Morphometrics: A reference manual. 1th ed. Utrecht: Bunge, 1996.

(7) J. Westrate, P. Deurenberg, H. Van Tinteren. Int J Obesity. 1989; 13: 465-477.

(8) G. Ogle, J. Allen, I. Humphries et al. Body-composition assessment by dual-energy x-ray absorptiometry in subjects aged 4-26 y. Am J Clin Nutr. 1995; 61:746-53.

(9) J. Westrate, P. Deurenberg. Body composition in children: proposal for a method for calculating body fat percentage from total body density or skinfold-thickness measurements. Am J Clin Nutr 1989; 50: 1104-15.

(10) R. Mazess, B. Collick, J. Trempe, H. Barden, J. Hanson. Performance evaluation of a dual-energy x-ray bone densitometer. Calcif Tissue Int 1989; 44: 228-232.

(11) W. Peppler, R. Mazess. Total body bone mineral and lean body mass by dual-photon absorptiometry. I. I heory and measurement procedure. Calcif Tissue Int 1981; 33: 353-359.

(12) R. Mazess, H. Barden. J. Bisek. J. Hanson. Dual-energy x-ray absorptiometry for totalbody regional bone-mineral and soft-tissue composition. Am J C'lin Nutr 1990; 51: 1106-12.

(13) B. Van Kreel, F. Van der Vegt, M. Meers, T. Wagenmakers, K. Westerterp, A. Coward. Determination of total body water by a simple and rapid mass spectrometric method. J Mass Spectrom 1996; 31: 108-111.

(14) B. Van Kreel. An improved bromide assay for the estimation of extracellular water 
volume by capillary gas chromatography. Clinica Chimica Acta 1994; 231: 117-128.

(15) B. Friis-Hansen. Body water compartments in children: Changes during growth and related changes in body composition. Pediatrics $1961 ; 28: 169-181$.

(16) S. Fomon, F. Haschke, E. Ziegler, S. Nelson. Body composition of reference children from birth to age 10 years. Am J Clin Nutr 1982; 35: 1169-1175.

(17) R. Boileau, T. Lohman, M. Slaughter, T. Ball, S. Going and M. Hendrix. Hydration of the fat-free body in children during maturation. Hum Biol 1984; 56: 651-666.

(18) J. Bland, D. Altman. Statistical methods for assessing agreement between two methots of clinical measurement. The Lancet 1986; 8: 307-310.

(19) M. Miller, D. Kornhauser. Bromide pharmacokinetics in cystic fibrosis. Arch Pediatr Adolesc Med 1994; 148:266-271.

(20) J. Johnston, M. Leong, E. Checkland, P. Zuberbuhler, P. Conger, A. Quinney. Body fit assessed from body density and estimated from skinfold thickness in normal children ard children with cystic fibrosis. Am J Clinn Nutr 1988; 48: 1362-6.

(21) M. Miller, L. Ward, B. Thomas, W. Cooksley, R. Shepherd. Altered body compositicn and muscle protein degradation in nutritionally growth-retarded children with cystic fibrosis. Am J Clin Nutr 1982; 36: 492-499.

(22) H. Rico, M. Revilla, L.F.Villa, E. Hernández, M. Alvarez de Buergo and M. Villa. Body composition in children and Tanner's stages: A study with Dual-energy X-ray absorptiometry. Metabolism 1993; 42: 967-970.

(23) R. Faulkner, D. Bailey, D. Drinkwater, A. Wilkinson, C. Houston and H. McKay. Regional and total body bone mineral content, bone mineral density and total body tissue composition in children 8 - 16 years of age. Calcif Tissue Int 1993; 53: 7-12.

(24) G. Forbes. Human body composition. New York: Springer-Verlag, 1987.

(25) T. Lohman. Advances in body composition assessment. Champaign, IL: Human Kinetics, 1992

(26) M. Newby, N. Keim, D. Brown. Body composition of adult cystic fibrosis patients and control subjects as deternined by densitometry, bioelectrical impedance, total body electrical conductivity, skinfold measurements, and deuterium oxide dilution. Am J Clin Nutr 1990; 52: 209-13.

(27) K. Ellis, R. Shypailo, J. Pratt, W. Pond. Accuracy of dual-energy x-ray absorptiometry 
for body composition measurements inn children. Am J Clin Nutr 1994; 60: 660-5.

(28) R. Wellens, W. Chumlea, S. Guo, A. Roche, N. Reo, R. Siervogel. Body composition in white adults by dual-energy $\mathrm{x}$-ray absorptiometry, densitometry, and total body water. Am J Clin Nutr 1994; 59: 547-55.

(29) M. Jensen, J. Kanaley, L. Roust et al. Assessment of body composition with use of dualenergy x-ray absorptiometry: Evaluation and comparison with other methods. Mayo Clin Proc 1993; 68: 867-873.

(30) J. Brunton, H. Bayley, S. Atkinson. Validation and application of dual-energy x-ray absorptiometry to measure bone mass and body composition in small infants. Am J Clin Nutr 1993; 58: 839-45.

(31) P. Chilibeck, A. Calder,D. Sale, C. Webber. Reproducibility of dual-energy x-ray absorptiometry. Can Assoc Radiol J 1994; 45: 297-302.

(32) S. Going, M. Massett, M. Hall et al. Detection of small changes in body composition by dual-energy x-ray absorptiometry. Am J Clin Nutr 1993; 57: 845-50. 


\section{CHAPTER 8}

\section{GENERAL DISCUSSION}

Chronic pulmonary infections and poor appetite together with fat malabsorption are the main causes of malnutrition and growth retardation in CF children (1-3). The ideal treatment of CF should be the correction of the underlying defect by introduction of a normal copy of the defective gene into these patients genetic material. Although gene therapy is presently under intensive scrutiny (4-6), the role of this treatment in CF patients is not yet settled. Until then, treatment of these patients has to focus on improving the nutritional condition, since malnutrition can adversely affect survival (7). As $85 \%$ of CF patients have pancreatic insufficiency (8), improved absorption by pancreatic enzymes substitution is one of the main goals. Diagnosis and regular monitoring of fecal fat loss along with close evaluation of growth and the nutritional condition are consequently necessary in the follow up of these patients. Although the fat balance method is considered to be the golden standard for the evaluation of steatorrhea, it is too cumbersome to be used for the frequent monitoring of fat losses in these children. Several studies have shown the measurement of fecal fat concentration to be a valuable alternative to fat excretion studies for the diagnosis of fat malabsorption (9). These studies also shown that the differences in fat excretion between either 3 or 1 day collections are mainly due to day to day variation in stool volume, the stool fat concentration being much more constant. These studies led us to suppose that the repeated measurement of stool fat concentration in stool samples would be a valuable aid to the monitoring of steatorrhea. As chemical measurement of stool fat is time consuming, we looked for an alternative easy measure of fat content. Although the steatocrit looked quite attractive (10) our first results and also results reported by others $(11,12)$ disappointingly often showed low steatocrit results in stools of high fat content.

By acidification of stool homogenates, we could show fat extraction to be much improved and to result in a satisfactory correlation coefficient between chemically measured fecal fat and "acid steatocrit" results. We consequently decided to use the acid steatocrit in an intervention study (proton pump inhibitor) aiming at improving both steatorrhea and the nutritional condi- 
tion in children with $\mathrm{CF}$.

Both anthropometric parameters and body composition methods were used for the evaluation of the nutritional condition. Difficulties arise due to the fact that weight, height and skinfolds are age and sex specific. Although several authors have overcome this problem by expressing results of these parameters as a percentage of the predicted values for age and sex, the use of Z-scores is the preferred method for most authors. Z-scores measure deviations from the median value expressed in standard deviation units. Improving Z-scores reflect catch-up growth while the reverse is true for deteriorating Z-scores. Recently, Gerver and de Bruin have constructed growth charts with standard deviation for weight, height armcircumferences and the 4 skinfolds (biceps, triceps, subscapular and suprailiac) (13). Anthropometric parameters can be easily converted into Z-scores through the use of these reference data for normal children. As weight changes could be due to either changes in fatmass, fat free mass or both, we measured body composition by several methods in order to evaluate body composition before and after our intervention (proton pump inhibitor) study.

Our study results show significant decreases of most measured anthropometric parameters in children with cystic fibrosis. Decrease in skinfold thicknesses were most significant and contrary to a commonly held belief triceps skinfolds were often nomal while subscapular and suprailiac skinfolds were very sensitive indicators of chronic malnutrition in these patients. Our findings support the use of these simple anthropometric measurements for the evaluation of the nutritional condition in children. As far as body composition results are concerned, interpretation of results is uneasy due to the lack of reference values for several measuring methods. Notwithstanding these drawbacks, results of the various methods used were strongly correlated with each other but, still showed differences which preclude the use of these various methods interchangeably. Results should be looked at both in relative and in absolute terms.

In absolute terms, the DEXA method showed a severe decrease of fatmass and a slight decrease of fat free mass and of bone mineral content. Results of the total body water and skinfold method agreed with the DEXA results but could not be accurately assessed due to the lack of reliable reference data.

In relative terms, the deuterium - bromide results showed a relatively increased total body water and extracellular water compartment while the relative body cell water mass appeared 
well maintained. These results imply a decrease of fatmass as percent of bodyweight. Likewise, the fat free mass (\%) measured by the skinfold method was increased in our CF children. All these results agree with each other rather well and show that children with CF have a lowered bodyweight accompanied by a decreased fatmass (\%), an increased fat free mass (\%) and an increased extracellular water compartment (\%) while the intracellular water comparment (\%) appears to be well maintained (table 1).

Table 1 Body composition in children with cystic fibrosis.

\begin{tabular}{||cccccc||}
\hline & $\begin{array}{c}\text { FM } \\
\text { kg (\%) }\end{array}$ & $\begin{array}{c}\text { FFM } \\
\mathbf{k g}(\%)\end{array}$ & $\begin{array}{c}\text { TBW } \\
(\%)\end{array}$ & $\begin{array}{c}\text { ECV } \\
(\%)\end{array}$ & $\begin{array}{c}\text { ICV } \\
(\%)\end{array}$ \\
\hline \hline DEXA & $!(!)$ & $!(1)$ & & & \\
Skinfold & $?(1)$ & $?(1)$ & & & \\
Deuterium & $?(1)$ & $?(1)$ & $(1)$ & $(1)$ & (i) \\
Bromide & $?(1)$ & & &
\end{tabular}

DEXA: Dual energy X - Ray Absorptiometry

FM: Fatmass

FFM: Fat free mass

TBW: Total Body Water

ECV: Extracellular volume

ICV: Intracellular volume

A positive effect of omeprazole on fat absorption has been found in adults with CF (14). However the role of proton pump inhibitors on steatorrhea and its effects on the nutritional condition has not been evaluated in children. We have studied the effect of 3 months treatment of lansoprazole on fat malabsorption and body composition in $15 \mathrm{CF}$ children, maintaining steatorrhea while on pancreatic enzymes. These children showed significant improvements of both fat absorption (as measured by the acid steatocrit) and Z-scores for all parameters except for the biceps and triceps skinfolds and deteriorated again 3 months after lansoprazole was stopped. The increase in skinfold thicknesses Z-scores were accompanied by signifi- 
cant increases in fatmass as measured by the skinfold and the DEXA methods.

Different body composition methods have been described but, only few studies have compared different measurement techniques in pediatric subjects. An important question to answer is whether or not any of these methods is capable of detecting body composition changes occuring during nutritional interventions. Our study comparing the changes in body composition measured by DEXA, TBW and skinfolds methods in 15 CF children, whose nutritional condition improved significantly after intervention with lansoprazole for 3 months, showed different results for each method. Both DEXA and skinfolds methods showed significant increases in fatmass but not in lean body mass in absolute terms. Likewise, the percentage of body cell water mass did not increase significantly after nutritional intervention. On the other hand, the increases in bodyweight were completely ascribed to increases in lean body mass but not in fatmass when evaluated by the TBW method. Since fatmass was mostly depleted in our CF children (as shown by DEXA, skinfolds and total body water methods), it is likely that this body compartment will normalize first as a result of an effective intervention. Our results do not allow firm conclusions as to the effect of lansoprazole on FFM while a significant increase in bone mineral content was found. The bodyweight changes occuring during lansoprazole intervention were unrelated to either fatmass or FFM changes measured by any of the three methods used. We think the weight changes in the various body compartments were too small to be accurately measured by body composition methods.

In conclusion, the acid steatocrit is a reliable, cheap and noninvasive altemative method for the monitoring of fat malabsorption. Most cystic fibrosis patients are malnourished even when lung functions are stable and a hypercaloric diet is used. Body composition studies in these patients mainly show a loss of fat mass and bone mineral content with a relative increase in extracellular water and a normal intracellular water mass (\%). Inhibition of gastric acid secretion by a proton pump inhibitor improved both fat absorption and the nutritional condition of our patients. Methods for the assessment of body composition are not interchangeable and not accurate enough for detecting small changes in fatmass and fat free mass such as measured in our 3 months study. A longterm study is needed in order to better evaluate the effects of lansoprazole on body composition in children with cystic fibrosis. 


\section{REFERENCES}

(1) J. Dodge, J. Yassa. Food intake and supplementary feeding programs. In: J. Sturgess, ed. perspectives in cystic fibrosis. Toronto: Canadian Cystic Fibrosis Foundation; 1980: 125-136. (2) M. Bronstein, R. Sokol, S. Abman et al. Pancreatic insufficiency, growth, and nutrition in infants identified by newborn screening as having cystic fibrosis. J Pediatr 1992; 120: 533-40. (3) J. Tomezsco, V. Stallings, D. Kawchak, J. Goin, G. Diamond, T. Scanlin. Energy expenditure and genotype of children with cystic fibrosis. Pediatr Res 1994; 35: 451-460.

(4) M. Rosenfeld, W. Siegfried, K. Yoshimura et al. Adenovirus-mediated transfer of a recombinant alpha 1-antitrypsin gene to the lung epithelium in vivo. Science. 1991;252: 431-4 (5) B. Pitt, M. Schwarz, J. Pilewski et al. Retrovirus-mediated gene transfer in lungs of living fetal sheep. Gene Ther 1995; 2: 344-50.

(6) M. Rosenfeld, K. Yoshimura, B. Trapnell et al. In vivo transfer of the human cystic fibrosis transmembrane conductance regulator gene to the airway epithelium. Cell. 1992; 68: $143-55$.

(7) R. Kraemer, A. Rüdeberg, B. Hadom, E. Rossi. Relative underweight in cystic fibrosis and its prognostic value. Acta Paediatr Scand 1978; 67: 33-37.

(8) M. Aitken, S. Fiel. Cystic fibrosis. Dis Mon 1993; 39: 1-52.

(9) N. Thorsgaard Pedersen, H. Halgreen, H. Worning. Estimation of the 3-day faecal fat excretion and fat concentration as a differential test of malabsorption and maldigestion. J Gastroenterol 1987; 22: 91-96.

(10) P. Phuapradit, A. Narang, P. Mendonca, D. Harris, J. Baum. The steatocrit: a simple method for estimating stool fat content in newbom infants. Arch Dis Child 1981; 56: 725-727. (11) M. Walters, J. Kelleher, J. Gilbert, J. Littlewood. Clinical monitoring of steatornhoea in cystic fibrosis. Arch Dis Child 1990; 65: 99-102.

(12) E. Sugai, G. Srar, H. Vazquez et al. Steatocrit: a reliable semiquantitative method for detection of steatorrhea. J Clin Gastroenterol 1994; 19: 206-9.

(13) W. Gerver, R. de Bruin. Paediatric Morphometrics: A reference manual. 1 th ed. Utrecht: Bunge, 1996.

(14) H. Heijerman, C. Lamers, W. Bakker. Omeprazole enhances the efficacy of pancreatin (pancrease) in cystic fibrosis. Ann Intern Med. 1991; 114: 200-201. 


\section{SUMMARY}

In chapter one, the pathogenesis, clinical manifestations and treatment modalities of cystic fibrosis are briefly summarized. CF is a multisystem disease, the basic defect is a mutation of the CFTR gene. Until now, more than 200 mutations have been characterized. CFTR has been found in epithelial cells of several organs with the lung and pancreas being mostly affected. The role of gene therapy in the management of CF patients is not yet settled. Until then treatment of these patients has to focus on support of lung function and improved fat absorption in order to maintain a normal nutritional status. From our litterature review, only predigested foods such as (semi)elemental diets and very high-energy polymeric diets, have been reported to improve the nutritional condition in $\mathrm{CF}$ patients. Low duodenal $\mathrm{pH}$ is thought to be at least partly responsible for the persisting maldigestion. Inhibition of gastric acid secretion by a proton pump inhibitor has been shown to improve steatorrhea in CF adults. The effect of proton pump inhibitors on fat absorption and on the nutritional status of children with $\mathrm{CF}$ has not been reported. The effect of treatment on steatorrhea can only be evaluated by regular monitoring of fecal fat loss. The fat balance method being too cumbersome for the repeated evaluation of steatornhea, we first aimed at developing an alternative test suituble for our purpose. This test (acid steatocrit) was subsequently used to evaluate the effect of lansoprizo-le (proton pump inhibitor) on steatorrhea in CF patients showing persisting malabsorption while on pancreatic enzymes. The effects of therapy on the nutritional condition of our patients was evaluated simultaneously.

In chapter two, the methods used in this study are described. For the determination of fecal fat, the titrimetric method described by van de Kamer and the Sudan staining method were used for the comparison of steatocrit and acid steatocrit methods. Anthropometry, dual-energy $\mathrm{X}$-ray absorptiometry. total body water and bromide dilution techniques were used to assess body composition.

In chapter three, four and five, we describe the steatocrit test as an alternative method for the 3 days fecal fat balance method for the monitoring of steatorrhea. Although the steatocrit 
test has been reported to be cheap, simple and noninvasive test, its reliability has been questioned. As this might be due to inadequate fat extraction during the centrifugation step of the steatocrit procedure, we aimed at improving fat extraction by acidification of the fecal homogenate. Results obtained by our modified steatocrit method, called the "acid steatocrit", were highly correlated with those obtained by chemical analysis. We found a high sensitivity and specificity for the acid steatocrit.

Results of the evaluation of the nutritional condition of our patients as well as results concerning the presence of persisting steatorrhea in patients on pancreatic enzymes are described in chapter six. Despite hypercaloric intake and the use of pancreatic enzymes, our CF patients maintained steatorthea and showed signs of malnutrition with significantly decreased Z-scores for weight, height, armcircumference, biceps, subscapular and suprailiac skinfolds. Moreover, their fatmass, lean body mass and bone mineral content were significantly decreased when compared to the reference population described by Oggle et al. Treatment of these CF children with lansoprazole as an adjunct therapy of pancreatic enzymes, resulted in a significant decrease in steatorrhea accompanied by a significant improvement in their nutritional condition.

In chapter seven, we describe results of our body composition studies in our patients before and after treatment with lansoprazole. Although highly correlated, results from these various methods were shown not to be interchangeable. In absolute terms, the DEXA, the TBW and the skinfold methods showed children with $\mathrm{CF}$ to have a severe depletion of fatmass and a slight decrease of FFM. In relative terms, the above results point to lower body fat percentage accompanied by a higher percentage of LBM. Our results with deuterium - bromide do confirm the above results by showing a high relative TBW content and consequently a low relative fat content. Bromide results further show the relative increase of water percentage to be due to a relatively increased extracellular water compartment with a maintained relative body cell water mass. Although small changes in bodyweight were correctly detected by DEXA examination, the latter method was not accurate enough for the differential detection of small changes in FM and FFM. The usefulness of DEXA, TBW and skinfold methods for the assessment of small body composition changes in children is therefore limited. 


\section{SAMENVATTING}

In hoofdstuk cen, zijn de pathogenese, de klinische manifestaties en de therapeutische mogelijkheden voor cystic fibrosis (CF) kort samengevat. Cystic fibrosis is een multisysteem ziekte, waarvan mutatie van de CFTR (cystic fibrosis transmembrane regulator) gene is het basis defect.

Tot dus ver, zijn er meer dan 200 mutaties beschreven. CFTR werd in de epitheel cellen van verschillende organen gevonden. De longen en de pancreas zijn het meest betrokken by deze erfelijke aandoening. De rol van de gen therapie is nog niet bevestigd in de behandeling van CF patienten. De behandeling van deze patienten is er dan ook gericht op de long functies te ondersteunen en een normale voedingstoestand te behouden door het verbeteren van de vet malabsorptie.

Uit het litteratuur overzicht blijkt dat de voedingsstatus van CF patienten alleen effectief te verbeteren is met voorverteerd voedsel zoals (semi)elementaire voeding, of met een zeer hoge energie inname. Een lage duodenale $\mathrm{pH}$ is mede verantwoordelijk voor het slechte verteringsproces. Het is bij volwassen CF patienten bekend dat de vet absorptie significant te verbeteren is door remming van de maagzuur secretie met een proton pomp remmer. $\mathrm{Er}$ is nog geen studie gedaan naar het effect van dit middel op de vet vertering en de voedings status bij $\mathrm{CF}$ kinderen.

Regelmatig monitoring van vet in de ontlasting is noodzakelijk voor de behandeling van vet malabsorptie. De gebruikelijke vet balans methode is hiervoor te omslachtig. Ons eerste doe! was het ontwikkelen van een alternatieve test die snel en makkelijk uitvoerbaar is. Deze test (zure steatocriet) werd dan gebruikt om het effect van een proton pomp remmer (lansoprazol) op steatorrhoea in CF patienten met persisterende malabsorptie onder pancreas enzymen, te evalueren. Daamaast, werd het effect van lansoprazol op de voedingstoestand van onze patienten geevalueerd.

In hoofdstuk twee. beschrijven we de methoden die we gebruikt hebben in deze studie. Voor de bepaling van vet in de ontlasting, werden de titrimetrische methode, beschreven door van de Kamer, en de Sudan kleurings techniek gebruikt om de klassieke steatocriet te: vergelijken 
met de zure steatocriet. De anthropometrische methode, de dual-energy X-ray absorptiometry (DEXA), het totale lichaamswater ( $T B W$ ) en de bromide dilutie technieken werden toegepast om de lichaamsamenstelling te beoordelen.

In hoofdstuk drie, vier en vijf, beschrijven we de steatocriet test als een alternatieve methode voor de 3 dagen vet balans ter monitoring van vet in de ontlasting. Hoewel de steatocriet test werd gezien als een goedkope, simpele en noninvasieve test, de betrouwbaarheid van deze test wordt betwist. Dit is mogelijk toe te schrijven aan de inadequate vet extractie tijdens het centrifugeren van de steatocriet procedure. Ons doel was de vet extractie te verbeteren door het aanzuren van het faeces homogenaat. De resultaten verkregen met deze gemodificeerde steatocriet genaamd "zure steatocriet", correleerden goed met de resultaten van de chemische vet analyse. We vonden een hoge sensitiviteit en specificiteit voor de zure steatocriet test.

In hoofdstuk zes, bestuderen we de mate van vet malabsorptie en de voedingstoestand van onze CF kinderen behandeld met pancreas enzymen. Ondanks de hypercalorische voeding en de behandeling met pancreas enzymen, hadden onze patienten aanhoudende steatorrhoea en toonden tekenen van malnutritie met significante verslechtering van de gemiddelde Z-scores voor gewicht, lengte, armomtrek, biceps, subscapulaire en suprailiacale huidplooien. Bovendien, hun vetmassa, spiermassa en botmineral is significant lager dan die van de normale kinderen, beschreven door Oggle. Na de behandeling van deze kinderen met een proton pomp remmer (lansoprazol) als supplementaire therapie by pancreas enzymen, vonden we een significante vermindering van steatorrhoea met verbetering van de voedingstoestand.

In hoofdstuk zeven, beschrijven we de resultaten van de lichasmsamenstelling van onze patienten voor en na de behandeling met lansoprazol. Ondanks de hoge: correlatie tussen de resultaten van de gebruikte lichamsamenstelling methodes, zijn deze technieken niet uitwisselbaar. In absolute zin, toonden de DEXA, de TBW en de huidplooi methode een emstige depletie van de vetmassa en een lichte afname van de vet-vrije massa by CF kinderen. In relatieve zin, wijzen deze resultaten in de richting van een afnarne van het vet percentage gepaard aan een hoger percentage van lean body mass (LBM). Dit komt overeen met de resultaten van deuterium-bromide, waarbij een hoog TBW' percentage en dus een laag vet 
percentage gevonden werd. De toename in het TBW percentage is toe te schrijven aan het verhoogde percentage extracellulair water terwijl intracellulair water normaal blijft. Alhoewel de verandering in lichaamsgewicht door het DEXA onderzoek correct werd geschat, was geen van de gebruikte lichaamsamenstelling methodes nauwkeurig genoeg voor het schatten van kleine veranderingen in de vetmassa en vet-vrije massa. De bruikbaarheid van DEXA, TBW en huidplooi methoden voor het schatten van kleine veranderingen in de lichaamsamenstelling bij kinderen is daarom beperkt. 


\section{DANKWOORD}

Woorden schieten tekort om mijn dank uit te drukken. Ik ben niet zo goed in taal expresse, toch hoop ik met enkele eenvoudige zinnen iedereen te kunnen bedanken, die het mij mogelik hebben gemaakt dit proefschrift vorm te geven.

Zonder iemand tekort te willen doen, richt ik een speciaal dankwoord tot de volgende peronen:

Prof. Dr. C. Blanco, promotor, beste Carlos, ondanks je drukke taak, heb je toch heel snelen kritisch mijn werkstukken doorgenomen. Hiervoor dank ik je extra.

Dr. P. Ph. Forget, copromotor, beste Philippe, het lukte mij nooit je te tutoyeren, niet vanvege onze persoonlijke contacten, maar vanwege mijn respect voor jou. De manier waarop je let onderzoek stuurde waarbij je mij geheel in mijn waarde en vrijheid liet, was van buitengewoon hoog niveau. Je leerde mij wetenschappelijk denken. Waar nodig was bood je hllp aan, soms ook met het verwerken van de resultaten. De correctie van het manuscript vas binnen korte tiid klaar. Zelfs in ie vakantie. nam ie miin werkstukken mee en was ie berid hiervoor terug te komen. Ik heb genoten van je onuitputtelijke bron van nieuwe ideeën.

Ook in het persoonlijk contact was je aangenaam. Je heb altijd in mij geloofd en stond altijd achter mij. Beste Philippe, zonder jouw inzet en je vertrouwen als begeleider, zou dit proefschrift nooit deze vorm hebben gekregen.

Dr. B. van Kreel, copromotor, de helft van mijn tijd als onderzoeker heb ik in uw laboratorium doorgebracht. Uw deur stond altijd voor mij open. Als het niet lukte met de steatocrit bepaling, heb u altijd nieuwe suggesties. Uw deskundigheid en eerlijkheid was onmisbaar voor het slagen van dit onderzoek.

Prof. Dr. R. H. Kuijten, bedankt voor de mogelijkheden die u hebt gecreeërd voor dit onderzoek.

Drs. A. Van den Neucker, beste Anita, al die jaren ben je voor mij een goede vriendin geweest. Ook als het mij tegen zat, wist je met je nuchtere kijk en eerlijkheid mijn problemen te relativeren. Ik heb genoten van onze discussies en van je gezelschap op verscheidene congressen. Je interesse in anderen en je brede algemene kennis maakte het zeer boeiend. Anita, je hebt mijn "gat" in de Westerse cultuur opgevuld. 
Hooggeleerde leden van de beoordelingscommissie, bedankt voor uw vlotte en kritische beoordeling van dit manuscript.

Alle kinderartsen, neonatologen en arts-assistenten kindergeneeskunde in het AZM dank ik hierbij voor de aanspraak in de afgelopen jaren.

Dr. W. J. M. Gerver en Dr. R. De Bruin, jullie groeicurven hebben grote waarde toegevoegd aan dit onderzoek. Bedankt voor jullie voortreffelijke bijdrage.

Jolanda vain Golde en Rony Nieefjes, beste Rony en Jolanda, bedankt voor het meeleven en de gezellige uren in het AlO-hok, in het restaurant, in het theater aan het Vrijthof, in de bioscoop, bij een van ons thuis of in het zwembad. Bedankt voor het aanhoren van mijn "gezeurd". We hebben goede en slechte tijjden met elkaar doorgemaakt. Ik hoop dat onze vrienschap hierdoor alleen maar sterker is geworden.

Alle medewerkers van het klinisch chemisch laboratorium van het $A Z M$, met name Serva, Lou, Michel, Mia, Theo, Peter en Marian, bedankt voor jullie inzet en betrokkenheid tijdens het onderzoek. Jullie wetenschappelijke interesse was van niveau. Als ik hulp nodig had waren jullie bereid, soms ook ongevraagd, het eigen werk neer te leggen en mij bij. te staan. Bedankt voor de aangename sfeer en de gezellige samenwerking.

Liesbeth van der Ploeg en Lianne Schoorlemmer, dietisten, wil ik danken voor het uitrekenen van de calorieën bij mijn patienten populatie.

Dr. G. A. K. Heidendal, Piet Willems en Sandra Zimny van de nucleaire afdeling, bedankt voor jullie fijnzinnige instructies over de DEXA scan.

Alle poli-assistenten en de secretaressen van de kindergeneeskunde, wil ik danken voor de samenwerking in de afgelopen jaren.

Oom Wim en tante Margriet van der Avoort, bebankt voor jullie steun en betrokkenheid in de afgelopen 15 jaren van mijn leven in Nederland.

Ik ben de firma's Hoechst Marion Roussel B.V. (Hoevelaken) en Janssen-Cilag B.V. (Tilburg) dankbaar voor hun financiële ondersteuning in de drukkosten van dit proefschrift.

Tenslotte, zou dit boek niet volledig zijn zonder hulp en meeleven van mijn familie. Lieve mama, oom Kiet, Manh Hung en Manh Coung, terwijl ik rustig aan mijn proefschrift werkte, hebben jullie voor mijn verbuizing gezorgd.

Manh Coung, bedankt voor het ter beschikbaar stellen van je computer en Manh Hung voor je 
deskundige steun. Als ik met de computer problemen had, kon ik altijd op jullie terugvallen. Oom Kiet, bedankt voor je inzet en betrokkenheid. Nooit hoefde ik je om hulp te vrager, je was er gewoon.

Lieve Mama, zonder jou zou dit boek er nooit zijn gekomen. Heel je leven lang heb je voor ons klaar gestaan. Jouw droom is een goede toekomst voor je kinderen. Daarvoor heb je 15 jaar geleden je leven op het spel gezet. Je stimuleerde ons om te studeren. Rijkdom is aiet belangrijk, maar kennis, dat is de beste bagage die je op onze weg aan ons hebt kumen meegeven. Mama, bedankt voor je betrokkenheid en het aanhoren van mijn frustraties. Met een glimlach en een schouderklop wist je al mijn problemen op te lossen. Mama, ik hou van jou en $\mathrm{ik}$ ben trots dat $\mathrm{jij}$ mijn moeder ben. 


\section{CURRICULUM VITAE}

Thi My Dung Tran werd. op 27 april 1967 te Dinh Tuong in Vietnam geboren.

Na het doorlopen van het basisonderwijs volgde zij, eveneens in Vietnam, drie jaren vervolgonderwijs op voorbereidend wetenschappelijk niveau.

In $1981 \mathrm{kwam}$ zij met haar familie in Nederland.

Op 2 juni 1986 verwierf zij aan de Rijksscholengemeenschap "Den Hulster" te Venlo het diploma Atheneum B. met als eindexamenpakket de vakken: Nederlands, Engels, Wiskunde I en II, Natuurkunde, Scheikunde en Biologie.

Vanaf het najaar 1986 studeerde zij geneeskunde aan de Rijksuniversiteit te Maastricht. Zij behaalde op 13 augustus 1990 haar doctoraal getuigschrift. Op 1 februari 1993 werd het diploma basisarts aldaar aan haar uitgereikt.

Tijdens haar studie verrichte zij wetenschappelijk onderzoek onder leiding van Dr. P. PH. Forget op de afdeling kindergeneeskunde van het Academisch Ziekenhuis Maastricht: "Singel Stool analysis for fat, alfa-animo nitrogen and electrolyt".

Vanaf 1 maart tot 3 november 1993 werkte zij als arts-onderzoeker bij de vakgroep kindergeneeskunde van het A.Z.M. aan het project "Effect of ranitidine in children with chronic abdominal pain".

Van 1 december 1993 tot 1 december 1994 was zij werkzaam als AGNIO kindergeneeskunde in het A.Z.M.

In de periode 1 december 1994 tot 1 april 1996 werkte zij onder leiding van Dr. P. PH. Forget, kinder-gastroenteroloog in het A.Z.M., aan haar promotie-onderzoek. 
